October 2003 - NREL/SR-550-34440

\title{
Assessment of Parabolic Trough and Power Tower Solar Technology Cost and Performance Forecasts
}

Sargent \& Lundy LLC Consulting Group Chicago, Illinois
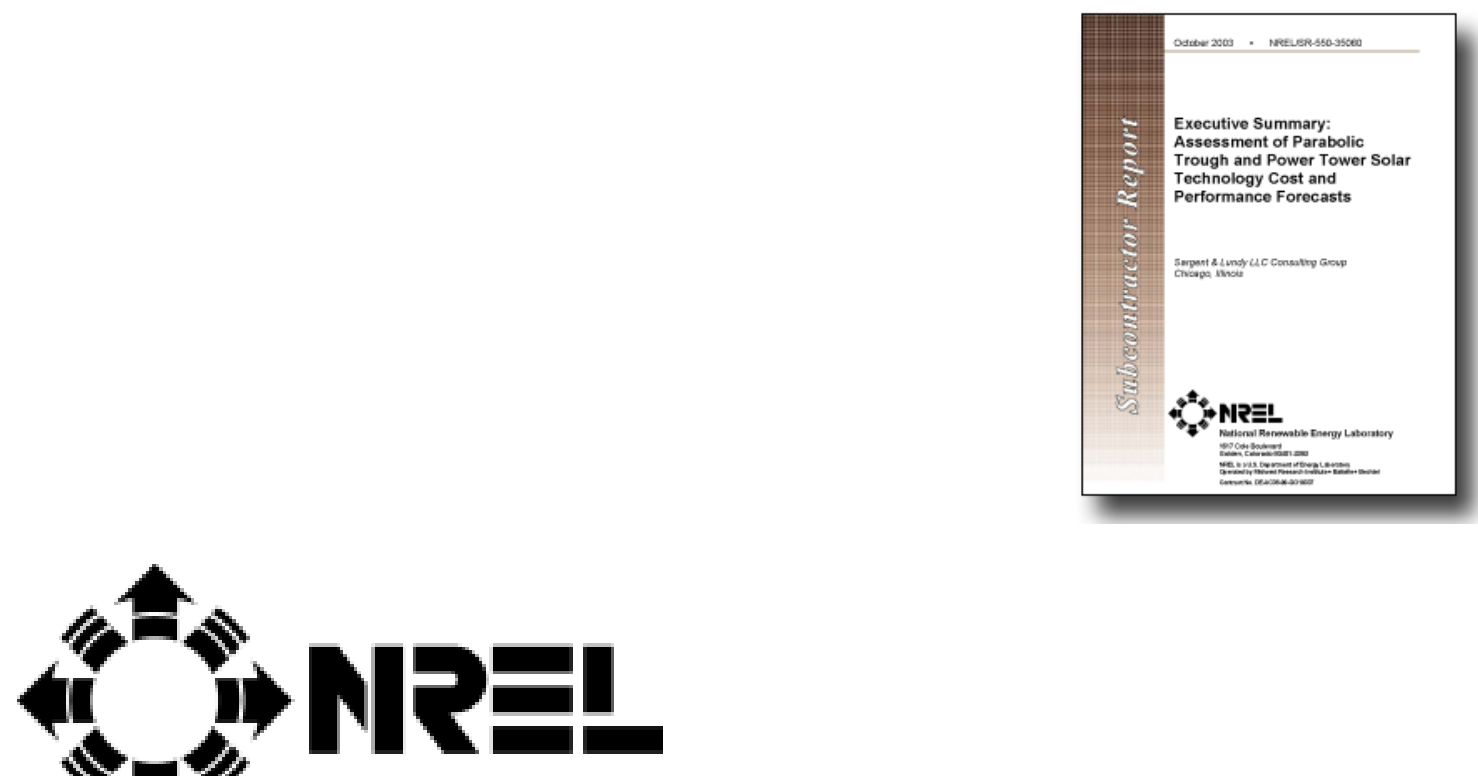

National Renewable Energy Laboratory

1617 Cole Boulevard

Golden, Colorado 80401-3393

NREL is a U.S. Department of Energy Laboratory

Operated by Midwest Research Institute $\bullet$ Battelle $\bullet$ Bechtel

Contract No. DE-AC36-99-G010337 


October $2003 \quad$ NREL/SR-550-34440

Assessment of Parabolic
Trough and Power Tower Solar
Technology Cost and
Performance Forecasts

Sargent \& Lundy LLC Consulting Group

Chicago, Illinois

NREL Technical Monitor: H. Price

Prepared under Subcontract No. LAA-2-32458-01

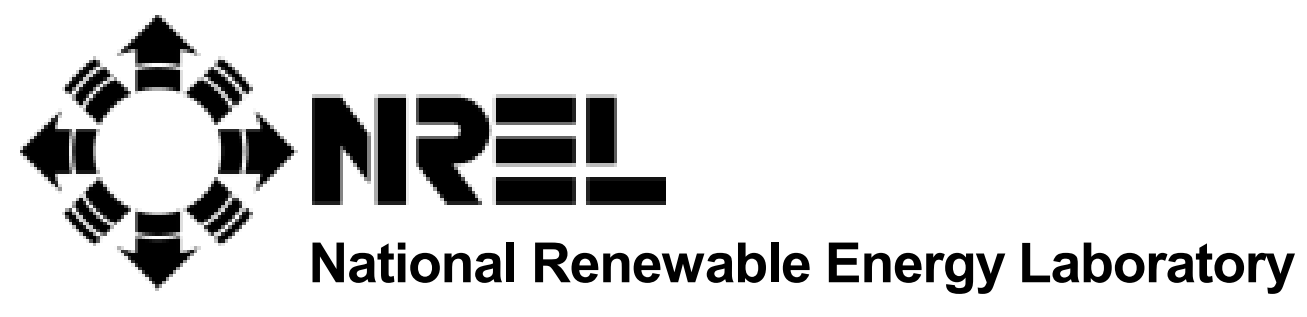

1617 Cole Boulevard

Golden, Colorado 80401-3393

NREL is a U.S. Department of Energy Laboratory

Operated by Midwest Research Institute • Battelle • Bechtel

Contract No. DE-AC36-99-G010337 


\section{NOTICE}

This report was prepared as an account of work sponsored by an agency of the United States government. Neither the United States government nor any agency thereof, nor any of their employees, makes any warranty, express or implied, or assumes any legal liability or responsibility for the accuracy, completeness, or usefulness of any information, apparatus, product, or process disclosed, or represents that its use would not infringe privately owned rights. Reference herein to any specific commercial product, process, or service by trade name, trademark, manufacturer, or otherwise does not necessarily constitute or imply its endorsement, recommendation, or favoring by the United States government or any agency thereof. The views and opinions of authors expressed herein do not necessarily state or reflect those of the United States government or any agency thereof.

Available electronically at http://www.osti.gov/bridge

Available for a processing fee to U.S. Department of Energy and its contractors, in paper, from:

U.S. Department of Energy

Office of Scientific and Technical Information

P.O. Box 62

Oak Ridge, TN 37831-0062

phone: 865.576.8401

fax: 865.576 .5728

email: reports@adonis.osti.gov

Available for sale to the public, in paper, from:

U.S. Department of Commerce

National Technical Information Service

5285 Port Royal Road

Springfield, VA 22161

phone: 800.553 .6847

fax:703.605.6900

email: orders@ntis.fedworld.gov

online ordering: http://www.ntis.gov/ordering.htm

\footnotetext{
Printed on paper containing at least $50 \%$ wastepaper, including $20 \%$ postconsumer waste
} 


\section{ASSESSMENT OF \\ PARABOLIC TROUGH AND POWER TOWER SOLAR TECHNOLOGY COST AND PERFORMANCE FORECASTS}

\section{CONTENTS}

$\underline{\text { Section }}$

EXECUTIVE SUMMARY

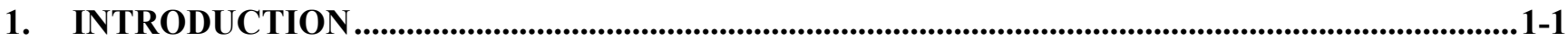

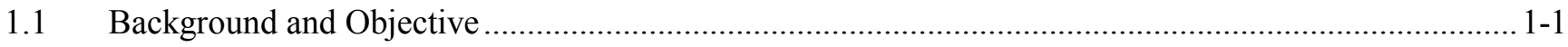

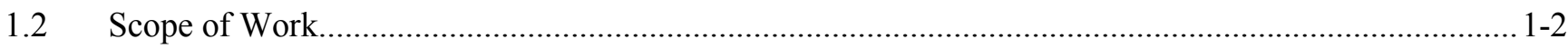

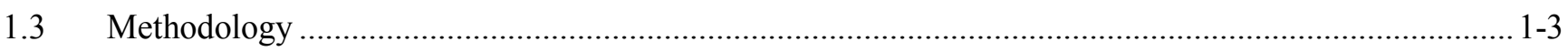

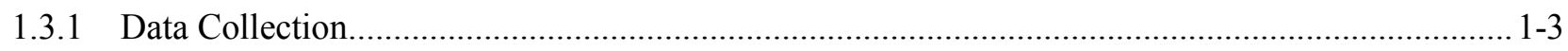

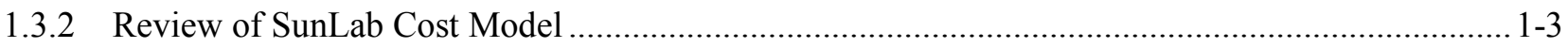

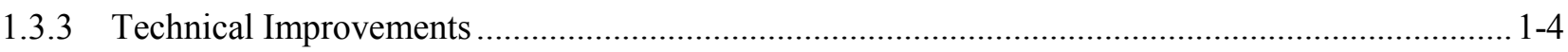

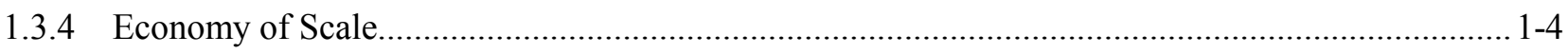

1.3.5 Volume Production (Volume and Learning Curve) .............................................................. 1-4

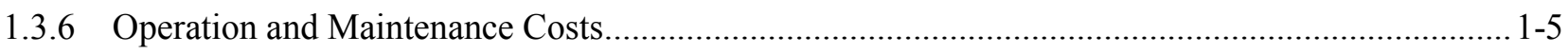

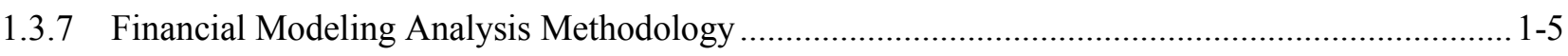

2. CONCENTRATING SOLAR POWER TECHNOLOGIES...........................................................2-1

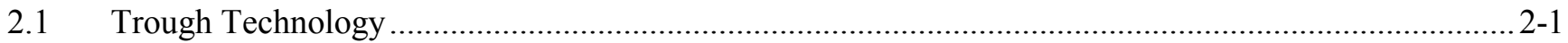

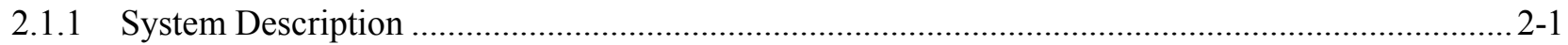

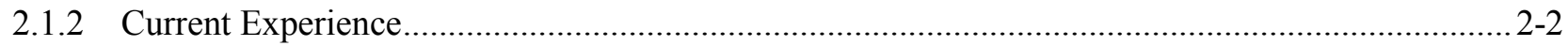

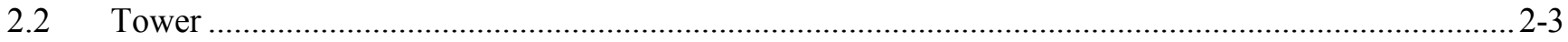

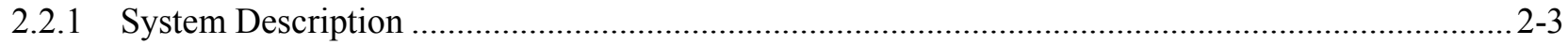




\section{CONTENTS (CONT.)}

$\underline{\text { Section }}$

2.2.2 Current Experience

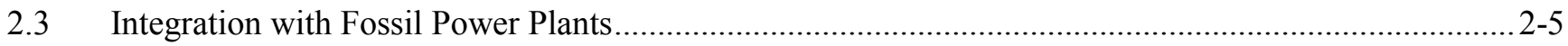

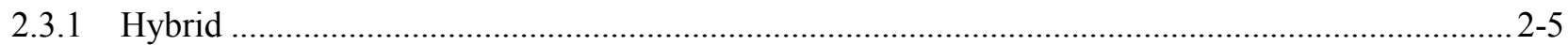

2.3.2 Integrated Solar Combined Cycle System (ISCCS) .............................................................. 2-5

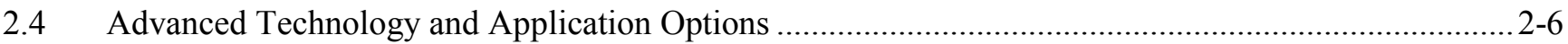

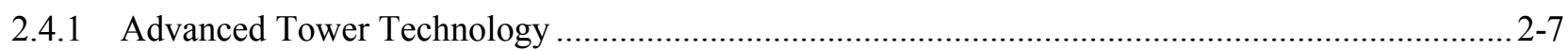

2.4.2 Current International Development Directions ...............................................................................

2.4.3 Long-Term CSP Advanced Applications Options ................................................................ 2-9

3. POWER GENERATION MARKET AND DEPLOYMENT FORECAST ............................................3-1

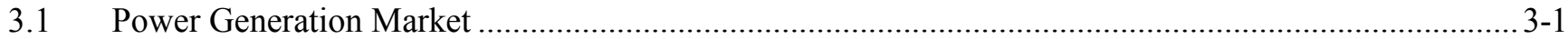

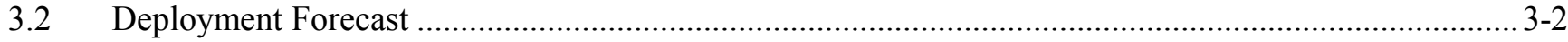

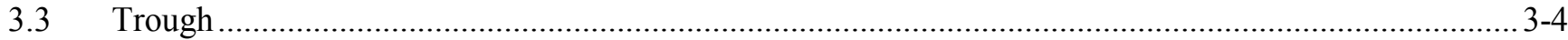

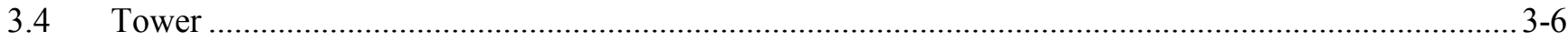

4. EVALUATION OF POTENTIAL FOR COST REDUCTIONS — TROUGH ...................................4-1

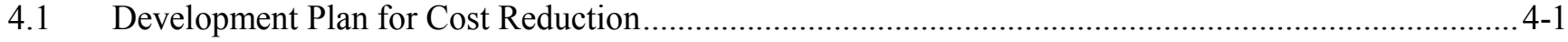

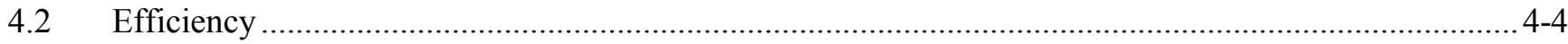

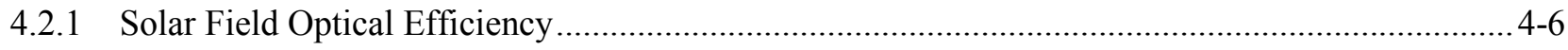

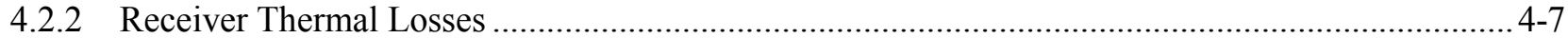

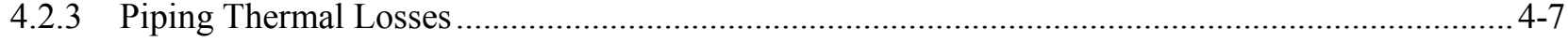

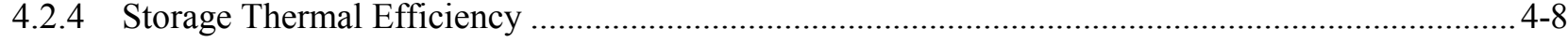

4.2.5 Turbine Cycle Annual Efficiency........................................................................................... $4-8$

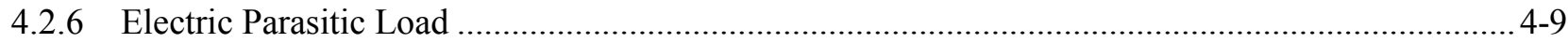

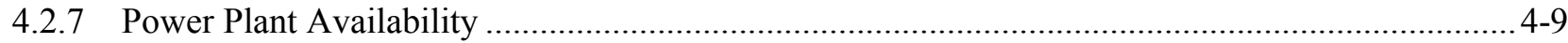

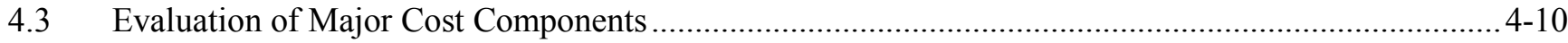

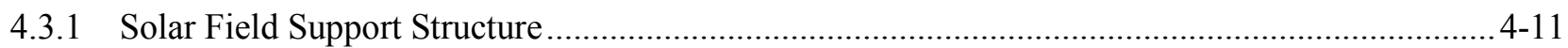




\section{CONTENTS (CONT.)}

$\underline{\text { Section }}$

4.3.2 Solar Field Heat Collection Elements (HCE) ...................................................................... 4-12

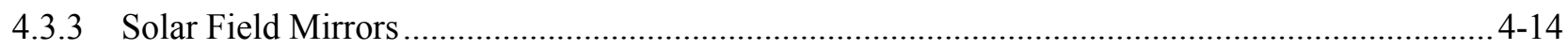

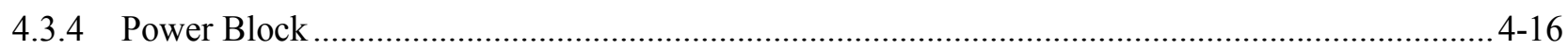

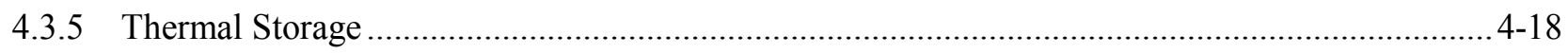

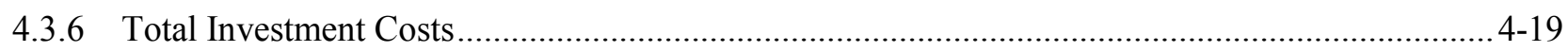

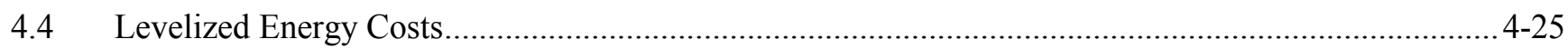

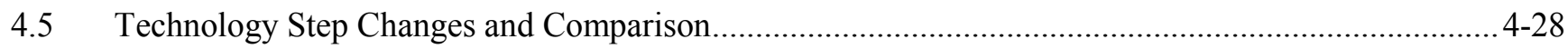

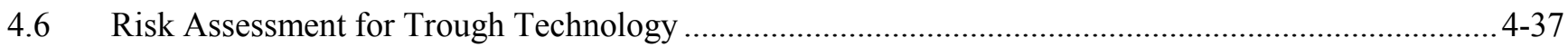

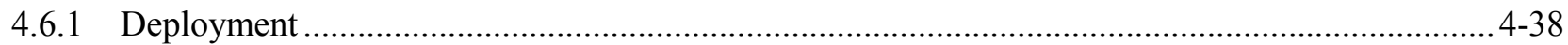

4.6.2 Net Annual Solar-to-Electric Efficiency ................................................................................. 4-39

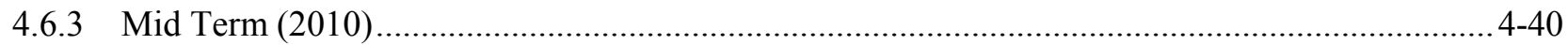

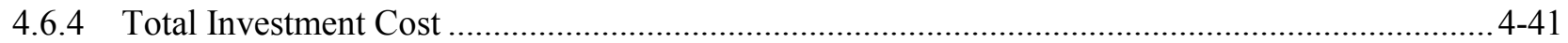

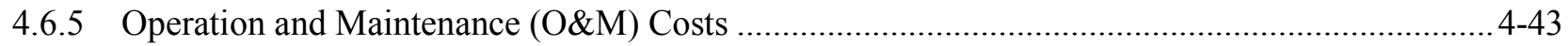

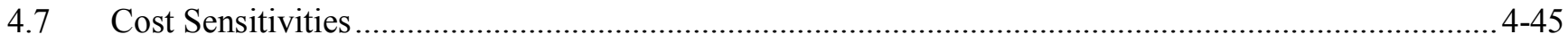

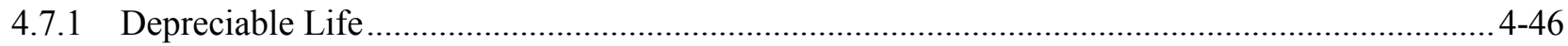

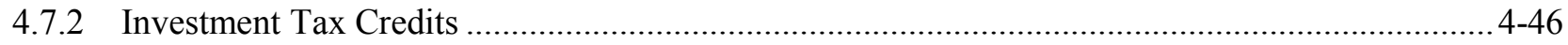

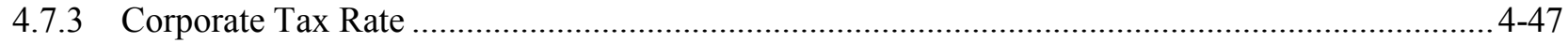

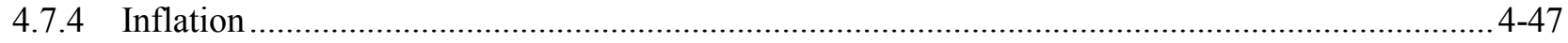

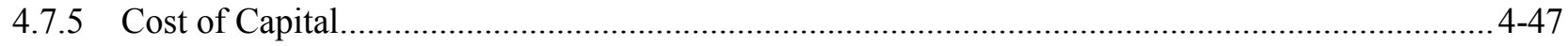

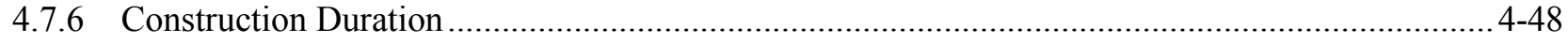

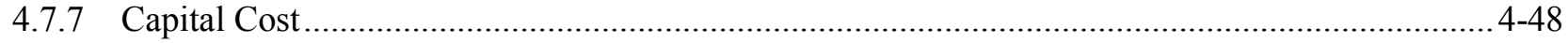

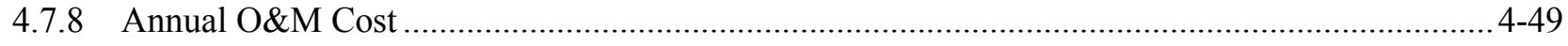

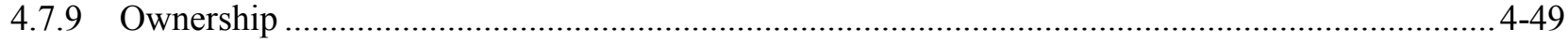

5. EVALUATION OF POTENTIAL FOR COST REDUCTIONS — TOWER......................................5-1

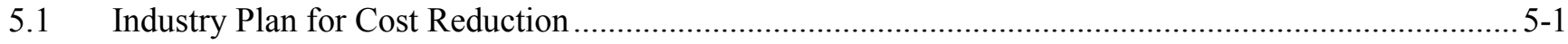

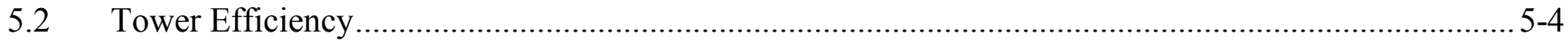




\section{CONTENTS (CONT.)}

$\underline{\text { Section }}$

Page

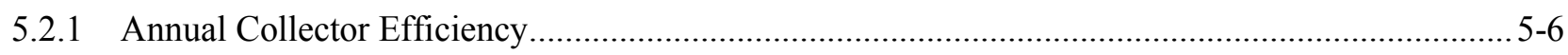

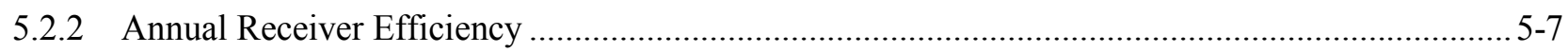

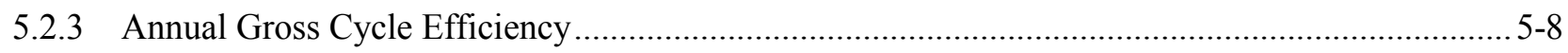

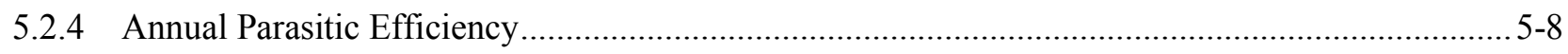

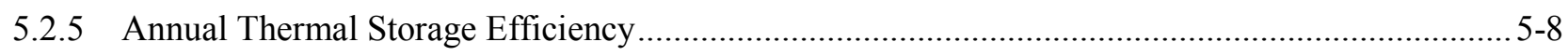

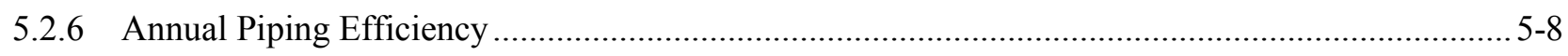

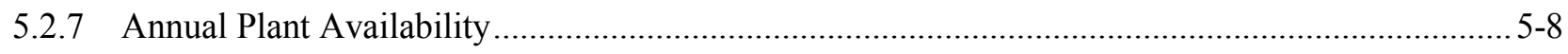

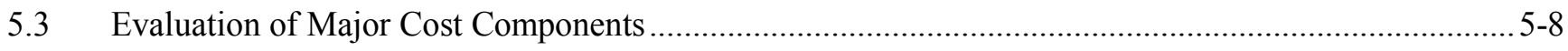

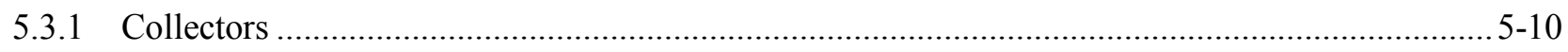

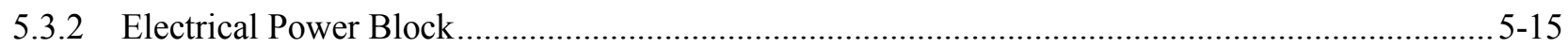

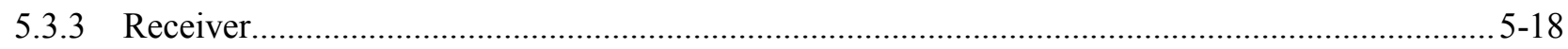

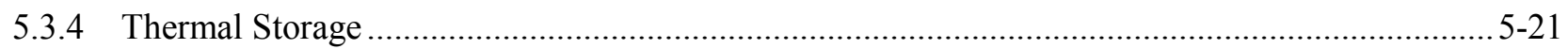

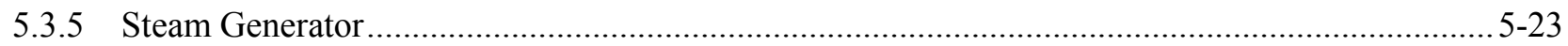

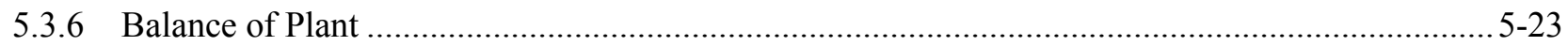

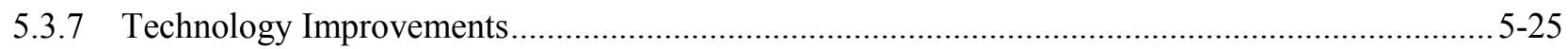

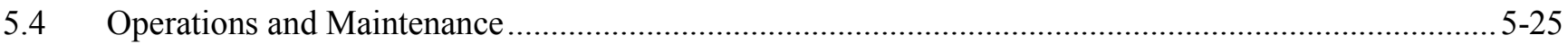

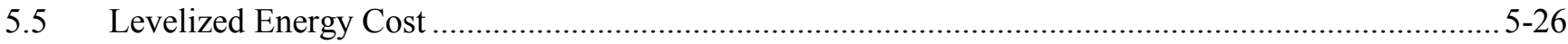

5.6 Power Tower Technology Step Changes and Comparison ........................................................ 5-32

5.7 Cost Reduction Step Changes and Breakdown Comparison........................................................5-40

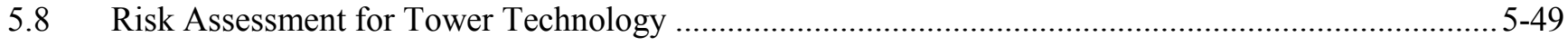

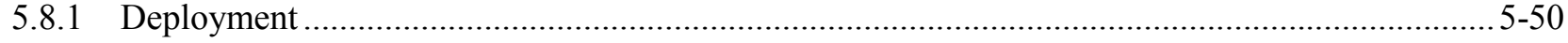

5.8.2 Net Annual Solar-to-Electric Efficiency ................................................................................ 5-52

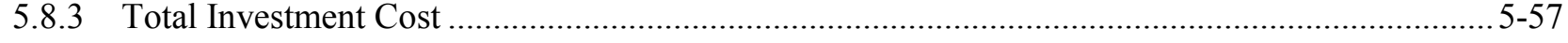

5.8.4 Operation and Maintenance (O\&M) Costs ............................................................................5-59

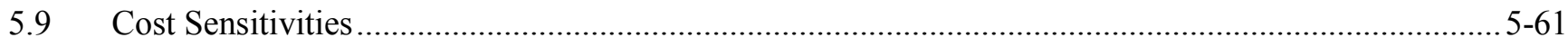

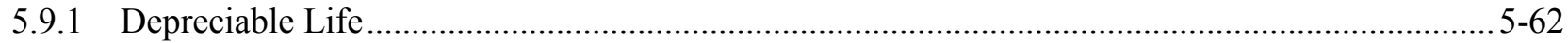

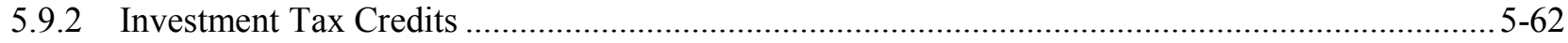




\section{CONTENTS (CONT.)}

$\underline{\text { Section }} \quad \underline{\text { Page }}$

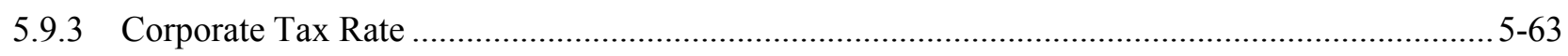

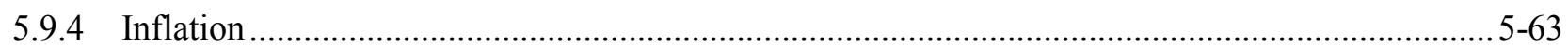

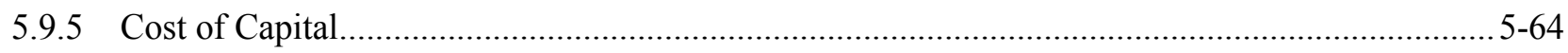

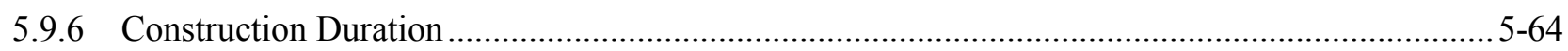

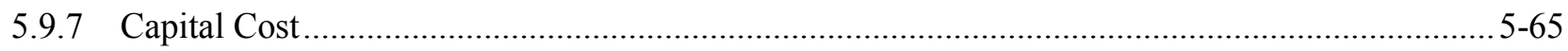

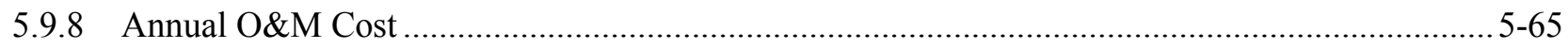

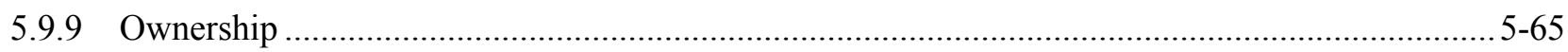




\section{APPENDIXES}
A. List of Documents
B. Methodology
C. Levelized Cost for Ranking Alternatives and Example Calculations
D. Evaluation Of Technology Improvements And Capital Cost Projections For Parabolic Trough Solar Plants
E. Evaluation of Technology Improvements and Capital Cost Projections - Tower
F. Evaluation of O\&M Costs - Trough
G. Evaluation of O\&M Costs - Tower
H. Mirror Reflectivity (SunLab Input)
I. Sargent \& Lundy Response to the NRC Issues and Observations 


\section{ACRONYMS AND ABBREVIATIONS}

Term

${ }^{\circ} \mathrm{C} /{ }^{\circ} \mathrm{F}$

ADL

ATS

CHP

CRADA

CSP

DOE

DSCR

DSG

EERE

EPSG

EU

GEF

GWe

HCE

HRSG

HTF

HTGR

IEA

IGC

ILR

IPP

IRD

IRR

ISCCS

$\mathrm{km}$

$\mathrm{kPa}$

\section{Definition or Clarification}

Degrees Celsius/degrees Fahrenheit

AD Little

Advanced Thermal Systems

Combined heat and power

Cooperative Research and Development Agreement

Concentrating Solar Power

Department of Energy

Debt service coverage ratio

Direct steam generation

Office of Energy Efficiency and Renewable Energy (a part of the DOE)

Electric power generating system

European Union

Global Environmental Facility

Gigawatts-electrical

Heat collection elements

Heat recovery steam generator

Heat transfer fluid

High-temperature gas-cooled reactor

International Energy Agency

Intergranular corrosion

Intermediate load range

Independent power producer

Industrial Research \& Development

Internal rate of return

Integrated Solar Combined Cycle System (s)

Kilometers

Kilopascals 


\section{ACRONYMS AND ABBREVIATIONS}

Term

$\mathrm{kW}$

$\mathrm{kWt}$

LCOE

LEC

MACRS

MW

MWe

MWt

NRC

NREL

O\&M

PR

PTC

PV

$\mathrm{R} \& \mathrm{D}$

Sargent \&

Lundy or S\&L

SCA

SEGS

SNL

SunLab

TES

\section{Definition or Clarification}

Kilowatts

Kilowatts-thermal

Levelized costs of energy

Levelized energy cost

Modified Accelerated Cost Recovery System

Megawatts

Megawatts-electrical

Megawatts-thermal

National Research Council

National Renewable Energy Laboratory

Operation and maintenance

Progress ratio

Energy Production Tax Credit

Photovoltaic

Research and development

Sargent \& Lundy LLC

Solar collector assembly

Solar Electric Generating Station

Sandia National Laboratories

SunLab comprises researchers from Sandia National Laboratories and the National Renewable Energy Laboratory working together on Concentrating Solar Power technology for the Department of Energy

Thermal energy storage 


\section{ACKNOWLEDGEMENTS}

Sargent \& Lundy would like to thank the following individuals and organizations for their important contributions to this study:
R. D. (Dale) Rogers Boeing
Robert Litwin Boeing
Pat DeLaquil Clean Energy Commercialization
Frank Wilkins Department of Energy
Gilbert Cohen Duke Solar
David Kearney Kearney \& Associates
Mark Mehos National Renewable Energy Laboratory
Fredrick Morse $\quad$ Morse Associates, Inc.
Henry Price National Renewable Energy Laboratory (SunLab)
William Gould Nexant
Scott Jones Sandia National Laboratories (SunLab) 


\section{EXECUTIVE SUMMARY}

\section{PURPOSE AND SCOPE}

A review of DOE's Renewable Energy Programs by the National Research Council in 2000 (Renewable Power Pathways: A Review of the U.S. Department of Energy's Renewable Energy Programs, NRC-2000) recommended that DOE "should limit or halt its $R \& D$ on power-tower and power-trough technologies because further refinements to these concepts will not further their deployment." Subsequent DOE funding requests for Concentrating Solar Power (CSP) technology development have been sharply reduced (FY02, FY03) or zero (FY04). In 2002, DOE's Office of Energy Efficiency and Renewable Energy (DOE/EERE) conducted a Strategic Program Review that, among other things, identified a need for further technical analysis of CSP R\&D. In response, DOE/EERE initiated a review process whereby an independent engineering firm would conduct a detailed analysis of CSP, which would in turn be reviewed by a second independent NRC panel.

Sargent \& Lundy LLC (S\&L) was selected by DOE/EERE to conduct this independent "due-diligence-like" analysis of parabolic trough and power tower solar technology cost and performance. The work by S\&L was done in close collaboration with the National Research Council (NRC) Committee, which was contracted by DOE/EERE to provide this second level of independent review.

As detailed below, S\&L's analysis of the cost-reduction potential of CSP technology over the next 10-20 years included the following:

- Examination of the current trough and tower baseline technologies that are examples of the next plants to be built, including a detailed assessment of the cost and performance basis for these plants.

- Analysis of the industry projections for technology improvement and plant scale-up out to 2020, including a detailed assessment of the cost and performance projections for future trough and tower plants based on factors such as technology R\&D progress, economies of scale, economies of learning resulting from increased deployment, and experience-related O\&M cost reductions resulting from deployments.

- Assessment of the level of cost reductions and performance improvements that, based on S\&L experience, are most likely to be achieved, and a financial analysis of the cost of electricity from such future solar trough and tower plants. 


\section{SARGENT \& LUNDY CONCLUSIONS}

Based on this review, it is S\&L's opinion that CSP technology is a proven technology for energy production, there is a potential market for CSP technology, and that significant cost reductions are achievable assuming reasonable deployment of CSP technologies occurs. S\&L independently projected capital and O\&M costs, from which the levelized energy costs were derived, based on a conservative approach whereby the technology improvements are limited to current demonstrated or tested improvements and with a relatively low rate of deployment (this does not mean that there is no technology development, only that the technologies have been demonstrated or tested at some scale so that no breakthroughs are required; further scale-up and engineering are required with associated risks).

The projections for electrical power consumption in the United States and worldwide vary depending on the study, but there will be a significant increase in installed capacity due to increased demand through 2020 . Trough and tower solar power plants can compete with technologies that provide bulk power to the electric utility transmission and distribution systems if market entry barriers are overcome:

- Market expansion of trough and tower technology will require incentives to reach market acceptance (competitiveness). Both tower and trough technology currently produce electricity that is more expensive than conventional fossil-fueled technology. Analysis of incentives required to reach market acceptance is not within the scope of the report.

- $\quad$ Significant cost reductions will be required to reach market acceptance (competitiveness). S\&L focused on the potential of cost reductions with the assumption that incentives will occur to support deployment through market expansion.

For the more technically aggressive low-cost case, S\&L found the National Laboratories" "SunLab" methodology and analysis to be credible. The projections by SunLab, developed in conjunction with industry, are considered by S\&L to represent a "best-case analysis" in which the technology is optimized and a high deployment rate is achieved. The two sets of estimates, by SunLab and S\&L, provide a band within which the costs can be expected to fall. The figure and table below highlight these results, with initial electricity costs in the range of 10 to $12.6 \phi / \mathrm{kWh}$ and eventually achieving costs in the range of 3.5 to $6.2 \phi / \mathrm{kWh}$. The specific values will depend on total capacity of various technologies deployed and the extent of R\&D program success. In the technically aggressive cases for troughs / towers, the $\mathrm{S} \& \mathrm{~L}$ analysis found that cost reductions were due to volume production $(26 \% / 28 \%)$, plant scale-up (20\%/48\%), and technological advance $(54 \% / 24 \%)$. 


\section{Figure ES-1 — Levelized Energy Cost Summary}

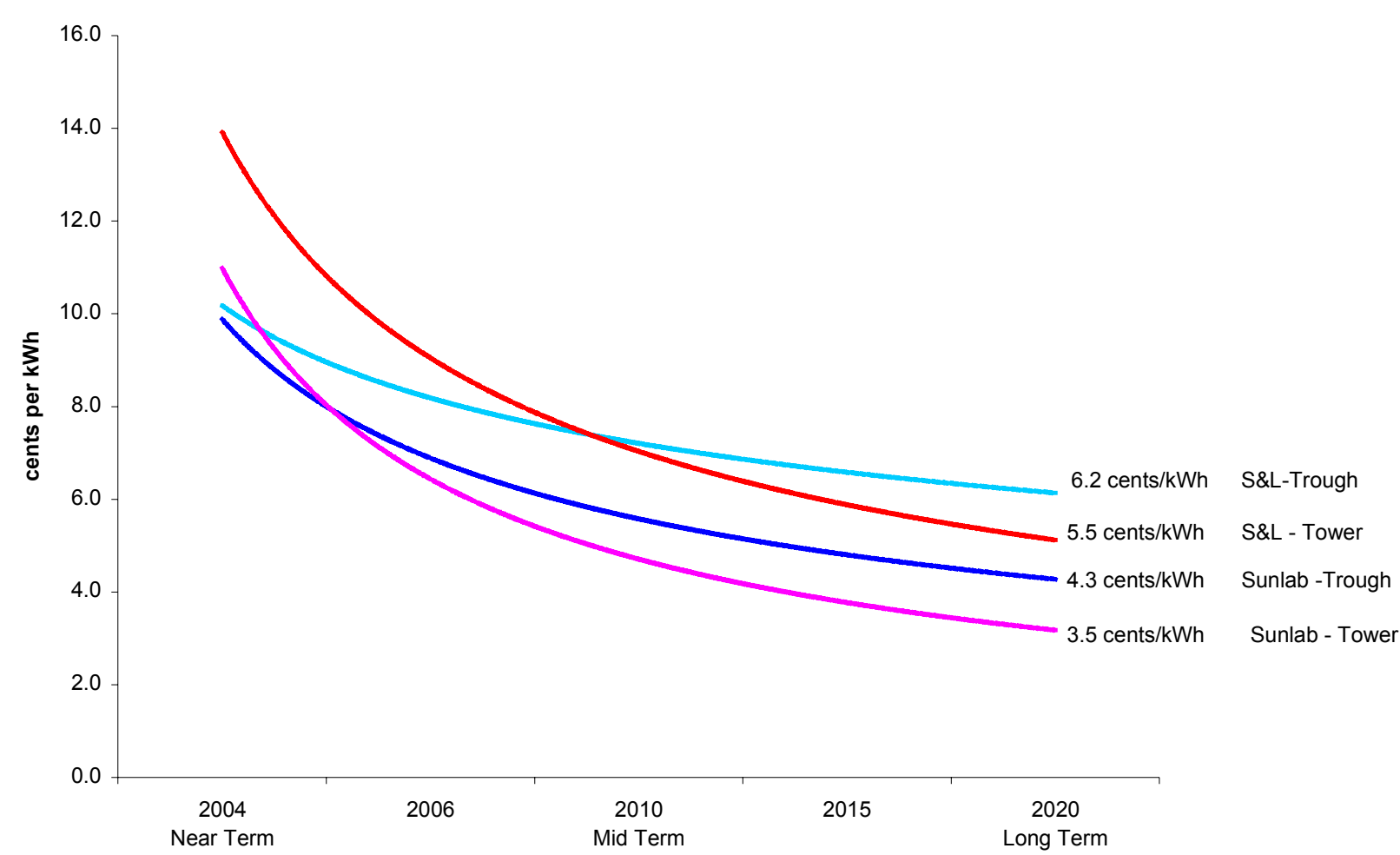

Sargent \& Lundy allocated cost reduction as follows:

\begin{tabular}{|l|c|c|c|c|}
\hline & $\begin{array}{c}\text { S\&L High-Cost } \\
\text { Bound }\end{array}$ & $\begin{array}{c}\text { Cumulative } \\
\text { Deployment } \\
\mathbf{2 0 0 2 - 2 0 2 0}\end{array}$ & $\begin{array}{c}\text { SunLab Low-Cost } \\
\text { Bound }\end{array}$ & $\begin{array}{c}\text { Cumulative } \\
\text { Deployment } \\
\text { 2002-2020 }\end{array}$ \\
\hline Troughs & 6.2 cents $/ \mathrm{kWh}$ & $2.8 \mathrm{GWe}$ & 4.3 cents $/ \mathrm{kWh}$ & $4.9 \mathrm{GWe}$ \\
\hline Towers & 5.5 cents $/ \mathrm{kWh}$ & $2.6 \mathrm{GWe}$ & $3.5 \mathrm{cents} / \mathrm{kWh}$ & $8.7 \mathrm{GWe}$ \\
\hline
\end{tabular}

Trough technology is further advanced than tower technology. Trough technology has $354 \mathrm{MW}$ of commercial generation in operation in the southwestern United States. Tower technology has been successfully demonstrated with a conceptual and pilot plants (Solar One and Solar Two). Trough technology is a fully mature technology, and there is low technical and financial risk in developing near-term plants. The long-term projection has a higher risk due to technology advances needed in thermal storage. The tower technology needs to proceed from demonstration to commercial development. There is a higher technical and financial risk in developing a first-of-its-kind commercial plant. The advantage of tower technology is that if commercial 
development is successful (e.g., if expected cost and performance targets are achieved), then the levelized energy cost (LEC) for long-term deployment will be less than for trough technology.

\section{TROUGH TECHNOLOGY}

\section{Trough Technology Summary}

The cost, performance, and risk of parabolic trough technology are fairly well established by the experience of the existing operating parabolic trough plants. Based on the data available to S\&L, the analysis bounds the future potential cost of parabolic trough power.

- Assuming the technology improvements are limited to current demonstrated or tested improvements and a deployment of $2.8 \mathrm{GWe}$ of installed capacity by the year 2020 and successful development of a thermal storage system, trough costs should be able to drop to approximately $6.2 \notin / \mathrm{kWh}$

- Assuming the projected technical improvements are achieved by an active R\&D program combined with incentives and deployment of $4.9 \mathrm{GWe}$, the trough costs projected by Sunlab of about $4 \phi / \mathrm{kWh}$ could be acheived.

\section{Trough Technology S\&L Base Case}

The base case for the S\&L trough technology cost estimates is as follows:

\begin{tabular}{lc} 
& Trough \\
\cline { 2 - 2 } Year & 2020 \\
Capacity, MWe & 400 \\
Capacity Factor, \% & $56.2 \%$ \\
Capital Cost, \$/kW & $\$ 3,220$ \\
Annual O\&M Cost, \$k & $\$ 14,129$ \\
Levelized Energy Cost (LEC), \$/kWh & $\$ 0.0621$ \\
Economic Life & $30 \mathrm{yrs}$ \\
General Inflation & $2.5 \%$ \\
Equity Rate of Return & $14 \%$ \\
Cost of Construction & $7 \%$ \\
Construction Duration & $1 \mathrm{yr}$. \\
Investment Tax Credit & $10 \%$ \\
Taxes & $40.2 \%$ \\
Depreciable Life & $5 \mathrm{yrs}$.
\end{tabular}




\begin{tabular}{lc} 
& Trough \\
\cline { 2 - 2 } Internal Rate of Return (IRR) & $14 \%$ \\
Debt Service Coverage Ratio (DSCR) & 1.35 \\
Ownership & IPP
\end{tabular}

\section{Differences and Rational for the S\&L Trough Technology Projection}

The DOE Concentrating Solar Power Program has developed detailed baseline cost and performance data for the parabolic trough technology. In addition, detailed technology R\&D plans specify how these technologies are expected to change over time. DOE also has established assumed plant deployment forecasts over time. The S\&L due-diligence-like approach used in this study reviewed the technology cost, performance, technology $\mathrm{R} \& \mathrm{D}$, and deployment assumptions and identified the areas where the assumptions have not been fully demonstrated. The S\&L review was based on discussions with SunLab, interaction with the CSP industry, input from other experts, and S\&L in-house technical expertise.

Relatively detailed cost and performance data are available from existing operating parabolic trough power plants. As a result, near-term estimates are relatively close between the SunLab case and the S\&L case. In the longer-term (2020), the S\&L projection differs from the SunLab trough cases in several key areas. A more conservative estimate of improvements in annual solar-to-electric efficiency is used, a less aggressive estimate in collector cost reductions due to lower expected deployments, and a somewhat higher O\&M cost.

The projected levelized energy cost of electricity in 2020 estimated by S\&L is $45 \%$ higher than the SunLab case. The main differences and rational for the S\&L projections are the following:

- The annual solar-to-electric efficiency in the S\&L case is lower than the SunLab case for the following reasons (SunLab 17.2\%, S\&L 15.5\%)

- Receiver performance based on demonstrated UVAC technology. Absorption of 94.4\% (SunLab 96\%), envelop transmittance of 96.5\% (SunLab of 97\%), and emittance of $10 \%$ at 400C (SunLab 7\%).

- Mirror reflectivity efficiency was not increased beyond the demonstrated value of $93.5 \%$ (SunLab 95\%). Increase would require advanced glass or other reflective membranes.

- Mirror cleanliness efficiency was not increased beyond the demonstrated value of $95 \%$ (SunLab 96\%). Increase would require new materials and significant enhancements in cleaning equipment and methods.

- The capital cost in the S\&L case is $45 \%$ higher than the SunLab case for the following reasons. (SunLab \$2,221/kWe, S\&L \$3,220/kWe) 
- The lower S\&L solar-to-electric efficiency requires a larger solar field to compensate. The S\&L case assume an $11 \%$ increase in solar field.

- The S\&L case assumes a lower deployment 2.8 GWe by 2020 verses the SunLab deployment assumption of $4.8 \mathrm{GWe}$. As a result, less production-based learning was assumed.

- Cost estimates for steam turbines and balance-of-plant costs were estimated by S\&L using the EPRI SOAPP model, compared to S\&L's internal cost database, and adjusted for labor and productivity rates in the southwestern states. The S\&L estimates for steam turbines were less than SunLab. The S\&L estimates for balance-of-plant costs were comparable to SunLab.

- S\&L estimated that the engineering, management, and development to be $15 \%$ of the capital cost as compared to SunLab estimate of $7.8 \%$.

- Sargent \& Lundy's estimate of the O\&M costs is higher than SunLab for the following reasons:

- S\&L scaled-up the cost of field and vehicle maintenance to account for the increase in field size

- Raw water cost used by S\&L is based on actual cost reports at SEGS of $\$ 0.00122$ per gallon $\left(\$ 0.32\right.$ per $\mathrm{m}^{3}$ ). SunLab estimated the cost to be $\$ 0.021 \mathrm{per}^{3}$, which is about 15 times less than the S\&L estimate.

\section{Trough Technology Cost Sensitivity}

Variations in the inputs for levelized energy costs were calculated to illustrate the sensitivity to variations.

\begin{tabular}{lll} 
& LEC & Variation \\
\hline Sargent \& Lundy Base Case for 2020 & $\$ 0.0621 / \mathrm{kWh}$ & \\
\hline Financial Incentives & & \\
$\quad$ Impact of Eliminating 5-year MACRS & $\$ 0.0698$ & $12.5 \%$ \\
$\quad$ Impact of Eliminating 10\% Investment Tax Credit & $\$ 0.067$ & $7.8 \%$ \\
$\quad$ ITC) & & $-26.9 \%$ \\
$\quad \begin{array}{l}\text { Replacing ITC with Production Tax Credit of } \\
1.8 \phi / \text { kWh }\end{array}$ & $\$ 0.049$ & \\
\hline $\begin{array}{l}\text { Project Cost } \\
\text { Increasing Cost of Equity by 1\% }\end{array}$ & & $7.7 \%$ \\
Increasing Construction Period to 2 Years & $\$ 0.0668$ & $5.5 \%$ \\
Increase in Capital Cost by 10\% & $\$ 0.0655$ & $8.8 \%$ \\
Increase in Annual O\&M Cost by 20\% & $\$ 0.0675$ & $2.3 \%$ \\
\hline
\end{tabular}




\begin{tabular}{lll} 
& LEC & Variation \\
\hline Ownership & & $-3.9 \%$ \\
$\quad$ Utility Ownership & $\$ 0.0597$ & $-26.1 \%$ \\
$\quad$ Municipal Utility Ownership & $\$ 0.0458$ & \\
\hline Technology \& Deployment & & $-4.7 \%$ \\
$\quad$ Increased Deployment from $2.8 \mathrm{GWe}$ to $4.9 \mathrm{GWe}$ & $\$ 0.0593$ & $-16.3 \%$
\end{tabular}

\section{Trough Technology Risk Analysis}

The major risk for parabolic trough solar plants to reach market acceptance (competitiveness) is the incentives that will allow the plant to be competitive with current non-renewable cost of generating power. Assuming incentives are provided the risk for achieving cost reduction over the next $10-20$ years is low to average.

The capital cost estimate for the initial deployment was developed by SunLab based on actual costs for the SEGS plants, detailed cost models developed by industry, and spare part data for the SEGS plant. S\&L reviewed published cost data and updated the information to include the latest cost estimate for receivers from Solel, mirrors from FlagSol, collector structure costs from EuroTrough and Duke Solar, electrical power generation system and balance-of-plant costs from the EPRI SOAPP program and S\&L's internal database, and increased contingencies. The S\&L estimate is $15 \%$ higher than the SunLab estimate, which is within an acceptable range.

Cost reductions are achieved from technology improvements, economy of scale, and volume production. The risk of achieving the technology improvements projected by S\&L is low based on field-demonstrated technology at the SEGS plants and ongoing research by Duke Solar, Solel, FlagSol, and others. The one technology risk element left in the S\&L case was the switch to molten-salt heat transfer fluid (HTF), which is key to driving down future costs. This switch adds some additional risk to the technology. A parametric case is included that assumes no thermal storage to see the impact of this technology.

Economy of scale is a well-established method of estimating the cost of components of a new size or quantity from the known cost for a different size or capacity. The risk of achieving the cost improvements projected by S\&L from economy of scale is low based on (a) using well-established scaling factor ratios from industry data (e.g. balance-of-plant, receivers, and electric power system) or (b) if no data are available, then using scaling 
factors slightly more conservative than the industry average. The risk of achieving the cost improvements from volume production projected by S\&L is low based on the cost reduction experience from the SEGS plants.

\section{Key Trough Technology Conclusions}

A number of key technology advances will cause near-term trough plants to be a significant improvement over the SEGS units. These include:

- Development of the new Solel UVAC receiver, improving collector field thermal performance by $20 \%$.

- Development of a near-term thermal storage option for troughs by Nexant and SunLab. The design is likely to be demonstrated at the first trough plant to be built in Spain.

- Replacement of flex hoses with ball joint assemblies in the collector field, significantly reducing HTF pumping parasitics and increasing the potential size of future parabolic trough solar fields.

The development of longer-term, more advanced thermal storage technologies is critical. This path offers the largest cost reduction potential, as follows.

- Integral with advanced thermal storage is the implementation of a higher temperature heat transfer fluid in the $450^{\circ}-500^{\circ} \mathrm{C}$ range. (SunLab and international $\mathrm{R} \& \mathrm{D}$ groups have significant efforts underway.)

- However, increasing trough-operating temperature to $500^{\circ} \mathrm{C}$ appears to have minimal impact on the eventual LEC compared to $450^{\circ} \mathrm{C}$. This is contrary to earlier conclusions, necessitating a more detailed assessment in the near future.

Significant cost reductions appear reachable in all three key trough components - structure, receiver, and reflectors- though brought about by different cost reduction mechanisms.

- Concentrator cost reduction will depend largely on size scale-up, production volume, and increased competition. (Significant industrial efforts are currently in progress by Duke Solar \& EuroTrough.)

- Alternative reflector (mirror) options and production volume are projected to drop costs significantly.

- Achieving an operating temperature of $450^{\circ} \mathrm{C}$ with current receiver technology appears feasible. However, the development of a higher performing and more reliable receiver is very important to achieve SunLab long-term cost and performance goals (labs and industry are addressing this).

O\&M procedures are expected to continue downward with scale-up, increasing field experience, and technology improvements in reliability. 


\section{TOWER TECHNOLOGY}

\section{Tower Technology Summary}

Because no commercial power tower plants have been built, there is more uncertainty in the cost, performance, and technical risk of this technology. Based on the data available to $S \& L$, the analysis bounds the future potential cost of power tower plants.

- Assuming the technology improvements are limited to current demonstrated or tested improvements and a deployment of $2.6 \mathrm{GWe}$ of installed capacity by the year 2020, tower costs should be able to drop to approximately $5.5 \notin / \mathrm{kWh}$

- Assuming the projected technical improvements are achieved by an active R\&D program combined with incentives and deployment of $8.7 \mathrm{GWe}$, the tower costs projected by Sunlab of about $3.5 \phi / \mathrm{kWh}$ could be achieved.

\section{Tower Technology S\&L Base Case}

The base case for the Sargent $\&$ Lundy tower technology cost estimates is as follows:

Year

Capacity, MWe

Capacity Factor, \%

Capital Cost, $\$ / \mathrm{kW}$

Annual O\&M Cost, \$k

Levelized Energy Cost (LEC), \$/kWh

Economic Life

General Inflation

Equity Rate of Return

Cost of Construction

Construction Duration

Investment Tax Credit

Taxes

Depreciable Life

Internal Rate of Return (IRR)

Debt Service Coverage Ratio (DSCR)

Ownership

\section{Tower}

2020

200

$72.9 \%$

$\$ 3,622$

$\$ 9,132$

$\$ 0.0547$

$30 \mathrm{yrs}$

$2.5 \%$

$14 \%$

$7 \%$

$1 \mathrm{yr}$.

$10 \%$

$40.2 \%$

5 yrs.

$14 \%$

1.35

IPP 


\section{Differences and Rational for the S\&L Tower Technology Projection}

The DOE Concentrating Solar Power Program has developed detailed baseline cost and performance data for the power tower technology. In addition, detailed technology R\&D plans specify how these technologies are expected to change over time. DOE also has established assumed plant deployment forecasts over time. The S\&L due-diligence-like approach used in this study reviewed the technology cost, performance, technology $\mathrm{R} \& \mathrm{D}$, and deployment assumptions and identified the areas where the assumptions have not been fully demonstrated. The S\&L review was based on discussions with SunLab, interaction with the CSP industry, input from other experts, and S\&L in-house technical expertise.

The projected levelized energy costs of electricity in 2020 estimated by S\&L are $65 \%$ higher than the projections by SunLab. The main differences and rational for the S\&L projections are the following:

- $\quad$ Sargent \& Lundy did not assume deployment of the advanced high temperature turbine and heliostats in 2020, whereas the SunLab assumed deployment in 2018.

- Sargent \& Lundy cost estimate for heliostats, which are about $45 \%$ of the total cost, are about $10 \%$ higher. The S\&L estimate is based on our evaluation of cost estimates prepared by SunLab, AD Little, Advanced Thermal Systems, Solar Kinetics, and Winsmith.

- S\&L used a contingency of $10 \%$ as compared to SunLab of $5 \%$.

- S\&L estimated deployment at about $25 \%$ of the SunLab estimate to take into consideration a realistic duration between the first and second deployment and between increases in plant size.

- S\&L manufacturing costs are higher as a result of our evaluation

- Sargent \& Lundy estimated the costs for steam turbines and balance of plant costs using the EPRI SOAPP model, compared to S\&L's internal cost database and adjusted for labor and productivity rates in the southwestern states. The $S \& L$ estimate for steam turbines were less than SunLab. The S\&L estimates for balance-of-plant costs were higher than SunLab.

- The S\&L receiver capital costs are based on a cost estimate provided by Boeing. Boeing was the supplier of the Solar Two receiver and is providing the receiver for Solar Tres.

- Sargent \& Lundy estimated that the engineering, management, and development to be $15 \%$ of the capital cost as compared to SunLab estimate of $7.8 \%$.

- SunLab included a risk pool contingency of $10 \%$ for Solar Tres, and S\&L concurs with this value. In addition, S\&L included a risk pool contingency of 5\% for Solar 50 .

- S\&L included a contingency of $12 \%$ for direct costs and $15 \%$ for cost reduction, in comparison to SunLab's contingency of $7.8 \%$ 
- The efficiency projections by S\&L were based on a review of the SunLab Reference Case, demonstrated efficiencies, design modifications based on lessons learned from Solar Two, and turbine generator computer model. The main differences are the following:

- Mirror reflectivity efficiency was not increased beyond the demonstrated value of $95 \%$. Increase would require advanced glass or other reflective membranes.

- Mirror cleanliness efficiency was not increased beyond the demonstrated value of $95 \%$. Increase would require new materials and significant enhancements in cleaning equipment and methods.

- Near-term efficiencies were based on the ABB-Brown Boveri heat balance for SEGS IX. The efficiency for other size units was verified by using the General Electric STGPer software program.

- Efficiency has a direct impact on the size of the collector field. The increase in collector field area and corresponding increase in capital cost was calculated based on the lower efficiency estimated by S\&L.

- S\&L estimate of the O\&M costs is higher than SunLab for the following reasons:

- S\&L scaled-up the cost of field and vehicle maintenance to account for the increase in field size.

- S\&L assumed that the average burdened rate would not decrease between Solar 100 and Solar 220.

- Raw water cost used by S\&L is based on actual cost reports at SEGS of $\$ 0.00122$ per gallon $\left(\$ 0.32\right.$ per $\left.\mathrm{m}^{3}\right)$. SunLab estimated the cost to be $\$ 0.021$ per $\left.\mathrm{m}^{3}\right)$, which is about 15 times less than the $\mathrm{S} \& \mathrm{~L}$ estimate.

- S\&L included a $10 \%$ contingency.

\section{Tower Technology Cost Sensitivity}

Variations in the inputs for levelized energy costs were calculated to illustrate the sensitivity to variations.

LEC

Variation

S\&L Base Case for 2020

Financial Incentives

Impact of Eliminating 5-year MACRS

Impact of Eliminating 10\% Investment Tax Credit (ITC)

Replacing ITC with Production Tax Credit of $1.8 \phi / \mathrm{kWh}$
$\$ 0.0547 / \mathrm{kWh}$

$\$ 0.0614$

$12.3 \%$

$\$ 0.0590$

$7.8 \%$

$\$ 0.0410$

$-30.5 \%$ 


\section{LEC}

\section{Variation}

\section{Project Cost}

Increasing Cost of Equity by $1 \%$

$\$ 0.0588$

$7.6 \%$

Increasing Construction Period to 2 Years

$\$ 0.0577$

$5.4 \%$

Increase in Capital Cost by $10 \%$

$\$ 0.0595$

$8.7 \%$

Increase in Annual O\&M Cost by $20 \%$

$\$ 0.0561$

$2.6 \%$

\section{Ownership \\ Utility Ownership \\ Municipal Utility Ownership}

$\$ 0.0526$

$-3.8 \%$

$\$ 0.0406$

$-25.7 \%$

\section{Technology \& Deployment}

Increased Deployment from 2.6 GWe to $8.7 \mathrm{GWe}$

$\$ 0.0524$

$-4.2 \%$

Advanced Technology Case with Advanced

$\$ 0.0487$

$-11.0 \%$

Heliostat and High Temperature Turbine-

Generator (from $16.5 \%$ to $17.4 \%$ )

Worst Case Efficiency (from $16.5 \%$ to $14.6 \%$ )

$\$ 0.0590$

$7.9 \%$

\section{Tower Technology Risk Analysis}

The major risk for tower solar plants to reach market acceptance (competitiveness) is the incentives that will allow the plant to be competitive with current non-renewable cost of generating power. Assuming incentives are provided, the risk for achieving cost reduction over the next 10-20 years is low to average.

The capital cost estimate for the initial deployment was developed by SunLab based on actual costs for Solar Two, the Central Receiver Utility Studies, the AD Little heliostat detailed cost estimate, detailed heliostat design from ATS, and industry data. S\&L reviewed published cost data and updated the information to include the latest cost estimate for receivers from Boeing, electrical power generation system and balance-of-plant costs from the EPRI SOAPP program and S\&L's internal database, and increased contingencies. The S\&L estimate is $15 \%$ higher than the SunLab estimate, which is within an acceptable range.

Cost reductions are achieved from technology improvements, economy of scale, and volume production. The risk of achieving the technology improvements projected by S\&L is low based on demonstrated technology, design enhancements from lessons learned during Solar Two, improved advances in control technology since Solar Two, and ongoing research by Boeing. Economy of scale is a well-established method of estimating the 
cost of components of a new size or quantity from the known cost for a different size or capacity. The risk of achieving the cost improvements projected by S\&L from economy of scale is low based on (a) using wellestablished scaling factor ratios from industry data (e.g. balance of plant, receivers, and electric power system) or (b) if no data are available, then using scaling factors slightly more conservative than the industry average. The risk of achieving the cost improvements from volume production projected by S\&L is low based on using a progress ratio of 0.97 , which is at the upper end of published data. Various studies on learning curves from actual data suggest a progress ratio of 0.82 for development of photovoltaics and 0.95 for development of wind power.

\section{Key Tower Technology Conclusions}

Solar plant and power plant scale-up provide the largest cost reduction opportunity for power tower technologies.

- Scale-up of the tower solar plant requires a total redesign and re-optimization of the field, tower, and receiver. This greatly reduces capital and O\&M costs, but has only a small effect on efficiency. R\&D support in the design, development, and testing of larger receivers, larger heliostats, and larger heliostat fields will reduce scale-up risk.

- Scale-up of the steam turbine increases efficiency, and reduces capital and O\&M costs. Probability of success here is very high, as no development is required until high-efficiency supercritical steam turbines become available (2020).

Key technical advances include increasing receiver solar flux levels, development of new heliostat designs with significantly lower costs, and the use of new highly efficient steam turbines.

- Increased receiver flux levels have been demonstrated at the prototype scale and require improved heliostat field flux monitoring/management systems and design optimization for use at large plants.

- Revolutionary heliostat designs with significantly lower cost have been proposed that use flexible, durable thin mirrors with a lower-weight 'stretched-membrane' design that can be manufactured in high volumes. Other novel designs like inflatable/rolling heliostats are also possible.

- High-efficiency supercritical steam turbines are now being demonstrated that operate at temperatures compatible with current tower technology or at temperatures that require increasing the operating temperature of the tower technology to $600^{\circ}-650^{\circ} \mathrm{C}$.

The major volume manufacturing benefit evaluated for tower technology was related to heliostats.

- Heliostat cost reduction will occur when they are produced at high volume. Sargent \& Lundy's evaluation of the current heliostat design and cost indicated that cost should decrease $3 \%$ with 
each doubling of cumulative capacity. This would reduce the cost of a field of $148 \mathrm{~m}^{2}$ heliostats from $\$ 148 / \mathrm{m}^{2}$ to $\$ 94 / \mathrm{m}^{2}$.

\section{DISCUSSION OF NRC COMMENTS ON THE S\&L DRAFT REPORT}

The draft report of the S\&L "due-diligence-like" analysis of parabolic trough and power tower solar technology cost and performance was reviewed the National Research Council Committee. The results of the NRC review were published in "Critique of the Sargent \& Lundy Assessment of Cost and Performance Forecasts for Concentrating Solar Power." The NRC Committee recommended several methodological approaches for S\&L to follow, identified areas for further investigation by S\&L, and critically reviewed the S\&L findings.

Much of the NRC critique of the S\&L analysis centered around assumed rates of deployment and incentive issues. Deployment and incentive issues were outside the scope of work for S\&L. As noted by the NRC: "The committee notes that CSP technology is not unique in the requirement for incentivizing the early market phases of emerging energy technologies" (NRC, page 11). "The committee notes the extensive reports and study literature on these issues cited by S\&L, including DOE/EERE's own August 2002 Report to Congress on the Feasibility of 1,000 Megawatts of Solar Power in the Southwest by 2006..." (NRC, page 11). DOE noted in their presentations to the NRC and S\&L that because such studies were available, DOE's primary concern, and the reason for this study, was to determine the potential technical feasibility of CSP. Nevertheless, there are several deployment issues worth considering. First, the "chicken-and-egg" (NRC, page 15) problem of driving down costs by deploying technologies, but facing high initial costs that impede deployment, is true of all energy technologies, not just CSP. Second, as noted by the NRC and S\&L, incentives are a key determinant of the rate at which CSP, or any new energy technology, penetrates the market. Evaluating this lies well outside the technical analysis requested of S\&L. Third, the level of deployment identified by S\&L is modest, at about $2.8 \mathrm{GW}$ by 2020 . The NRC also noted that "The SunLab deployment scenarios evaluated by S\&L represent a range from a modest rate of adding one $100 \mathrm{MWe}$ plant per year (the first becoming operational in 2004) to an aggressive approach that would result in almost 5,000 MWe of new capacity by 2020" (NRC, page 5). To place this in context, the wind industry added 1,700 MW of new capacity in the U.S. in 2001 alone.

The main NRC findings that support the S\&L study are the following:

1. The NRC committee believed that a plausible estimate of levelized energy cost would lie somewhere between S\&L's and Sunlab's projections in 2020. 
- "Based on the level of uncertainty that is inherently present in projecting these deployment rates and technology advances, a more plausible estimate would lie somewhere between the two projections (S\&L's and SunLab's) in 2020. However, if deployment does not proceed at the assumed rate, the projected LEC could be much higher than either of these estimates." (NRC page 6)

2. The NRC committee agreed with S\&L on a number of its technical findings.

- "Since 1999, significant progress has been made in understanding the potential impacts of thermal storage technologies, thin film glass mirrors, improved heat collection units, improved trough support structures, and other technical opportunities to improve CSP technology." (NRC Page 4)

- “The committee agrees with S\&L's identification of key technology components for increasing the performance of trough systems to lower costs." (NRC, page 6)

- The committee has a high confidence in the estimate for power block cost reductions that will result in increasing plant sizes. (NRC, pages 7 and 8)

- "The committee believes that S\&L did a reasonable job of assessing the improvements in annual tower efficiency of power plant progression...." (NRC, page 7)

- "It is anticipated that industry R\&D will deliver the technical advances appropriate for receivers." (NRC, page 9)

- "S\&L appears to have done a reasonable job of assessing the design and capital cost potential for systems based on a near-term (or demonstrated) technologies." (NRC, page 8)

- The NRC committee agreed with S\&L's methods and review of the O\&M costs. (NRC, page 5 and 9)

3. The NRC committee agreed with S\&L that policy-based incentives are needed for initial introduction of technologies and that both R\&D and deployment of technology are necessary.

4. The committee agreed that S\&L's selection of the base case economic parameters are reasonable, but did not 'sufficiently examine the effect of uncertainties (NRC, page 5). S\&L concurs with the NRC and has included expanded sensitivity analysis in the final report.

5. The NRC committee found that S\&L was not biased and provided a creditable process within the constraints of time and the information available. Furthermore, the NRC committee stated that S\&L did reasonable job assimilating information within time and resource constraints.

- “...that S\&L took any potential conflict of interest very seriously and made a concerted effort to address and avoid it. No obvious example of bias was apparent in S\&L's interpretation of the available data nor was there any deliverate omission of pertinent facts. If anything, the S\&L 
analysis was more conservative than SunLab's estimates in assessing areas like time to develop new materials or power conversion technologies." (NRC, page 18)

- “...that S\&L attempted to maintain a credible process by filling in the gaps in its knowledge base with the advice of world-recognized experts." (NRC, page 18)

The main NRC committee recommendations to S\&L are the following:

1. The NRC committee asked for a risk assessment. The S\&L final report has been modified to include a risk assessment section per NRC recommendations.

2. The NRC committee asked for additional sensitivity analysis. The S\&L final report has been modified to include an expanded sensitivity analysis per NRC recommendations.

3. The NRC committee asked for clarification of the differences and rational for the S\&L cost estimate. The S\&L final report has been modified to include a comparison summary of the differences in the executive summary.

4. The NRC committee would have preferred a bottoms-up cost analysis. This study was never intended to provide a bottoms-up cost assessment. Unfortunately time and budgets did not allow for this type of cost analysis. Instead, a typical financial review was conducted to assess the validity of the existing data.

A considerable portion of the NRC's critique was focused on the S\&L scope of work, not results of our review as documented in the report. Sargent \& Lundy had a defined scope of work for this project, which was clearly identified in our contract. Most of the areas identified by the NRC as a critique to the S\&L Report are in fact critiques of the defined work scope. The most significant areas identified by the NRC, which were not in our scope of work, are the following:

- The type or value of incentives needed to reach market acceptance. Our report clearly identifies that this was not part of the work scope and is one of the most significant market entry barriers to overcome.

- The S\&L projection of deployment is 'not creditable'. The scope of work did not include a market analysis, which would be required to provide a deployment projection. One of the key drivers for deployment is overcoming market entry barriers, in particular incentives. As previously mentioned, incentives are needed, but the political climate and assessment of whether or when incentives would become available require significant review not considered within our scope.

- Power generation market. The S\&L draft report issued September 2002 included a discussion of power generation markets, including geography, access to established power grids, 
environmental restrictions or incentives, and taxes. Subsequently, due to a tight schedule and because such work had already been done elsewhere, the DOE directed that the scope of work not include an evaluation of the power generation market and associated issues.

- The S\&L report did not include a bottoms-up cost estimate. Our scope of work was an independent review of the cost estimates developed by SunLab for trough and tower technology. It is typical for due diligence or due diligence-like reviews to perform an independent assessment of cost estimates and documentation provided for our review and to point out areas where the estimates may be inaccurate. Typically, this type of review does not include an independent bottoms-up cost estimate. Instead, S\&L drew heavily from industry experience, vendor quotes, and other sources rather than recreate all this analysis on its own.

Sargent \& Lundy agrees that the recommended expanded scope proposed by the NRC provides additional value to the DOE. However, we believe the methodology used by S\&L stands on its own as a credible assessment of the status and potential of parabolic trough and power tower technologies. Sargent \& Lundy's response to the more significant findings in the NRC critique is included in Appendix I. 


\section{INTRODUCTION}

\subsection{BACKGROUND AND OBJECTIVE}

Several years ago, the National Research Council (NRC) issued a report (Hubbard 2000) recommending that the Department of Energy (DOE) should "limit or halt its research and development on power-tower and powertrough technologies because further refinements would not lead to deployment." Unfortunately, the report provided no analysis or description of the various advanced technology options, their costs, or their associated technical risks that the NRC considered in arriving at these conclusions.

To examine the possible factors contributing to the NRC recommendations, the DOE had the Concentrating Solar Power (CSP) Program (which provides funding for trough and tower research and development) peer reviewed in the fall of 2001. This review concluded that "the CSP Program can play an important role in catalyzing further CSP technology advances, which will further improve CSP economics and market penetration" (Tester 2001).

In order to resolve the differing conclusions between the NRC report and the Peer Review, and in accordance with its own strategic program review recommendations, the Office of Energy Efficiency and Renewable Energy (EERE), a part of the DOE, contracted Sargent \& Lundy (S\&L) to conduct a "due diligence-like" analysis of both trough and tower technologies and to have the results of the "due diligence" analysis reviewed by a new panel assembled by the NRC.

The objective of this evaluation was to assess the cost-reduction potential of CSP technology over the next 10 to 20 years. The analysis proceeded along the following steps:

1. Examination of the current trough and tower baseline technologies that are examples of the next plants to be built, including a detailed assessment of the cost and performance basis for these plants.

2. Analysis of the industry projections for technology improvement and plant scale-up out to 2020, including a detailed assessment of the cost and performance projections for future trough and tower plants based on factors such as technology research and development (R\&D) progress, economies of scale, economies of learning resulting from increased deployment, and experience-related operation and maintenance (O\&M) cost reductions resulting from deployments.

3. Assessment of the level of cost reductions and performance improvements that, based on S\&L experience, are most likely to be achieved, and a financial analysis of the cost of electricity from such future solar trough and tower plants. 
Sargent \& Lundy, with technical support from its expert consultants, reviewed available information and data to make our independent assessment. The detailed review was performed by S\&L, with only technical input from our consultants, so that we maintain as much independence as possible from the industry and from our expert consultants.

Sargent \& Lundy is not an active participant in the solar market. However, our experience includes design of the power block and civil/structural portions for the Solar Electric Generating Station (SEGS) VIII and IX in 19881989. Any future involvement in CSP plants would entail a similar scope (design of the power block and civil/structural portions). S\&L's core competence is as an architect-engineer and designer for the power block. Although we may be a participant in the project, our independence is maintained since any work would be a small portion of our overall business.

\subsection{SCOPE OF WORK}

Sargent \& Lundy received and organized data from the DOE, National Renewable Energy Laboratory (NREL), Sandia National Laboratories (SNL), and members of the CSP industry. These data included technology assessments and supporting studies for troughs and towers.

The first meeting with the NRC panel to discuss the work approach and agree on the focus of the work scope occurred on August 12, 2002. Before the meeting, S\&L, with approval from NREL, proceeded with the review based on our contractual work scope. Among the technical experts within the industry from whom we received guidance, including support on a subcontract basis, were Dave Kearney for Trough Technology and Pat DeLaquil for Tower Technology.

The work scope was modified during the first NRC meeting to focus on cost reductions and technology improvements. S\&L's scope of work included “estimate the expected competitiveness of these technologies (CSP) in peaking, cycling, and baseload applications for operation as grid-connected generators, comparing CSP technologies with other technologies commercially used for such service today (e.g. combined-cycle natural gas fired power plants)." S\&L had completed considerable work in this area before the August 12, 2002 meeting. The DOE stated that it was not the intent, nor should it be the intent, to include this in the work scope. The analysis of competing technologies will be addressed separately by the DOE. S\&L's evaluation or assessment focused on cost reduction, improvements in technology and financial analysis of levelized energy cost (LEC). Our evaluation review was based on our examination of relevant data, technical assistance from our subcontractors, our experience in the power industry and due diligence process, and industry input. The 
evaluation review is an independent evaluation of the reasonableness and feasibility that cost reductions and technology improvements can be achieved based on available information and our experience. The evaluation review does not include detailed engineering or detailed bottom-up cost estimates.

Sargent \& Lundy issued the final draft report 'Assessment of Parabolic Trough and Power Tower Solar Technology Cost and Performance Forecasts' in October 2002. The National Research Council (NRC) Committee for the Review of a Technology Assessment of Solar Power Energy Systems reviewed the report. The results of the NRC review were published in 'Critique of the Sargent \& Lundy Assessment of Cost and Performance Forecasts for Concentrating Solar Power' dated October 12, 2002. S\&L was authorized by NREL to update the report to expand the executive summary to provide more information as suggested by the NRC and perform additional sensitivity analysis. S\&L response to the NRC issues and observations are included in Appendix I.

\subsection{METHODOLOGY}

A summary of the methodology for performing this evaluation is provided in this section. A detailed discussion of the methodology and example is included in Appendix B.

\subsubsection{Data Collection}

Sargent \& Lundy received relevant documents from NREL and SNL for our independent review. During the review process, additional documents were gathered from industry sources, the Internet, and our internal S\&L library. The list of documents is included in Appendix A.

\subsubsection{Review of SunLab Cost Model}

Sargent \& Lundy reviewed the SunLab cost model and determined that the SunLab cost model approach and methodology is reasonable. The SunLab cost model was developed based on industry cost data and engineering evaluation. S\&L evaluated the assumptions in the SunLab cost model: efficiency improvements, capital cost for the near-term deployment, and cost reductions through the year 2020. The review of cost reductions included technology improvements, increase in the size of the plant (scale-up), and production volume.

The cost model was compared to S\&L's internal cost database, as appropriate (e.g., turbine, equipment, and commodities such as steel prices). 
Differences between the SunLab and S\&L cost estimates were a result of different assumptions. For example, S\&L increased the duration between the deployment of the next generation plant from 1 year to 2 years to account for lessons learned and an adequate time for steady-state operation. The differences in assumptions are identified in the main body of the report.

\subsubsection{Technical Improvements}

Projected technical improvements that reduce costs by improving plant efficiency or by reducing initial capital costs were evaluated with respect to probability of the improvement and the estimated magnitude of cost reduction. The projected technical improvements investigated were those identified in the SunLab models, and the probability and magnitude of cost reductions are based on data from DOE, NREL, SNL, and members of the CSP industry, including technology assessments and supporting studies for troughs and towers.

\subsubsection{Economy of Scale}

Economy of scale was used, as appropriate; to estimate or evaluate cost estimates for components. Scaling factors were used to estimate the cost of a new size or capacity from the known cost for a different size or capacity.

\subsubsection{Volume Production (Volume and Learning Curve)}

Experience curves define how unit costs decrease with cumulative production. The specific characteristics of the experience curve are that the cost declines by a constant percentage with each doubling of the total number of units produced (Neij 1997).

Many of the previous studies that assessed the cost reduction potential for tower and trough technologies based their findings on experience curves (World Bank 1999). As pointed out in the Teagan report (2001), "the review documents do not make a strong case that the cost of technologies (particularly the solar field) can be reduced to

a point that they approach economic viability...." His primary example was the collector field: "the "learning curve' arguments put forth lack sufficient backup to be credible given the fact that the materials of construction are already commodities and the fabrication techniques, for the most part standard." He also stated that he believed cost reductions are likely "via a combination of 'learning curve' and technology refinement." In response, S\&L performed a thorough review of the cost reduction potential for heliostats. Heliostat cost reduction potential is more difficult to estimate since it is not based on actual costs of significant volume, whereas trough costs and the cost reductions are known based on actual SEGS construction data and recent costs 
for replacement during operations and maintenance. Our detailed evaluation of cost reduction potential is provided in Appendix E.5.

Sargent \& Lundy reviewed the engineering assumptions, industry data, and studies that constitute the basis of the SunLab Cost Model for the major cost drivers. The review was not based on just applying an experience curve, but an engineering review. We reviewed the assumptions and made adjustments as deemed appropriate based on our experience. We calculated the progress ratio and compared it to actual experience curves from other industries. The calculated progress ratio value was then used to determine estimated costs for a range of deployments.

\subsubsection{Operation and Maintenance Costs}

Sargent \& Lundy reviewed the SunLab cost model against interviews and actual data provided to us during a site visit to Kramer Junction and our knowledge and internal database of O\&M costs for electric power plants. We reviewed the SunLab assumptions and made adjustments as appropriate based on our experience and information provided by Kramer Junction.

\subsubsection{Financial Modeling Analysis Methodology}

The financial model used for developing generating costs is a spreadsheet pro forma financial model of the type used in competitive industry to support power project planning and financing. S\&L regularly reviews such models as part of our due diligence practice, working with lenders and investors in project financing. In some cases we also support project developers by writing and maintaining such models for them.

The main analysis engine is a standard income statement that includes calculations of energy production, revenues, operation and maintenance expenses, fuel expenses, depreciation, insurance, property taxes, interest, investment tax credit, and income tax. The investment tax credit for solar technologies is represented. Once after-tax income was determined in the income statement, depreciation was added back and payback of debt principal was subtracted to obtain cash available for dividends. The dividend stream and equity investment into the project was combined to compute the equity internal rate of return for the project. All evaluations were done on a lifetime $\$ / \mathrm{MWh}$ evaluated cost basis, covering 30 years of service. 


\section{CONCENTRATING SOLAR POWER TECHNOLOGIES}

\subsection{TROUGH TECHNOLOGY}

\subsubsection{System Description}

The collector field in the trough technology consists of a large field of single-axis tracking parabolic trough solar collectors, as shown on the illustration to the right. The solar field is modular and is composed of many parallel rows of solar collectors aligned on a north-south horizontal axis. Each solar collector has a linear parabolicshaped reflector that focuses the sun's direct beam radiation on a linear receiver located at the focus of the parabola. The collectors track the sun from

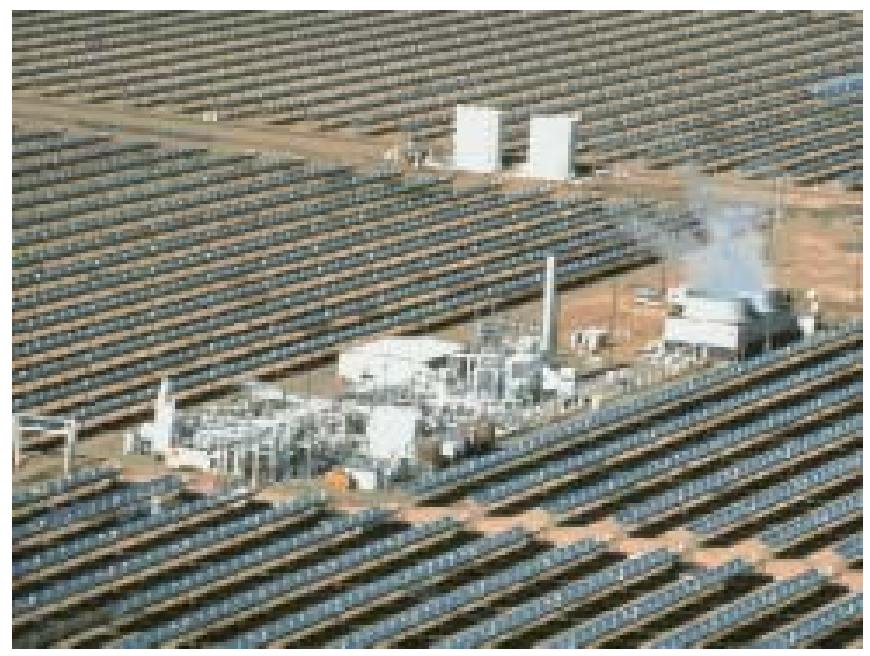
east to west during the day to ensure that the sun is continuously focused on the linear receiver. A heat transfer fluid (HTF) is heated as it circulates through the receiver and returns to a series of heat exchangers in the power block where the fluid is used to generate highpressure superheated steam. The superheated steam is then fed to a conventional reheat steam turbine/generator to produce electricity. The spent steam from the turbine is condensed in a standard condenser and returned to the heat exchangers via condensate and feedwater pumps to be transformed back into steam. After passing through the HTF side of the solar heat exchangers, the cooled HTF is recirculated through the solar field. Figure 2-1 is a process flow diagram for the trough technology. 
Figure 2-1 - Process Flow Diagram for Trough Technology

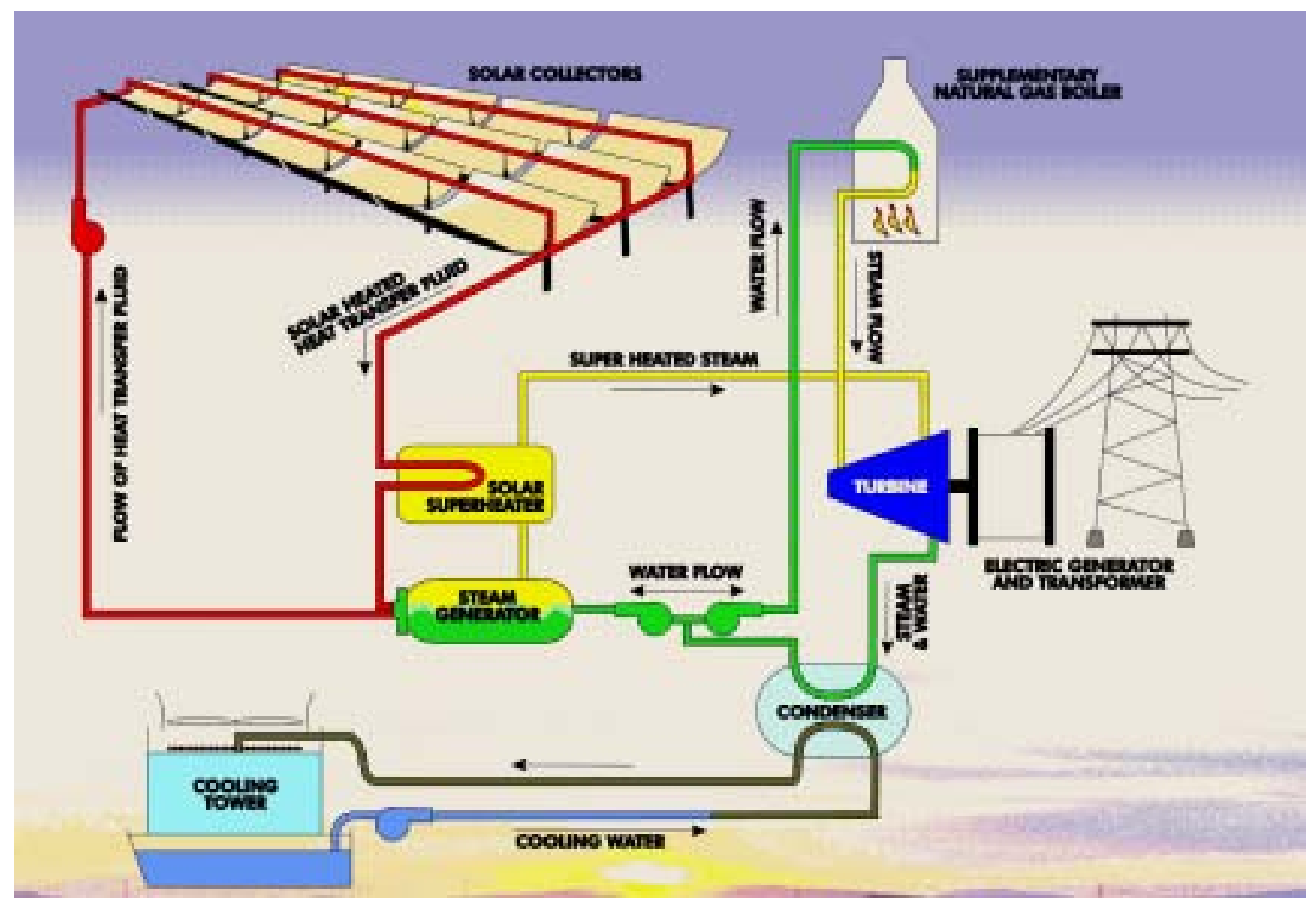

\subsubsection{Current Experience}

Parabolic trough technology is currently the most proven of the solar thermal electric technologies. The success of this technology is primarily indicated by the operation of nine large commercial-scale solar power plants, the first of which has been operating in the California Mojave Desert since 1984 (SEGS I). These plants, which continue to operate daily, range in size from 14 to 80 megawatts (MW) and represent a total of $354 \mathrm{MW}$ of installed electric generating capacity. SEGS gross production for 1985 to 2001 was 8,305,477 MWh. 


\subsection{TOWER}

\subsubsection{System Description}

Solar power towers generate electric power from sunlight by focusing concentrated solar radiation on a tower-mounted heat exchanger (receiver). The system uses hundreds to thousands of sun-tracking mirrors called heliostats to reflect the incident sunlight onto the receiver (see illustration to the right). These plants are best suited for utility-scale applications in

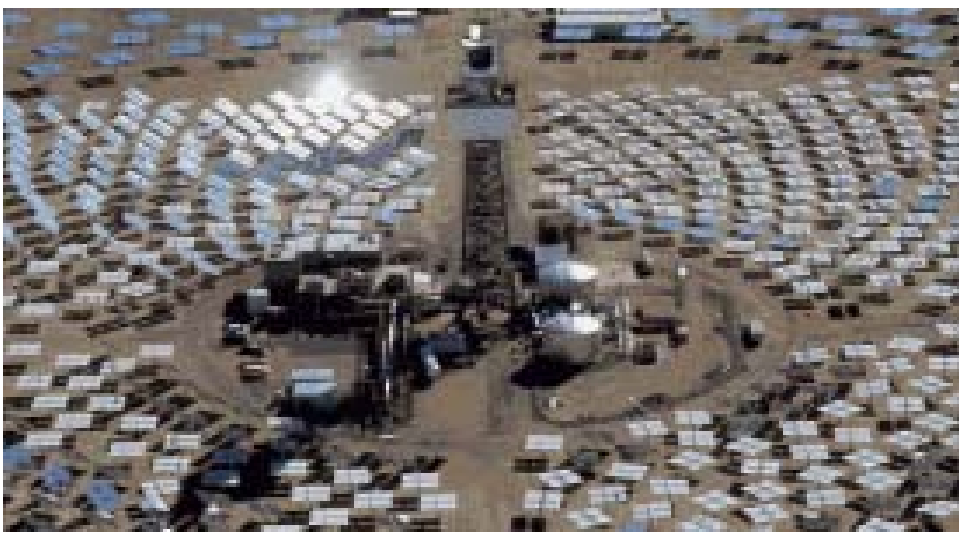
the 30- to 400 -MWe ranges. In a molten-salt solar power tower, liquid salt at $290^{\circ} \mathrm{C}\left(554^{\circ} \mathrm{F}\right)$ is pumped from a "cold" storage tank through the receiver where it is heated to $565^{\circ} \mathrm{C}\left(1,049^{\circ} \mathrm{F}\right)$ and then on to a "hot" tank for storage. When power is needed from the plant, hot salt is pumped to a steam generating system that produces superheated steam for a conventional Rankine-cycle turbine/generator system. From the steam generator, the salt is returned to the cold tank where it is stored and eventually reheated in the receiver. Figure 2-2 is a molten salt power tower system schematic diagram. 


\section{Figure 2-2 - Molten-Salt Power Tower System Schematic (Solar Two, baseline configuration)}

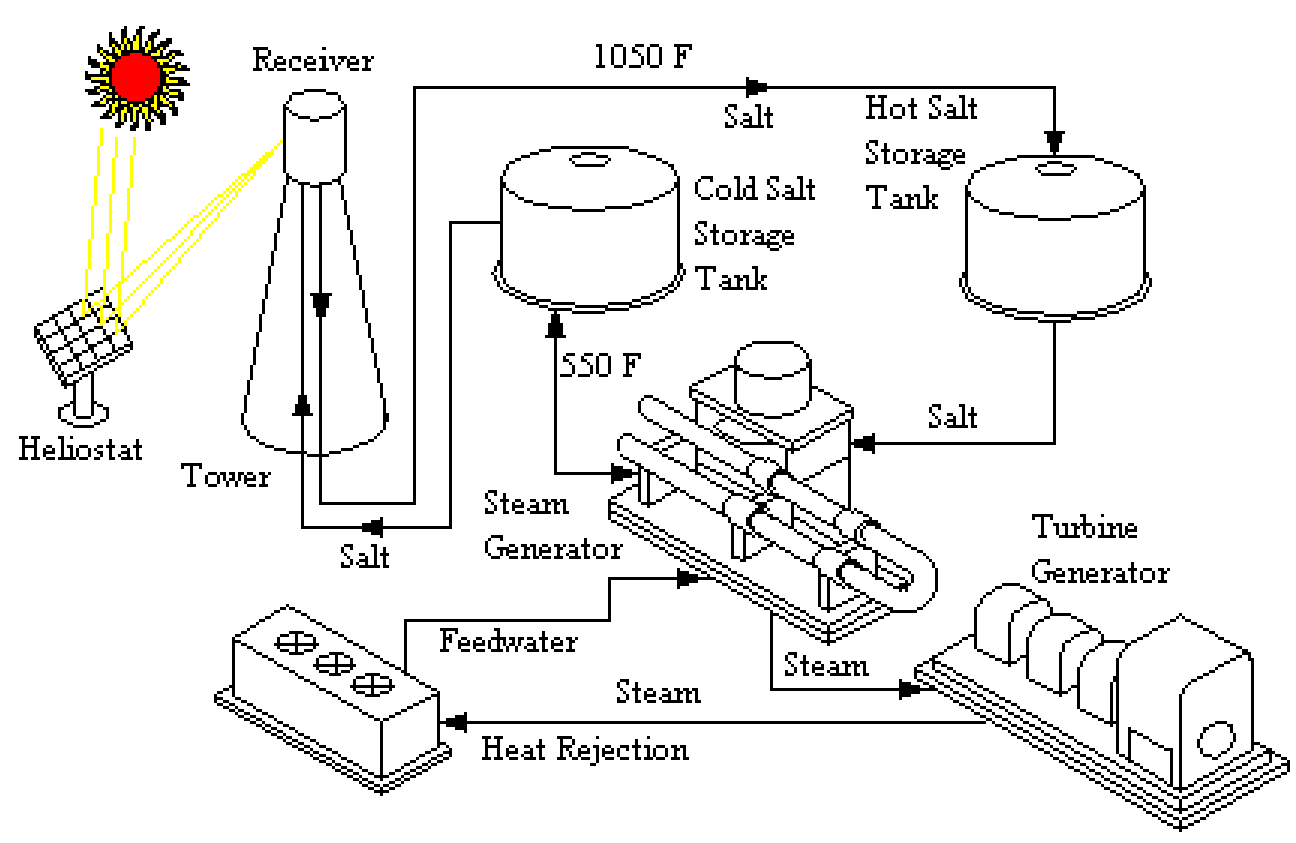

\subsubsection{Current Experience}

To date, the largest power towers ever built are the 10-MWe Solar One and Solar Two plants in southern California. Although power towers are commercially less mature than parabolic trough systems, a number of component and experimental systems have been field tested around the world in the last 15 years, demonstrating the engineering feasibility and economic potential of the technology.

The Solar One Pilot plant was an important step in the development of power tower technology and operated from 1982 to 1988. After the initial startup (test and evaluation) phase, Solar One operated reliably.

The goals of the redesigned demonstration plant, called Solar Two, were to validate nitrate salt technology, to reduce the technical and economic risk of power towers, and to stimulate the commercialization of power tower technology. Solar Two succeeded in meeting these objectives and has led to the formation of a commercialization consortia to build the first commercial power tower plant, Solar Tres, in Spain. Solar Two produced $10 \mathrm{MW}$ of electricity with enough thermal storage to continue to operate the turbine at full capacity for 3 hours after the sun has set, proving the ability to dispatch to meet peak utility loads. Solar Two also demonstrated continuous operation for nearly a week, frequently at part-load output. 


\subsection{INTEGRATION WITH FOSSIL POWER PLANTS}

\subsubsection{Hybrid}

Many solar-fossil hybrid options are possible with natural gas combined-cycle and coal-fired or oil-fired Rankine plants, and may accelerate near-term deployment of projects due to improved economics and reduced overall project risk. One opportunity for hybrid integration is with a power tower hybridized with a combinedcycle plant. In this power boost hybrid plant, a solar-only plant has, in effect, been "piggybacked" on top of a base-loaded fossil-fueled plant. Power is produced in the gas turbine (fossil only) and from the steam turbine (fossil and solar). Steam from the solar steam generator is blended with fossil steam from the heat recovery steam generator (HRSG) before entering a steam turbine.

In the power boost hybrid plant, additional electricity is produced by over sizing the steam turbine, contained within a coal-fired Rankine plant or the bottoming portion of a combined-cycle plant, so that it can operate on both full fossil and solar energy when solar is available. Studies of this concept have typically oversized the steam turbine from $25 \%$ to $50 \%$ beyond what the turbine can produce in the fossil-only mode. Oversizing beyond this range is not recommended because the thermal-to-electric conversion efficiency will degrade at the partial loads associated with operating in the fuel-only mode.

When hybridizing a solar power tower with a base-load fossil-fired plant, solar contributes about $25 \%$ of the peak power output from the plant and between $10 \%$ and $25 \%$ of the annual electricity. (The higher annual solar fraction can be achieved with 13 hours of thermal storage and the lower solar fraction with just a few hours of storage.)

\subsubsection{Integrated Solar Combined Cycle System (ISCCS)}

The Integrated Solar Combined Cycle System (ISCCS) was initially proposed as a way of integrating a parabolic trough solar plant with modern combined-cycle power plants. The approach reduces the effective cost of the conventional power plant equipment, leveraging O\&M and project development costs over a much larger plant and potentially increasing the solar-to-electric conversion efficiency. The initial concept was simply to increase the size of the steam turbine, use solar energy to generate steam, and use the waste heat from the gas turbine to preheat and superheat the steam. The general concept called for doubling the size of the steam turbine in the bottoming cycle. The ISCCS plant would operate at the combined-cycle output during non-solar periods, and then output would increase by up to one third when solar energy was available (referred to as the solar increment). However if the combined-cycle plant is operated in a baseload operating profile, the annual solar 
fraction (percent of electric generation from solar) will only be about $10 \%$. In addition, detailed design integration issues must be considered to make sure the solar integration does not have a significant impact on the combined-cycle fossil operation. A number of recent studies have looked at the best approaches for this integration. ISCCS plants are being considered for all four of the Global Environmental Facility (GEF) grant projects (India, Egypt, Morocco, and Mexico). Figure 2-3 shows a process flow schematic of a parabolic trough ISCCS plant concept.

\section{Figure 2-3 - Scheme of an ISCCS power plant with a dual-pressure-reheat steam cycle and the usage of solar energy to replace latent heat of evaporation in the high pressure part}

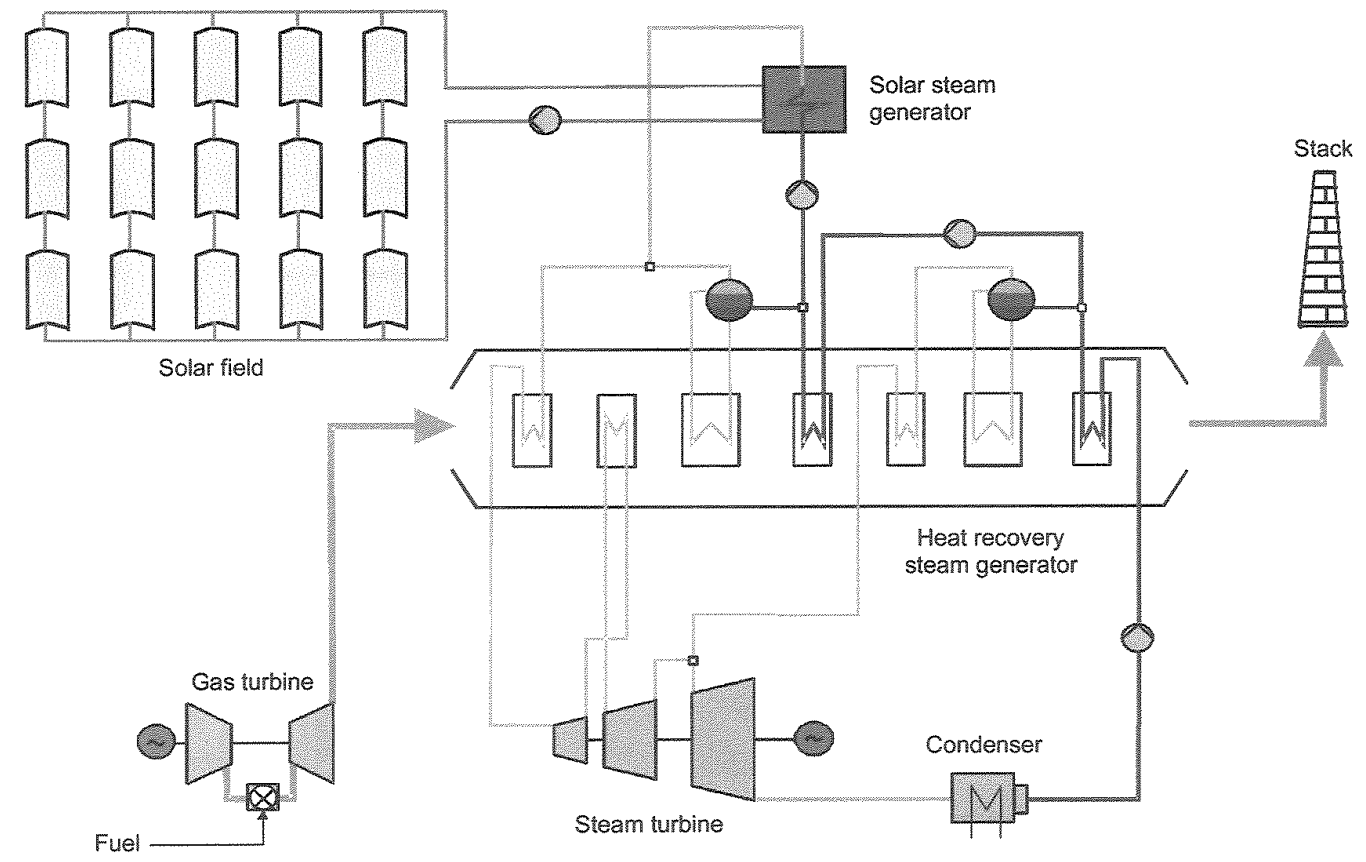

Source: Price et al. (2002)

\subsection{ADVANCED TECHNOLOGY AND APPLICATION OPTIONS}

By charter, this report addresses trough and tower technologies and focuses on Rankine cycle power generation at temperatures in the range of $350^{\circ}-550^{\circ} \mathrm{C}$, as currently being pursued by U.S. industry and the CSP program. For completeness, we have also included here some high-level information on other options, namely variants of trough and tower technology that are being pursued by international competitors, as well as other options for future applications of large-scale CSP technology. This information was supplied by SunLab and has not been verified by S\&L. 


\subsubsection{Advanced Tower Technology}

One idea under consideration for future power tower technology is an advanced receiver that is capable of efficiently heating air to gas-turbine temperatures $\left(>1,400^{\circ} \mathrm{C} / 2,552^{\circ} \mathrm{F}\right)$ and pressures $(>1,500 \mathrm{kPa})$ in conjunction with a high-temperature phase-change thermal storage system. If this can be achieved, large solaronly plants with a combined-cycle power block efficiency of $60 \%$ or more might be achieved. In addition, as receiver temperatures exceed $800^{\circ} \mathrm{C}\left(1,832^{\circ} \mathrm{F}\right)$, thermo-chemical approaches to hydrogen generation could be exploited using solar power towers. Another interesting option is the thermo-chemical production of syngas by reforming methane. Since existing natural gas pipelines can accept about $10 \%$ hydrogen content, this concept could be used before the development of a hydrogen infrastructure. A CSP plant located in the desert could effectively convert $10 \%$ of the downstream gas appliances (water heaters, stoves, industrial equipment, etc.) into "solar-powered" appliances without needing to have any solar facilities on site. Significant research would certainly be required to develop these concepts, and they have not been reviewed by S\&L as part of this study.

\subsubsection{Current International Development Directions}

Internationally, trough or tower technology development, along with related project development, is being aggressively pursued in Germany, Spain, Italy, Israel, and South Africa. While international trough technology is fundamentally the same as that in the United States, there are some differences. European partners (with significant funding from the European Union (EU), national and state programs) have developed and extensively tested a prototype of a competing trough structure (EuroTrough) that will begin full-scale prototype testing at the Kramer Junction solar plant in California in the spring of 2003. Germany and Spain are pursuing steam as a high-temperature working fluid in addition to near-term development based on the same heat transfer oil as used here in the United States. Trough receiver development includes advances by Solel in Israel (which would be implemented by U.S. industry as well); development by the EU (through Germany and Spain) of a completely new heat collection elements (HCE), including an advanced selective surface capable of operation at the temperatures of their steam working fluid (up to $550^{\circ} \mathrm{C}$ ); and a new effort by Schott Rohrglas to develop an entire HCE product. A German/Spanish consortium is in the final stages of planning for two commercial 50-MW trough plants in Spain. Italy has a major new program $(\$ 100 \mathrm{M})$ focused on troughs with a molten salt working fluid, to allow both higher temperatures and better integration with storage. Both activities plan to use the Solar Two-proven molten salt technology for storage.

South Africa has extensively assessed both trough and tower technology and recently selected U.S. tower technology (with extensive in-country content and manufacturing) for a 100-MW proposed project. However, in 
Europe and Israel, tower technology has evolved quite differently. The Europeans (specifically, the Germans and Spanish) have focused on systems using air as the working fluid. The near-term application pulls air at atmospheric pressure through a porous metal or ceramic mesh (the so-called volumetric receiver concept) illuminated by the heliostat field, generating temperatures of about $700^{\circ} \mathrm{C}$, ultimately for use in steam generation at $550^{\circ} \mathrm{C}$ for Rankine cycles (identical to current U.S. molten-salt system Rankine temperatures). The Europeans have investigated rock and ceramic packed-bed storage options that, while not nearly as efficient as two-tank molten salt systems, have continued to drop in cost through the development process, although they have not yet achieved the costs of molten salt systems. A Spanish/German consortium plans to use this technology in the 10-MW PS10 project, which was expected to begin construction in Southern Spain in late 2002 or early 2003. Because $700^{\circ} \mathrm{C}$ is a relatively conservative temperature limit for this technology (there are no temperature limits on air, and ceramic receivers of this design can go to much higher temperatures), temperature increases to accommodate advanced steam turbines operating above $600^{\circ} \mathrm{C}$ are relatively straightforward.

To expand options further, the Germans are also aggressively investigating pressurized volumetric receiver concepts using quartz windows, reflective secondary concentrators, and ceramic mesh absorbers capable of operating at several atmospheres and temperatures of $900^{\circ}-1,200^{\circ} \mathrm{C}$. The quartz windows limit the size of each receiver, so they are packed into hexagonal arrays (the secondary concentrators have a hexagonal entrance aperture) to achieve higher power levels. Individual receiver elements have been successfully demonstrated over the past 10 years, and they are currently testing the first multi-module array (Sugarman et al. 2002). If successful, this technology will ultimately open options for coupling to higher-efficiency Brayton cycles or combined cycles. There are, of course, many technical challenges to this receiver concept (in the secondary reflectors, the windows, and the ceramic mesh durability), and commercial implementation is still quite a few years away, at best. Nonetheless, DOE/SunLab follows the European development closely and considers this technology credible. For a variety of reasons (see advanced applications below), DOE/SunLab has conducted preliminary development in this area in the past, with those investigations ultimately being terminated due to budget restrictions, not a lack of technology promise.

The Israelis have carried this concept one step further, proposing to put a large hyperbolic secondary reflector on top of a tower to "beam down" the concentrated solar energy to ground level (Yogev et al. 1998). This would theoretically allow more options for the high-temperature receiver and coupling of the high-temperature air working fluid to a Brayton cycle or other application. They have successfully demonstrated (without the beamdown mirror) pressurized air volumetric receiver operation at temperatures above $1,200^{\circ} \mathrm{C}$ (Kribus 2001). They 
are currently testing a $700-\mathrm{kW}$ beam-down experiment on the tower at the Weizmann Institute of Technology solar power tower test facility. The higher precision required for the heliostat field, as well as thermal and wind loads on the tower-mounted secondary mirror, have limited success to date. This technology likely has years of development ahead, if indeed it will ever be feasible.

\subsubsection{Long-Term CSP Advanced Applications Options}

Over the last dozen years or so, budget restrictions in the U.S. CSP program have limited the focus to near-term electric power generation options. Since power generation is the simplest interface for CSP technologies and since low-cost, reliable concentrators will be needed for any advanced applications, this continues to be the most productive approach with limited budgets. However, there are a number of potential, long-term applications that take advantage of the high-temperature capabilities of tower technology. These include not only the higher temperature (and thus more efficient) Rankine and Brayton electric power cycles discussed above, but also a range of solar chemistry applications that could potentially make CSP a major source of energy in the fuels and chemicals sector.

For example, the DOE has successfully demonstrated the thermo-catalytic reforming of natural gas and other organics with steam or carbon dioxide (at temperatures of $800^{\circ}-900^{\circ} \mathrm{C}$ ). The Israelis, Swiss, Germans, and Australians continue to develop this technology today. In this approach, a tower uses reactors similar to the closed volumetric receivers described above, except that a rhodium or another catalyst is dispersed on the surface of the ceramic mesh, directly absorbing the solar energy to produce syngas, hydrogen, and carbon monoxide (Moller et al. 2002). In an open-loop system, the syngas can be further hydrogen enriched via a watergas shift reaction for several possible applications, including hydrogen production for other uses, including direct combustion, or further conversion to methanol for liquid fuel use. In a closed-loop system, the syngas can be stored (effectively chemically storing solar energy for longer periods than thermal storage) or transported over distances up to a hundred kilometers for process heat or power generation via the reverse reaction (methanation), in which the syngas is converted back to methane for reuse in the solar reactor.

With their high-temperature capabilities, towers (and CSP dish technology) can also be used to drive a number of thermochemical, hydrogen production cycles that operate at $800^{\circ} \mathrm{C}$ and higher. For example, towers could "fuel" the following thermochemical cycles: the sulfur-iodine cycle currently being investigated by the nuclear industry for powering by a nuclear high-temperature gas-cooled reactor (HTGR); the $\mathrm{Zn} / \mathrm{ZnO}$ cycle under intensive study in Switzerland and Israel (Wieckert et al. 2002); U.S. activity in methane decomposition (Dahl et 
al. 2002); and other high-temperature, solar thermal decomposition reactions. While CSP can theoretically generate the temperatures required for hydrogen production by direct water splitting, theory is a long way from practice in both receiver design and separation technology. Nonetheless, high-temperature electrolysis (where a portion of the electrical energy needed for electrolysis is offset by high-temperature thermal energy) is considered feasible in the long term and has been investigated at a variety of institutions.

Finally, technology advancements in the last 20 years have been dramatic (e.g., computers, communications, and biotechnology) and have been characterized by unforeseen developments in other areas of research. It is not unreasonable to expect that, over the course of the next 20 years, we will see advancements not now anticipated in areas such as materials research that could have a significant impact on CSP technology. 


\section{POWER GENERATION MARKET AND DEPLOYMENT FORECAST}

The projections for electrical power consumption in the United States and worldwide vary depending on the study, but there will be a significant increase in installed capacity due to increased demand through 2020 . Trough and tower solar power plants will compete with technologies that provide bulk power to the electric utility transmission and distribution systems. The following market entry barriers are the most significant to overcome:

- Market expansion of trough and tower technology will require incentives to reach market acceptance (competitive). Incentives include environmental $\left(\mathrm{CO}_{2}\right.$ emission credits), favorable tax credits, favorable peak energy tariff, premium consumer pricing, loan guarantees, low interest loans, and grants. Both tower and trough technology currently produce electricity that is more expensive than conventional fossil-fueled technology. Analysis of incentives required to reach market acceptance is not within the scope of the report.

- Significant cost reductions will be required to reach market acceptance (competitive). Cost reductions occur from technical improvements, increase in plant size (scaling), and volume production (learning curves). This report focuses on the potential of cost reductions with the assumption that incentives will occur that will support deployment through market expansion.

\subsection{POWER GENERATION MARKET}

There are several recent studies that discuss the market for CSP technology (Teagan 2001; World Bank 1999; EERE 2002). A number of international and national project developments for commercial or commercial-entry trough or tower power plants typically in the capacity range of 15 MWe to 100 MWe are being pursued by the industry. These entry opportunities largely arise from activities of the Global Environment Facility, selected nations and U.S. programs on Renewable Portfolio Standards, or other incentives to encourage renewable energy systems.

A summary of the current market is as follows:

- Global Environmental Facility. The Global Environmental Facility (GEF) has identified CSP technology as one of their renewable energy options, and has approved four $\$ 50 \mathrm{M}$ grants for CSP solar power plants in India, Egypt, Morocco, and Mexico.

- United States. The parabolic trough industry (specifically Duke Solar Energy) is aggressively pursuing individual IPP projects opportunities in Nevada, California, Arizona, and Oregon as

\footnotetext{
${ }^{*}$ The Global Environment Facility (GEF) helps developing countries fund projects and programs that protect the global environment. Established in 1991, GEF is the designated financial mechanism for international agreements on biodiversity, climate change, and persistent organic pollutants. GEF also supports projects that combat desertification and protect international waters and the ozone layer. GEF funding comes via the World Bank and UNDP.
} 
large as $80-\mathrm{MWe}$ steam Rankine cycle projects to as small as 1-MWe organic Rankine cycle systems. From a more general perspective, Congress asked DOE with the fiscal year 2002 funding authorization to "develop and scope out an initiative to fulfill the goal of having 1,000 MW of new parabolic trough, power tower, and dish/engine solar capacity supplying the southwestern United States by 2006" (EERE 2002). DOE, the CSP industry, and SunLab have collaborated on the development of a report to Congress on the implementation of a plan to achieve this goal. In early 2002, the Western Governors' Association expressed its high interest in the implementation of 1,000 MW of CSP in the Southwest in a letter directed to Congress.

- South Africa. ESKOM, the national utility in South Africa, has been comparing troughs and towers to select a single technology for their first CSP plant in South Africa. In September 2002, their board approved the recommendation to proceed with the central receiver technology only. Their plan is to gather the cost inputs in sufficient detail to take a proposal to their Board of Directors by the end of this year proposing a 100-MW central receiver station with molten salt thermal storage to be sited somewhere in the northwest part of the country, probably in the vicinity of the city of Upingt.

- Spain. In August 2002, the Spanish Government approved a modification of Royal Decree 2818 providing substantial incentives for the erection of IPP solar thermal power plants fueled exclusively by solar radiation, i.e., no hybrid operation. This modification of Royal Decree 2818 grants a premium of $€ 0.12$ above the market price for electricity generated from solar thermal energy in facilities with a maximum unit power of $50 \mathrm{MW}$. Four projects have been proposed by industry, as follows: 10-MWe tower project based on European technology; 15-MWe tower project based on U.S. technology; 10-MWe trough prototype based on U.S. technology; two 50 -MWe trough projects based on European technology. Work is now proceeding on the commercial financing and development of these projects.

- Israel. The Israel Ministry of National Infrastructures, which is also responsible for the energy sector, decided in November 2001 to propose CSP as a strategic ingredient into the Israel electricity market over the next several years, with a minimal power unit of $100 \mathrm{MWe}$. There is an option to increase the CSP contribution up to $500 \mathrm{MWe}$ at a later stage, after the successful operation of the first unit. The plant is to operate in hybrid mode, $4,400 \mathrm{hr} / \mathrm{yr}, 50 \%$ of which is solar and the rest natural gas. A final decision on the plan is expected in late 2002.

Industry participation is also an indicator of market potential. There are a number of companies actively participating in research and development, marketing, and engineering in support of tower and trough technology. Nexant, Boeing, and Duke Solar are the key participants in the United States. Internationally, the key participants are Solel, Flabeg, Solar Millennium, and Fichtner.

\subsection{DEPLOYMENT FORECAST}

Cost reductions occur from technical improvements, increase in plant size (scaling), and volume production (learning curves). All three are dependent on deployment (development) of CSP technology. Deployment requires movement through various phases: pilot testing, commercial validation, commercial niche market, 
market expansion, and market acceptance (Morse 2000). Deployment provides a means for continued research in technology improvements, cost reductions due to increased production, and economy of scale from constructing larger plants. The cost reduction analysis provided in this report is based on the assumption that trough and tower plants will be constructed. S\&L's review is based on a deployment range between 2.4 gigawatts-electrical $(\mathrm{GWe})$ and $9.5 \mathrm{GWe}$ of installed tower and trough solar power plants. The major cost reduction is from the increased size of the plant and increased electrical production. The cost reduction associated with increased volume production between 2.6 GWe and 9.5 GWe (from year 2004 to 2020) is about $10 \%$.

Estimates of tower and trough solar power plants deployment have been identified in several reports (Morse 2000). Comparison of these estimates and the SunLab and S\&L estimates are shown in Figure 3-1.

\section{Figure 3-1 - Summary of CSP Worldwide Deployment Forecast}

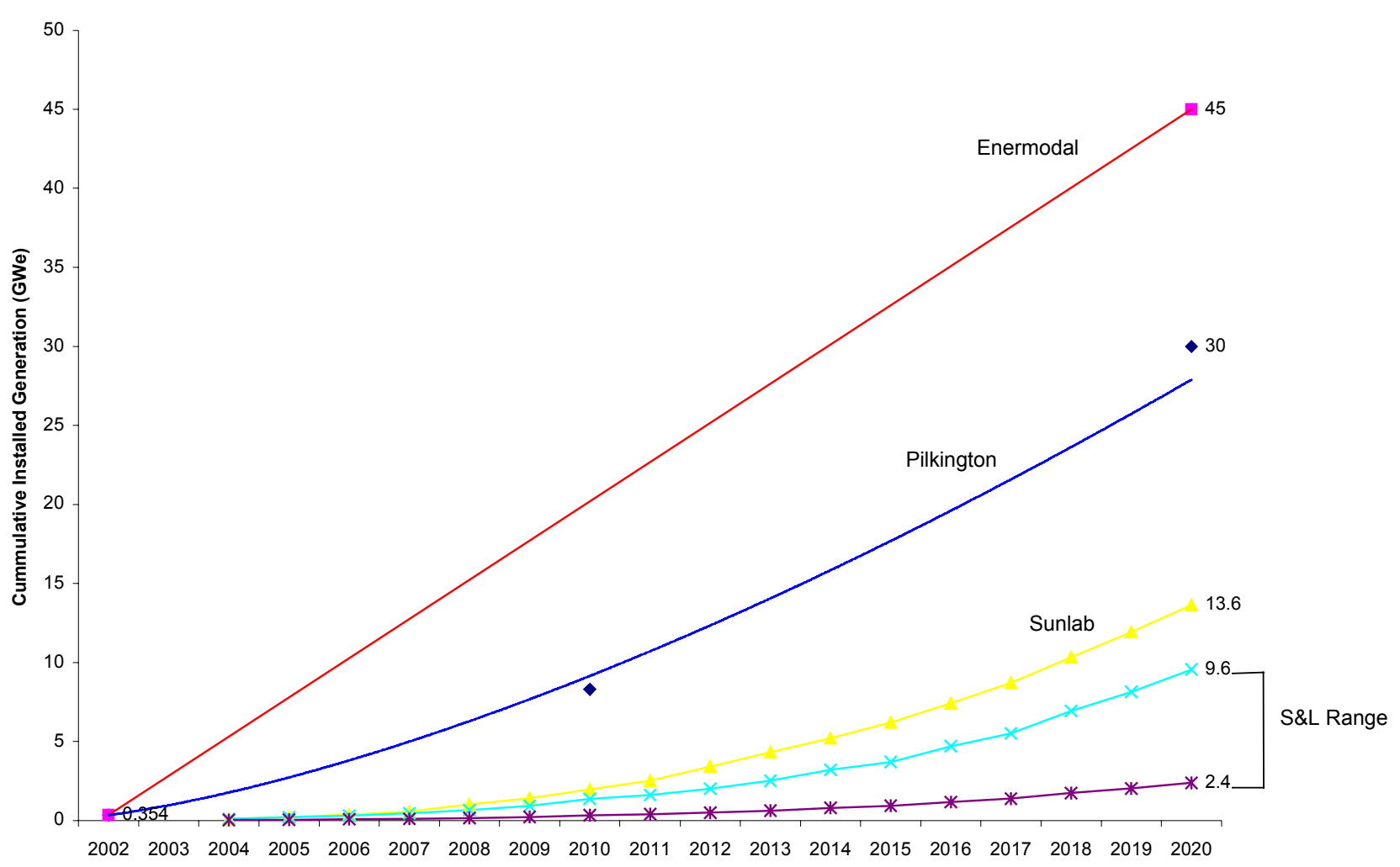

The commercialization path for trough and tower technologies was presented in the Morse report (2000) as occurring in five phases: pilot testing, commercial validation, commercial niche market (entry), market 
expansion, and market acceptance. The program to move CSP technologies through commercial niche market and market expansion to market acceptance is shown in Figure 3-2:

\begin{tabular}{|c|c|c|c|c|c|c|c|c|c|}
\hline & \multicolumn{7}{|c|}{ Figure 3-2 - CSP Path to Market Acceptance } & \multirow[b]{2}{*}{2018} & \multirow[b]{2}{*}{2020} \\
\hline & 2004 & 2006 & 2008 & 2010 & 2012 & 2014 & 2016 & & \\
\hline \multirow[t]{3}{*}{$\begin{array}{l}\text { Trough Solar Power } \\
\text { Plants }\end{array}$} & \multicolumn{3}{|c|}{$\begin{array}{c}\text { Commercial Niche } \\
\text { Market }\end{array}$} & & & & & & \\
\hline & & & \multicolumn{2}{|c|}{$\begin{array}{l}\text { Market } \\
\text { Expansion }\end{array}$} & & & & & \\
\hline & & & & & & & & & $\begin{array}{c}\text { Market } \\
\text { Acceptance }\end{array}$ \\
\hline \multirow[t]{4}{*}{$\begin{array}{l}\text { Tower Solar Power } \\
\text { Plants }\end{array}$} & \multicolumn{3}{|c|}{$\begin{array}{l}\text { Commercial } \\
\text { Validation }\end{array}$} & & & & & & \\
\hline & & & \multicolumn{3}{|c|}{$\begin{array}{c}\text { Commercial Niche } \\
\text { Market }\end{array}$} & & & & \\
\hline & & & & & \multicolumn{2}{|c|}{$\begin{array}{l}\text { Market } \\
\text { Expansion }\end{array}$} & & & \\
\hline & & & & & & & & & $\begin{array}{c}\text { Market } \\
\text { Acceptance }\end{array}$ \\
\hline
\end{tabular}

\subsection{TROUGH}

Sargent \& Lundy's review and assessment of the SunLab deployment projections for trough solar power plants is included in Appendix D.2. While the trough technology was commercialized for a brief period, no trough plants have been built in nearly a decade. Trough solar plants are a proven technology, and $354 \mathrm{MW}$ of trough technology generation at the SEGS plants have and are still being operated commercially.

The following Table 3-1 shows a case of two scenarios set forth by SunLab that are representative of how systems would be deployed commercially if a market existed. The first assumes one plant built per year. The second assumes a doubling of cumulative installed capacity with each new technology case introduced. This second case is an aggressive development scenario; however, if the projects were financially competitive, this represents a plausible development scenario. The second case is the type of scale-up that Luz envisioned and actually achieved with the SEGS plants to some degree, building multiple plants in the same year. 
Table 3-1 - Trough Deployment Scenarios

\begin{tabular}{|c|c|c|c|c|c|c|c|c|c|c|c|c|c|c|c|c|c|c|c|c|}
\hline & 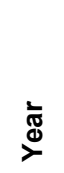 & ষ্ণ & 只 & 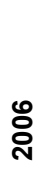 & 옹 & 足 & 옹 & 웅 & $\frac{\tau}{\delta}$ & $\frac{N}{\delta}$ & ำ & $\stackrel{+}{\grave{N}}$ & 운 & $\stackrel{0}{\circ}$ & 훙 & $\stackrel{\infty}{\circ}$ & $\stackrel{0}{\circ}$ & ণ্ণ & 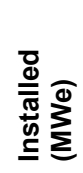 & 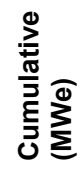 \\
\hline $\begin{array}{l}\text { Technology } \\
\text { Cases }\end{array}$ & & $\mathrm{X}$ & & & $\mathrm{X}$ & & & $\mathrm{X}$ & & & & & $\mathrm{X}$ & & & & & $\mathrm{X}$ & & \\
\hline \multicolumn{21}{|c|}{ Case 1 Deployment Scenario: One Plant per Year Deployment } \\
\hline $\begin{array}{l}2004 \\
\text { Technology }\end{array}$ & $\begin{array}{l}100 \\
\text { MW }\end{array}$ & 1 & 1 & 1 & & & & & & & & & & & & & & & 300 & 650 \\
\hline $\begin{array}{l}2007 \\
\text { Technology }\end{array}$ & $\begin{array}{l}100 \\
\text { MW }\end{array}$ & & & & 1 & 1 & 1 & & & & & & & & & & & & 300 & 950 \\
\hline $\begin{array}{l}2010 \\
\text { Technology }\end{array}$ & $\begin{array}{l}150 \\
\text { MW }\end{array}$ & & & & & & & 1 & 1 & 1 & 1 & 1 & & & & & & & 750 & 1,700 \\
\hline $\begin{array}{l}2015 \\
\text { Technology }\end{array}$ & $\begin{array}{l}200 \\
\text { MW }\end{array}$ & & & & & & & & & & & & 1 & 1 & 1 & 1 & 1 & & 1,000 & 2,700 \\
\hline $\begin{array}{l}2020 \\
\text { Technology }\end{array}$ & $\begin{array}{l}400 \\
\text { MW }\end{array}$ & & & & & & & & & & & & & & & & & 1 & 400 & 3,100 \\
\hline Total & & & & & & & & & & & & & & & & & & & 2,750 & \\
\hline \multicolumn{21}{|c|}{ Case 2 Deployment Scenario: Cumulative Capacity Doubled with Each New Technology Case } \\
\hline $\begin{array}{l}2004 \\
\text { Technology }\end{array}$ & $\begin{array}{l}100 \\
\mathrm{MW}\end{array}$ & 1 & 1 & 1 & & & & & & & & & & & & & & & 300 & 650 \\
\hline $\begin{array}{l}2007 \\
\text { Technology }\end{array}$ & $\begin{array}{l}100 \\
\text { MW }\end{array}$ & & & & 1 & 2 & 2 & 1 & & & & & & & & & & & 600 & 1,250 \\
\hline $\begin{array}{l}2010 \\
\text { Technology }\end{array}$ & $\begin{array}{l}150 \\
\text { MW }\end{array}$ & & & & & & & 1 & 1 & 2 & 2 & 2 & & & & & & & 1,200 & 2,450 \\
\hline $\begin{array}{l}2015 \\
\text { Technology }\end{array}$ & $\begin{array}{l}200 \\
\text { MW }\end{array}$ & & & & & & & & & & & & 1 & 2 & 2 & 3 & 3 & 1 & 2,400 & 4,850 \\
\hline $\begin{array}{l}2020 \\
\text { Technology }\end{array}$ & $\begin{array}{l}400 \\
\text { MW }\end{array}$ & & & & & & & & & & & & & & & & & 1 & 400 & 5,250 \\
\hline Total & & & & & & & & & & & & & & & & & & & 4,900 & \\
\hline
\end{tabular}

The actual strategy employed by the plant suppliers can be significantly diverse, with more emphasis on nearterm cost reduction with a minimum of risk. The suppliers may opt to provide multiple plants in the 50-MWe to 100-MWe size range with no thermal storage but with a supplemental steam generator, replicating the proven technology of the existing SEGS plants. The suppliers can rely more on initial production volume to reduce costs as opposed to efficiency and technology improvements and scale-up factors. Minimizing or eliminating thermal storage, with its current elevated cost, appreciably reduces the total direct cost of the plant as discussed 
later in this section of the report. The suppliers' strategy will vary depending on the extent of trough plant deployment.

\subsection{TOWER}

Sargent \& Lundy's review and assessment of the SunLab deployment projections for tower solar power plants is included in Appendix E.2. The first step will be deployment of the first commercial power tower facility in Spain (Solar Tres). The Solar Tres design and cost estimate are based on the successful demonstration projects Solar One and Solar Two. "Commercial" is defined as when a power plant is providing electrical power to customers. The next commercial plant will be Solar 50, which is a significant increase in plant size. The net electrical output increases $36.5 \mathrm{MWe}$ (factor of 3.7) and the thermal capacity increases by $260 \mathrm{MWt}$ (factor of 3.2). Solar 50 is the first commercial plant of sufficient size to allow a number of larger plants to be developed. The next commercial steps include Solar 100 and Solar 200. Solar 200, which consists of a net electrical capacity of $200 \mathrm{MWe}$ and thermal capacity of 1,400 MWt (12.7 hours operation at peak output), is about the optimum size monolithic single receiver plant based on physical limitations of technology (specifically, the distance from the heliostat to the receiver). Larger plants are feasible with multiple power towers deployed. The final deployment is Solar 220, which considers an advanced heliostat design and advanced electrical turbinegenerator.

Table 3-2 shows two scenarios: projection by SunLab and projection by S\&L.

Table 3-2 - Power Tower Deployment Projections, SunLab and S\&L

\begin{tabular}{|c|c|c|c|c|c|c|c|c|c|c|c|c|c|c|c|c|c|c|c|c|}
\hline & 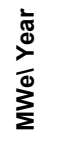 & 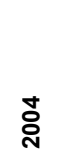 & :ัे & : & ڤั่ & :̊ & :̊․․ & ํํํ & $\overline{\text { Nे }}$ & $\stackrel{N}{\text { กे }}$ & $\stackrel{m}{\stackrel{m}{N}}$ & $\stackrel{+}{\text { N }}$ & $\stackrel{n}{\grave{n}}$ & $\stackrel{\circ}{\grave{n}}$ & $\hat{\grave{n}}$ & $\sum_{\text {N }}^{\infty}$ & స̊ํे & స్․ & 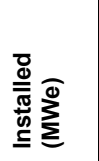 & 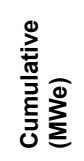 \\
\hline $\begin{array}{l}\text { SunLab - } \\
8.7 \mathrm{GWe}\end{array}$ & & & & & & & & & & & & & & & & & & & & \\
\hline Solar Tres & 13.5 & 1 & & & & & & & & & & & & & & & & & 13.5 & 14 \\
\hline Solar 50 & 50 & & & 1 & 2 & 3 & & & & & & & & & & & & & 300 & 314 \\
\hline Solar 100 & 100 & & & & & 1 & 2 & 3 & 4 & 4 & 4 & 4 & 2 & 2 & 1 & & & & 2,700 & 3,014 \\
\hline Solar 200 & 200 & & & & & & & & & 1 & 1 & 1 & 3 & 3 & 4 & 4 & 5 & & 4,400 & 7,414 \\
\hline Solar 220 & 220 & & & & & & & & & & & & & & & 1 & & 5 & 1,320 & 8,734 \\
\hline & & 13.5 & 0 & 50 & 100 & 250 & 200 & 300 & 400 & 600 & 600 & 600 & 800 & 800 & 900 & 1,020 & 1,000 & 1,100 & 8,734 & \\
\hline
\end{tabular}




\begin{tabular}{|c|c|c|c|c|c|c|c|c|c|c|c|c|c|c|c|c|c|c|c|c|}
\hline & & ڤั่ & ๕ి & ๕ั & ڤั & ڤั้ & :ัे & ํํํ & $\overline{\text { กे }}$ & กั & ஸे & ڤั่ & ஸั & $\stackrel{\circ}{\text { N }}$ & $\hat{\grave{~}}$ & $\stackrel{\infty}{\stackrel{n}{n}}$ & $\stackrel{\circ}{\grave{n}}$ & సิి & 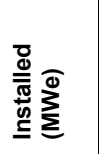 & 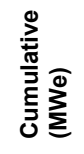 \\
\hline $\begin{array}{l}\text { S\&L - } 2.6 \\
\text { GWe }\end{array}$ & & & & & & & & & & & & & & & & & & & & \\
\hline Solar Tres & 13.5 & 1 & & & & & & & & & & & & & & & & & 13.5 & 14 \\
\hline Solar 50 & 50 & & & & & & 1 & & 1 & 1 & 1 & & & & & & & & 200 & 214 \\
\hline Solar 100 & 100 & & & & & & & & & & 1 & & 1 & 1 & 1 & & & & 400 & 614 \\
\hline Solar 200 & 200 & & & & & & & & & & & & & & 1 & & 1 & 1 & 600 & 1,214 \\
\hline Solar 220 & 220 & & & & & & & & & & & & & & & & & & 0 & 0 \\
\hline & & 13.5 & 0 & 0 & 0 & 0 & 50 & 0 & 50 & 50 & 150 & 0 & 100 & 100 & 300 & 0 & 200 & 200 & 1,214 & \\
\hline
\end{tabular}




\section{EVALUATION OF POTENTIAL FOR COST REDUCTIONS - TROUGH}

\subsection{DEVELOPMENT PLAN FOR COST REDUCTION}

The SunLab trough model DueDiligence11-Excelergy11-14-01.xls (SunLab 2001) depicts the industry plan for long-term cost reduction. The industry plan keys on thermal storage to obtain a high capacity factor, which reduces the O\&M costs $(\$ / \mathrm{MWh})$ by obtaining a higher annual MWh generation. In combination with thermal storage, increased annual net efficiency, and reduced equipment cost via technology advancements, competition and deployment are primary elements in reducing the long-term capital costs of the trough plant.

The parabolic trough industry has developed a proprietary plan to lower costs, emphasizing the near-term, which cannot be shared in detail since it would compromise their ability to compete in the domestic and international market. However, the SunLab model provides a cost estimate that closely follows the industry expectations for research and development advances in component and subsystem improvements. Whereas the SunLab plan for plant implementation assumes, for comparative purposes, the use of thermal storage starting in 2004, the U.S. trough industry is pursuing a commercialization plan that favors implementation of SEGS-type plants in the near-term. With this plan, industry has set cost goals that target a solar field cost less than $\$ 200 / \mathrm{m}^{2}$ and an installed plant cost in the $2,000-2,400 \$ / \mathrm{kW}$ range by 2006 . The industry considers this plan a low-risk approach, with plants similar to the existing SEGS type plants able to produce electricity in a hybrid model. By incorporating this hybrid option, the only increase to the solar-only portion of the project is the relatively small capital cost of a boiler cost of fuel and fuel costs during hybrid operation. Near-term development of this plan is shown below in Table 4-1.

Table 4-1 — Near-Term Development for Trough Industry

\begin{tabular}{|l|c|c|c|c|}
\hline & Case $^{*}$ & Baseline & \multicolumn{3}{|c|}{ Trough Industry Near Term } \\
\hline Project & $\begin{array}{c}\text { SEGS VI } \\
\text { Hybrid }\end{array}$ & $\begin{array}{c}\text { Trough 50 } \\
\text { Hybrid (US) }\end{array}$ & $\begin{array}{c}\text { Trough 50 } \\
\text { TES (Spain) }\end{array}$ & $\begin{array}{c}\text { Trough 40 } \\
\text { ISCCS (GEF) }\end{array}$ \\
\hline In Service & $\mathbf{1 9 8 9}$ & $\mathbf{2 0 0 4}$ & $\mathbf{2 0 0 4}$ & $\mathbf{2 0 0 4}$ \\
\hline Net Power (MWe) & 30 & 50 & 50 & 40 \\
\hline Solapacity Factor (\%) & $22 / 34 \% * *$ & $29 / 40 \% * *$ & $47 \%$ & $28 \%$ \\
\hline Heat Transfer Fluid & 0.188 & 0.312 & 0.496 & 0.184 \\
\hline
\end{tabular}




\begin{tabular}{|l|c|c|c|c|}
\hline & Case* $^{*}$ & Baseline & \multicolumn{2}{|c|}{ Trough Industry Near Term } \\
\hline Project & $\begin{array}{c}\text { SEGS VI } \\
\text { Hybrid }\end{array}$ & $\begin{array}{c}\text { Trough 50 } \\
\text { Hybrid (US) }\end{array}$ & $\begin{array}{c}\text { Trough 50 } \\
\text { TES (Spain) }\end{array}$ & $\begin{array}{c}\text { Trough 40 } \\
\text { ISCCS (GEF) }\end{array}$ \\
\hline SF Operating Temperature $\left({ }^{\circ} \mathrm{C}\right)$ & $\mathbf{1 9 8 9}$ & $\mathbf{2 0 0 4}$ & $\mathbf{2 0 0 4}$ & $\mathbf{2 0 0 4}$ \\
\hline Thermal Storage (hrs) & 391 & 391 & 391 & 391 \\
\hline Thermal Energy Storage & 0 & 0 & 9 & 0 \\
\hline Thermal Storage Fluid & NA & NA & $\begin{array}{c}\text { Indirect } \\
\text { 2-Tank }\end{array}$ & NA \\
\hline Land Area $\left(\mathrm{km}^{2}\right.$ ) & NA & NA & Solar Salt & NA \\
\hline Comment & $\begin{array}{c}\text { Hybrid } \\
\text { backup }\end{array}$ & $\begin{array}{c}\text { Hybrid } \\
\text { backup }\end{array}$ & $\begin{array}{c}\text { Indirect } \\
\text { 2-Tank TES }\end{array}$ & None \\
\hline
\end{tabular}

* All cases assume Kramer Junction 1999 radiation $8.054 \mathrm{~kW} / \mathrm{m}^{2} /$ day.

** Solar Only / Hybrid Operation

Cost reductions in parabolic trough plants are discussed from a reference point of the nine operating SEGS plants in the California Mojave Desert. Future cost reductions derive from technical improvements, scale-up in individual plant megawatt capacity, increased deployment rates, competitive pressures, use of thermal storage, and advancements in O\&M methods. Cost drivers have been identified from SunLab activities and from industry input. Duke Solar Energy is a key industrial participant in trough technology and is actively engaged in developing trough power plant opportunities as well as an advanced collector design.

The development and operation of the SEGS plants by Luz International, totaling $354 \mathrm{MWe}$ net installed capacity, provide the baseline for future performance and cost projections. Projected cost reductions are tied to the future development path shown in Table 4-2. 
Table 4-2 - Trough Technology Summary for SunLab Technology Cases

\begin{tabular}{|c|c|c|c|c|}
\hline \multirow[b]{2}{*}{ Case } & \multirow[b]{2}{*}{ Baseline } & \multicolumn{3}{|c|}{ SunLab Technology Cases } \\
\hline & & Near Term & Mid Term & Long Term \\
\hline Project & $\begin{array}{l}\text { SEGS VI } \\
\text { Hybrid }\end{array}$ & Trough 100 & Trough 100 & Trough 400 \\
\hline In Service & 1989 & 2004 & 2010 & 2020 \\
\hline Net Power (MWe) & 30 & 100 & 150 & 400 \\
\hline Capacity Factor (\%) & $\begin{array}{c}22 \\
\text { (solar only) }\end{array}$ & $54 \%$ & $56 \%$ & $57 \%$ \\
\hline Solar Field $\left(\mathrm{km}^{2}\right)$ & 0.188 & 1.120 & 1.477 & 3.910 \\
\hline Heat Transfer Fluid & VP-1 & VP-1 & Hitec XL & Advanced \\
\hline $\begin{array}{l}\text { Solar Field Operating } \\
\text { Temperature }\left({ }^{\circ} \mathrm{C}\right)\end{array}$ & 391 & 391 & 500 & 500 \\
\hline Thermal Storage (hrs) & 0 & 12 & 12 & 12 \\
\hline Thermal Energy Storage & NA & $\begin{array}{l}\text { Indirect 2- } \\
\text { Tank }\end{array}$ & $\begin{array}{c}\text { Direct } \\
\text { Thermocline }\end{array}$ & $\begin{array}{c}\text { Direct } \\
\text { Thermocline }\end{array}$ \\
\hline Thermal Storage Fluid & NA & Solar Salt & Hitec XL & Advanced \\
\hline Land Area $\left(\mathrm{km}^{2}\right)$ & 0.635 & 3.780 & 4.98 & 13.189 \\
\hline
\end{tabular}

However, the actual strategy employed by the plant suppliers can be significantly diverse, with more emphasis on near-term cost reduction with a minimum of risk. As discussed above, for the near-term, the suppliers may opt to provide multiple plants in the 50-MWe to 100 -MWe size range with no thermal storage but with a supplemental steam generator, replicating the proven technology of the existing SEGS plants. In a series of evolutionary design improvements, the following major advancements formed the basis of the SunLab estimates:

- Collector

- A comprehensive series of wind tunnel tests on parabolic trough collector models was carried out in 2001-2002, establishing design pressure force coefficients for various wind approach angles and collector orientations, with and without a wind fence.

- Using these coefficients, finite element methods stress analyses were used to optimize the collector structure for wind survival conditions, minimizing collector weight and defining design parameters for mirror strength, pylons, and foundations. With more tightly known design parameters, the collector weight, and thus costs, can be lowered. 
- High efficiency and durable receivers are assumed to be developed, with selective surfaces (consisting of special selective coatings on the metal tube receivers) to maximize the absorption of incident solar radiation and minimize radiation losses from the receiver. High efficiencies result in smaller solar fields for a given thermal energy delivery and in longer lifetimes to reduce operation and maintenance costs.

- Advanced receivers are assumed utilizing selective surfaces that can operate efficiently at temperatures of $500^{\circ} \mathrm{C}$ or higher, paving the way for major advancements in thermal storage and power block operation for trough plants.

- Alternative mirror design development using thin-glass with non-metallic structural elements or using thin silverized films is assumed. Both approaches reduce weight and offer less expensive reflector options.

- Heat transfer fluid (HTF)

- Alternate HTFs, such as inorganic molten salts and ionic fluids, are being investigated that will permit operation at higher temperatures (at or above $500^{\circ} \mathrm{C}$ ), leading to lower thermal storage costs and higher power block efficiencies.

- Thermal Storage System

- The Solar Two two-tank molten salt storage system is designed for commercial operation in a trough plant for the case of the conventional synthetic oil HTF. Termed an indirect storage system, this also requires an oil-to-salt heat exchanger in the system.

- This same two-tank molten salt storage system is designed for direct operation with a molten salt HTF.

- A single-tank direct molten salt thermocline system is designed to reduce thermal storage costs.

- $\quad$ Electric Power Block

- The efficiency of a SEGS-type plant is improved by refining the integration of the solar field with the power block.

- Turbine efficiencies are improved through use of the higher temperature heat transfer fluids in the solar field.

\subsection{EFFICIENCY}

The efficiency of the existing SEGS parabolic trough plants has been well documented and provides the basis for evaluating the potential performance improvements of future parabolic trough plants. SEGS VI, a 14-yearold 30-MWe plant currently in operation in California, is used as a reference plant to evaluate future efficiency improvements. SEGS VI was selected because it was the last plant built using all second-generation Luz collector (LS-2) technology. The later third-generation Luz collector (LS-3) used at the larger 80-MWe SEGS plants had alignment problems and never operated at the same level of performance achieved at SEGS VI. 
The technological advances and research, upon which the SunLab efficiency improvement estimates are based, include the following:

- The development of the new Solel UVAC receiver. The UVAC has improved thermal and optic properties. Field tests of the new receiver at SEGS VI shows a $20 \%$ increase in thermal performance compared to original receiver tubes.

- The development of ball joint assembly replacements for flexhoses. A demonstration of new ball joint assemblies has been shown to reduce the hydraulic pressure drop in the solar field by approximately $50 \%$. This results in lower solar field heat transfer fluid pumping electric parasitics.

- Improvements in mirror washing techniques have resulted in increased solar field average mirror reflectance.

- Investigation of higher temperature heat transfer fluids.

- $\quad$ Research of direct thermal energy storage.

- $\quad$ Research of higher temperature receiver selective coatings.

Table 4-3 shows a breakdown of the elements that contribute to the annual efficiency. The table shows both the SunLab goal efficiencies and the S\&L estimates based on a less aggressive technology development scenario. A more detailed breakdown of all the SunLab cases is shown in Appendix D. The SEGS VI data are based on actual plant data from 1999 .

Table 4-3 - Trough Annual Efficiency Summary

\begin{tabular}{|c|c|c|c|c|c|c|c|}
\hline \multirow[b]{2}{*}{ Case } & \multirow[b]{2}{*}{$\begin{array}{l}\text { Base- } \\
\text { line }\end{array}$} & \multicolumn{3}{|c|}{ SunLab Forecast } & \multicolumn{3}{|c|}{ Sargent \& Lundy } \\
\hline & & $\begin{array}{l}\text { Near } \\
\text { Term }\end{array}$ & $\begin{array}{l}\text { Mid } \\
\text { Term }\end{array}$ & $\begin{array}{l}\text { Long } \\
\text { Term }\end{array}$ & $\begin{array}{l}\text { Near } \\
\text { Term }\end{array}$ & $\begin{array}{l}\text { Mid } \\
\text { Term }\end{array}$ & $\begin{array}{l}\text { Long } \\
\text { Term }\end{array}$ \\
\hline Project & $\begin{array}{c}\text { SEGS } \\
\text { VI }\end{array}$ & $\begin{array}{c}\text { Trough } \\
100\end{array}$ & $\begin{array}{c}\text { Trough } \\
150\end{array}$ & $\begin{array}{c}\text { Trough } \\
400\end{array}$ & $\begin{array}{c}\text { Trough } \\
100\end{array}$ & $\begin{array}{c}\text { Trough } \\
150\end{array}$ & $\begin{array}{l}\text { Trough } \\
\quad \mathbf{4 0 0}\end{array}$ \\
\hline Year In Service & 1989 & 2004 & 2010 & 2020 & 2004 & 2010 & 2020 \\
\hline Solar Field Optical Efficiency & 0.533 & 0.567 & 0.598 & 0.602 & 0.567 & 0.570 & 0.570 \\
\hline Receiver Thermal Losses & 0.729 & 0.860 & 0.852 & 0.853 & 0.843 & 0.810 & 0.810 \\
\hline Piping Thermal Losses & 0.961 & 0.965 & 0.967 & 0.968 & 0.965 & 0.967 & 0.968 \\
\hline Storage Thermal Losses & NA & 0.991 & 0.996 & 0.996 & 0.991 & 0.996 & 0.996 \\
\hline EPGS Efficiency & 0.350 & 0.370 & 0.400 & 0.400 & 0.370 & 0.400 & 0.400 \\
\hline Electric Parasitic Load & 0.827 & 0.884 & 0.922 & 0.928 & 0.884 & 0.922 & 0.928 \\
\hline
\end{tabular}




\begin{tabular}{|c|c|c|c|c|c|c|c|}
\hline \multirow{2}{*}{ Case } & \multirow{2}{*}{$\begin{array}{c}\text { Base- } \\
\text { line }\end{array}$} & \multicolumn{3}{|c|}{ SunLab Forecast } & \multicolumn{3}{c|}{ Sargent \& Lundy } \\
\cline { 3 - 8 } & Term & $\begin{array}{c}\text { Mid } \\
\text { Term }\end{array}$ & $\begin{array}{c}\text { Long } \\
\text { Term }\end{array}$ & $\begin{array}{c}\text { Near } \\
\text { Term }\end{array}$ & $\begin{array}{c}\text { Mid } \\
\text { Term }\end{array}$ & $\begin{array}{c}\text { Long } \\
\text { Term }\end{array}$ \\
\hline Project & $\begin{array}{c}\text { SEGS } \\
\text { VI }\end{array}$ & $\begin{array}{c}\text { Trough } \\
100\end{array}$ & $\begin{array}{c}\text { Trough } \\
150\end{array}$ & $\begin{array}{c}\text { Trough } \\
\mathbf{4 0 0}\end{array}$ & $\begin{array}{c}\text { Trough } \\
100\end{array}$ & $\begin{array}{c}\text { Trough } \\
150\end{array}$ & $\begin{array}{c}\text { Trough } \\
\mathbf{4 0 0}\end{array}$ \\
\hline Year In Service & 1989 & $\mathbf{2 0 0 4}$ & $\mathbf{2 0 1 0}$ & $\mathbf{2 0 2 0}$ & $\mathbf{2 0 0 4}$ & $\mathbf{2 0 1 0}$ & $\mathbf{2 0 2 0}$ \\
\hline Power Plant Availability & 0.980 & 0.94 & 0.94 & 0.94 & 0.94 & 0.94 & 0.94 \\
\hline $\begin{array}{l}\text { Annual Solar-to-Electric } \\
\text { Efficiency }\end{array}$ & $\mathbf{1 0 . 6 \%}$ & $\mathbf{1 4 . 3 \%}$ & $\mathbf{1 7 . 0 \%}$ & $\mathbf{1 7 . 2 \%}$ & $\mathbf{1 4 . 0 \%}$ & $\mathbf{1 5 . 4 \%}$ & $\mathbf{1 5 . 5 \%}$ \\
\hline
\end{tabular}

\subsubsection{Solar Field Optical Efficiency}

The solar field optical efficiency includes incident angle effects, solar field availability, collector tracking error and twist, the geometric accuracy of the mirrors to focus light on the receiver, mirror reflectivity, cleanliness of the mirrors, shadowing of the receiver, transmittance of the receiver glass envelope, cleanliness of the glass envelope, absorption of solar energy by the receiver, end losses, and row-to-row shadowing. The SunLab projected improvements in optical efficiency are due primarily to improvements in the receiver optical properties, including the following:

- Receiver Solar Absorptance. Significant improvements in selective coatings have occurred since the last SEGS plant was built. The solar absorptance of the cermet tubes used at SEGS VI was approximately $91.5 \%$. According to test data, the Solel UVAC receiver tubes have a solar weighted absorptance of $94.4 \%$ and further optimization of the selective coating is expected to yield solar absorptances of $96 \%$ or higher.

- Receiver Glass Envelope Transmittance. Anti reflective coatings for glass have been improved in the last 10 years to improve durability. The new receiver tubes have anti-reflective coatings that deliver solar transmittances of $96.5 \%$ compared with earlier coating that only allowed $92.5 \%$.

- New Front Surface Reflectors. New front surface reflectors with solar-weighted reflectivity of $95 \%$ are assumed for the SunLab long-term case compared to $93.5 \%$ for current thick glass mirrors.

The S\&L evaluation is based on a less aggressive technology development approach, basing the maximum optical efficiency on the tested receiver tubes weighted absorptance of $94.4 \%$ and receiver coatings solar transmittances of $96.5 \%$. 


\subsubsection{Receiver Thermal Losses}

Receiver thermal losses are primarily driven by the thermal emittance of the receiver's selective coating (radiation losses) and by the vacuum in the receiver (convection losses). As long as vacuum is maintained, convection losses are negligible. Radiation losses, on the other hand, are a function of the receiver's absolute surface temperature to the fourth power. The thermal emittance measures the ability of the surface to radiate energy away from the receiver. The lower the thermal emittance, the lower the radiation losses from the surface.

- $\quad$ Receiver Thermal Emittance. SEGS VI had a combination of black chrome and the original generation of Luz Cermet receiver tubes. The average thermal emittance of these tubes is approximately greater than $20 \%$ at $350^{\circ} \mathrm{C}$. The UVAC receiver first installed at SEGS VI had a thermal emittance of $14 \%$ at $400^{\circ} \mathrm{C}$. According to tests performed for Solel, the secondgeneration UVAC receiver had a thermal emittance of about $9 \%$ at $400^{\circ} \mathrm{C}$. SunLab currently has a research and development effort exploring high temperature coating designs with low thermal emittance and high solar absorptance.

- Receiver Reliability. As long as vacuum is maintained, convective thermal losses are minimal from the receiver. When receivers lose vacuum, the thermal losses from the receiver are approximately doubled. Breakage of the glass envelope results in significantly higher thermal losses. Loss of vacuum and breakage of the receiver glass envelope have been significant issues at the existing SEGS plants.

\subsubsection{Piping Thermal Losses}

Piping thermal losses corresponds to thermal losses from the solar field header piping and heat transfer fluid (HTF) system piping. Piping heat losses are a function of the piping surface area and the temperature of the fluid in the pipe above ambient temperature. Nexant has developed a parabolic trough solar field piping model for sizing the layout of piping headers. This model has been used to determine the heat losses for the various cases. The piping model has been baselined against the thermal performance of the SEGS VI solar field.

- The near-term case operates at temperatures similar to SEGS VI $\left(391{ }^{\circ} \mathrm{C}\right)$, thus the heat losses are considered to be similar.

- $\quad$ Piping losses in future cases are similar due to a combination of offsetting factors. The mid-term case is based on operating at a higher temperature of $450^{\circ} \mathrm{C}$ and maintaining the field at a minimum of $150^{\circ} \mathrm{C}$ during non-operational periods to prevent the molten-salt HTF from freezing. This higher temperature results in increased thermal losses per unit area of piping. However, the new salt fluid has a higher density that requires lower flow rates and smaller heater piping. These result in the thermal losses from the solar field being reduced. The longterm case is based on operating at higher temperatures $\left(500^{\circ} \mathrm{C}\right)$ and lower flow rates. 


\subsubsection{Storage Thermal Efficiency}

Thermal storage efficiency accounts for thermal losses from the thermal storage system. Storage thermal losses are a function of the surface area of the storage tanks and the temperature of the fluid above ambient. Large high temperature thermal storage systems have been demonstrated at the SEGS I trough plant and Solar Two power tower. In these systems, thermal losses have been shown to be minimal; thus the storage thermal efficiency approaches $100 \%$. Nexant has developed a thermal storage design model, which was used to determine the heat losses. This model is based on the Solar Two thermal storage design and operational experience.

- Storage thermal losses for the near-term trough plants are slightly larger for trough plants than for tower plants. Due to the smaller temperature difference between the hot and cold storage tanks in the trough plant, the thermal storage system must be larger to hold the same amount of thermal energy. Thus, there is more surface area for the trough plant. However, the hot tank temperature at the trough plant will be lower than the tower plants and the thermal losses per unit area of tank will be lower. Overall, storage losses are slightly larger at the trough plant; however, the storage thermal efficiency is still greater than $99 \%$.

- Mid-term and long-term thermal storage systems operate at higher temperatures; however, the temperature difference between hot and cold is greater. As a result, a smaller volume is required to store energy. Also, single tank thermocline storage systems are anticipated. These further reduce the required tank volume by replacing a large fraction of the storage fluid with low cost filler, sand and gravel, that typically has a higher volumetric heat capacity than the fluid it is replacing. Therefore, even though future thermal storage systems operate at higher fluid temperatures, the surface area of the thermal storage system is reduced compared to the nearterm storage case and results in improved storage thermal efficiency.

\subsubsection{Turbine Cycle Annual Efficiency}

The turbine cycle annual efficiency accounts for the design point turbine cycle efficiency, start-up losses, partload operation, and losses due to minimum turbine load requirements (especially important for plants without thermal storage).

- The near-term case has the same turbine cycle design point efficiency as SEGS VI (37.7\%); however, because of thermal storage, the annual turbine cycle efficiency is better than the case without thermal storage. The near-term plant with thermal storage has a higher capacity factor than SEGS VI (47\% versus 34\%). Thus, the number of turbine start-ups per MWh generated is lower. Thermal storage allows the plant to operate more hours at full load close to peak efficiency and reduces the number of hours the plant is operating at part load efficiencies. Thermal storage also allows thermal energy to be collected even when it is not sufficient to operate the power plant.

- The power cycle efficiency of the mid-term and long-term cases increases to $39 \%$ and $40 \%$ as solar field operating temperatures are increased to $450^{\circ} \mathrm{C}$ and $500^{\circ} \mathrm{C}$, respectively. 


\subsubsection{Electric Parasitic Load}

The main parasitic electric loads are the motors for the heat transfer fluid (HTF) pumps, condensate/feedwater pumps, cooling water pumps, cooling tower fans, and boiler of heater forced draft fans. Additional parasitic loads are a result of instrumentation, controls, computers, valve actuators, air compressors, and lighting. The solar field also adds parasitic loads for the collector drives and communications.

- A significant reduction in parasitic electric load for the near-term trough technology is based primarily on the replacement of flex hoses with balljoint assemblies in the solar field. These ball-joint assemblies reduce the pressure drop across the solar field by approximately $50 \%$. The addition of thermal storage is also expected to reduce parasitics by spreading the station load over increased annual generation.

- A further reduction in pumping parasitics will occur when the switch is made to molten-salt HTF. Because of the higher density of molten salt, lower volumetric HTF flow rates, and thus less pumping power, are required.

\subsubsection{Power Plant Availability}

Availability accounts for forced and scheduled outages and deratings of the power plant. Typically, plant availability is only affected if solar energy collection/conversion is reduced by an outage or derating.

- $\quad$ For the most part, the SEGS plants have demonstrated very high power plant availability. Normally, plants will take a 1- to 2-week outage during the winter to conduct required annual inspections and any corrective maintenance that cannot be accomplished during the normal daily operation. Every 10 years, a 5-week major turbine overhaul is conducted. During 1999, SEGS VI had a power plant availability of approximately $98 \%$ but did not take any planned scheduled maintenance outages during the year.

- $\quad$ Future plants are conservatively assumed to have a $6 \%$ annual outage rate. This includes both scheduled and forced outages.

If a higher temperature HTF and compatible thermal storage system can be developed and implemented in the mid-term, a 17.0\% annual net solar-to-electric efficiency is feasible. Additional investigation and development of storage systems, including the optimum HTF for steam cycle efficiency and storage compatibility is required to achieve the mid-term efficiency projection. Long-term objectives will require continuing investigation and development of thermal storage systems and high temperature HTF. The long-term objectives will also necessitate an advanced $\mathrm{HCE}$ absorber coating for the projected $500^{\circ} \mathrm{C}$ operating temperature. 


\subsection{EVALUATION OF MAJOR COST COMPONENTS}

The major cost contributors in direct cost of a parabolic trough solar plant with thermal storage are the solar collector field (53\%), thermal storage system (23\%), and power block (14\%), as illustrated in Figure 4-1.

Figure 4-1 - Major Cost Categories for Parabolic Trough Plant 2004 Near-Term Case: 100 MWe, 12 hours TES, 2.5 Solar Multiple

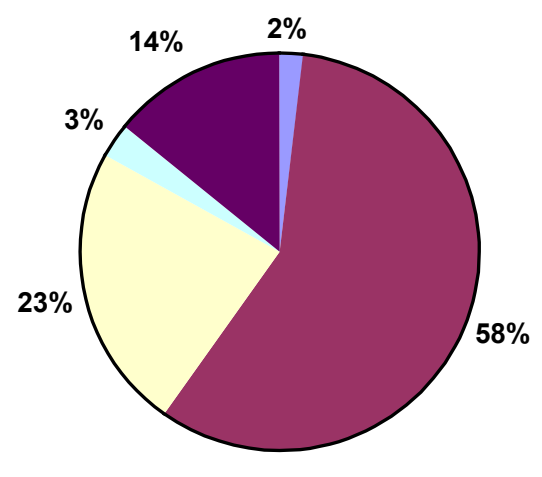

$\square$ Structures and Improvements
$(2 \%)$
$\square$ Solar Collection System
$(58 \%)$
$\square$ Thermal Storage System
$(23 \%)$
$\square$ Steam Gen or HX System
$(3 \%)$
$\square$ Power Block (EPGS, BOP)
$(14 \%)$

The major component costs in the solar field are illustrated in Figure 4-2. The key cost elements in the solar field are the receiver (20\%), the mirrors (19\%), and the concentrator structure $(29 \%)$.

\section{Figure 4-2 - Solar Field Component Cost Breakdown for Parabolic Trough Plant 2004 Near-Term Case: 100 MWe, 12 hours TES, 2.5 Solar Multiple}

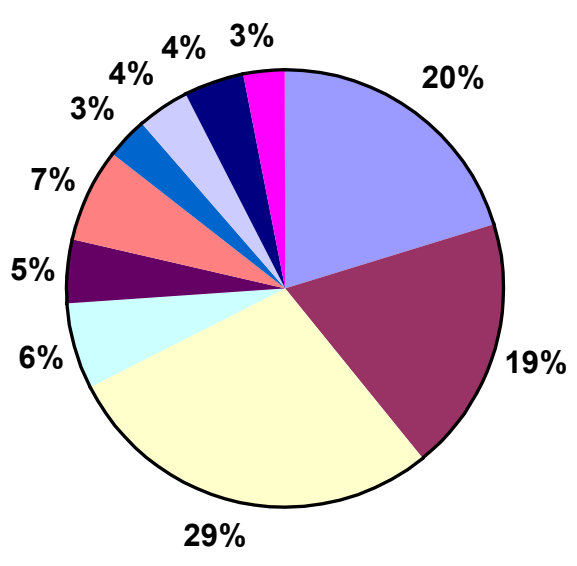

\footnotetext{
口Receiver (HCE) (20\%)

$\square$ Mirror (19\%)

$\square$ Metal support structure (29\%)

口Drive (6\%)

IInterconnection Piping (5\%)

$\square$ Electronics \& control (7\%)

$\square$ Header piping (3\%)

口Pylon Foundations (4\%)

口Other Civil Works (4\%)

口Heat Transfer Fluid (3\%)
}

The S\&L review focuses on these five major cost components: concentrator structure, mirrors, receivers, thermal energy storage, and the power block. Table 4-4 provides a summary of the SunLab and S\&L cost projections for these five cost elements. 
Table 4-4 — Trough Capital Cost Summary

\begin{tabular}{|c|c|c|c|c|c|c|c|}
\hline \multirow[b]{2}{*}{ Case } & \multirow[b]{2}{*}{$\begin{array}{l}\text { Base- } \\
\text { line }\end{array}$} & \multicolumn{3}{|c|}{ SunLab } & \multicolumn{3}{|c|}{ Sargent \& Lundy } \\
\hline & & $\begin{array}{l}\text { Near } \\
\text { Term }\end{array}$ & $\begin{array}{l}\text { Mid } \\
\text { Term }\end{array}$ & $\begin{array}{l}\text { Long } \\
\text { Term }\end{array}$ & $\begin{array}{l}\text { Near } \\
\text { Term }\end{array}$ & $\begin{array}{l}\text { Mid } \\
\text { Term }\end{array}$ & $\begin{array}{l}\text { Long } \\
\text { Term }\end{array}$ \\
\hline Project & $\begin{array}{c}\text { SEGS } \\
\mathrm{VI}\end{array}$ & $\begin{array}{c}\text { Trough } \\
50\end{array}$ & $\begin{array}{c}\text { Trough } \\
150\end{array}$ & $\begin{array}{c}\text { Trough } \\
400\end{array}$ & $\begin{array}{c}\text { Trough } \\
50\end{array}$ & $\begin{array}{c}\text { Trough } \\
150\end{array}$ & $\begin{array}{l}\text { Trough } \\
400\end{array}$ \\
\hline In Service & 1989 & 2004 & 2010 & 2020 & 2004 & 2010 & 2020 \\
\hline Solar Collection System $\left(\$ / \mathrm{m}^{2}\right)$ & 250 & 234 & 161 & 122 & 234 & 195 & 181 \\
\hline Support Structure, $\$ / \mathrm{m}^{2}$ & 67 & 61 & 54 & 46 & 67 & 56 & 52 \\
\hline Heat Collection Elements, \$/unit & 847 & 847 & 635 & 400 & 847 & 675 & 525 \\
\hline Mirrors, $\$ / \mathrm{m}^{2}$ & 43 & 43 & 28 & 18 & 40 & 32 & 26 \\
\hline Power Block, $\$ / \mathrm{kWe}$ & 527 & 367 & 293 & 197 & 306 & 270 & 198 \\
\hline Thermal Storage, $\$ / \mathrm{kWe}$ & NA & 958 & 383 & 383 & 958 & 383 & 383 \\
\hline Total Plant Cost, $\$ / k W e$ & 3,008 & 4,856 & 3,416 & 2,225 & 4,816 & 3,562 & 3,220 \\
\hline
\end{tabular}

\subsubsection{Solar Field Support Structure}

The structure consists of the metal support system of the collectors consisting of the pylons and reflector support elements. Wind loads during maximum wind speeds dictate the required strength of these units. Recent wind tunnel testing has provided improved data for use in optimizing the structural design, and reducing the weight, necessary for long-term reliability.

The SunLab projections for the structure material and erection are shown in the following Table 4-5.

Table 4-5 - SunLab Cost Projections

\begin{tabular}{|l|c|c|c|}
\hline \multicolumn{2}{|c|}{} & \multicolumn{2}{c|}{ Reduction from } \\
\cline { 3 - 4 } \multicolumn{2}{|c|}{} & SEGS VI & $\$ / \mathbf{k W e}$ \\
\hline SEGS VI & $\$ 67 / \mathrm{m}^{2}$ & - & $420^{*}$ \\
\hline 2004 & $\$ 61 / \mathrm{m}^{2}$ & $9 \%$ & 683 \\
\hline 2007 & $\$ 57 / \mathrm{m}^{2}$ & $15 \%$ & 591 \\
\hline 2010 & $\$ 54 / \mathrm{m}^{2}$ & $19 \%$ & 531 \\
\hline
\end{tabular}




\begin{tabular}{|l|c|c|c|}
\hline \multicolumn{2}{|c|}{} & \multicolumn{2}{c|}{ Reduction from } \\
\cline { 3 - 4 } \multicolumn{2}{|c|}{} & SEGS VI & $\$ / \mathbf{k W e}$ \\
\hline 2015 & $\$ 50 / \mathrm{m}^{2}$ & $25 \%$ & 489 \\
\hline 2020 & $\$ 46 / \mathrm{m}^{2}$ & $31 \%$ & 450 \\
\hline
\end{tabular}

*Smaller solar field per kWe due to no storage.

The baseline cost of $\$ 67 / \mathrm{m}^{2}$ is consistent with estimates prepared by Pilkington International (1999) indicating $\$ 63 / \mathrm{m}^{2}$. Cost comparisons based on weight for the various structures are illustrated below in Table 4-6. Additional cost reductions will be realized by minimization of the number of required parts, simplification of fabrication and field erection reducing labor costs for on-site assembly and erection. This cost reduction potential has not been quantified in this evaluation since there has not been an actual erection of a new collector structure. The individual metal parts of the structure can readily be manufactured by suppliers worldwide, leading to potential cost reductions through competition. However, structure cost reductions due to commercialization were not specifically considered in this evaluation.

Table 4-6 - Costs of Various Structures

\begin{tabular}{|l|l|}
\hline LS-2 & $\$ 58 / \mathrm{m}^{2}$ \\
\hline LS-3 & $\$ 66 / \mathrm{m}^{2}$ \\
\hline EuroTrough & $\$ 58 / \mathrm{m}^{2}$ \\
\hline Duke Solar & $\$ 48 / \mathrm{m}^{2}$ \\
\hline IST & $\$ 48 / \mathrm{m}^{2}$ \\
\hline
\end{tabular}

Based on the current activity in progress by the various suppliers, obtaining the projected cost reductions for the structure represents a low risk. The current weight reduction presented by the suppliers has the potential to meet the projected cost reduction.

\subsubsection{Solar Field Heat Collection Elements (HCE)}

The receivers, or heat collection elements (HCEs), are a major contributor to trough solar field performance. Luz manufactured this solar field component in-house, which has continued under Solel Solar Systems who acquired the Luz manufacturing facilities. HCEs supplied to the SEGS plants for spare parts over the last decade by Solel have shown improvements in performance and reliability. These include improved optical properties 
with regards to absorptivity and better protection of the glass-to-metal seal to increase in-service lifetime. The SunLab projected HCE deployment and costs are shown in Table 4-7.

Table 4-7 — SunLab Projected HCE Deployment and Costs

\begin{tabular}{|l|c|r|r|r|r|c|}
\hline \multicolumn{1}{|c|}{ Project } & SEGS VI & $\begin{array}{c}\text { Trough } \\
\mathbf{1 0 0}\end{array}$ & $\begin{array}{c}\text { Trough } \\
\mathbf{1 0 0}\end{array}$ & $\begin{array}{c}\text { Trough } \\
\mathbf{1 5 0}\end{array}$ & $\begin{array}{c}\text { Trough } \\
\mathbf{2 0 0}\end{array}$ & $\begin{array}{c}\text { Trough } \\
\mathbf{4 0 0}\end{array}$ \\
\hline In Service & $\mathbf{1 9 9 9}$ & $\mathbf{2 0 0 4}$ & $\mathbf{2 0 0 7}$ & $\mathbf{2 0 1 0}$ & $\mathbf{2 0 1 5}$ & $\mathbf{2 0 2 0}$ \\
\hline Number of HCE & 9,600 & 57,216 & 45,700 & 65,072 & 86,101 & 172,201 \\
\hline Number of HCE Accumulative & 9,600 & 66,816 & 112,516 & 177,588 & 263,688 & 435,889 \\
\hline Cost, $\$ / m^{2}$ field & 43 & 43 & 34 & 28 & 22 & 18 \\
\hline Cost, \$/unit & 847 & 847 & 762 & 635 & 508 & 400 \\
\hline
\end{tabular}

A comparison of the S\&L estimated HCE costs and the SunLab projected costs is shown below in Table 4-8.

Table 4-8 - Comparison of HCE Costs

\begin{tabular}{|c|c|c|}
\hline Year & $\begin{array}{c}\text { SunLab Projected } \\
\text { Cost, \$/unit }\end{array}$ & $\begin{array}{c}\text { S\&L Estimate, } \\
\text { \$/unit }\end{array}$ \\
\hline 2004 & 847 & 847 \\
\hline 2007 & 762 & 762 \\
\hline 2010 & 635 & 675 \\
\hline 2015 & 508 & 625 \\
\hline 2020 & 400 & 600 \\
\hline
\end{tabular}

The heat collection elements, which constitute a major portion of the direct capital cost, currently have only one supplier (Solel). Additional suppliers will promote competition and reduce costs. A major European and worldwide specialty glass parts supplier, Schott Rohrglas, has recently announced its intent to produce this component. An increase in the number of HCEs as projected by SunLab will reduce the cost based on the experience curve cost reduction, but not to the projected \$400/unit.

Advanced development of the HCE is required for the higher operating temperatures in the planned molten-salt heat transfer fluid (HTF) applications, as discussed in the thermal storage section of this report. Additional development is also required to address the excess failure rates that have occurred at the SEGS plants compared 
to expected levels. The HCE development focus now is on developing a more robust and lower cost glass-tometal seal design and on identifying higher-temperature selective coating with better thermo/optic properties. Sandia has identified new materials that could be used in the glass-to-metal seal to reduce the potential stress in the seal. In general, however, the current Housekeeper seal used in the HCE is very expensive and a significant part of the total receiver cost. Sandia has also identified some new glass-to-metal seal options that have the potential to be much lower in cost to manufacture and be more robust at the same time. NREL has been evaluating new selective coatings. Several new cermet coatings have been identified that may be easier to manufacture and have better thermo/optic properties. These are multi-layer cermets as opposed to the graded cermet used by Solel. The graded cermets require a sputtered manufacturing process, whereas the multilayer coating can probably be deposited with simpler coating processes and should also have better quality control of the final properties. NREL is also looking into changing the materials used in the cermet to give better high temperature performance and stability. Both the design work and the coating development are being funded in the current DOE budget and will be continued next year.

Alternate HCE designs (Zhang et al. 1998; Morales and Ajona 1998; San Vicente, Morales, and Gutiérrez 2001), which are in various stages of development, indicate a lower cost than the Solel UVAC HCE, but at reduced efficiency levels. Reduced HCE efficiency will result in a lower net annual solar-to-electric efficiency and require a larger collector area. As noted above, Schott Rohrglas, a large international supplier of specialty glass and related products, has recently announced its entry into the HCE supply market. However, start-up of HCE production is a significant cost, and a viable market growth is imperative to justify market entry for a new supplier.

\subsubsection{Solar Field Mirrors}

The reflectors used in the SEGS plants consist of 4-mm low-iron float glass mirrors thermally sagged during manufacturing into a parabolic shape. A single manufacturer supplied the mirrors for the SEGS plants at construction and for spare parts since that time. Mass production and competition can lower the cost significantly, as can technical improvements. The SunLab projected mirror costs are shown in Table 4-9. 
Table 4-9 - SunLab Projected Mirrors Costs

\begin{tabular}{|r|c|c|c|c|c|c|}
\hline Project & $\begin{array}{c}\text { SEGS } \\
\text { VI }\end{array}$ & $\begin{array}{c}\text { Trough } \\
\mathbf{1 0 0}\end{array}$ & $\begin{array}{c}\text { Trough } \\
\mathbf{1 0 0}\end{array}$ & $\begin{array}{c}\text { Trough } \\
\mathbf{1 5 0}\end{array}$ & $\begin{array}{c}\text { Trough } \\
\mathbf{2 0 0}\end{array}$ & $\begin{array}{c}\text { Trough } \\
\mathbf{4 0 0}\end{array}$ \\
\hline In Service & $\mathbf{1 9 9 9}$ & $\mathbf{2 0 0 4}$ & $\mathbf{2 0 0 7}$ & $\mathbf{2 0 1 0}$ & $\mathbf{2 0 1 5}$ & $\mathbf{2 0 2 0}$ \\
\hline Mirrors, $\$ / \mathrm{m}^{2}$ field & 40 & 40 & 36 & 28 & 22 & 16 \\
\hline
\end{tabular}

Alternatives to glass mirror reflectors have been in service and under development for more than 15 years. It is noted that all the identified alternatives are in various stages of initial development or testing. The major current developments are listed below.

- Thin glass mirrors are as durable as a glass reflector and relatively lightweight in comparison to thick glass. However, the mirrors are more fragile, which increases handling costs and breakage losses. To address corrosion problems, new thin glass experimental samples were recently developed and are being tested under controlled conditions.

- $\quad 3 \mathrm{M}$ is developing a nonmetallic, thin-film reflector that uses a multi-layer Radiant Film technology. The technology employs alternating co-extruded polymer layers of differing refractive indices to create a reflector without the need for a metal reflective layer. $3 \mathrm{M}$ plans to develop an improved solar reflector with improved UV screening layers and a top layer hardcoat to improve outdoor durability.

- ReflecTech and NREL are jointly developing a laminate reflector material that uses a commercial silvered-polymer reflector base material with a UV-screening film laminated to it to result in outdoor durability. Initial prototype accelerated-exposure test results have been promising, although additional work on material production is needed. The material would also benefit from a hardcoat for improved washability.

- Luz Industries Israel created a front surface mirror that consists of a polymeric substrate with a metal or dielectric adhesion layer; a silver reflective layer; and a proprietary, dense, protective top hardcoat.

- $\quad$ SAIC of McLean, Virginia, and NREL have been developing a material called Super Thin Glass. This is also a front surface mirror concept with a hard coat protective layer.

- Alanod of Germany has developed a front surface aluminized reflector that uses a polished aluminum substrate, an enhanced aluminum reflective layer, and a protective oxidized alumina topcoat. These reflectors have inadequate durability in industrial environments. A product with a polymeric overcoat to protect the alumina layer has improved durability.

At this point, thick glass will likely remain the preferred approach for large-scale parabolic trough plants, although alternative reflector technologies may be more important in the future as more advanced trough concentrator designs are developed. 
Based on the current activity underway by the various suppliers, obtaining the projected cost reductions for the mirrors represents a low risk. The current costs presented by the suppliers have the potential to meet the projected cost reduction. Having active suppliers performing development promotes lower costs through competition. It is expected a portion of the mirror development will be in the realm of the manufacturers.

\subsubsection{Power Block}

There are recognized scale-up cost reductions for the power block. Using the SOAPP software program (SOAPP undated), S\&L estimated the scale-up factor for increasing the plant size from $100 \mathrm{MW}$ to $400 \mathrm{MW}$, as depicted on Figure 4-3. The projected SunLab values are included for comparative purposes. Power block costs (Figure 4-3A) include the steam turbine and generator, steam turbine and generator auxiliaries, feedwater, and condensate systems. Balance-of-plant costs (Figure 4-3B) include general balance-of-plant equipment, condenser and cooling tower system, water treatment system, fire protection, piping, compressed air systems, closed cooling water system, plant control system, electrical equipment, and cranes and hoists.

Figure 4-3A - Scale-Up Cost Reductions: Power Block (\$/kW)

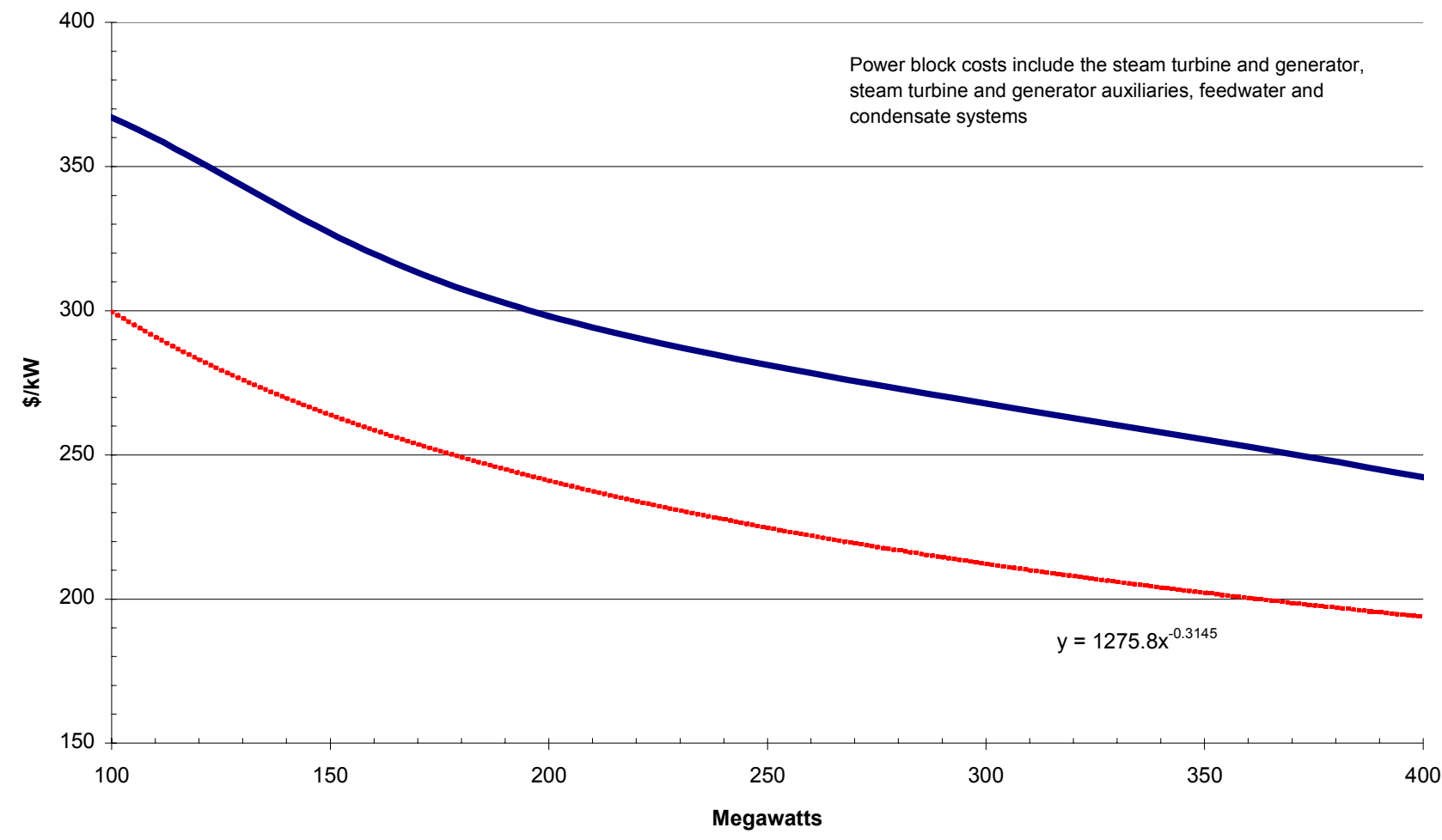


Figure 4-3B - Scale-Up Cost Reductions: Balance-of-Plant (\$/kW)

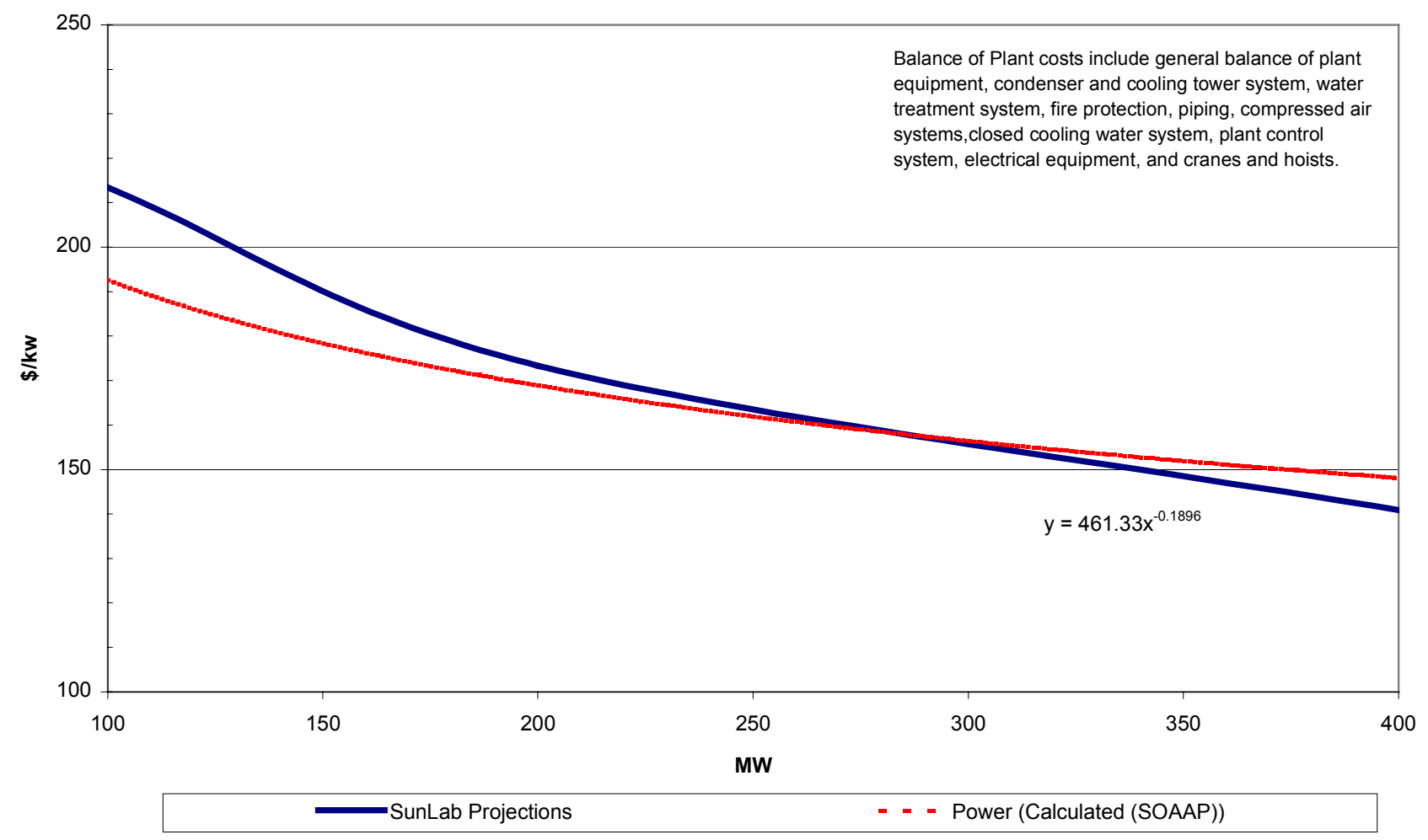

A comparison of the SunLab projected cost versus the SOAPP predicted $\$ / \mathrm{kW}$ cost for the power block plus the balance-of-plant is shown in Table 4-10.

Table 4-10 - Power Block and BOP Cost Comparison

\begin{tabular}{|l|c|c|c|c|}
\hline Total Power Block + BOP & $\mathbf{2 0 0 4 - 2 0 0 7}$ & $\mathbf{2 0 1 0}$ & $\mathbf{2 0 1 5}$ & $\mathbf{2 0 2 0}$ \\
\hline Plant size, MWe & 100 & 150 & 200 & 400 \\
\hline SunLab Projected Cost, \$/kWe & 581 & 525 & 472 & 383 \\
\hline SOAPP Estimate Cost, \$/kWe & 499 & 450 & 399 & 346 \\
\hline
\end{tabular}

The estimated costs based on the SOAPP program indicate that the SunLab projected costs for the power block are conservative (on the high side), approximately $\$ 50 / \mathrm{kW}$ higher than estimated by the SOAPP program. The SunLab power block cost estimates are based on a 1990 ABB quotation for a 100-MW steam turbine. The ABB quotation was escalated and scaled-up for the larger sizes. The SunLab power block cost estimates are based on dated information, and the escalation and scale-up factors add to the uncertainty of the data with respect to 
current pricing. Equipment prices in the SOAPP program reflect 2001 actual costs. Since the SOAPP pricing is current, the SOAPP-generated costs were used in this evaluation.

As previously discussed, to achieve the near-term increased Rankine cycle efficiency, the HTF will have to be changed to obtain higher inlet steam temperatures. For the near-term, additional development and field testing is required on alternate HTF for higher temperature applications. For the long-term, not only is alternate HTF development required but the current $\mathrm{HCE}$ absorber coating upper temperature limit must be raised by new developments to the projected $500^{\circ} \mathrm{C}$ operating temperature.

\subsubsection{Thermal Storage}

The SunLab projected thermal storage costs are shown in Table 4-11. Note that the SunLab projections are based on 12 hours of thermal storage for each case.

Table 4-11 - SunLab Projected Thermal Storage Cost

\begin{tabular}{|l|c|c|c|c|c|}
\hline & $\mathbf{2 0 0 4}$ & $\mathbf{2 0 0 7}$ & $\mathbf{2 0 1 0}$ & $\mathbf{2 0 1 5}$ & $\mathbf{2 0 2 0}$ \\
\hline Plant size, gross, MWe & 110 & 110 & 165 & 220 & 440 \\
\hline Storage, $\mathrm{MWh}_{\mathrm{t}}$ & 3,525 & 3,349 & 4,894 & 6,525 & 13,050 \\
\hline Type & $\begin{array}{c}\text { Indirect } \\
\text { Two-Tank }\end{array}$ & $\begin{array}{c}\text { Direct } \\
\text { Thermocline }\end{array}$ & $\begin{array}{c}\text { Direct } \\
\text { Thermocline }\end{array}$ & $\begin{array}{c}\text { Direct } \\
\text { Thermocline }\end{array}$ & $\begin{array}{c}\text { Direct } \\
\text { Thermocline }\end{array}$ \\
\hline Heat Transfer Fluid & $\begin{array}{c}\text { VP-1 / Solar } \\
\text { Salt }\end{array}$ & HitecXL & HitecXL & HitecXL & HitecXL \\
\hline HTF Temperature, ${ }^{\circ} \mathrm{C}$ & 400 & 450 & 500 & 500 & 500 \\
\hline SunLab Projected $\$ / \mathrm{kWh}_{\mathrm{t}}$ & 27.1 & 12.7 & 11.7 & 11.7 & 11.7 \\
\cline { 2 - 6 } & 958 & 425 & 383 & 383 & 383 \\
\hline
\end{tabular}

Definitive cost estimates for an indirect two-tank storage system based on detailed design drawings and material takeoffs were developed by Nextant. The unit costs were $\$ 36.4 / \mathrm{kWh}_{\mathrm{t}}$ for a $470-\mathrm{kWh}_{\mathrm{t}}$ system and $\$ 31 / \mathrm{kWh}_{\mathrm{t}}$ for a $688 \mathrm{kWh}_{\mathrm{t}}$ system. The SunLab projection appears to be conservative (on the high side) based on the previous estimates.

However, the goal to reduce the thermal storage system capital cost in the $\$ 10 / \mathrm{kWh}_{\mathrm{t}}$ to $\$ 12 / \mathrm{kWh}_{\mathrm{t}}$ range will require additional investigation and development of both indirect and direct storage systems, including the 
optimum HTF and storage fluid for steam cycle efficiency and storage compatibility. The amount and type of storage have significant impacts on the total cost of the plant and are key considerations for cost reductions.

The year 2007 projection for a direct thermocline storage uses HitecXL (ternary) HTF in both the solar field and the thermal storage system, which eliminated the need for the heat exchangers between the solar field and storage system. In addition, the solar field can be operated to higher outlet temperatures $\left(450^{\circ} \mathrm{C}\right)$, increasing the power cycle efficiency and further reducing the cost of thermal storage. The 2007 direct thermocline storage value of $\$ 12.7 / \mathrm{kWh}_{\mathrm{t}}$ in the SunLab projection appears to be reasonable, if the direct thermocline storage system is successfully developed, based on the following:

- $\quad$ The power tower storage cost is $\$ 8.3 / \mathrm{kWh}_{\mathrm{t}}$ for 12 hours at Solar 100 .

- Trough plants have a smaller temperature differential in the thermal energy storage system $450^{\circ} \mathrm{C}-293^{\circ} \mathrm{C}\left(157^{\circ} \mathrm{C}\right)$ vs. $566^{\circ} \mathrm{C}-288^{\circ} \mathrm{C}\left(278^{\circ} \mathrm{C}\right)$ in tower plants.

- Trough plants have a lower power cycle efficiency, $39 \%$ at $450^{\circ} \mathrm{C}$ vs. $44 \%$ at $550^{\circ} \mathrm{C}$.

- The trough plants use a thermocline storage system that eliminates one tank and replaces the majority of storage fluid with a lower-cost filler material. Nextant estimates indicate that a $35 \%$ cost reduction can be achieved going from a two-tank system to a thermocline system.

Trough Storage Cost $(2007) \quad=\$ 8.3 / \mathrm{kWh}_{\mathrm{t}} *\left(278^{\circ} \mathrm{C} / 157^{\circ} \mathrm{C}\right) *(44 \% / 39 \%) *(1-0.35)$

$$
=\$ 10.7 / \mathrm{kWh}_{\mathrm{t}}
$$

Subsequent projections after the year 2007 also use a direct thermocline system with HitecXL (ternary) solar salt as the storage media and HTF. The SunLab TES cost estimate of $\$ 11.7 / \mathrm{kWh}_{\mathrm{t}}$ appears to be reasonable, if the solar field can be operated to higher outlet temperatures of $500^{\circ} \mathrm{C}$ and an advanced heat collection element for the $500^{\circ} \mathrm{C} \mathrm{HTF}$ operating temperature is developed, based on the following calculation:

$$
\begin{aligned}
\text { Trough Storage Cost }(2010) & =\$ 8.3 / \mathrm{kWh}_{\mathrm{t}} *\left(278^{\circ} \mathrm{C} / 207^{\circ} \mathrm{C}\right) *(44 \% / 40 \%) *(1-0.35) \\
& =\$ 7.9 / \mathrm{kWh}_{\mathrm{t}}
\end{aligned}
$$

\subsubsection{Total Investment Costs}

The SunLab model projects parabolic trough plant capital and O\&M costs based on various technology advances and commercial deployment predictions. The SunLab projections are considered the best-case analysis where the technology is optimized and a high deployment rate is achieved. S\&L developed capital and O\&M costs based on a more conservative approach whereby the technology improvements are limited to current demonstrated or tested improvements and with a lower rate of deployment than used in the SunLab model. The 
two sets of estimates, by SunLab and S\&L, provide a band in which the costs can be expected to fall. The capital costs without thermal storage is included for informational purposes.

Table 4-12 and Figure 4-4 illustrates the SunLab projected total installed capital cost $(\$ / \mathrm{kWe})$ compared to S\&L's more conservative values. Figure 4-4 also shows the total installed capital cost based on achieving the annual net efficiencies projected by SunLab, but not the projected cost reductions. The curves highlight the impact of the annual net efficiencies on the capital cost. The curves also indicate that additional cost reductions above and beyond the more conservative $\mathrm{S} \& \mathrm{~L}$ values, due to technology improvements and increased deployment rates, will result in convergence of the capital costs toward the SunLab values.

Table 4-12 - Comparison of Total Investment Cost Estimates (\$/kWe): SunLab vs. Sargent \& Lundy

\begin{tabular}{|l|r|r|r|r|r|}
\hline & $\mathbf{2 0 0 4}$ & $\mathbf{2 0 0 7}$ & $\mathbf{2 0 1 0}$ & $\mathbf{2 0 1 5}$ & $\mathbf{2 0 2 0}$ \\
\hline SunLab & $\mathbf{\$ 4 , 8 5 9}$ & $\mathbf{\$ 3 , 4 0 8}$ & $\mathbf{\$ 2 , 8 7 6}$ & $\mathbf{\$ 2 , 5 4 6}$ & $\mathbf{\$} 2,221$ \\
\hline S\&L - S\&L Efficiencies & 4,816 & 3,854 & 3,562 & 3,389 & 3,220 \\
\hline S\&L - SunLab Efficiencies & 4,791 & 3,687 & 3,331 & 3,165 & 2,725 \\
\hline S\&L - No Storage & 2,453 & 2,265 & 2,115 & 1,990 & 1,846 \\
\hline
\end{tabular}


Figure 4-4 - Total Installed Capital Costs: Operations and Maintenance

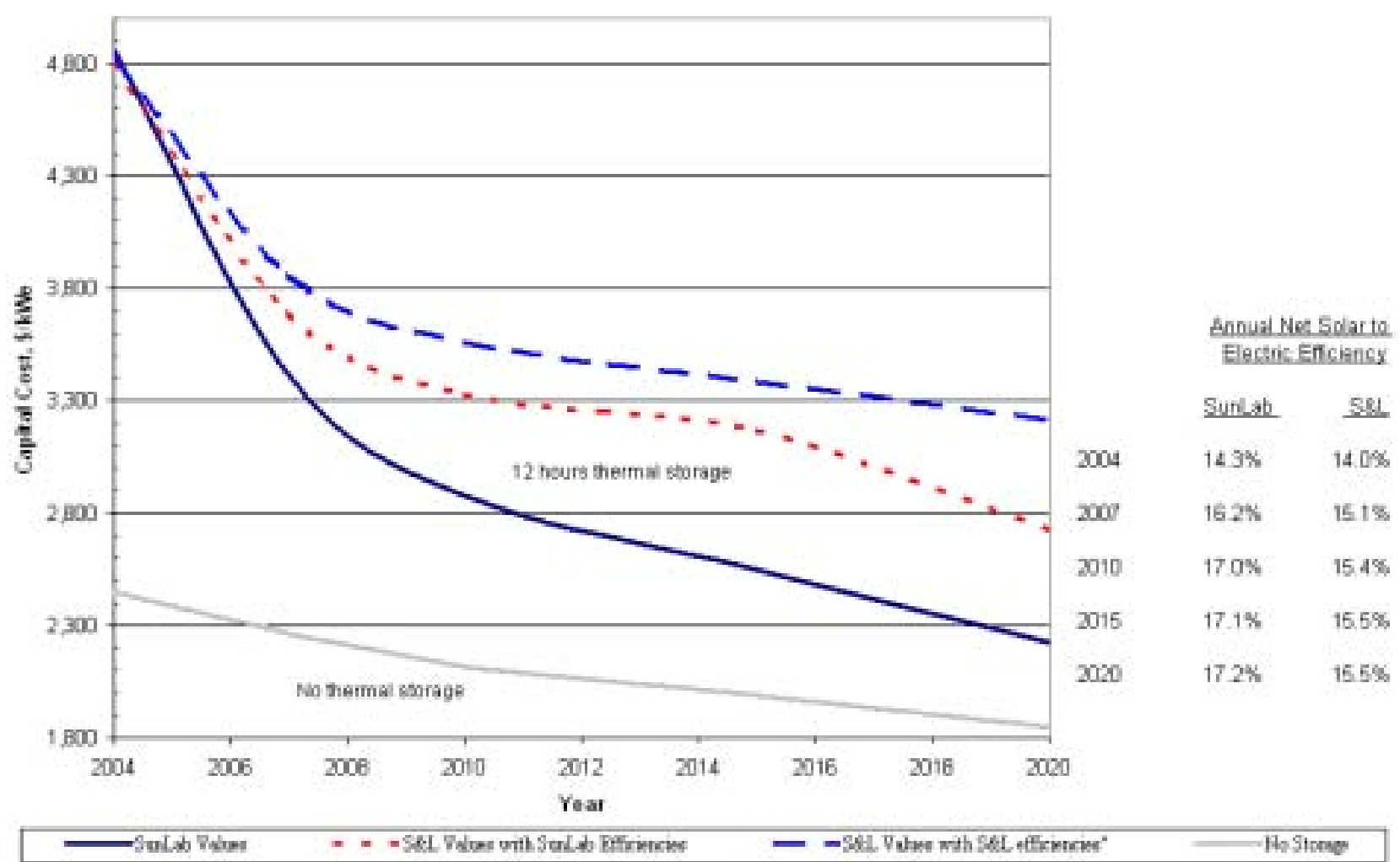

Sargent \& Lundy reviewed the SunLab O\&M cost model based on our experience with fossil and other power plant technologies and in the course of a site visit to KJC Operating Company, the operator of the five 30-MWe trough projects located at Kramer Junction. KJC Operating Company provided proprietary information on the last five years of operation. The SunLab O\&M estimate is based largely on the experience at the KJC Operating Company SEGS plants. The model assumes a stand-alone trough power plant (as opposed to the five co-located plants at Kramer Junction) and adjusts cost depending on the size of the solar field and total electric generation per year. It breaks out the specific staffing requirements for operations and maintenance crews for both the conventional power plant and for the solar field. Administrative staffing is also included. In addition to labor breakdown, the model breaks out service contracts, water treatment costs, spares and equipment costs, miscellaneous costs, and periodic capital equipment requirements. S\&L conducted a review of the SunLab model and compared it to general power industry experience. 
The Sargent \& Lundy O\&M costs for comparison to the SunLab projections are based on the following:

- Solar Field

- The initial unit costs are based on the SunLab values, and cost reductions for years beyond 2004 are based on a $P R=0.92$

- Replacement rate for the mirrors and HCE are based on the average actual replacement rates for SEGS III - VII for the period 1997-2001

- The replacement rates for the balance of the solar field are based on the SunLab values

- $\quad$ Power Block and Balance-of-Plant

- Costs are based on S\&L data for the respective MW-size plant for the steam turbine systems and balance-of-plant

- Water and Process

— Costs are based on the average actual costs for SEGS III - VII for the period 1997-2001

- Staffing, Services Contracts, Miscellaneous, and Capital Equipment

- The costs are based on the SunLab values since the SunLab values were determined to be reasonable

- Thermal Storage

- The costs are based on $0.4 \%$ of the capital cost per annum

Analyzing the two estimates revealed the major component to account for the cost difference is the HCE replacement rate. Table 4-13 shows a comparison of the SunLab and S\&L projected replacement rates.

Table 4-13 - Projected Trough Receiver Replacement Rates

\begin{tabular}{|l|c|c|c|c|c|c|}
\hline $\begin{array}{l}\text { Annual Failures } \\
\text { (Percent of Field) }\end{array}$ & Current & $\mathbf{2 0 0 4}$ & $\mathbf{2 0 0 7}$ & $\mathbf{2 0 1 0}$ & $\mathbf{2 0 1 5}$ & $\mathbf{2 0 2 0}$ \\
\hline SunLab & $3.5 \%$ & $2 \%$ & $1 \%$ & $0.5 \%$ & $0.5 \%$ & $0.5 \%$ \\
\hline S\&L & $5.5 \%$ & $5.5 \%$ & $2.5 \%$ & $1.5 \%$ & $1.0 \%$ & $0.5 \%$ \\
\hline
\end{tabular}

The SunLab near-term values are not consistent with the average actual HCE replacement rate of 5.5\% reported for SEGS III - VII for the period 1997-2001.

Sargent \& Lundy reviewed the actual receiver (HCE) replacement rate reported by KJC Operating Company over the last five years. The S\&L evaluation is based on total HCE replacement reported for the SEGS III - VII for the period 1997-2001. S\&L's evaluation is based on the current replacement rate at all the SEGS plants, with step reductions in the replacement rate based on the following considerations: 
- The average actual HCE replacement rate of 5.5\% was reported for SEGS III - VII for the period 1997-2001. The total HCE replacement includes breakage and fluorescence. Fluorescence is due to cermet coating failures. This failure is due to the existence of molybdenum in the original Luz cermet coating. Solel no longer uses molybdenum in the UVAC cermet coating, so this type of failure will presumably no longer occur. Eliminating replacements due to these failures reduces the site failure/replacement rate.

- $\quad$ SunLab used the SEGS VI plant as the baseline reference plant. The SEGS III - V plants had problems during initial startup and the early years of operation that caused bowing of the HCEs, which increased breakage at those plants. SEGS VII has had higher breakage on the LS-3 half of the field, although the LS-2 failures are similar to SEGS VI. SEGS VI was the last full plant constructed with LS-2 collectors and represents the most mature version of this generation of collector technology. The HCE total replacement rate at SEGS VI during the 5 years is in the $5.5 \%$ range. Discounting the fluorescence failures, the replacement rate was $4.2 \%$ over the 5 -year period.

- The high HCE failure rate at the existing plants is due in part to issues that would not be found at a future plant. A significant portion of the failures has been due to the hydrogen remover (HR) device installed in the HCEs at SEGS VI - X, operational problems that caused bowing, and HCE installation procedures. The HR is no longer part of the HCEs provided by Solel.

Based on these factors, it is very possible that future plants will have substantially lower HCE failure rates than those currently found at the SEGS plants. The SunLab assumption of a $2 \%$ failure rate assumes that current approaches for reducing failures are successful. S\&L believes that this is an aggressive assumption that cannot be assured for future plants without the field data to verify the failure rate reduction. Using the current replacement rate occurring at all the SEGS plants, with step reductions in the replacement rate, reflects the current conditions and allows for the aforementioned improvements to reduce the replacement rate.

Additional development of the HCE will likely be necessary to achieve the future receiver reliability goals. The current glass-to-metal seal is one of the more expensive elements and the key failure point of the current receiver design. The current seal design, known as a Housekeeper seal, relies on a sharp metal point being inserted into a glass bead. Failures occur when concentrated light focuses on seal and the differential expansion between the glass and metal causes the failure of the seal. New designs are currently under investigation that attempt to improve the match between the coefficient of thermal expansion of the metal and glass. Kramer Junction is currently testing a new design, UVAC2, with a revised internal shield.

To achieve the SunLab projected replacement rates, the reliability of the HCE will have to improve significantly. Table 4-14 and Figure 4-5 compare the O\&M costs and illustrate the impact of the HCE replacement rate. The O\&M costs without thermal storage are included for informational purposes. 
Table 4-14 - Comparison of O\&M Cost Estimates $\left(\$ / \mathbf{k W h}_{\mathrm{e}}\right)$ : SunLab vs. S\&L

\begin{tabular}{|l|c|c|c|c|c|}
\hline & $\mathbf{2 0 0 4}$ & $\mathbf{2 0 0 7}$ & $\mathbf{2 0 1 0}$ & $\mathbf{2 0 1 5}$ & $\mathbf{2 0 2 0}$ \\
\hline SunLab & 0.0228 & 0.0171 & 0.0135 & 0.0118 & 0.0097 \\
\hline S\&L - S\&L HCE Replacement & 0.0280 & 0.0218 & 0.0180 & 0.0157 & 0.0139 \\
\hline S\&L - SunLab HCE Replacement & 0.0246 & 0.0197 & 0.0167 & 0.0154 & 0.0139 \\
\hline S\&L - No Storage & 0.0377 & 0.0339 & 0.0278 & 0.0241 & 0.0206 \\
\hline
\end{tabular}

Figure 4-5 - Levelized O\&M Cost Comparison

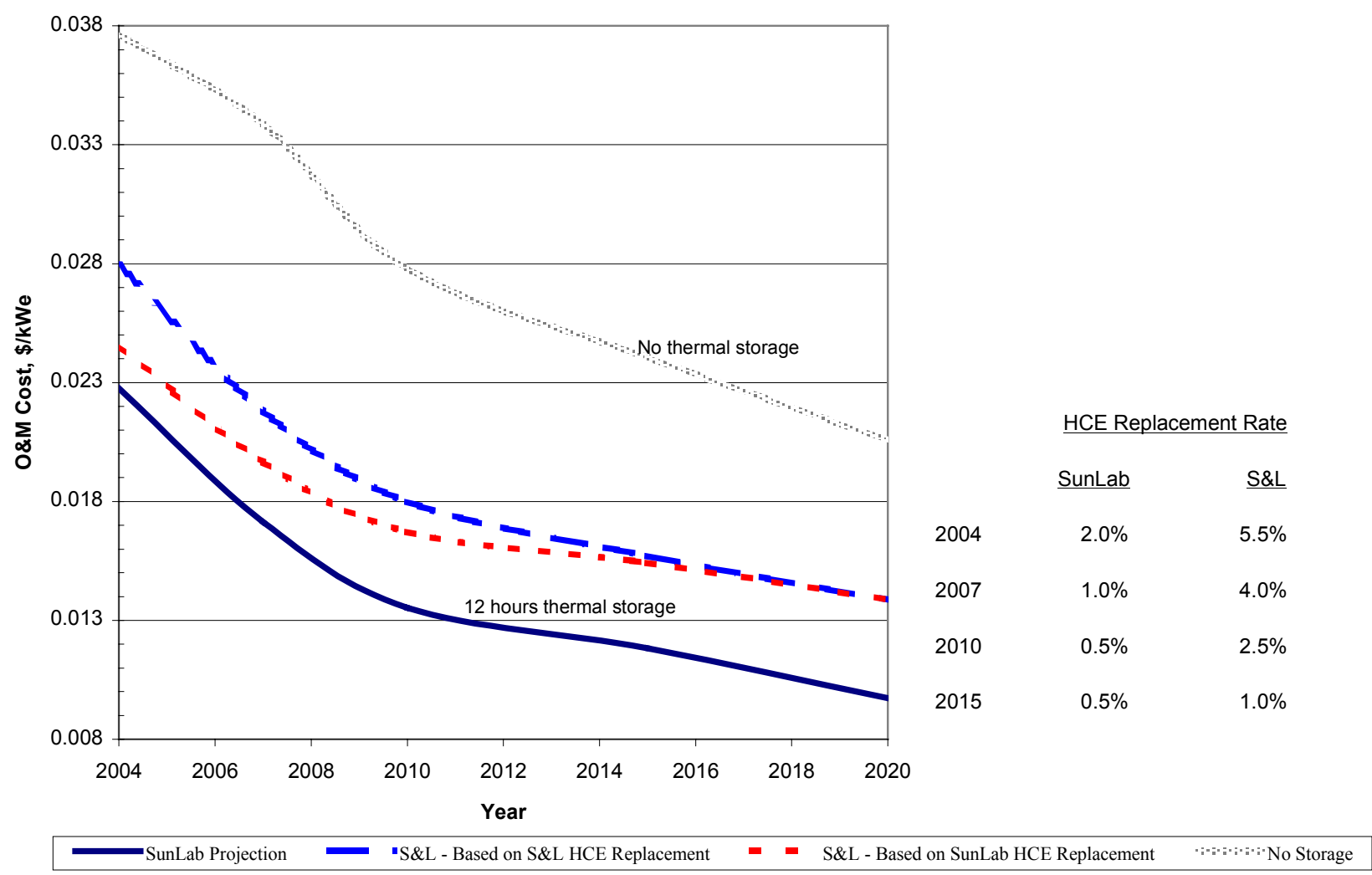

The reduction in O\&M cost is primarily a result of the increase in plant size and the increase in annual plant capacity factor. The plant capacity increases directly as a result of the increases in thermal storage. Increasing the size (MWe) and capacity factor of the power plant incurs minimal increase in the fixed O\&M expenses (\$/year). 


\subsection{LEVELIZED ENERGY COSTS}

Table 4-15 and Figure 4-6 below illustrate the SunLab projected levelized energy cost ( $\$ / \mathrm{kWhe}$ ) compared to the S\&L values. The figure also shows the levelized energy cost based on achieving the annual net efficiencies projected by SunLab. For comparison, the estimated levelized energy cost for the trough plants without thermal storage is included in Figure 4-6 to underscore the importance of thermal storage in the reduction of the levelized energy cost.

Table 4-15 - Comparison of Levelized Energy Cost Estimates (\$/kWhe): SunLab vs. S\&L

\begin{tabular}{|l|r|r|r|r|r|}
\hline & $\mathbf{2 0 0 4}$ & $\mathbf{2 0 0 7}$ & $\mathbf{2 0 1 0}$ & $\mathbf{2 0 1 5}$ & $\mathbf{2 0 2 0}$ \\
\hline SunLab & 0.0991 & 0.0681 & 0.0566 & 0.0476 & 0.0428 \\
\hline S\&L - S\&L Efficiencies & 0.1037 & 0.0795 & 0.0713 & 0.0664 & 0.0621 \\
\hline S\&L - SunLab Efficiencies & 0.1031 & 0.0763 & 0.0670 & 0.0624 & 0.0534 \\
\hline S\&L - No Storage & 0.1201 & 0.1100 & 0.0989 & 0.0910 & 0.0826 \\
\hline
\end{tabular}


Figure 4-6 - Levelized Energy Costs

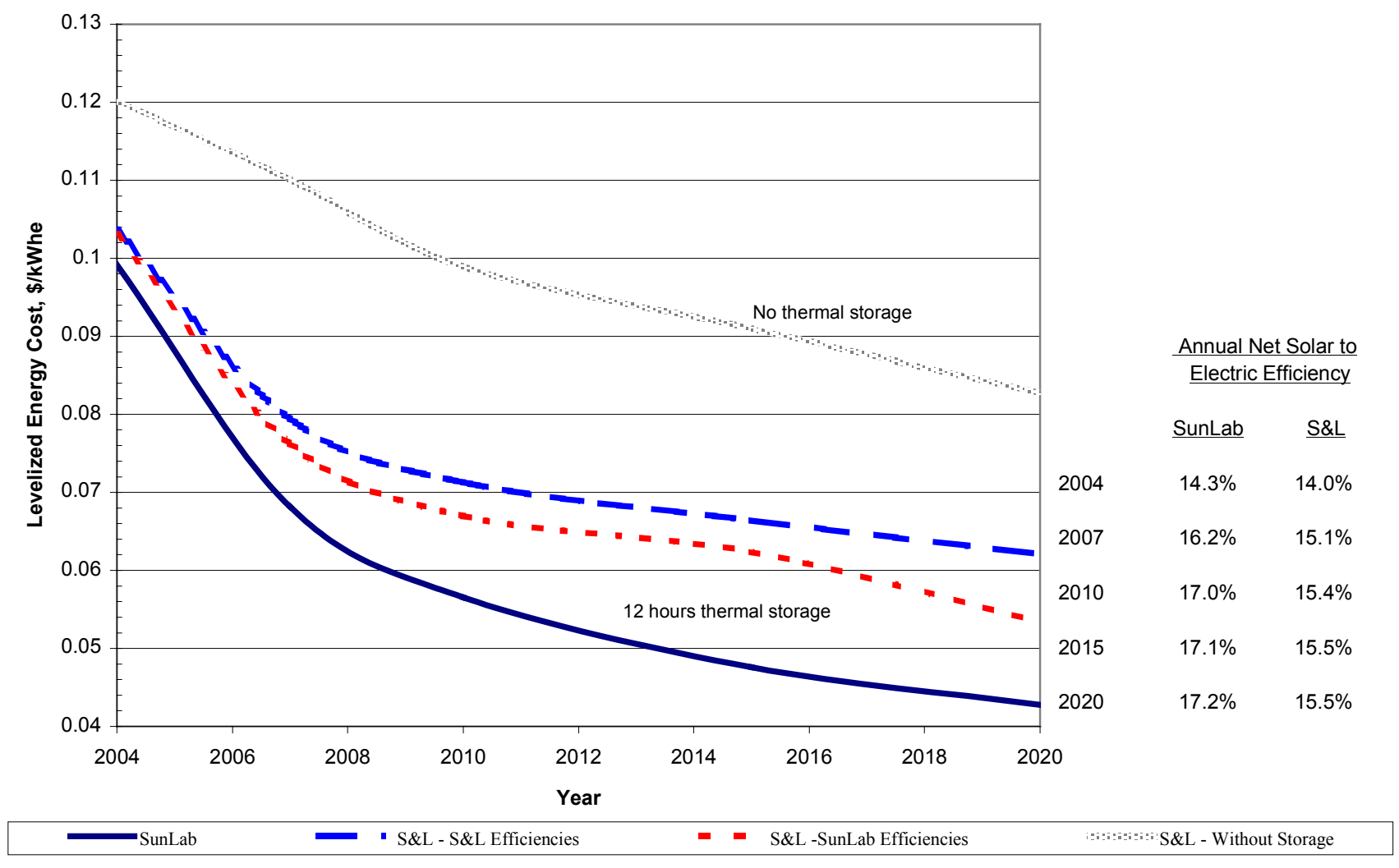

The curves highlight the impact of the annual net efficiencies on the levelized energy costs. The curves also indicate that additional cost reductions above and beyond the more conservative S\&L values, due to technology improvements, reduced HCE replacement rates, and increased deployment rates, will result in further convergence of the levelized energy costs toward the projected SunLab values.

Figure 4-7 shows the levelized energy cost for the SunLab technology forecasts with a breakdown that shows the source of the cost reduction from plant scale-up, technology $R \& D$, and cost reduction through learning. Of the projected cost reduction in 2020, plant scale-up is projected to provide $20 \%$ of the total cost reduction, technology development will provide over half of the cost reduction at 54\%, and production volume and competition will provide approximately $26 \%$ of the cost reduction. 
Figure 4-7 - Breakdown of LEC Cost Reduction (Scale-up, R\&D, Volume Production)

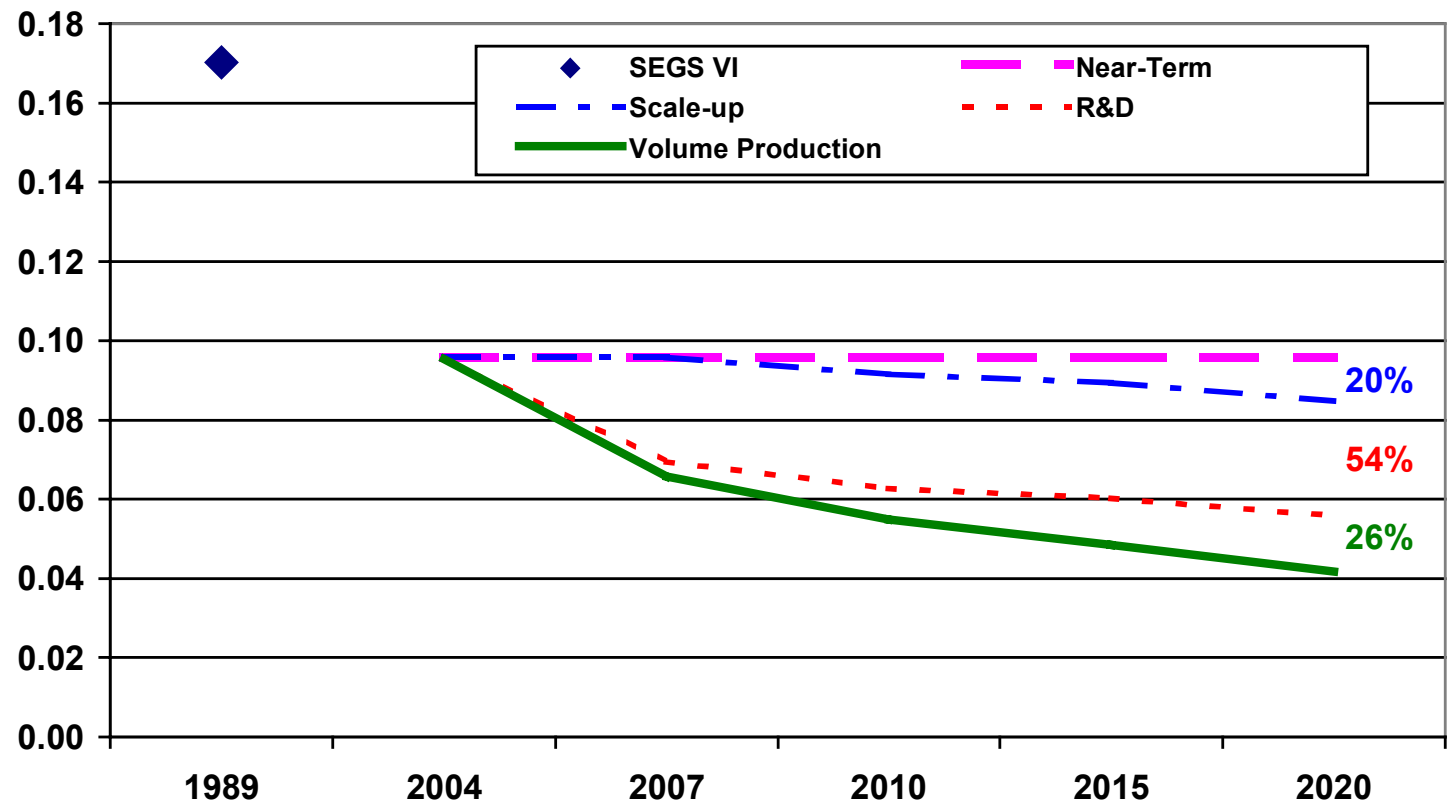

Figure 4-8 below shows the importance of the five major cost components in Section 4.3 in reducing the LEC.

Figure 4-8 - Breakdown of LEC Cost Reduction (by Major Cost Component)

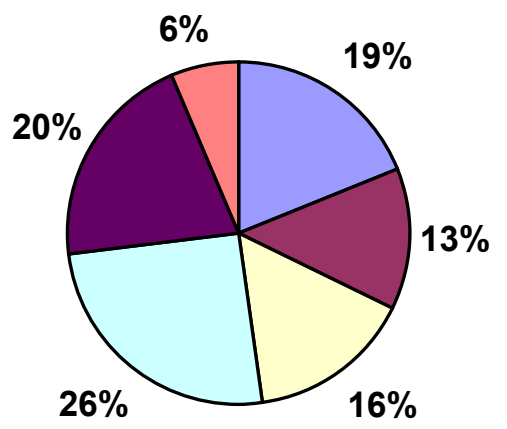

$\square$ Concentrator (19\%)

$\square$ Mirror (13\%)

口HCE (16\%)

$\square$ Storage (26\%)

Power Block (20\%)

$\square$ Other $(6 \%)$ 
The impact of levelized cost of energy for tax credit is shown in Table 4-16. The difference between $10 \%$ tax credit and no tax credit is about $8 \%$ in 2020 .

Table 4-16 - Impact of Tax Credit on Levelized Cost of Energy

\begin{tabular}{|c|c|c|c|c|c|c|c|c|}
\hline & & & & & lized Ene & y Cost, & Whe, by & ase \\
\hline & & & & $\begin{array}{l}\text { Near } \\
\text { Term }\end{array}$ & & $\begin{array}{l}\text { Mid } \\
\text { Term }\end{array}$ & & $\begin{array}{l}\text { Long } \\
\text { Term }\end{array}$ \\
\hline & & & & $\begin{array}{l}\text { Solar } \\
\text { Tres } \\
\text { USA }\end{array}$ & Solar 50 & $\begin{array}{c}\text { Solar } \\
100\end{array}$ & $\begin{array}{c}\text { Solar } \\
200\end{array}$ & $\begin{array}{c}\text { Solar } \\
220\end{array}$ \\
\hline & IRR & $\%$ Debt & DSCR & 2004 & 2006 & 2010 & 1015 & 2020 \\
\hline $10 \%$ Tax Credit & $12.12 \%$ & $59.90 \%$ & 1.35 & 0.0991 & 0.0681 & 0.0566 & 0.0476 & 0.0428 \\
\hline No Tax Credit & $12.12 \%$ & $66.50 \%$ & 1.35 & 0.1075 & 0.0737 & 0.0613 & 0.0541 & 0.0461 \\
\hline
\end{tabular}

\subsection{TECHNOLOGY STEP CHANGES AND COMPARISON}

The following tables provide a summary of the major 2004 through 2020 technology changes and a comparison of the SunLab and S\&L values.

Table 4-17 - Current (SEGS VI) to Trough 100 - 2004

\begin{tabular}{|c|c|c|c|c|}
\hline \multirow{3}{*}{\begin{tabular}{|l} 
\\
Plant Size
\end{tabular}} & \multirow[b]{2}{*}{ Current } & \multicolumn{2}{|c|}{ Trough $100-2004$} & \multirow[b]{2}{*}{ Basis } \\
\hline & & Sun Lab & S\&L & \\
\hline & $30 \mathrm{MWe}$ & \multicolumn{2}{|l|}{$100 \mathrm{MWe}$} & \\
\hline Field Aperture Area & $188,000 \mathrm{~m}^{2}$ & $1,120,480 \mathrm{~m}^{2}$ & $1,138,709 \mathrm{~m}^{2}$ & $\begin{array}{l}\text { Greater aperture area required for S\&L } \\
\text { estimate due to lower estimated annual } \\
\text { efficiency }\end{array}$ \\
\hline Thermal Storage & 0 hours & 12 hours & 2-tank Indirect & $\begin{array}{l}\text { Based on Nexant design being proposed } \\
\text { for } 50-\mathrm{MW} \text { trough project in Spain }\end{array}$ \\
\hline Annual Plant Capacity & $22.2 \%$ & \multicolumn{2}{|c|}{$53.5 \%$} & Capacity increased by thermal storage. \\
\hline Heat Transfer Fluid & VP-1 oil & \multicolumn{2}{|c|}{ VP-1 oil } & \\
\hline Storage Media & None & \multicolumn{2}{|c|}{ Solar Salt } & Technically proven at Solar 2 \\
\hline Operating Temperature & $391^{\circ} \mathrm{C}$ & \multicolumn{2}{|c|}{$391^{\circ} \mathrm{C}$} & \\
\hline Receiver & Luz & \multicolumn{2}{|c|}{ Solel } & Solel $2^{\text {nd }}$ Generation UVAC HCE \\
\hline
\end{tabular}




\begin{tabular}{|c|c|c|c|c|}
\hline & \multirow[b]{2}{*}{ Current } & \multicolumn{2}{|c|}{ Trough $100-2004$} & \multirow[b]{2}{*}{ Basis } \\
\hline & & Sun Lab & S\&L & \\
\hline Coating & Cermet & \multicolumn{2}{|c|}{ UVAC2 } & $\begin{array}{l}\text { Second-generation Solel UVAC cermet } \\
\text { coating currently being field tested at } \\
\text { KJCOC }\end{array}$ \\
\hline Collector & LS-2 & \multicolumn{2}{|c|}{ LS-2+ } & $\begin{array}{l}\text { Updated version of LS-2 collector based } \\
\text { on discussions with Duke Solar and } \\
\text { KJCOC }\end{array}$ \\
\hline $\begin{array}{l}\text { Annual solar-to-electric } \\
\text { efficiency }\end{array}$ & $10.6 \%$ & $14.3 \%$ & $14.0 \%$ & $\begin{array}{l}\text { S\&L used lower receiver efficiency than } \\
\text { SunLab based on current data }\end{array}$ \\
\hline $\begin{array}{l}\text { Solar Field Optical } \\
\text { Efficiency: }\end{array}$ & $53.3 \%$ & $56.7 \%$ & $56.7 \%$ & \multirow{9}{*}{$\begin{array}{l}\text { The incident angle modifier improves } \\
\text { slightly in plants with thermal storage, } \\
\text { because more energy is collected early in } \\
\text { the day. } \\
\text { The increase in envelope transmittance } \\
\text { is based on improved anti-reflective } \\
\text { coatings on inside and outside of the } \\
\text { receiver glass envelope. The new value } \\
\text { is based on property testing of Solel } \\
\text { UVAC HCE by Sandia National Labs. } \\
\text { SunLab increase of absorption based on } \\
\text { property measurement of second- } \\
\text { generation UVAC receiver (SPF, 2001). } \\
\text { Mirror and envelope cleanlinesses of } \\
\text { 95\% and } 98.5 \% \text { are reasonable based } \\
\text { on Kramer Junction experience. }\end{array}$} \\
\hline IAM, end loss & $89.9 \%$ & $91 \%$ & $91 \%$ & \\
\hline Mirror reflectivity & $93.5 \%$ & $93.5 \%$ & $93.5 \%$ & \\
\hline Envelope transmittance & $92.5 \%$ & $96.5 \%$ & $96.5 \%$ & \\
\hline Solar absorption & $92 \%$ & $94.4 \%$ & $94.4 \%$ & \\
\hline Mirror cleanliness & $93.1 \%$ & $95 \%$ & $95 \%$ & \\
\hline Envelope cleanliness & $98 \%$ & $98.5 \%$ & $98.5 \%$ & \\
\hline Dumped energy & $99.9 \%$ & $95.6 \%$ & $95.6 \%$ & \\
\hline Concentrator length & 50 meters & 50 meters & 50 meters & \\
\hline Receiver Efficiency: & $72.9 \%$ & $85.9 \%$ & $84.3 \%$ & \multirow{2}{*}{$\begin{array}{l}\text { Latest Solel UVAC selective coating. } \\
\text { Solel testing at SPF showed an } \\
\text { emittance of } 0.091 \text {, however field testing } \\
\text { required. S\&L used } 0.10 \text { based on the } \\
\text { test data }\end{array}$} \\
\hline Thermal emittance & $\begin{array}{l}0.135 \text { at } \\
400^{\circ} \mathrm{C}\end{array}$ & $\begin{array}{l}0.091 \text { at } \\
400^{\circ} \mathrm{C}\end{array}$ & $\begin{array}{l}0.100 \text { at } \\
400^{\circ} \mathrm{C}\end{array}$ & \\
\hline Piping Thermal Losses & $96.1 \%$ & $96.5 \%$ & $96.5 \%$ & \\
\hline $\begin{array}{l}\text { Thermal Storage Thermal } \\
\text { Losses }\end{array}$ & NA & $99.1 \%$ & $99.1 \%$ & $\begin{array}{l}\text { Based on thermal losses at Solar Two } \\
\text { and detailed thermal storage design } \\
\text { model. }\end{array}$ \\
\hline Gross steam cycle efficiency & $35.1 \%$ & $37.0 \%$ & $37.0 \%$ & \multirow{5}{*}{$\begin{array}{l}\text { Verified by SEGS IX ABB Heat Balances } \\
\text { HTDG 582395, Sheets 1-7 (in LUZ } \\
\text { International Limited 1990) } \\
\text { The addition of thermal storage reduces } \\
\text { part load operation, reduces the percent } \\
\text { of energy used for startup, and eliminates } \\
\text { losses due to minimum turbine load. }\end{array}$} \\
\hline Turbine Design & $37.5 \%$ & $37.5 \%$ & $37.5 \%$ & \\
\hline Part Load & $98 \%$ & $99.5 \%$ & $99.5 \%$ & \\
\hline Startup & $96.9 \%$ & $99.2 \%$ & $99.2 \%$ & \\
\hline Turbine Minimum & $98.5 \%$ & $100 \%$ & $100 \%$ & \\
\hline
\end{tabular}




\begin{tabular}{|c|c|c|c|c|}
\hline & \multirow[b]{2}{*}{ Current } & \multicolumn{2}{|c|}{ Trough $100-2004$} & \multirow[b]{2}{*}{ Basis } \\
\hline & & Sun Lab & S\&L & \\
\hline Parasitics & $82.4 \%$ & $87.7 \%$ & $87.7 \%$ & \multirow{9}{*}{$\begin{array}{l}\text { Conversion from Flex hoses to ball joint } \\
\text { assemblies. Reduces pressure drop in } \\
\text { collector loop. Demonstrated in KJCOC } \\
\text { O\&M cost reduction study. } \\
\text { The fixed station load is spread over } \\
\text { higher plant capacity factor. For a larger } \\
\text { plant the station load is a smaller \% of } \\
\text { total load. } \\
\text { SEGS VI parasitics included control } \\
\text { building and Maintenance shop at SEGS } \\
\text { VII. }\end{array}$} \\
\hline Solar Field & $0.23 \%$ & $0.20 \%$ & $0.20 \%$ & \\
\hline HTF Cold Pumps & $5.90 \%$ & $3.75 \%$ & $3.75 \%$ & \\
\hline HTF Hot Pumps & $0.00 \%$ & $1.06 \%$ & $1.06 \%$ & \\
\hline HTF Freeze Protection & $1.52 \%$ & $1.16 \%$ & $1.16 \%$ & \\
\hline Backup Heater/Boiler & $0.00 \%$ & $0.00 \%$ & $0.00 \%$ & \\
\hline Hotel Load (24 hr) & $3.67 \%$ & $1.62 \%$ & $1.62 \%$ & \\
\hline Balance-of-Plant & $4.36 \%$ & $2.73 \%$ & $2.73 \%$ & \\
\hline Cooling Towers & $1.89 \%$ & $1.81 \%$ & $1.81 \%$ & \\
\hline Plant-wide Availability & $98.0 \%$ & $94.0 \%$ & $94.0 \%$ & $\begin{array}{l}\text { Reasonable based on Kramer Junction } \\
\text { experience. }\end{array}$ \\
\hline
\end{tabular}

Table 4-18 - Trough 100 - 2004 (Near-Term Case) to Trough 100 - 2007

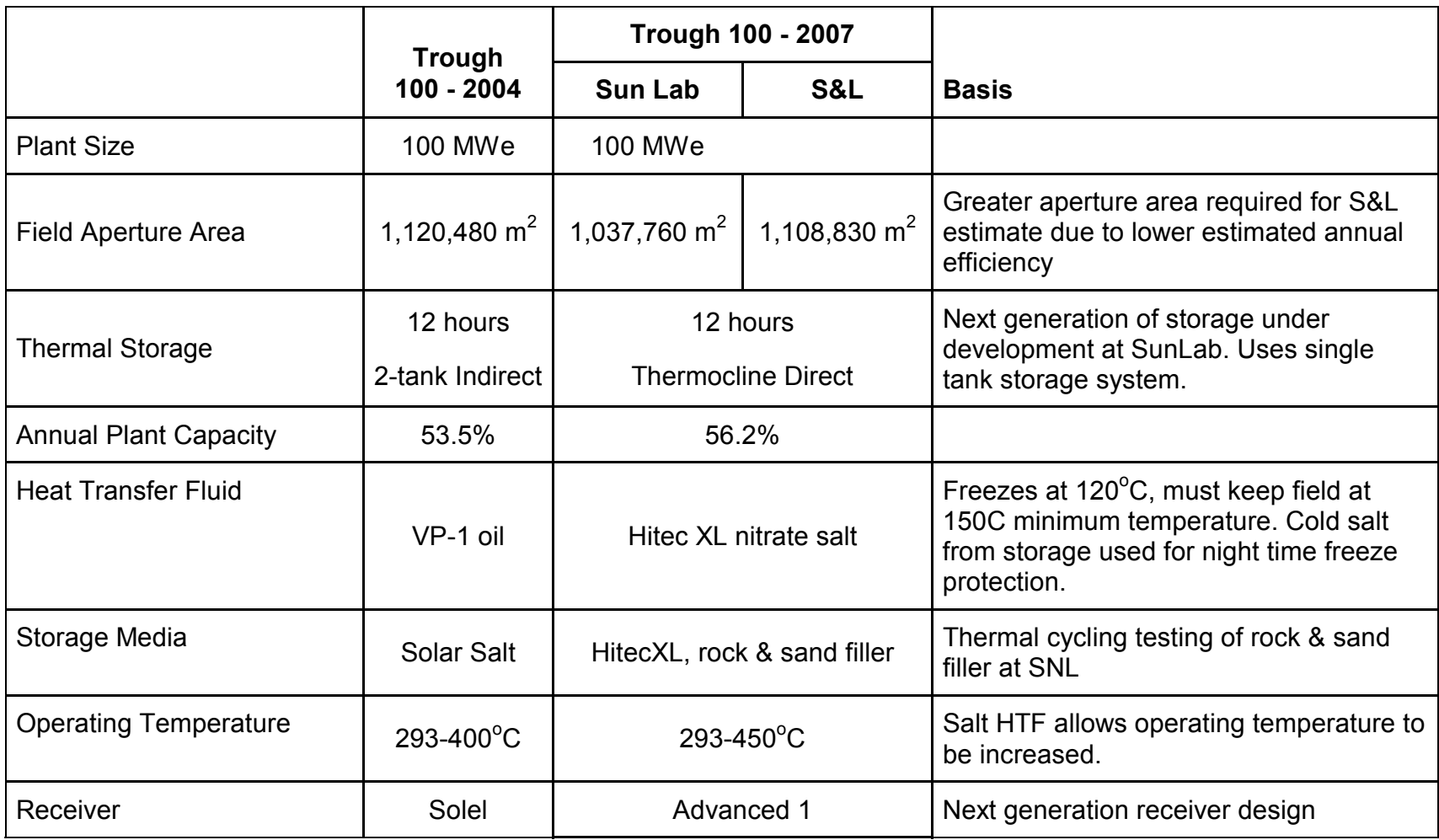




\begin{tabular}{|c|c|c|c|c|}
\hline & \multirow{2}{*}{$\begin{array}{c}\text { Trough } \\
100-2004\end{array}$} & \multicolumn{2}{|c|}{ Trough $100-2007$} & \multirow[b]{2}{*}{ Basis } \\
\hline & & Sun Lab & S\&L & \\
\hline Coating & UVAC2 & \multicolumn{2}{|c|}{ Advanced 1} & $\begin{array}{l}\text { Advanced cermet either by Solel or other } \\
\text { source }\end{array}$ \\
\hline Collector & LS-2+ & \multicolumn{2}{|c|}{ LS-3+ } & $\begin{array}{l}\text { Assumes the larger aperture of the LS-3 } \\
\text { and } 1.5 x \text { the length. Optical performance } \\
\text { is assumed to be similar to the LS- } 2 \\
\text { collector. This is the EuroTrough or } \\
\text { equivalent. }\end{array}$ \\
\hline $\begin{array}{l}\text { Annual solar-to-electric } \\
\text { efficiency }\end{array}$ & $14.2 \%$ & $16.1 \%$ & $15.1 \%$ & \\
\hline $\begin{array}{l}\text { Solar Field Optical } \\
\text { Efficiency: }\end{array}$ & $56.4 \%$ & $57.9 \%$ & $57.0 \%$ & \multirow{9}{*}{$\begin{array}{l}\text { The incident angle modifier improves } \\
\text { slightly with longer collector. } \\
\text { Mirror cleanliness of } 95 \% \text { is reasonable } \\
\text { based on Kramer Junction experience. } \\
\text { SunLab increase in envelope } \\
\text { transmittance based on Sandia test data } \\
\text { SunLab assumed increase in absorption } \\
\text { based on selective coating modeling at } \\
\text { NREL. }\end{array}$} \\
\hline IAM, end loss & $91 \%$ & $91.8 \%$ & $91.8 \%$ & \\
\hline Mirror reflectivity & $93.5 \%$ & $93.5 \%$ & $93.5 \%$ & \\
\hline Envelope transmittance & $96.5 \%$ & $97 \%$ & $96.5 \%$ & \\
\hline Solar absorption & $94.4 \%$ & $96 \%$ & $94.4 \%$ & \\
\hline Mirror cleanliness & $95 \%$ & $95 \%$ & $95 \%$ & \\
\hline Envelope cleanliness & $98.5 \%$ & $98.5 \%$ & $98.5 \%$ & \\
\hline Dumped energy & $95.6 \%$ & $95.2 \%$ & $95.6 \%$ & \\
\hline Concentrator length & 50 meters & 150 meters & 150 meters & \\
\hline Receiver Efficiency: & $85.9 \%$ & $86.2 \%$ & $82.3 \%$ & \multirow{2}{*}{$\begin{array}{l}\text { SunLab decrease in emittance based on } \\
\text { SunLab selective coating modeling. }\end{array}$} \\
\hline Thermal emittance & $\begin{array}{l}0.091 \text { at } \\
400^{\circ} \mathrm{C}\end{array}$ & $\begin{array}{l}0.070 \text { at } \\
400^{\circ} \mathrm{C}\end{array}$ & $\begin{array}{l}0.100 \text { at } \\
400^{\circ} \mathrm{C}\end{array}$ & \\
\hline Gross steam cycle efficiency & $37.0 \%$ & $39.0 \%$ & $39.0 \%$ & \multirow{5}{*}{$\begin{array}{l}\text { Reasonable based on increase of } \\
\text { temperature from } 400^{\circ} \mathrm{C} \text { to } 450^{\circ} \mathrm{C} \text {. } \\
\text { GEPerf computer program check used to } \\
\text { verify increase. }\end{array}$} \\
\hline Turbine Design & $37.5 \%$ & $39.4 \%$ & $39.4 \%$ & \\
\hline Part Load & $99.5 \%$ & $99.7 \%$ & $99.7 \%$ & \\
\hline Startup & $99.2 \%$ & $99.2 \%$ & $99.2 \%$ & \\
\hline Turbine Minimum & $100 \%$ & $100.0 \%$ & $100.0 \%$ & \\
\hline
\end{tabular}




\begin{tabular}{|c|c|c|c|c|}
\hline & \multirow{2}{*}{$\begin{array}{c}\text { Trough } \\
100-2004\end{array}$} & \multicolumn{2}{|c|}{ Trough $100-2007$} & \multirow[b]{2}{*}{ Basis } \\
\hline & & Sun Lab & S\&L & \\
\hline Parasitics & $87.7 \%$ & $91.1 \%$ & $91.1 \%$ & \multirow{9}{*}{$\begin{array}{l}\text { SunLab parasitics reduction based on } \\
\text { replacement of VP-1 with HitecXL in the } \\
\text { solar field and elimination of need to run } \\
\text { two sets of pumps in the indirect storage } \\
\text { system. } \\
\text { The Nexant piping model calculates a } \\
65 \% \text { reduction in HTF pumping parasitics } \\
\text { with molten-salt. }\end{array}$} \\
\hline Solar Field & $0.20 \%$ & $0.13 \%$ & $0.13 \%$ & \\
\hline HTF Cold Pumps & $3.75 \%$ & $1.75 \%$ & $1.75 \%$ & \\
\hline HTF Hot Pumps & $1.06 \%$ & $0.53 \%$ & $0.53 \%$ & \\
\hline HTF Freeze Protection & $1.16 \%$ & $1.06 \%$ & $1.06 \%$ & \\
\hline Backup Heater/Boiler & $0.00 \%$ & $0.00 \%$ & $0.00 \%$ & \\
\hline Hotel Load (24 hr) & $1.62 \%$ & $1.60 \%$ & $1.60 \%$ & \\
\hline Balance of Plant & $2.73 \%$ & $2.05 \%$ & $2.05 \%$ & \\
\hline Cooling Towers & $1.81 \%$ & $1.81 \%$ & $1.81 \%$ & \\
\hline Plant-wide Availability & $94.0 \%$ & $94.0 \%$ & $94.0 \%$ & \\
\hline
\end{tabular}

Table 4-19 - Trough 100 - 2007 (mid-Term) to Trough 150 - 2010

\begin{tabular}{|c|c|c|c|c|}
\hline & \multirow{2}{*}{$\begin{array}{l}\text { Trough } 100- \\
2007\end{array}$} & \multicolumn{2}{|c|}{ Trough 150 - 2010} & \multirow[t]{2}{*}{ Basis } \\
\hline & & Sun Lab & S\&L & \\
\hline Plant Size & $100 \mathrm{MWe}$ & \multicolumn{2}{|l|}{$150 \mathrm{MWe}$} & \\
\hline Field Aperture Area & $1,120,480 \mathrm{~m}^{2}$ & $1,477,680 \mathrm{~m}^{2}$ & $1,632,301 \mathrm{~m}^{2}$ & $\begin{array}{l}\text { Greater aperture area required for S\&L } \\
\text { estimate due to lower estimated annual } \\
\text { efficiency }\end{array}$ \\
\hline Thermal Storage & $\begin{array}{l}12 \text { hours } \\
\text { 2-tank Direct }\end{array}$ & \multicolumn{2}{|c|}{$\begin{array}{l}12 \text { hours } \\
\text { Thermocline Direct }\end{array}$} & \\
\hline Annual Plant Capacity & $56.2 \%$ & \multicolumn{2}{|c|}{$56.2 \%$} & \\
\hline Heat Transfer Fluid & HitecXL & \multicolumn{2}{|c|}{ HitecXL nitrate salt } & $\begin{array}{l}\text { Testing currently in progress to make } \\
\text { sure Hitec } X L \text { can be used up to } 500^{\circ} \mathrm{C} \text {. }\end{array}$ \\
\hline Storage Media & $\begin{array}{l}\text { HitecXL, rock } \\
\& \text { sand filler }\end{array}$ & \multicolumn{2}{|c|}{ HitecXL, rock \& sand filler } & $\begin{array}{l}\text { Thermal cycling testing of rock \& sand } \\
\text { filler at SNL }\end{array}$ \\
\hline Operating Temperature & $450^{\circ} \mathrm{C}$ & \multicolumn{2}{|c|}{$500^{\circ} \mathrm{C}$} & \\
\hline Receiver & Advanced 1 & \multicolumn{2}{|c|}{ Advanced 2} & Higher temperature capability \\
\hline Coating & Advanced 1 & \multicolumn{2}{|c|}{ Advanced 2} & $\begin{array}{l}\text { Same thermal \& optical properties but } \\
\text { able to operate to } 500^{\circ} \mathrm{C}\end{array}$ \\
\hline
\end{tabular}




\begin{tabular}{|c|c|c|c|c|}
\hline & \multirow{2}{*}{$\begin{array}{l}\text { Trough } 100 \text { - } \\
2007\end{array}$} & \multicolumn{2}{|c|}{ Trough 150 - 2010} & \multirow[t]{2}{*}{ Basis } \\
\hline & & Sun Lab & S\&L & \\
\hline Collector & LS-3+ & \multicolumn{2}{|c|}{ Next Generation } & $\begin{array}{l}\text { New design based on use of front } \\
\text { surface reflectors and structural mirror } \\
\text { facets. }\end{array}$ \\
\hline $\begin{array}{l}\text { Annual solar-to-electric } \\
\text { efficiency }\end{array}$ & $14.2 \%$ & $17.0 \%$ & $15.4 \%$ & \\
\hline $\begin{array}{l}\text { Solar Field Optical } \\
\text { Efficiency: }\end{array}$ & $57.9 \%$ & $59.8 \%$ & $57.0 \%$ & \multirow{9}{*}{$\begin{array}{l}\text { S\&L estimate mirror cleanliness of } 95 \% \\
\text { based on Kramer Junction experience. } \\
\text { SunLab mirror reflectivity increase from } \\
0.935 \text { to } 0.95 \text { based on use of front } \\
\text { Surface mirror with anti-soiling coating to } \\
\text { reduce mirror soiling rate, mirror } \\
\text { cleanliness from } 0.95 \text { to } 0.96 \text {. }\end{array}$} \\
\hline IAM, end loss & $91.8 \%$ & $91.8 \%$ & $91.8 \%$ & \\
\hline Mirror reflectivity & $93.5 \%$ & $95 \%$ & $93.5 \%$ & \\
\hline Envelope transmittance & $97.0 \%$ & $97.0 \%$ & $96.5 \%$ & \\
\hline Solar absorption & $96 \%$ & $96 \%$ & $94.4 \%$ & \\
\hline Mirror cleanliness & $95 \%$ & $96 \%$ & $95 \%$ & \\
\hline Envelope cleanliness & $98.5 \%$ & $98.5 \%$ & $98.5 \%$ & \\
\hline Dumped energy & $95.2 \%$ & $95.2 \%$ & $95.2 \%$ & \\
\hline Concentrator length & 150 meters & 150 meters & 150 meters & \\
\hline Receiver Efficiency: & $86.2 \%$ & $85.2 \%$ & $81.0 \%$ & \multirow{2}{*}{$\begin{array}{l}\text { S\&L assumes no improvement over } \\
\text { current demonstrated Solel UVAC } \\
\text { receiver, except higher temperature } \\
\text { capability to } 500^{\circ} \mathrm{C} \text {. }\end{array}$} \\
\hline Thermal emittance & $\begin{array}{l}0.070 \text { at } \\
400^{\circ} \mathrm{C}\end{array}$ & $\begin{array}{l}0.070 \text { at } \\
400^{\circ} \mathrm{C}\end{array}$ & $\begin{array}{l}0.100 \text { at } \\
400^{\circ} \mathrm{C}\end{array}$ & \\
\hline Gross steam cycle efficiency & $39.0 \%$ & $40.0 \%$ & $40.0 \%$ & \multirow{5}{*}{$\begin{array}{l}\text { GEPerf computer program check used to } \\
\text { verify increase. }\end{array}$} \\
\hline Turbine Design & $39.4 \%$ & $40.5 \%$ & $40.5 \%$ & \\
\hline Part Load & $99.7 \%$ & $99.7 \%$ & $99.7 \%$ & \\
\hline Startup & $99.2 \%$ & $99.2 \%$ & $99.2 \%$ & \\
\hline Turbine Minimum & $100.0 \%$ & $100.0 \%$ & $100.0 \%$ & \\
\hline
\end{tabular}




\begin{tabular}{|c|c|c|c|c|}
\hline & \multirow{2}{*}{$\begin{array}{c}\text { Trough } 100 \text { - } \\
2007\end{array}$} & \multicolumn{2}{|c|}{ Trough 150 - 2010} & \multirow[t]{2}{*}{ Basis } \\
\hline & & Sun Lab & S\&L & \\
\hline Parasitics & $91.1 \%$ & $91.8 \%$ & $91.8 \%$ & \multirow{9}{*}{$\begin{array}{l}\text { Reduction in parasitics is reasonable. } \\
\text { SunLab reduction in HTF parasitics } \\
\text { based on increasing operating } \\
\text { temperature to } 500^{\circ} \mathrm{C} \text {. } \\
\text { BOP parasitics reduced due to larger } \\
\text { plant size. }\end{array}$} \\
\hline Solar Field & $0.13 \%$ & $0.13 \%$ & $0.13 \%$ & \\
\hline HTF Cold Pumps & $1.75 \%$ & $1.33 \%$ & $1.33 \%$ & \\
\hline HTF Hot Pumps & $0.53 \%$ & $0.42 \%$ & $0.42 \%$ & \\
\hline HTF Freeze Protection & $1.06 \%$ & $1.02 \%$ & $1.02 \%$ & \\
\hline Backup Heater/Boiler & $0.00 \%$ & $0.00 \%$ & $0.00 \%$ & \\
\hline Hotel Load (24 hr) & $1.60 \%$ & $1.62 \%$ & $1.62 \%$ & \\
\hline Balance of Plant & $2.05 \%$ & $1.91 \%$ & $1.91 \%$ & \\
\hline Cooling Towers & $1.81 \%$ & $1.81 \%$ & $1.81 \%$ & \\
\hline Plant-wide Availability & $94.0 \%$ & $94.0 \%$ & $94.0 \%$ & \\
\hline
\end{tabular}

Table 4-20 - Trough 150 - 2010 to Trough 200 - 2015

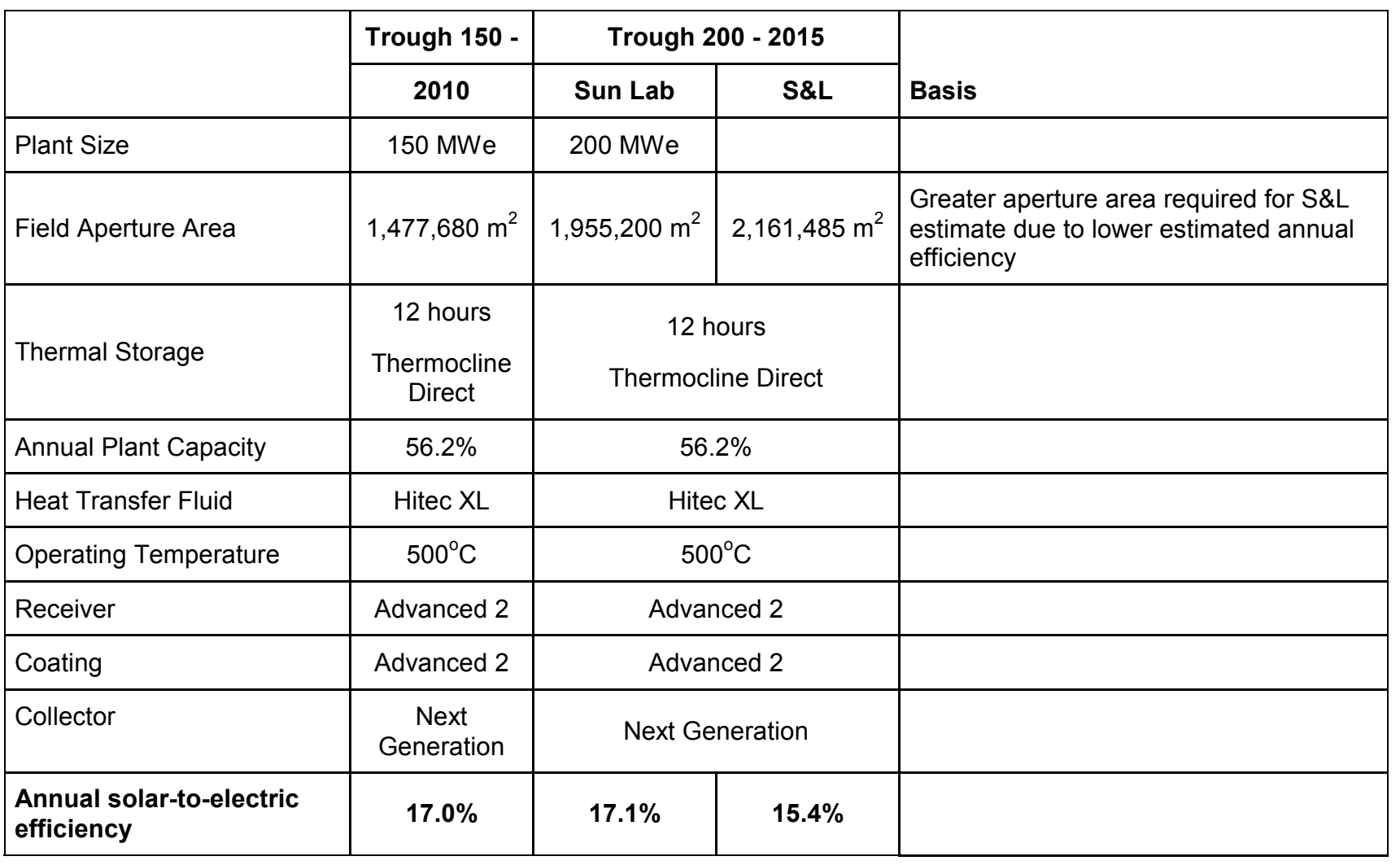




\begin{tabular}{|c|c|c|c|c|}
\hline & \multirow{2}{*}{$\begin{array}{c}\text { Trough } 150- \\
2010\end{array}$} & \multicolumn{2}{|c|}{ Trough $200-2015$} & \multirow[b]{2}{*}{ Basis } \\
\hline & & Sun Lab & S\&L & \\
\hline $\begin{array}{l}\text { Solar Field Optical } \\
\text { Efficiency: }\end{array}$ & $59.8 \%$ & $60.2 \%$ & $57.0 \%$ & \multirow{9}{*}{$\begin{array}{l}\text { SunLab estimate assumes anti-soiling } \\
\text { treatment added to receiver envelope to } \\
\text { improve cleanliness. } \\
\text { Sargent \& Lundy assumes no } \\
\text { improvement from earlier case. }\end{array}$} \\
\hline IAM, end loss & $91.8 \%$ & $91.8 \%$ & $91.8 \%$ & \\
\hline Mirror reflectivity & $95 \%$ & $95 \%$ & $93.5 \%$ & \\
\hline Envelope transmittance & $97.0 \%$ & $97.0 \%$ & $96.5 \%$ & \\
\hline Solar absorption & $96 \%$ & $96 \%$ & $94.4 \%$ & \\
\hline Mirror cleanliness & $96 \%$ & $96 \%$ & $95 \%$ & \\
\hline Envelope cleanliness & $98.5 \%$ & $99 \%$ & $98.5 \%$ & \\
\hline Dumped energy & $95.2 \%$ & $95.2 \%$ & $95.2 \%$ & \\
\hline Concentrator length & 150 meters & 150 meters & 150 meters & \\
\hline Receiver Efficiency: & $85.2 \%$ & $85.3 \%$ & $81.0 \%$ & \multirow{2}{*}{$\begin{array}{l}\text { No change for SunLab case, S\&L } \\
\text { assumes current UVAC design. }\end{array}$} \\
\hline Thermal emittance & $\begin{array}{l}0.070 \text { at } \\
400^{\circ} \mathrm{C}\end{array}$ & $\begin{array}{l}0.070 \text { at } \\
400^{\circ} \mathrm{C}\end{array}$ & $\begin{array}{l}0.100 \text { at } \\
400^{\circ} \mathrm{C}\end{array}$ & \\
\hline Gross steam cycle efficiency & $40.0 \%$ & $40.0 \%$ & $40.0 \%$ & \\
\hline Turbine Design & $40.5 \%$ & $40.5 \%$ & $40.5 \%$ & \\
\hline Part Load & $99.7 \%$ & $99.7 \%$ & $99.7 \%$ & \\
\hline Startup & $99.2 \%$ & $99.2 \%$ & $99.2 \%$ & \\
\hline Turbine Minimum & $100.0 \%$ & $100.0 \%$ & $100.0 \%$ & \\
\hline Parasitics & $91.8 \%$ & $91.8 \%$ & $91.8 \%$ & \\
\hline Solar Field & $0.13 \%$ & $0.13 \%$ & $0.13 \%$ & \\
\hline HTF Cold Pumps & $1.33 \%$ & $1.32 \%$ & $1.32 \%$ & \\
\hline HTF Hot Pumps & $0.42 \%$ & $0.42 \%$ & $0.42 \%$ & \\
\hline HTF Freeze Protection & $1.02 \%$ & $1.01 \%$ & $1.01 \%$ & \\
\hline Backup Heater/Boiler & $0.00 \%$ & $0.00 \%$ & $0.00 \%$ & \\
\hline Hotel Load (24 hr) & $1.62 \%$ & $1.62 \%$ & $1.62 \%$ & \\
\hline Balance of Plant & $1.91 \%$ & $1.91 \%$ & $1.91 \%$ & \\
\hline Cooling Towers & $1.81 \%$ & $1.81 \%$ & $1.81 \%$ & \\
\hline Plant-wide Availability & $94.0 \%$ & $94.0 \%$ & $94.0 \%$ & \\
\hline
\end{tabular}


Table 4-21 - Trough 200 - 2015 to Trough 400 - 2020

\begin{tabular}{|c|c|c|c|c|}
\hline & \multirow{2}{*}{$\begin{array}{l}\text { Trough } 200- \\
\quad 2015\end{array}$} & \multicolumn{2}{|c|}{ Trough 400 - 2020} & \multirow[b]{2}{*}{ Basis } \\
\hline & & Sun Lab & S\&L & \\
\hline Plant Size & $200 \mathrm{MWe}$ & \multicolumn{2}{|l|}{$400 \mathrm{MWe}$} & \\
\hline Field Aperture Area & $1,955,200 \mathrm{~m}^{2}$ & $3,910,400 \mathrm{~m}^{2}$ & $4,348,931 \mathrm{~m}^{2}$ & $\begin{array}{l}\text { Greater aperture area required for S\&L } \\
\text { estimate due to lower estimated annual } \\
\text { efficiency }\end{array}$ \\
\hline Thermal Storage & $\begin{array}{l}12 \text { hours } \\
\text { Thermocline } \\
\text { Direct }\end{array}$ & \multicolumn{2}{|c|}{$\begin{array}{l}12 \text { hours } \\
\text { Thermocline Direct }\end{array}$} & \\
\hline Annual Plant Capacity & $56.2 \%$ & \multicolumn{2}{|c|}{$56.5 \%$} & \\
\hline Heat Transfer Fluid & Hitec XL & \multicolumn{2}{|c|}{ Hitec XL } & \\
\hline Operating Temperature & $500^{\circ} \mathrm{C}$ & \multicolumn{2}{|c|}{$500^{\circ} \mathrm{C}$} & \\
\hline Receiver & Advanced 2 & \multicolumn{2}{|c|}{ Advanced 2} & \\
\hline Coating & Advanced 2 & \multicolumn{2}{|c|}{ Advanced 2} & \\
\hline Collector & $\begin{array}{c}\text { Next } \\
\text { Generation }\end{array}$ & \multicolumn{2}{|c|}{ Advanced Generation 1} & \\
\hline $\begin{array}{l}\text { Annual solar-to-electric } \\
\text { efficiency }\end{array}$ & $17.1 \%$ & $17.2 \%$ & $15.5 \%$ & \\
\hline $\begin{array}{l}\text { Solar Field Optical } \\
\text { Efficiency: }\end{array}$ & $59.8 \%$ & $60.2 \%$ & $57.0 \%$ & \multirow[t]{9}{*}{$\begin{array}{l}\text { S\&L \& SunLab estimates assume no } \\
\text { change from earlier case. }\end{array}$} \\
\hline IAM, end loss & $91.8 \%$ & $91.8 \%$ & $91.8 \%$ & \\
\hline Mirror reflectivity & $95 \%$ & $95 \%$ & $93.5 \%$ & \\
\hline Envelope transmittance & $97.0 \%$ & $97.0 \%$ & $96.5 \%$ & \\
\hline Solar absorption & $96 \%$ & $96 \%$ & $94.4 \%$ & \\
\hline Mirror cleanliness & $96 \%$ & $96 \%$ & $95 \%$ & \\
\hline Envelope cleanliness & $98.5 \%$ & $99 \%$ & $98.5 \%$ & \\
\hline Dumped energy & $95.2 \%$ & $95.2 \%$ & $95.2 \%$ & \\
\hline Concentrator length & 150 meters & 150 meters & 150 meters & \\
\hline Receiver Efficiency: & $85.3 \%$ & $85.3 \%$ & $81 \%$ & \\
\hline Thermal emittance & $\begin{array}{c}0.070 \text { at } \\
400^{\circ} \mathrm{C}\end{array}$ & $\begin{array}{c}0.070 \text { at } \\
400^{\circ} \mathrm{C}\end{array}$ & $\begin{array}{c}0.100 \text { at } \\
400^{\circ} \mathrm{C}\end{array}$ & \\
\hline
\end{tabular}




\begin{tabular}{|c|c|c|c|c|}
\hline & \multirow{2}{*}{$\begin{array}{l}\text { Trough } 200- \\
2015\end{array}$} & \multicolumn{2}{|c|}{ Trough $400-2020$} & \multirow[b]{2}{*}{ Basis } \\
\hline & & Sun Lab & S\&L & \\
\hline Gross steam cycle efficiency & $40.0 \%$ & $40.0 \%$ & $40.0 \%$ & \multirow{5}{*}{$\begin{array}{l}\text { GEPerf computer program check used to } \\
\text { verify increase. }\end{array}$} \\
\hline Turbine Design & $40.5 \%$ & $40.5 \%$ & $40.5 \%$ & \\
\hline Part Load & $99.7 \%$ & $99.7 \%$ & $99.7 \%$ & \\
\hline Startup & $99.2 \%$ & $99.2 \%$ & $99.2 \%$ & \\
\hline Turbine Minimum & $100.0 \%$ & $100.0 \%$ & $100.0 \%$ & \\
\hline Parasitics & $91.8 \%$ & $92.4 \%$ & $92.4 \%$ & \multirow{9}{*}{$\begin{array}{l}\text { SunLab parasitics assume increase in } \\
\text { HTF pumping parasitics for larger size } \\
\text { solar field and a reduction in hotel load } \\
\text { based on scale-up in size to } 400 \mathrm{MWe}\end{array}$} \\
\hline Solar Field & $0.13 \%$ & $0.13 \%$ & $0.13 \%$ & \\
\hline HTF Cold Pumps & $1.32 \%$ & $1.45 \%$ & $1.45 \%$ & \\
\hline HTF Hot Pumps & $0.42 \%$ & $0.43 \%$ & $0.43 \%$ & \\
\hline HTF Freeze Protection & $1.01 \%$ & $1.01 \%$ & $1.01 \%$ & \\
\hline Backup Heater/Boiler & $0.00 \%$ & $0.00 \%$ & $0.00 \%$ & \\
\hline Hotel Load (24 hr) & $1.62 \%$ & $0.90 \%$ & $0.90 \%$ & \\
\hline Balance of Plant & $1.91 \%$ & $1.92 \%$ & $1.92 \%$ & \\
\hline Cooling Towers & $1.81 \%$ & $1.81 \%$ & $1.81 \%$ & \\
\hline Plant-wide Availability & $94.0 \%$ & $94.0 \%$ & $94.0 \%$ & \\
\hline
\end{tabular}

\subsection{RISK ASSESSMENT FOR TROUGH TECHNOLOGY}

This section provides an overview and assessment of the risks associated with attaining competitive commercialization for the parabolic trough technology on a short-term, mid-term, and long-term basis. Competitiveness is measured by the levelized energy cost (LEC), expressed as $\$ / \mathrm{kWh}$, consisting of two elements: total investment cost and operation and maintenance (O\&M) cost.

The major total investment cost drivers of the trough plant are the solar field, power block, and thermal storage, which account for approximately $90 \%$ of the total costs (based on 12 hours of thermal storage). Also, the net annual solar-to-electric efficiency has a significant impact on the cost of a trough plant. For every one percentage point improvement in the net efficiency, the cost is reduced by approximately $7 \%$.

Total cost reductions occur from technical improvements, increase in plant size (scaling), and volume production (learning curves). All three are dependent on deployment of the technology. Deployment provides a 
means for continued research in technology improvements, cost reductions due to increased production, and economy of scale from constructing larger plants.

The second element of the levelized energy cost is the O\&M costs. For the trough plant, O\&M costs represent $25 \%$ or more of the LEC.

As such, the focus of the risk assessment covers the following main categories:

- Deployment

- $\quad$ Net Annual Solar-to-Electric Efficiency

- Total Investment Cost

- Operation and Maintenance

\subsubsection{Deployment}

Market expansion of trough technology will require incentives to reach market competitiveness. Numerous potential incentives exist, such as: environmental $\left(\mathrm{CO}_{2}\right.$ emission credits), favorable tax credits, favorable peak energy tariff, premium consumer pricing, loan guarantees, low interest loans, and grants. Analysis of incentives required to reach market acceptance is not within the scope of this report.

\subsubsection{Near Term (2004)}

The SunLab near-term deployment projection is one identical 100-MW plant per year in the years 2004 through 2006 (three plants total).

The actual strategy employed by the plant suppliers can be significantly diverse, with more emphasis on nearterm cost reduction with a minimum of risk. The trough plant suppliers may opt to provide multiple plants in the $50 \mathrm{MWe}$, to $100 \mathrm{MWe}$ size with no thermal storage but with a supplemental steam generator, replicating the proven technology of the existing SEGS plants. The suppliers can rely more on initial production volume to reduce costs as opposed to efficiency and technology improvements and scale-up factors. Minimizing or eliminating thermal storage, with its current elevated cost, appreciably reduces the total direct cost of the plant. Without thermal storage, the direct capital cost is approximately $50 \%$ less for the $100-\mathrm{MW}$ plant deployed in the 2004-2006 time frame. However, due to the lower annual MWh generation, the LEC ( $\$ / M W h)$ is approximately $20 \%$ higher than for a plant with 12 hours of thermal storage. 


\subsubsection{Mid Term (2010)}

The SunLab mid-term deployment projection is six 100-MW plants and one 150-MW plant with improved technology being deployed in the years 2007 through 2010 .

\subsubsection{Long Term (2020)}

The SunLab long-term deployment projection is eight 150-MW plants with improved technology being deployed in the years 2010 through 2014; twelve advanced technology 200-MW plants in the years 2015 through 2020; and one 400-MW advanced technology plant in 2020. The SunLab total long-term deployment is 4,900 MW of installed capacity.

\subsubsection{Net Annual Solar-to-Electric Efficiency}

\subsubsection{Near Term (2004)}

The SunLab projected near-term net annual solar-to-electric efficiency is $14.3 \%$, an improvement of 3.7 percentage points from the SEGS VI $10.6 \%$ efficiency. The increased efficiency is mainly attributable to improved receiver optical and thermal emittance properties. The demonstrated improvements are the following:

- Significant improvements in selective coatings have occurred since the last SEGS plant was built. The solar absorptance of the cermet tubes used at SEGS VI was approximately $91.5 \%$. According to test data (SPF 2001), the Solel UVAC receiver tubes have a solar weighted absorptance of $94.4 \%$.

- Anti reflective coatings for glass have been improved in the last 10 years to improve durability. The new receiver tubes have anti-reflective coatings that deliver solar transmittances of $96.5 \%$, compared with earlier coating that only allowed $92.5 \%$.

- SEGS VI had a combination of black chrome and the original generation of Luz Cermet receiver tubes. The average thermal emittance of these tubes is approximately $20 \%$ greater at $350^{\circ} \mathrm{C}$. The UVAC receiver first installed at SEGS VI had a thermal emittance of $14 \%$ at $400^{\circ} \mathrm{C}$. According to tests performed for Solel, the second-generation UVAC receiver had a thermal emittance of about $9 \%$ at $400^{\circ} \mathrm{C}$

There is a low risk of achieving the near-term net annual solar-to-electric efficiency of $14.3 \%$, since the receiver properties that the improvement is dependent on have been demonstrated either by operating experience at the SEGS plants or from test data. 


\subsubsection{Mid Term (2010)}

The SunLab projected mid-term net annual solar-to-electric efficiency is $17.0 \%$, an improvement of 2.7 percentage points from the near-term projected efficiency of $14.3 \%$. This improvement is mainly attributable to the following:

- Second-generation advanced receiver with an optical design point efficiency of $79.1 \%$ (compared to near-term 75\%) as a result of a solar absorptance of $96 \%$ (compared to near-term $94.4 \%$ ) and mirror reflectivity of $95 \%$ (compared to near-term $93.5 \%$ ).

- Improved steam turbine cycle efficiency of 3 percentage points as a result of increasing the solar field operating temperature to $500^{\circ} \mathrm{C}$.

There is a high risk of achieving the mid-term net annual solar-to-electric efficiency of $17.0 \%$ based on the following considerations:

- The optical efficiency improvement is based on two steps of receiver advancements, an advanced heat collection element $(\mathrm{HCE})$ coating for the projected $500^{\circ} \mathrm{C}$ operating temperature. Alternate HCE designs are under various stages of development that indicate lower cost than the Solel UVAC HCE, but at reduced efficiency levels. Reduced HCE efficiency will result in a lower net annual solar-to-electric efficiency.

- While there are no steam turbine technological risks in achieving the improved efficiency, the type of heat transfer fluid (HTF) will have to be changed to obtain the $500^{\circ} \mathrm{C}$ inlet steam temperature. The SunLab projections assume a nitrate salt HTF with an upper operating range of $500^{\circ} \mathrm{C}$. Alternate HTF development will be required since use of nitrate salt has not been demonstrated for the trough technology.

- A direct thermocline thermal storage system is assumed for the mid-term case. At the present time, preliminary assessments have been made on the potential impact that a thermocline storage system might have on the annual performance of the plant and more detailed analyses and research are required. The current ball joints will not work with the high-temperature salt HFT, and flexhose and ball joint sealing options have to be researched and developed. Various thermal storage options are in the early stages of development.

A mid-term net annual solar-to-electric efficiency in the $15.4 \%$ range represents a low risk by limiting the technology improvements to currently demonstrated or tested improvements.

The reduction in efficiency from the projected $17.0 \%$ to $15.4 \%$ results in an increase in the mid-term levelized energy cost of approximately $\$ 0.0045 / \mathrm{kWhe}$. 


\subsubsection{Long Term (2020)}

The SunLab projected long-term net annual solar-to-electric efficiency is $17.2 \%$, an improvement of 0.2 percentage points from the mid-term projected efficiency of $17.0 \%$. This modest improvement is mainly attributable to operational improvements to reduce thermal losses and reducing the amount of dust on the envelope.

There is a high risk of achieving the long-term net annual solar-to-electric efficiency of $17.2 \%$ due to the midterm risks discussed previously. However, the risk is greatly reduced if the trough technology is successfully deployed to the extent that the competitive market prompts research and development of technological advances.

\subsubsection{Total Investment Cost}

The major cost contributors in total investment cost of a parabolic trough solar plant with thermal storage are the solar collector field (53\%), thermal storage system (23\%), and the power block (14\%).

In combination with thermal storage, increased annual net efficiency, and reduced equipment cost via technology advancements, competition and deployment are the primary elements in reducing the long-term cost of the trough plant.

\subsubsection{Near Term (2004)}

The SunLab projected near-term total investment cost, with the exception of the thermal storage, is based on actual values from the SEGS plants. Costs for components such as the HCE and mirrors are based on current pricing of replacement parts for the SEGS plants.

The near-term indirect two-tank thermal storage system is based on cost estimates from detailed design drawings and material takeoffs developed by Nextant. The technological risk using the two-tank molten-salt storage system is low based on the successful utilization at the Solar Two plant.

Estimated costs based on the SOAPP program indicate that the SunLab projected capital costs for the power block are conservative (on the high side), approximately $\$ 50 / \mathrm{kW}$ higher than estimated by the SOAPP program. The SunLab power block cost estimates are based on a 1990 ABB quotation for a 100-MW steam turbine. The $\mathrm{ABB}$ quotation was escalated and scaled-up for the larger sizes. The SunLab power block cost estimates are based on dated information and the escalation and scale-up factors add to the uncertainty of the data with respect 
to current pricing. Equipment prices in the SOAPP program reflect 2001 actual costs. Since the SOAPP pricing is current, the SOAPP-generated costs are more characteristic of current power block costs.

Based on the above considerations, there is a low risk of achieving the near-term total investment cost.

\subsubsection{Mid Term (2010)}

The SunLab projected mid-term total investment cost indicates a total cost of $\$ 2,876 / \mathrm{kWe}$, a reduction of $\$ 1,983 / \mathrm{kWe}$ from the near-term projected cost of $\$ 4,859 / \mathrm{kWe}$, mainly attributable to the following:

- An increase in the plant size from $100 \mathrm{MW}$ to $150 \mathrm{MW}$, which reduces the $\$ / \mathrm{kWe}$ cost by virtue of the larger kWe size.

- Reduced cost of solar collection system components, such as HCE and mirrors, of approximately $35 \%$ as a result of technological advances, competition, and production volume.

- Reduction of the thermal storage capital cost from the near-term $\$ 958 / \mathrm{kWe}$ to $\$ 383 / \mathrm{kWe}$ by using a direct thermocline thermal storage system.

There is a high risk of achieving the SunLab projected mid-term total investment cost of $\$ 2,876 / \mathrm{kWe}$, based on the following considerations:

- The SunLab projected reduced cost of solar collection system components, such as HCE and mirrors, is based on six 100-MW plants and one 150-MW plant with improved technology being deployed in the years 2007 through 2010. Market expansion of trough technology will require incentives to reach the projected level of deployment.

- The SunLab projected mid-term net annual solar-to-electric efficiency is $17.0 \%$, an improvement of 2.7 percentage points from the near-term projected efficiency of $14.3 \%$. The solar field size, and thus the solar field cost, is directly proportional to the net annual solar-toelectric efficiency of a trough plant. As previously discussed, there is a high risk of achieving the mid-term net annual solar-to-electric efficiency of $17.0 \%$. Using a mid-term net annual solar-to-electric efficiency in the $15.4 \%$ range, which represents a lower risk by limiting the technology improvements to currently demonstrated or tested improvements, results in a 8\% decrease in the solar field size compared to $19 \%$ decrease for a $17.0 \%$ efficiency.

- The SunLab projected mid-term direct thermocline system with HitecXL (ternary) solar salt as the storage media and heat transfer fluid (HTF), allowing the solar field to be operated to higher outlet temperatures $\left(500^{\circ} \mathrm{C}\right)$. No thermal storage technology has been commercially demonstrated for the higher solar field operating temperatures. Additional development is required for the thermocline system. In addition to the development of a thermocline system, an advanced $\mathrm{HCE}$ will be required to obtain the $500^{\circ} \mathrm{C} \mathrm{HTF}$ operating temperature. 


\subsubsection{Long Term (2020)}

The SunLab projected long-term total investment cost indicates a total cost of $\$ 2,221 / \mathrm{kWe}$, a reduction of $\$ 655 / \mathrm{kWe}$ from the mid-term projected cost of $\$ 2,876 / \mathrm{kWe}$, mainly attributable to the following:

- An increase in the plant sizes from the 100-150-MW range to the 200-400-MW range, which reduces the $\$ / \mathrm{kWe}$ cost by virtue of the larger $\mathrm{kWe}$ size.

- $\quad$ Reduced cost of solar collection system components from mid-term costs, such as HCE and mirrors, of approximately $25 \%$ as a result of technological advances, competition, and production volume.

There is a high risk of achieving the SunLab projected long-term total investment cost due to the mid-term risks discussed previously. However, the risk is mitigated if the trough technology is successfully deployed to the extent that the competitive market prompts research and development of technological advances and plant sizes in the 200-400-MW range.

\subsubsection{Operation and Maintenance (O\&M) Costs}

The SunLab O\&M estimate is based largely on the experience at the KJC Operating Company SEGS plants. The model assumes a stand-alone trough power plant (as opposed to the five co-located plants at Kramer Junction) and adjusts costs depending on the size of the solar field and total electric generation per year. KJC Operating Company provided proprietary information on the last five years of operation.

The major cost contributors for O\&M costs are as follows:

- Solar field replacement of the heat collection elements (HCE)

- $\quad$ Staffing

The staffing is a fixed cost, and the SunLab projected manpower requirements are reasonable based on data from similar-sized power plants.

The industry plan keys on thermal storage to obtain a high capacity factor, which reduces the O\&M costs (\$/MWh) by obtaining a higher annual MWh generation. The net annual solar-to-electric efficiency has a significant impact on the O\&M costs. Increased efficiency reduces the size of the solar field and thus reduces the number of mirror and HCE replacements required. 


\subsubsection{Near Term (2004)}

The SunLab projected near-term O\&M cost is based on an HCE replacement rate of $2 \%$, a net annual solar-toelectric efficiency of $14.3 \%$, and 12 hours of thermal storage. As previously indicated, there is a low risk of achieving the near-term net annual solar-to-electric efficiency and the technological risk using the two-tank molten-salt storage system is low. However, the HCE replacement rate of $2 \%$ is not consistent with the average actual HCE replacement rate of 5.5\% reported for SEGS III - VII for the period 1997-2001. Using the average replacement rate of $5.5 \%$ increases the levelized O\&M cost by approximately $\$ 0.004 / \mathrm{kWhe}$, an increase of $17 \%$.

There is a high risk of achieving the SunLab projected near-term O\&M cost since the SunLab assumption of a 2\% HCE replacement rate assumes that current approaches for reducing failures are successful. S\&L believes this is an aggressive assumption that cannot be assured for future plants without the field data to verify the failure rate reduction. A lower risk would be using a HCE replacement rate of 5.5\% and an annual solar-toelectric efficiency of $14.0 \%$

\subsubsection{Mid Term (2010)}

The SunLab projected mid-term O\&M cost is based on an HCE replacement rate of $0.5 \%$, a net annual solar-toelectric efficiency of $17 \%$, and 12 hours of thermal storage using a direct thermocline system with HitecXL (ternary) solar salt.

As previously indicated, there is a high risk of achieving the mid-term net annual solar-to-electric efficiency of $17.0 \%$ and a mid-term net annual solar-to-electric efficiency in the $15.4 \%$ range represents a low risk by limiting the technology improvements to currently demonstrated or tested improvements. Also, the direct thermocline thermal storage system has not been commercially demonstrated for the higher solar field operating temperatures and additional development is required for the thermocline system. In addition to the development of a thermocline system, an advanced $\mathrm{HCE}$ will be required to obtain the $500^{\circ} \mathrm{C} \mathrm{HTF}$ operating temperature.

New designs are currently under investigation that attempt to improve the reliability of the HCE. Kramer Junction is currently testing a new design UVAC2 with a revised internal shield. A more conservative replacement rate for the $\mathrm{S} \& \mathrm{~L}$ comparison is $2.5 \%$.

There is a high risk of achieving the SunLab projected mid-term O\&M cost. A lower risk would be using a HCE replacement rate of $2.5 \%$ and an annual solar-to-electric efficiency of $15.4 \%$. 


\subsubsection{Long Term (2020)}

The SunLab projected long-term O\&M cost is based on an HCE replacement rate of $0.5 \%$, a net annual solar-toelectric efficiency of $17.2 \%$, and 12 hours of thermal storage using a direct thermocline system with HitecXL (ternary) solar salt. The projected long-term plant is basically the same configuration as the projected mid-term plant with the reduction in O\&M cost primarily as a result of the increase in plant size to $400 \mathrm{MW}$. As such, there is the same high risk of achieving the SunLab projected O\&M cost.

\subsection{COST SENSITIVITIES}

In this section, variations in the inputs for levelized energy costs are shown to illustrate the sensitivity of energy calculated cost to variations. The sensitivity analysis revealed that the impact on the LEC of the various scenarios are basically the same for both trough and tower technologies. The base case for the sensitivity analysis for the trough in 2020 is $400 \mathrm{MW}$ with a capital cost of $\$ 3,204$ per $\mathrm{kW}$ and annual O\&M costs of $\$ 14,129$, as is shown in Table 4-22. The tower base case is shown for reference.

Table 4-22 - S\&L Base Case for the Year 2020

\begin{tabular}{|l|c|c|}
\hline & Trough & Tower \\
\hline Year & 2020 & 2020 \\
\hline Capacity, MWe & 400 & 200 \\
\hline Capacity Factor, & $56.2 \%$ & $72.9 \%$ \\
\hline Capital Cost, \$/kW & $\$ 3,220$ & $\$ 3,591$ \\
\hline Annual O\&M Cost, \$k & $\$ 14,129$ & $\$ 9,132$ \\
\hline LEC, \$/kWh & $\$ 0.0621$ & $\$ 0.0547$ \\
\hline Economic Life & \multicolumn{2}{|c|}{$30 \mathrm{yrs}$} \\
\hline General Inflation $2.5 \%$ \\
\hline Equity Rate of Return & \multicolumn{2}{|c|}{$14 \%$} \\
\hline Cost of Construction & \multicolumn{2}{|c|}{$7 \%$} \\
\hline Construction Duration & \multicolumn{2}{|c|}{$10 \%$} \\
\hline Investment Tax Credit & \multicolumn{2}{|c|}{$40.2 \%$} \\
\hline Taxes & $5 \mathrm{yrs}$. \\
\hline Depreciable Life & \multicolumn{2}{|c|}{} \\
\hline
\end{tabular}




\begin{tabular}{|l|c|c|}
\hline & Trough & Tower \\
\hline IRR & \multicolumn{2}{|c|}{$14 \%$} \\
\hline DSCR & \multicolumn{2}{|c|}{1.35} \\
\hline
\end{tabular}

\subsubsection{Depreciable Life}

The tax depreciation allowances for renewable energy provide a favorable 5-year depreciable life. The Modified Accelerated Cost Recovery System (MACRS) defined depreciation schedules for 5, 10, and 15 years. If the tax laws are changed or reinterpreted, the variation in LEC in 2020 is shown below.

\section{Table 4-23 - Effect of Depreciable Life on Levelized Energy Cost}

\begin{tabular}{|c|c|c|}
\hline \multirow{2}{*}{$\begin{array}{c}\text { Depreciable Life } \\
\text { (years) }\end{array}$} & \multicolumn{2}{|c|}{ LEC in $\mathbf{2 0 2 0}$} \\
\cline { 2 - 3 } & $\mathbf{\$ / \mathbf { k W }}$ & $\mathbf{\%}$ difference \\
\hline 5 & $\$ 0.0621$ & Base Case \\
\hline 10 & $\$ 0.0658$ & $6.1 \%$ \\
\hline 15 & $\$ 0.0698$ & $12.5 \%$ \\
\hline
\end{tabular}

\subsubsection{Investment Tax Credits}

The investment tax credits have a major impact on the economic feasibility of a renewable energy power plant. Current tax law allows a 10\% investment tax credit. Future tax laws may allow a larger tax credit such as the $15 \%$ before 1985 or disallow investment tax credits. Tax credits from $0 \%$ to $15 \%$ and Energy Production Tax Credit (PTC) result in the LEC in 2020 to vary as shown below.

Table 4-24 - Effect of Investment Tax Credits on Levelized Energy Cost

\begin{tabular}{|c|c|c|}
\hline \multirow{2}{*}{$\begin{array}{c}\text { Tax Credits } \\
(\%)\end{array}$} & \multicolumn{2}{|c|}{ LEC in 2020} \\
\hline & $\$ / \mathbf{k W h}$ & $\%$ difference \\
\hline $0 \%$ & $\$ 0.0670$ & $7.8 \%$ \\
\hline $5 \%$ & $\$ 0.0645$ & $3.4 \%$ \\
\hline $10 \%$ & $\$ 0.0621$ & Base Case \\
\hline $15 \%$ & $\$ 0.0596$ & $-4.0 \%$ \\
\hline PTC of $1.8 \phi / k W h$ & $\$ 0.0490$ & $-26.9 \%$ \\
\hline
\end{tabular}




\subsubsection{Corporate Tax Rate}

Corporate tax rates are currently at $35 \%$. State taxes vary depending on the plant location but are assumed to be $8 \%$. The composite base tax rate is $43 \%$. The present Government Administration is currently considering reductions in the corporate tax rate, but the rate can vary depending on the economic conditions at the time. The impact on LEC in 2020 from changes in the tax rate is shown below.

Table 4-25 - Effect of Corporate Tax Rates on Levelized Energy Cost

\begin{tabular}{|c|c|c|c|c|}
\hline \multicolumn{3}{|c|}{ Corporate Tax Rates } & \multicolumn{2}{c|}{ LEC in 2020} \\
\hline Federal & State & Composite & $\$ / \mathbf{k W h}$ & $\%$ Difference \\
\hline $30 \%$ & $8 \%$ & $38 \%$ & $\$ 0.0632$ & $1.9 \%$ \\
\hline $35 \%$ & $8 \%$ & $43 \%$ & $\$ 0.0621$ & Base Case \\
\hline $38 \%$ & $10 \%$ & $48 \%$ & $\$ 0.0610$ & $-1.7 \%$ \\
\hline
\end{tabular}

\subsubsection{Inflation}

Inflation assumptions do not affect the real dollar levelized energy cost. Increases and decreases in the inflation rate impact the LEC in 2020 as shown below.

Table 4-26 - Effect of Inflation on Levelized Energy Cost

\begin{tabular}{|c|c|c|c|}
\hline \multicolumn{2}{|c|}{ Inflation Rate } & \multicolumn{2}{c|}{ LEC in $\mathbf{2 0 2 0}$} \\
\hline Rate & IRR & $\$ / \mathbf{k W h}$ & $\%$ difference \\
\hline $1.5 \%$ & $12.9 \%$ & $\$ 0.0614$ & $-1.0 \%$ \\
\hline $2.5 \%$ & $14.0 \%$ & $\$ 0.0621$ & Base Case \\
\hline $3.5 \%$ & $15.1 \%$ & $\$ 0.0627$ & $1.1 \%$ \\
\hline
\end{tabular}

\subsubsection{Cost of Capital}

Cost of capital for the base case is such that there is an internal rate of return (IRR) of 14\%. The impact on LEC in 2020 from a change in the cost of capital is shown in the following table. 


\section{Table 4-27 - Effect of Cost of Capital on Levelized Energy Cost}

\begin{tabular}{|c|c|c|}
\hline Cost of Capital & \multicolumn{2}{|c|}{ LEC in 2020 } \\
\hline IRR & $\$ / \mathbf{k W h}$ & $\%$ Difference \\
\hline $13 \%$ & $\$ 0.0575$ & $-7.3 \%$ \\
\hline $14 \%$ & $\$ 0.0621$ & Base Case \\
\hline $15 \%$ & $\$ 0.0668$ & $7.7 \%$ \\
\hline
\end{tabular}

\subsubsection{Construction Duration}

The plant construction period for the base case is one year based on experience at the SEGS plants. The amount of interest during construction (IDC) is included in the LEC. The impact on LEC in 2020 for construction of two and three years is shown below.

Table 4-28 - Effect of Construction Duration on Levelized Energy Cost

\begin{tabular}{|c|c|c|}
\hline \multirow{2}{*}{$\begin{array}{c}\text { Construction } \\
\text { Period } \\
\text { (yr) }\end{array}$} & \multicolumn{2}{|c|}{ LEC in $\mathbf{2 0 2 0}$} \\
\cline { 2 - 3 } & $\mathbf{\$ / k W h}$ & $\%$ Difference \\
\hline 1 & $\$ 0.0621$ & Base Case \\
\hline 2 & $\$ 0.0655$ & $5.5 \%$ \\
\hline 3 & $\$ 0.069$ & $11.3 \%$ \\
\hline
\end{tabular}

\subsubsection{Capital Cost}

The variation for increases in capital costs is shown below.

Table 4-29 - Effect of Capital Cost Increases on Levelized Energy Cost

\begin{tabular}{|c|c|c|}
\hline $\begin{array}{c}\text { Increase in Capital } \\
\text { Cost } \\
(\%)\end{array}$ & \multicolumn{2}{|c|}{ LEC in $\mathbf{2 0 2 0}$} \\
\cline { 2 - 3 } & $\$ \mathbf{k W h}$ & $\%$ difference \\
\hline $0 \%$ & $\$ 0.0621$ & Base Case \\
\hline $10 \%$ & $\$ 0.0675$ & $8.8 \%$ \\
\hline $20 \%$ & $\$ 0.0730$ & $17.7 \%$ \\
\hline
\end{tabular}




\subsubsection{Annual O\&M Cost}

The variation for increases in annual O\&M costs is shown below

\section{Table 4-30 - Effect of O\&M Cost Increase on Levelized Energy Cost}

\begin{tabular}{|c|c|c|}
\hline \multirow{2}{*}{$\begin{array}{c}\text { Increase in Annual } \\
\text { O\&M Cost } \\
(\%)\end{array}$} & \multicolumn{2}{|c|}{ LEC in $\mathbf{2 0 2 0}$} \\
\cline { 2 - 3 } & $\mathbf{\$} \mathbf{k W h}$ & $\mathbf{\%}$ difference \\
\hline $0 \%$ & $\$ 0.0621$ & Base Case \\
\hline $10 \%$ & $\$ 0.0628$ & $1.2 \%$ \\
\hline $20 \%$ & $\$ 0.0635$ & $2.3 \%$ \\
\hline
\end{tabular}

\subsubsection{Ownership}

The S\&L base case considers ownership by an Independent Power Producer (IPP). An investment by developer/owners and financial institutions would require an IRR of at least 14\%. It is more likely that the first several power plants will be owned by utilities. Utilities require a lower IRR and would be more receptive to renewable initiatives. As the industry matures (e.g., capital cost declines and the technology is proven), the IPPs would become involved. There is the potential for private ownership in the early plants, but it would most likely be from manufacturers who could offset the lower IRR with increased sales for solar equipment. The impact of ownership on LEC for 2020 is shown below.

Table 4-31 — Effect of Ownership on Levelized Energy Cost

\begin{tabular}{|l|c|c|c|}
\hline & IPP & $\begin{array}{c}\text { Utility } \\
\text { Ownership }\end{array}$ & Muni \\
\hline IRR, $\%$ & $14 \%$ & $11.5 \%$ & $0 \%$ \\
\hline Leverage & $60 / 40$ & $50 / 50$ & $100 / 0$ \\
\hline Cost of Debt & $5 \%$ & $7 \%$ & $5 \%$ \\
\hline DSCR & 1.35 & 1.74 & 1.0 \\
\hline LEC, $\$ / \mathrm{kWh}$ & $\$ 0.0621$ & $\$ 0.0597$ & $\$ 0.0458$ \\
\hline$\%$ difference & Base Case & $-3.9 \%$ & $-26.1 \%$ \\
\hline
\end{tabular}




\section{EVALUATION OF POTENTIAL FOR COST REDUCTIONS — TOWER}

\subsection{INDUSTRY PLAN FOR COST REDUCTION}

SunLab worked closely with industry in the development and demonstration of Solar One and Solar Two. The key industry participants were Boeing, Nexant (formerly Bechtel) and numerous utilities led by Southern California Edison. Since Solar Two, SunLab has continued working with industry to solve problems identified during the Solar Two demonstration project and identify technology improvements to reduce costs. The problems identified during Solar Two demonstration project are discussed in detail later. The tower industry has developed a comprehensive plan to lower costs. Industry participants have certain confidential information that cannot be shared since it would compromise their ability to compete in the domestic and international markets. The SunLab model (SunLab 2002) provides a cost estimate and plan that closely follows the industry comprehensive plan. S\&L used the SunLab plan as the basis of our independent review and supplemented with industry information and our experience. Table 5-1 lists the SunLab tower development plant and indicates the 'near-term', 'mid-term' and 'long-term' cases discussed previously.

Table 5-1 - Tower Technology Summary: SunLab Reference Case

\begin{tabular}{|l|c|c|c|c|c|c|}
\hline \multicolumn{1}{|c|}{ Case* $^{*}$ Project } & Baseline & \multicolumn{2}{|c|}{ Near-Term } & \multicolumn{2}{c|}{ Mid-Term } & Long-Term \\
\hline \multicolumn{1}{|c|}{ In Service Date } & $\mathbf{1 9 9 6}$ & $\mathbf{2 0 0 4}$ & $\mathbf{2 0 0 6}$ & $\mathbf{2 0 0 8}$ & $\mathbf{2 0 1 4}$ & $\mathbf{2 0 1 8}$ \\
\hline Power Cycle & Rankine & Rankine & Rankine & Rankine & Rankine & $\begin{array}{c}\text { Supercritical } \\
\text { Rankine }\end{array}$ \\
\hline Net Power, MWe & 10 & 13.65 & 50 & 100 & 200 & 220 \\
\hline Capacity Factor, \% & $21 \%$ & $78 \%$ & $75 \%$ & $73 \%$ & $74 \%$ & $72 \%$ \\
\hline Heliostat Size & $39 / 95$ & 95 & 95 & 148 & 148 & 148 \\
\hline Heliostat Design & glass/metal & glass/metal & glass/metal & glass/metal & glass/metal & Advanced \\
\hline Solar Field Size, $\mathrm{km}^{2}$ & 0.08 & 0.23 & 0.72 & 1.32 & 2.61 & 2.65 \\
\hline Receiver Area, $\mathrm{m}^{2}$ & 100 & 280 & 710 & 1,110 & 1,930 & 1,990 \\
\hline $\begin{array}{l}\text { Receiver Peak } \\
\text { Incident Flux, } \\
\text { MW/m }\end{array}$ & 0.8 & 0.95 & 1.2 & 1.4 & 1.6 & 1.6 \\
\hline
\end{tabular}




\begin{tabular}{|l|c|c|c|c|c|c|}
\hline \multicolumn{1}{|c|}{ Case $^{*}$} & Baseline & \multicolumn{2}{|c|}{ Near-Term } & \multicolumn{2}{c|}{ Mid-Term } & Long-Term \\
\hline \multicolumn{1}{|c|}{ In Service Date } & Solar Two & $\begin{array}{c}\text { Solar Tres } \\
\text { USA }\end{array}$ & Solar 50 & Solar 100 & Solar 200 & Solar 220 \\
\hline $\begin{array}{l}\text { Ratio Average/Peak } \\
\text { Incident Flux }\end{array}$ & 0.60 & $\mathbf{2 0 0 4}$ & $\mathbf{2 0 0 6}$ & $\mathbf{2 0 0 8}$ & $\mathbf{2 0 1 4}$ & $\mathbf{2 0 1 8}$ \\
\hline $\begin{array}{l}\text { Receiver Average } \\
\text { Incident Flux, } \\
\text { MW/m }\end{array}$ & 0.48 & 0.49 & 0.60 & 0.70 & 0.80 & 0.80 \\
\hline $\begin{array}{l}\text { Heat Transfer Fluid } \\
\text { Solar salt }\end{array}$ & 565 & 565 & 565 & 565 & 565 & 650 \\
\hline $\begin{array}{l}\text { Operating } \\
\text { Temperature, }{ }^{\circ} \mathrm{C}\end{array}$ & solar salt & solar salt & solar salt & solar salt & solar salt \\
\hline $\begin{array}{l}\text { Thermal Storage } \\
\text { Fluid }\end{array}$ & solar salt & solar salt & solar salt & solar salt & solar salt & $\begin{array}{c}\text { solar salt w/ } \\
\mathrm{O}_{2} \text { blanket }\end{array}$ \\
\hline Thermal Storage, hr & 3 & 16 & 16 & 13 & 13 & 17 \\
\hline Land Area, km ${ }^{2}$ & 0.4 & 1.1 & 3.4 & 6.6 & 13.8 & 14 \\
\hline
\end{tabular}

*All cases assume Kramer Junction 1999 radiation of $8.054 \mathrm{~kW} / \mathrm{m}^{2} /$ day.

Industry and the national laboratories are actively working together to enhance technology to reduce costs. This is being accomplished with industry research and development (IRD) funding and cooperative work with the national laboratories. For example, Boeing and Sandia are currently participating in solar research through a joint Cooperative Research and Development Agreement (CRADA). Boeing reported that they committed $\$ 2$ million of IRD funds for the Solar Two demonstration project. Boeing is continuing to pursue improvements to the receiver and other systems through internal funding. This effort has resulted in multiple patents and disclosures and in advanced codes (SUNSPOT and RISROC) for field and receiver optimization. A previous CRADA with SunLab was completed to study fabrication of large heliostats. Nexant and Sandia have worked closely to develop improved plant designs and specifications to utilize the lessons learned at Solar Two.

Some of the design improvements that are or will be pursued are listed below.

- Collector

- Mirrors will improve by the use of higher reflectivity thin glass or films, and additional support structure will be made cost-effective by higher volume production (see Appendix H). 
- Cleanliness can improve though the development of contact cleaning tools for heliostats and the adaptation of 'self-cleaning," glass for use with solar mirrors.

- Novel heliostat designs like stretched membrane (drum-like) or inflatable/rolling concepts that are lower in weight than traditional glass/metal designs.

- Drive mechanisms can be simplified. Presently the drives use complex gearing.

- New flux monitoring and management systems that will permit higher solar flux levels on the receiver.

- Receiver

- Changes in receiver tube material have been accomplished to correct problems identified during Solar Two. The tube material changes were validated by molten salt corrosion tests and high flux testing at Sandia. The development of this material was performed jointly by Boeing and Sandia (CRADA).

- Simplified redesign of the receiver panels was accomplished jointly by Boeing and Sandia (CRADA).

- Tube internal heat transfer enhancements can improve receiver flux capability.

- Simpler and more efficient header oven covers can allow faster preheat in the morning and more efficient operation in partly cloudy weather and high winds.

- Redesigned fill and drain system can accelerate receiver start-up and simplifies operation.

- High-temperature selective surfaces for receiver tubes can reduce radiative losses while maintaining high absorptivity.

- Advanced header design, including new materials and nozzle designs, was modified and parts deleted. This is the key reason in achieving cost reduction from $\$ 8.33$ per $\mathrm{kWt}$ for Solar Two to $\$ 3.96$ per $\mathrm{kWt}$ for Solar Tres.

- $\quad$ HTF and Thermal Storage

- Improved tank venting system and better instrumentation.

- Advanced tower piping design that eliminates drag valves in the down flow pipe.

- Simplified foundation cooling system can lower cost.

- Optimize the tank overall configuration (shape and location).

- Higher temperature molten salt to improve cycle performance.

- An advanced molten salt with a lower freezing point can reduce heat tracing, simplify operation, and result in decreased parasitic power consumption.

- Direct resistance heating of piping and components can lower maintenance costs.

- Steam Generator System

- Installing the hot and cold pumps directly in the hot and cold storage tanks eliminates significant piping and valves, which results in reduced cost.

\footnotetext{
* Several glass manufacturers are releasing 'self-cleaning' glass, including Pilkington Active TM (www.activglass.com/index_eng.htm) and PPG SunClean TM (www.ppg.com/gls_sunclean/)
} 
- Elevating the steam generator heat exchangers allows full gravity draining, which provides less equipment and simplifies operation of the system.

- Improved operating procedures have been developed to provide more reliable operation.

- $\quad$ Electric Power Block

- Larger plants can utilize the more efficient Rankine cycles that are currently available technology.

- Even higher cycle efficiencies are possible via parallel paths: (1) the availability of more efficient Rankine cycles in the appropriate size range and (2) the introduction of supercritical steam turbines operating at higher temperatures can increase Rankine cycle efficiencies.

\subsection{TOWER EFFICIENCY}

Many of the advances just described can reduce capital costs and/or improve plant efficiency, which indirectly decreases capital costs. For example, given a fixed plant size and capacity factor, the net annual solar-electric efficiency sets the required collector area (Appendix E.3). As the efficiency increases, the collector area and cost decrease in proportion. Table 5-2 lists the subsystem annual efficiencies of selected tower plants from the development plan and summarizes the S\&L analysis of these projections.

Table 5-2 - Tower Annual Efficiency Summary

\begin{tabular}{|c|c|c|c|c|c|c|c|c|c|}
\hline & \multirow[b]{2}{*}{ Baseline } & \multicolumn{3}{|c|}{ SunLab } & \multicolumn{3}{|c|}{ Sargent \& Lundy } & \multirow[b]{4}{*}{ Discussion } & \multirow[b]{4}{*}{$\begin{array}{l}\text { Detailed } \\
\text { Discussion }\end{array}$} \\
\hline & & $\begin{array}{l}\text { Near } \\
\text { Term }\end{array}$ & $\begin{array}{l}\text { Mid- } \\
\text { Term }\end{array}$ & $\begin{array}{l}\text { Long } \\
\text { Term }\end{array}$ & $\begin{array}{l}\text { Near } \\
\text { Term }\end{array}$ & $\begin{array}{l}\text { Mid- } \\
\text { Term }\end{array}$ & $\begin{array}{l}\text { Long } \\
\text { Term }\end{array}$ & & \\
\hline & 1996 & 2004 & 2008 & 2020 & 2004 & 2008 & 2020 & & \\
\hline & $\begin{array}{l}\text { Solar } \\
\text { Two }\end{array}$ & $\begin{array}{l}\text { Solar } \\
\text { Tres }\end{array}$ & $\begin{array}{c}\text { Solar } \\
100\end{array}$ & $\begin{array}{l}\text { Solar } \\
220\end{array}$ & $\begin{array}{l}\text { Solar } \\
\text { Tres }\end{array}$ & $\begin{array}{c}\text { Solar } \\
100\end{array}$ & Solar 220 & & \\
\hline $\begin{array}{l}\text { Collector } \\
\text { Efficiency }\end{array}$ & $\begin{array}{l}50.3 \% \\
58 \% \text { at } \\
\text { Solar } \\
\text { One }\end{array}$ & $56.0 \%$ & $56.3 \%$ & $57.0 \%$ & $56.0 \%$ & $56.0 \%$ & $56.0 \%$ & $\begin{array}{l}\text { The collector efficiency should decrease } \\
\text { at larger plants because the average } \\
\text { distance between heliostat field and tower } \\
\text { increases, as does the atmospheric } \\
\text { attenuation of light. The SunLab projected } \\
\text { improvements in reflectivity and } \\
\text { cleanliness more then compensate for } \\
\text { this effect, but S\&L projects that the } \\
\text { mirror cleanliness will not exceed } 95 \% \\
\text { based on discussions with operators at } \\
\text { Kramer Junction. }\end{array}$ & $\begin{array}{l}\text { Section } \\
\text { E.3.6 }\end{array}$ \\
\hline $\begin{array}{l}\text { Receiver } \\
\text { Efficiency }\end{array}$ & $76.0 \%$ & $78.3 \%$ & $83.1 \%$ & $82.0 \%$ & $78.3 \%$ & $83.1 \%$ & $82.0 \%$ & $\begin{array}{l}\text { Efficiency increases in with solar flux level } \\
\text { the mid-term plant due to reduced thermal } \\
\text { losses. Flux increases cannot } \\
\text { compensate for increased losses due to } \\
\text { higher temperature operation in the long- } \\
\text { term plant. }\end{array}$ & $\begin{array}{l}\text { Section } \\
\text { E.7.2 }\end{array}$ \\
\hline
\end{tabular}




\begin{tabular}{|c|c|c|c|c|c|c|c|c|c|}
\hline & \multirow[b]{2}{*}{ Baseline } & \multicolumn{3}{|c|}{ SunLab } & \multicolumn{3}{|c|}{ Sargent \& Lundy } & \multirow[b]{4}{*}{ Discussion } & \multirow[b]{4}{*}{$\begin{array}{l}\text { Detailed } \\
\text { Discussion }\end{array}$} \\
\hline & & $\begin{array}{l}\text { Near } \\
\text { Term }\end{array}$ & $\begin{array}{l}\text { Mid- } \\
\text { Term }\end{array}$ & $\begin{array}{l}\text { Long } \\
\text { Term }\end{array}$ & $\begin{array}{l}\text { Near } \\
\text { Term }\end{array}$ & $\begin{array}{l}\text { Mid- } \\
\text { Term }\end{array}$ & $\begin{array}{l}\text { Long } \\
\text { Term }\end{array}$ & & \\
\hline & 1996 & 2004 & 2008 & 2020 & 2004 & 2008 & 2020 & & \\
\hline & $\begin{array}{l}\text { Solar } \\
\text { Two }\end{array}$ & $\begin{array}{l}\text { Solar } \\
\text { Tres }\end{array}$ & $\begin{array}{c}\text { Solar } \\
100\end{array}$ & $\begin{array}{c}\text { Solar } \\
220\end{array}$ & $\begin{array}{l}\text { Solar } \\
\text { Tres }\end{array}$ & $\begin{array}{c}\text { Solar } \\
100\end{array}$ & Solar 220 & & \\
\hline $\begin{array}{l}\text { Gross } \\
\text { Cycle } \\
\text { Efficiency }\end{array}$ & $31.7 \%$ & $40.5 \%$ & $42.0 \%$ & $46.3 \%$ & $38.0 \%$ & $41.4 \%$ & $45.6 \%$ & $\begin{array}{l}\text { The Solar Two steam turbine was } \\
\text { designed for marine propulsion and } \\
\text { lacked reheat. Current, proven Rankine } \\
\text { technology is being used up to Solar } 200 \text {. } \\
\text { Solar } 220 \text { is projecting that current } \\
\text { research on advanced turbines will be } \\
\text { complete and available to support in } \\
2018 \text {. The turbine efficiencies are } \\
\text { reasonable based on guarantees. Actual } \\
\text { efficiencies will be less depending on } \\
\text { actual conditions (i.e., cooling water } \\
\text { temperature). }\end{array}$ & $\begin{array}{l}\text { Section } \\
\text { E.6.2 }\end{array}$ \\
\hline Parasitic & $73.0 \%$ & $86.4 \%$ & $90.0 \%$ & $90.0 \%$ & $86.4 \%$ & $90.0 \%$ & $90.0 \%$ & $\begin{array}{l}\text { The parasitic efficiency will increase } \\
\text { based on higher capacity factors, larger } \\
\text { plants, design improvements and lessons } \\
\text { learned from Solar Two and Solar Tres. }\end{array}$ & $\begin{array}{l}\text { Section } \\
\text { E.3.5 }\end{array}$ \\
\hline $\begin{array}{l}\text { Thermal } \\
\text { Storage }\end{array}$ & $97.0 \%$ & $98.3 \%$ & $99.5 \%$ & $99.5 \%$ & $98.3 \%$ & $99.5 \%$ & $99.5 \%$ & $\begin{array}{l}\text { Efficiencies increase at future plants } \\
\text { because tank surface area to volume ratio } \\
\text { (and heat losses) decreases with } \\
\text { increasing tank size. }\end{array}$ & $\begin{array}{l}\text { Section } \\
\text { E.8.2 }\end{array}$ \\
\hline Piping & $99.0 \%$ & $99.5 \%$ & $99.9 \%$ & $99.9 \%$ & $99.5 \%$ & $99.9 \%$ & $99.9 \%$ & $\begin{array}{l}\text { The piping efficiencies are reasonable } \\
\text { and increase due to larger piping and } \\
\text { shorter lengths per kWe }\end{array}$ & - \\
\hline Availability & $90.0 \% *$ & $92.0 \%$ & $94.0 \%$ & $94.0 \%$ & $92.0 \%$ & $94.0 \%$ & $94.0 \%$ & $\begin{array}{l}\text { The availability should be reached after } \\
\text { the first } 12 \text { to } 18 \text { months of operation. } \\
\text { Actual availability for SEGS VI in } 1999 \\
\text { was } 98 \%\end{array}$ & - \\
\hline $\begin{array}{l}\text { Annual } \\
\text { Solar-to- } \\
\text { Electric } \\
\text { Efficiency }\end{array}$ & $7.6 \%$ & $13.7 \%$ & $16.6 \%$ & $18.1 \%$ & $13.0 \%$ & $16.1 \%$ & $17.3 \%$ & $\begin{array}{l}\text { The large jump from Solar Two to Solar } \\
\text { Tres is due to the use of (1) a steam } \\
\text { turbine with reheat, (2) a new collector } \\
\text { field that performs to the level proven at } \\
\text { Solar One, and ( } 3 \text { ) miscellaneous small } \\
\text { improvements due mostly to the increase } \\
\text { in plant size. S\&L agrees with these } \\
\text { projections, except uses a lower mirror } \\
\text { cleanliness estimate for Solar } 220 \text {. }\end{array}$ & Section E.3 \\
\hline
\end{tabular}

${ }^{*}$ Based on the mature plant operation of Solar One.

The projected increases in net annual solar-to-electric efficiency have a significant impact on the capital cost of the plants. The S\&L analysis of the impact of these incremental efficiency improvements the SunLab capital cost at the subsystem level appears in Table 5-2. More details of this analysis are presented in Section E.4.6. For illustration, the impact of solar-to-electric efficiency improvements on required collector area and cost is shown in Figure 5-1. 


\section{Figure 5-1 - Comparison of Annual Solar-to-Electrical Efficiency Technology Step Changes:}

\section{SunLab vs. S\&L}

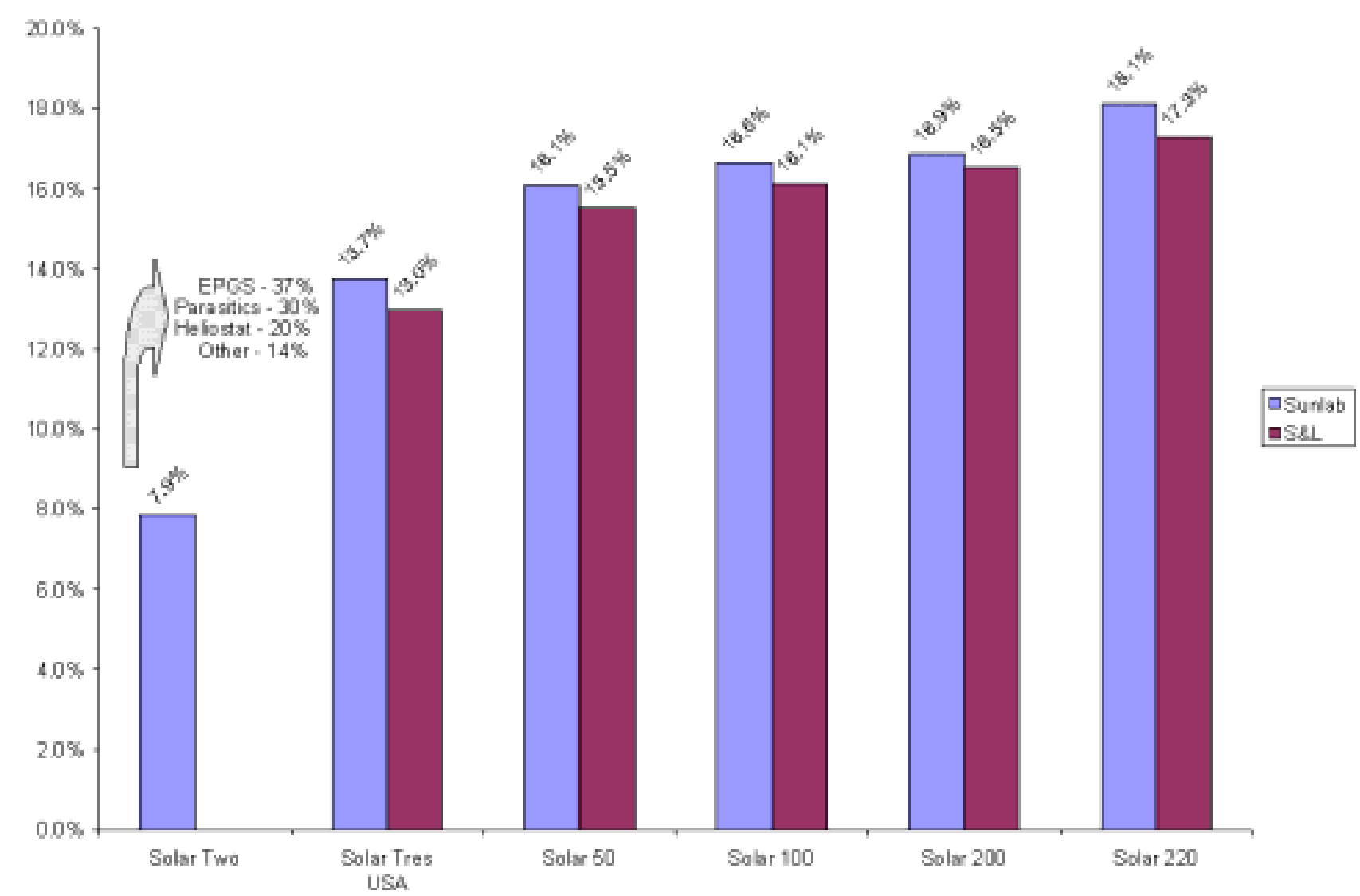

\subsubsection{Annual Collector Efficiency}

Collector efficiency includes mirror reflectivity (see Appendix $\mathrm{H}$ for the definition of reflectivity and the impact of microscopic defects on plant performance), field optical efficiency, ${ }^{*}$ field availability, mirror corrosion avoidance, mirror cleanliness, and high wind outages. SunLab projections for each of these contributing collector field efficiencies are listed in Appendix E, Table E-6 for all plants. The detailed S\&L analysis of collector field efficiency appears in Appendix E, Section E.3.6. The prime adjustment was regarding mirror

\footnotetext{
* Includes the cosine effect, blocking of incident sunlight, shading of reflected sunlight by adjacent heliostats, and the intercept. The intercept is the fraction of light directed toward the receiver that actually strikes it. Errors in heliostat tracking, focal length, and shape reduce the intercept below unity. Economic optimizations typically yield an intercept of about $95 \%$.
} 
cleanliness. Based on discussions during the KJC site visit, S\&L estimates the upper bound on mirror cleanliness to be $95 \%$, as opposed to the SunLab upper limit of $97 \%$.

\subsubsection{Annual Receiver Efficiency}

Receiver efficiency includes absorptivity, thermal efficiency, and plant operational losses. When sunlight strikes the receiver, some energy is reflected. The fraction absorbed is called the absorptivity, and the Pyromark ${ }^{\mathrm{TM}}$ paint used on the tower receiver has an absorptivity of $95 \%$ when new. Slow degradation of the paint observed at Solar One dictates that it be reapplied every few years and results in a lower time-average absorptivity (Radosevich 1988). Improved durability of the paint and/or ease of application and curing can raise the average up to the as-new value of $95 \%$. In addition, the receiver suffers radiation and convective losses that reduce its thermal efficiency below $100 \%$.

Increasing the solar flux levels on the receiver permits a reduction in size that reduces these losses and increases thermal efficiency. A new high-nickel receiver tube material will be used on future plants because (1) it eliminates stress corrosion cracking, which can occur in the receiver because moist air can enter when it is drained at night, and (2) it permits higher solar flux levels. The stress corrosion cracking resistance has been validated in testing with Sandia. A small prototype panel of the new material has been tested to flux levels in excess of 1.6 MWt $/ \mathrm{m}^{2}$. A full size panel was also constructed and installed at Solar Two where it operated at the lower flux levels of that plant. Achieving the increased solar flux levels will require improved flux monitoring and management systems.

Plant operational losses occur when the plant is unable to use all of the available energy for a short period. For example, times of very high solar resource can 'overpower' the receiver so part of the field must be 'defocused' to avoid damage. This reduces annual efficiency. Times of very low solar resource (e.g., sunrise) do not justify plant operation because losses outpace gains. Likewise, when clouds shade the plant, the receiver enters a cloud standby state with salt circulating through the receiver and incurring thermal losses without any energy collection. The plant operating and dispatch strategy can also create a situation where the thermal storage system is full and cannot accept any additional energy, so energy collection must again be curtailed (called 'dumping.') Economic optimization of the plant design typically results in a few percent of defocusing and dumping losses. 


\subsubsection{Annual Gross Cycle Efficiency}

The annual gross cycle efficiency includes the design point gross cycle efficiency, startup losses, and part-load operation. Losses due to minimum turbine load requirements do not apply because all of the plants have thermal storage. The gross cycle efficiency is the thermal input to the turbine divided by the gross (nameplate) output. Electrical parasitic loads are considered next. The high-storage, high-capacity factor plants have minimal startup losses and are normally not run at part load, so these losses are minimal.

\subsubsection{Annual Parasitic Efficiency}

The main parasitic electric loads are the motors for the salt pumps, condensate/feedwater pumps, cooling water pumps, cooling tower fans, and boiler. Additional parasitic loads are a result of instrumentation, controls, computers, valve actuators, air compressors, and lighting. The solar field also adds parasitic loads for the collector drives and communications. Electric parasitic loads decrease with larger plant size and are based on detailed analysis at Solar One and Solar Two (Reilly and Kolb 2001)

\subsubsection{Annual Thermal Storage Efficiency}

The annual thermal storage efficiency accounts for thermal losses from the thermal storage system. Storage thermal losses are a function of the surface area of the storage tanks and the temperature of the fluid above ambient. Large high-temperature thermal storage systems have been demonstrated at SEGS I and Solar Two. In these systems, thermal losses have been shown to be small; thus, the storage thermal efficiency is very close to $100 \%$. As the size of the tanks increases, their surface area increases more slowly than their volume, so that thermal losses are reduced and efficiency increases.

\subsubsection{Annual Piping Efficiency}

The piping efficiency includes losses from the salt piping in the tower and at ground level.

\subsubsection{Annual Plant Availability}

Annual plant availability accounts for scheduled plant outages for regular maintenance and unscheduled plant outages due to equipment failures.

\subsection{EVALUATION OF MAJOR COST COMPONENTS}

The solar field, electric power block, and receiver encompass approximately $74 \%$ of the total direct costs as shown in Figure 5-2. The major cost component is the heliostat field, which encompasses $43 \%$ of total costs for 
Solar Tres. The next three categories are electric power block, 13\%; receiver, $18 \%$; and balance-of-plant, $6 \%$. Our review focused on these three major cost components, with a less stringent review of thermal storage and steam generator. Table 5-3 provides a summary of the SunLab and S\&L cost projection.

Figure 5-2 - Cost Components for Solar Tres

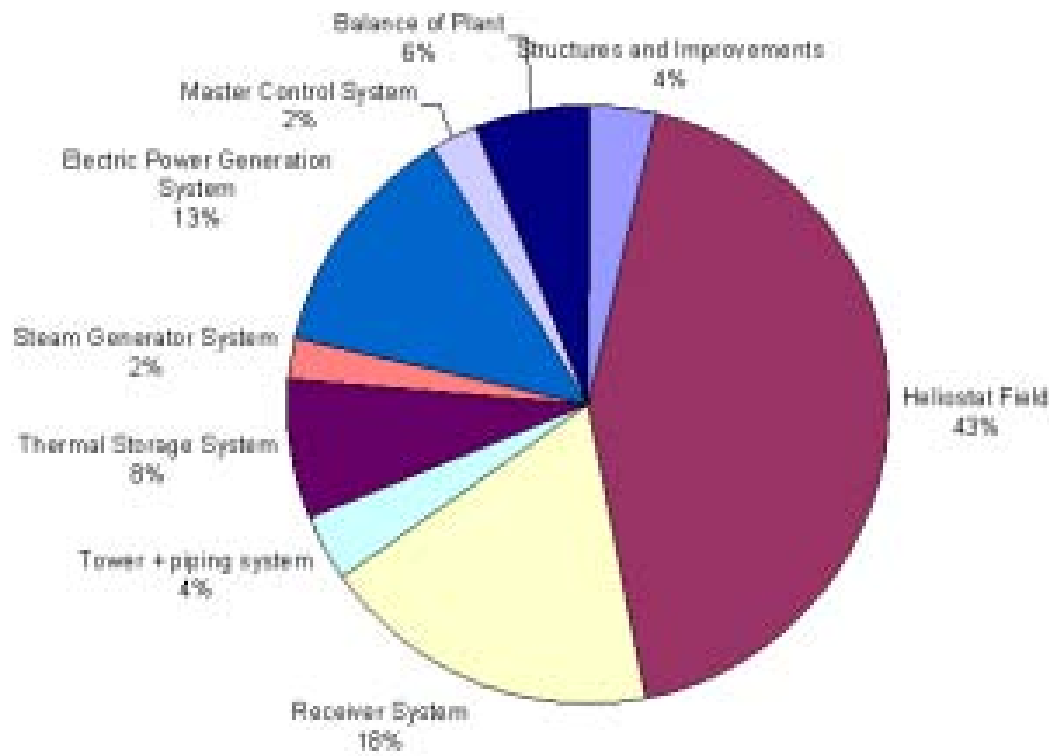

Table 5-3 - Summary of Tower Cost Projections

\begin{tabular}{|l|c|c|c|c|c|c|}
\hline \multirow{2}{*}{ Case } & \multicolumn{3}{|c|}{ SunLab Forecast } & \multicolumn{3}{c|}{ Sargent \& Lundy } \\
\cline { 2 - 8 } & $\begin{array}{c}\text { Near } \\
\text { Term }\end{array}$ & $\begin{array}{c}\text { Mid } \\
\text { Term }\end{array}$ & $\begin{array}{c}\text { Long } \\
\text { Term }\end{array}$ & $\begin{array}{c}\text { Near } \\
\text { Term }\end{array}$ & $\begin{array}{c}\text { Mid } \\
\text { Term }\end{array}$ & $\begin{array}{c}\text { Long } \\
\text { Term }\end{array}$ \\
\hline \multicolumn{1}{|c|}{ Year In Service } & $\begin{array}{c}\text { Solar } \\
\text { Tres }\end{array}$ & $\begin{array}{c}\text { Solar } \\
\mathbf{1 0 0}\end{array}$ & $\begin{array}{c}\text { Solar } \\
\mathbf{2 2 0}\end{array}$ & $\begin{array}{c}\text { Solar } \\
\text { Tres }\end{array}$ & $\begin{array}{c}\text { Solar } \\
\mathbf{1 0 0}\end{array}$ & $\begin{array}{c}\text { Solar } \\
\mathbf{2 0 0}\end{array}$ \\
\hline $\begin{array}{l}\text { Structures and Improvements, } \\
\text { \$/m }{ }^{2} \text { field }\end{array}$ & 12.3 & $\mathbf{2 0 1 0}$ & $\mathbf{2 0 2 0}$ & $\mathbf{2 0 0 4}$ & $\mathbf{2 0 1 0}$ & $\mathbf{2 0 2 0}$ \\
\hline Heliostat Field, \$/m ${ }^{2}$ field & 145 & 107 & 76 & 160 & 134 & 117 \\
\hline Receiver, \$k/m ${ }^{2}$ recv & 50 & 27 & 21 & 57.143 & 30.631 & 23.834 \\
\hline Tower and Piping, \$/m field & 12.1 & 9.1 & 9.2 & 11.6 & 8.7 & 9.1 \\
\hline Thermal Storage, \$/kWt & 49 & 41 & 40 & 49 & 41 & 40 \\
\hline
\end{tabular}




\begin{tabular}{|c|c|c|c|c|c|c|}
\hline \multirow[b]{2}{*}{ Case } & \multicolumn{3}{|c|}{ SunLab Forecast } & \multicolumn{3}{|c|}{ Sargent \& Lundy } \\
\hline & $\begin{array}{l}\text { Near } \\
\text { Term }\end{array}$ & $\begin{array}{l}\text { Mid } \\
\text { Term }\end{array}$ & $\begin{array}{l}\text { Long } \\
\text { Term }\end{array}$ & $\begin{array}{l}\text { Near } \\
\text { Term }\end{array}$ & $\begin{array}{c}\text { Mid } \\
\text { Term }\end{array}$ & $\begin{array}{l}\text { Long } \\
\text { Term }\end{array}$ \\
\hline Project & $\begin{array}{l}\text { Solar } \\
\text { Tres }\end{array}$ & $\begin{array}{c}\text { Solar } \\
100\end{array}$ & $\begin{array}{c}\text { Solar } \\
220\end{array}$ & $\begin{array}{l}\text { Solar } \\
\text { Tres }\end{array}$ & $\begin{array}{c}\text { Solar } \\
100\end{array}$ & $\begin{array}{c}\text { Solar } \\
200\end{array}$ \\
\hline Year In Service & 2004 & 2010 & 2020 & 2004 & 2010 & 2020 \\
\hline Steam Generator, $\$ / \mathrm{kWt}$ & 14 & 8 & 7 & 14 & 8 & 7 \\
\hline Electric Power, $\$ / \mathrm{kWe}$ & 733 & 400 & 380 & 557 & 306 & 231 \\
\hline Balance of Plant, $\$ / \mathrm{kWe}$ & 532 & 116 & 7 & 733 & 367 & 169 \\
\hline Subtotal Direct Costs, $\$ / \mathrm{kWe}$ & 5,700 & 2,700 & 1,900 & 6,424 & 3,375 & 2,684 \\
\hline Indirect Costs, \$/kWe & 440 & 241 & 183 & 1,134 & 629 & 524 \\
\hline Contingency, $\$ / \mathrm{kWe}$ & 453 & 202 & 152 & 890 & 604 & 383 \\
\hline Risk Pool, \$/kWe & 580 & 0 & 0 & 642 & 0 & 0 \\
\hline Total Cost, $\$ / \mathrm{kWe}$ & 7,110 & 3,100 & 2,270 & 9,090 & 4,608 & 3,591 \\
\hline
\end{tabular}

\subsubsection{Collectors}

The first plants (Solar Tres and Solar 50) will use the $95-\mathrm{m}^{2}$ heliostats. The heliostat size will be increased to $148 \mathrm{~m}^{2}$ for Solar 100. S\&L evaluation focused on the capital costs and cost improvement for the $148 \mathrm{~m}^{2}$ heliostat. Our review is primarily based on the SunLab model, the detailed cost model developed by AD Little, and Winsmith drive cost and technology improvement studies. The $148-\mathrm{m}^{2}$ heliostat was compared against the $95 \mathrm{~m}^{2}$ heliostat. We reviewed the major cost components and provided a discussion of the assumptions and reasonableness of the cost estimate in Appendix E.

AD Little (ADL) was contracted by the DOE to prepare a detailed cost estimate for the current $148 \mathrm{~m}^{2}$ Heliostat design from Advanced Thermal Systems (Arthur D. Little, 2001). The study was based on detailed design drawings, material takeoff, and proven assembly techniques. ADL applied manufacturing and assembly times based on their experience and material costs to develop a rigorous cost estimate. Manufacturers and vendors were contacted to develop and validate material costs. ADL used the detailed design information from Advanced Thermal Systems (ATS) ${ }^{*}$ to estimate the costs. This bottoms-up cost estimate is rigorous and provides

\footnotetext{
* Advanced Thermal Systems is a small company formed in 1985 by former ARCO engineers with licensing rights for the tracker technology. DOE funded the development of the previous generation $53-\mathrm{m}^{2}$ heliostat. ARCO funded the design, development, and first prototype $95-$ and $148-\mathrm{m}^{2}$ trackers for use as heliostats or PV trackers. The design was optimized to
} 
a fairly accurate cost estimate. It is our opinion that the cost estimate prepared by ADL is a reasonable cost estimate of manufacturing $148 \mathrm{~m}^{2}$ based on producing 300 units $\left(444,000 \mathrm{~m}^{2}\right)$. Our estimate of heliostat costs is shown in Table 5-4. We reviewed the ADL study in detail and compared cost material cost estimates to our internal cost database (e.g., \$ per lb for steel). Based on our evaluation, we determined that the cost of a 95- $\mathrm{m}^{2}$ heliostat for initial deployment is about $\$ 160$. The cost for the $95-\mathrm{m}^{2}$ heliostat was estimated based on a scaling factor of 0.8 , which is more conservative that the industry average of 0.7 .

\section{Table 5-4 - Heliostat Cost Estimate Comparison: Direct Capital Cost - Initial Deployment}

\begin{tabular}{|l|c|c|c|c|}
\hline \multirow{2}{*}{ Heliostat Size } & \multicolumn{2}{|c|}{ SunLab } & \multicolumn{2}{c|}{ Sargent \& Lundy } \\
\cline { 2 - 5 } & $\begin{array}{c}\text { Heliostat } \\
\text { Cost }\end{array}$ & $\$ / \mathrm{m}^{2}$ & $\begin{array}{c}\text { Heliostat } \\
\text { Cost }\end{array}$ & $\$ / \mathrm{m}^{2}$ \\
\hline $\begin{array}{l}95 \mathrm{~m}^{2} \text { (scaled from } 148 \mathrm{~m}^{2} \text { at a } \\
\text { scaling factor of 0.8) }\end{array}$ & $\$ 14,214$ & $\$ 150$ & $\$ 15,168$ & $\$ 160$ \\
\hline $148 \mathrm{~m}^{2}$ (from Table E-14) & $\$ 20,288$ & $\$ 137$ & $\$ 21,688$ & $\$ 146$ \\
\hline
\end{tabular}

Cost improvements are categorized into technology improvements, scaling factor and volume production.

\subsubsection{Technology Improvements}

The technology improvements include (1) thinner glass to increase reflectivity and reduce cost, (2) improved aiming techniques, (3) better maintenance practices and updated control system to increase field availability, and (4) advanced heliostat for Solar 220.

Sargent \& Lundy has evaluated the technology improvements for efficiency:

- Mirror cleanliness efficiency shows an increase from 95\% to 97\%. Based on our interviews at Kramer Junction, there is no evidence that the cleanliness will get much better than 95\% without a major technology breakthrough. There is current research on glass with surfaces to maintain high cleanliness efficiencies for large high-rise buildings. ${ }^{*}$ S\&L's cost estimate assumes that the mirror cleanliness will stay at $95 \%$.

use the maximum number of commodity parts and provide the lowest possible cost for near-term deployment. Approximately 1000 solar trackers of this basic design have been built. Most were the $95-\mathrm{m}^{2}$ units. One hundred eight of the heliostats used at Solar Two were second-hand ATS trackers.

* Several glass manufacturers are releasing 'self-cleaning' glass, including Pilkington Active TM (www.activglass.com/index eng.htm) and PPG SunClean ${ }^{\text {TM }}$ (www.ppg.com/gls_sunclean/) 
- Mirror reflectivity efficiency shows an increase from $93.5 \%$ to $95 \%$. This will require additional research in the use of thin glass. The use of thin glass will have to overcome several issues: breakage, corrosion, manufacturing, and maintaining cleanliness. The current glass with a low lead content has a reflectivity of $93.5 \%$ to $94 \%$ depending on the amount of lead. As production volume increases, there will be greater incentive and quality control to provide higher reflectivity glass. For additional discussion on glass research, see Section 4.3.3.

- The field optical efficiency shows a decrease from $64.6 \%$ to $62.8 \%$. This is reasonable based on the larger collector field size and longer distance to the receiver.

- The field availability shows an increase from $98.5 \%$ to $99.5 \%$. This is based on better maintenance practices, better quality of heliostats as a result of volume production, and an updated control system. Solar One demonstrated a field availability of $99 \%$. We assumed that actual field availability based on longer-term commercial operation would increase from $98.5 \%$ to $99 \%$. The field availability of $99.5 \%$ will be difficult to achieve without at least a $5 \%$ additional collector field to cover maintenance and outages.

- Mirror corrosion avoidance efficiency is projected to be $100 \%$. This is reasonable using the present glass based on the experience at Kramer Junction. Additional research, which is presently ongoing, will be required as thinner glass is used.

\subsubsection{Scaling Factor}

Scaling factor cost improvements are based on heliostat size changes: Solar Two $\left(48 \mathrm{~m}^{2}\right)$ to Solar Tres $\left(95 \mathrm{~m}^{2}\right)$ and Solar $50\left(95 \mathrm{~m}^{2}\right)$ to Solar $100\left(95 \mathrm{~m}^{2}\right)$. Increasing to a $148-\mathrm{m}^{2}$ heliostat can be achieved based on detailed engineering performed by ATS and actual construction and operation as PV trackers. The scaling factor of 0.8 is a reasonable assumption, even though there have not been a larger quantity of $148-\mathrm{m}^{2}$ heliostats built. The average industry standard used if no information is available is 0.7 (Humphreys and English 1993). Additional discussion is provided in Appendix B, Methodology.

\subsubsection{Production Volume}

Production Volume has a significant impact on cost improvements. The SunLab cost estimate for production volume cost reductions is based on evaluating each cost component and determining the impact on cost reduction (see Appendix E.4.4). S\&L performed a detailed review of each cost component to determine the impact. For example the PR ratio for mirrors was calculated to be 0.97 , which is reasonable since mirror costs will decrease due to the increased production runs by mirror manufacturers resulting in lower costs (see Appendix E.5.1 for additional discussion).

The comparison of heliostat costs based on a cumulative deployment of 8.7 GWe for S\&L and SunLab is shown in Figure 5-3. The range of cost estimates by SunLab and S\&L fall within a reasonable cost range established by 
S\&L (see Appendix B for additional discussion). The range of progress ratios used for the comparison by S\&L is between 0.85 and 0.96 . Various studies on learning curves from actual data suggest that a progress ratio of 0.82 has been observed for photovoltaics (PV) and 0.82 for development of wind energy during early deployment (1980 to 1995). The higher end of the range is from the Enermodal study for the World Bank, which identified a PV of 0.96 and the Wind Learning Rates compiled by Kobos for development of wind plants.

The progress ratio calculated for the S\&L base case is 0.97 and 0.96 for $95-\mathrm{m}^{2}$ heliostats and 0.93 for $148-\mathrm{m}^{2}$ heliostats. The average progress ratio calculated for SunLab is 0.93 . These values fall within the range of 0.85 to 0.96, as shown in Figure 5-3.

Figure 5-3 - Heliostat Cost Improvements (Cumulative Deployment of 8.7 GWe)

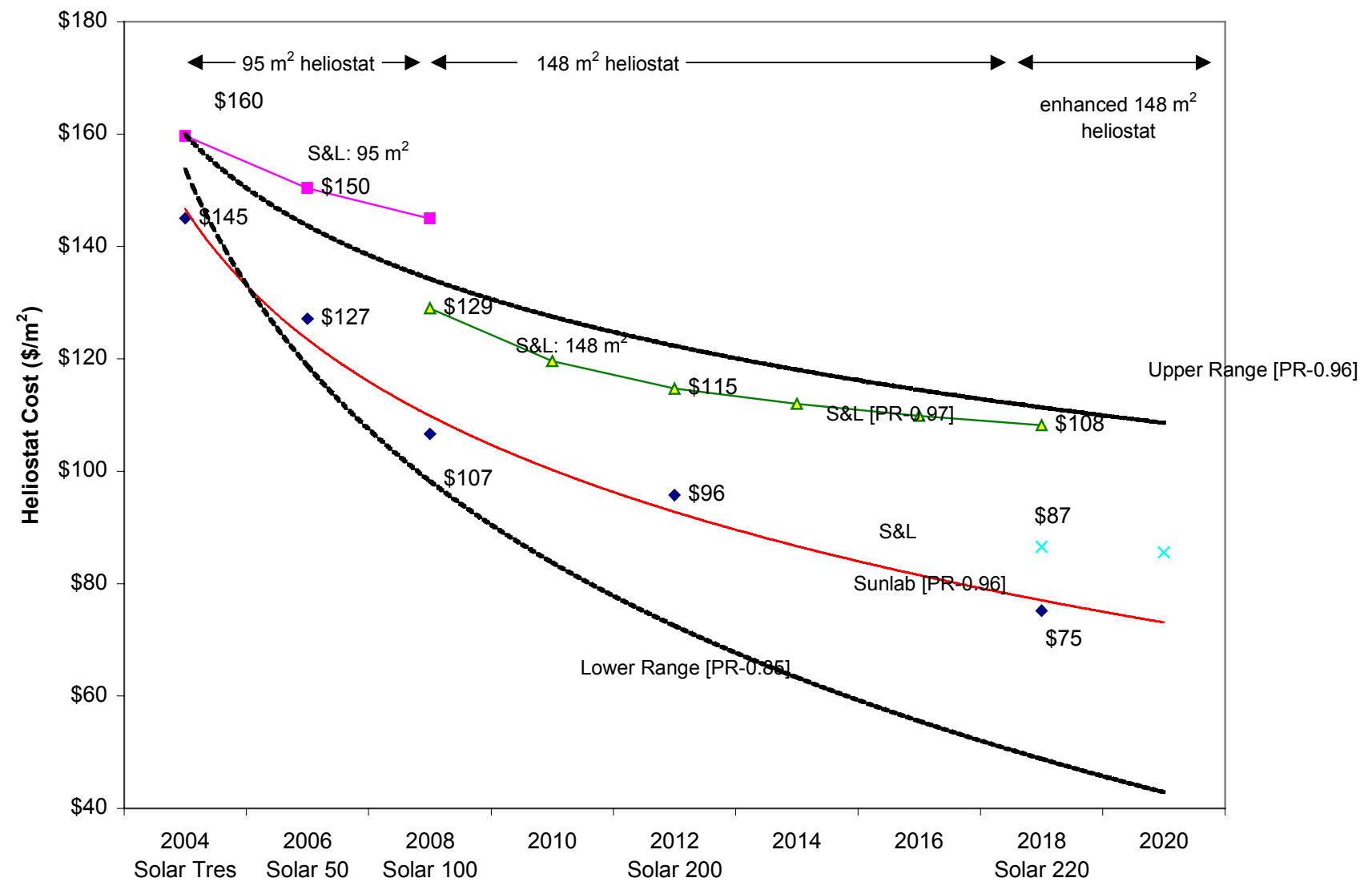

The comparison of heliostat costs for various deployments are shown Table 5-5. The S\&L cost estimate is based on a deployment of $2.6 \mathrm{GWe}$. 
Table 5-5 - Heliostat Cost vs. Deployment

\begin{tabular}{|l|c|c|c|c|c|}
\hline Case & $\begin{array}{c}\text { Solar Tres } \\
\text { USA }\end{array}$ & Solar 50 & Solar 100 & Solar 200 & Solar 220 \\
\hline Year & $\mathbf{2 0 0 4}$ & $\mathbf{2 0 0 6}$ & $\mathbf{2 0 1 0}$ & $\mathbf{2 0 1 5}$ & $\mathbf{2 0 2 0}$ \\
\hline Field Area, m ${ }^{2}$ & 232,809 & 721,838 & $1,330,792$ & $2,622,777$ & $2,678,000$ \\
\hline $\begin{array}{l}\text { S\&L Heliostat Cost at 1.4 GWe } \\
\text { deployment, \$/m }\end{array}$ & $\$ 160$ & $\$ 150$ & $\$ 136$ & $\$ 128$ & $\$ 98$ \\
\hline $\begin{array}{l}\text { S\&L Heliostat Cost at 2.6 GWe } \\
\text { deployment, \$/m }\end{array}$ & $\$ 160$ & $\$ 150$ & $\$ 134$ & $\$ 124$ & $\$ 94$ \\
\hline $\begin{array}{l}\text { S\&L Heliostat Cost at 4.7 GWe } \\
\text { deployment, \$/m }\end{array}$ & $\$ 160$ & $\$ 150$ & $\$ 132$ & $\$ 119$ & $\$ 91$ \\
\hline $\begin{array}{l}\text { S\&L Heliostat Cost at 8.7 GWe } \\
\text { deployment, \$/m }\end{array}$ & $\$ 160$ & $\$ 150$ & $\$ 129$ & $\$ 114$ & $\$ 87$ \\
\hline
\end{tabular}

The cost estimates shown in the above table do not include contingency. Contingency is included in the total plant installed cost as shown in Table E-2.

\subsubsection{Summary}

Cost improvements for the three categories - technology, economy of scale, and volume production - are shown in Table 5-6 based on our evaluation and assumptions. The method and analysis to arrive at the breakdown is described in Section E.4.7.

Table 5-6 - Breakdown of Tower Collector System Cost Improvements

\begin{tabular}{|c|c|c|c|c|c|c|}
\hline & $\begin{array}{c}\text { Solar Two to } \\
\text { Solar Tres }\end{array}$ & $\begin{array}{l}\text { Solar Tres } \\
\text { to Solar } 50\end{array}$ & $\begin{array}{l}\text { Solar } 50 \text { to } \\
\text { Solar } 100\end{array}$ & $\begin{array}{l}\text { Solar } 100 \text { to } \\
\text { Solar } 200\end{array}$ & $\begin{array}{l}\text { Solar } 200 \text { to } \\
\text { Solar } 220\end{array}$ & Average \\
\hline Heliostat Size, $\mathrm{m}^{2}$ & $48 / 95$ to 95 & 95 & 95 to 148 & 148 & $\begin{array}{c}148 \text { to } \\
\text { advanced } 148\end{array}$ & - \\
\hline Technology & $27 \%$ & $11 \%$ & $35 \%$ & $5 \%$ & $72 \%$ & $30 \%$ \\
\hline Economy of Scale & $36 \%$ & $0 \%$ & $57 \%$ & $0 \%$ & $0 \%$ & $19 \%$ \\
\hline $\begin{array}{l}\text { Production } \\
\text { Volume }\end{array}$ & $37 \%$ & $89 \%$ & $8 \%$ & $95 \%$ & $28 \%$ & $51 \%$ \\
\hline
\end{tabular}




\subsubsection{Conclusion}

DOE, SunLab, and the industry have spent considerable time and effort in research and development of heliostats. The technology has been successfully demonstrated for design, manufacturing, construction, and operation. S\&L reviewed the information available and it is our opinion as substantiated by our review that the heliostat costs and cost reductions are within an acceptable range assuming deployment of the technology.

\subsubsection{Electrical Power Block}

Sargent \& Lundy estimated the cost for the power block based on the SOAPP model, compared it to our internal database, and then adjusted the output for labor and productivity rates in the Southwest. The results of our review are shown in Table 5-7 and Figure 5-4. The power block costs include the steam turbine and generator, steam turbine and generator auxiliaries, feedwater and condensate systems.

Table 5-7 - Capital Cost of Electrical Power Block

\begin{tabular}{|l|c|c|c|c|c|}
\hline & Solar Tres & Solar 50 & Solar 100 & Solar 200 & Solar 220 \\
\hline Output, MWe & 13.5 & 50 & 100 & 200 & 220 \\
\hline SunLab, \$M & $\$ 10.0$ & $\$ 24.5$ & $\$ 40.0$ & $\$ 64.0$ & $\$ 83.6$ \\
\hline S\&L, \$M & $\$ 7.6$ & $\$ 18.6$ & $\$ 30.6$ & $\$ 46.2$ & $\$ 61.8$ \\
\hline
\end{tabular}

Cost improvements are categorized into technology improvements, plant scaling, and volume production.

\subsubsection{Technology Improvements}

The technology improvements include (1) reheat turbine at $540^{\circ} \mathrm{C}$ for Solar Tres, Solar 50 and Solar 100 , (2) dual reheat turbine $540^{\circ} \mathrm{C}$ for Solar 200, and (3) an advanced dual reheat turbine at $640^{\circ} \mathrm{C}$.

The near-term turbine efficiency is verified based on the ABB-Brown Boveri heat balances (HTGD 582395, Sheets 1-7) for SEGS IX, which show an efficiency of 37.7\% (in LUZ International Limited 1990). The Rankine cycle efficiency gains for increasing the inlet steam temperature from $540^{\circ} \mathrm{C}$ to $640^{\circ} \mathrm{C}$ were verified by S\&L using General Electric STGPER software program (Version 4.08.00, January 2002). The results from the STGPER software for Solar 200 and Solar 220 were extrapolated to account for dual reheat turbines. The turbine efficiencies are summarized in Table 5-8. 
Table 5-8 - Turbine Efficiencies

\begin{tabular}{|l|c|c|c|c|c|c|c|}
\hline & Solar One & Solar Two & Solar Tres & Solar 50 & Solar 100 & Solar 200 & Solar 220 \\
\hline SunLab & $32 \%$ & $34 \%$ & $40.5 \%$ & $42 \%$ & $42.5 \%$ & $43 \%$ & $46.3 \%$ \\
\hline S\&L & - & - & $38 \%$ & $40.6 \%$ & $41.4 \%$ & $42.8 \%$ & $45.6 \%$ \\
\hline
\end{tabular}

The type of heat transfer fluid (HTF) determines the operational temperature and thus the maximum power cycle efficiency that can be obtained. The HTF molten nitrate salt (60 wt $\% \mathrm{NaNO}_{3}$ and $40 \mathrm{wt} \% \mathrm{KNO}_{3}$ ) nitrate salt used in Solar Two demonstrated that steam temperatures of $540^{\circ} \mathrm{C}$ were achieved (Pacheco et al. 2002); for example, test no. 5 at full flow conditions measured actual $\mathrm{HTF}$ at $557^{\circ} \mathrm{C}$ and steam temperature at $542^{\circ} \mathrm{C}$.

There are no steam turbine technological risks in achieving the SunLab projected efficiencies up to Solar 200. There are currently numerous steam turbines operating with steam inlet conditions over 250 bar pressure and $590^{\circ} \mathrm{C}$ temperature, with gross efficiencies over 44\%. ${ }^{*}$ The advance from Solar 200 to Solar 220 is based on current research on increasing the inlet steam pressure and temperature conditions. This increase in efficiency for steam turbines is technically feasible and should be available by 2018 . The major issue will be the higher temperatures and impact on materials. The S\&L cost estimate did not consider the advanced turbine, but included it as a sensitivity analysis.

\subsubsection{Scaling Factor}

Scaling factor is the major factor for cost improvement. There are recognized scale-up cost reductions for the power block. Using the SOAPP software program and S\&L's internal database, the scale-up factor was estimated for the projected increased of increasing the power block from 13.5 MW to $200 \mathrm{MW}$, as depicted on Figure 5-4.

\footnotetext{
* Plant (commercial operation date): Nanaoota 1 (1995), Noshiro 2 (1995), Haramachi 1 (1997), Haramachi 2 (1998), Millmerran (2002), Matauura 2 (1997), Misumi 1 (1998), Tachibana Bay (2000), Bexback (2002), Lubeck (1995), Aledore 1 (2000), Nordjylland (1998). From Power (Swanekamp 2002).
} 
Figure 5-4 - Capital Cost of Electrical Power Block

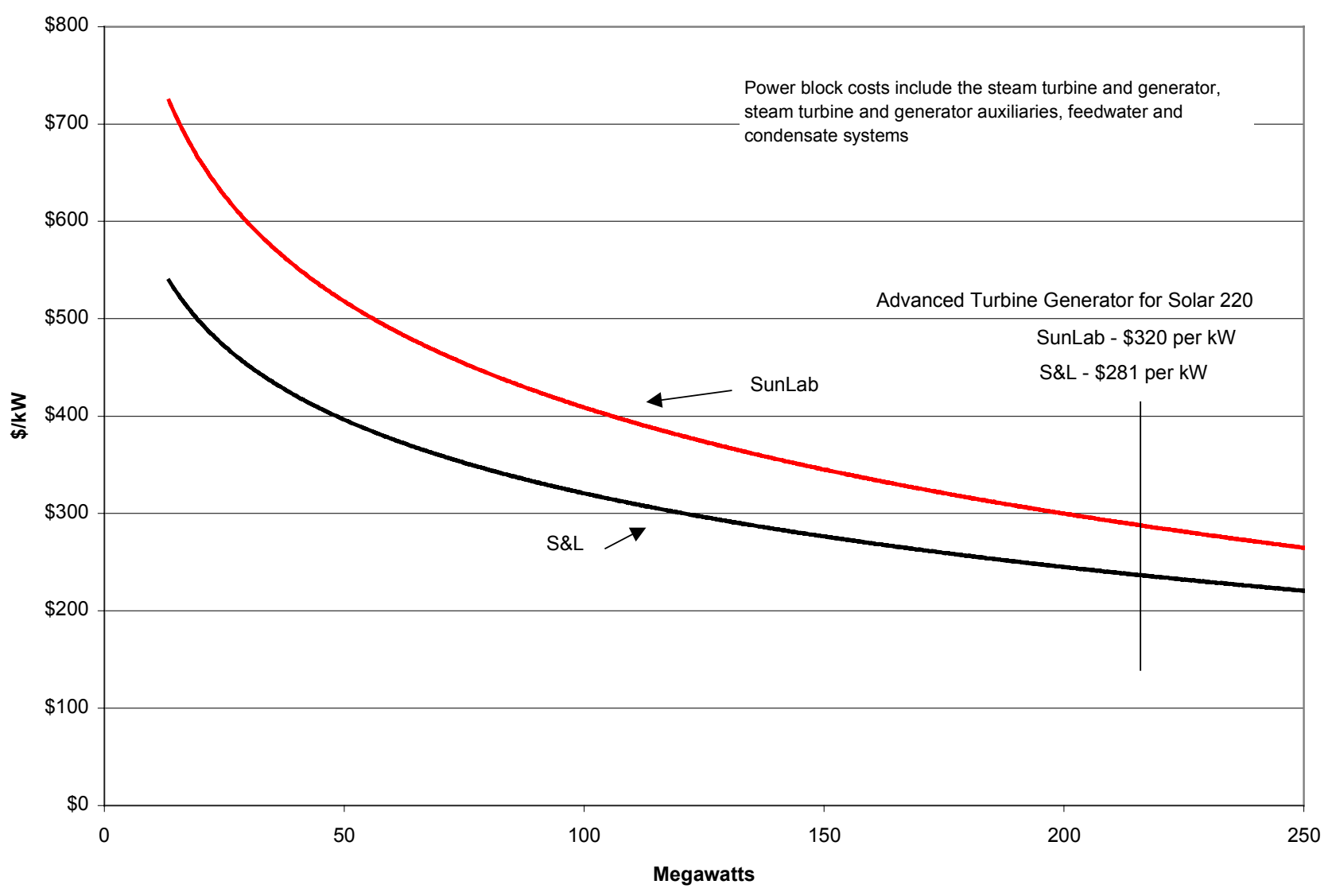

\subsubsection{Production Volume}

Production volume has no impact on cost improvements since a single steam turbine is supplied with each tower plant.

\subsubsection{Summary}

Cost improvements for the three categories — technology, economy of scale, and volume production — are shown in Table 5-9 based on our evaluation and assumptions. 
Table 5-9 - Breakdown of Power Block Cost Improvements

\begin{tabular}{|l|c|c|c|c|c|c|}
\hline & $\begin{array}{c}\text { Solar Two to } \\
\text { Solar Tres }\end{array}$ & $\begin{array}{c}\text { Solar Tres } \\
\text { to Solar 50 }\end{array}$ & $\begin{array}{c}\text { Solar } \mathbf{5 0} \text { to } \\
\text { Solar } \mathbf{1 0 0}\end{array}$ & $\begin{array}{c}\text { Solar } \mathbf{1 0 0} \text { to } \\
\text { Solar 200 }\end{array}$ & $\begin{array}{c}\text { Solar 200 to } \\
\text { Solar 220 }\end{array}$ & Average \\
\hline Net Electrical Generation, MWe & 10 to 13.5 & 13.5 to 50 & 50 to 100 & 100 to 200 & 200 to 220 & - \\
\hline Technology & $3 \%$ & $3 \%$ & $1 \%$ & $1 \%$ & $80 \%$ & $18 \%$ \\
\hline Economy of Scale & $97 \%$ & $97 \%$ & $99 \%$ & $99 \%$ & $20 \%$ & $82 \%$ \\
\hline Production Volume & $0 \%$ & $0 \%$ & $0 \%$ & $0 \%$ & $0 \%$ & $0 \%$ \\
\hline
\end{tabular}

\subsubsection{Receiver}

Sargent \& Lundy reviewed the cost estimate and cost improvements provided by Boeing and SunLab. The SunLab cost estimate for the capital cost for receiver is lower than the latest Boeing cost estimate. The SunLab cost estimate should be adjusted to be in accordance with the detailed Boeing cost estimate. The Boeing cost estimate is reasonable. Boeing is allocating funds for research (e.g., \$2M was spent for Solar Two). Boeing is looking for the DOE to support CSP technology and continued collaboration with the national laboratories.

Table 5-10 - Capital Cost of Receiver

\begin{tabular}{|l|c|c|c|c|c|c|c|}
\hline & $\begin{array}{c}\text { Solar } \\
\text { One }\end{array}$ & $\begin{array}{c}\text { Solar } \\
\text { Two }\end{array}$ & $\begin{array}{c}\text { Solar } \\
\text { Tres }\end{array}$ & $\begin{array}{c}\text { Solar } \\
\mathbf{5 0}\end{array}$ & $\begin{array}{c}\text { Solar } \\
\mathbf{1 0 0}\end{array}$ & $\begin{array}{c}\text { Solar } \\
\mathbf{2 0 0}\end{array}$ & $\begin{array}{c}\text { Solar } \\
\mathbf{2 2 0}\end{array}$ \\
\cline { 2 - 8 } & $\mathbf{1 9 8 8}$ & $\mathbf{1 9 9 9}$ & $\mathbf{2 0 0 4}$ & $\mathbf{2 0 0 6}$ & $\mathbf{2 0 0 8}$ & $\mathbf{2 0 1 2}$ & $\mathbf{2 0 1 8}$ \\
\hline Net Plant Size - Thermal, MWt & 46 & 42 & 120 & 380 & 700 & 1,400 & 1,400 \\
\hline $\begin{array}{l}\text { Receiver System Capital Cost - } \\
\text { SunLab, \$M }\end{array}$ & 39.2 & 9.1 & 14.7 & 23 & 29.1 & 39.4 & 43.3 \\
\hline $\begin{array}{l}\text { Receiver System Capital Cost - } \\
\text { S\&L (based on Boeing), \$M }\end{array}$ & - & - & 16 & 26 & 34 & 46 & - \\
\hline
\end{tabular}

\subsubsection{Technology Improvements}

The technology improvements include (1) increases in receiver absorbtivity, (2) decrease of absorbtivity from selected coatings, (3) high nickel tubes to allow higher solar flux and smaller tube surface, (4) improved heliostat aiming allows higher average flux, and (5) improved insulation and receiver header covers to further reduce heat loss. 
The increased receiver efficiency is reasonable based on the following:

- Reduction in heat loss, which is approximately proportional to reduction in receiver surface area per incident power.

- Increase of receiver absorbtivity through Industry Research \& Development (IR\&D).

- Decrease of receiver emissivity from selected coatings achieved through IR\&D.

- High nickel tubes to allow higher solar flux and smaller tube surface for Solar 200.

- Improved heliostat aiming.

- Gradual increase in solar flux as operating experience is gained from the preceding plant.

- Constant defocus, dump, startup, and cloud factor at $93.4 \%$. The increase from Solar Two is reasonable based on design changes and revised operating methods.

- Increase in absorbance from $93 \%$ to $94.5 \%$. This increase will require additional research into receiver tube material and coatings and/or more frequent painting.

- Change in receiver thermal losses from $93.1 \%$ to $94.7 \%$. This increase will require additional research to increase thermal flux. The research includes new materials, smaller tube surfaces, operating experience, better heliostat aiming, and improved insulation and receiver header covers.

Cost improvements are categorized into technology improvements, scaling factor, and volume production.

\subsubsection{Scaling Factor}

Scaling factor cost improvements is the major factor for cost improvements. Boeing, based on their experience in manufacturing receivers and similar components, used a scaling factor of 0.7 . The estimated capital cost for receivers was calculated based on a scaling factor of 0.7 as shown in Table E-42. The difference between the capital cost calculated for a scale-up of 0.7 and the projected capital cost is cost savings, which are attributed to technical and volume production (for example: the receiver cost for Solar 50 is estimated to be $\$ 26$ million. The cost projection based on a scaling factor of 0.7 would be $\$ 31.6$ million [Receiver Cost for Solar $100=\$ 16 \mathrm{x}$ $(710 / 269)^{0.7}=\$ 31.6$ million]). The difference is $\$ 5.6$, which is attributed to technical improvements and production volume as discussed in Section E.7.4.

\subsubsection{Production Volume}

Production volume (fabrication learning curve) from previous projects will provide cost improvements due to the repetitive assembly related with manufacturing receiver panels. For Solar Tres, 6,000 clips are welded onto 850 individual tubes that are then welded to 34 headers, which are part of 17 identical receiver panels. Boeing is 
expecting $85 \%$ to $90 \%$ learning curve based on experience. Boeing has also identified cost improvements due to improved manufacturing and quantity discount of material, which are reasonable assumptions. Material and components are about $35 \%$ of receiver costs. The cost improvements are shown below in Table 5-11:

Table 5-11 - Effect of Production Volume (Percent of Total Savings)

\begin{tabular}{|c|c|c|c|c|c|c|c|}
\hline & $\begin{array}{c}\text { Solar } \\
\text { One }\end{array}$ & $\begin{array}{c}\text { Solar } \\
\text { Two }\end{array}$ & $\begin{array}{c}\text { Solar } \\
\text { Tres }\end{array}$ & $\begin{array}{c}\text { Solar } \\
\mathbf{5 0}\end{array}$ & $\begin{array}{c}\text { Solar } \\
\mathbf{1 0 0}\end{array}$ & $\begin{array}{c}\text { Solar } \\
\mathbf{2 0 0}\end{array}$ & $\begin{array}{c}\text { Solar } \\
\mathbf{2 2 0}\end{array}$ \\
\cline { 2 - 8 } & $\mathbf{1 9 8 8}$ & $\mathbf{1 9 9 9}$ & $\mathbf{2 0 0 4}$ & $\mathbf{2 0 0 6}$ & $\mathbf{2 0 0 8}$ & $\mathbf{2 0 1 2}$ & $\mathbf{2 0 1 8}$ \\
\hline Net Plant Size - Thermal, MWt & 46 & 42 & 120 & 380 & 700 & 1,400 & 1,400 \\
\hline Total, \% & - & - & $7 \%$ & $14 \%$ & $12 \%$ & $5 \%$ & - \\
\hline
\end{tabular}

The cost improvements for technology, scaling, and production volume are shown below in Table 5-12:

Table 5-12 - Cost Improvements for Technology, Scaling, and Production Volume

\begin{tabular}{|l|c|c|c|c|c|c|}
\hline & $\begin{array}{c}\text { Solar Two } \\
\text { to Solar } \\
\text { Tres }\end{array}$ & $\begin{array}{c}\text { Solar Tres } \\
\text { to Solar 50 }\end{array}$ & $\begin{array}{c}\text { Solar 50 to } \\
\text { Solar 100 }\end{array}$ & $\begin{array}{c}\text { Solar } \mathbf{1 0 0} \text { to } \\
\text { Solar 200 }\end{array}$ & $\begin{array}{c}\text { Solar 200 to } \\
\text { Solar 220 }\end{array}$ & Average \\
\hline $\begin{array}{l}\text { Cost Reduction Due } \\
\text { to Technical } \\
\text { (Efficiency) }\end{array}$ & $32 \%$ & $35 \%$ & $66 \%$ & $65 \%$ & $31 \%$ & $46 \%$ \\
\hline $\begin{array}{l}\text { Cost Reduction Due } \\
\text { to Scaling }\end{array}$ & $50 \%$ & $43 \%$ & $25 \%$ & $24 \%$ & $61 \%$ & $41 \%$ \\
\hline $\begin{array}{l}\text { Cost Reduction Due } \\
\text { to Production } \\
\text { Volume }\end{array}$ & $18 \%$ & $22 \%$ & $9 \%$ & $11 \%$ & $8 \%$ & $13 \%$ \\
\hline
\end{tabular}

\subsubsection{Conclusion}

Sargent \& Lundy reviewed the information provided and the capital cost and cost improvements are reasonable based on the following:

- The Boeing cost estimate is based on actual costs from Solar Two, with adjustments to compensate for design improvements, manufacturing improvements, construction labor rates, and escalation.

- The Boeing cost estimate is based on detailed design drawings and material take-offs (bottomsup cost estimate), which provides a high degree of accuracy. 
- Estimates for Solar 50, 100, and 200 receivers were developed from Solar Two and Solar Tres with appropriate scale-up and available industry data.

- Boeing has considerable experience in the design and manufacturer of receivers for the tower technology.

- Boeing has a dedicated technical team presently working on technical improvements and preparing for authorization of Solar Tres.

- Boeing is actively pursuing markets for tower technology.

\subsubsection{Thermal Storage}

The SunLab capital cost estimates for thermal storage are as follows:

Table 5-13 - Capital Cost for Thermal Storage

\begin{tabular}{|l|c|c|c|c|c|c|c|}
\hline & $\begin{array}{c}\text { Solar } \\
\text { One }\end{array}$ & $\begin{array}{c}\text { Solar } \\
\text { Two }\end{array}$ & $\begin{array}{c}\text { Solar } \\
\text { Tres }\end{array}$ & $\begin{array}{c}\text { Solar } \\
\mathbf{5 0}\end{array}$ & $\begin{array}{c}\text { Solar } \\
\mathbf{1 0 0}\end{array}$ & $\begin{array}{c}\text { Solar } \\
\mathbf{2 0 0}\end{array}$ & $\begin{array}{c}\text { Solar } \\
\mathbf{2 2 0}\end{array}$ \\
\hline & $\mathbf{1 9 8 8}$ & $\mathbf{1 9 9 9}$ & $\mathbf{2 0 0 4}$ & $\mathbf{2 0 0 6}$ & $\mathbf{2 0 0 8}$ & $\mathbf{2 0 1 2}$ & $\mathbf{2 0 1 8}$ \\
\hline $\begin{array}{l}\text { Thermal Storage - Duration at } \\
\text { peak output, hr }\end{array}$ & NA & 3 & 16 & 16 & 13 & 13 & 12.7 \\
\hline Net Plant Size - Thermal, MWt & 46 & 42 & 120 & 380 & 700 & 1,400 & 1,400 \\
\hline $\begin{array}{l}\text { Thermal Storage System Direct } \\
\text { Cost, \$M }\end{array}$ & $\$ 20.1$ & $\$ 3.7$ & $\$ 5.9$ & $\$ 18.7$ & $\$ 28.9$ & $\$ 56.3$ & $\$ 57.2$ \\
\hline $\begin{array}{l}\text { Thermal Storage System Direct } \\
\text { Cost, \$/kWe }\end{array}$ & - & - & $\$ 431$ & $\$ 374$ & $\$ 289$ & $\$ 281$ & $\$ 261$ \\
\hline
\end{tabular}

The SunLab cost estimate for the capital cost for thermal storage is reasonable based on the following:

- The cost estimate is a definitive cost estimate based on detailed design drawings and material takeoff.

- The unit cost parameters are within typical industry values.

- The contingency is $10 \%$.

- The binary nitrate salt cost is based on vendor quotes, which includes shipping. 


\subsubsection{Technology Improvements}

Solar Two demonstrated molten salt as a viable, large-scale thermal energy storage medium. Energy storage efficiencies of $99 \%$ were achieved. The storage design point efficiency is projected to be $99.9 \%$ for all cases. The efficiency of Solar Two was demonstrated to be $99.9 \%$, and since there is no significant technology changes, it can be expected to remain constant. The design, construction, and performance of large, fielderected, externally insulated tanks for storing molten salt were demonstrated during Solar Two.

There are several ongoing studies for improvement of the design and construction:

- $\quad$ Alternative valve designs for hot salt service.

- Alternative salt downcomer designs.

- Materials testing on stainless steels 347 and 321, which have demonstrated their resistance to IGC in salt service.

The scaling factor from Solar Two to Solar 220 power block for the SunLab cost estimate is 0.78 .

Table 5-14 - Economy of Scale for Thermal Storage

\begin{tabular}{|l|c|c|c|c|c|c|}
\hline Steam Generator & $\begin{array}{c}\text { Solar } \\
\text { Two }\end{array}$ & $\begin{array}{c}\text { Solar } \\
\text { Tres }\end{array}$ & $\begin{array}{c}\text { Solar } \\
\mathbf{5 0}\end{array}$ & $\begin{array}{c}\text { Solar } \\
\mathbf{1 0 0}\end{array}$ & $\begin{array}{c}\text { Solar } \\
\mathbf{2 0 0}\end{array}$ & $\begin{array}{c}\text { Solar } \\
\mathbf{2 2 0}\end{array}$ \\
\hline Direct Cost & $\$ 3.70$ & $\$ 5.90$ & $\$ 18.70$ & $\$ 29.30$ & $\$ 56.30$ & $\$ 57.30$ \\
\hline $\begin{array}{l}\text { Cost Reduction Due to Scaling based } \\
\text { on Scaling Factor of 0.78 }\end{array}$ & - & - & $\$ 3.75$ & $\$ 5.81$ & $\$ 9.69$ & $\$ 9.40$ \\
\hline Cost Reduction Due to Scaling, \$M & - & - & $\$ 13.85$ & $\$ 29.39$ & $\$ 48.94$ & $\$ 56.30$ \\
\hline $\begin{array}{l}\text { Cost Due to Technology } \\
\text { Improvements, \$M }\end{array}$ & - & - & $\$ 4.85$ & $(\$ 0.09)$ & $\$ 7.36$ & $\$ 1.00$ \\
\hline $\begin{array}{l}\text { Cost Due to Technology } \\
\text { Improvement, \% }\end{array}$ & - & - & $26.0 \%$ & $-0.3 \%$ & $13.1 \%$ & $1.7 \%$ \\
\hline
\end{tabular}

These values are reasonable based on the following:

- The main components are the hot storage tank, cold storage tank, and piping.

- The SunLab estimate is conservative, since the typical industry standard for economy of scale is 0.7 .

Since the thermal storage system is comprised of single components, production volume is not a consideration for cost improvement. 
Cost improvements for thermal storage and parasitic were evaluated against technical efficiency improvements. Parasitic was included since thermal storage is the key contributor to minimizing parasitic losses.

The cost improvements for technology, scaling, and production volume are shown below in Table 5-15:

Table 5-15 - Cost Improvements for Technology, Scaling, and Production Volume

\begin{tabular}{|l|c|c|c|c|c|c|}
\hline & $\begin{array}{c}\text { Solar Two to } \\
\text { Solar Tres }\end{array}$ & $\begin{array}{c}\text { Solar Tres } \\
\text { to Solar 50 }\end{array}$ & $\begin{array}{c}\text { Solar } \mathbf{5 0} \text { to } \\
\text { Solar 100 }\end{array}$ & $\begin{array}{c}\text { Solar 100 to } \\
\text { Solar 200 }\end{array}$ & $\begin{array}{c}\text { Solar 200 to } \\
\text { Solar 220 }\end{array}$ & Average \\
\hline $\begin{array}{l}\text { Cost Reduction Due to } \\
\text { Technical (Efficiency) }\end{array}$ & $0 \%$ & $23 \%$ & $0 \%$ & $11 \%$ & $2 \%$ & $7 \%$ \\
\hline $\begin{array}{l}\text { Cost Reduction Due to } \\
\text { Scaling }\end{array}$ & $100 \%$ & $77 \%$ & $100 \%$ & $89 \%$ & $98 \%$ & $93 \%$ \\
\hline $\begin{array}{l}\text { Cost Reduction Due to } \\
\text { Production Volume }\end{array}$ & $0 \%$ & $0 \%$ & $0 \%$ & $0 \%$ & $0 \%$ & $0 \%$ \\
\hline
\end{tabular}

\subsubsection{Steam Generator}

The capital cost estimated by SunLab and the cost improvement for production volume is shown in Table 5-16.

Table 5-16 - Steam Generator Capital Cost and Economy of Scale

\begin{tabular}{|l|l|l|l|l|l|l|}
\hline Steam Generator & $\begin{array}{l}\text { Solar } \\
\text { Two }\end{array}$ & $\begin{array}{l}\text { Solar } \\
\text { Tres }\end{array}$ & Solar 50 & $\begin{array}{l}\text { Solar } \\
\mathbf{1 0 0}\end{array}$ & $\begin{array}{l}\text { Solar } \\
\mathbf{2 0 0}\end{array}$ & $\begin{array}{l}\text { Solar } \\
\mathbf{2 2 0}\end{array}$ \\
\hline Direct Cost & - & $\$ 1.6$ & $\$ 3.7$ & $\$ 5.8$ & $\$ 9.4$ & $\$ 9.3$ \\
\hline $\begin{array}{l}\text { Cost Reduction Attributed to Scaling } \\
\text { based on Scaling Factor of 0.74 }\end{array}$ & - & - & $\$ 3.75$ & $\$ 5.81$ & $\$ 9.69$ & $\$ 9.69$ \\
\hline
\end{tabular}

Note: The difference between cost reduction due to scaling and direct cost is attributed to technology improvements and calculates to an average of $3.7 \%$.

\subsubsection{Balance of Plant}

Sargent \& Lundy estimated the cost for the balance of plant based on the SOAPP model, ${ }^{*}$ compared it to our internal database, and then adjusted the output for labor and productivity rates in the Southwest. The results of our review are shown in Table 5-17 and Figure 5-5. The balance-of-plant costs include general balance-of-plant

\footnotetext{
* EPRI SOAPP is a fully integrated program for technology evaluation, conceptual design, costing, and financial analysis of combustion-turbine-based power plants for project and proposal development. SOAPP-CT integrates process design, costing, and financial analysis of combustion turbine simple- and combined-cycle power plants, including cogeneration. Sargent \& Lundy developed SOAPP under contract to EPRI.
} 
equipment, condenser and cooling tower system, water treatment system, fire protection, piping, compressed air systems, closed cooling water system, instrumentation, electrical equipment, and cranes and hoists.

Table 5-17 - Capital Cost of Balance of Plant

\begin{tabular}{|l|c|c|c|c|c|}
\hline & Solar Tres & Solar 50 & Solar $\mathbf{1 0 0}$ & Solar 200 & Solar 220 \\
\hline Power Block, MWe & 13.5 & 50 & 100 & 200 & 220 \\
\hline SunLab, \$M & $\$ 4.8$ & $\$ 6.5$ & $\$ 7.8$ & $\$ 9.6$ & $\$ 9.9$ \\
\hline S\&L, \$M & $\$ 10$ & $\$ 24.5$ & $\$ 36.7$ & $\$ 33.8$ & $\$ 35.5$ \\
\hline
\end{tabular}

Figure 5-5 - Balance of Plant

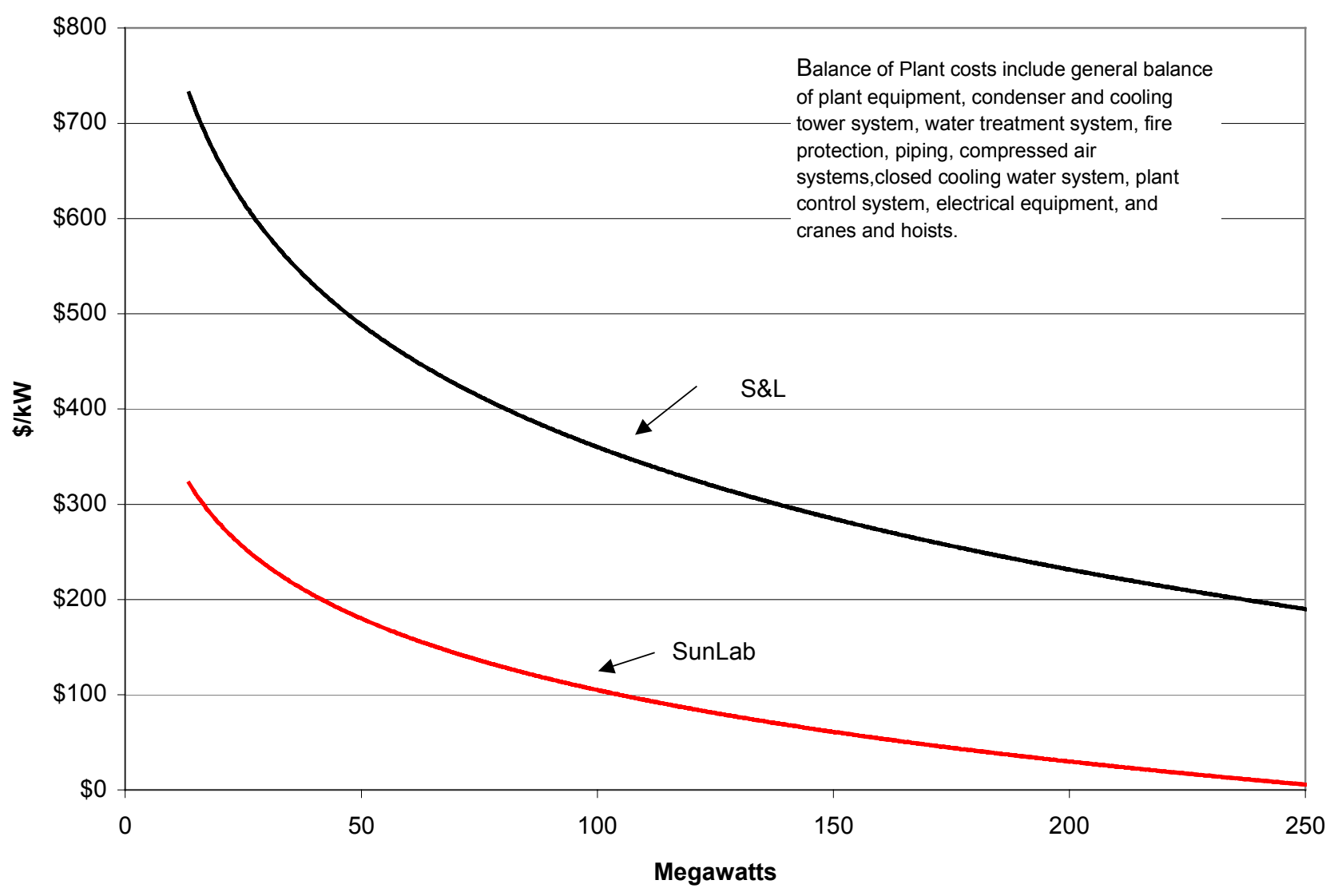




\subsubsection{Technology Improvements}

\subsubsection{Efficiencies}

There are no efficiency improvements projected for the balance of plant.

Table 5-18 - Cost Improvements for Technology, Scaling, and Production Volume

\begin{tabular}{|l|c|c|c|c|c|c|}
\hline & $\begin{array}{c}\text { Solar Two to } \\
\text { Solar Tres }\end{array}$ & $\begin{array}{c}\text { Solar Tres } \\
\text { to Solar 50 }\end{array}$ & $\begin{array}{c}\text { Solar } \mathbf{5 0} \text { to } \\
\text { Solar 100 }\end{array}$ & $\begin{array}{c}\text { Solar 100 to } \\
\text { Solar 200 }\end{array}$ & $\begin{array}{c}\text { Solar 200 to } \\
\text { Solar 220 }\end{array}$ & Average \\
\hline $\begin{array}{l}\text { Cost Reduction Due to } \\
\text { Technical (Efficiency) }\end{array}$ & $0 \%$ & $0 \%$ & $0 \%$ & $0 \%$ & $\mathbf{0 \%}$ & $0 \%$ \\
\hline $\begin{array}{l}\text { Cost Reduction Due to } \\
\text { Scaling }\end{array}$ & $100 \%$ & $100 \%$ & $100 \%$ & $100 \%$ & $100 \%$ & $100 \%$ \\
\hline $\begin{array}{l}\text { Cost Reduction Due to } \\
\text { Production Volume }\end{array}$ & $0 \%$ & $0 \%$ & $0 \%$ & $0 \%$ & $0 \%$ & $0 \%$ \\
\hline
\end{tabular}

\subsection{OPERATIONS AND MAINTENANCE}

The SunLab O\&M estimate is based on the data and experience from the operating solar trough power plants with adjustments accordingly for tower solar field and technology. The reduction in O\&M cost is primarily a result of the increase in annual plant capacity factor. The plant capacity increases directly as a result of the increases in thermal storage. Increasing the size (MWe) and utilization (capacity factor) of the power plant incurs very little increase in O\&M expenses (\$/year). This is because the quantity and complexity of the equipment remain constant and staffing remains fairly constant. Our review of conventional fossil power plants show this 'economy of scale' in staffing for increases in plant size. The details of the S\&L review are provided in Appendix G.

The comparison between the SunLab cost estimate and S\&L's estimate is shown in Table 5-19. The major differences are the following:

- $\quad$ Sargent \& Lundy scaled-up the cost of collector field maintenance contracts associated with increase in field size (e.g., weed control).

- Sargent \& Lundy scaled-up the cost of fuel and maintenance of vehicles to account for the increase in field size.

- Sargent \& Lundy assumed that the average burdened rate would not decrease between Solar 100 and Solar 220. 
- Raw water cost used by S\&L is based on actual costs reports at SEGS of $\$ 0.00122$ per gallon $\left(\$ 0.32\right.$ per $\left.\mathrm{m}^{3}\right)$. SunLab estimated the cost to be $\$ 0.021$ per $\left.\mathrm{m}^{3}\right)$, which is about 15 times less than the S\&L estimate.

- $\quad$ Sargent \& Lundy included a contingency of $10 \%$.

Table 5-19 - Comparison of O\&M Cost Estimates: SunLab vs. S\&L

\begin{tabular}{|l|c|c|c|c|c|c|c|}
\hline & Current & \multicolumn{2}{|c|}{ SunLab Estimates } & \multicolumn{3}{c|}{ S\&L Estimates } \\
\cline { 2 - 8 } & $\begin{array}{c}\text { Solar } \\
\text { One/Two } \\
\mathbf{1 9 8 7 / 1 9 9 9}\end{array}$ & $\begin{array}{c}\text { Solar } \\
\text { Tres } \\
\mathbf{2 0 0 4}\end{array}$ & $\begin{array}{c}\text { Solar 100 } \\
\mathbf{2 0 0 8}\end{array}$ & $\begin{array}{c}\text { Solar 220 } \\
\mathbf{2 0 2 0}\end{array}$ & $\begin{array}{c}\text { Solar } \\
\text { Tres } \\
\mathbf{2 0 0 4}\end{array}$ & $\begin{array}{c}\text { Solar 100 } \\
\mathbf{2 0 0 8}\end{array}$ & $\begin{array}{c}\text { Solar 220 } \\
\mathbf{2 0 2 0}\end{array}$ \\
\hline Plant Characteristics & & & & & & & \\
\hline Net Power, MWe & 10 & 15 & 100 & 220 & 15 & 100 & 220 \\
\hline Plant Capacity Factor, \% & $19.0 \%$ & $78.0 \%$ & $73.2 \%$ & $72.9 \%$ & $78.0 \%$ & $73.2 \%$ & $72.9 \%$ \\
\hline Annual Solar-Electric Efficiency & $7.6 \%$ & $13.7 \%$ & $16.6 \%$ & $18.1 \%$ & $13.0 \%$ & $16.5 \%$ & $17.3 \%$ \\
\hline Thermal Storage, hrs & 3 & 16 & 13 & 13.1 & 16 & 13 & 13.1 \\
\hline Solar Field, m & & & & & & & $2,771,730$ \\
\hline O\&M Characteristics & 81,400 & 231,000 & $1,311,000$ & $2,642,000$ & 233,772 & $1,354,452$ & $2 \%$ \\
\hline Number of Staff (FTE) & 35 & 31 & 47 & 67 & 33 & 46 & 67 \\
\hline Avg. Burdened Labor Rate, \$k/yr & $\$ 71$ & $\$ 62$ & $\$ 50$ & 42 & $\$ 62$ & $\$ 50$ & $\$ 50$ \\
\hline Staff Cost, \$k/yr & $\$ 2,485$ & $\$ 1,922$ & $\$ 2,350$ & $\$ 2,814$ & $\$ 2,046$ & $\$ 2,299$ & $\$ 3,364$ \\
\hline $\begin{array}{l}\text { Ann. Material \& Services Cost, } \\
\text { \$k/yr }\end{array}$ & $\$ 750$ & $\$ 600$ & $\$ 1,200$ & $\$ 1,900$ & $\$ 686$ & $\$ 2,065$ & $\$ 4,277$ \\
\hline \multicolumn{1}{|c|}{ Total O\&M Cost, \$k/yr } & $\$ 3,235$ & $\$ 2,522$ & $\$ 3,550$ & $\$ 4,714$ & $\$ 3,041$ & $\$ 5,127$ & $\$ 9,132$ \\
\hline Total O\&M Cost, \$/kWhe & $\$ 0.194$ & $\$ 0.027$ & $\$ 0.006$ & $\$ 0.003$ & $\$ 0.033$ & $\$ 0.008$ & $\$ 0.006$ \\
\hline
\end{tabular}

Note: the Solar One/Two values are a blended from both plants to provide a "best available" estimate for a typical salt plant of this size with utility staffing. Future plants assume lower staffing plans typical of independent, non-utility power plants as is also expected for trough plants.

\subsection{LEVELIZED ENERGY COST}

The projections by SunLab and S\&L for capital cost and operations \& maintenance were used to estimate levelized energy costs (LEC). After completing the report, SunLab revised its reference case (from August 2002 to October 2002) as shown below. The Sunlab LEC projections are based on the October 2002 reference case. 
Revised SunLab Reference Case

\begin{tabular}{|l|c|c|c|c|c|c|}
\hline & $\begin{array}{c}\text { Solar Two } \\
\mathbf{1 9 9 9}\end{array}$ & $\begin{array}{c}\text { Solar 15 } \\
\mathbf{2 0 0 4}\end{array}$ & $\begin{array}{c}\text { Solar 50 } \\
\mathbf{2 0 0 6}\end{array}$ & $\begin{array}{c}\text { Solar 100 } \\
\mathbf{2 0 0 8}\end{array}$ & $\begin{array}{c}\text { Solar 200 } \\
\mathbf{2 0 1 4}\end{array}$ & $\mathbf{2 0 1 8}$ \\
\hline Net Electrical (MWe) & 10 & 13.7 & 50 & 100 & 200 & 220 \\
\hline Plant Size Solar (MWt) & 42 & 120 & 380 & 700 & 1400 & 1400 \\
\hline Heliostat Size $\left(\mathrm{m}^{2}\right)$ & $39 / 95$ & 95 & 95 & 148 & 148 & 148 \\
\hline Heliostat Field $\left(\mathrm{m}^{2}\right)$ & 81,400 & 231,000 & 715,000 & $1,317,000$ & $2,614,000$ & $2,651,000$ \\
\hline $\begin{array}{l}\text { Annual Solar-to- } \\
\text { Electicity Efficiency }\end{array}$ & $7.6 \%$ & $13.7 \%$ & $15.7 \%$ & $16.5 \%$ & $16.8 \%$ & $17.8 \%$ \\
\hline Capital Cost (\$/kWe) & - & 7,180 & 4,160 & 3,160 & 2,700 & 2,340 \\
\hline O\&M Annual Cost (\$k) & - & 2,489 & 3,166 & 4,005 & 5,893 & 6,006 \\
\hline LEC (\$/kWh) & - & $\$ 114.8$ & $\$ 61.5$ & $\$ 47.6$ & $\$ 39.6$ & $\$ 35.0$ \\
\hline
\end{tabular}

The cost estimates were inputted to the financial model developed by S\&L (see Appendix B for a description of the financial model). The results are shown in Table 5-20.

\section{Table 5-20 - Capital Cost, O\&M Costs and Levelized Energy Cost Summary: SunLab and S\&L}

\begin{tabular}{|l|c|c|c|c|c|c|}
\hline \multirow{2}{*}{} & \multicolumn{2}{|c|}{ Near Term } & \multicolumn{2}{c|}{ Mid Term } & \multicolumn{2}{c|}{ Long Term } \\
\cline { 2 - 7 } & SunLab & S\&L & SunLab & S\&L & SunLab & S\&L \\
\cline { 2 - 7 } & Solar Tres USA & \multicolumn{2}{|c|}{ Solar 100 } & Solar 220 & Solar 200 \\
\cline { 2 - 7 } & 2004 & 2004 & $\mathbf{2 0 0 8}$ & $\mathbf{2 0 1 0}$ & $\mathbf{2 0 1 8}$ & $\mathbf{2 0 2 0}$ \\
\hline Capital Cost, \$/MWh & $\$ 77.4$ & $\$ 97.1$ & $\$ 36.3$ & $\$ 52.9$ & $\$ 27.0$ & $\$ 41.8$ \\
\hline Fixed O\&M Costs, \$/MWh & $\$ 37.4$ & $\$ 46.1$ & $\$ 11.3$ & $\$ 15.3$ & $\$ 8.0$ & $\$ 12.9$ \\
\hline Variable O\&M Costs, \$/MWh & $\$ 0.0$ & $\$ 0.0$ & $\$ 0.0$ & $\$ 0.0$ & $\$ 0.0$ & $\$ 0.0$ \\
\hline LEC, \$/MWh & $\$ 114.8$ & $\$ 143.1$ & $\$ 47.6$ & $\$ 68.2$ & $\$ 35.0$ & $\$ 54.7$ \\
\hline
\end{tabular}

SunLab - Deployment of 8.7 GWe / S\&L - Deployment of 2.6 GWe

Sargent \& Lundy's estimate of the direct capital cost and operation \& maintenance costs for the near-term deployment includes a contingency of about 10\%. Based on our review of the SunLab cost estimate, which we determined was based on industry cost data and engineering judgment, the cost estimate for the near-term deployment (Solar Tres) is reasonable. The projection from near-term deployment (2003) to long-term 
deployment (2020) includes cost reduction due to technology improvements, scaling, and volume production. S\&L included a composite contingency of $15 \%$ for cost reductions ( $15 \%$ for technology, $10 \%$ for scaling, and $20 \%$ for volume production). For comparison, the effect of deployment and annual net efficiencies are shown in Table 5-21.

Table 5-21 — Impact of Deployment and Net Solar-to-Electric Efficiency on LEC

\begin{tabular}{|c|c|c|c|c|}
\hline \multirow[b]{2}{*}{ Year 2020} & \multirow{2}{*}{$\begin{array}{l}\text { Total } \\
\text { Deployment } \\
\text { (GWe) }\end{array}$} & \multirow{2}{*}{$\begin{array}{c}\text { Net Solar-to- } \\
\text { Electric Efficiency } \\
(\%)\end{array}$} & \multicolumn{2}{|r|}{ LEC } \\
\hline & & & (\$/kWh) & $\begin{array}{l}\text { Percent change from } \\
\text { S\&L Base Case }\end{array}$ \\
\hline SunLab & 8.7 & 18.1 & 0.0350 & SunLab Base \\
\hline S\&L & 8.7 & $16.5^{\star}$ & 0.0524 & $-4.2 \%$ \\
\hline S\&L & 4.7 & $16.5^{*}$ & 0.0538 & $-1.6 \%$ \\
\hline S\&L & 2.6 & $16.5^{*}$ & 0.0547 & S\&L Base \\
\hline S\&L & 1.2 & $16.5^{*}$ & 0.0559 & $2.2 \%$ \\
\hline S\&L & $2.6^{* *}$ & 17.3 & 0.0476 & $-13.0 \%$ \\
\hline S\&L & $2.6^{* *}$ & 16.5 & 0.0547 & S\&L Base \\
\hline S\&L & $2.6^{* *}$ & 14.6 & 0.0590 & $7.9 \%$ \\
\hline
\end{tabular}

* Fixed net solar-to-electric efficiency

${ }^{* *}$ Fixed total deployment.

The range of LEC between the SunLab cost estimate and S\&L's estimate is about 56\% as shown in Figure 5-6. 
Figure 5-6 - Levelized Energy Cost Comparison: SunLab and S\&L

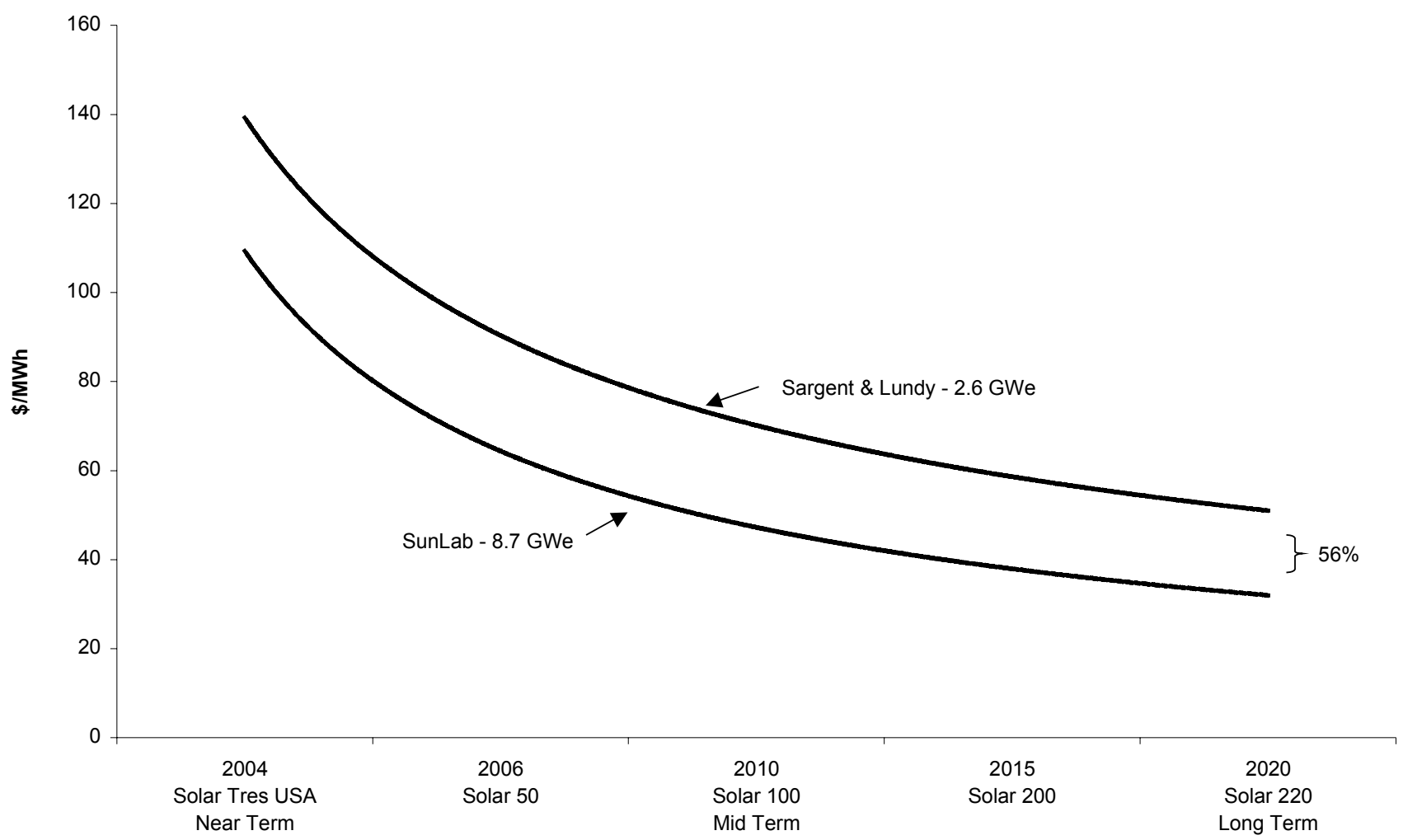

Cost improvements were evaluated by S\&L against three categories: technical improvements, scale-up, and production volume. The contribution of these three categories to the S\&L LEC projection is shown in Figure $5-7$. 
Figure 5-7 — Sargent \& Lundy LEC Projection Breakout by Category

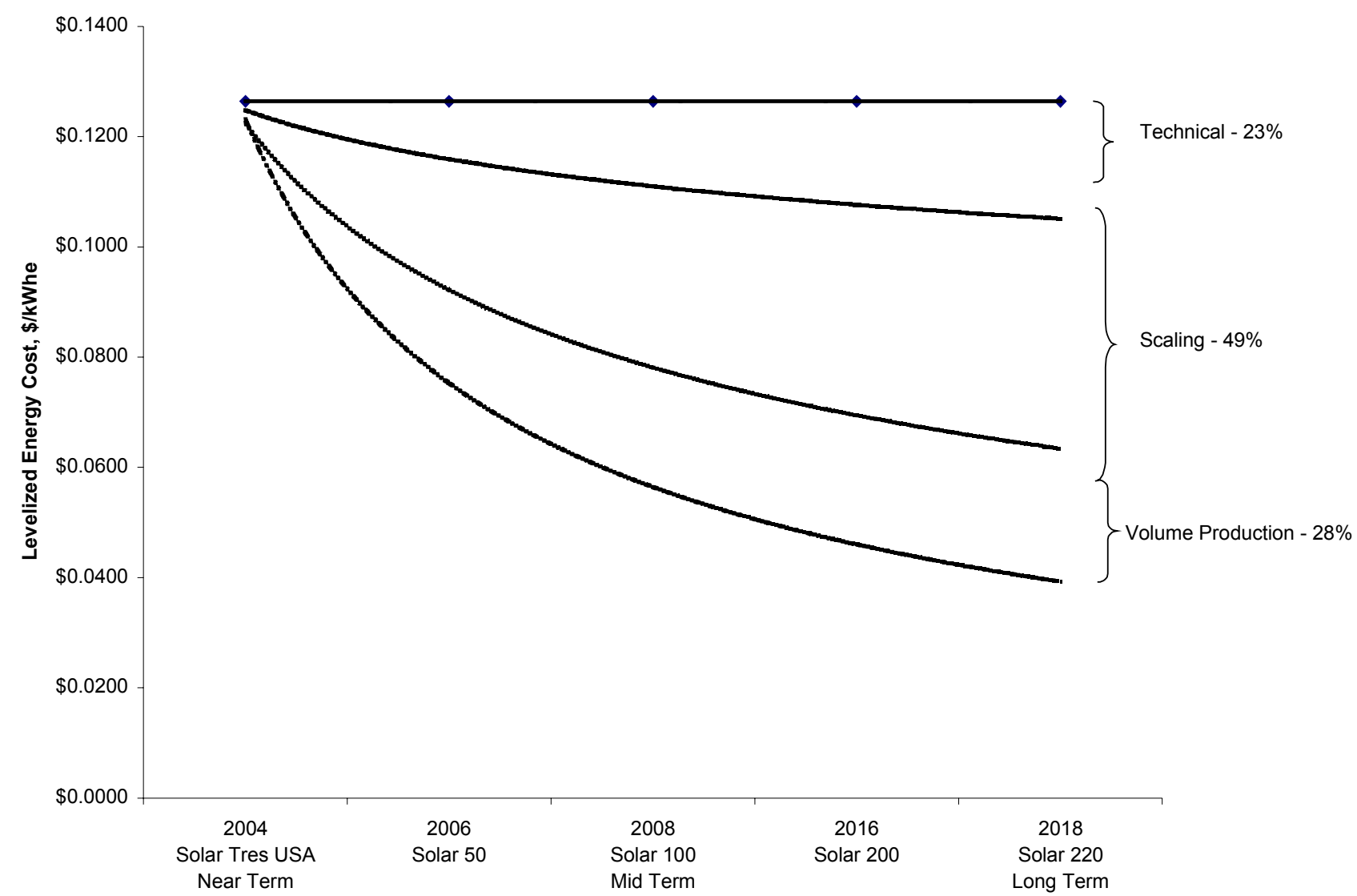

The major contributor to cost reduction from Solar Tres to Solar 50 is due to the increase in electrical generation (13.5 MWe to 50 MWe) as shown in Figure 5-8. The annual net energy production increased from 93.2 GWh/yr to $331 \mathrm{GWh} / \mathrm{yr}$. 
Figure 5-8 - Comparison of SunLab and S\&L LEC Estimates: 2004 to 2020

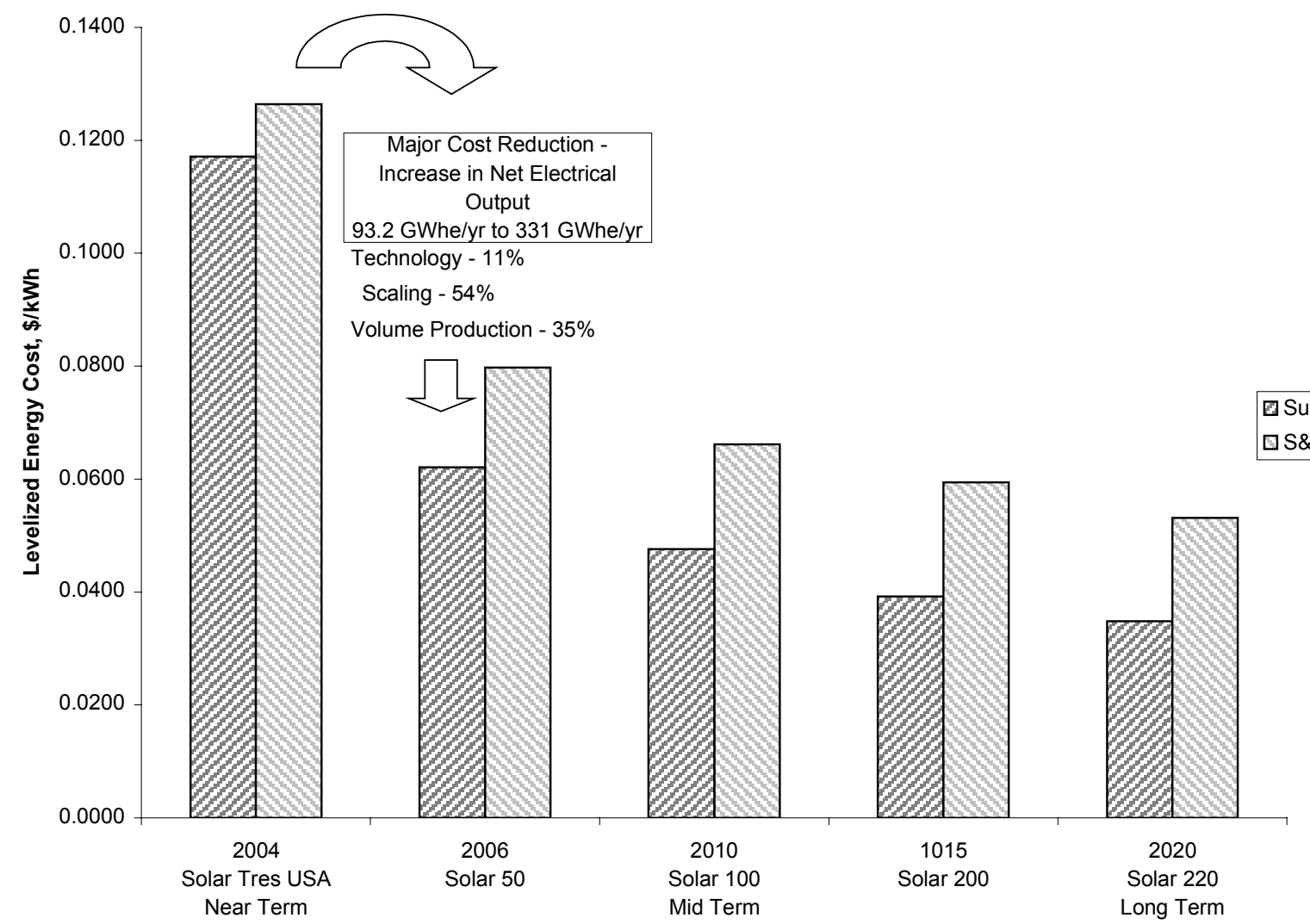

The impact of levelized cost of energy for tax credit is shown in Table 5-22. The difference between $10 \%$ tax credit and no tax credit is about $9 \%$ in 2020 .

Table 5-22 — Impact of Tax Credit on Levelized Cost of Energy

\begin{tabular}{|l|c|c|c|c|c|c|c|c|}
\hline & & & & Near Term & & Mid Term & & $\begin{array}{c}\text { Long } \\
\text { Term }\end{array}$ \\
\cline { 5 - 10 } & IRR & $\begin{array}{c}\text { Percent } \\
\text { Debt }\end{array}$ & DSCR & $\begin{array}{c}\text { Solar Tres } \\
\text { USA }\end{array}$ & Solar 50 & Solar 100 & Solar 200 & Solar 220 \\
\cline { 5 - 10 } & & & $\mathbf{2 0 0 4}$ & $\mathbf{2 0 0 6}$ & $\mathbf{2 0 1 0}$ & $\mathbf{1 0 1 5}$ & $\mathbf{2 0 2 0}$ \\
\hline $\begin{array}{l}\text { SunLab Tower LEC - 10 \% } \\
\text { Tax Credit }\end{array}$ & $12.12 \%$ & $59.90 \%$ & 1.35 & 0.1171 & 0.0621 & 0.0476 & 0.0392 & 0.0348 \\
\hline $\begin{array}{l}\text { SunLab Tower LEC - No } \\
\text { Tax Credit }\end{array}$ & $12.12 \%$ & $66.50 \%$ & 1.35 & 0.1257 & 0.0672 & 0.0516 & 0.0426 & 0.0378 \\
\hline
\end{tabular}




\subsection{POWER TOWER TECHNOLOGY STEP CHANGES AND COMPARISON}

Table 5-23 - Solar Two to Solar Tres Technology Comparison

\begin{tabular}{|c|c|c|c|c|}
\hline \multirow{3}{*}{ Plant Size - Net Electrical } & \multirow{2}{*}{$\begin{array}{l}\text { Solar } 2 \\
\text { SunLab }\end{array}$} & \multicolumn{2}{|c|}{ Solar Tres } & \multirow[b]{2}{*}{ Basis } \\
\hline & & SunLab & S\&L & \\
\hline & $10 \mathrm{MWe}$ & \multicolumn{2}{|c|}{ 13.7 MWe } & \\
\hline Plant Size - Thermal & $42 \mathrm{MWt}$ & \multicolumn{2}{|c|}{$120 \mathrm{MWt}$} & \\
\hline Field Area, $\mathrm{m}^{2}$ & 81,400 & 231,000 & 244,966 & \\
\hline Thermal Storage & $3 \mathrm{hrs}$ & \multicolumn{2}{|c|}{$16 \mathrm{hrs}$} & \\
\hline Annual Plant Capacity & $19 \%$ & \multicolumn{2}{|c|}{$78 \%$} & \\
\hline Heat Transfer Fluid & Solar Salt & \multicolumn{2}{|c|}{ Solar Salt } & \\
\hline Storage Media & Solar Salt & \multicolumn{2}{|c|}{ Solar Salt } & \\
\hline Operating Temperature & $565^{\circ} \mathrm{C}$ & \multicolumn{2}{|c|}{$565^{\circ} \mathrm{C}$} & \\
\hline Receiver, $\mathrm{m}^{2}$ & & 280 & 280 & \\
\hline Heliostat Size, $\mathrm{m}^{2}$ & $40 / 95$ & \multicolumn{2}{|c|}{95} & \\
\hline Number of Heliostats & 1,912 & 2,432 & 2,579 & $\begin{array}{l}\text { S\&L reference case efficiency lower resulting in a } \\
\text { larger field area }\end{array}$ \\
\hline $\begin{array}{l}\text { Annual Solar-to-Electric } \\
\text { Efficiency }\end{array}$ & $7.9 \%$ & $13.7 \%$ & $13.0 \%$ & - \\
\hline Collector Efficiency & $50.3 \%$ & $56 \%$ & $56 \%$ & - \\
\hline a. Mirror Reflectivity & $90.7 \%$ & $93.5 \%$ & $93.5 \%$ & $\begin{array}{l}\text { This is reasonable since the increase is due to new } \\
\text { mirrors. Solar Two mirrors were not maintained after } \\
\text { Solar One was shut down. }\end{array}$ \\
\hline b. Field Efficiency & $62 \%$ & $64.6 \%$ & $64.6 \%$ & $\begin{array}{l}\text { The increase is reasonable due to improvements in } \\
\text { aiming }\end{array}$ \\
\hline c. Field Availability & $98 \%$ & $98.5 \%$ & $98.5 \%$ & $\begin{array}{l}\text { This is reasonable since Solar Two was a } \\
\text { demonstration plant and did not operate for an } \\
\text { extended duration and used old heliostats. }\end{array}$ \\
\hline $\begin{array}{l}\text { d. Mirror Corrosion } \\
\text { Avoidance }\end{array}$ & $97 \%$ & $100 \%$ & $100 \%$ & $\begin{array}{l}\text { This is reasonable since Solar Two mirrors, which } \\
\text { had not been maintained since Solar One were } \\
\text { used for Solar Two. This was done to minimize } \\
\text { costs. The mirror corrosion avoidance for Solar One } \\
\text { was } 100 \% \text {. Experience at Kramer Junction shows } \\
\text { that the mirror surface does not experience } \\
\text { corrosion as long as they are properly maintained } \\
\text { (i.e., cleaned) }\end{array}$ \\
\hline e. Mirror Cleanliness & $95 \%$ & $95 \%$ & $95 \%$ & $\begin{array}{l}\text { The mirror cleanliness projection of } 95 \% \text { is the } \\
\text { same as demonstrated for Solar One and Solar } \\
\text { Two. }\end{array}$ \\
\hline
\end{tabular}




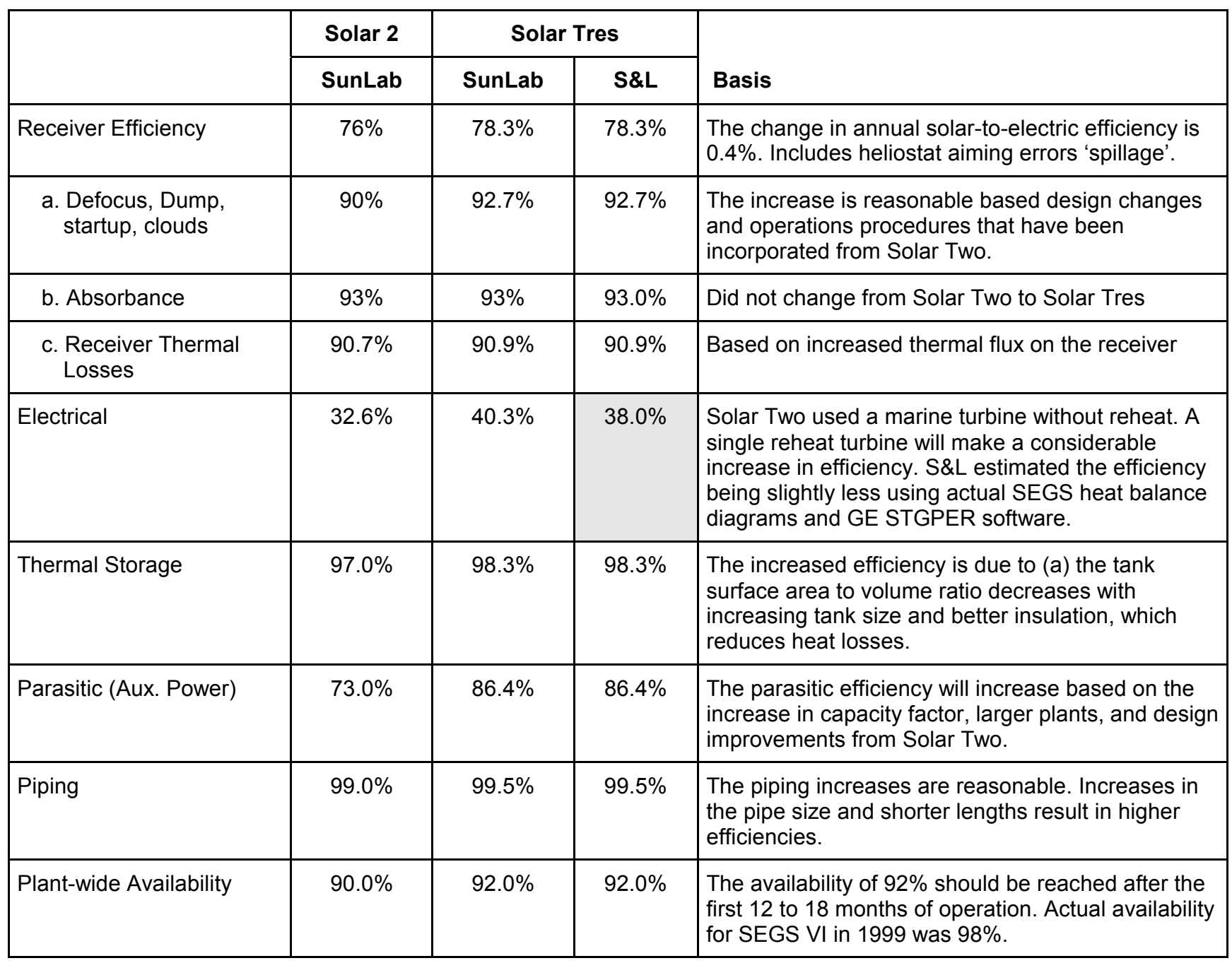

Table 5-24 - Solar Tres to Solar 50 Technology Comparison

\begin{tabular}{|l|c|c|c|}
\hline \multirow{2}{*}{} & Solar Tres & \multicolumn{2}{|c|}{ Solar $\mathbf{5 0}$} \\
\cline { 2 - 3 } & SunLab & SunLab & \multicolumn{2}{|c|}{ S\&L } & Basis \\
\hline Plant Size - Net Electrical & $13.7 \mathrm{MWe}$ & \multicolumn{2}{|c|}{$50 \mathrm{MWe}$} \\
\hline Plant Size - Thermal & $120 \mathrm{MWt}$ & \multicolumn{2}{|c|}{$380 \mathrm{MWt}$} \\
\hline Field Area, m & 231,000 & 709,000 & \multicolumn{2}{|c|}{742,703} \\
\hline Thermal Storage & $16 \mathrm{hrs}$ & \multicolumn{2}{|c|}{$16 \mathrm{hrs}$} \\
\hline Annual Plant Capacity & $78 \%$ & \multicolumn{2}{|c|}{$76 \%$} \\
\hline Heat Transfer Fluid & Solar Salt & \multicolumn{2}{|c|}{ Solar Salt } \\
\hline
\end{tabular}




\begin{tabular}{|c|c|c|c|c|}
\hline \multirow{3}{*}{\begin{tabular}{|l|} 
\\
Storage Media
\end{tabular}} & \multirow{2}{*}{$\begin{array}{l}\text { Solar Tres } \\
\text { SunLab }\end{array}$} & \multicolumn{2}{|c|}{ Solar 50} & \multirow[b]{2}{*}{ Basis } \\
\hline & & SunLab & S\&L & \\
\hline & Solar Salt & \multicolumn{2}{|c|}{ Solar Salt } & \\
\hline Operating Temperature & $565^{\circ} \mathrm{C}$ & \multicolumn{2}{|c|}{$574^{\circ} \mathrm{C}$} & \\
\hline Receiver, $\mathrm{m}^{2}$ & 280 & 580 & 710 & \\
\hline Heliostat Size, $\mathrm{m}^{2}$ & 95 & \multicolumn{2}{|c|}{95} & \\
\hline Number of Heliostats & 2,432 & 7,463 & 7,818 & $\begin{array}{l}\text { S\&L reference case efficiency lower resulting in a } \\
\text { larger field area }\end{array}$ \\
\hline $\begin{array}{l}\text { Annual Solar-to-Electric } \\
\text { Efficiency }\end{array}$ & $13.7 \%$ & $16.1 \%$ & $15.5 \%$ & - \\
\hline Collector Efficiency & $56 \%$ & $56.5 \%$ & $56.5 \%$ & - \\
\hline a. Mirror Reflectivity & $93.5 \%$ & $94 \%$ & $94 \%$ & The change is due to improved glass. \\
\hline b. Field Efficiency & $64.6 \%$ & $64.6 \%$ & $64.6 \%$ & $\begin{array}{l}\text { Field efficiency did not change from Solar Tres to } \\
\text { Solar } 50 .\end{array}$ \\
\hline c. Field Availability & $98.5 \%$ & $99 \%$ & $99 \%$ & $\begin{array}{l}\text { This is reasonable due to better maintenance } \\
\text { practices and the updated control system. }\end{array}$ \\
\hline $\begin{array}{l}\text { d. Mirror Corrosion } \\
\text { Avoidance }\end{array}$ & $100 \%$ & $100 \%$ & $100 \%$ & $\begin{array}{l}\text { Mirror corrosion avoidance did not change from } \\
\text { Solar Tres to Solar } 50 .\end{array}$ \\
\hline e. Mirror Cleanliness & $95 \%$ & $95 \%$ & $95 \%$ & $\begin{array}{l}\text { Mirror cleanliness did not change from Solar Tres to } \\
\text { Solar } 50 .\end{array}$ \\
\hline Receiver Efficiency & $78.3 \%$ & $80.9 \%$ & $80.9 \%$ & $\begin{array}{l}\text { The change in annual solar-to-electric efficiency is } \\
0.5 \% \text {. Includes heliostat spillage. }\end{array}$ \\
\hline $\begin{array}{l}\text { a. Defocus, Dump, } \\
\text { startup, clouds }\end{array}$ & $92.7 \%$ & $93.4 \%$ & $93.4 \%$ & $\begin{array}{l}\text { The increase of } 0.7 \text { is reasonable based better } \\
\text { operating methods learned during operation of Solar } \\
\text { Tres. }\end{array}$ \\
\hline b. Absorbance & $93 \%$ & $93 \%$ & $93 \%$ & Did not change from Solar Tres to Solar 50 \\
\hline $\begin{array}{l}\text { c. Receiver Thermal } \\
\text { Losses }\end{array}$ & $90.9 \%$ & $93.1 \%$ & $93.1 \%$ & Based on increased thermal flux on the receiver \\
\hline Electrical & $40.3 \%$ & $41.8 \%$ & $40.4 \%$ & $\begin{array}{l}\text { S\&L estimated the efficiency being slightly less } \\
\text { using actual SEGS heat balance diagrams and GE } \\
\text { STGPER software. }\end{array}$ \\
\hline Thermal Storage & $98.3 \%$ & $99.5 \%$ & $99.5 \%$ & $\begin{array}{l}\text { The increased efficiency is due to (a) the tank } \\
\text { surface area to volume ratio decreases with } \\
\text { increasing tank size and better insulation, which } \\
\text { reduces heat losses. }\end{array}$ \\
\hline Parasitic (Aux. Power) & $86.4 \%$ & $90.0 \%$ & $90.0 \%$ & $\begin{array}{l}\text { The parasitic efficiency will increase based on the } \\
\text { increase in capacity factor, larger plants, and design } \\
\text { improvements from Solar Two. }\end{array}$ \\
\hline
\end{tabular}




\begin{tabular}{|l|c|c|c|l|}
\hline & Solar Tres & \multicolumn{2}{|c|}{ Solar $\mathbf{5 0}$} & \multirow{2}{*}{ Basis } \\
\cline { 2 - 4 } & SunLab & SunLab & S\&L & Ban \\
\hline Piping & $99.5 \%$ & $99.9 \%$ & $99.9 \%$ & $\begin{array}{l}\text { The piping increases are reasonable. Increases in } \\
\text { the pipe size and shorter lengths result in higher } \\
\text { efficiencies. }\end{array}$ \\
\hline Plant-wide Availability & $92.0 \%$ & $94.0 \%$ & $94.0 \%$ & $\begin{array}{l}\text { The availability of } 94 \% \text { should be reached after the } \\
\text { first 12 to 18 months of operation. Actual availability } \\
\text { for SEGS VI in 1999 was } 98 \% .\end{array}$ \\
\hline
\end{tabular}

Table 5-25 - Solar 50 to Solar 100 Technology Comparison

\begin{tabular}{|c|c|c|c|c|}
\hline & \multirow{2}{*}{$\frac{\text { Solar } 50}{\text { SunLab }}$} & \multicolumn{2}{|c|}{ Solar 100} & \multirow[b]{2}{*}{ Basis } \\
\hline & & SunLab & S\&L & \\
\hline Plant Size - Net Electrical & $50 \mathrm{MWe}$ & \multicolumn{2}{|c|}{$100 \mathrm{MWe}$} & \\
\hline Plant Size - Thermal & $380 \mathrm{MWt}$ & \multicolumn{2}{|c|}{$700 \mathrm{MWe}$} & \\
\hline Field Area, $\mathrm{m}^{2}$ & 709,000 & $1,311,000$ & $1,366,100$ & \\
\hline Thermal Storage & $16 \mathrm{hrs}$ & \multicolumn{2}{|c|}{$13 \mathrm{hrs}$} & \\
\hline Annual Plant Capacity & $76 \%$ & \multicolumn{2}{|c|}{$73 \%$} & \\
\hline Heat Transfer Fluid & Solar Salt & \multicolumn{2}{|c|}{ Solar Salt } & \\
\hline Storage Media & Solar Salt & \multicolumn{2}{|c|}{ Solar Salt } & \\
\hline Operating Temperature & $574^{\circ} \mathrm{C}$ & \multicolumn{2}{|c|}{$574^{\circ} \mathrm{C}$} & \\
\hline Receiver, $\mathrm{m}^{2}$ & 580 & 930 & 1,110 & \\
\hline Heliostat Size, $\mathrm{m}^{2}$ & 95 & \multicolumn{2}{|c|}{148} & \\
\hline Number of Heliostats & 7,463 & 8,858 & 9,230 & $\begin{array}{l}\text { S\&L reference case efficiency lower resulting in a } \\
\text { larger field area }\end{array}$ \\
\hline $\begin{array}{l}\text { Annual Solar-to-Electric } \\
\text { Efficiency }\end{array}$ & $16.1 \%$ & $16.6 \%$ & $16.1 \%$ & - \\
\hline Collector Efficiency & $56.5 \%$ & $56.3 \%$ & $56.0 \%$ & $\begin{array}{l}\text { The change in annual solar-to-electric efficiency is } \\
-0.1 \% \text {. }\end{array}$ \\
\hline a. Mirror Reflectivity & $94 \%$ & $94 \%$ & $94 \%$ & $\begin{array}{l}\text { Mirror reflectivity did not change from Solar } 50 \text { to } \\
\text { Solar } 100 .\end{array}$ \\
\hline b. Field Efficiency & $64.6 \%$ & $63.7 \%$ & $63.7 \%$ & $\begin{array}{l}\text { This is reasonable since the larger field results in a } \\
\text { longer average distance from the receiver, which } \\
\text { reduces the accuracy. }\end{array}$ \\
\hline c. Field Availability & $99 \%$ & $99.5 \%$ & $99.5 \%$ & $\begin{array}{l}\text { This is reasonable due to better maintenance } \\
\text { practices and the updated control system. }\end{array}$ \\
\hline
\end{tabular}




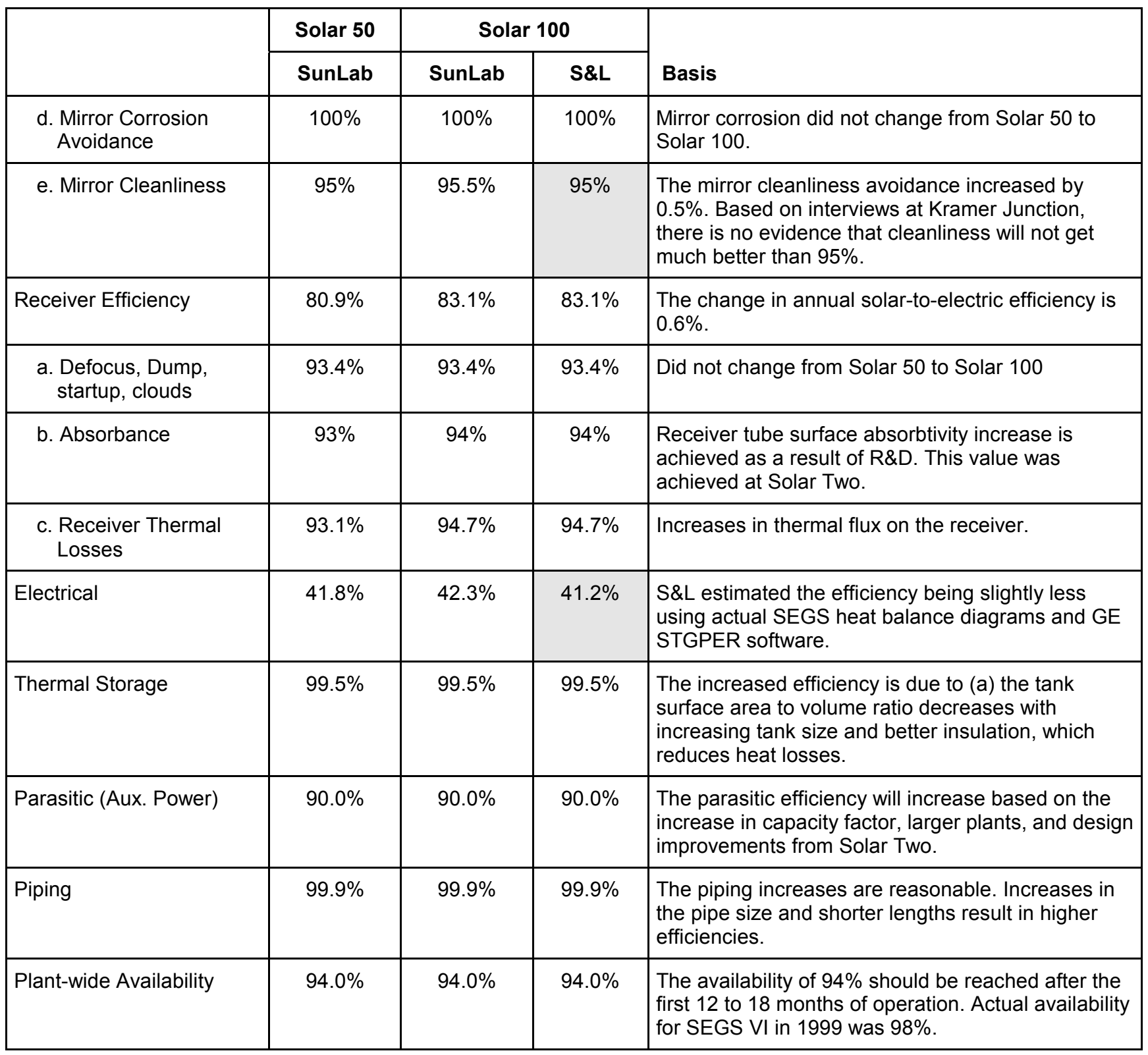


Table 5-26 - Solar 100 to Solar 200 Technology Comparison

\begin{tabular}{|c|c|c|c|c|}
\hline & \multirow{2}{*}{$\begin{array}{l}\text { Solar } 100 \\
\text { SunLab }\end{array}$} & \multicolumn{2}{|c|}{ Solar 200} & \multirow[b]{2}{*}{ Basis } \\
\hline & & SunLab & S\&L & \\
\hline Plant Size - Net Electrical & $100 \mathrm{MWe}$ & \multicolumn{2}{|c|}{$200 \mathrm{MWe}$} & \\
\hline Plant Size - Thermal & $700 \mathrm{MWt}$ & \multicolumn{2}{|c|}{$1,400 \mathrm{MWt}$} & \\
\hline Field Area, $\mathrm{m}^{2}$ & $1,311,000$ & $2,606,000$ & $2,667,099$ & \\
\hline Thermal Storage & $13 \mathrm{hrs}$ & \multicolumn{2}{|c|}{$13 \mathrm{hrs}$} & \\
\hline Annual Plant Capacity & $73 \%$ & \multicolumn{2}{|c|}{$74 \%$} & \\
\hline Heat Transfer Fluid & Solar Salt & \multicolumn{2}{|c|}{ Solar Salt } & \\
\hline Storage Media & Solar Salt & \multicolumn{2}{|c|}{ Solar Salt } & \\
\hline Operating Temperature & $574^{\circ} \mathrm{C}$ & \multicolumn{2}{|c|}{$574^{\circ} \mathrm{C}$} & \\
\hline Receiver, $\mathrm{m}^{2}$ & 930 & 1,870 & 1,930 & \\
\hline Heliostat Size, $\mathrm{m}^{2}$ & 148 & \multicolumn{2}{|c|}{148} & \\
\hline Number of Heliostats & 8,858 & 17,608 & 18,021 & $\begin{array}{l}\text { S\&L reference case efficiency lower resulting in a } \\
\text { larger field area }\end{array}$ \\
\hline $\begin{array}{l}\text { Annual solar-to-electric } \\
\text { efficiency }\end{array}$ & $16.6 \%$ & $16.9 \%$ & $16.5 \%$ & - \\
\hline Collector Efficiency & $56.3 \%$ & $56.1 \%$ & $55.2 \%$ & - \\
\hline a. Mirror Reflectivity & $94 \%$ & $94.5 \%$ & $94.0 \%$ & $\begin{array}{l}\text { SunLab improvement is due to improved glass. S\&L } \\
\text { base case did not consider improved glass. }\end{array}$ \\
\hline b. Field Efficiency & $63.7 \%$ & $62.8 \%$ & $62.8 \%$ & $\begin{array}{l}\text { This is reasonable since the larger field results in a } \\
\text { longer average distance from the receiver, which } \\
\text { reduces the accuracy. }\end{array}$ \\
\hline c. Field Availability & $99.5 \%$ & $99.5 \%$ & $99.5 \%$ & $\begin{array}{l}\text { Field availability did not change from Solar } 100 \text { to } \\
\text { Solar } 200 .\end{array}$ \\
\hline $\begin{array}{l}\text { d. Mirror Corrosion } \\
\text { Avoidance }\end{array}$ & $100 \%$ & $100 \%$ & $100 \%$ & $\begin{array}{l}\text { Mirror corrosion avoidance did not change from } \\
\text { Solar } 100 \text { to Solar } 200 .\end{array}$ \\
\hline e. Mirror Cleanliness & $95.5 \%$ & $96 \%$ & $95 \%$ & $\begin{array}{l}\text { The mirror cleanliness increased by } 0.5 \% \text {. Based on } \\
\text { interviews at Kramer Junction, there is no evidence } \\
\text { that cleanliness will not get much better than } 95 \% \text {. }\end{array}$ \\
\hline Receiver Efficiency & $83.1 \%$ & $83.5 \%$ & $83.5 \%$ & $\begin{array}{l}\text { The change in annual solar-to-electric efficiency is } \\
0.1 \% \text {. }\end{array}$ \\
\hline $\begin{array}{l}\text { a. Defocus, Dump, } \\
\text { startup, clouds }\end{array}$ & $93.4 \%$ & $93.4 \%$ & $93.4 \%$ & Did not change from Solar 100 to Solar 200 \\
\hline b. Absorbance & $94 \%$ & $94.5 \%$ & $94.5 \%$ & $\begin{array}{l}\text { Receiver tube surface absorbtivity increase is } \\
\text { achieved as a result of R\&D on coatings and/or } \\
\text { more frequent repainting. }\end{array}$ \\
\hline
\end{tabular}




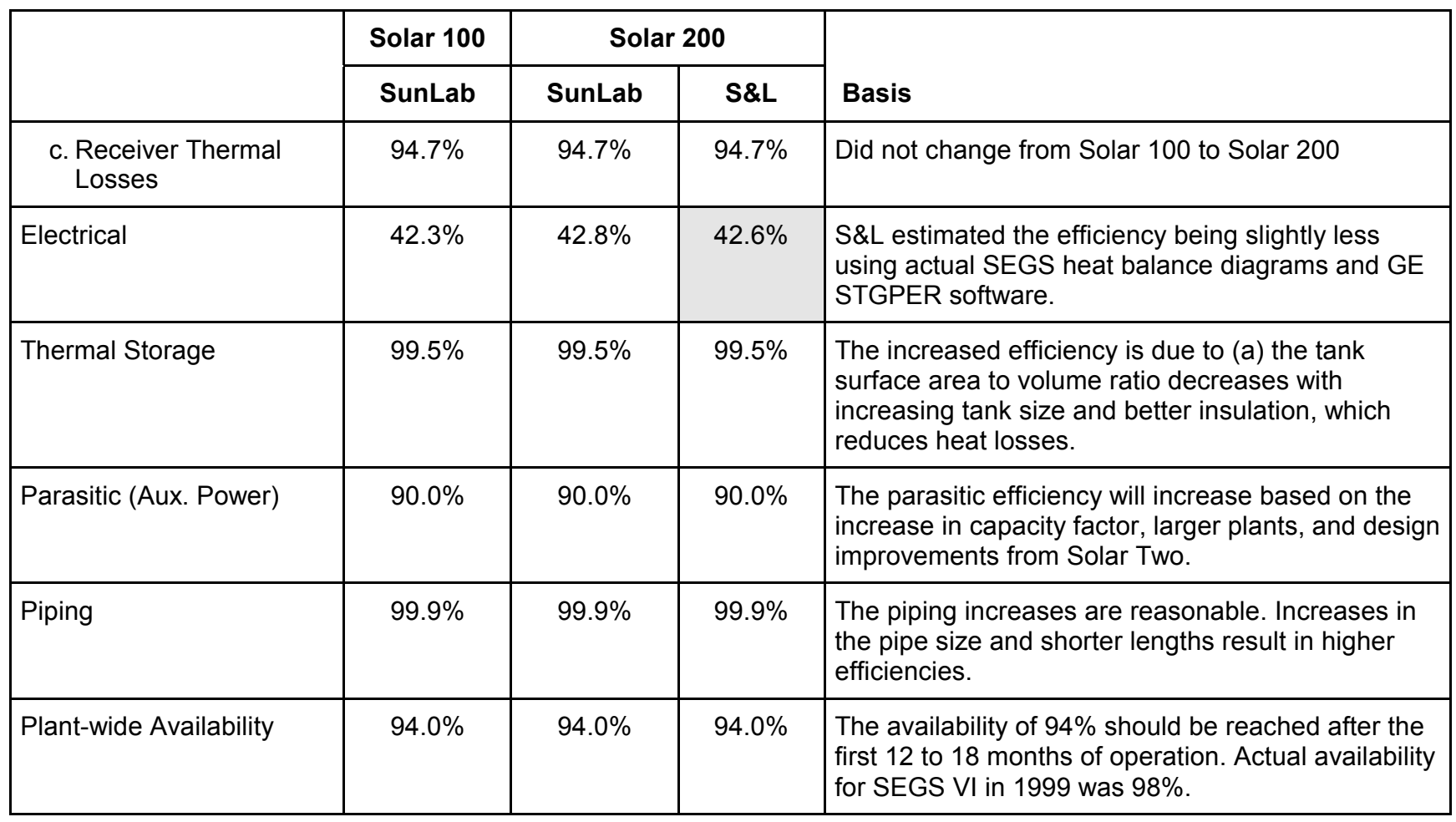

Table 5-27 - Solar 200 to Solar 220 Technology Comparison

\begin{tabular}{|c|c|c|c|c|}
\hline & \multirow{2}{*}{$\begin{array}{c}\text { Solar } 200 \\
\text { SunLab }\end{array}$} & \multicolumn{2}{|c|}{ Solar 220} & \multirow[b]{2}{*}{ Basis } \\
\hline & & SunLab & S\&L & \\
\hline Plant Size - Net Electrical & $200 \mathrm{MWe}$ & \multicolumn{2}{|c|}{$220 \mathrm{MWe}$} & \\
\hline Plant Size - Thermal & $1,400 \mathrm{MWt}$ & \multicolumn{2}{|c|}{$1,400 \mathrm{MWt}$} & \\
\hline Field Area, $\mathrm{m}^{2}$ & $2,606,000$ & $2,642,000$ & $2,789,322$ & \\
\hline Thermal Storage & $13 \mathrm{hrs}$ & \multicolumn{2}{|c|}{$16 \mathrm{hrs}$} & \\
\hline Annual Plant Capacity & $74 \%$ & \multicolumn{2}{|c|}{$73 \%$} & \\
\hline Heat Transfer Fluid & Solar Salt & \multicolumn{2}{|c|}{ Solar Salt } & \\
\hline Storage Media & Solar Salt & \multicolumn{2}{|c|}{$\begin{array}{c}\text { Solar Salt with } \mathrm{O}_{2} \\
\text { blanket }\end{array}$} & \\
\hline Operating Temperature & $574^{\circ} \mathrm{C}$ & \multicolumn{2}{|c|}{$650^{\circ} \mathrm{C}$} & \\
\hline Receiver & 1,870 & 1,650 & 1,990 & \\
\hline Heliostat Size $\left(\mathrm{m}^{2}\right)$ & 148 & \multicolumn{2}{|c|}{148} & \\
\hline Number of Heliostats & 17,608 & 17,851 & 18,847 & $\begin{array}{l}\text { S\&L reference case efficiency lower resulting in a } \\
\text { larger field area }\end{array}$ \\
\hline
\end{tabular}




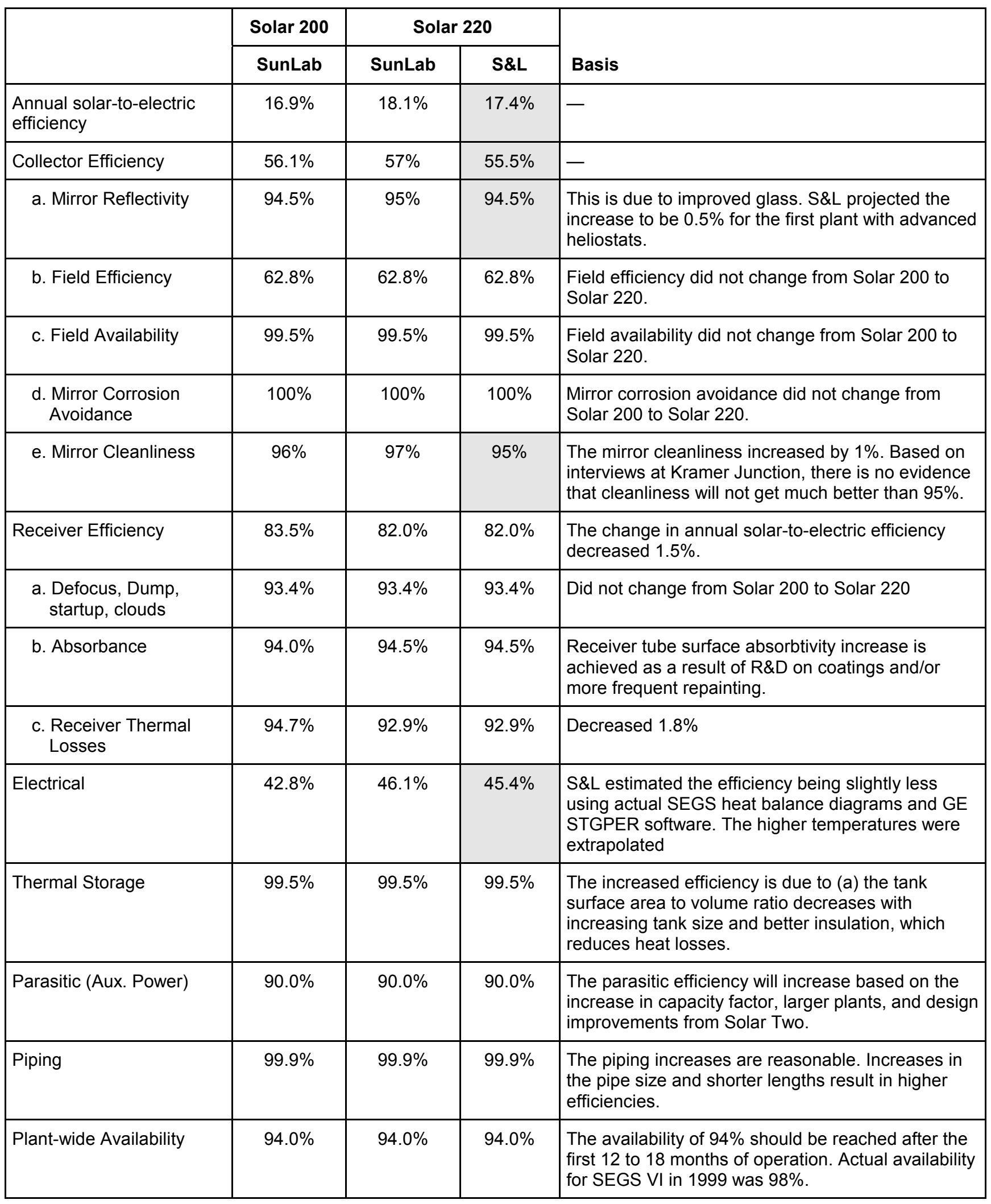




\subsection{COST REDUCTION STEP CHANGES AND BREAKDOWN COMPARISON}

\section{Table 5-28 - Solar Two to Solar Tres Cost Reduction Comparison}

\begin{tabular}{|c|c|c|c|c|}
\hline \multirow{2}{*}{$\begin{array}{l}\text { Heliostat Cost } \\
\text { Improvements }\end{array}$} & \multirow{2}{*}{$\begin{array}{l}\text { Solar } 2 \\
\text { SunLab }\end{array}$} & \multicolumn{2}{|c|}{ Solar Tres } & \multirow[b]{2}{*}{ Basis } \\
\hline & & SunLab & S\&L & \\
\hline $\begin{array}{l}\text { Plant Size - Electrical, } \\
\text { MWe }\end{array}$ & 10 & \multicolumn{2}{|c|}{13.7} & \\
\hline Plant Size - Thermal, MWt & 42 & \multicolumn{2}{|c|}{120} & \\
\hline Heliostat Size, $\mathrm{m}^{2}$ & $48 / 95$ & \multicolumn{2}{|c|}{95} & \\
\hline Field Area, $\mathrm{m}^{2}$ & 81,400 & 231,000 & 244,966 & \\
\hline Number of Heliostats & 1,912 & 2,432 & 2,579 & \\
\hline Capital Cost, \$M & & $\$ 33.5$ & $\$ 39.1$ & \\
\hline Cost per $\mathrm{m}^{2}$ & & $\$ 145$ & $\$ 160$ & \\
\hline A. Technology & - & & & $\begin{array}{l}\text { The annual heliostat efficiency went from } 50.3 \% \text { to } \\
56 \% \text {. Major design improvements include the } \\
\text { enhanced azimuth drive, elevation drive, and } \\
\text { communication equipment }\end{array}$ \\
\hline B. Economy of Scale & - & & & $\begin{array}{l}\text { There is economy of scale since Solar Tres is based } \\
\text { on } 95^{2} \text { heliostat whereas Solar Two used mostly } \\
40-\mathrm{m}^{2} \text { heliostats ( } 1,818 \text { out of } 1,926 \text { heliostats) }\end{array}$ \\
\hline C. Production Volume & 一 & & & $\begin{array}{l}\text { Production volume is a significant contributor to the } \\
\text { cost reduction. As the volume increases the cost per } \\
\text { unit decreases by three factors: fixed cost decrease } \\
\text { proportionally to the number of units produced, } \\
\text { volume purchasing discounts, and learning curve } \\
\text { from repetitive assembly improvements. }\end{array}$ \\
\hline
\end{tabular}

\begin{tabular}{|c|c|c|c|c|}
\hline \multirow{2}{*}{$\begin{array}{l}\text { Electric Power Block } \\
\text { Cost Improvements }\end{array}$} & \multirow{2}{*}{$\begin{array}{c}\text { Solar } 2 \\
\text { SunLab }\end{array}$} & \multicolumn{2}{|c|}{ Solar Tres } & \multirow[b]{2}{*}{ Basis } \\
\hline & & SunLab & S\&L & \\
\hline $\begin{array}{l}\text { Plant Size - Electrical, } \\
\text { MWe }\end{array}$ & 10 & \multicolumn{2}{|c|}{13.7} & \\
\hline Plant Size - Thermal, MWt & 42 & \multicolumn{2}{|c|}{120} & \\
\hline Capital Cost, \$M & & $\$ 10$ & $\$ 7.6$ & SunLab Cost Estimate \\
\hline Cost per installed kWe & & $\$ 733$ & $\$ 557$ & \\
\hline A. Technology & - & \multicolumn{2}{|c|}{$3 \%$} & $\begin{array}{l}\text { The annual efficiency went from } 40.3 \% \text { to } 41.8 \% \text {. } \\
\text { The turbine generator design is based on proven } \\
\text { standard industry technology. }\end{array}$ \\
\hline B. Economy of Scale & - & \multicolumn{2}{|c|}{$97 \%$} & $\begin{array}{l}\text { The economy of scale is the major cost } \\
\text { improvement. }\end{array}$ \\
\hline
\end{tabular}




\begin{tabular}{|c|c|c|c|c|}
\hline \multirow{2}{*}{$\begin{array}{l}\text { Electric Power Block } \\
\text { Cost Improvements }\end{array}$} & \multirow{2}{*}{$\begin{array}{c}\text { Solar } 2 \\
\text { SunLab }\end{array}$} & \multicolumn{2}{|c|}{ Solar Tres } & \multirow[b]{2}{*}{ Basis } \\
\hline & & SunLab & S\&L & \\
\hline C. Production Volume & - & & & $\begin{array}{l}\text { No production volume contribution since there is } \\
\text { only one turbine-generator per plant. } \\
\text { The learning curve is not a factor due to the turbine- } \\
\text { generator being a standard proven technology. }\end{array}$ \\
\hline
\end{tabular}

\begin{tabular}{|c|c|c|c|c|}
\hline \multirow{2}{*}{$\begin{array}{l}\text { Receiver Cost } \\
\text { Improvements }\end{array}$} & \multirow{2}{*}{$\begin{array}{l}\text { Solar } 2 \\
\text { SunLab }\end{array}$} & \multicolumn{2}{|c|}{ Solar Tres } & \multirow[b]{2}{*}{ Basis } \\
\hline & & SunLab & S\&L & \\
\hline $\begin{array}{l}\text { Plant Size - Electrical, } \\
\text { MWe }\end{array}$ & 10 & \multicolumn{2}{|c|}{13.7} & \\
\hline Plant Size - Thermal, MWt & 42 & \multicolumn{2}{|c|}{120} & \\
\hline Receiver Surface Area, $\mathrm{m}^{2}$ & 100 & \multicolumn{2}{|c|}{280} & \\
\hline Peak Solar Flux, MWt/m² & 0.8 & \multicolumn{2}{|c|}{0.95} & \\
\hline Capital Cost, \$M & $\$ 9.1$ & $\$ 14.0$ & $\$ 16.0$ & \\
\hline Cost per $\mathrm{m}^{2}, \mathrm{k} \$ / \mathrm{m}^{2}$ & $\$ 91$ & $\$ 50$ & $\$ 57$ & \\
\hline A Technology & - & \multicolumn{2}{|c|}{$32 \%$} & $\begin{array}{l}\text { The efficiency went from } 76 \% \text { to } 78.3 \% \text {. Major } \\
\text { design changes include the following: } \\
\text { Change from } 316 \text { SS to high nickel alloy provides a } \\
\text { higher peak solar flux which decreases the surface } \\
\text { area, elimination of receiver outlet vessel, improved } \\
\text { inlet vessel operational design, simpler header } \\
\text { design with fewer components, more internal space, } \\
\text { elimination of vents \& drains, and improved stress } \\
\text { analysis. }\end{array}$ \\
\hline B. Economy of Scale & - & \multicolumn{2}{|c|}{$50 \%$} & $\begin{array}{l}\text { The size scale up factor of } 3 \text { is feasible based } \\
\text { technical advances projected by Boeing. }\end{array}$ \\
\hline C Production Volume & - & \multicolumn{2}{|c|}{$18 \%$} & $\begin{array}{l}\text { Production volume is not a significant factor. The } \\
\text { cost improvements are for automation of panel } \\
\text { assembly, improved tools, optimized factory layout, } \\
\text { replication, and reduced labor rates in Spain }(7 \%) \text {. } \\
\text { Learning curve is reasonable based on repetitive } \\
\text { assembly operations and Boeing's experience. } \\
6,000 \text { clips are welded on } 850 \text { individual tubes that } \\
\text { are welded to } 34 \text { headers, which are part of } 17 \\
\text { identical receiver panels. }\end{array}$ \\
\hline
\end{tabular}


Table 5-29 - Solar Tres to Solar 50 Cost Reduction Comparison

\begin{tabular}{|c|c|c|c|c|}
\hline \multirow{2}{*}{$\begin{array}{l}\text { Heliostat Cost } \\
\text { Improvements }\end{array}$} & \multirow{2}{*}{$\begin{array}{c}\text { Solar Tres } \\
\text { SunLab }\end{array}$} & \multicolumn{2}{|c|}{ Solar 50} & \multirow[b]{2}{*}{ Basis } \\
\hline & & SunLab & S\&L & \\
\hline $\begin{array}{l}\text { Plant Size - Electrical, } \\
\text { MWe }\end{array}$ & 13.7 & \multicolumn{2}{|c|}{50} & \\
\hline Plant Size - Thermal, MWt & 120 & \multicolumn{2}{|c|}{380} & \\
\hline Heliostat Size, $\mathrm{m}^{2}$ & 95 & \multicolumn{2}{|c|}{95} & \\
\hline Field Area, $\mathrm{m}^{2}$ & 231,000 & 709,000 & 742,703 & \\
\hline Number of Heliostats & 2,432 & 7,463 & 7,818 & \\
\hline Capital Cost, \$M & $\$ 33.5$ & $\$ 89.8$ & $\$ 111.7$ & \\
\hline Cost per $\mathrm{m}^{2}$ & $\$ 145$ & $\$ 127$ & $\$ 150$ & \\
\hline A. Technology & $26 \%$ & \multicolumn{2}{|c|}{$11 \%$} & $\begin{array}{l}\text { The annual heliostat efficiency went from } 56 \% \text { to } \\
56.5 \% \text {. Major design improvements include the } \\
\text { enhanced azimuth drive, elevation drive, and } \\
\text { communication equipment }\end{array}$ \\
\hline B. Economy of Scale & $37 \%$ & \multicolumn{2}{|c|}{$0 \%$} & $\begin{array}{l}\text { There is no economy of scale since Solar } 50 \text { is } \\
\text { based on the same size heliostat as Solar Tres } \\
\left(95 \mathrm{~m}^{2}\right) \text {. }\end{array}$ \\
\hline C. Production Volume & $37 \%$ & \multicolumn{2}{|c|}{$89 \%$} & $\begin{array}{l}\text { Production volume is the largest contributor to the } \\
\text { cost reduction. As the volume increases the cost per } \\
\text { unit decreases by three factors: fixed cost decrease } \\
\text { proportionally to the number of units produced, } \\
\text { volume purchasing discounts, and learning curve } \\
\text { from repetitive assembly improvements. }\end{array}$ \\
\hline
\end{tabular}

\begin{tabular}{|c|c|c|c|c|}
\hline \multirow{2}{*}{$\begin{array}{l}\text { Electric Power Block } \\
\text { Cost Improvements }\end{array}$} & \multirow{2}{*}{$\frac{\text { Solar Tres }}{\text { SunLab }}$} & \multicolumn{2}{|c|}{ Solar 50} & \multirow[b]{2}{*}{ Basis } \\
\hline & & SunLab & S\&L & \\
\hline $\begin{array}{l}\text { Plant Size - Electrical, } \\
\text { MWe }\end{array}$ & 13.7 & \multicolumn{2}{|c|}{50} & \\
\hline Plant Size - Thermal, MWt & 120 & \multicolumn{2}{|c|}{380} & \\
\hline Capital Cost, \$M & $\$ 10$ & $\$ 24.5$ & $\$ 18.6$ & SunLab Cost Estimate \\
\hline Cost per installed kWe & $\$ 733$ & $\$ 490$ & $\$ 372$ & \\
\hline A. Technology & $3 \%$ & \multicolumn{2}{|c|}{$3.2 \%$} & $\begin{array}{l}\text { The annual efficiency went from } 40.3 \% \text { to } 41.8 \% \text {. } \\
\text { The turbine generator design is based on proven } \\
\text { standard industry technology. }\end{array}$ \\
\hline B. Economy of Scale & $97 \%$ & \multicolumn{2}{|c|}{$96.7 \%$} & $\begin{array}{l}\text { The economy of scale is the major cost } \\
\text { improvement. }\end{array}$ \\
\hline
\end{tabular}




\begin{tabular}{|l|c|c|c|l|}
\hline \multirow{2}{*}{$\begin{array}{l}\text { Electric Power Block } \\
\text { Cost Improvements }\end{array}$} & Solar Tres & \multicolumn{2}{|c|}{ Solar $\mathbf{5 0}$} & \multirow{2}{*}{ Basis } \\
\cline { 2 - 4 } & SunLab & SunLab & S\&L & No production volume contribution since there is \\
C. Production Volume & $0 \%$ & \multicolumn{2}{|c|}{$0 \%$} & $\begin{array}{l}\text { Thly one turbine-generator per plant. } \\
\text { generator being a standard proven technology. }\end{array}$ \\
\hline
\end{tabular}

\begin{tabular}{|c|c|c|c|c|}
\hline \multirow{2}{*}{$\begin{array}{l}\text { Receiver Cost } \\
\text { Improvements }\end{array}$} & \multirow{2}{*}{$\begin{array}{c}\text { Solar Tres } \\
\text { SunLab }\end{array}$} & \multicolumn{2}{|c|}{ Solar 50} & \multirow[b]{2}{*}{ Basis } \\
\hline & & SunLab & S\&L & \\
\hline $\begin{array}{l}\text { Plant Size - Electrical, } \\
\text { MWe }\end{array}$ & 13.7 & \multicolumn{2}{|c|}{50} & \\
\hline Plant Size - Thermal, MWt & 120 & \multicolumn{2}{|c|}{380} & \\
\hline Receiver Surface Area, $\mathrm{m}^{2}$ & 280 & 580 & 710 & \\
\hline Peak Solar Flux, MWt/m² & 0.95 & 1.2 & 1.2 & \\
\hline Capital Cost, \$M & $\$ 14.0$ & $\$ 19.8$ & $\$ 26$ & \\
\hline Cost per $\mathrm{m}^{2}, \mathrm{k} \$ / \mathrm{m}^{2}$ & $\$ 50$ & $\$ 34$ & $\$ 37$ & \\
\hline A. Technology & $32 \%$ & \multicolumn{2}{|c|}{$35 \%$} & $\begin{array}{l}\text { The efficiency went from } 78.3 \% \text { to } 80.9 \% \text {. Major } \\
\text { design changes include the following: } \\
\text { Receiver fluid side heat transfer enhancements, } \\
\text { improved thermal storage tank design, increase } \\
\text { peak solar flux based on operational experience } \\
\text { from Solar Tres, further elimination of vent \& drain } \\
\text { valves }\end{array}$ \\
\hline B. Economy of Scale & $50 \%$ & \multicolumn{2}{|c|}{$43 \%$} & $\begin{array}{l}\text { The size scale up factor of } 2 \text { is feasible based } \\
\text { technical advances projected by Boeing. }\end{array}$ \\
\hline C. Production Volume & $18 \%$ & \multicolumn{2}{|c|}{$22 \%$} & $\begin{array}{l}\text { Production volume is not a significant factor. The } \\
\text { cost improvement for moderate automation of panel } \\
\text { assembly, optimized factory layout and quantity } \\
\text { discount of materials for multiple plant orders based } \\
\text { on a } 3 \% \text { decrease in material and component cost. } \\
\text { Learning curve is reasonable based on repetitive } \\
\text { assembly operations and Boeing's experience. }\end{array}$ \\
\hline
\end{tabular}


Table 5-30 - Solar 50 to Solar 100 Cost Reduction Comparison

\begin{tabular}{|c|c|c|c|c|}
\hline \multirow{2}{*}{$\begin{array}{l}\text { Heliostat Cost } \\
\text { Improvements }\end{array}$} & \multirow{2}{*}{$\begin{array}{l}\text { Solar } 50 \\
\text { SunLab }\end{array}$} & \multicolumn{2}{|c|}{ Solar 100} & \multirow[b]{2}{*}{ Basis } \\
\hline & & SunLab & S\&L & \\
\hline $\begin{array}{l}\text { Plant Size - Electrical, } \\
\text { MWe }\end{array}$ & 50 & \multicolumn{2}{|c|}{100} & \\
\hline Plant Size - Thermal, MWt & 380 & \multicolumn{2}{|c|}{700} & \\
\hline Heliostat Size, $\mathrm{m}^{2}$ & 95 & \multicolumn{2}{|c|}{148} & \\
\hline Field Area, $\mathrm{m}^{2}$ & 709,000 & $1,311,000$ & $1,366,100$ & \\
\hline Number of Heliostats & 7,463 & 8,858 & 9,230 & \\
\hline Capital Cost, \$M & $\$ 89.8$ & $\$ 139.8$ & $\$ 182.7$ & \\
\hline Cost per $\mathrm{m}^{2}$ & $\$ 127$ & $\$ 107$ & $\$ 134$ & \\
\hline A. Technology & $11 \%$ & \multicolumn{2}{|c|}{$35 \%$} & $\begin{array}{l}\text { The annual heliostat efficiency went from } 56.5 \% \text { to } \\
56.3 \% \text {. Major design improvements include the } \\
\text { enhanced azimuth drive, elevation drive, and } \\
\text { communication equipment to support the } 148 \mathrm{~m} 2 \\
\text { heliostat. The major technical advance is thin glass } \\
\text { to increase reflectivity. }\end{array}$ \\
\hline B. Economy of Scale & $0 \%$ & \multicolumn{2}{|c|}{$57 \%$} & $\begin{array}{l}\text { There is economy of scale since Solar } 50 \text { uses a } \\
95-\mathrm{m}^{2} \text { heliostat and Solar } 100 \text { uses a } 148-\mathrm{m}^{2} \\
\text { heliostat. }\end{array}$ \\
\hline C. Production Volume & $89 \%$ & \multicolumn{2}{|c|}{$8 \%$} & $\begin{array}{l}\text { Production volume is a small large contributor to the } \\
\text { cost reduction. }\end{array}$ \\
\hline
\end{tabular}

\begin{tabular}{|c|c|c|c|c|}
\hline \multirow{2}{*}{$\begin{array}{l}\text { Electric Power Block } \\
\text { Cost Improvements }\end{array}$} & \multirow{2}{*}{$\begin{array}{l}\text { Solar } 50 \\
\text { SunLab }\end{array}$} & \multicolumn{2}{|c|}{ Solar 100} & \multirow[b]{2}{*}{ Basis } \\
\hline & & SunLab & S\&L & \\
\hline $\begin{array}{l}\text { Plant Size - Electrical, } \\
\text { MWe }\end{array}$ & 50 & \multicolumn{2}{|c|}{100} & \\
\hline Plant Size - Thermal, MWt & 380 & \multicolumn{2}{|c|}{700} & \\
\hline Capital Cost, \$M & $\$ 24.5$ & $\$ 40$ & $\$ 30.8$ & \\
\hline Cost per installed kWe & $\$ 490$ & $\$ 400$ & $\$ 308$ & \\
\hline A. Efficiency & $3 \%$ & \multicolumn{2}{|c|}{$1 \%$} & $\begin{array}{l}\text { The annual efficiency went from } 41.8 \% \text { to } 42.3 \% \text {. } \\
\text { The turbine generator design is based on proven } \\
\text { standard industry technology. }\end{array}$ \\
\hline B. Economy of Scale & $97 \%$ & \multicolumn{2}{|c|}{$99 \%$} & $\begin{array}{l}\text { The economy of scale is the major cost } \\
\text { improvement. }\end{array}$ \\
\hline
\end{tabular}




\begin{tabular}{|c|c|c|c|c|}
\hline \multirow{2}{*}{$\begin{array}{l}\text { Electric Power Block } \\
\text { Cost Improvements }\end{array}$} & \multirow{2}{*}{$\begin{array}{c}\text { Solar } 50 \\
\text { SunLab }\end{array}$} & \multicolumn{2}{|c|}{ Solar 100} & \multirow[b]{2}{*}{ Basis } \\
\hline & & SunLab & S\&L & \\
\hline C. Production Volume & $0 \%$ & & & $\begin{array}{l}\text { No production volume contribution since there is } \\
\text { only one turbine-generator per plant. } \\
\text { The learning curve is not a factor due to the turbine- } \\
\text { generator being a standard proven technology. }\end{array}$ \\
\hline
\end{tabular}

\begin{tabular}{|c|c|c|c|c|}
\hline \multirow{2}{*}{$\begin{array}{l}\text { Receiver Cost } \\
\text { Improvements }\end{array}$} & \multirow{2}{*}{$\begin{array}{l}\text { Solar } 50 \\
\text { SunLab }\end{array}$} & \multicolumn{2}{|c|}{ Solar 100} & \multirow[b]{2}{*}{ Basis } \\
\hline & & SunLab & S\&L & \\
\hline $\begin{array}{l}\text { Plant Size - Electrical, } \\
\text { MWe }\end{array}$ & 50 & \multicolumn{2}{|c|}{100} & \\
\hline Plant Size - Thermal, MWt & 380 & \multicolumn{2}{|c|}{700} & \\
\hline Receiver Surface Area, $\mathrm{m}^{2}$ & 580 & 930 & 1,110 & \\
\hline Peak Solar Flux, MWt/m² & 1.2 & 1.4 & 1.4 & \\
\hline Capital Cost, \$M & $\$ 19.8$ & $\$ 25$ & $\$ 34$ & \\
\hline Cost per $\mathrm{m}^{2}, \mathrm{k} \$ / \mathrm{m}^{2}$ & $\$ 34$ & $\$ 27$ & $\$ 31$ & \\
\hline A. Technology & $35 \%$ & \multicolumn{2}{|c|}{$66 \%$} & $\begin{array}{l}\text { The efficiency went from } 80.9 \% \text { to } 83.1 \% \text {. Major } \\
\text { design changes include the following: } \\
\text { Further elimination of components, development of } \\
\text { Boeing optimization codes, increase peak solar flux } \\
\text { based on operational experience from Solar } 50 \text {. }\end{array}$ \\
\hline B. Economy of Scale & $43 \%$ & \multicolumn{2}{|c|}{$25 \%$} & $\begin{array}{l}\text { The size scale up factor of } 1.6 \text { is feasible based } \\
\text { technical advances projected by Boeing. }\end{array}$ \\
\hline C. Production Volume & $22 \%$ & \multicolumn{2}{|c|}{$9 \%$} & $\begin{array}{l}\text { Production volume is not a significant factor. The } \\
\text { cost improvement for automated equipment } \\
\text { amortized over several plants, and quantity discount } \\
\text { of materials for multiple plant orders based on a } 3 \% \\
\text { decrease in material and component cost. Learning } \\
\text { curve is reasonable based on repetitive assembly } \\
\text { operations and Boeing's experience. }\end{array}$ \\
\hline
\end{tabular}


Table 5-31 - Solar 100 to Solar 200 Cost Reduction Comparison

\begin{tabular}{|c|c|c|c|c|}
\hline \multirow{2}{*}{$\begin{array}{l}\text { Heliostat Cost } \\
\text { Improvements }\end{array}$} & \multirow{2}{*}{$\begin{array}{l}\text { Solar } 100 \\
\text { SunLab }\end{array}$} & \multicolumn{2}{|c|}{ Solar 200} & \multirow[b]{2}{*}{ Basis } \\
\hline & & SunLab & S\&L & \\
\hline $\begin{array}{l}\text { Plant Size - Electrical, } \\
\text { MWe }\end{array}$ & 100 & \multicolumn{2}{|c|}{200} & \\
\hline Plant Size - Thermal, MWt & 700 & \multicolumn{2}{|c|}{1,400} & \\
\hline Heliostat Size, $\mathrm{m}^{2}$ & 148 & \multicolumn{2}{|c|}{148} & \\
\hline Field Area, $\mathrm{m}^{2}$ & $1,311,000$ & $2,600,000$ & $2,667,099$ & \\
\hline Number of Heliostats & 8,858 & 17,608 & 18,021 & \\
\hline Capital Cost, \$M & $\$ 141.2$ & $\$ 249.6$ & $\$ 330.0$ & \\
\hline Cost per $\mathrm{m}^{2}$ & $\$ 107$ & $\$ 96$ & $\$ 124$ & \\
\hline A. Technology & $35 \%$ & & & $\begin{array}{l}\text { The annual heliostat efficiency went from } 56.3 \% \text { to } \\
56.1 \% \text {. Major design improvements include the } \\
\text { enhanced azimuth drive, elevation drive, and } \\
\text { communication equipment }\end{array}$ \\
\hline B. Economy of Scale & $57 \%$ & & & $\begin{array}{l}\text { There is no economy of scale since Solar } 200 \text { is } \\
\text { based on the same size heliostat as Solar } 100(148 \\
\left.\mathrm{m}^{2}\right) \text {. }\end{array}$ \\
\hline C.1 Production Volume & $8 \%$ & & & $\begin{array}{l}\text { Production volume is the largest contributor to the } \\
\text { cost reduction. As the volume increases the cost per } \\
\text { unit decreases by three factors: fixed cost decrease } \\
\text { proportionally to the number of units produced, } \\
\text { volume purchasing discounts, and learning curve } \\
\text { from repetitive assembly improvements. }\end{array}$ \\
\hline
\end{tabular}

\begin{tabular}{|c|c|c|c|c|}
\hline \multirow{2}{*}{$\begin{array}{l}\text { Electric Power Block } \\
\text { Cost Improvements }\end{array}$} & \multirow{2}{*}{$\frac{\text { Solar } 100}{\text { SunLab }}$} & \multicolumn{2}{|c|}{ Solar 200} & \multirow[b]{2}{*}{ Basis } \\
\hline & & SunLab & S\&L & \\
\hline $\begin{array}{l}\text { Plant Size - Electrical, } \\
\text { MWe }\end{array}$ & 100 & \multicolumn{2}{|c|}{200} & \\
\hline Plant Size - Thermal, MWt & 700 & \multicolumn{2}{|c|}{1,400} & \\
\hline Capital Cost, \$M & $\$ 40$ & $\$ 64$ & $\$ 46.2$ & \\
\hline Cost per installed kWe & $\$ 400$ & $\$ 320$ & $\$ 231$ & \\
\hline A. Technology & $1 \%$ & \multicolumn{2}{|c|}{$1 \%$} & $\begin{array}{l}\text { The annual efficiency went from } 42.3 \% \text { to } 42.8 \% \text {. } \\
\text { The turbine generator design is based on proven } \\
\text { standard industry technology. }\end{array}$ \\
\hline B. Economy of Scale & $99 \%$ & \multicolumn{2}{|c|}{$99 \%$} & $\begin{array}{l}\text { The economy of scale is the major cost } \\
\text { improvement. }\end{array}$ \\
\hline
\end{tabular}




\begin{tabular}{|c|c|c|c|c|}
\hline \multirow{2}{*}{$\begin{array}{l}\text { Electric Power Block } \\
\text { Cost Improvements }\end{array}$} & \multirow{2}{*}{$\frac{\text { Solar } 100}{\text { SunLab }}$} & \multicolumn{2}{|c|}{ Solar 200} & \multirow[b]{2}{*}{ Basis } \\
\hline & & SunLab & S\&L & \\
\hline C. Production Volume & $0 \%$ & & & $\begin{array}{l}\text { No production volume contribution since there is } \\
\text { only one turbine-generator per plant. } \\
\text { The learning curve is not a factor due to the turbine- } \\
\text { generator being a standard proven technology. }\end{array}$ \\
\hline
\end{tabular}

\begin{tabular}{|c|c|c|c|c|}
\hline \multirow{2}{*}{$\begin{array}{l}\text { Receiver Cost } \\
\text { Improvements }\end{array}$} & \multirow{2}{*}{$\frac{\text { Solar } 100}{\text { SunLab }}$} & \multicolumn{2}{|c|}{ Solar 200} & \multirow[b]{2}{*}{ Basis } \\
\hline & & SunLab & S\&L & \\
\hline $\begin{array}{l}\text { Plant Size - Electrical, } \\
\text { MWe }\end{array}$ & 100 & \multicolumn{2}{|c|}{200} & \\
\hline Plant Size - Thermal, MWt & 700 & \multicolumn{2}{|c|}{1,400} & \\
\hline Receiver Surface Area, $\mathrm{m}^{2}$ & 930 & 1,650 & 1,990 & \\
\hline Peak Solar Flux, MWt/m² & 1.4 & 1.6 & 1.6 & \\
\hline Capital Cost, \$M & $\$ 25$ & $\$ 36.9$ & $\$ 46.0$ & \\
\hline Cost per $\mathrm{m}^{2}, \mathrm{k} \$ / \mathrm{m}^{2}$ & $\$ 27$ & $\$ 22$ & $\$ 23$ & \\
\hline A. Technology & $66 \%$ & \multicolumn{2}{|c|}{$65 \%$} & $\begin{array}{l}\text { The efficiency went from } 83.1 \% \text { to } 83.5 \% \text {. Major } \\
\text { design changes include the following: } \\
\text { Further elimination of components, continued } \\
\text { development of Boeing optimization codes, increase } \\
\text { peak solar flux based on operational experience } \\
\text { from Solar } 100 \text {. }\end{array}$ \\
\hline B. Economy of Scale & $25 \%$ & \multicolumn{2}{|c|}{$24 \%$} & $\begin{array}{l}\text { The size scale up factor of } 1.8 \text { is feasible based } \\
\text { technical advances projected by Boeing. }\end{array}$ \\
\hline C. Production Volume & $9 \%$ & \multicolumn{2}{|c|}{$11 \%$} & $\begin{array}{l}\text { Production volume is not a significant factor. The } \\
\text { cost improvement for moderate automation in panel } \\
\text { assembly and optimized factory layout, costs for } \\
\text { automated equipment is amortized over several } \\
\text { plants, and quantity discount of materials for } \\
\text { multiple plant orders based on a } 2 \% \text { decrease in } \\
\text { material and component cost. Learning curve is } \\
\text { reasonable based on repetitive assembly operations } \\
\text { and Boeing's experience. }\end{array}$ \\
\hline
\end{tabular}


Table 5-32 - Solar 200 to Solar 220 Cost Reduction Comparison

\begin{tabular}{|c|c|c|c|c|}
\hline \multirow{2}{*}{$\begin{array}{l}\text { Heliostat Cost } \\
\text { Improvements }\end{array}$} & \multirow{2}{*}{$\begin{array}{c}\text { Solar } 200 \\
\text { SunLab }\end{array}$} & \multicolumn{2}{|c|}{ Solar 220} & \multirow[b]{2}{*}{ Basis } \\
\hline & & SunLab & S\&L & \\
\hline $\begin{array}{l}\text { Plant Size - Electrical, } \\
\text { MWe }\end{array}$ & 200 & \multicolumn{2}{|c|}{220} & \\
\hline Plant Size - Thermal, MWt & 1,400 & \multicolumn{2}{|c|}{1,400} & \\
\hline Heliostat Size, $\mathrm{m}^{2}$ & 148 & \multicolumn{2}{|c|}{148} & \\
\hline Field Area, $\mathrm{m}^{2}$ & $2,600,000$ & $2,642,000$ & $2,789,322$ & \\
\hline Number of Heliostats & 17,608 & 17,851 & 18,847 & \\
\hline Capital Cost, \$M & $\$ 249.6$ & $\$ 198.8$ & $\$ 263.0$ & \\
\hline Cost per $\mathrm{m}^{2}$ & $\$ 96$ & $\$ 75$ & $\$ 94$ & \\
\hline A. Technology & $5 \%$ & & & $\begin{array}{l}\text { The annual heliostat efficiency went from } 56.1 \% \text { to } \\
57 \% \text {. Major design improvements are new } \\
\text { advanced heliostat. }\end{array}$ \\
\hline B. Economy of Scale & $0 \%$ & & & $\begin{array}{l}\text { There is no economy of scale since Solar } 220 \text { is } \\
\text { based on the same size heliostat as Solar } 200 \\
\left(148 \mathrm{~m}^{2}\right) .\end{array}$ \\
\hline C. Production Volume & $95 \%$ & & & $\begin{array}{l}\text { Production volume is a contributor to the cost } \\
\text { reduction. As the volume increases the cost per unit } \\
\text { decreases by three factors: fixed cost decrease } \\
\text { proportionally to the number of units produced, } \\
\text { volume purchasing discounts, and learning curve } \\
\text { from repetitive assembly improvements. }\end{array}$ \\
\hline
\end{tabular}

\begin{tabular}{|c|c|c|c|c|}
\hline \multirow{2}{*}{$\begin{array}{l}\text { Electric Power Block } \\
\text { Cost Improvements }\end{array}$} & \multirow{2}{*}{$\frac{\text { Solar } 200}{\text { SunLab }}$} & \multicolumn{2}{|c|}{ Solar 220} & \multirow[b]{2}{*}{ Basis } \\
\hline & & SunLab & S\&L & \\
\hline $\begin{array}{l}\text { Plant Size - Electrical, } \\
\text { MWe }\end{array}$ & 200 & \multicolumn{2}{|c|}{220} & \\
\hline Plant Size - Thermal, MWt & 1,400 & \multicolumn{2}{|c|}{1,400} & \\
\hline Capital Cost, \$M & $\$ 64$ & $\$ 83.6$ & $\$ 61.8$ & \\
\hline Cost per installed kWe & $\$ 320$ & $\$ 380$ & $\$ 281$ & \\
\hline A.1 Technology & $1 \%$ & \multicolumn{2}{|c|}{$80 \%$} & $\begin{array}{l}\text { The annual efficiency went from } 42.8 \% \text { to } 46.1 \% \text {. } \\
\text { The increase is due to turbine advances in } \\
\text { technology. The cost reduction from the increase in } \\
\text { efficiency is } \$ 6.2 \text { million. The higher efficiency } \\
\text { turbine is estimated to cost an additional } 20 \% \text {. } \\
\text { The cost reduction from increase in efficiency of } \\
\$ 6.2 \text { million is offset by the higher cost ( } \$ 83.6 \mathrm{M}- \\
\$ 64 \mathrm{M}=\$ 19.6 \mathrm{M}) \text { and increased capacity. }\end{array}$ \\
\hline
\end{tabular}




\begin{tabular}{|c|c|c|c|c|}
\hline \multirow{2}{*}{$\begin{array}{l}\text { Electric Power Block } \\
\text { Cost Improvements }\end{array}$} & \multirow{2}{*}{$\frac{\text { Solar } 200}{\text { SunLab }}$} & \multicolumn{2}{|c|}{ Solar 220} & \multirow[b]{2}{*}{ Basis } \\
\hline & & SunLab & S\&L & \\
\hline B. Economy of Scale & $99 \%$ & \multicolumn{2}{|c|}{$20 \%$} & $\begin{array}{l}\text { Economy of scale is a contributor due to the } \\
\text { increase in size. }\end{array}$ \\
\hline C. Production Volume & $0 \%$ & \multicolumn{2}{|c|}{$0 \%$} & $\begin{array}{l}\text { No production volume contribution since there is } \\
\text { only one turbine-generator per plant. }\end{array}$ \\
\hline
\end{tabular}

\begin{tabular}{|c|c|c|c|c|}
\hline \multirow{2}{*}{$\begin{array}{l}\text { Receiver Cost } \\
\text { Improvements }\end{array}$} & \multirow{2}{*}{$\frac{\text { Solar } 200}{\text { SunLab }}$} & \multicolumn{2}{|c|}{ Solar 220} & \multirow[b]{2}{*}{ Basis } \\
\hline & & SunLab & S\&L & \\
\hline $\begin{array}{l}\text { Plant Size - Electrical, } \\
\text { MWe }\end{array}$ & 200 & \multicolumn{2}{|c|}{220} & \\
\hline Plant Size - Thermal, MWt & 1,400 & \multicolumn{2}{|c|}{1,400} & \\
\hline Receiver Surface Area, $\mathrm{m}^{2}$ & 1,650 & 1,650 & 1,990 & \\
\hline Peak Solar Flux, MWt/m² & 1.6 & 1.6 & 1.6 & \\
\hline Capital Cost, \$M & $\$ 36.9$ & $\$ 34.4$ & $\$ 48.0$ & \\
\hline Cost per $\mathrm{m}^{2}, \mathrm{k} \$ / \mathrm{m}^{2}$ & $\$ 22$ & $\$ 21$ & $\$ 24$ & \\
\hline A. Technology & $65 \%$ & \multicolumn{2}{|c|}{31} & $\begin{array}{l}\text { The efficiency went from } 83.5 \% \text { to } 82 \% \text {. Major } \\
\text { design changes include the following: } \\
\text { Further elimination of components, continued } \\
\text { development of Boeing optimization codes, increase } \\
\text { peak solar flux based on operational experience } \\
\text { from Solar } 100 \text {. }\end{array}$ \\
\hline B. Economy of Scale & $24 \%$ & \multicolumn{2}{|c|}{61} & $\begin{array}{l}\text { The size scale up factor of } 1.8 \text { is feasible based } \\
\text { technical advances projected by Boeing. }\end{array}$ \\
\hline C. Production Volume & $11 \%$ & \multicolumn{2}{|c|}{8} & $\begin{array}{l}\text { Production volume is not a significant factor. The } \\
\text { cost improvement for moderate automation in panel } \\
\text { assembly and optimized factory layout, costs for } \\
\text { automated equipment is amortized over several } \\
\text { plants, and quantity discount of materials for } \\
\text { multiple plant orders based on a } 2 \% \text { decrease in } \\
\text { material and component cost. Learning curve is } \\
\text { reasonable based on repetitive assembly operations } \\
\text { and Boeing's experience. }\end{array}$ \\
\hline
\end{tabular}

\subsection{RISK ASSESSMENT FOR TOWER TECHNOLOGY}

This section provides an overview and assessment of the risks associated with attaining competitive commercialization for the tower technology on a short-term, mid-term, and long-term basis. Competitiveness is measured by the levelized energy cost (LEC), expressed as $\$ / \mathrm{kWh}$, consisting of two elements: total investment cost and operation and maintenance (O\&M) cost. 
- The major total investment cost drivers of the tower plant are the solar field, power block, and receiver, which account for approximately $74 \%$ of the total costs. Also, the net annual solar-toelectric efficiency has an impact on the cost of a tower plant. The solar field (heliostats and receiver) has to be increased proportionally for decrease in efficiency. For every one-percentage point improvement in the net efficiency, the LEC for is reduced by approximately $0.5 \%$.

Total cost reductions occur from technical improvements, increase in plant size (scaling), and volume production (learning curves). All three are dependent on deployment of the technology. Deployment provides a means for continued research in technology improvements, cost reductions due to increased production, and economy of scale from constructing larger plants.

The second element of the levelized energy cost is the O\&M costs. For the tower plant, O\&M costs represent about $25 \%$ of the LEC.

As such, the focus of the risk assessment covers the following main categories:

- Deployment

- $\quad$ Net Annual Solar-to-Electric Efficiency

- Total Investment Cost

- $\quad$ Operation and Maintenance

\subsubsection{Deployment}

Market expansion of trough technology will require incentives to reach market competitiveness. Numerous potential incentives exist, such as: environmental $\left(\mathrm{CO}_{2}\right.$ emission credits), favorable tax credits, favorable peak energy tariff, premium consumer pricing, loan guarantees, low interest loans, and grants. Analysis of incentives required to reach market acceptance is not within the scope of this report. S\&L's estimate corresponds to the SunLab Reference Cases with near-term deployment in 2004, mid-term deployment in 2010, and long-term deployment in 2020 for comparison. Sensitivity analysis was done to consider the more realistic deployment of the first commercial plant being placed in service in 2006. The earliest a plant would be operational in the United States is 2009 based on the first commercial plant going in service in 2006 in Spain or South Africa, operational experience of at least one year, and two years for design enhancements, manufacturing, and construction.

The risk is mid to high for development in the United States since market expansion will require incentives to reach market acceptance (competitive). S\&L's projection is more conservative than the SunLab projection of 
8.7 GWe. The S\&L projected range is a maximum deployment of $4.7 \mathrm{GWe}$ and a minimum deployment of 1.2 GWe. The S\&L base case is a deployment of $2.6 \mathrm{GWe}$.

\subsubsection{Near Term (2004)}

The SunLab near-term deployment projection is based on the first commercial plant (Solar Tres) being built in Spain in 2004. Upon successful completion of Solar Tres, a 50-MW plant will be built in 2006.

The risk for meeting the near-term goals is low to mid outside of the United States and mid to high in the United States. Project development is in progress for two projects: Solar Tres in Spain and ESKOM in South America. The governments have provided the incentives necessary for the projects to be competitive so that financing can be secured. The Solar Tres current schedule is for permits and financing to be in place by the end of 2003 with commercial operation early in 2006. The risk for meeting the goals in the United States is high since there are no current plans for government-sponsored incentives. However, the Western Governors' Association provided recent favorable support for CSP technology (EERE 2002).

\subsubsection{Mid Term (2010)}

The SunLab mid-term deployment projection is five 50-MW plants and six 100-MW plants being deployed in the years 2007 through 2010 .

The S\&L mid-term deployment projection is one 50-MW plan being deployed in the years 2007 through 2010. The S\&L projection is based on Solar Tres being deployed in 2006 and the first 50-MW plant being deployed in 2009. The S\&L projection took into consideration additional time between the first plant and subsequent plants of the same size. The first plant of each size will take longer to complete and reach steady-state operation.

Sargent \& Lundy projects one 50-MW plant being deployed in 2009 and one 100-MW plant being deployed in the years 2007 through 2010. SunLab projected the first 50-MW plant for 2006, whereas S\&L projected it for 2007. SunLab projected the first 100-MW plant for 2008, whereas S\&L projected it for 2010. Our estimate takes into consideration the time to identify and incorporate lessons learned into the subsequent plants. S\&L was also not as aggressive in deployment projections as SunLab. The difference between the two projections provides a range of deployment. Again, deployment is entirely based on market expansion and the incentives to reach market acceptance. Without incentives, there is no market for towers in the United States in the near future. If market expansion occurs in foreign countries based on incentives, then tower power could be introduced to the United States after it reaches market acceptance. 


\subsubsection{Long Term (2020)}

The SunLab long-term deployment projection is twenty-one 100-MW plants with improved technology being deployed in the years 2011 through 2017; twenty-two advanced technology 200-MW plants in the years 2012 through 2019; and six 220-MW advanced technology plants in the years 2018 to 2020. The SunLab total longterm deployment is $8,734 \mathrm{MW}$ installed capacity.

The S\&L long-term projection is three 50-MWe plants, four 100-MWe plants, and three 200-MWe plants being deployed in the years 2011 through 2020. The S\&L total long-term deployment is 1,214 MW installed capacity.

The risk is high for development in the United States since market expansion will require incentives to reach market acceptance (competitive). If there are governmental incentives, the risk of deploying $1.2 \mathrm{GWe}$ from 2006 to 2020, without the advanced 220-MW plant is low. The number or plants is achievable and provides adequate duration between each larger plant to allow for lessons learned and design enhancements.

The impact of deployment on LEC is noted in the following table:

Table 5-33 - Impact of Deployment on LEC (Keeping Net Efficiency Constant)

\begin{tabular}{|c|c|c|c|c|}
\hline \multirow[b]{2}{*}{ Year 2020} & \multirow{2}{*}{$\begin{array}{l}\text { Total } \\
\text { Deployment } \\
\text { (GWe) }\end{array}$} & \multirow{2}{*}{$\begin{array}{c}\text { Net Solar-to- } \\
\text { Electric Efficiency } \\
\text { (\%) }\end{array}$} & \multicolumn{2}{|r|}{ LEC } \\
\hline & & & (\$/kWh) & $\begin{array}{l}\text { Percent change from } \\
\text { S\&L Base Case }\end{array}$ \\
\hline SunLab & 8.7 & 18.1 & 0.0350 & SunLab Base \\
\hline S\&L & 8.7 & 16.5 & 0.0524 & $-4.2 \%$ \\
\hline S\&L & 4.7 & 16.5 & 0.0538 & $-1.6 \%$ \\
\hline S\&L & 2.6 & 16.5 & 0.0547 & S\&L Base \\
\hline S\&L & 1.2 & 16.5 & 0.0559 & $2.2 \%$ \\
\hline
\end{tabular}

\subsubsection{Net Annual Solar-to-Electric Efficiency}

\subsubsection{Near Term (2004)}

The SunLab projected near-term net annual solar-to-electric efficiency of $13.7 \%$, an improvement of 6.1 percentage points from the Solar Two Demonstration Project $7.6 \%$ efficiency. The increased efficiency is 
mainly attributable to improved collector properties, parasitic load, receiver, and reheat turbine. The demonstrated improvements and design enhancements are as follows:

- Solar Two demonstration used $40-\mathrm{m}^{2}$ and $95-\mathrm{m}^{2}$ heliostats. The near-term plant uses $95-\mathrm{m}^{2}$ heliostats. The risk of achieving this technology is low since the technology has been demonstrated. There have been $86595-\mathrm{m}^{2}$ ARCO/ATS heliostats built and successfully operated.

- $\quad$ The collector (heliostat) efficiency is $5.7 \%$ higher than that demonstrated during Solar Two. The risk of achieving the improvements is low for the following reasons:

- There is no significant change in the technology.

- Mirror reflectivity efficiency is projected to increase $2.8 \%$ as a result of using new mirrors. The mirrors used at Solar Two were not maintained after the shutdown of Solar One.

- Field efficiency is projected to increase $2.6 \%$ as a result of improvements in aiming technology. This should be achieved since there have been significant improvements in controls systems throughout many industries since Solar Two that can be applied to control aiming.

- Mirror corrosion avoidance efficiency is projected to increase 3\% as a result of new mirrors. The mirrors used for Solar Two had not been maintained. Experience at Kramer Junction shows that the mirror surfaces do not corrode as long as they are properly maintained.

- Field availability is projected to increase $0.5 \%$, which is reasonable based on design improvements from lessons learned during Solar Two and improved reliability of new equipment.

- Improved steam turbine cycle efficiency projection of $6.5 \%$ is as a result of increasing steam temperature from $510^{\circ} \mathrm{C}$ to $540^{\circ} \mathrm{C}$ and using single reheat turbine technology. There is no steam turbine technological risk since there are numerous single reheat steam turbines operating with the same steam inlet conditions.

- Improved parasitic power efficiency projection of $13.4 \%$ is a result of increasing the plant size. As the size of a plant increases, the parasitic power efficiency decreases exponentially. The risk of achieving parasitic power efficiency improvements is low to medium.

- The receiver efficiency is projected to increase 2.3 percentage points from $76 \%$, as demonstrated at Solar 2, to $78.3 \%$. The increase is based on the following design changes: receiver fluid side heat transfer enhancements, improved thermal storage tank design, increased peak solar flux based on operational data from Solar 2, and elimination of vent and drain valves. The risk of achieving these efficiency increases is low based on the demonstration at Solar 2, on the design changes, and because Boeing, who is the supplier of the Solar Tres receiver, must meet guaranteed design conditions.

- Improved thermal storage efficiency is projected to be $1.3 \%$. The risk of achieving this is low since Solar Two demonstrated (a) molten salt as a viable, large-scale thermal energy storage medium and (b) the design, construction, and performance of large, field-erected externally insulated tanks for storing molten salt. The increase in efficiency can be achieved as a result 
decreases in heat loss due to the tank surface area-to-volume ratio decreasing with increasing tank size.

The risk of achieving the near-term net annual solar-to-electric efficiency of $13.7 \%$ is low, since the technology has been demonstrated at Solar One and Solar Two, the proposed enhancements do not constitute a change to the basis technology, and the proposed design enhancements are reasonable.

\subsubsection{Mid Term (2010)}

The SunLab projected mid-term net annual solar-to-electric efficiency is 16.6\%; an improvement of 2.9 percentage points from the near-term projected efficiency of $13.7 \%$, mainly attributable to these improvements:

- Improved collector efficiency of $0.3 \%$

- Improved steam turbine cycle efficiency of 2 percentage points as a result of increasing from $15 \mathrm{MW}$ to $100 \mathrm{MW}$.

- Improved receiver efficiency of $4.8 \%$ as a result of increases in the solar flux level from reduced thermal losses.

- Improved parasitic efficiency of $3.6 \%$ as a result of the increasing from $15 \mathrm{MW}$ to $100 \mathrm{MW}$.

- Improved thermal storage efficiency of $1.2 \%$

The risk of achieving the mid-term net annual solar-to-electric efficiency of $16.6 \%$ is average based on the following:

- The collector size is being increased from $95 \mathrm{~m}^{2}$ to $148 \mathrm{~m}^{2}$ heliostats. There are no significant technical design changes to the heliostat. The risk of increasing to a $148 \mathrm{~m}^{2}$ heliostat is low based on the following: (a) the technology of the $148-\mathrm{m}^{2}$ heliostat is essentially the same as the $95-\mathrm{m}^{2}$ heliostat, (b) ATS has performed detailed engineering and design for the $148-\mathrm{m}^{2}$ heliostat and (c) forty-five 148- $\mathrm{m}^{2}$ collectors ( 2 heliostats and 43 PV trackers) have been built and are in operation.

- The projected collector efficiency is from (a) increases in field availability from better maintenance practices and updated control systems, and (b) increases in mirror cleanliness. S\&L projected that there would be no increase in efficiency as a result of mirror cleanliness efficiency demonstrated at Kramer Junction. The risk of increasing mirror cleanliness is mid to high as a result of the research required to develop materials and cleanliness methods.

- There are numerous steam turbines in the 100-MWe range in operation throughout the world. The efficiency was independently determined by S\&L using the General Electric STGPR software program to be $41.4 \%$, which is slightly lower than the $42.3 \%$ efficiency used by SunLab.

- $\quad$ The projected receiver efficiency increase is 4.8 percentage points from $78.3 \%$ to $83.1 \%$. Boeing has projected the increase based on further elimination of components, development of 
Boeing optimization codes, and increased peak solar flux based on operational experience of previous plants. The risk in achieving these projections is average. The information and specific basis for the efficiency increase is propriety but the concepts for efficiency increases are reasonable: reduced receiver thermal losses due to thermal flux increasing and increased receiver tube surface absorbtivity as a result of Boeing R\&D.

- The projected efficiency increase for thermal storage is $1.2 \%$ and should be achieved based on using the same technology demonstrated at Solar Two and reducing heat loss due to the tank surface area-to-volume ratio decreasing with increasing tank size.

- Improved parasitic power efficiency of $3.6 \%$ is a result of increasing the plant size. As the size of a plant increases, the parasitic power efficiency decreases exponentially. The risk of not achieving parasitic power efficiency improvements is low.

- Improved plant availability efficiency of 2 percentage points from $92 \%$ to $94 \%$ is a result of the operational knowledge and equipment reliability improvements gained from experience in operating numerous plants. The availability of tower technology should be similar to the demonstrated high availability of the SEGS plants.

A mid-term net annual solar-to-electric efficiency of $16.6 \%$ represents an average risk.

Sargent \& Lundy estimated net annual solar-to-electric efficiency to be $16.1 \%$ by limiting the technology improvements to currently demonstrated technology, tested improvements, and realistic assumptions. The difference between SunLab and S\&L estimates is that S\&L limited the mirror cleanliness to an efficiency of 95\% based actual experience at Kramer Junction and there is no proven technology or methods to achieve cleanliness above $95 \%$.

\subsubsection{Long Term (2020)}

The SunLab projected long-term net annual solar-to-electric efficiency is $18.1 \%$, an improvement of 1.5 percentage points from the mid-term projected efficiency of $16.6 \%$. This improvement is mainly attributable to the following:

- Improved steam turbine cycle efficiency of 3.8 percentage points as a result of increasing from $100 \mathrm{MW}$ to $220 \mathrm{MW}$ and use of advanced dual reheat turbine at $640^{\circ} \mathrm{C}$.

- Improved collector efficiency of $0.7 \%$ as a result of new advanced heliostat design.

The risk of achieving the long-term net annual solar-to-electric efficiency of $18.1 \%$ is high based on projecting advanced technology being available for advanced steam turbines and heliostats. However, the risk is greatly reduced if (a) the tower technology is successfully deployed to the extent that the competitive market prompts research and development of technological advances for heliostats, (b) the competitiveness of the energy market 
prompts continued research and development on advanced steam turbines, and (c) research continues on hightemperature metallurgy.

The advanced heliostat design is projected to use thin glass mirrors to increase reflectivity. Conversion to the thin glass will require additional structural support. Alternatives to glass mirror reflectors have been in various stages of initial development and/or testing. The risk for achieving a heliostat design with thin glass or thin-film reflector is high.

The risk for advanced turbines with higher inlet steam temperature and pressure is high. There is current research on increasing steam turbine efficiencies with increased inlet steam temperature and pressure. The increase is technically feasible, but is dependent on continued research and market. The focus will be on largersized steam turbines and will not be available for the smaller units unless there is a market. There is also a technical risk in identifying and solving the higher temperature impact on materials.

The risk of achieving thermal storage efficiency of $99.9 \%$ is low since it was demonstrated at Solar Two. Use of solar salt with an $\mathrm{O}_{2}$ blanket to account for the higher operating temperature (e.g. $650^{\circ} \mathrm{C}$ ) is a medium to high risk.

A long-term net annual to solar efficiency of $17.3 \%$, which does not include the advanced turbine or advanced heliostat technology, represents a low to medium risk. In addition, the mirror cleanliness efficiency is maintained at a demonstrated value of $95 \%$, and the mirror reflectivity efficiency is maintained at a demonstrated value of $94 \%$ (e.g., no advanced glass).

The impact of net annual solar-to-electric efficiency on LEC is as follows:

Table 5-34 - Impact of Net Solar-to-Electric Efficiency on LEC (Keeping Deployment Constant)

\begin{tabular}{|c|c|c|c|c|}
\hline & \multirow{2}{*}{$\begin{array}{c}\text { Total } \\
\text { Deployment } \\
\text { Year 2020 }\end{array}$} & $\begin{array}{c}\text { Net Solar-to- } \\
\text { Electric Efficiency } \\
\mathbf{( G )}\end{array}$ & \multicolumn{2}{|c|}{ LEC } \\
\cline { 4 - 5 } & $\mathbf{( \% )}$ & $\mathbf{( \$ / k W h )}$ & $\begin{array}{c}\text { Percent change from } \\
\text { S\&L Base Case }\end{array}$ \\
\hline SunLab & 8.7 & $18.1 \%$ & 0.0350 & SunLab Base \\
\hline S\&L & 2.6 & $17.3 \%$ & 0.0476 & $-13.0 \%$ \\
\hline S\&L & 2.6 & $16.5 \%$ & 0.0547 & S\&L Base \\
\hline S\&L & 2.6 & $14.6 \%$ & 0.0590 & $7.9 \%$ \\
\hline
\end{tabular}




\subsubsection{Total Investment Cost}

The major cost contributors in total investment cost of a tower solar plant are the solar collector field (43\%), receiver system (16\%), and the power block (13\%).

In combination with thermal storage, increased annual net efficiency, and reduced equipment cost via technology advancements, competition and deployment are the primary elements in reducing the long-term cost of the tower plant.

\subsubsection{Near Term (2004)}

The SunLab projected near-term total investment cost is $\$ 7,135 / \mathrm{kW}_{\mathrm{e}}$ as compared to S\&L's estimate of $\$ 8,209 / \mathrm{kWe}$. The SunLab projected near-term total investment cost is based on (a) actual values from Solar Two, (b) detailed cost estimates done by industry, and (c) scaling projections and escalation done by SunLab. The basis for the near-term cost is as follows:

- The capital cost of the heliostat estimated by SunLab is $\$ 145$ per $\mathrm{m}^{2}$ as compared to the S\&L estimate of $\$ 160$. S\&L reviewed several detailed cost estimates and developed a composite cost analysis. The detailed cost estimates used were developed by ADLittle (2001), PeerlessWinsmith (1989, 1996, 1999), Advanced Thermal Systems (1996), and Solar Kinetics (1996) for the 148- $\mathrm{m}^{2}$ heliostat. S\&L evaluated each cost component associated with the manufacturing of heliostats. The largest cost components are the drive mechanisms, which are about $50 \%$ of the total cost. This cost is relativity accurate since there are detailed cost estimates from the manufacturer. The cost for the $95-\mathrm{m}^{2}$ heliostat was then estimated based on a scaling factor of 0.80 , which is more conservative than the industry standard of 0.7 .

- The receiver cost estimate is based on information provided by Boeing. Boeing is the supplier of the receiver for Solar Tres. The receiver cost estimate is based on actual costs from the Solar Two demonstration project, detailed design and material lists, and cost estimates by Boeing.

- The SunLab cost estimate for near term is based on actual costs for Solar Two and vendor quotes obtained during the Central Receiver Utility Studies (1989), which was a 100-MWe plant. S\&L reviewed the vendors' quotes and validated that the component costs were within typical industry costs.

- The near-term indirect two-tank thermal storage system is based on cost estimates from detailed design drawings and material takeoffs developed by Nextant. The technological risk using the two-tank molten-salt storage system is low based on the successful utilization at the Solar Two plant.

- Sargent \& Lundy estimated costs for the power block and balance of plant using the EPRI SOAPP program. The result was that the capital cost estimated by S\&L for the electrical power block is less than the SunLab estimate $(\$ 563 / \mathrm{kWe}$ versus $\$ 730 / \mathrm{kWe})$. The capital cost estimated by S\&L for the balance of plant is higher than the SunLab estimate $(\$ 741 / \mathrm{kWe}$ versus $\$ 356 / \mathrm{kWe}$ ). The SunLab power block cost estimates are based on a 1990 ABB quotation for a 
100-MW steam turbine. The ABB quotation was escalated and scaled-up for the larger sizes. The SunLab power block cost estimates are based on dated information and the escalation and scale-up factors add to the uncertainty of the data with respect to current pricing. Equipment prices in the SOAPP program reflect 2001 actual costs. Since the SOAPP pricing is current, the SOAPP-generated costs are more characteristic of current power block costs.

- SunLab cost estimate included an average contingency of $7.8 \%$, compared to S\&L's estimate of $10 \%$ for direct costs and $15 \%$ for cost reductions.

- The SunLab estimate for engineering, management, and development is $7.8 \%$, whereas S\&L estimated $15 \%$.

- SunLab estimated a risk pool factor of $10 \%$ for only Solar Tres, whereas S\&L estimated that risk pool factor of 10\% for Solar Tres and 5\% for Solar 50.

Based on the above, the risk of achieving the near-term total investment cost is low to average.

\subsubsection{Mid Term (2010)}

The SunLab projected mid-term total investment cost indicates a total cost of $\$ 3,103 / \mathrm{kWe}$, a reduction of $\$ 4,032 / \mathrm{kWe}$ from the near-term projected cost of $\$ 7,135 / \mathrm{kWe}$, mainly attributable to the following:

- An increase in the plant size from $15 \mathrm{MW}$ to $100 \mathrm{MW}$, which reduces the $\$ / \mathrm{kWe}$ cost by virtue of the larger $\mathrm{kWe}$ size.

- Reduced cost of solar collection system components from near-term cost of $\$ 145 / \mathrm{m}^{2}$ to $\$ 107 / \mathrm{m}^{2}$ as a result of technological advances, scale-up, and production volume.

- Reduced cost of electric power generation system components from a near-term cost of $\$ 733 / \mathrm{kWe}$ to $\$ 400 / \mathrm{kWe}$, primarily as a result of scale-up.

- Reduction of the receiver system capital cost from the near-term cost of $\$ 50 / \mathrm{m}^{2}$ to $\$ 27 / \mathrm{m}^{2}$ as a result of technology, scale-up, and volume production.

There is a mid to high risk of achieving the SunLab projected mid-term total investment cost of $\$ 2,876 / \mathrm{kWe}$, based on the following:

- The SunLab projected reduced cost of solar collection system components is based on one 15-MW plant, six 50-MW plants and six 100-MW plants with an increase from $95 \mathrm{~m}^{2}$ to $148 \mathrm{~m}^{2}$ for the 100-MW plants. Market expansion of tower technology will require incentives to reach the projected level of deployment.

- The SunLab projected mid-term net annual solar-to-electric efficiency is $16.6 \%$; an improvement of 2.9 percentage points from the near-term projected efficiency of $13.7 \%$. The solar field size, and thus the solar field cost, is directly proportional to the net annual solar-toelectric efficiency of a tower plant. As previously discussed, there is a high risk of achieving the mid-term net annual solar-to-electric efficiency of $17.0 \%$. A mid-term net annual solar-to- 
electric efficiency of approximately $15.4 \%$ represents a lower risk by limiting the technology improvements to currently demonstrated or tested improvements.

\subsubsection{Long Term (2020)}

The SunLab projected long-term total investment cost indicates a total cost of $\$ 2,272 / \mathrm{kWe}$, a reduction of $\$ 831 / \mathrm{kWe}$ from the mid-term projected cost of $\$ 3,103 / \mathrm{kWe}$, mainly attributable to the following:

- Reduced cost of solar collection system components from near-term cost of $\$ 107 / \mathrm{m}^{2}$ to $\$ 75 / \mathrm{m}^{2}$ as a result of technological advances, scale-up, and production volume.

- An increase in the plant sizes from $100 \mathrm{MW}$ to $220 \mathrm{MW}$, which reduces the $\$ / \mathrm{kWe}$ cost by virtue of the larger kWe size.

There is a high risk of achieving the SunLab projected long-term total investment cost based on the following:

- The SunLab projected reduced cost of solar collection system components is based on twentyone 100-MW plants, twenty-two 200-MW plants, and six 220-MW advanced technology plants. Market expansion of tower technology will require incentives to reach the projected level of deployment.

- The SunLab projected long-term net annual solar-to-electric efficiency is $18.1 \%$, an improvement of 1.5 percentage points from the mid-term projected efficiency of $16.6 \%$. The solar field size, and thus the solar field cost, is directly proportional to the net annual solar-toelectric efficiency of a tower plant. As previously discussed, there is a high risk of achieving the long-term net annual solar-to-electric efficiency of $18.1 \%$. A long-term net annual solar-toelectric efficiency of $16.2 \%$ represents a lower risk by limiting the technology improvements to those not requiring advanced technology.

The long-term risks are similar to the mid-term risks discussed previously. However, the risk is mitigated if the tower technology is successfully deployed to the extent that the competitive market prompts research and development of technological advances and plant sizes in the 200-220-MW range.

\subsubsection{Operation and Maintenance (O\&M) Costs}

The SunLab O\&M estimate is based largely on the experience at the KJC Operating Company SEGS plants, modified to account for tower technology. The model assumes a stand-alone tower power plant (as opposed to the five co-located plants at Kramer Junction) and adjusts cost depending on the size of the solar field and total electric generation per year. KJC Operating Company provided proprietary information on the last five years of operation. 
The major contributor for O\&M costs is staffing. The staffing is a fixed cost, and the SunLab projected manpower requirements are reasonable based on data from similar-sized power plants and adjusted for the size of the solar field.

The industry plan keys on thermal storage to obtain a high capacity factor, which reduces the O\&M costs (\$/MWh) by obtaining a higher annual MWh generation. The net annual solar-to-electric efficiency has a significant impact on the O\&M costs. Increased efficiency reduces the size of the solar field and thus reduces the number of heliostats.

\subsubsection{Near Term (2004)}

The SunLab projected near-term O\&M cost of $\$ 0.027 / \mathrm{kWh}$ is based on an annual solar-to-electric efficiency of $13.7 \%$, annual capacity factor of $78 \%$, and 16 hours of thermal storage. S\&L projected near-term O\&M costs of $\$ 0.033 / \mathrm{kWe}$. As previously indicated, there is a low risk of achieving the near-term net annual solar-to-electric efficiency, and the technological risk using the two-tank molten-salt storage system is low.

The risk of not achieving the SunLab projected near-term O\&M costs are low because-

- The labor staffing and average annual rate are consistent with the SEGS plants; similar sized fossil-fired power plants adjusted for O\&M of the solar field, and labor rates in the Southwest.

- The material and service costs were developed based on actual costs for SEGS and adjusted for the differences in technology.

\subsubsection{Mid Term (2010)}

The SunLab projected near-term O\&M cost of $\$ 0.006 / \mathrm{kWh}$ is based on an annual solar-to-electric efficiency of $16.6 \%$, annual capacity factor of $73 \%$, and 13 hours of thermal storage. S\&L projected near-term O\&M costs of $\$ 0.008 / \mathrm{kWe}$. As previously indicated, there is a low risk of achieving the mid-term net annual solar-to-electric efficiency, and the technological risk using the two-tank molten-salt storage system is low.

The risk of not achieving the SunLab projected mid-term O\&M cost is average for the reasons identified previously for near term and for the following reasons:

- The staffing does not increase proportionally as the size of the units increases. The core staff for operation and management of the plant will be the same. The increases in staff are for maintenance of the solar field and are estimated to be proportional to the size of the field.

- The plant capacity increases directly as a result of thermal storage. Increasing the size (MWe) and utilization (capacity factor) of the power plant incurs very little increase in O\&M expenses 
(\$/yr). This is because the quantity and complexity of the equipment remain constant and staffing remains fairly constant. Our review of conventional fossil plant shows this 'economy of scale' in staffing for increases in plant size.

The S\&L projected near-term O\&M cost is $\$ 0.006 / \mathrm{kWh}$. The differences are as follows:

- $\quad$ Sargent \& Lundy scaled-up the cost of contracts associated with increases in field size.

- $\quad$ Sargent \& Lundy scaled-up the cost of fuel and maintenance of vehicles to account for increase in field size.

- $\quad$ Sargent \& Lundy assumed that the average burden rate would not decrease.

\subsubsection{Long Term (2020)}

The SunLab projected long-term O\&M cost of $\$ 0.003 / \mathrm{kWh}$ is based on an annual solar-to-electric efficiency of $18.1 \%$, and annual capacity factor of $73 \%$, and 12.7 hours of thermal storage. S\&L projected long-term O\&M costs of $\$ 0.006 / \mathrm{kWh}$. As previously indicated, there is a high risk of achieving the long-term net annual solar-toelectric efficiency as a result of the advanced turbine and heliostat.

The risk of not achieving the S\&L projected long-term O\&M cost (e.g., no advanced turbine and heliostats) is average for the reasons identified previously for near- and mid-term.

\subsection{COST SENSITIVITIES}

In this section, variations in the inputs for levelized energy costs are shown to illustrate the sensitivity of energy calculated cost to variations. The sensitivity analysis revealed that the impact on the LEC of the various scenarios is basically the same for both trough and tower technologies. The base case for the sensitivity analysis for the tower in 2020 is $200 \mathrm{MW}$ with a capital cost of $\$ 3,591$ per $\mathrm{kW}$ and annual O\&M costs of $\$ 9,132$ is shown in Table 5-35. The trough base case is shown for reference.

Table 5-35 - S\&L Base Case for the Year 2020

\begin{tabular}{|l|c|c|}
\hline & Trough & Tower \\
\hline Year & 2020 & 2020 \\
\hline Capacity, MWe & 400 & 200 \\
\hline Capacity Factor, & $56.2 \%$ & $72.9 \%$ \\
\hline Capital Cost, \$/kW & $\$ 3,220$ & $\$ 3,591$ \\
\hline Annual O\&M Cost, \$k & $\$ 14,129$ & $\$ 9,132$ \\
\hline
\end{tabular}




\begin{tabular}{|l|c|c|}
\hline & Trough & Tower \\
\hline LEC, \$/kWh & $\$ 0.0621$ & $\$ 0.0547$ \\
\hline Economic Life & $30 \mathrm{yrs}$ \\
\hline General Inflation & $2.5 \%$ \\
\hline Equity Rate of Return & $14 \%$ \\
\hline Cost of Construction & $7 \%$ \\
\hline Construction Duration & $1 \mathrm{yr}$. \\
\hline Investment Tax Credit & $10 \%$ \\
\hline Taxes & $40.2 \%$ \\
\hline Depreciable Life & $5 \mathrm{yrs}$. \\
\hline IRR & $14 \%$ \\
\hline DSCR & 1.35 \\
\hline
\end{tabular}

\subsubsection{Depreciable Life}

The tax depreciation allowances for renewable energy provide a favorable 5-year depreciable life. The Modified Accelerated Cost Recovery System (MACRS) defined depreciation schedules for 5, 10, and 15 years. If the tax laws are changed or reinterpreted the variation in LEC in 2020 is shown below.

Table 5-36 - Effect of Depreciable Life on Levelized Energy Cost

\begin{tabular}{|c|c|c|}
\hline \multirow{2}{*}{$\begin{array}{c}\text { Depreciable Life } \\
\text { (years) }\end{array}$} & \multicolumn{2}{|c|}{ LEC in 2020} \\
\hline & $\$ / k W h$ & $\%$ difference \\
\hline 5 & $\$ 0.0547$ & Base Case \\
\hline 10 & $\$ 0.0580$ & $6.0 \%$ \\
\hline 15 & $\$ 0.0614$ & $12.3 \%$ \\
\hline
\end{tabular}

\subsubsection{Investment Tax Credits}

The investment tax credits have a major impact on the economic feasibility of a renewable energy power plant. Current tax law allows a $10 \%$ investment tax credit. Future tax laws may allow a larger tax credit such as the $15 \%$ before 1985 or disallow investment tax credits. Tax credits from $0 \%$ to $15 \%$ and Energy Production Tax Credit (PTC) result in the LEC in 2020 to vary as shown below. 


\section{Table 5-37 - Effect of Investment Tax Credits on Levelized Energy Cost}

\begin{tabular}{|c|c|c|}
\hline \multirow{2}{*}{$\begin{array}{c}\text { Tax Credits } \\
(\%)\end{array}$} & \multicolumn{2}{|c|}{ LEC in 2020 } \\
\cline { 2 - 3 } & $\$ / \mathbf{k W h}$ & $\%$ difference \\
\hline $0 \%$ & $\$ 0.0590$ & $7.8 \%$ \\
\hline $5 \%$ & $\$ 0.0568$ & $3.9 \%$ \\
\hline $10 \%$ & $\$ 0.0547$ & Base Case \\
\hline $15 \%$ & $\$ 0.0526$ & $-3.9 \%$ \\
\hline PTC of $1.8 \phi / k W h$ & $\$ 0.0410$ & $-30.5 \%$ \\
\hline
\end{tabular}

\subsubsection{Corporate Tax Rate}

Corporate tax rates are currently at $35 \%$. State taxes vary depending on the plant location but are assumed to be $8 \%$. The composite base tax rate is $43 \%$. The present Government Administration is currently considering reductions in the corporate tax rate but the rate can vary depending on the economic conditions at the time. The impact on LEC in 2020 from changes in the tax rate is below.

Table 5-38 - Effect of Corporate Tax Rates on Levelized Energy Cost

\begin{tabular}{|c|c|c|c|c|}
\hline \multicolumn{3}{|c|}{ Corporate Tax Rates } & \multicolumn{2}{c|}{ LEC in 2020} \\
\hline Federal & State & Composite & $\$ / \mathbf{k W h}$ & $\%$ Difference \\
\hline $30 \%$ & $8 \%$ & $38 \%$ & $\$ 0.0557$ & $1.9 \%$ \\
\hline $35 \%$ & $8 \%$ & $43 \%$ & $\$ 0.0547$ & Base Case \\
\hline $38 \%$ & $10 \%$ & $48 \%$ & $\$ 0.0538$ & $-1.7 \%$ \\
\hline
\end{tabular}

\subsubsection{Inflation}

Inflation assumptions does not affect the real dollar levelized energy cost. Increases and decreases in the inflation rate impact the LEC in 2020 as shown below. 
Table 5-39 - Effect of Inflation on Levelized Energy Cost

\begin{tabular}{|c|c|c|c|}
\hline \multicolumn{2}{|c|}{ Inflation Rate } & \multicolumn{2}{c|}{ LEC in $\mathbf{2 0 2 0}$} \\
\hline Rate & IRR & $\$ \mathbf{k W h}$ & $\%$ difference \\
\hline $1.5 \%$ & $12.9 \%$ & $\$ 0.0542$ & $-1.0 \%$ \\
\hline $2.5 \%$ & $14.0 \%$ & $\$ 0.0547$ & Base Case \\
\hline $3.5 \%$ & $15.1 \%$ & $\$ 0.0553$ & $1.0 \%$ \\
\hline
\end{tabular}

\subsubsection{Cost of Capital}

Cost of capital for the base case is such that there is an internal rate of return (IRR) of 14\%. The impact on LEC in 2020 from a change in the cost of capital is shown below.

Table 5-40 - Effect of Cost of Capital on Levelized Energy
\begin{tabular}{|c|c|c|}
\hline Cost of Capital & \multicolumn{2}{|c|}{ LEC in $\mathbf{2 0 2 0}$} \\
\hline IRR & $\$ / \mathbf{k W h}$ & $\%$ Difference \\
\hline $13 \%$ & $\$ 0.0508$ & $-7.1 \%$ \\
\hline $14 \%$ & $\$ 0.0547$ & Base Case \\
\hline $15 \%$ & $\$ 0.0588$ & $7.6 \%$ \\
\hline
\end{tabular}

\subsubsection{Construction Duration}

The plant construction period for the base case is one year based on experience at the SEGS plants. The amount of interest during construction (IDC) is included in the LEC. The impact on LEC in 2020 for construction of two and three years is shown below.

Table 5-41 - Effect of Construction Duration on Levelized Energy Cost

\begin{tabular}{|c|c|c|}
\hline \multirow{2}{*}{$\begin{array}{c}\text { Construction } \\
\text { Period } \\
\text { (yr) }\end{array}$} & \multicolumn{2}{|c|}{ LEC in $\mathbf{2 0 2 0}$} \\
\cline { 2 - 3 } & $\mathbf{\$ / k W h}$ & $\%$ Difference \\
\hline 1 & $\$ 0.0547$ & Base Case \\
\hline 2 & $\$ 0.0577$ & $5.4 \%$ \\
\hline 3 & $\$ 0.0608$ & $11.1 \%$ \\
\hline
\end{tabular}




\subsubsection{Capital Cost}

The variation for increases in capital costs is shown below.

Table 5-42 - Effect of Capital Cost Increases on Levelized Energy Cost

\begin{tabular}{|c|c|c|}
\hline \multirow{2}{*}{$\begin{array}{c}\text { Increase in Capital } \\
\text { Cost } \\
(\%)\end{array}$} & \multicolumn{2}{|c|}{ LEC in 2020 } \\
\cline { 2 - 3 } & $\$ / \mathbf{k W h}$ & $\%$ difference \\
\hline $0 \%$ & $\$ 0.0547$ & Base Case \\
\hline $10 \%$ & $\$ 0.0595$ & $8.7 \%$ \\
\hline $20 \%$ & $\$ 0.0642$ & $17.4 \%$ \\
\hline
\end{tabular}

\subsubsection{Annual O\&M Cost}

The variation for increases in annual O\&M costs is shown below.

Table 5-43 - Effect of O\&M Cost Increase on Levelized Energy Cost

\begin{tabular}{|c|c|c|}
\hline \multirow{2}{*}{$\begin{array}{c}\text { Increase in Annual } \\
\text { O\&M Cost } \\
(\%)\end{array}$} & \multicolumn{2}{|c|}{ LEC in 2020} \\
\hline & $\$ / k W h$ & $\%$ difference \\
\hline $0 \%$ & $\$ 0.0547$ & Base Case \\
\hline $10 \%$ & $\$ 0.0554$ & $1.3 \%$ \\
\hline $20 \%$ & $\$ 0.0561$ & $2.6 \%$ \\
\hline
\end{tabular}

\subsubsection{Ownership}

The S\&L base case considers ownership by an Independent Power Producer (IPP). An investment by developer/owners and financial institutions would require an IRR of at least $14 \%$. It is more likely that the first several power plants will be owned by utilities. Utilities require a lower IRR and would be more receptive to renewable initiatives. As the industry matures (e.g., capital cost declines and the technology is proven), the IPPs would become involved. There is the potential for private ownership in the early plants, but it would most likely be from manufacturers who could offset the lower IRR with increased sales for solar equipment. The impact of ownership on LEC for 2020 is shown below. 
Table 5-44 - Effect of Ownership on Levelized Energy Cost

\begin{tabular}{|l|c|c|c|}
\hline & IPP & $\begin{array}{c}\text { Utility } \\
\text { Ownership }\end{array}$ & Muni \\
\hline IRR, $\%$ & $14 \%$ & $11.5 \%$ & $0 \%$ \\
\hline Leverage & $60 / 40$ & $50 / 50$ & $100 / 0$ \\
\hline Cost of Debt & $5 \%$ & $7 \%$ & $5 \%$ \\
\hline DSCR & 1.35 & 1.74 & 1.0 \\
\hline LEC, $\$ /$ kWh & $\$ 0.0547$ & $\$ 0.0526$ & $\$ 0.0406$ \\
\hline$\%$ difference & Base Case & $-3.8 \%$ & $-25.7 \%$ \\
\hline
\end{tabular}


Appendix A List of Documents 


\section{A. LIST OF DOCUMENTS}

This list contains both the documents cited in footnotes in the text and other documents reviewed for the report.

Advanced Thermal Systems, Inc., 1996. Solmat Phase 1 Final Review, Model H-150 Heliostat Design, May 15, 1996

AeroVironment, Inc., 1995. "Fugitive Emissions Testing - Final Report," for KJC Operating Company, Monrovia, California, January 1995.

Akhil, A.A., S.K. Swaminathan, and R.K. Sen, 1997. Cost Analysis of Energy Storage for Electric Utility Applications, Sandia National Laboratories: February 1997. Report SAND97-0443.

Alpert, D.J., and G.J. Kolb, 1988. Performance of the Solar One Power Plant as Simulated by the SOLERGY Computer Code, Sandia National Laboratories, Albuquerque, NM: 1988. Report SAND88-0321.

Anderson, 1998. The Economics of Photovoltaic Technologies.

Anderson, D. and K. Ahmed, 1995. The Case for the Solar Energy Investments, World Bank Technical Paper Number 279 - Energy Series, World Bank, Washington D.C.: February 1995. ISBN 0-8213-3196-5.

Arthur D. Little, Inc., 2001. “Heliostat Cost Review,” June

ASME, 2001. "EUROTROUGH Design Issues And Prototype Testing At PSA," Proceedings of ASME International Solar Energy Conference - Forum 2001, Solar Energy.

Bechtel National Inc., 1995. "Central Receiver Commercialization Plan," for the California Energy Commission: June 1995. Report 01-0444-35-3027-2777.

Boeing, Roadmap: Power Tower Receiver System (not publicly available).

Boer, Karl W., ed., 1997. Advances in Solar Energy - An Annual Review of Research and Development, Volume 11, Chapter 1, article by Mancini, T.R., M.R. Prairie, and G.J. Kolb, American Solar Energy Society, Inc., Boulder, CO, 1997. ISBN 0-89553-254-9. 
Central Receiver Utility Studies, 1989. A series of reports prepared by Pacific Gas and Electric (and its principal subcontractor, Bechtel National, Inc.) and Arizona Public Service (and its principal subcontractor, Black and Veatch Engineers-Constructors) cofunded by the U.S. Department of Energy, the Electric Power Research Institute, and the utilities themselves.

Chiang, C. J., 1987. SUNBURN: A Computer Code for Evaluating the Economic Viability of Hybrid Solar Central Receiver Electric Power Plants, Sandia National Laboratories, Albuquerque, NM: June 1987. Report SAND86-2165.

Christiansson, L., 1995. Diffusion and Learning Curves of Renewable Energy Technologies. Working Paper WP-95-126. International Institute for Applied Systems Analysis. Laxenburg, Austria. [Note: Christiansson is Neij's maiden name.]

Cohen, G., and S. Frier, 1997. "Ten Years of Solar Power Plant Operation in the Mojave Desert," Proceedings of Solar 97, the 1997 ASES Annual Conference, Washington, D.C. (April 1997).

Dahl, Jaimee, Karen Buechler, Alan Weimer, Allan Lewandowski, and Carl Bingham, 2002. "Rapid Solarthermal Dissociation of Natural Gas in an Aerosol Flow Reactor," 11th SolarPACES International Symposium on Concentrated Solar Power and Chemical Energy Technologies, Zurich, Sep 4-6, 2002.

Dudley, V., G. Kolb, A. R. Mahoney, T. Mancini, C. Matthews, M. Sloan, and D. Kearney, 1994. Test Results: SEGS LS-2 Solar Collector, Sandia National Laboratories, Albuquerque, New Mexico: December 1994. Report SAND94-1884.

Duke Solar, 2000. “Task 2 Report: New Space-Frame Parabolic Trough Structure,' Prepared for NREL by Duke Solar, Raleigh, NC.

Durstewitz, M., 1999. Using information of Germany's "250 MW Wind" Programme for the construction of Wind power experience curves. Proceedings of the IEA International Workshop "Experience Curves for Policy Making: The case of energy technologies," Stuttgart, Germany, 10-11 May.

EERE, 2002. "Feasibility of 1,000 Megawatts of Solar Power in the Southwest by 2006."

Electric Power Research Institute (EPRI). State of the Art Power Plant (SOAPP) computer program: developed, distributed, and supported by EPRI. 
Energy Information Administration, 2002. “Annual Energy Outlook 2002 with Projections to 2020," U.S. Department of Energy.

Energy Information Administration, 2002. "International Energy Outlook 2002," U.S. Department of Energy.

Enermodal Engineering Limited, 1999. "Cost Reduction Study for Solar Thermal Power Plants," prepared for the World Bank.

Falcone, P.K., 1986. A Handbook for Solar Central Receiver Design, Sandia National Laboratories, Livermore, CA: December, 1986. Report SAND86-8009.

Flachglas Solartechnik GmbH, 1994. "Assessment of Solar Thermal Trough Power Plant Technology and Its Transferability to the Mediterranean Region - Final Report," for European Commission Directorate General I External Economic Relations, and Centre de Developpement des Energies Renouvelables and Grupo Endesa, Cologne, Germany: June 1994.

Gee, Cohen, and Winston, 2002. "A Non-Imaging Receiver for Parabolic Trough Concentrating Collectors," Proceedings of Solar 2002.

Gorman, D., 1993. "Heliostat Costs at Reduced Production Volumes - Report to Sandia National Laboratories," Advanced Thermal Systems:

Hubbard, H., et al., 2000. Renewable Power Pathways; A Review of the U.S. Department of Energy's Renewable Energy Programs, National Research Council, National Academy Press, 2000.

Humphreys, K.K., and L.M. English, 1993. "Project and Cost Engineers' Handbook," Third Edition, AACE International, Marcel Dekker, Inc., New York, 1993.

Humphreys, K.K., and L.M. English, Project \& Cost Engineer's Handbook, AACE International.

IEA, 2000. Experience Curves for Energy Technology Policy. International Energy Agency, Paris, France. (ISBN 92-64-17650-0).

Integrated Solar Combined Cycle Systems (ISCCS) 1996. Using Parabolic Trough Technology, Phase 1B Technical and Financial Review, Spencer Management Associates, Diablo, CA: March 1996, draft. 
International Energy Agency, 2001a. "2000 Energy Technologies and Systems: A View to 2050," PCADT 1997, cited in Anderson 1998 as cited in the UK Project on Resource Productivity and Renewable Resource, Energy Technologies and Systems: A View to 2050, Part 1. Technical and Economic Potential of Generating Technologies, Draft May 4, 2001.

International Energy Agency, 2001b. "2000, Experience Curves for Energy Policy Assessment” as cited in the UK Project on Resource Productivity and Renewable Resource, Energy Technologies and Systems: A View to 2050, Part 1. Technical and Economic Potential of Generating Technologies, Draft May 4, 2001.

IST, 2001, “Collector Development,” Presentation at Solar Forum 2001, Solar Energy.

Kearney, D., 2001a. Engineering Evaluation of a Molten Salt HTF in a Parabolic Trough Solar Field, Task 6 Report, Final System Performance and Cost Comparisons, August 20, 2001.

Kearney, D., 2001b. "Engineering Evaluation of a Molten Salt HTF in a Parabolic Trough Solar Field," Task 7 Report, Recommendations on Development Needs, September 15, 2001.

Kearney, D., and C. Miller, 1988. Solar Electric Generating System VI - Technical Evaluation of Project Feasibility, LUZ Partnership Management, Inc.: January 15, 1988.

KJC Operating Company, 1994, “O\&M Cost Reduction in Solar Thermal Electric Power Plants - Interim Report on Project Status," for Sandia National Laboratories: September 1, 1994.

KJCOC, 1999. “O\&M Cost Reduction Report,” June.

Klenow, "Learning Curves and the Cyclical Behavior of Manufacturing Industries."

Kobos, P., 2002. “The Implications of Renewable Energy Research and Development: Policy Scenario Analysis with Experience and Learning Effects.” Ph.D. thesis, Rensselaer Polytechnic Institute. (Forthcoming).

Kolb, G. J., 1995. "Evaluation of Power Production from the Solar Electric Generating Systems at Kramer Junction: 1988 to 1993”, Solar Engineering - 1995, Proceedings of the ASME Solar Energy Conference, Maui, HI (March 19-24, 1995). 
Kolb, G. J., 1996. "Economic Evaluation of Solar-Only and Hybrid Power Towers Using Molten Salt Technology", Proceedings of the 8th International Symposium on Solar Thermal Concentrating Technologies, Cologne, Germany (October 6-11, 1996). Accepted for publication in the journal Solar Energy.

Kolb, G., J. Chavez, and W. Meinecke, 1993. "Second Generation Central Receiver Technologies: A Status Report,” M. Becker, and P. Klimas, eds., Verlag C.F. Muller Karlsruhe, DLR, and Sandia National Laboratories: 1993. Report ISBN 3-7880-7482-5.

Kouvaritakis, N., Soria, A., and Isoard, S., 2000. "Modeling Energy Technology Dynamics: Methodology for Adaptive Expectations Models with Learning by Doing and Learning by Searching.” Int. J. Global Energy Issues, Vol. 14, Nos. 1-4, pp. 104-115.

Kribus, A., P. Doron, R. Rubin, R. Reuven, E. Taragan, S. Duchan, and J. Karni, 2001. "Performance of the Directly Illuminated Annular Pressurized Receiver (DIAPR) Operating at 20 Bar and 1200 C," 123:10-17, Journal of Solar Energy Engineering.

Lotker, M., 1991. "Barriers to Commercialization of Large-Scale Solar Electricity: Lessons Learned from the LUZ Experience,” Sandia National Laboratories, Albuquerque, New Mexico: Report SAND91-7014.

LUZ International Limited, 1990. "Solar Electric Generating System IX Technical Description," LUZ International Limited.

Mackay, R.M. and S.D. Probert, 1998. "Likely Market-Penetration of Renewable-energy Technologies," Applied Energy. Vol. 59, No. 1. pp. 1-38.

Marion, W., and S. Wilcox, 1994. "Solar Radiation Data Manual for Flat-Plate and Concentrating Collectors," National Renewable Energy Laboratory, Golden, Colorado: April 1994. Report NREL/TP-463-5607.

McDonald, A. and L. Schrattenholzer, 2001. "Learning Rates for Energy Technologies." Energy Policy, Vol. 29, Issue 4, pp. 255-261, March.

Meinecke, W., and M. Bohn, 1995. "Solar Energy Concentrating Systems: Applications and Technologies," edited by M. Becker, and B. Gupta, Muller Verlag, Heidelberg, Germany. 
Moller, S., R. Buck, R. Tamme, M. Epstein, D. Liebermann, M. Meri, U. Fisher, A. Rotstein, and C. Sugarman, 2002. "Solar Production of Syngas for Electricity Generation: SOLASYS Project Test-Phase," 11th SolarPACES International Symposium on Concentrated Solar Power and Chemical Energy Technologies, Zurich, Sep 4-6, 2002.

Morales, A., and Ajona, J. I., 1998. 'DDurability, Performance and Scalability of Sol-Gel Front Surface Mirrors and Selective Absorbers," Proc. of 9th International Symposium on Solar Thermal Concentrating Technologies.

Morse, Frederick H., 2000. "The Commercial Path Forward for Concentrating Solar Power Technologies: A Review of Existing Treatments of Current and Future Markets," Morse Associates, Inc., Washington D.C., December 13, 2000.

Muller, M., 1994. "Direct Solar Steam in Parabolic Trough Collectors (DISS), Plataforma Solar de Almeria (PSA)," CIEMAT and DLR, May 1994, ISBN 84-605-1479-X.

National Construction Estimator, 49th Edition, erected structural steel for California.

National Research Council (NRC) Committee for the Review of a Technology Assessment of Solar Power Energy Systems, 2002. "Critique of the Sargent \& Lundy Assessment of Cost and Performance Forecasts for Concentrating Solar Power," October 12, 2002 [Note the review was performed on Draft 3 of the Sargent \& Lundy Report, SL-5641, dated October 2002]

Neij, Lena, 1997. "Use of Experience Curves to Analyze the Prospects for Diffusion and Adoption of Renewable Energy Technology."

Neij, Lena, 1999. “Cost dynamics of wind power.” Energy. Vol. 24, pp. 375-389.

Nextant Inc., 2001. USA Trough Initiative: Nitrate Salt Heat Transport Fluid Rankine Cycle, Steam Generator, and Thermal Storage Analysis, January 19, 2001.

O\&M Cost Reduction in Solar Thermal Electric Power Plants - 2nd Interim Report on Project Status, KJC Operating Company, for Sandia National Laboratories: July 1, 1996. 
Pacheco, J.E. (ed), G.J. Kolb, H.E. Reilly, S.K. Showalter, S.H. Goods, R.W. Bradshaw, D.B. Dawson, S.A. Jones, M.J. Hale, R.L. Gilbert, M.R. Prairie, and P. Jacobs, 2002. "Final Test and Evaluation Results from the Solar Two Project,” SAND2002-0120, Sandia National Laboratories, Albuquerque, NM.

Pacific Gas \& Electric Company, 1988. "Solar Central Receiver Technology Advancement for Electric Utility Application, Phase 1 Topical Report,”San Francisco, CA: September 1988. Report 007.2-88.2.

PCADT 1997. "US President's Committee of Advisors on Science and Technology report the President on Federal Energy Research and Development Challenges for the $21^{\text {st }}$ Century."

Peerless-Winsmith, Inc, 1989. "Development of a Low-Cost Drive Tracking Mechanism for Solar Heliostats or PV Arrays - Final Report,” for Sandia National Laboratories: February 1989. Report 90-5753.

Peerless-Winsmith, Inc., 1996. "Results of Dual Axis Solar Drive DFMA Workshop," Contract ACG-5-1520901, January 26, 1996.

Peerless-Winsmith, Inc., 1999. "Enhanced Azimuth Solar Drive Project Summary Report,” for Sandia National Laboratories, Contract Number BF-0031, October 1999.

Pilkington International, 1999. "Solar Steam System Investment Cost," prepared for Midwest Research Institute, December 1999.

Pilkington Solar International, 1996. "Status Report on Solar Thermal Power Plants," Report ISBN 3-9804901$0-6$.

Price, H., E. Lüpfert, D. Kearney, E. Zarza, G. Cohen, R. Gee, and R. Mahoney, 2002. "Advances in Parabolic Trough Solar Power Technology,” Journal of Solar Energy Engineering, May 2002.

Price, H., and Kearney, D., 1999. "Parabolic-Trough Technology Roadmap: A Pathway for Sustained Commercial Development and Deployment of Parabolic-Trough Technology," NREL/TP-550-24748, NREL, Golden, Colorado.

Radosevich, L., 1988. "Final Report on the Power Production Phase of the 10 MWe Solar Thermal Central Receiver Power Plant,” SAND87-8022, Sandia National Laboratories, Livermore, CA, March 1988. 
Regional Economic Research, Inc., 1991. “Technical Potential of Alternative Technologies - Final Report,” for California Energy Commission, Contract No. 500-89-001, San Diego, CA: December 2, 1991.

Reilly, H.E., and G.J. Kolb, 2001. "An Evaluation of Molten-Salt Power Towers Including the Results of the Solar Two Project," SAND2001-3674, Sandia National Laboratories.

San Vicente, G., Morales, A., and Gutiérrez, M. T., 2001. "Preparation and Characterization of Sol-Gel TiO 2 Antireflective Coatings for Silicon."

Sandia National Laboratories, 2001. "Development of a Molten-Salt Thermocline Thermal Storage System for Parabolic Trough Plants," Proceeding of Solar Forum 2001.

Science Applications International Corporation, 1996. "Heliostat Cost Study for SOLMAT Program," for National Renewable Energy Laboratory, Golden, CO.

Smith, D.C., and J.M. Chavez, A, 1988. "Final Report on the Phase 1 Testing of a Molten-Salt Cavity Receiver," Sandia National Laboratories, Albuquerque, NM: 1988. Report SAND87-2290.

Solar Kinetics, Inc., 1996. SolMatT, Mirror Module Assembly Plan and Cost Estimate.

Stoddard, M.C., et al., 1987. "SOLERGY - A Computer Code for Calculating the Annual Energy from Central Receiver Power Plants," Sandia National Laboratories, Livermore, California: May 1987. Report SAND868060 .

Strachan, J.W., and R.M. Houser, 1993. "Testing and Evaluation of Large-Area Heliostats for Solar Thermal Applications," Sandia National Laboratories, Albuquerque, NM: February 1993. Report SAND92-1381.

Sugarman, C., A. Ring, R. Buck, R. Uhlig, M. Beuter, M. J. Marcos, and V. Fernandez, 2002. "Solar-Hybrid Gas Turbine Power System," 11th SolarPACES International Symposium on Concentrated Solar Power and Chemical Energy Technologies, Zurich, Sep 4-6, 2002.

SunLab, 2001. Trough: DueDiligence11-Excelergy 11-14-01.xls.

SunLab, 2002. Tower: Tower Reference Case Aug 2.xls; Tower Costs.xls; and Heliostat Costs.xls. 
Sutton, W.F., 1989. Prices of Drives at Different Production Volumes - Report to Sandia National Labs, Peerless-Winsmith, Inc.: April 4, 1989.

Swanekamp, R., 2002. "Return of the Supercritical Boiler,” Power, Vol. 146, No. 4, July 2002.

Teagan, W. Peter, 2001. "Review: Status of Markets for Solar Thermal Power Systems," Arthur D. Little, Sandia Report SAND2001-2521P, May 2001.

Tester J. et al., 2001. CSP Peer Review, December 7, 2001.

UK Project on Resource Productivity and Renewable Resource, Energy Technologies and Systems: A View to 2050, Part 1. Technical and Economic Potential of Generating Technologies, Draft May 4, 2001.

Virtus Energy Research Associates, 1995. "Texas Renewable Energy Resource Assessment: Survey, Overview \& Recommendations," for the Texas Sustainable Energy Development Council, July 1995, ISBN 09645526-0-4.

Weiz Institute of Science, "High-Concentration Solar Energy Optics,” Sun Day Symposium.

Wene, C.O., 2000. Experience Curves for Energy Technology Policy. International Energy Agency, Paris, France. (ISBN 92-64-17650-0).

Wieckert, C., M. Epstein, G. Olalde, R. Palumbo, H. J. Pauling, H.-U. Reichardt, J.-F. Robert, S. Santen, and A. Steinfeld, 2002. "The SOLZINC-Project for Solar Carbothermic Production of Zn from ZnO," 11th SolarPACES International Symposium on Concentrated Solar Power and Chemical Energy Technologies, Zurich, Sep 4-6, 2002.

Williams, T., M. Bohn, and H. Price, 1995. "Solar Thermal Electric Hybridization Issues", Proceedings of the ASME/JSME/JSES International Solar Energy Conference, Maui, HI (March 19-24, 1995).

Winter, C. J., R. Sizmann, and L. Vant-Hull, eds., 1990. Solar Power Plants - Fundamentals, Technology, Systems, Economics. Springer-Verlag, Berlin, 1990, ISBN 3-540-18897-5.

World Bank, 1999. "Cost Reduction Study for Solar Thermal Power Plants." Prepared by Enermodal Engineering Limited in association with Marbek Resource Consultants Ltd. 
Yogev, A., A. Kribus, M. Epstein, A. Kogan, 1998. Solar “Tower Reflector” Systems: A New Approach for High-Temperature Solar Plants, Int. J. Hydrogen Energy, 23(4):239-245, 1998.

Zhang, Q., Zhao, K., Zang, B., Wang, L., Shen, A., Zhou, Z., Lu, D., Xie, D., and Li, B., 1998. “New Cermet Solar Coatings for Solar Thermal Electricity Applications," Solar Energy. 
Appendix B

Methodology 


\section{B. METHODOLOGY}

\section{B.1 SUMMARY}

The study was carried out as follows. The methodology Sargent used to carry out the study is described in this section.

- Sargent \& Lundy collected data and analyses of the current status of trough and tower technologies.

- Sargent \& Lundy reviewed the SunLab Cost Models, industry data, and relevant studies regarding capital cost projections for near-term deployment, cost projections for technology improvements, and plant scale-up through 2020.

- Sargent \& Lundy assessed the level of cost reductions and performance improvements, based on our experience, that are likely to be achieved.

- Sargent \& Lundy developed a financial model to calculate LEC based on project financing assumptions, investment costs, and operations and maintenance costs.

\section{B.2 COLLECTION OF DATA}

Sargent \& Lundy received relevant documents from NREL and Sandia Laboratory for our independent review. During the review process, additional documents were gathered from industry sources, the Internet, and our internal S\&L library. The list of documents is included in Appendix A. Our objective was to review relevant documents, both pro and con, to make our assessment. For example, the Teagan report was critical of the methods used in previous reports to predict cost reductions, in particular learning curves (Teagan 2001).

\section{B.3 REVIEW OF SUNLAB COST MODEL}

Sargent \& Lundy reviewed the SunLab cost model and determined that the SunLab cost model approach and methodology is reasonable. The SunLab cost model was developed based on industry cost data and engineering evaluation.

The following industry cost data were used for the cost models:

- Actual cost data from construction of the SEGS plants and costs of equipment being supplied for O\&M were used (e.g., HCEs).

- Actual cost data from Solar Two were used as the "starting point" and adjusted for present prices. The steam generator cost estimate was based on four vendors' designs and quotes for 
100 MWe (SAND93-7083) and actual costs from Solar Two. The scaling factor was calculated and used to estimate other plant sizes.

An example of engineering evaluation is shown in Table B-1. The cost estimate for the tower height is based on an engineering formula and vendor cost information provided in the Central Receiver Utility Studies (1989).

\section{Table B-1 - Cost Estimate for the Receiver Tower Based on the Central Receiver Utility Studies}

\begin{tabular}{|c|c|c|c|l|}
\hline $\begin{array}{c}\text { Receiver Rating } \\
\text { (MWt) }\end{array}$ & $\begin{array}{c}\text { Tower Height } \\
(\mathbf{m})\end{array}$ & $\begin{array}{c}\text { Installed Cost } \\
\mathbf{( 0 0 0} \mathbf{s})\end{array}$ & $\begin{array}{c}\text { 2001 Cost } \\
\mathbf{( 0 0 0} \mathbf{s})\end{array}$ & \multicolumn{1}{|c|}{ Source } \\
\hline 100 & 75.8 & $\$ 1,160$ & $\$ 1,600$ & Central Receiver Utility Studies \\
\hline 195 & 94.7 & $\$ 1,550$ & $\$ 2,200$ & Central Receiver Utility Studies \\
\hline 343 & 140.0 & $\$ 3,010$ & $\$ 4,200$ & Central Receiver Utility Studies \\
\hline 390 & 149.3 & $\$ 3,410$ & $\$ 4,800$ & Central Receiver Utility Studies \\
\hline 468 & 185.0 & $\$ 5,290$ & $\$ 7,500$ & Central Receiver Utility Studies \\
\hline 780 & 190.0 & $\$ 5,600$ & $\$ 7,900$ & Central Receiver Utility Studies \\
\hline 936 & 247.5 & $\$ 10,020$ & $\$ 14,100$ & Central Receiver Utility Studies \\
\hline
\end{tabular}

Notes:

Tower height, $m=29.1+0.51129589$ * $($ Rating, $M W t)-0.0088703442$ * $(\text { Rating, } M W t)^{1.5}+32,801.719 *(R a t i n g, M W t)^{-2}$ Tower cost $=600,000+17.72 *(\text { Tower height, } \mathrm{m})^{2.392}$

Crane cost $=\$ 500,000$

Sargent \& Lundy evaluated the assumptions in the SunLab cost model: efficiency improvements, capital cost for the near-term deployment, and cost reductions through 2020. The review of cost reductions included technology improvements, increase in the size of the plant (scale-up), and production volume. Scale-up and production volume is discussed in more detail in this section. The cost model was compared to S\&L's internal cost database, where appropriate (e.g., turbine, equipment, and commodities such as steel prices).

Differences between the SunLab and S\&L cost estimates were a result of different assumptions. For example, S\&L increased the duration between the deployment of the next generation plant from 1 year to 2 years to account for lessons learned and an adequate time for steady-state operation. The differences in assumptions are identified in the main body of the report. 


\section{B.4 TECHNICAL IMPROVEMENTS}

Projected technical improvements that reduce costs by improving plant efficiency or by reducing initial capital costs were evaluated with respect to probability of the improvement and the estimated magnitude of cost reduction. The projected technical improvements investigated were those identified in the SunLab models, and the probability and magnitude of cost reductions are based on data from DOE, NREL, Sandia, and members of the CSP industry, including technology assessments and supporting studies for troughs and towers.

\section{B.5 ECONOMY OF SCALE}

Economy of scale was used, as appropriate; to estimate or evaluate cost estimates for components. Scaling factors were used to estimate the cost of a new size or capacity from the known cost for a different size or capacity. The Association for the Advancement of Cost Engineering (AACE) defines this method of estimating as plant component ratios (Humphreys and English 1993). The relationship is based on the following formula:

$$
\begin{aligned}
& \mathrm{C}_{2}=\mathrm{C}_{1}\left(\mathrm{~S}_{2} / \mathrm{S}_{1}\right) \text { Sf } \\
& \text { Where: } \\
& \qquad \mathrm{C}_{2}=\text { desired cost of equipment at size (or capacity) of } \mathrm{S}_{2} \\
& \mathrm{C} 1 \text { = desired cost of equipment at size (or capacity) of } \mathrm{S}_{1} \\
& \mathrm{Sf}=\text { scaling factor }
\end{aligned}
$$

Example: If the cost of a $95-\mathrm{m}^{2}$ heliostat is $\$ 13,654\left(\$ 143.73\right.$ per $\left.\mathrm{m}^{2}\right)$, then the cost of a $148-\mathrm{m}^{2}$ heliostat is estimated at $\$ 19,466\left(\$ 131.53\right.$ per $\left.\mathrm{m}^{2}\right)$ based on a scaling factor of 0.80 .

$$
\mathrm{C}_{2}=\$ 13,654(148 / 95)^{0.8}=\$ 19,466
$$

\section{B.6 VOLUME PRODUCTION (VOLUME AND LEARNING CURVE)}

Experience curves define how unit costs decrease with cumulative production. The specific characteristics of the experience curve are that the cost declines by a constant percentage with each doubling of the total number of units produced. The formula is as follows:

$$
\mathrm{C}_{\mathrm{CUM}}=\mathrm{C}_{0} \times \mathrm{CUM}^{\mathrm{b}}
$$

Where:

$\mathrm{C}_{\mathrm{CUM}}=$ the cost per unit as a function of output

$\mathrm{C}_{0}=$ the cost of the first unit produced 
$\mathrm{CUM}=$ the cumulative production over time

$\mathrm{b}=$ the experience index

The cost reduction is $\left(1-2^{b}\right)$ for each doubling of cumulative production, where the value $\left(2^{b}\right)$ is called the progress ratio (PR). The progress ratio is used to express the progress of cost reductions for different technologies.

The formula is simplified for use as follows:

$$
\begin{aligned}
& \mathrm{PR}=\left(\mathrm{C}_{2} / \mathrm{C}_{1}\right)^{1 /(\text { no. of doublings })} \\
& \begin{array}{l}
\text { Where: } \\
\text { Number of doublings }=\log 2(\mathrm{Q} 2 / \mathrm{Q} 1) \\
\mathrm{C}_{1}=\text { cost of initial unit produced } \\
\mathrm{Q}_{1}=\text { production quantity for the initial unit cost } \\
\mathrm{C}_{2}=\text { desired cost of unit produced } \\
\mathrm{Q}_{2}=\text { cumulative production quantity for desired unit cost } \\
\mathrm{PR}=\text { Progress Ratio }
\end{array}
\end{aligned}
$$

Example: The cost of a $148-\mathrm{m}^{2}$ heliostat is $\$ 160$ per $\mathrm{m}^{2}$ based on production of $227,000 \mathrm{~m}^{2}$. The cost estimate based on a production of $56,000,000 \mathrm{~m}^{2}$ is $\$ 109$. The progress ratio is 0.95 .

$$
\begin{aligned}
& \text { Number of doublings }=\log _{2}(56,000,000 / 227,000)=7.9 \\
& P R=(\$ 109 / \$ 160)^{(1 / 7.9)}=0.95
\end{aligned}
$$

Many of the previous studies that assessed the cost reduction potential for tower and trough technologies based their findings on experience curves, including the World Bank (1999). As pointed out in the Tegan report (2001), "the review documents do not make a strong case that the cost of technologies (particularly the solar field) can be reduced to a point that they approach economic viability...." His primary example was the collector field: "the 'learning curve' arguments put forth lack sufficient backup to be credible given the fact that the materials of construction are already commodities and the fabrication techniques, for the most part standard." He also stated that he believed cost reductions are likely "via a combination of 'learning curve' and technology refinement." In response, S\&L performed a thorough review of the cost reduction potential for heliostats. Heliostat cost reduction potential is more difficult to estimate since it is not based on actual costs with significant volume produced, whereas trough costs and the cost reductions are known based on actual SEGS 
construction data and recent costs for replacement during operations and maintenance. Our detailed evaluation of cost reduction potential for heliostats is provided in Appendix E.5.

We reviewed the engineering assumptions, industry data, and studies that constitute the basis of the SunLab Cost Model for the major cost drivers. The review was not based on just applying an experience curve, but an engineering review. We reviewed the assumptions and made adjustments as deemed appropriate based on our experience. We calculated the progress ratio and compared it to actual experience curves from other industries. The calculated progress ratio value was then used to determine estimated costs for a range of deployments.

For example, cost reductions for $148-\mathrm{m}^{2}$ heliostats due to a volume production of 100 million $\mathrm{m}^{2}$ were calculated to be 0.961 by SunLab and 0.971 by S\&L (see Table E-18). Each cost component was reviewed based on reviewing the initial cost estimate and final cost estimate and then calculating the progress ratio. One of the cost components is fabrication: initial fabrication costs were estimated based on the productivity (hr/unit) and labor rate $(\$ / \mathrm{hr})$ for performing specific tasks (fabricating the mirror support structure, mirror modules, controls, and drives), and then final fabrication costs were estimated based on productivity improvements from volume production (see Section E.5.5). The calculated progress ratio was 0.96 .

The range of progress ratios used for the comparison by S\&L is between 0.85 and 0.96 . Various studies on learning curves from actual data suggest that a progress ratio of 0.82 has been observed for photovoltaics (PV) and 0.82 for development of wind energy during early deployment (1980 to 1995). The higher end of the range is from the Enermodal study for the World Bank (1999), which identified a PV of 0.96 and the Wind Learning Rates compiled by Kobos (Table B-2) for development of wind plants. The Enermodal study projected a reasonable experience curve for trough and tower technologies to be between 0.85 to 0.92 .

Table B-2 - Wind Learning Rates

\begin{tabular}{|l|c|c|l|l|l|l|}
\hline $\begin{array}{l}\text { Country } \\
\text { or Region }\end{array}$ & $\begin{array}{c}\text { Time } \\
\text { Period }\end{array}$ & $\begin{array}{c}\text { Est. Learning } \\
\text { Rate (\%) }\end{array}$ & $\begin{array}{c}\text { Performance Metric } \\
\text { (dependent variable) }\end{array}$ & $\begin{array}{c}\text { Experience Metric } \\
\text { (independent variable) }\end{array}$ & R2* $^{*}$ & $\begin{array}{l}\text { Reference or Data } \\
\text { Source }\end{array}$ \\
\hline OECD & $\begin{array}{c}1981- \\
1995\end{array}$ & 17 & investment cost $(\$ / k W)$ & $\begin{array}{l}\text { cumulative capacity } \\
(M W)\end{array}$ & 0.94 & $\begin{array}{l}\text { Kouvaritakis, Soria, } \\
\text { and Isoard }(2000)\end{array}$ \\
\hline USA & $\begin{array}{c}1981- \\
1996\end{array}$ & 14 & investment cost $(\$ / k W)$ & $\begin{array}{l}\text { cumulative capacity } \\
(M W)\end{array}$ & 0.95 & $\begin{array}{l}\text { Mackay and } \\
\text { Probert }(1998)\end{array}$ \\
\hline USA & $\begin{array}{c}1981- \\
1987\end{array}$ & 16 & investment price $(\$ / \mathrm{kW})$ & $\begin{array}{l}\text { cumulative "production" } \\
(\mathrm{MW})\end{array}$ & n.a. & $\begin{array}{l}\text { Christiansson } \\
(1995)\end{array}$ \\
\hline Denmark & $\begin{array}{c}1982- \\
1997\end{array}$ & 4 & investment price $(\$ / \mathrm{kW})$ & $\begin{array}{l}\text { cumulative capacity } \\
(\mathrm{MW})\end{array}$ & n.a. & $\begin{array}{l}\text { Wene }(2000), \text { Neij } \\
(1999)\end{array}$ \\
\hline
\end{tabular}




\begin{tabular}{|l|c|c|c|l|l|l|}
\hline $\begin{array}{l}\text { Country } \\
\text { or Region }\end{array}$ & $\begin{array}{c}\text { Time } \\
\text { Period }\end{array}$ & $\begin{array}{c}\text { Est. Learning } \\
\text { Rate (\%) }\end{array}$ & $\begin{array}{c}\text { Performance Metric } \\
\text { (dependent variable) }\end{array}$ & $\begin{array}{c}\text { Experience Metric } \\
\text { (independent variable) }\end{array}$ & R2 $^{*}$ & $\begin{array}{c}\text { Reference or Data } \\
\text { Source }\end{array}$ \\
\hline Denmark & $\begin{array}{c}1982- \\
1997\end{array}$ & 8 & investment price (\$/kW) & $\begin{array}{l}\text { cumulative capacity } \\
(\mathrm{MW})\end{array}$ & n.a. & Neij (1999) ${ }^{* * *}$ \\
\hline Germany & $\begin{array}{c}1990- \\
1998\end{array}$ & 8 & investment price (\$/kW) & $\begin{array}{l}\text { cumulative capacity } \\
(\mathrm{MW})\end{array}$ & 0.95 & Durstewitz (1999) \\
\hline
\end{tabular}

Note: Adapted from Kobos (2002)

* $\quad$ As described in McDonald and Schrattenholzer (2001), comparing $\mathrm{R}^{2}$ values between sources must be done with caution (e.g., different sources use differently sized data sets; therefore, the respective $\mathrm{R}^{2}$ is relative to that data set).

** The Wene (2000) reference adapts results from Neij (1999).

*** The Neij (1999) results include all Danish-produced wind turbines.

\section{B.7 OPERATION AND MAINTENANCE COSTS}

The O\&M cost projections provided in the SunLab cost model are based on actual data from Kramer Junction with projections for increased plant size and improvements in operation and maintenance. Kramer Junction provides a dependable basis for costs associated for near-term deployment.

Sargent \& Lundy reviewed the SunLab cost model against interviews and actual data provided to us during our site visit and our knowledge and internal database information of O\&M costs for electric power plants. We reviewed the SunLab assumptions and made adjustments as appropriate based on our experience and information provided by Kramer Junction.

\section{B.8 FINANCIAL MODELING}

\section{B.1.1 Analysis Methodology}

The financial model used for developing generating costs is a spreadsheet pro forma financial model of the type used in competitive industry to support power project planning and financing. S\&L regularly reviews such models as part of our due diligence practice, working with lenders and investors in project financing. In some cases we also support project developers by writing and maintaining such models for them.

The main analysis engine is a standard income statement that includes calculations of energy production, revenues, operation and maintenance expenses, fuel expenses, depreciation, insurance, property taxes, interest, investment tax credit, and income tax. The investment tax credit for solar technologies is represented. Once after-tax income was determined in the income statement, depreciation was added back and payback of debt principal was subtracted to obtain cash available for dividends. The dividend stream and equity investment into 
the project was combined to compute the equity internal rate of return for the project. All evaluations were done on a lifetime $\$ / M W h$ evaluated cost basis, covering 30 years of service.

All costs are expressed in constant 2002-dollar terms. Financing rates (return or equity and interest rates) were adjusted to remove the inflation premium rates.

Revenues were set to cover investment-related costs and fixed operation and maintenance costs, including property taxes. Revenues covering fixed operation and maintenance costs were treated as pass-through costs, with revenue assumed to exactly offset expenses. Investment costs were covered by a level $\$ / \mathrm{kW} /$ year capacity payment.

\section{B.1.2 Cost of Capital}

The financial analyses considered project financing, where the project is set up as a separate project company that is financed using borrowed funds and equity investments by the project company's owners. Costs of debt and costs of equity were developed from review of current market rates, resulting in the following assumptions shown in Table B-3:

Table B-3 - Costs of Debt and Equity

\begin{tabular}{|l|c|c|}
\hline & Current Dollars & Constant Dollars \\
\hline Return on equity & $14.0 \%$ & $11.5 \%$ \\
\hline Permanent debt interest rate & $8.5 \%$ & $6.0 \%$ \\
\hline Construction debt interest & $7.0 \%$ & $4.5 \%$ \\
\hline
\end{tabular}

The Project Company is subject to corporate income tax, assumed to be $35 \%$ at the federal level and $8 \%$ at the state level.

Although a high degree of financial leverage normally is used in project financing, favorable economics for solar plants correspond to lower degrees of leverage than with conventional power projects because of the $10 \%$ investment tax credit and favorable tax depreciation allowances for solar units (5-year MACRS). In these analyses, the financial leverage and revenue requirement to cover investment-related costs have been set to achieve the target return on equity and target debt service coverage ratio. The target debt service coverage ratio is 1.35 for all cases. Debt is paid off using a mortgage-style amortization over 20 years. Annual insurance expense was estimated to be $0.5 \%$ of initial cost, escalating. Annual property taxes were estimated to be $0.5 \%$ of 
initial investment, constant over the evaluation period. The evaluation period covers 30 years. Investment costs in the pro forma were adjusted for construction period financing costs by assuming that spending on average will be two years before the facility's initial commercial service. The cost of capital for this interest during construction adjustment was assumed to be $7 \%$ per year.

The summary of assumptions used for cost of capital is shown in Table B-4.

Table B-4 - Summary of Cost of Capital Assumptions

\begin{tabular}{|l|c|l|}
\hline General & & \\
\hline Length of analysis period, yr & 30 & \\
\hline General inflation, \%/yr & $2.5 \%$ & For non-fuel expenses \\
\hline Base year for cost escalation & 2002 & When not otherwise specified in the model \\
\hline
\end{tabular}

\begin{tabular}{|l|c|c|}
\hline Financial & Nominal \$ & Constant \$ \\
\hline Equity rate of return & $14.000 \%$ & $11.50 \%$ \\
\hline Debt rate of return & $8.50 \%$ & $6.00 \%$ \\
\hline Debt repayment period & 20 & 20 \\
\hline Percent equity in capital structure & Varies & Varies \\
\hline Percent debt in capital structure & Varies & Varies \\
\hline Entity is subject to income tax (yes/no) & Yes & Yes \\
\hline Cost of construction, \%/yr & $7.00 \%$ & $4.5 \%$ \\
\hline Target DSCR & 1.35 & 1.35 \\
\hline
\end{tabular}

\begin{tabular}{|c|c|c|}
\hline $\begin{array}{l}\text { Amortization period for non-depreciable } \\
\text { investment }\end{array}$ & 20 & \\
\hline $\begin{array}{l}\text { Percentage of investment not depreciable } \\
\text { (exclusive of IDC) }\end{array}$ & $2 \%$ & \\
\hline Investment tax credit & $10 \%$ & $\begin{array}{l}\text { Applies only to solar investment, equal to this } \\
\text { percentage of depreciable investment }\end{array}$ \\
\hline State income tax rate & $8.00 \%$ & Similar to $8.84 \%$ in California or $6.97 \%$ in Arizona \\
\hline Federal income tax rate & $35.00 \%$ & \\
\hline Composite income tax rate & $40.20 \%$ & Income tax rate (composite federal and state) \\
\hline Insurance & $0.50 \%$ & Of project cost; escalated at inflation rate \\
\hline Property taxes & $0.50 \%$ & $\begin{array}{l}\text { Of project cost; remains constant in nominal terms } \\
\text { throughout project life }\end{array}$ \\
\hline Investment cost escalation rate & $1.50 \%$ & \\
\hline
\end{tabular}




\section{B.1.3 Levelized Cost of Energy}

Levelized cost of energy was calculated based on the assumptions for cost of capital and the investment cost (capital cost) and operation and maintenance costs. S\&L assessed the level of cost reductions and performance improvements, based on our experience, that are likely to be achieved in determining the investment and operations and maintenance costs. 
Appendix C

Power Generation Markets 


\section{LEVELIZED COST FOR RANKING ALTERNATIVES AND EXAMPLE CALCULATIONS}

Economic choice between electricity generating alternatives is often done on the basis of levelized cost, which is

the level revenue requirement that would cover all operating expenses and capital-related costs for the generating facility. Capital-related costs include return on invested debt, return on invested equity, federal and state income taxes associated with the return on equity, book depreciation (for recovery of debt and equity capital), and property taxes and insurance. Operating costs include fuel and non-fuel operation and maintenance costs.

A levelized unit cost is a delivered product unit cost that, if charged for each year's production over the analysis period, would yield the same net present value of revenues as if the actual annual cost for each alternative were collected instead over the period. It is $\mathrm{C}$ in the following equation:

$$
\sum_{i=1}^{n} \frac{\mathrm{CE}_{i}}{(1+r)^{i}}=\sum_{i=1}^{n} \frac{c_{i} E_{i}}{(1+r)^{i}}
$$

where $\mathrm{C}$ is a constant $\$ / \mathrm{kWh}$ cost to be charged each $\mathrm{i}^{\text {th }}$ year over the analysis period ( $\mathrm{n}=30$ years, for example), $\mathrm{E}_{\mathrm{i}}$ is the $\mathrm{kWh}$ sold in each such year, and $\mathrm{c}_{\mathrm{i}}$ is the actual annual $\$ / \mathrm{kWh}$ cost for each year, comprised of a current expense for fuel, labor, etc. plus a component for recovery of the investment cost, which may be a level series or may vary through time in some fashion.

The constant $\mathrm{C}$ can be brought outside the summation on the left side. Then the expression on the right can be divided by the remaining summation on the left, leaving just $\mathrm{C}$ on the left side. Since the product inside the summation on top on the right, $c_{i} E_{i}$, is dollars for each year, and the $1 /(1+r)^{i}$ is a discount factor, the top of the right side looks like the present value of revenue requirements. The bottom is denominated in $\mathrm{kWh}$ and looks like the present value of energy. This is why one often hears that levelized cost is computed as the present value of costs divided by the present value of energy.

The levelized costs of energy (LCOE) in this study are computed as described above. In our calculations we have assumed that costs which vary over the evaluation period are covered by revenues of equal magnitude (i.e., operating costs are treated as a pass-through). Property taxes and insurance also are handled as pass-throughs. 
All other capital-related costs (debt service, return on and of equity, income tax, etc.) are recovered as a uniform charge over the evaluation period.

The financial model which developed the LCOE figures in this report performs the levelized cost calculation two ways: (1) in nominal dollars, where capital and operating costs escalate due to inflation and money rates are nominal values that include an inflation premium and (2) in real terms, where capital and operating costs do not escalate and the cost of debt in the financial calculations has had the inflation premium removed.

Exhibits C-1 shows an example calculation for a CSP alternative in nominal dollar terms, where inflation is included for capital and operating costs and market costs of money are used in the financial calculations. Exhibit C-2 is the same calculation when done in real terms, with no inflation in capital and operating costs and using a deflated cost of debt. The inflation assumption used in these calculations is $2 \frac{1}{2} \%$ per year. In both cases the capacity payment for recovering capital-related charges is set to achieve a 1.35 debt service coverage ratio using the financial leverage from the nominal dollar calculation. 


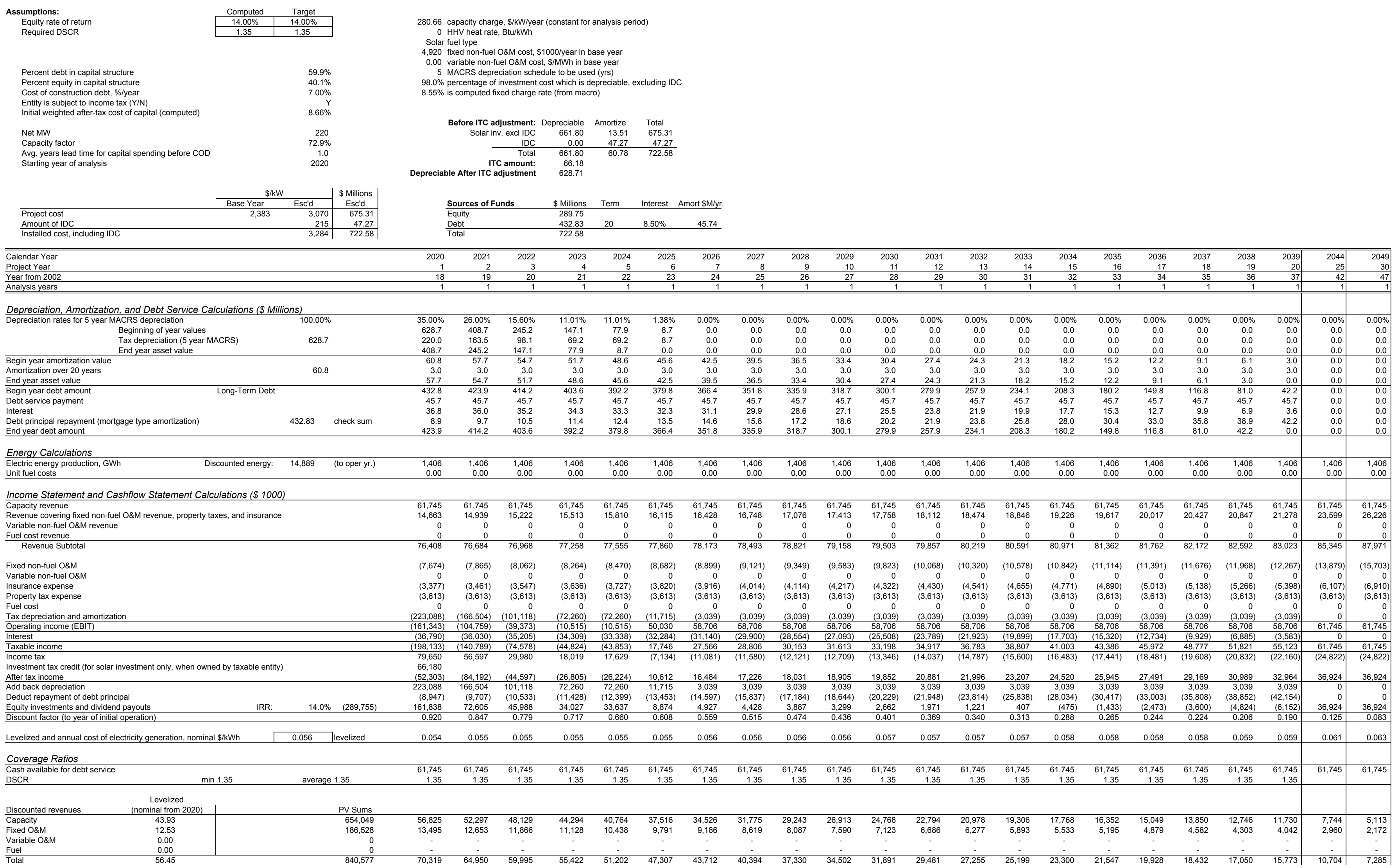




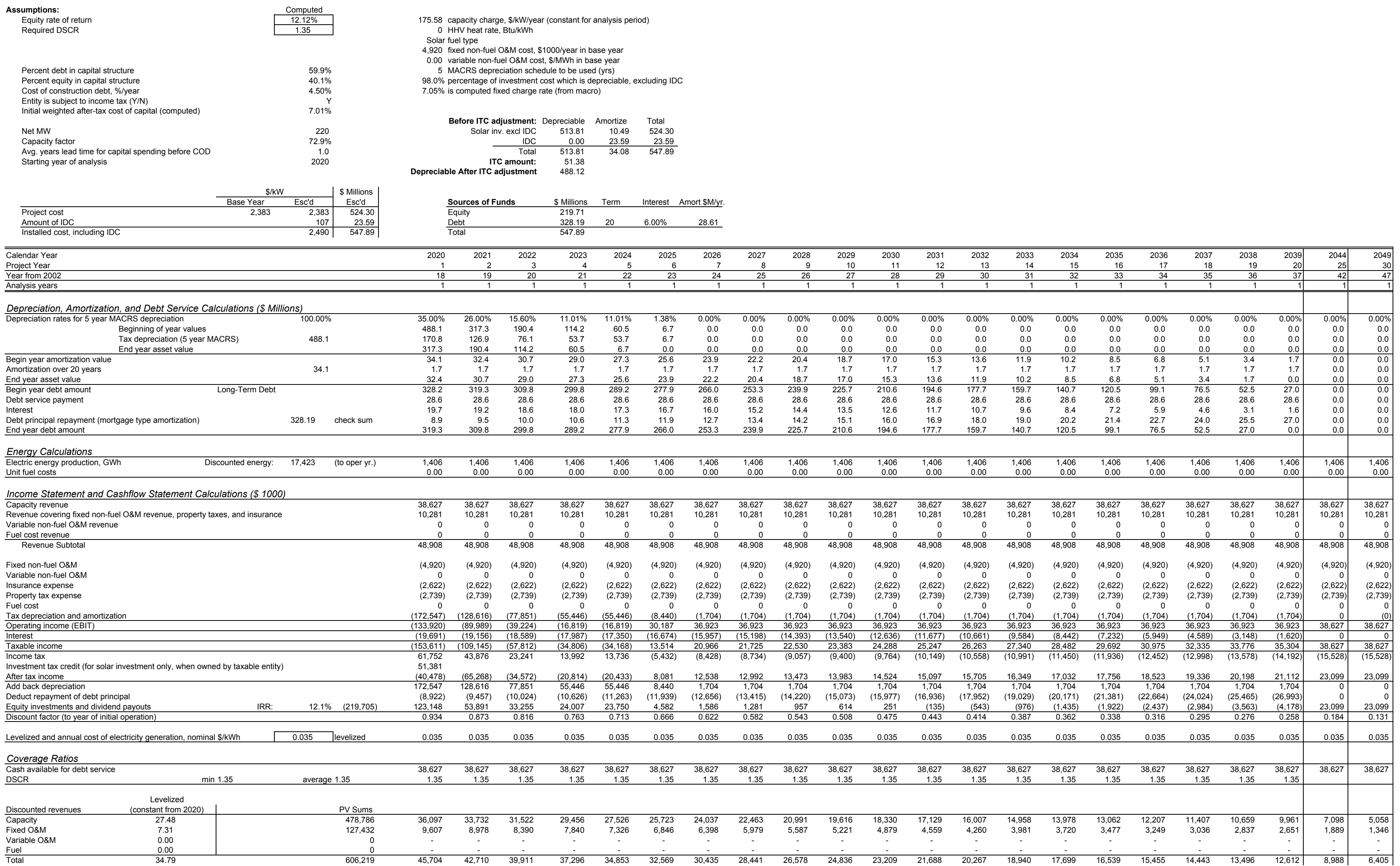


Appendix D

Evaluation of Technology Improvements and Capital Cost Projections for Parabolic Trough Solar Plants 


\section{EVALUATION OF TECHNOLOGY IMPROVEMENTS AND \\ CAPITAL COST PROJECTIONS FOR \\ PARABOLIC TROUGH SOLAR PLANTS}

\section{CONTENTS}

Section

$\underline{\text { Page }}$

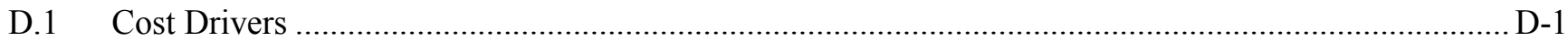

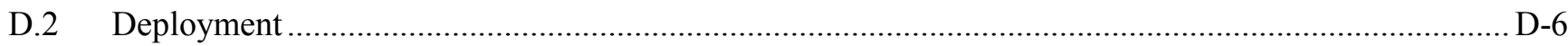

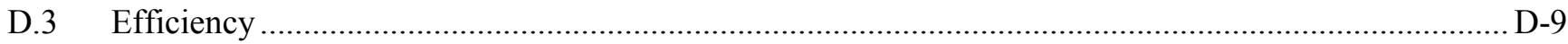

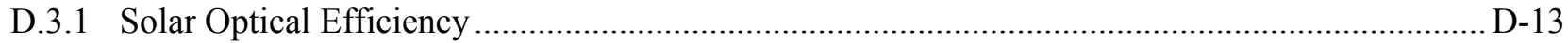

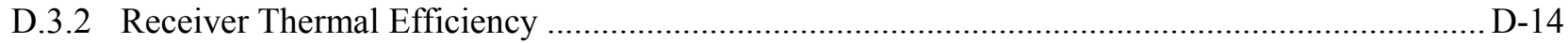

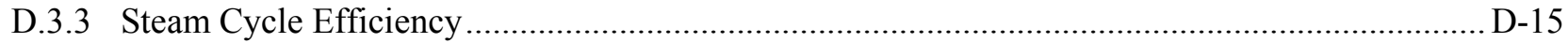

D.3.4 Thermal to Power Plant Efficiency — Parasitics ....................................................................... D-16

D.3.5 Efficiency Improvements Summary ……............................................................................... D-17

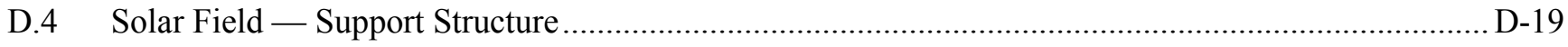

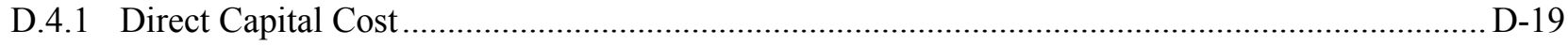

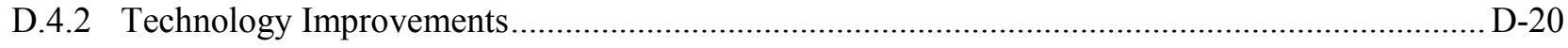

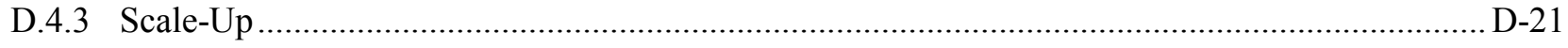

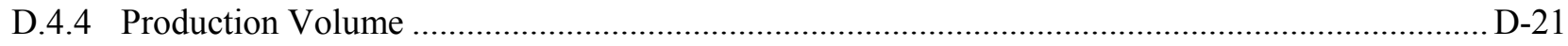

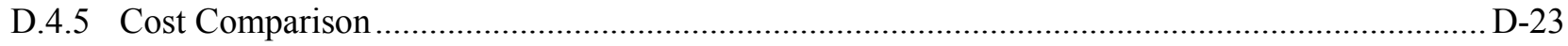

D.5 Solar Field - Heat Collection Element (HCE) …........................................................................ D-24

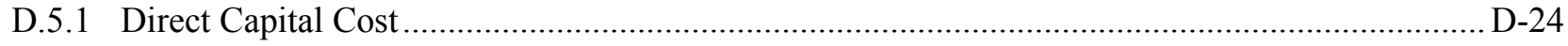

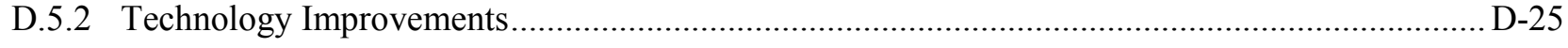

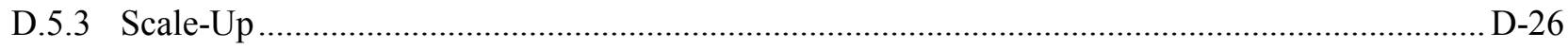

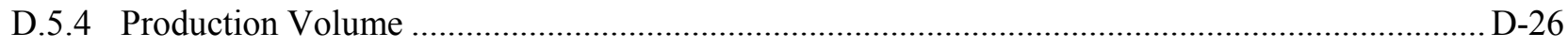

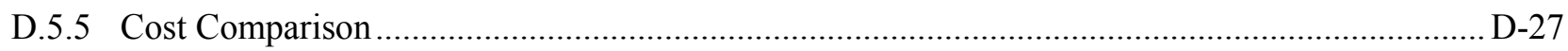

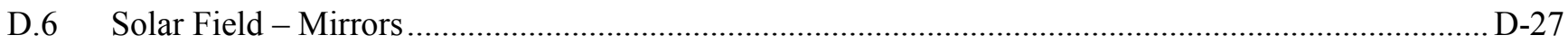

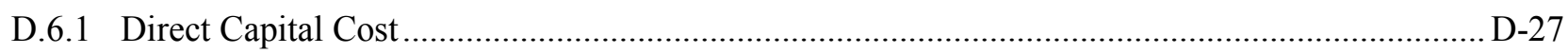




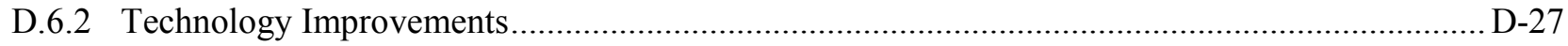

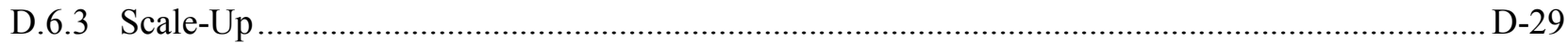

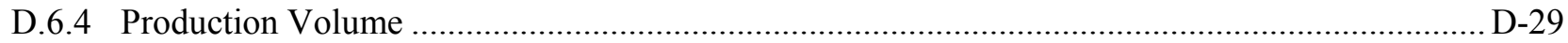

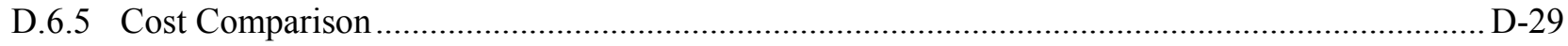

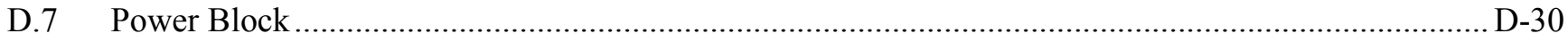

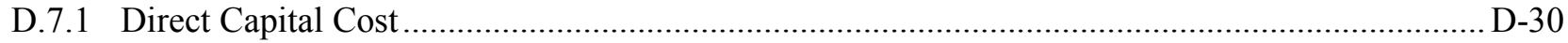

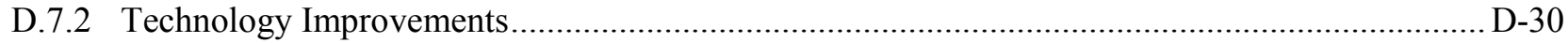

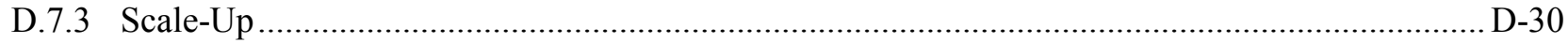

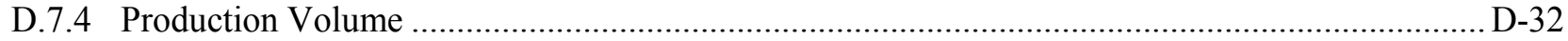

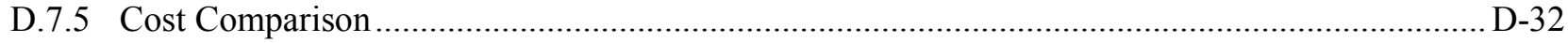

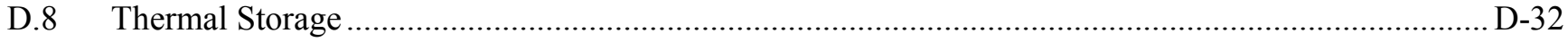

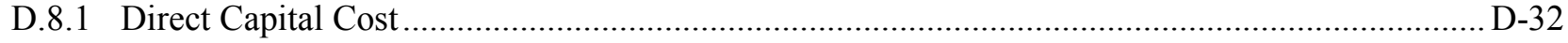

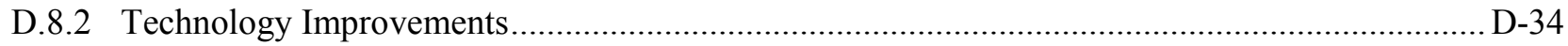

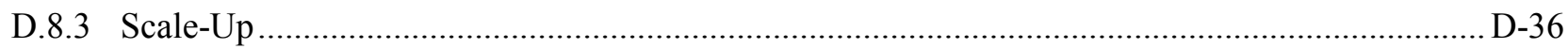

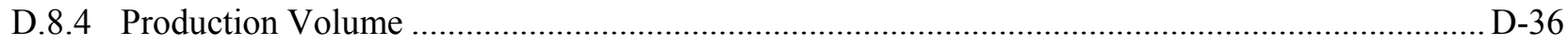

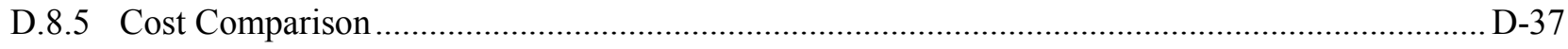

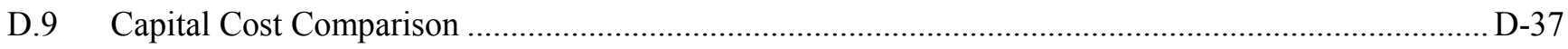

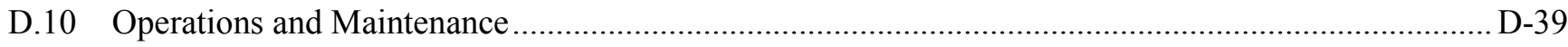

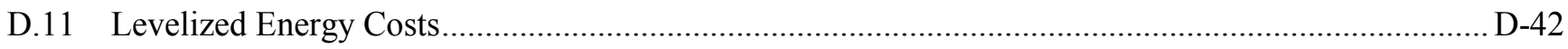




\section{EVALUATION OF TECHNOLOGY IMPROVEMENTS AND CAPITAL COST PROJECTIONS FOR PARABOLIC TROUGH SOLAR PLANTS}

\section{D.1 COST DRIVERS}

The direct costs of a parabolic solar plant can be summarized into the following five major categories:

- $\quad$ Siteworks and Infrastructure

- Solar Field

- Heat Collection Element (HCE)

- Mirror

- Support Structure

- Drive

- Piping

- Civil Work

- $\quad$ Power Block

- Steam Turbine and Generator

- Electric Auxiliaries

- Thermal Storage/Heat Transfer Fluid System

- Balance of Plant (BOP)

- Cooling System

- Water treatment

- $\quad$ Electrical

- Instrumentation \& control

- Miscellaneous Civil Work

The Solar Field, Thermal Storage and Power Block costs encompass approximately $95 \%$ of the total direct costs, as illustrated in Figure D-1. Of these three highest cost categories, the Solar Field cost comprises 58\% of the total direct cost. Figure D-2 shows the solar field component cost breakdown. The component cost breakdown of the Solar Field reveals the Support Structures are 29\%, the Heat Collection Elements (HCE) 19\%, and the Mirrors $18 \%$ of the Solar Field direct costs, for a total of $68 \%$ of the Solar Field direct costs. 


\section{Figure D-1 - Major Cost Categories for Parabolic Trough Plant 2004 Near-Term Case: 100 MWe, 12 hrs TES, 2.5 Solar Multiple}

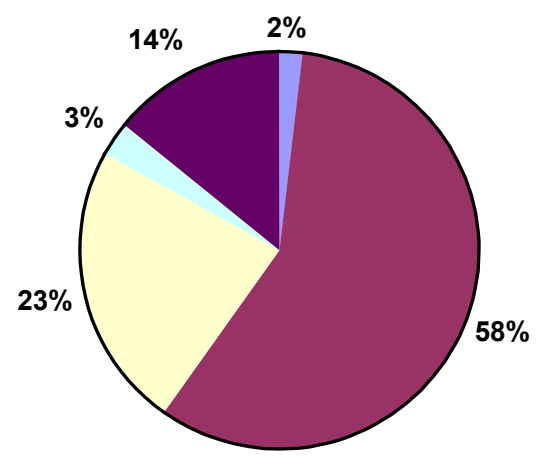

$\square$ Structures and Improvements
$(2 \%)$
$\square$ Solar Collection System
$(58 \%)$
$\square$ Thermal Storage System
$(23 \%)$
$\square$ Steam Gen or HX System
$(3 \%)$
$\square$ Power Block (EPGS, BOP)
$(14 \%)$

\section{Figure D-2 - Solar Field Component Cost Breakdown for Parabolic Trough Plant 2004 Near-Term Case: 100 MWe, 12 hrs TES, 2.5 Solar Multiple}

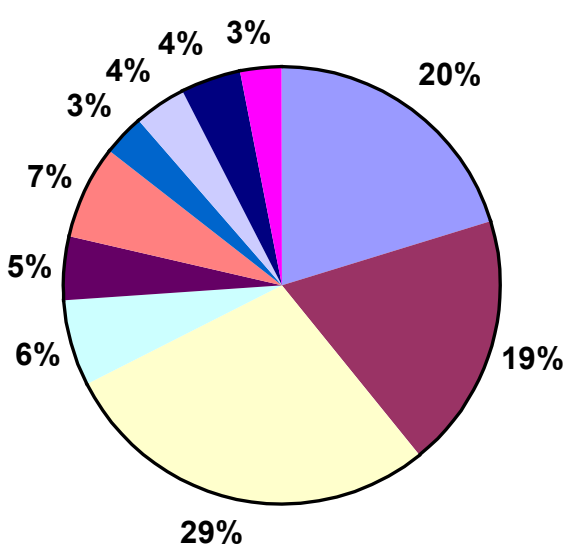

口Receiver (HCE) (20\%)

口Mirror (19\%)

Metal support structure (29\%)

口Drive (6\%)

DInterconnection Piping (5\%)

$\square$ Electronics \& control (7\%)

$\square$ Header piping (3\%)

$\square$ Pylon Foundations (4\%)

DOther Civil Works (4\%)

$\square$ Heat Transfer Fluid (3\%)

The evaluation of cost reductions for a parabolic trough plant focuses on the solar field, power block, and thermal storage since these three areas account for approximately $90 \%$ of the total direct costs (based on 12 hours of thermal storage). As pointed out previously and illustrated in Figure D-2, the support structures are $29 \%$, the HCE $19 \%$, and the mirrors $18 \%$ of the solar field direct costs; $68 \%$ of the total solar field direct cost. As such, the following main items were focused on for evaluation of cost reductions:

- Net annual solar-to-electric efficiency

- $\quad$ Solar field 


\section{- $\mathrm{HCE}$ \\ — Mirrors}

- Power block

- Thermal storage

The following major potential cost reductions were considered:

- Technology improvements

- $\quad$ Scale-up (economy of scale)

- Production volume

Table D-1 provides a summary of SunLab's design, deployment, and cost projections for trough plants with the SEGS VI plant as the base case.

Table D-1 - SunLab Cost Projections

\begin{tabular}{|l|c|c|c|c|c|c|}
\hline & SEGS VI & $\begin{array}{c}\text { Trough } \\
\mathbf{1 0 0}\end{array}$ & $\begin{array}{c}\text { Trough } \\
\mathbf{1 0 0}\end{array}$ & $\begin{array}{c}\text { Trough } \\
\mathbf{1 5 0}\end{array}$ & $\begin{array}{c}\text { Trough } \\
\mathbf{2 0 0}\end{array}$ & $\begin{array}{c}\text { Trough } \\
\mathbf{4 0 0}\end{array}$ \\
\hline & $\mathbf{1 9 9 9}$ & $\mathbf{2 0 0 4}$ & $\mathbf{2 0 0 7}$ & $\mathbf{2 0 1 0}$ & $\mathbf{2 0 1 5}$ & $\mathbf{2 0 2 0}$ \\
\hline Plant size, net electric, MWe & 30 & 100 & 100 & 150 & 200 & 400 \\
\hline $\begin{array}{l}\text { Plant size, gross thermal input, } \\
\text { MWt }\end{array}$ & 88 & 294 & 279 & 408 & 544 & 1,087 \\
\hline Thermal Storage, hr & 0 & 12 & 12 & 12 & 12 & 12 \\
\hline Annual Plant Capacity Factor & $22.2 \%$ & $53.5 \%$ & $56.2 \%$ & $56.2 \%$ & $56.2 \%$ & $56.5 \%$ \\
\hline $\begin{array}{l}\text { Annual Solar-to-Electric } \\
\text { Efficiency }\end{array}$ & $10.6 \%$ & $14.2 \%$ & $16.1 \%$ & $17.0 \%$ & $17.1 \%$ & $17.2 \%$ \\
\hline & & & & & & \\
\hline Solar Field Design: & & & & & & \\
\hline Number of Collectors & 800 & 4,768 & 1,269 & 1,808 & 2,392 & 4,783 \\
\hline Receivers per SCA & 12 & 12 & 36 & 36 & 36 & 36 \\
\hline Number HCE & 9,600 & 57,216 & 45,700 & 65,072 & 86,101 & 172,201 \\
\hline Number HCE Accumulative & 9,600 & 66,816 & 112,516 & 177,588 & 263,688 & 435,889 \\
\hline Collector Size, m & 235 & 235 & 817.5 & 817.5 & 817.5 & 817.5 \\
\hline Field Aperture Area, m & 188,000 & $1,120,480$ & $1,037,760$ & $1,477,680$ & $1,955,200$ & $3,910,400$ \\
\hline & & & & & & \\
\hline
\end{tabular}




\begin{tabular}{|c|c|c|c|c|c|c|}
\hline & SEGS VI & $\begin{array}{l}\text { Trough } \\
100\end{array}$ & $\begin{array}{l}\text { Trough } \\
100\end{array}$ & $\begin{array}{l}\text { Trough } \\
150\end{array}$ & $\begin{array}{l}\text { Trough } \\
200\end{array}$ & $\begin{array}{l}\text { Trough } \\
400\end{array}$ \\
\hline & 1999 & 2004 & 2007 & 2010 & 2015 & 2020 \\
\hline \multicolumn{7}{|l|}{ Heat Transfer Fluid System } \\
\hline HTF Type & VP-1 & VP-1 & Hitec XL & Hitec XL & Hitec XL & Hitec XL \\
\hline Fluid Volume, gallons & 115,500 & 688,380 & 637,560 & 907,830 & $1,201,200$ & $2,402,400$ \\
\hline \multicolumn{7}{|l|}{ Direct Capital Cost: } \\
\hline Structures \& Improvements & 2,526 & 7,279 & 6,538 & 8,097 & 9,596 & 16,284 \\
\hline Collector System & 44,793 & 249,654 & 181,533 & 226,753 & 259,852 & 452,825 \\
\hline Thermal Storage System & 0 & 95,807 & 42,475 & 57,426 & 76,567 & 153,135 \\
\hline Steam Gen or HX System & 4,304 & 9,964 & 9,227 & 11,161 & 12,772 & 19,394 \\
\hline EPGS & 15,805 & 36,713 & 34,877 & 44,008 & 51,134 & 78,915 \\
\hline Balance of Plant & 9,190 & 21,346 & 20,279 & 25,588 & 29,732 & 45,884 \\
\hline Total Direct Costs & 76,619 & 420,763 & 294,929 & 373,033 & 439,654 & 766,438 \\
\hline $\begin{array}{l}\text { Solar Collection System, } \$ / \mathrm{m}^{2} \\
\text { field }\end{array}$ & 250 & 234 & 184 & 161 & 140 & 122 \\
\hline $\begin{array}{ll}\text { Receivers, } & \$ / \mathrm{m}^{2} \text { field } \\
& \$ / \text { unit }\end{array}$ & $\begin{array}{c}43 \\
847\end{array}$ & $\begin{array}{c}43 \\
847\end{array}$ & $\begin{array}{c}34 \\
762\end{array}$ & $\begin{array}{c}28 \\
635\end{array}$ & $\begin{array}{c}22 \\
508\end{array}$ & $\begin{array}{c}18 \\
400\end{array}$ \\
\hline Mirrors, $\$ / \mathrm{m}^{2}$ field & 40 & 40 & 36 & 28 & 20 & 16 \\
\hline $\begin{array}{l}\text { Concentrator Structure, } \$ / \mathrm{m}^{2} \\
\text { field }\end{array}$ & 50 & 47 & 44 & 42 & 39 & 36 \\
\hline $\begin{array}{l}\text { Concentrator Erection, } \$ / \mathrm{m}^{2} \\
\text { field }\end{array}$ & 17 & 14 & 13 & 12 & 11 & 10 \\
\hline Drive, $\$ / \mathrm{m}^{2}$ field & 14 & 13 & 6 & 6 & 6 & 5 \\
\hline $\begin{array}{l}\text { Interconnection Piping, } \$ / \mathrm{m}^{2} \\
\text { field }\end{array}$ & 11 & 10 & 3 & 3 & 3 & 2 \\
\hline Electronics \& control, $\$ / \mathrm{m}^{2}$ field & 16 & 14 & 4 & 4 & 4 & 3 \\
\hline Header piping, $\$ / \mathrm{m}^{2}$ field & 8 & 7 & 7 & 6 & 6 & 5 \\
\hline $\begin{array}{l}\text { Foundations/Other Civil, } \$ / \mathrm{m}^{2} \\
\text { field }\end{array}$ & 21 & 18 & 17 & 15 & 14 & 12 \\
\hline
\end{tabular}




\begin{tabular}{|c|c|c|c|c|c|c|}
\hline & SEGS VI & $\begin{array}{l}\text { Trough } \\
100\end{array}$ & $\begin{array}{l}\text { Trough } \\
100\end{array}$ & $\begin{array}{l}\text { Trough } \\
150\end{array}$ & $\begin{array}{l}\text { Trough } \\
200\end{array}$ & $\begin{array}{l}\text { Trough } \\
\quad \mathbf{4 0 0}\end{array}$ \\
\hline & 1999 & 2004 & 2007 & 2010 & 2015 & 2020 \\
\hline $\begin{array}{l}\text { Other (Spares, HTF, freight), } \\
\$ / \mathrm{m}^{2} \text { field }\end{array}$ & 17 & 17 & 11 & 10 & 9 & 8 \\
\hline Contingency, $\$ / \mathrm{m}^{2}$ field & 12 & 11 & 9 & 8 & 7 & 6 \\
\hline \multicolumn{7}{|l|}{ Direct Capital Cost, $\$ / k W e$} \\
\hline $\begin{array}{l}\text { Structures and Improvements, } \\
\$ / \mathrm{kWe}\end{array}$ & 84 & 73 & 65 & 54 & 48 & 41 \\
\hline Solar Collection System, $\$ / k W e$ & 1,493 & 2,497 & 1,815 & 1,512 & 1,299 & 1,132 \\
\hline $\begin{array}{l}\text { Thermal Storage System, } \\
\$ / \mathrm{kWe}\end{array}$ & 0 & 958 & 425 & 383 & 383 & 383 \\
\hline $\begin{array}{l}\text { Steam Generator or } \mathrm{HX} \\
\text { System, } \$ / \mathrm{kWe}\end{array}$ & 143 & 100 & 92 & 74 & 64 & 48 \\
\hline EPGS, $\$ / k W e$ & 527 & 367 & 349 & 293 & 256 & 197 \\
\hline Balance of Plant, $\$ / \mathrm{kWe}$ & 306 & 213 & 203 & 171 & 149 & 115 \\
\hline Total Direct Cost, $\$ / \mathrm{kWe}$ & 2,554 & 4,208 & 2,949 & 2,487 & 2,198 & 1,916 \\
\hline
\end{tabular}

In a series of evolutionary design improvements, the following major advancements formed the basis of the SunLab estimates:

- Collector

- A comprehensive series of wind tunnel tests on parabolic trough collector models was carried out in 2001-2002, establishing design pressure force coefficients for various wind approach angles and collector orientations, with and without a wind fence.

- Using these coefficients, finite element methods stress analyses were used to optimize the collector structure for wind survival conditions, minimizing collector weight and defining design parameters for mirror strength, pylons, and foundations. With more tightly known design parameters, collector weight, and thus costs, can be lowered.

- High efficiency and durable receivers are assumed to be developed, with selective surfaces (consisting of special selective coatings on the metal tube receivers) to maximize the absorption of incident solar radiation and minimize radiation losses from the receiver. High efficiencies result in smaller solar fields for a given thermal energy delivery, and longer lifetimes to reduce operation and maintenance costs.

- Advanced receivers are assumed utilizing selective surfaces that can operate efficiently at temperatures of $500^{\circ} \mathrm{C}$ or higher, paving the way for major advancements in thermal storage and power block operation for trough plants. 
- Alternative mirror design development using thin-glass with non-metallic structural elements, or using thin silverized films is assumed. Both approaches reduce weight and offer less expensive reflector options.

- Heat transfer fluid (HTF)

- Alternate HTFs, such as inorganic molten salts and ionic fluids, are being investigated that will permit operation at higher temperatures (at or above $500^{\circ} \mathrm{C}$ ), leading to lower thermal storage costs and higher power block efficiencies.

- Thermal Storage System

- The Solar Two two-tank molten salt storage system is designed for commercial operation in a trough plant for the case of the conventional synthetic oil HTF. Termed an indirect storage system, this also requires an oil-to-salt heat exchanger in the system.

- This same two-tank molten salt storage system is designed for direct operation with a molten salt HTF.

- A single-tank direct molten salt thermocline system is designed to reduce thermal storage costs.

- $\quad$ Electric Power Block

- The efficiency of a SEGS-type plant is improved by refining the integration of the solar field with the power block.

- Turbine efficiencies are improved through use of the higher temperature heat transfer fluids in the solar field.

\section{D.2 DEPLOYMENT}

The inherent capital-intensive nature of the technology and the current high costs and early mass-production hurdles are disadvantages for the trough technology. While the trough technology was commercialized for a brief period, no trough plants have been built in nearly a decade. Trough solar plants are a proven technology and $354 \mathrm{MW}$ of trough technology generation at the SEGS plants have and are still being operated commercially.

Deployment is a key element in the cost reductions as it impacts the component production volume. Table D-2 below shows a case of two scenarios set forth by SunLab that could be realistically representative of how systems would be deployed commercially if a market existed considering the potential trough deployment presented in Table D-3. The first assumes one plant built per year. The second assumes a doubling of cumulative installed capacity with each new technology case introduced. This second case is an aggressive development scenario; however, if the projects were financially competitive, this represents a plausible development scenario. The second case is the type of scale-up that Luz envisioned and actually achieved with the SEGS plants to some 
degree, building multiple plants in the same year. The SunLab projections are based on the Case 2 deployment scenario. S\&L estimates are based on the Case 1 deployment scenario.

Table D-2 - Trough Deployment Scenarios

\begin{tabular}{|c|c|c|c|c|c|c|c|c|c|c|c|c|c|c|c|c|c|c|c|c|}
\hline & 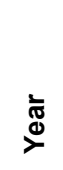 & ষ্ণ & ஜั & ๕ & ๖્̀ & ঃ્స & : & 웅 & হ্ণ & ֻั & $\grave{N}_{\text {N }}^{m}$ & $\stackrel{+}{i}$ & $\sum_{\text {ก }}^{n}$ & $\stackrel{\circ}{\circ}$ & $\stackrel{N}{\circ}$ & $\grave{N}^{\infty}$ & 오ํ & ণ্ণি & 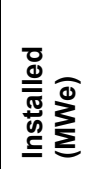 & 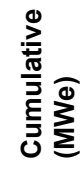 \\
\hline $\begin{array}{l}\text { Technology } \\
\text { Cases }\end{array}$ & & $X$ & & & $X$ & & & $X$ & & & & & $\mathrm{X}$ & & & & & $\mathrm{X}$ & & \\
\hline \multicolumn{21}{|c|}{ Case 1 Deployment Scenario: One Plant per Year Deployment } \\
\hline $\begin{array}{l}2004 \\
\text { Technology }\end{array}$ & $\begin{array}{l}100 \\
\text { MW }\end{array}$ & 1 & 1 & 1 & & & & & & & & & & & & & & & 300 & 650 \\
\hline $\begin{array}{l}2007 \\
\text { Technology }\end{array}$ & $\begin{array}{l}100 \\
\mathrm{MW}\end{array}$ & & & & 1 & 1 & 1 & & & & & & & & & & & & 300 & 950 \\
\hline $\begin{array}{l}2010 \\
\text { Technology }\end{array}$ & $\begin{array}{l}150 \\
\mathrm{MW}\end{array}$ & & & & & & & 1 & 1 & 1 & 1 & 1 & & & & & & & 750 & 1,700 \\
\hline $\begin{array}{l}2015 \\
\text { Technology }\end{array}$ & $\begin{array}{l}200 \\
\text { MW }\end{array}$ & & & & & & & & & & & & 1 & 1 & 1 & 1 & 1 & & 1,000 & 2,700 \\
\hline $\begin{array}{l}2020 \\
\text { Technology }\end{array}$ & $\begin{array}{l}400 \\
\mathrm{MW}\end{array}$ & & & & & & & & & & & & & & & & & 1 & 400 & 3,100 \\
\hline Total & & & & & & & & & & & & & & & & & & & 2,750 & \\
\hline \multicolumn{21}{|c|}{ Case 2 Deployment Scenario: Cumulative Capacity Doubled with Each New Technology Case } \\
\hline $\begin{array}{l}2004 \\
\text { Technology }\end{array}$ & $\begin{array}{l}100 \\
\text { MW }\end{array}$ & 1 & 1 & 1 & & & & & & & & & & & & & & & 300 & 650 \\
\hline $\begin{array}{l}2007 \\
\text { Technology }\end{array}$ & $\begin{array}{l}100 \\
\text { MW }\end{array}$ & & & & 1 & 2 & 2 & 1 & & & & & & & & & & & 600 & 1,250 \\
\hline $\begin{array}{l}2010 \\
\text { Technology }\end{array}$ & $\begin{array}{l}150 \\
M W\end{array}$ & & & & & & & 1 & 1 & 2 & 2 & 2 & & & & & & & 1,200 & 2,450 \\
\hline $\begin{array}{l}2015 \\
\text { Technology }\end{array}$ & $\begin{array}{l}200 \\
\text { MW }\end{array}$ & & & & & & & & & & & & 1 & 2 & 2 & 3 & 3 & 1 & 2,400 & 4,850 \\
\hline $\begin{array}{l}2020 \\
\text { Technology }\end{array}$ & $\begin{array}{l}400 \\
\mathrm{MW}\end{array}$ & & & & & & & & & & & & & & & & & 1 & 400 & 5,250 \\
\hline Total & & & & & & & & & & & & & & & & & & & 4,900 & \\
\hline
\end{tabular}

Approximate estimates of CSP deployment have been identified in several reports (Morse 2000). Based on the projections presented in those reports, a potential trough deployment is presented in Table D-3. The potential 
trough deployment estimates are significantly greater than the two deployment scenarios investigated; thus, cost reductions would be greater if the potential deployment estimate proves to be accurate.

Table D-3 - Potential Trough Deployment

\begin{tabular}{|l|c|c|c|c|}
\hline \multirow{2}{*}{} & \multicolumn{2}{|c|}{2010} & \multicolumn{2}{c|}{2020} \\
\cline { 2 - 5 } & International & U.S. & International & U.S. \\
\hline Total Deployment & $8,300 \mathrm{MW}$ & $1,800 \mathrm{MW}$ & $30,000 \mathrm{MW}$ (min.) & $2,900 \mathrm{MW}$ (min.) \\
\hline Estimated Trough Deployment & $4,980 \mathrm{MW}$ & $1,080 \mathrm{MW}$ & $18,000 \mathrm{MW}$ (min.) & $1,740 \mathrm{MW}$ (min.) \\
\hline Total Estimated Trough Deployment & \multicolumn{3}{|c|}{$6,060 \mathrm{MW}$} & \multicolumn{2}{c|}{$19,740 \mathrm{MW}$ (min.) } \\
\hline
\end{tabular}

The actual strategy employed by the plant suppliers can be significantly diverse, with more emphasis on nearterm cost reduction with a minimum of risk. The suppliers may opt to provide multiple plants in the 50-MWe to 100-MWe size range with no thermal storage but with a supplemental steam generator, replicating the proven technology of the existing SEGS plants. The suppliers can rely more on initial production volume to reduce costs as opposed to efficiency and technology improvements and scale-up factors. Minimizing or eliminating thermal storage, with its current elevated cost, appreciably reduces the total direct cost of the plant as discussed later in this section of the report. The suppliers' strategy will depend on the deployment of trough plants.

Figure D-3 below illustrates the SunLab projected range in cost of power from various near-term trough plant configurations. The first three plants are all $50 \mathrm{MWe}$ in size. The first is a solar-only plant with no hybrid backup or thermal energy storage. This plant has the lowest capital cost but the highest levelized energy cost (LEC) expressed as $\$ / \mathrm{kWh}$. The next plant is the 50 -MWe hybrid plant that is assumed to produce $25 \%$ of its electricity from natural gas, similar to the existing SEGS plants. This plant has the lowest LEC of the 50-MWe plants. This is the type of plant that Duke Solar is proposing for development in the U.S. Southwest, where lowest cost and on-peak capacity is required. The third configuration is a 50-MWe plant with 9 hours of thermal storage and an oversized solar field. Note that the LEC is lower than the solar-only plant without thermal storage. This is the configuration of the proposed 40-MWe trough project in Spain. Note that this plant is preferred in Spain because of the requirements of the solar tariff. The fourth plant configuration is a trough hybrid that is integrated with a combined-cycle plant. This configuration, referred to as an integrated solar combined-cycle system (ISCCS), is what is proposed for several of the GEF projects in India, Mexico, Egypt, and Morocco. This configuration has the lowest LEC, but it must be integrated into a much larger combinedcycle plant. Depending on the specific market, different configurations of plants are typically proposed. The 
fifth plant is the near-term SunLab 100-MW configuration with 12 hours of thermal storage. With the exception of the ISCCS, this plant provides the lowest cost of power. This plant represents a low-cost technically feasible design, but is not necessarily the configuration that will be built.

Figure D-3 - Cost of Near-Term Trough Technology Configurations

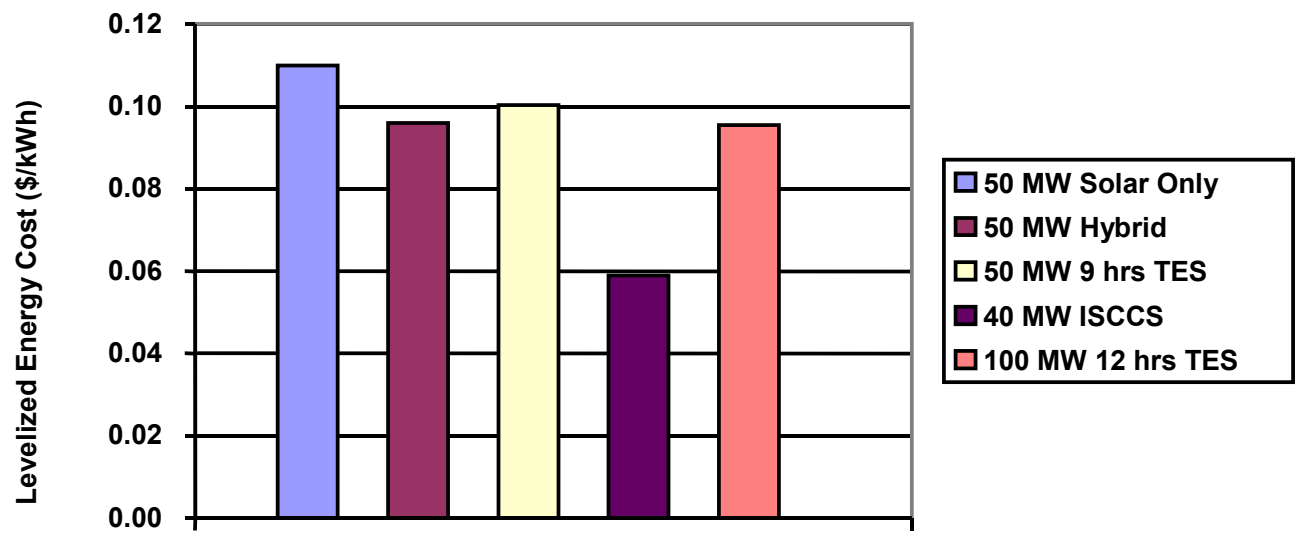

\section{D.3 EFFICIENCY}

The Solar Field is defined by the collector area in square meters $\left(\mathrm{m}^{2}\right)$, which can be estimated by the following simplified equation:

$$
\mathrm{C}=\frac{(\mathrm{kW}}{\eta \mathrm{d}} \frac{\mathrm{CF} \times \mathrm{h})}{\eta \times \mathrm{I}}
$$

Where:

$$
\begin{aligned}
& \mathrm{C}=\text { Collector area square meters }\left(\mathrm{m}^{2}\right) \\
& \mathrm{kW}_{\mathrm{d}}=\text { electric generation design capacity, kilowatts } \\
& \mathrm{CF}=\text { Capacity Factor }=\mathrm{kWh} \text { actual } /\left(\mathrm{kW}_{\mathrm{d}} \times 8,760\right) \\
& \mathrm{h}=\text { hours per year }(8,760) \\
& \eta \quad=\text { net annual solar-to-electric efficiency } \\
& \text { I = annual insolation }\left(\mathrm{kWh}_{\mathrm{t}} / \mathrm{m}^{2}\right) \\
& \mathrm{kWe}=\text { kilowatts electric } \\
& \mathrm{kWh}_{\mathrm{t}}=\text { kilowatts thermal }
\end{aligned}
$$

For a given plant size and capacity factor the net annual efficiency is the determining factor in the collector area; as the efficiency increases the collector area decreases on the same percentage basis. 
The annual net solar-to-electric efficiency determination and the current efficiency of the 1989 era 33-MW SEGS parabolic trough plant are shown in Table D-4.

Table D-4 - Annual Solar-to-Electric Efficiency

\begin{tabular}{|c|l|}
\hline Solar Field & \\
\hline Incidence Angle & $87.3 \%$ \\
\hline Solar Field Availability & $99.0 \%$ \\
\hline Solar Field Optical Efficiency & $61.7 \%$ \\
\hline Receiver Thermal Efficiency & $72.9 \%$ \\
\hline \multicolumn{1}{|l|}{ Piping Thermal Losses } & $96.1 \%$ \\
\hline \multicolumn{1}{|l|}{ No Op Low Insolation } & $99.6 \%$ \\
\hline \multicolumn{1}{|l|}{ Solar Field Thermal Delivered Efficiency (SFE) } & $37.2 \%$ \\
\hline $\begin{array}{l}\text { Thermal to Power Plant Efficiency (TPPE) } \\
\text { (Start-up/shutdown losses) }\end{array}$ & $37.4 \%$ \\
\hline Gross Steam Cycle Efficiency (ST) & $82.7 \%$ \\
\hline $\begin{array}{l}\text { Parasitics (P) } \\
(1-\% \text { auxiliary power consumed by plant) }\end{array}$ & $98.0 \%$ \\
\hline Plant-Wide Availability (A) & \\
\hline $\begin{array}{l}\text { Annual Solar-to-Electric Efficiency (E } \\
E_{\text {net }} \text { = SFE x TPPE x ST x P x A }\end{array}$ & \\
\hline
\end{tabular}

The net annual solar-to-electric efficiency has a significant impact on the cost of a trough plant. An example of the difference in solar field cost for a 100-MWe plant is illustrated in Table D-5.

Table D-5 - Annual Solar-to-Electric Impact on Cost

\begin{tabular}{|l|c|c|c|c|c|c|c|}
\hline Plant Size net electric, MWe & & 100 & 100 & 100 & 100 & 100 & 100 \\
\hline Annual Plant Capacity Factor & & $25 \%$ & $25 \%$ & $25 \%$ & $25 \%$ & $25 \%$ & $25 \%$ \\
\hline Annual Solar-to-Electric Efficiency & & $\mathbf{1 0 . 6} \%$ & $\mathbf{1 4 . 2 \%}$ & $\mathbf{1 6 . 1 \%}$ & $\mathbf{1 7 . 0 \%}$ & $\mathbf{1 7 . 1 \%}$ & $\mathbf{1 7 . 2 \%}$ \\
\hline Field Aperture Area, $\mathbf{m}^{2}$ & & 709,248 & 527,138 & 464,854 & 440,880 & 437,692 & 435,079 \\
\hline Solar Collection System & ${\mathbf{\$ / \mathbf { m } ^ { * }}}^{*}$ & \multicolumn{5}{|c|}{ Thousands \$ } \\
\hline Receivers & 43 & 30,680 & 22,802 & 20,108 & 19,071 & 18,933 & 18,820 \\
\hline Mirrors & 40 & 28,507 & 21,187 & 18,684 & 17,720 & 17,592 & 17,487 \\
\hline
\end{tabular}




\begin{tabular}{|c|c|c|c|c|c|c|c|}
\hline Solar Collection System & $\$ / m^{2}$ & \multicolumn{6}{|c|}{ Thousands \$ } \\
\hline Concentrator Structure & 47 & 32,981 & 24,513 & 21,616 & 20,501 & 20,353 & 20,232 \\
\hline Concentrator Erection & 14 & 9,777 & 7,267 & 6,408 & 6,077 & 6,033 & 5,997 \\
\hline Drive & 13 & 9,484 & 7,049 & 6,216 & 5,895 & 5,852 & 5,817 \\
\hline Interconnection Piping & 10 & 7,172 & 5,331 & 4,701 & 4,458 & 4,426 & 4,400 \\
\hline Electronics \& control & 14 & 10,276 & 7,638 & 6,735 & 6,388 & 6,341 & 6,304 \\
\hline Header piping & 7 & 4,875 & 3,623 & 3,195 & 3,030 & 3,008 & 2,990 \\
\hline Foundations/Other Civil & 18 & 12,429 & 9,237 & 8,146 & 7,726 & 7,670 & 7,624 \\
\hline Other (Spares, HTF, freight) & 17 & 11,841 & 8,801 & 7,761 & 7,360 & 7,307 & 7,264 \\
\hline Contingency & $\underline{11}$ & $\underline{7,901}$ & $\underline{5,872}$ & $\underline{5,178}$ & $\underline{4,911}$ & $\underline{4,876}$ & $\underline{4,846}$ \\
\hline Total, $\$ / \mathrm{m}^{2}$ & 234 & 165,928 & 123,323 & 108,752 & 103,143 & 102,397 & 101,786 \\
\hline Total, \$/kWe & & 1,659 & 1,233 & 1,088 & 1,031 & 1,024 & 1,018 \\
\hline Relative Cost & & 1.00 & 0.74 & 0.66 & 0.62 & 0.62 & 0.61 \\
\hline
\end{tabular}

$\$ / \mathrm{m}^{2}$ costs based on SunLab values for 2004 case.

Table D-5 shows that the solar field cost for a 100-MWe plant can be reduced by approximately $40 \%$ by improving the net annual solar-to-electric efficiency from the current $10.6 \%$ to $17.2 \%$.

The collector area is directly proportional to the plant megawatt size and the capacity factor, as evident in the preceding equation. There are economies of scale associated with increasing the plant megawatt size.

Without thermal storage, the annual capacity factor of the solar plant is limited to approximately $20 \%$ to $25 \%$. To provide generation during non-solar periods and thereby increase the plant capacity factor, thermal storage is required. Thermal storage can reduce plant thermal losses by reducing the number of steam turbine start-stop cycles and decreasing the heat transfer fluid heating during no-load periods. The plant megawatt size and thermal storage will be discussed in further detail later in the report.

The major efficiency improvements projected by SunLab and the approximate corresponding contribution to the annual net solar-to-electric efficiency improvement are indicated in Table D-6. 
Table D-6 - Projected Efficiency Improvements

\begin{tabular}{|c|c|c|c|}
\hline $\begin{array}{l}\text { Annual Values (not Design Point) } \\
\text { referenced to 1999 SEGS VI }\end{array}$ & Current & $\begin{array}{c}\text { SunLab } \\
\text { Short-Term } \\
\mathbf{2 0 0 7}\end{array}$ & $\begin{array}{c}\text { SunLab } \\
\text { Long-Term } \\
\mathbf{2 0 2 0}\end{array}$ \\
\hline Solar Field Optical Efficiency & $61.7 \%$ & $70.4 \%$ & $73.0 \%$ \\
\hline Percentage Point Improvement ${ }^{* *}$ & - & +1.5 & +2.0 \\
\hline Receiver Thermal Efficiency & $72.9 \%$ & $86.2 \%$ & $85.3 \%$ \\
\hline Percentage Point Improvement ${ }^{* *}$ & - & +2.0 & +1.8 \\
\hline Steam Cycle Efficiency & $37.5 \%$ & $39.3 \%$ & $40.3 \%$ \\
\hline Percentage Point Improvement** & - & +1.0 & +1.4 \\
\hline $\begin{array}{c}\text { Thermal to Power Plant Efficiency } \\
\text { (Start-up/shutdown losses) }\end{array}$ & $93.4 \%$ & $99.2 \%$ & $99.2 \%$ \\
\hline Percentage Point Improvement ${ }^{* *}$ & - & +0.7 & +0.7 \\
\hline Parasitics * & $82.7 \%$ & $88.3 \%$ & $92.8 \%$ \\
\hline Percentage Point Improvement ${ }^{* *}$ & - & +0.4 & $+0.8 \%$ \\
\hline Total Percentage Point Improvement $^{* *}$ & - & +5.6 & +6.7 \\
\hline
\end{tabular}

* Improvements based on 12 hours thermal storage

** Relative to net annual efficiency

The technological advances and research, upon which the SunLab efficiency improvement estimates are based, include the following:

- The development of the new Solel UVAC receiver. The UVAC has improved thermal and optic properties. Field tests of the new receiver at SEGS VI shows a $20 \%$ increase in thermal performance compared to original receiver tubes.

- The development of ball joint assembly replacements for flexhoses. A demonstration of new ball joint assemblies has shown that they can reduce the hydraulic pressure drop in the solar field by approximately $50 \%$. This results in lower solar field heat transfer fluid pumping electric parasitics.

- Improvements in mirror washing techniques have resulted in increased solar field average mirror reflectance.

- Investigation of higher temperature heat transfer fluids.

- Research of direct thermal energy storage.

- Research of higher temperature receiver selective coatings. 


\section{D.3.1 Solar Optical Efficiency}

The near-term projected optical efficiency improvement from $61.7 \%$ to $70.4 \%$ optical efficiency is based on the following considerations:

- Increase in mirror cleanliness from $93.1 \%$ in 1999 to $95 \%$ in 2005 . The standard mirror cleanliness assumption is $95 \%$, and this is considered achievable with a normal, reasonably aggressive mirror wash program.

- Increase in receiver envelope glass transmissivity from $92.5 \%$ to $97 \%$. Solel has developed improved anti-reflective coatings for the glass envelope.

- Increase in receiver absorption from $92 \%$ to $96 \%$. The new Solel cermet coating has demonstrated solar absorption of $96 \%$. Additional optimization of the coating is needed to maintain this level and achieve the desired low emittance.

- The concentrator is increased in length from 50 meters to 150 meters. This longer length reduces end losses, light that reflects off the end of the collector, by $2.2 \%$.

The projected near-term efficiency improvement is summarized in the following equation:

$$
\eta_{\text {Opt, near-term }}=\eta p *(\mathrm{Cn} / \mathrm{Cp}) *(\mathrm{Tn} / \mathrm{Tp}) *(\mathrm{An} / \mathrm{Ap}) *(1+\mathrm{EL})
$$

where:

$$
\begin{aligned}
\eta & =\text { efficiency } \\
\mathrm{C} & =\text { mirror cleanliness } \\
\mathrm{T} & =\text { transmissivity } \\
\mathrm{A} & =\text { absorption } \\
\mathrm{EL} & =\text { end loss reduction } \\
\mathrm{n} & =\text { new } \\
\mathrm{p} & =\text { present } \\
\eta \text { Opt, near-term } & =0.617 *(0.95 / 0.931) *(0.97 / 0.925) *(0.96 / 0.92) * 1.022=0.704
\end{aligned}
$$

The long-term projected optical efficiency improvement from $70.4 \%$ to $73 \%$ optical efficiency is based on the following considerations:

- The Solar weighted mirror reflectivity is assumed to increase from $93.5 \%$ for current back silvered $4 \mathrm{~mm}$ thick glass to $95 \%$ for next generation reflectors that are front surface reflectors with a hard coat for protection.

- Mirror cleanliness of new reflectors is projected to be maintained at higher levels of cleanliness due to new glass anti-soiling coatings that are now being sold on building window glass. Mirror cleanliness is projected to increase from $95 \%$ to $96 \%$ in future plants. 
- Anti-soiling coatings will also be added to the receiver glazing. The coatings are expected to have a bigger impact due to the receiver glazing orientation. The important side of the receiver to keep clean is normally facing in a downward direction, where as the mirror normally face up. Receiver soiling factor improves from 0.98 to 0.99 .

The projected long-term efficiency improvement is summarized in the following equation:

$$
\eta_{\text {Opt, long-term }}=0.704 *(0.95 / 0.935) *(0.96 / 0.95) *(0.99 / 0.98)=0.730
$$

\section{D.3.2 Receiver Thermal Efficiency}

The projected receiver thermal efficiency improvement from $72.9 \%$ to $86.2 \%$ receiver thermal efficiency is based on the following considerations:

- The primary factor in reducing solar field thermal losses is through reduction in the emittance of the receiver selective coating. The selective coating on the receivers in the SEGS VI solar field is half cermet and half black chrome. These receivers had fairly high emittance in comparison to the latest Solel UVAC selective coating. Solel testing at SPF showed an emittance of 0.091. Solel believes that with further optimization, an emittance of 0.07 at $400^{\circ} \mathrm{C}$ is possible while maintaining high solar absorptance $98 \%$. Some R\&D and testing are required to achieve the near-term receiver assumptions. SunLab believes these projections are aggressive and have set the receiver absorptance and emittance goals at 0.96 and 0.07 (at $400^{\circ} \mathrm{C}$ ), respectively.

- A secondary factor in reducing solar field thermal losses is through increasing receiver reliability, which results in fewer receiver tubes in the solar field with lost vacuum, broken glass, or coating defects. Field test results on the Solel UVAC receiver indicate failure rates below historic levels. In addition, the new UVAC selective coating will not fail even when exposed to air at temperature. Thus no coating failures are assumed in future plants.

- The near-term plant is assumed to operate at $450^{\circ} \mathrm{C}$ outlet temperature. This results in a slight decrease in solar field thermal efficiency. Piping heat losses are actually reduced because the plant is assumed to use HitecXL, and a three component inorganic molten salt, that has a higher heat capacity/density product than Therminol VP-1 that allows substantially smaller piping to be used in the solar field. This results in lower solar field piping heat losses overall.

There is some uncertainty in the current properties of the Solel UVAC receiver. The tubes tested at Kramer Junction had their properties measured by Sandia. These had a solar absorptance of $96 \%$ and a thermal emittance of $13.5 \%$ at $400^{\circ} \mathrm{C}$. These tubes showed a $20 \%$ thermal performance increase on the test loop at SEGS VI. Solel had the properties measured from a later batch of tubes that indicated an absorptance of $94.4 \%$ and an emittance of $9.1 \%$ at $400^{\circ} \mathrm{C}$. There is significant uncertainty in the property measurements but better properties are expected by SunLab. The following table lists the receiver tube property assumptions used in the SunLab cases. 
Table D-7 — Receiver Tube Property Assumptions

\begin{tabular}{|l|c|c|c|c|}
\hline & $\begin{array}{c}\text { Luz } \\
\text { (original) }\end{array}$ & $\begin{array}{c}\text { Current } \\
\text { (SEGS 1999) }\end{array}$ & $\begin{array}{c}\text { SunLab } \\
\text { Near-Term }\end{array}$ & $\begin{array}{c}\text { SunLab } \\
\text { Long-Term }\end{array}$ \\
\cline { 2 - 5 } & SEGS VI & UVAC 1/2 & Assumption & Assumption \\
\hline Absorptance & 0.92 & $0.96 / 0.944$ & 0.96 & 0.96 \\
\hline Envelope Glass Transmissivity & 0.92 & $0.965 / 0.965$ & 0.97 & 0.97 \\
\hline Emittance at $400^{\circ} \mathrm{C}$ & $>0.18$ & $0.135 / 0.091$ & 0.07 & 0.07 \\
\hline Operating Temperature & $392^{\circ} \mathrm{C}$ & $>450^{\circ} \mathrm{C}$ & $450^{\circ} \mathrm{C}$ & $500^{\circ} \mathrm{C}$ \\
\hline
\end{tabular}

\section{D.3.3 Steam Cycle Efficiency}

The steam cycle foundation is the Rankine cycle. As the inlet steam conditions (pressure and temperature) increase, the Rankine cycle efficiency increases. The near-term steam cycle gross efficiency from $37.5 \%$ to $39.3 \%$ is predicated on increasing the inlet steam temperature from $390^{\circ} \mathrm{C}$ to $450^{\circ} \mathrm{C}$. The long-term increase to $40.3 \%$ is based on $500^{\circ} \mathrm{C}$ steam inlet temperature. The net steam turbine efficiency (gross efficiency minus the percentage of parasitic power consumption required for plant operation) is accounted for by calculation of the parasitic consumption separately, as shown on Table D-6, "Projected Efficiency Improvements," and discussed in the following section.

The near-term turbine efficiency is verified based on the ABB-Brown Boveri heat balances (HTGD 582395, Sheets 1-7) for SEGS IX, which show an efficiency of 37.7\% (in LUZ International Limited 1990). The Rankine cycle efficiency gains for increasing the inlet steam temperature from $390^{\circ} \mathrm{C}$ to $500^{\circ} \mathrm{C}$ were verified by $\mathrm{S} \& \mathrm{~L}$ by using General Electric STGPER software program (Version 4.08.00, January 2002). The turbine efficiencies are summarized in Table D-8.

Table D-8 - Steam Turbine Efficiencies

\begin{tabular}{|c|c|c|c|}
\hline $\begin{array}{c}\text { Turbine Inlet } \\
\text { Temperature }\end{array}$ & $\begin{array}{c}\text { ABB-Brown Boveri } \\
\text { (SEGS IX) }\end{array}$ & SunLab Projection & $\begin{array}{c}\text { S\&L Estimate } \\
\text { (GE STGPER basis) }\end{array}$ \\
\hline $390^{\circ} \mathrm{C}$ & $37.7 \%$ & $37.5 \%$ & $37.5 \%$ \\
\hline $450^{\circ} \mathrm{C}$ & - & $39.3 \%$ & $39.5 \%$ \\
\hline $500^{\circ} \mathrm{C}$ & - & $40.3 \%$ & $40.6 \%$ \\
\hline
\end{tabular}


There are no steam turbine technological risks in achieving the SunLab projected efficiencies. There are currently numerous steam turbines operating with steam inlet conditions over 250 bar pressure and $590^{\circ} \mathrm{C}$ temperature, with gross efficiencies over $44 \%{ }^{*}$

However, the type of heat transfer fluid (HTF) used determines the operational temperature range of the solar field and thus the maximum power cycle efficiency that can be obtained. Currently, synthetic oil (Therminol VP-1) is used in the trough technology as the HTF with an operating temperature of approximately $390^{\circ} \mathrm{C}$.

To achieve the near-term increased Rankine cycle efficiency the HTF will have to be changed to obtain the $450^{\circ} \mathrm{C}$ inlet steam temperature. The SunLab projections assume a nitrate salt HTF with an upper operating range of $500^{\circ} \mathrm{C}$, such as HitecXL, similar to the HTF used for the power tower technology. Use of nitrate salt has not been demonstrated for the trough technology.

For the near-term, additional development and field testing is required on alternate HTFs for higher temperature applications. For the long-term, not only is alternate HTF development required but the current HCE absorber coating upper temperature limit is approximately $450^{\circ} \mathrm{C}$, which will necessitate an advanced HCE coating for the projected $500^{\circ} \mathrm{C}$ operating temperature.

\section{D.3.4 Thermal to Power Plant Efficiency — Parasitics}

The parasitic electric consumption is reduced from $17.3 \%$ at SEGS VI to $8.4 \%$ in the near-term case and to $7.2 \%$ in the long-term case. The major reasons for the reductions are the following:

- $\quad$ SEGS VI uses flex hoses for interconnection of collectors. Future plants will use ball joint assemblies. Ball joints reduce pressure drop in the collector loop by about $50 \%$. Increasing from a 50-meter to a 150-meter collector length reduces the number of collector interconnections by 3 , thereby reducing the pressure drop. The HTF pumping parasitics is reduced from $5.9 \%$ of gross generation to $3.8 \%$.

- Changing the HTF from VP-1 to HitecXL reduces HTF pumping parasitics from $3.8 \%$ to $1.7 \%$. This is based on a new solar field piping model developed by Nexant.

- Additional plant parasitic reduction is assumed through further optimization of power plant motors and other electrical equipment through the use of more energy efficient components and control systems. Current parasitic models are based on the parasitics at the SEGS plants. Significant improvement in motors and other parasitic equipment have occurred in the last 15 years.

\footnotetext{
* Plant (commercial operation date): Nanaoota 1 (1995), Noshiro 2 (1995), Haramachi 1 (1997), Haramachi 2 (1998), Millmerran (2002), Matauura 2 (1997), Misumi 1 (1998), Tachibana Bay (2000), Bexback (2002), Lubeck (1995), Aledore 1 (2000), Nordjylland (1998). From Power (Swanekamp 2002).
} 
The efficiency improvements are based on 12 hours of thermal storage. The storage allows the plant to operate during non-insolation periods, thereby reducing thermal losses by minimizing the energy loss during plant start/stop cycles (thermal to plant power efficiency) and HTF heating during off-line periods. Even though efficiency improvements can be gained by thermal storage, additional direct costs will be incurred. First, the cost of the storage system is estimated to be between $\$ 20 / \mathrm{kWh}_{\mathrm{t}}$ and $\$ 31 / \mathrm{kWh}_{\mathrm{t}}$ (Price et al. 2002), and second, the collector area required will be approximately doubled for 12 hours storage capability. For a 33-MWe plant, approximately $1,060-\mathrm{MWh}_{\mathrm{t}}$ storage will be required for 12 hours storage at an estimated cost between $\$ 21,000,000$ and $\$ 33,000,000(\$ 640 / \mathrm{kWe}$ and $\$ 1,000 / \mathrm{kWe})$ and an increased collector cost of approximately $\$ 37,000,000(\$ 1,100 / \mathrm{kWe})$. Offsetting the additional capital expenditures is the additional revenues for the extra electrical generation (approximately double for 12 hours of storage).

\section{D.3.5 Efficiency Improvements Summary}

The S\&L evaluation is based on a less aggressive technology development approach, basing the maximum optical efficiency on the tested receiver tubes weighted absorptance of $94.4 \%$, receiver coatings solar transmittances of $96.5 \%$, mirror reflectivity of $93.5 \%$, and mirror cleanliness factor of $95 \%$. A comparison of SunLab and S\&L efficiencies is illustrated in Table D-9.

Table D-9 - Comparison of SunLab and S\&L Efficiencies

\begin{tabular}{|c|c|c|c|c|c|c|c|}
\hline & & $\begin{array}{l}\text { SEGS } \\
\text { VI }\end{array}$ & $\begin{array}{l}\text { Trough } \\
100\end{array}$ & $\begin{array}{l}\text { Trough } \\
100\end{array}$ & $\begin{array}{c}\text { Trough } \\
150\end{array}$ & $\begin{array}{l}\text { Trough } \\
200\end{array}$ & $\begin{array}{l}\text { Trough } \\
400\end{array}$ \\
\hline & & 1999 & 2004 & 2007 & 2010 & 2015 & 2020 \\
\hline \multirow[t]{2}{*}{ Solar Field Efficiency } & SunLab & 0.533 & 0.567 & 0.582 & 0.598 & 0.602 & 0.602 \\
\hline & S\&L & 0.533 & 0.567 & 0.570 & 0.570 & 0.570 & 0.570 \\
\hline Incidence Angle & & 0.873 & 0.873 & 0.873 & 0.873 & 0.873 & 0.873 \\
\hline Solar Field Availability & & 0.990 & 0.990 & 0.990 & 0.990 & 0.990 & 0.990 \\
\hline $\begin{array}{l}\text { Other (IAM, row to row } \\
\text { shadowing, end loss) }\end{array}$ & & 0.899 & 0.910 & 0.918 & 0.918 & 0.918 & 0.918 \\
\hline Tracking Error and Twist & & 0.994 & 0.994 & 0.994 & 0.994 & 0.994 & 0.994 \\
\hline Geometric Accuracy & & 0.980 & 0.980 & 0.980 & 0.980 & 0.980 & 0.980 \\
\hline \multirow[t]{2}{*}{ Mirror Reflectivity } & SunLab & 0.935 & 0.935 & 0.935 & 0.950 & 0.950 & 0.950 \\
\hline & S\&L & 0.935 & 0.935 & 0.935 & 0.935 & 0.935 & 0.935 \\
\hline
\end{tabular}




\begin{tabular}{|c|c|c|c|c|c|c|c|}
\hline & & $\begin{array}{c}\text { SEGS } \\
\text { VI }\end{array}$ & $\begin{array}{c}\text { Trough } \\
100\end{array}$ & $\begin{array}{c}\text { Trough } \\
100\end{array}$ & $\begin{array}{c}\text { Trough } \\
150\end{array}$ & $\begin{array}{l}\text { Trough } \\
200\end{array}$ & $\begin{array}{l}\text { Trough } \\
400\end{array}$ \\
\hline & & 1999 & 2004 & 2007 & 2010 & 2015 & 2020 \\
\hline \multirow[t]{2}{*}{ Mirror Cleanliness Factor } & \multirow{2}{*}{$\begin{array}{l}\text { SunLab } \\
\text { S\&L }\end{array}$} & 0.931 & 0.950 & 0.950 & 0.960 & 0.960 & 0.960 \\
\hline & & 0.931 & 0.950 & 0.950 & 0.950 & 0.950 & 0.950 \\
\hline Concentrator Factor & & 1.000 & 1.000 & 1.000 & 1.000 & 1.000 & 1.000 \\
\hline Bellows Shadowing & & 0.971 & 0.971 & 0.971 & 0.971 & 0.971 & 0.971 \\
\hline Dust on Envelope & & 0.980 & 0.985 & 0.985 & 0.985 & 0.985 & 0.985 \\
\hline \multirow[t]{2}{*}{ Envelope Transmissivity } & \multirow{2}{*}{$\begin{array}{l}\text { SunLab } \\
\text { S\&L }\end{array}$} & 0.925 & 0.965 & 0.970 & 0.970 & 0.970 & 0.970 \\
\hline & & 0.925 & 0.965 & 0.965 & 0.965 & 0.965 & 0.965 \\
\hline \multirow[t]{2}{*}{ Receiver Solar Absorption } & \multirow{2}{*}{$\begin{array}{l}\text { SunLab } \\
\text { S\&L }\end{array}$} & 0.920 & 0.944 & 0.960 & 0.960 & 0.960 & 0.960 \\
\hline & & 0.920 & 0.944 & 0.944 & 0.944 & 0.944 & 0.944 \\
\hline \multirow[t]{2}{*}{ Receiver Thermal Efficiency } & \multirow{2}{*}{$\begin{array}{l}\text { SunLab } \\
\text { S\&L }\end{array}$} & 0.729 & 0.859 & 0.862 & 0.852 & 0.853 & 0.853 \\
\hline & & 0.729 & 0.843 & 0.823 & 0.810 & 0.810 & 0.810 \\
\hline \multicolumn{2}{|l|}{ Piping Thermal Losses } & 0.961 & 0.965 & 0.967 & 0.967 & 0.968 & 0.968 \\
\hline \multicolumn{2}{|l|}{ Storage Thermal Losses } & 1.000 & 0.991 & 0.997 & 0.996 & 0.996 & 0.996 \\
\hline \multicolumn{2}{|l|}{ EPGS Efficiency } & 0.351 & 0.370 & 0.390 & 0.400 & 0.400 & 0.400 \\
\hline \multicolumn{2}{|l|}{ Electric Parasitics } & 0.827 & 0.883 & 0.916 & 0.922 & 0.922 & 0.928 \\
\hline \multicolumn{2}{|l|}{ Power Plant Availability } & 0.980 & 0.940 & 0.940 & 0.940 & 0.940 & 0.940 \\
\hline \multirow{2}{*}{$\begin{array}{l}\text { Annual Solar-to-Electric } \\
\text { Efficiency }\end{array}$} & \multirow{2}{*}{$\begin{array}{l}\text { SunLab } \\
\text { S\&L }\end{array}$} & 0.106 & 0.143 & 0.162 & 0.170 & 0.171 & 0.172 \\
\hline & & 0.106 & 0.140 & 0.151 & 0.154 & 0.155 & 0.155 \\
\hline
\end{tabular}

While the SunLab efficiency improvements are theoretically reasonable, the 12 hours of thermal storage is problematic since it has not been commercially demonstrated for the higher solar field operating temperatures (approximately $390^{\circ} \mathrm{C}$ ) of the later SEGS plants. Thermal storage is discussed in greater detail later in this report.

The near-term (2007) efficiency improvement from $10.6 \%$ to $16.2 \%$, based on available information, appears to be optimistic. A more conservative efficiency improvement, based on maximum optical efficiency on the tested receiver tubes weighted absorptance of $94.4 \%$, receiver coatings solar transmittances of 96.5\%, mirror reflectivity of $93.5 \%$, and mirror cleanliness factor of $95 \%$, is $15.1 \%$. If an HCE performance improvements, 
higher temperature HTF, and compatible thermal storage system can be developed and implemented in the nearterm, a $16.2 \%$ annual net solar-to-electric efficiency is feasible. Additional investigation and development of HCE, storage systems, including the optimum HTF for steam cycle efficiency and storage compatibility, is required to achieve the near-term efficiency projection.

\section{D.4 SOLAR FIELD — SUPPORT STRUCTURE}

\section{D.4.1 Direct Capital Cost}

The SunLab projections for the structure material and erection are shown in the Table D-10.

Table D-10 - SunLab Cost Projections

\begin{tabular}{|l|c|c|c|}
\hline \multicolumn{2}{|c|}{} & \multicolumn{2}{c|}{ Reduction from } \\
\cline { 3 - 4 } \multicolumn{2}{|c|}{} & SEGS VI & $\$ / \mathbf{k W e}$ \\
\hline SEGS VI & $\$ 67 / \mathrm{m}^{2}$ & - & 420 \\
\hline 2004 & $\$ 61 / \mathrm{m}^{2}$ & $9 \%$ & 683 \\
\hline 2007 & $\$ 57 / \mathrm{m}^{2}$ & $15 \%$ & 591 \\
\hline 2010 & $\$ 54 / \mathrm{m}^{2}$ & $19 \%$ & 531 \\
\hline 2015 & $\$ 50 / \mathrm{m}^{2}$ & $25 \%$ & 489 \\
\hline 2020 & $\$ 46 / \mathrm{m}^{2}$ & $31 \%$ & 450 \\
\hline
\end{tabular}

The baseline cost of $\$ 67 / \mathrm{m}^{2}$ is consistent with estimates prepared by Pilkington International (1999) indicating $\$ 63 / \mathrm{m}^{2}$. Using $\$ 1,500$ per ton for erected structural steel (National Construction Estimator 49th edition) results in a total direct cost of $\$ 12,400,000$ for the SEGS VI $188,000-\mathrm{m}^{2}$ collector area, which is also consistent with the Pilkington estimate of $\$ 13,252,000$ for a $209,280-\mathrm{m}^{2}$ collector area $\left(209,280 \mathrm{~m}^{2} / 188,000 \mathrm{~m}^{2} \times \$ 12,400,000=\right.$ $\$ 13,785,000)$.

Cost comparisons based on weight, as discussed in the following section, for the various structures are illustrated in Table D-11. 


\section{Table D-11 - Costs of Various Structures}

\begin{tabular}{|l|l|}
\hline LS-2 & $\$ 58 / \mathrm{m}^{2}$ \\
\hline LS-3 & $\$ 66 / \mathrm{m}^{2}$ \\
\hline EuroTrough & $\$ 58 / \mathrm{m}^{2}$ \\
\hline Duke Solar & $\$ 48 / \mathrm{m}^{2}$ \\
\hline IST & $\$ 48 / \mathrm{m}^{2}$ \\
\hline
\end{tabular}

Additional cost reductions will be realized by minimization of the number of required parts, simplification of fabrication and field erection reducing labor costs for on-site assembly and erection. This cost reduction potential has not been quantified since there has not been an actual erection of a new collector structure. While the trough technology was commercialized for a brief period, no trough plants have been built in nearly a decade. There are active solar field suppliers, which will reduce costs through competition; however, structure cost reductions due to commercialization was not considered in this evaluation.

\section{D.4.2 Technology Improvements}

The Luz LS-3 collector was the final concentrator design used at the newest SEGS plants (SEGS VII-IX). The thermal performance and alignment maintainability of the LS-3 collector has not proved to be equal to the earlier LS-2 design used on the SEGS II-IX plants. There are at least three new parabolic trough collector structure designs under various stages of development:

- $\quad$ EuroTrough (ASME 2001)

- $\quad$ Duke Solar (Duke Solar 2000)

- Industrial Solar Technology (IST 2001))

The new collectors concentrate on weight reduction and emphasize simplicity of fabrication and a minimum number of required parts. A weight comparison of the LS-2, LS-3, and the aforementioned new design structures is provided in Table D-12. 


\section{Table D-12 - Structure Weight Comparison}

\begin{tabular}{|l|c|c|}
\hline Structure & $\begin{array}{c}\text { Weight } \\
\left(\mathbf{k g} / \mathbf{m}^{2} \mathbf{)}\right.\end{array}$ & Reduction \\
\hline LS-2 & 29 & $12 \%$ \\
\hline LS-3 & 33 & Base \\
\hline IST & 24 & $27 \%$ \\
\hline Eurotrough & 29 & $12 \%$ \\
\hline Duke Solar & 24 & $27 \%$ \\
\hline
\end{tabular}

\section{D.4.3 Scale-Up}

Structure cost reductions due to scale-up were not considered since the collector area for the same net annual solar-to-electric efficiency, and thus the structure, is directly proportional to the plant size. The collector area is inversely proportional to the efficiency and will influence the structure cost by reducing the collector area with the improvement of the efficiency.

\section{D.4.4 Production Volume}

The experience curve (Neij 1997) is related to the commercialization of the solar plants. The experience curve describes how unit costs decline with cumulative production, with a specific characteristic that cost declines by a constant percentage with each doubling of the total number of units produced.

The formula is as follows:

$$
\begin{aligned}
& \mathrm{C}_{\mathrm{CUM}}=\mathrm{C}_{0} \times \mathrm{CUM}^{\mathrm{b}} \\
& \text { Where: } \\
& \mathrm{C}_{\mathrm{CUM}}=\text { the cost per unit as a function of output } \\
& \mathrm{C}_{0}=\text { the cost of the first unit produced } \\
& \mathrm{CUM}=\text { the cumulative production over time } \\
& \mathrm{b}=\text { the experience index }
\end{aligned}
$$

The cost reduction is $\left(1-2^{b}\right)$ for each doubling of cumulative production, where the value $\left(2^{b}\right)$ is called the progress ratio (PR). PR is used to express the progress of cost reductions for different technologies. The lower the PR value the higher the cost reduction realized. The cost reductions refer to the total costs (labor, capital, 
administration, research, etc.). Experience curves is not an established method, but a correlation that has been observed for several different technologies. Cost reductions were projected based on evaluation of technology improvements and experience curves.

The SEGS solar field areas are shown below. The cumulative area indicates approximately five doublings were experienced for the SEGS plants. One of the criteria for the applicability of experience curves, according to the Neij literature (1997), is at least three doublings of production volume.

Table D-13 - SEGS Solar Field Area

\begin{tabular}{|c|c|c|c|}
\hline $\begin{array}{c}\text { SEGS Plant } \\
\text { Number }\end{array}$ & MW & $\begin{array}{c}\text { Solar Field } \\
\text { Area, } \mathbf{~ m}^{\mathbf{2}}\end{array}$ & $\begin{array}{c}\text { Solar Field Area, } \\
\mathbf{m}^{\mathbf{2}} \text { - Cumulative }\end{array}$ \\
\hline I & 13.8 & 82,960 & 82,960 \\
\hline II & 30 & 190,338 & 273,298 \\
\hline III & 37 & 230,300 & 503,598 \\
\hline IV & 37 & 230,300 & 733,898 \\
\hline V & 39 & 250,500 & 984,398 \\
\hline VI & 35.5 & 188,000 & $1,172,398$ \\
\hline VII & 35.5 & 194,280 & $1,366,678$ \\
\hline VIII & 80 & 464,340 & $1,831,018$ \\
\hline IX & 80 & 483,960 & $2,314,978$ \\
\hline
\end{tabular}

There are recognized scale-up cost reductions for increasing the plant size:

$$
\$ B=\$ A \times\left(B_{M W} / A_{M W}\right)^{S f}
$$

Where:

Plant B is larger than Plant A

$\$ \mathrm{~B}=$ cost of Plant $\mathrm{B}$

$\$ \mathrm{~A}=$ cost of Plant $\mathrm{A}$

$\mathrm{B}_{\mathrm{MW}}=\mathrm{MW}$ size of Plant $\mathrm{B}$

$\mathrm{A}_{\mathrm{MW}}=\mathrm{MW}$ size of Plant $\mathrm{A}$

$\mathrm{Sf}=$ scale-up factor 
Based on the cost data provided by the SEGS Plant (SEGS Data Package obtained during plant visit), an average scale-up factor of 0.7 was attained: SEGS I to SEGS II had a 0.6 scale-up factor; SEGS II to SEGS III, a 0.8 scale-up factor; and SEGS V to SEGS VII, a 0.7 scale-up factor. The SEGS Cost Data in 2001 dollars from "Advances in Parabolic Trough Technology" (Price et al. 2002) show a savings of $\$ 1,643 / \mathrm{kWe}$ from SEGS VI to SEGS IX. Three doublings of the solar field area had occurred before SEGS VI. Using the average scale-up factor of $0.7, \$ 1,447 / \mathrm{kWe}$ cost reduction was realized by plant scale-up. The majority of the remaining $\$ 196 / \mathrm{kWe}$ savings $(\$ 1,643 / \mathrm{kWe}-\$ 1,447 / \mathrm{kWe}=\$ 196 / \mathrm{kWe})$ was assumed to be attributable to production volume cost reduction since there were no significant technological advances from SEGS VI to SEGS IX. Applying the SEGS VI solar field cost $\left(\$ / \mathrm{m}^{2}\right)$ to the SEGS IX plant and then reducing that cost by the $\$ 196 /$ kWe savings yielded a progress ratio (PR) value of 0.92. The Enermodal Study (undated) shows a PR range between 0.85 and 0.92 for the installed capital cost of a trough power plant. Arguably, for the highly automated manufactured components, such as the support structure, receiver tubes, and mirrors, a PR of 0.80 , as used in the Neij literature (1997), may be more representative based on manufacturing experience. The S\&L cost estimates for comparison to the SunLab model are based on a progress ratio (PR) value of 0.92 based on the estimated PR value from the SEGS cost data and since establishing an experience curve for a given component is somewhat speculative. A PR value of 0.92 will be more conservative, and if the actual PR value is less than 0.92 used in this evaluation, then the cost reductions will be greater than the estimated values.

The initial starting point for estimating the cumulative production is the 2004 Technology Trough Plant. The cumulative production does not include the nine original SEGS plants because 10 years have elapsed since commercial production occurred for these plants.

\section{D.4.5 Cost Comparison}

A comparison of the SunLab projected costs are compared to the estimated cost based on a progress ratio of 0.92 in Table D-14.

Table D-14 - Support Structure Cost Comparison $\left(\$ / \mathrm{m}^{2}\right)$

\begin{tabular}{|c|c|c|}
\hline Year & SunLab & S\&L \\
\hline SEGS VI & 67 & 67 \\
\hline 2004 & 61 & 61 \\
\hline 2007 & 57 & 58 \\
\hline 2010 & 54 & 56 \\
\hline
\end{tabular}




\begin{tabular}{|c|c|c|}
\hline Year & SunLab & S\&L \\
\hline 2015 & 50 & 54 \\
\hline 2020 & 46 & 52 \\
\hline
\end{tabular}

The baseline cost of $\$ 67 / \mathrm{m}^{2}$ (SEGS VI) is consistent with estimates prepared by Pilkington International (1999) indicating $\$ 63 / \mathrm{m}^{2}$. Cost comparisons based on weight for the various structures are illustrated below. Recent wind tunnel testing has provided improved data for use in optimizing the structural design, and reducing the weight, necessary for long-term reliability. Future designs may include more efficient integration of the reflectors into the overall structure, thus sharing the loads and reducing material requirements. Non-metallic materials are being considered, but may not be cost-effective. Additional cost reductions can be realized by minimization of the number of required parts and simplification of fabrication and field erection reducing labor costs for on-site assembly and erection. This cost reduction potential has not been quantified in this evaluation since there has not been an actual erection of a new collector structure. The individual metal parts of the structure can readily be manufactured by suppliers worldwide, leading to potential cost reductions through competition. However, structure cost reductions due to commercialization were not specifically considered in this evaluation.

The estimated cost reductions are a result of the experience curve and indicate that the SunLab projected costs are reasonable. Even lower costs can be expected if lower structure weights, such as shown in Table D-12, are employed. Other potential cost reductions are simplification of fabrication and decreasing the number of required parts.

\section{D.5 SOLAR FIELD - HEAT COLLECTION ELEMENT (HCE)}

\section{D.5.1 Direct Capital Cost}

The SunLab projected HCE deployment and costs are shown in Table D-15. 
Table D-15 - SunLab Projected HCE Deployment and Costs

\begin{tabular}{|l|c|c|c|c|c|c|}
\hline & SEGS VI & $\begin{array}{c}\text { Trough } \\
\mathbf{1 0 0}\end{array}$ & $\begin{array}{c}\text { Trough } \\
\mathbf{1 0 0}\end{array}$ & $\begin{array}{c}\text { Trough } \\
\mathbf{1 5 0}\end{array}$ & $\begin{array}{c}\text { Trough } \\
\mathbf{2 0 0}\end{array}$ & $\begin{array}{c}\text { Trough } \\
\mathbf{4 0 0}\end{array}$ \\
\hline & $\mathbf{1 9 9 9}$ & $\mathbf{2 0 0 4}$ & $\mathbf{2 0 0 7}$ & $\mathbf{2 0 1 0}$ & $\mathbf{2 0 1 5}$ & $\mathbf{2 0 2 0}$ \\
\hline Number HCE & 9,600 & 57,216 & 45,700 & 65,072 & 86,101 & 172,201 \\
\hline $\begin{array}{l}\text { Number HCE } \\
\text { Accumulative }\end{array}$ & 9,600 & 66,816 & 112,516 & 177,588 & 263,688 & 435,889 \\
\hline Cost, \$/m ${ }^{2}$ field & 43 & 43 & 34 & 28 & 22 & 18 \\
\hline Cost, \$/unit & 847 & 847 & 762 & 635 & 508 & 400 \\
\hline
\end{tabular}

\section{D.5.2 Technology Improvements}

The Solel UVAC HCE is considered the current state-of-the-art receiver and will be used in the new near-term trough plants.

Sandia National Laboratories (SNL) is investigating new concepts in receiver design that could result in substantially lower-cost receivers with nearly the same high performance as the Solel receivers (Price and Kearney 1999). One of the SNL designs uses a high-temperature gasketing approach for connecting the glass envelope to the metal absorber, in place of the glass-to-metal seal. To reduce convective heat losses, the receiver annulus between the glass and metal tube would be pressurized with an inert gas. Although preliminary testing shows potential, extensive long-term field-testing is required on any new receiver design to evaluate and validate the reliability and also to assess whether the receiver's life-cycle costs have been lowered. In the last couple of years, the focus of the research has returned to evacuated receiver designs. The focus now is on developing a more robust and lower-cost glass-to-metal seal design and on identifying higher temperature selective coatings with better thermo/optic properties. Sandia has identified new materials that could be used in the glass-to-metal seal to reduce the potential stress in the seal. In general, however, the current Housekeeper seal used in the HCE is very expensive and a significant part of the total receiver cost. Sandia has also identified some new glass-to-metal seal options that have the potential to be much lower in cost to manufacture and be more robust at the same time. NREL has been evaluating new selective coatings. Several new cermet coatings have been identified that may be easier to manufacture and have better thermo/optic properties. These are multilayer cermets as opposed to the graded cermet used by Solel. The graded cermets require a sputtered manufacturing process, whereas the multilayer coating can probably be deposited with simpler coating processes that facilitate better quality control of the final properties. NREL is also investigating changing the materials 
used in the cermet to give better high temperature performance and stability. Both the design work and the coating development are being funded in the current DOE budget and will be continued next year.

Alternate HCE designs (Zhang et al. 1998; Morales and Ajona 1998; San Vicent, Morales, and Gutiérrez 2001) are under various stages of development that indicate lower cost than the Solel UVAC HCE, although at reduced efficiency levels. Reduced HCE efficiency will result in a lower net annual solar-to-electric efficiency and require a larger collector area. Schott Glass, a large international supplier of specialty glass and related products, has recently announced its entry into the HCE supply market. However, start-up of HCE production is a significant cost, and a viable market growth is imperative to justify market entry for a new supplier.

\section{D.5.3 Scale-Up}

Cost reductions due to scale-up is not considered applicable since the collector area for the same net annual solar-to-electric efficiency, and thus the number of $\mathrm{HCE}$, is directly proportional to the plant size. The collector area is inversely proportional to the efficiency and will influence the HCE cost by reducing the collector area with the improvement of the efficiency.

\section{D.5.4 Production Volume}

Cost reductions were projected based on evaluation of technology improvements and a progress ratio of 0.92. The Case 1 deployment values are used in the S\&L evaluation. The Case 2 deployment values, used in the SunLab projections, are provided for comparison of the production volume between the two cases in Table D-16.

Table D-16 - Number of HCE

\begin{tabular}{|l|c|c|c|c|c|}
\hline Number HCE, Cumulative & $\mathbf{2 0 0 4}$ & $\mathbf{2 0 0 7}$ & $\mathbf{2 0 1 0}$ & $\mathbf{2 0 1 5}$ & $\mathbf{2 0 2 0}$ \\
\hline Case 1 Deployment & 57,545 & 219,535 & 380,117 & 735,606 & $1,265,782$ \\
\hline Case 2 Deployment & 57,545 & 219,535 & 520,817 & $1,076,652$ & $2,225,366$ \\
\hline
\end{tabular}




\section{D.5.5 Cost Comparison}

A comparison of the SunLab projected costs to the SunLab estimated costs are shown in Table D-17.

Table D-17 - HCE Cost Comparison (\$/unit)

\begin{tabular}{|c|c|c|}
\hline Year & SunLab & S\&L \\
\hline 2004 & 847 & 847 \\
\hline 2007 & 762 & 762 \\
\hline 2010 & 635 & 675 \\
\hline 2015 & 508 & 625 \\
\hline 2020 & 400 & 525 \\
\hline
\end{tabular}

\section{D.6 SOLAR FIELD - MIRRORS}

\section{D.6.1 Direct Capital Cost}

The SunLab projected mirror costs are shown in Table D-18.

Table D-18 - SunLab Projected Mirrors Costs

\begin{tabular}{|l|c|c|c|c|c|c|}
\hline & $\begin{array}{c}\text { SEGS } \\
\text { VI }\end{array}$ & $\begin{array}{c}\text { Trough } \\
\mathbf{1 0 0}\end{array}$ & $\begin{array}{c}\text { Trough } \\
\mathbf{1 0 0}\end{array}$ & $\begin{array}{c}\text { Trough } \\
\mathbf{1 5 0}\end{array}$ & $\begin{array}{c}\text { Trough } \\
\mathbf{2 0 0}\end{array}$ & $\begin{array}{c}\text { Trough } \\
\mathbf{4 0 0}\end{array}$ \\
\cline { 2 - 7 } & $\mathbf{1 9 9 9}$ & $\mathbf{2 0 0 4}$ & $\mathbf{2 0 0 7}$ & $\mathbf{2 0 1 0}$ & $\mathbf{2 0 1 5}$ & $\mathbf{2 0 2 0}$ \\
\hline Mirrors, $\$ / \mathrm{m}^{2}$ field & 40 & 40 & 36 & 28 & 20 & 16 \\
\hline
\end{tabular}

\section{D.6.2 Technology Improvements}

Alternatives to glass mirror reflectors have been in service and under development for more than 15 years. It is noted that all the identified alternatives are in various stages of initial development or testing. The major current developments are listed below.

- Thin glass mirrors are as durable as a glass reflector and relatively lightweight in comparison to thick glass. However, the mirrors are more fragile, which increases handling costs and breakage losses. To address corrosion problems, new thin glass experimental samples were recently developed and are being tested under controlled conditions.

- $\quad 3 \mathrm{M}$ is developing a nonmetallic, thin-film reflector that uses a multi-layer Radiant Film technology. The technology employs alternating co-extruded polymer layers of differing refractive indices to create a reflector without the need for a metal reflective layer. $3 \mathrm{M}$ plans to 
develop an improved solar reflector with improved UV screening layers and a top layer hardcoat to improve outdoor durability.

- ReflecTech and NREL are jointly developing a laminate reflector material that uses a commercial silvered-polymer reflector base material with a UV-screening film laminated to it to result in outdoor durability. Initial prototype accelerated-exposure test results have been promising, although additional work on material production is needed. The material would also benefit from a hardcoat for improved washability.

- Luz Industries Israel created a front surface mirror that consists of a polymeric substrate with a metal or dielectric adhesion layer; a silver reflective layer; and a proprietary, dense, protective top hardcoat.

- $\quad$ SAIC of McLean, Virginia, and NREL have been developing a material called Super Thin Glass. This is also a front-surface mirror concept with a hard coat protective layer.

- Alanod of Germany has developed a front-surface aluminized reflector that uses a polished aluminum substrate, an enhanced aluminum reflective layer, and a protective oxidized alumina topcoat. These reflectors have inadequate durability in industrial environments. A product with a polymeric overcoat to protect the alumina layer has improved durability.

Table D-19 summarizes the characteristics of the reflector technology alternatives. At this point, thick glass will likely remain the preferred approach for large-scale parabolic trough plants, although alternative reflector technologies may be more important in the future as more advanced trough concentrator designs are developed.

Table D-19 - Alternate Mirror Technologies

\begin{tabular}{|l|c|c|l|}
\hline & $\begin{array}{c}\text { Weighted } \\
\text { Reflectivity } \mathbf{( \% )}\end{array}$ & Cost $\mathbf{( \$ / \mathbf { m } ^ { 2 } )}$ & Issues \\
\hline Flabeg Thick Glass & 94 & 40 & Cost, breakage \\
\hline Thin Glass & $93-96$ & $15-40$ & Handling, breakage \\
\hline All-Polymeric & 99 & 10 & UV protective coating needed with hard coat \\
\hline ReflecTech Laminate & $>93$ & $10-15$ & Hard coat and improved production \\
\hline Solel FSM & $>95$ & - & Solel product durability currently unknown \\
\hline SAIC Super Thin Glass & $>95$ & 10 & Manufacturing scale-up \\
\hline Alanod & $\sim 90$ & $<20$ & Reflectivity \\
\hline
\end{tabular}

There are active mirror suppliers, which will reduce costs through competition, however mirror cost reductions due to commercialization was not considered in this evaluation. 


\section{D.6.3 Scale-Up}

Similar to the collectors, cost reductions due to scale-up are not considered applicable since the mirror area for the same net annual solar-to-electric efficiency, and thus the mirror area, is directly proportional to the plant size. The mirror area is inversely proportional to the efficiency and will influence the mirror cost by reducing the collector area with the improvement of the efficiency.

\section{D.6.4 Production Volume}

Cost reductions were projected based on evaluation of technology improvements and a progress ratio of 0.92. The Case 1 deployment values are used in the S\&L evaluation. The Case 2 deployment values, used in the SunLab projections, are provided for comparison of the production volume between the two cases. These are shown in Table D-20.

Table D-20 -Mirror Volume (Square Meters, Cumulative, Thousands)

\begin{tabular}{|l|c|c|c|c|c|}
\hline & $\mathbf{2 0 0 4}$ & $\mathbf{2 0 0 7}$ & $\mathbf{2 0 1 0}$ & $\mathbf{2 0 1 5}$ & $\mathbf{2 0 2 0}$ \\
\hline Case 1 Deployment & 1,120 & 4,399 & 7,952 & 15,818 & 27,550 \\
\hline Case 2 Deployment & 1,120 & 4,399 & 11,066 & 23,365 & 48,782 \\
\hline
\end{tabular}

\section{D.6.5 Cost Comparison}

A comparison of the SunLab projected costs are compared to the SunLab estimated costs in Table D-21.

Table D-21 - Mirror Cost Comparison $\left(\$ / \mathrm{m}^{2}\right)$

\begin{tabular}{|c|c|c|}
\hline Year & SunLab & S\&L \\
\hline 2004 & 40 & 40 \\
\hline 2007 & 36 & 36 \\
\hline 2010 & 28 & 32 \\
\hline 2015 & 20 & 29 \\
\hline 2020 & 16 & 26 \\
\hline
\end{tabular}




\section{D.7 POWER BLOCK}

\section{D.7.1 Direct Capital Cost}

The SunLab projected power block costs are shown in Table D-22.

Table D-22 - SunLab Projected Power Block and Balance of Plant Costs

\begin{tabular}{|l|c|c|c|c|c|c|}
\hline & SEGS VI & $\mathbf{2 0 0 4}$ & $\mathbf{2 0 0 7}$ & $\mathbf{2 0 1 0}$ & $\mathbf{2 0 1 5}$ & $\mathbf{2 0 2 0}$ \\
\hline Plant size, gross electric, MWe & $\mathbf{3 3}$ & $\mathbf{1 1 0}$ & $\mathbf{1 1 0}$ & $\mathbf{1 6 5}$ & $\mathbf{2 2 0}$ & $\mathbf{4 4 0}$ \\
\hline Power Block, \$/kWe & 410 & 349 & 349 & 293 & 256 & 197 \\
\hline Balance of Plant, \$/kWe & 248 & 203 & 203 & 171 & 149 & 115 \\
\hline \multicolumn{1}{|c|}{ Total, \$/kWe } & 658 & 552 & 552 & 464 & 405 & 312 \\
\hline
\end{tabular}

There are multiple suppliers for the power block equipment, and costs will be market-driven. While a trough plant will benefit from competitive prices, power block cost reductions due to commercialization were not considered in this evaluation.

\section{D.7.2 Technology Improvements}

The power block is a conventional Rankine-cycle steam turbine. The Rankine-cycle steam turbine is an established technology with future major improvements focusing on increased inlet steam pressure and temperature conditions to increase the cycle efficiency.

\section{D.7.3 Scale-Up}

There are recognized scale-up cost reductions for the power block. Using the SOAPP software program, S\&L estimated the scale-up factor for increasing the plant size from $100 \mathrm{MW}$ to $400 \mathrm{MW}$, as depicted on Figure D-4. The projected SunLab values are included for comparative purposes. Power block costs (Figure D-4A) include the steam turbine and generator, steam turbine and generator auxiliaries, feedwater and condensate systems. Balance-of-plant costs (Figure D-4B) include general balance-of-plant equipment, condenser and cooling tower system, water treatment system, fire protection, piping, compressed air systems, closed cooling water system, plant control system, electrical equipment, and cranes and hoists. 
Figure D-4A - Estimated Scale-Up Costs: Power Block (\$/kW)

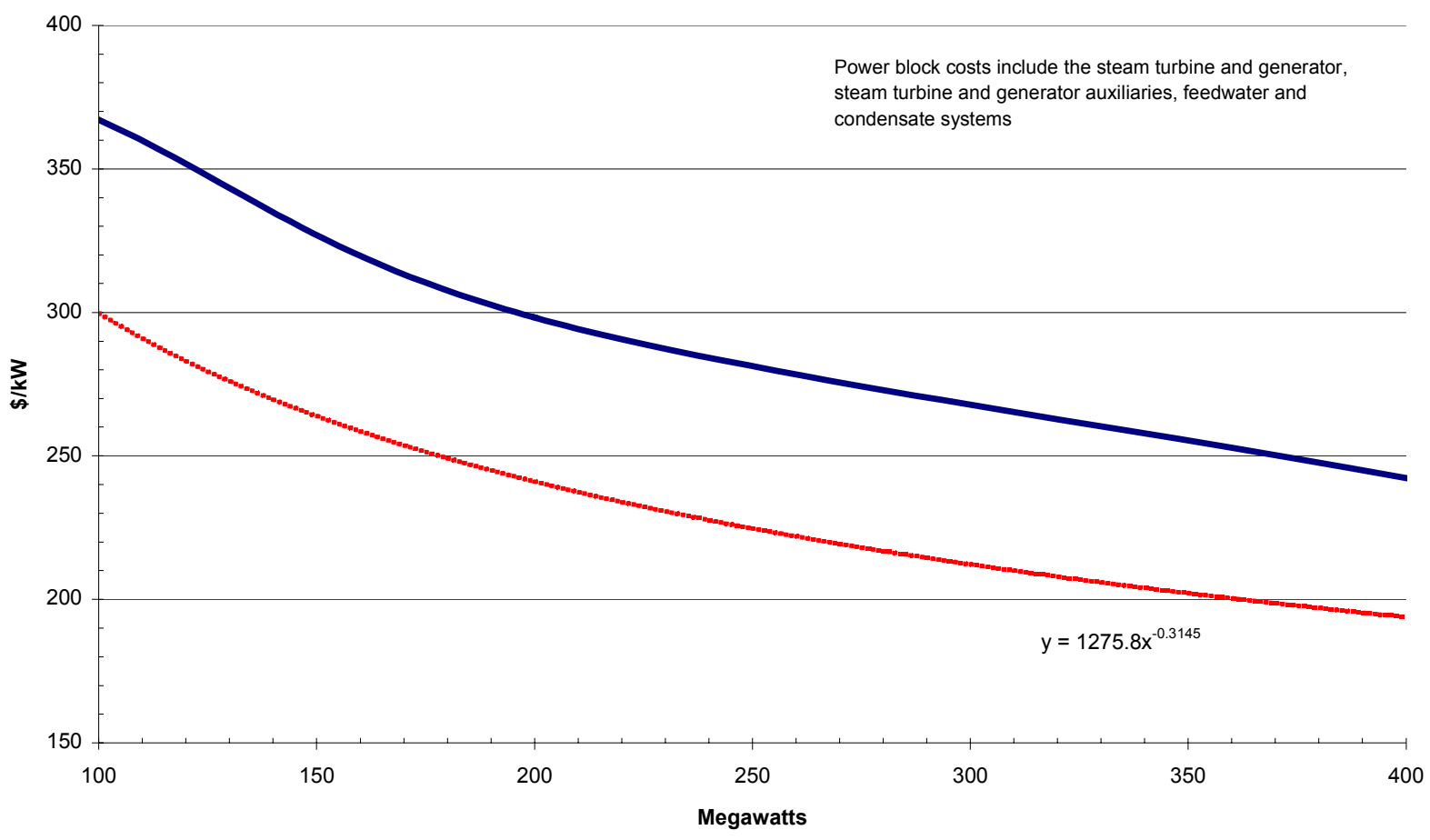

Figure D-4B - Estimated Scale-Up Costs: Balance-of-Plant (\$/kW)

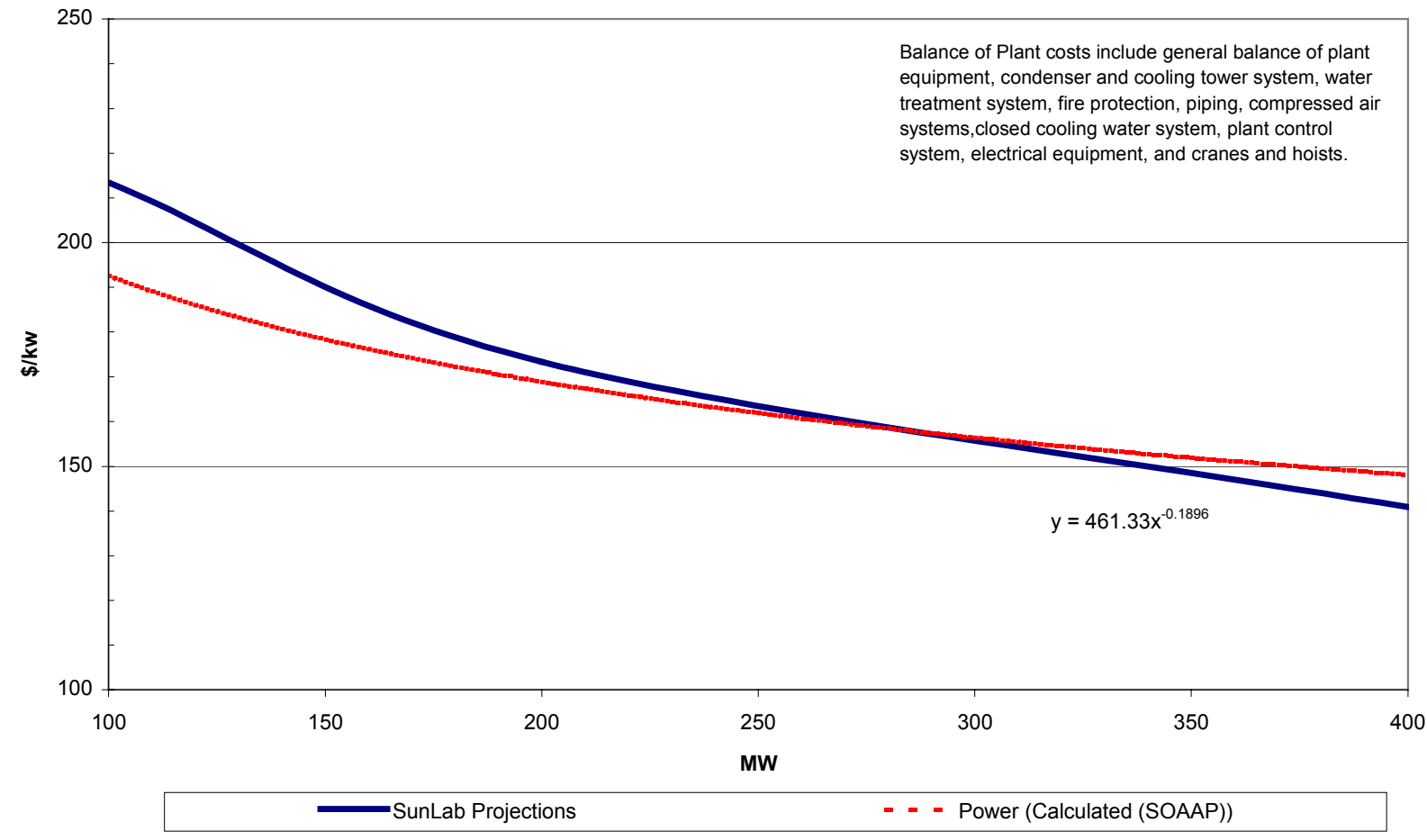


The estimated costs based on the SOAPP program indicate that the SunLab projected costs for the power block are conservative (on the high side), approximately $\$ 50 / \mathrm{kW}$ higher than estimated by the SOAPP program. The SunLab power block cost estimates are based on a 1990 ABB quotation for a 100-MW steam turbine. The ABB quotation was escalated and scaled-up for the larger sizes. The SunLab power block cost estimates are based on dated information and the escalation and scale-up factors add to the uncertainty of the data with respect to current pricing. Equipment prices in the SOAPP program reflect 2001 actual costs. Since the SOAPP pricing is current, the SOAPP-generated costs were used in this evaluation.

\section{D.7.4 Production Volume}

Since a single steam turbine is supplied with each trough plant, production volume is not a consideration for cost reduction.

\section{D.7.5 Cost Comparison}

A comparison of the SunLab projected cost versus the SOAPP predicted $\$ / \mathrm{kW}$ for the power block plus the balance of plant is shown in Table D-23.

Table D-23 - Power Block \& BOP Cost Comparison

\begin{tabular}{|l|c|c|c|c|}
\hline Total Power Block + BOP & $\mathbf{2 0 0 4 - 2 0 0 7}$ & $\mathbf{2 0 1 0}$ & $\mathbf{2 0 1 5}$ & $\mathbf{2 0 2 0}$ \\
\hline Plant size, MWe & 100 & 150 & 200 & 400 \\
\hline SunLab Projected, \$/kWe & 581 & 525 & 472 & 383 \\
\hline SOAPP Estimate, \$/kWe & 499 & 450 & 399 & 346 \\
\hline
\end{tabular}

\section{D.8 THERMAL STORAGE}

\section{D.8.1 Direct Capital Cost}

The SunLab projected thermal storage costs are shown in Table D-24. Note that the SunLab projections are based on 12 hours of thermal storage for each case. 
Table D-24 - SunLab Projected Thermal Storage Cost

\begin{tabular}{|l|c|c|c|c|c|}
\hline & $\mathbf{2 0 0 4}$ & $\mathbf{2 0 0 7}$ & $\mathbf{2 0 1 0}$ & $\mathbf{2 0 1 5}$ & $\mathbf{2 0 2 0}$ \\
\hline Plant size, gross electric, MWe & 110 & 110 & 165 & 220 & 440 \\
\hline Storage, $\mathrm{MWh}_{\mathrm{t}}$ & 3,525 & 3,349 & 4,894 & 6,525 & 13,050 \\
\hline Type & $\begin{array}{c}\text { Indirect } \\
\text { Two-Tank }\end{array}$ & $\begin{array}{c}\text { Direct } \\
\text { Two-Tank }\end{array}$ & $\begin{array}{c}\text { Direct } \\
\text { Thermo- } \\
\text { cline }\end{array}$ & $\begin{array}{c}\text { Direct } \\
\text { Thermo- } \\
\text { cline }\end{array}$ & $\begin{array}{c}\text { Direct } \\
\text { Thermo- } \\
\text { cline }\end{array}$ \\
\hline Heat Transfer Fluid & $\begin{array}{c}\text { VP-1/ Solar } \\
\text { Salt }\end{array}$ & HitecXL & HitecXL & HitecXL & HitecXL \\
\hline HTF Temperature, ${ }^{\circ} \mathrm{C}$ & 400 & 450 & 500 & 500 & 500 \\
\hline SunLab Projected, $\$ / \mathrm{KWh}_{\mathrm{t}}$ & 27.18 & 12.68 & 11.73 & 11.73 & 11.73 \\
\cline { 2 - 6 } & 958 & 425 & 383 & 383 & 383 \\
\hline
\end{tabular}

Binary solar salt (sodium and potassium nitrate) is the same HTF as used for the power tower Solar Two project, whereas HitecXL is a ternary salt (sodium, potassium, and calcium nitrate). The main advantage of ternary salt is a lower freezing temperature $\left(120^{\circ} \mathrm{C}\right)$ compared to $225^{\circ} \mathrm{C}$ for binary salt and a high HTF operating temperature of $500^{\circ} \mathrm{C}$. Ternary salt costs approximately 2 times more than binary salt.

The number of hours of storage impact on the total capital cost is illustrated below in Table D-25 for the year 2004 case (100 MWe) with a two-tank indirect storage system.

Table D-25 - Thermal Storage Impact on Cost

\begin{tabular}{|l|c|c|c|c|c|c|c|}
\hline & \multicolumn{7}{|c|}{ Hours of Thermal Energy Storage } \\
\cline { 2 - 8 } & $\mathbf{0}$ & $\mathbf{2}$ & $\mathbf{4}$ & $\mathbf{6}$ & $\mathbf{8}$ & $\mathbf{1 2}$ & $\mathbf{1 6}$ \\
\hline Annual Capacity Factor & $32.0 \%$ & $33.6 \%$ & $37.8 \%$ & $41.7 \%$ & $46.7 \%$ & $53.5 \%$ & $54.1 \%$ \\
\hline Net Annual Generation, GWh & 280.1 & 294.6 & 331.1 & 365.2 & 408.9 & 468.6 & 473.9 \\
\hline Installed Capital Cost, \$/kWe & 2,816 & 3,074 & 3,471 & 3,867 & 4,280 & 4,859 & 5,190 \\
\hline
\end{tabular}

The impact of the type of storage system on the total capital cost is shown in Table D-26 for the year 2004 case (100 MWe) for 12 hours of storage. 
Table D-26 - Type of Thermal Storage Impact on Cost

\begin{tabular}{|l|c|}
\hline Type of Thermal Storage System - 12 Hours & $\begin{array}{c}\text { Plant Capital Cost } \\
\mathbf{( \$ / k W e )}\end{array}$ \\
\hline Two-Tank Indirect, VP-1 HTF, Solar Salt Storage & 4,859 \\
\hline Thermocline Indirect, VP-1 HTF, Solar Salt Storage & 4,668 \\
\hline Two-Tank Direct, Solar Salt $\left(450^{\circ} \mathrm{C}\right)$ & 4,427 \\
\hline Direct Thermocline, Solar Salt $\left(450^{\circ} \mathrm{C}\right)$ & 4,115 \\
\hline Direct Thermocline, HitecXL $\left(500^{\circ} \mathrm{C}\right)$ & 4,027 \\
\hline
\end{tabular}

As exemplified in Tables D-25 and D-26, the amount of storage and the type of storage have significant impacts on the total cost of the plant and are key considerations for cost reductions.

\section{D.8.2 Technology Improvements}

Thermal storage allows solar electricity to be dispatched to the times when it is needed most and allows solar plants to achieve higher annual capacity factors. Although the first commercial 14-MWe trough plant included thermal storage, a simple two-tank storage system that used the plant HTF for a storage media, later plants operated at higher temperatures that precluded the same method due to the higher vapor pressure and high cost of the HTF. No thermal storage technology has been commercially demonstrated for the higher solar field operating temperatures (approximately $400^{\circ} \mathrm{C}$ ) required for more efficient steam cycles in the later SEGS plants.

Various studies point to an indirect thermal storage system for near-term application where the heat from the collector field is transferred from the synthetic oil (VP-1) HTF to another thermal storage media, such as molten salt, which can be stored at atmospheric pressure (Kearney 2001a, 2001b; Sandia National Laboratories 2001; Nextant Inc. 2001). For the two-tank indirect system, heat from the collector field is transferred from the synthetic oil HTF to another thermal storage media, such as molten salt, which can be stored at atmospheric pressure. However, the molten salt storage temperature is limited by the synthetic oil HTF operating temperature of $390^{\circ} \mathrm{C}$. The technological risk using the two-tank molten-salt storage system is low based on the successful utilization at the Solar Two plant but the cost of this system is high $(\$ 958 / \mathrm{kWe}$ for 2004 SunLab case). The thermocline system will also reduce the storage system costs with synthetic oil HTF and binary molten salt storage fluid by the elimination of one storage tank and the reduction in the fluid volume requirement compared to the indirect two-tank system. Estimates show a $35 \%$ reduction in the storage system cost $\left(\$ 31 / \mathrm{kWh}_{\mathrm{t}}\right.$ to 
$\$ 20 / \mathrm{kWh}_{\mathrm{t}}$ ) using a thermocline system as opposed to a two-tank system (Sandia National Laboratories 2001; Kearney 2001a; Nextant Inc. 2001).

The year 2007 projection for a direct two-tank storage will use HitecXL (ternary) HTF in both the solar field and the thermal storage system, eliminating the need for the heat exchangers between the solar field and storage system. In addition, the solar field can be operated to higher outlet temperatures $\left(450^{\circ} \mathrm{C}\right)$, increasing the power cycle efficiency and further reducing the cost of thermal storage. The primary disadvantages are the high freezing temperature of the salt $\left(120^{\circ} \mathrm{C}\right)$, higher heat losses from the solar field, concerns about the durability of the selective coating on the trough receivers, and the need for more expensive piping and materials to withstand the increased operating temperatures.

Subsequent projections after the year 2007 use a direct thermocline system with HitecXL (ternary) solar salt as the storage media and HTF. The solar field can be operated to higher outlet temperatures $\left(500^{\circ} \mathrm{C}\right)$, increasing the power cycle efficiency. The thermocline uses a single tank that is slightly larger than one of the tanks in the twotank system. A low-cost filler material, which is used to pack the single storage tank, acts as the primary thermal storage medium. The filler displaces the majority of the salt in the two-tank system. With the hot and cold fluid in a single tank, the thermocline storage system relies on thermal buoyancy to maintain thermal stratification. To date, a preliminary assessment was made on the potential impact that a thermocline storage system might have on the annual performance of the plant, and a more detailed analysis is in progress this year. However, this system will have similar concerns as the binary solar salt direct storage system. In addition to the development of a thermocline system, an advanced $\mathrm{HCE}$ will be required to obtain the $500^{\circ} \mathrm{C} \mathrm{HTF}$ operating temperature.

The use of HitecXL solar salt is a major factor in lowering costs for future trough plants in the SunLab projections. The benefits and risks of the use of HitecXL are summarized below.

- Benefits:

- Higher temperature - increases the power cycle efficiency

- Single fluid in solar field and storage eliminates expensive heat exchanger required of earlier storage technology

- Larger temperature difference across the solar field reduces the size of storage.

- Molten-salt has better density and thermal capacity product reducing the amount of storage, shrinking flow rates and piping sizes, and heat losses. 
- Risks:

- Freeze protection in the solar field. The solar field must be maintained at temperatures higher than the freeze point. Impedance heating is envisioned for the HCEs. Nexant is currently working on a design for this.

- Special O\&M procedures are required to drain and refill loops for maintenance.

- Solar salt corrodes graph-oil seals, and as such the current ball joints will not work with HitecXL. Sandia is working on flexhose and balljoint sealing options to resolve this issue.

- The receiver selective coating needs to withstand higher temperatures. The Solel cermet coating will hold up to $500^{\circ} \mathrm{C}$ in vacuum. It is only when vacuum is lost that this is a problem.

The SunLab technology forecasts assume future storage will be based on the using HitecXL directly in the solar field and thermal energy storage. A number of alternative storage technologies are currently under development. The Europeans have a thermal energy storage research and development focusing on the development of two thermal storage systems for troughs. The first is a system that uses concrete for the storage media. The second uses phase-change materials and could be applicable for use with direct steam in the solar field. SunLab has also been working on the development of a new class of organic salt HTFs. The organic fluids offer the potential advantage of a molten-salt that is liquid at room temperature, eliminating the major drawback of inorganic molten-salts like HitecXL. Cost and temperature stability appear to be the main hurdles for organic salt HTF. Although all of these storage options are in the early stages of development, they provide alternative paths to achieving cost targets in a range similar to HitecXL.

\section{D.8.3 Scale-Up}

Cost reductions due to scale-up are not considered applicable since the storage system size, for the same number of hours' storage, is directly proportional to the plant size. The SunLab projections also change the type of storage system in the years 2004, 2007, and 2010, which will tend to negate near-term potential scale-up cost reduction.

\section{D.8.4 Production Volume}

The storage system is not a manufactured module but consists of individual single components combined to create a system. The SunLab projections show a constant $\$ / \mathrm{kWh}_{\mathrm{t}}$ and $\$ / \mathrm{kWh}$ for the direct thermocline system from the year 2010 and forward. 


\section{D.8.5 Cost Comparison}

Definitive cost estimates for an indirect two-tank storage system based on detailed design drawings and material takeoffs were developed by Nextant (2001). The unit costs were $\$ 36.40 / \mathrm{kWh}_{\mathrm{t}}$ for $470 \mathrm{kWh}_{\mathrm{t}}$ system and $\$ 31 / \mathrm{kWh}_{\mathrm{t}}$ for a $688-\mathrm{kWh}_{\mathrm{t}}$ system. The SunLab projection appears to be conservative (on the high side) based on the previous estimates.

The direct two-tank storage value of $\$ 12.68 / \mathrm{kWh}_{\mathrm{t}}$ in the SunLab projection also appears to be conservative (on the high side) based on the power tower estimated values of $\$ 8.65 / \mathrm{kWh}_{\mathrm{t}}($ Solar 50$)$ and $\$ 8.25 / \mathrm{kWh}_{\mathrm{t}}($ Solar 100$)$.

The direct thermocline system value of $\$ 11.73 / \mathrm{kWh}_{\mathrm{t}}$ also appears to be conservative (on the high side) based on the Nextant estimates, which indicate a $35 \%$ cost reduction $\left(\$ 8.37 \mathrm{kWh}_{\mathrm{t}}\right)$ going from a two-tank system to a thermocline system.

Since the values used in the SunLab projections appear to be at least 25\% higher than expected based on other thermal storage estimates, the SunLab values were used in the cost analysis.

\section{D.9 CAPITAL COST COMPARISON}

The SunLab model projects parabolic trough plant capital and O\&M costs based on various technology advances and commercial deployment predictions. The SunLab projections are considered the best case analysis where the technology is optimized and a high deployment rate is achieved. S\&L developed capital and O\&M costs based on a more conservative approach whereby the technology improvements are limited to current demonstrated or tested improvements and with a lower rate of deployment than used in the SunLab model. The two sets of estimates, SunLab's and S\&L's, provides a band in which the costs can be expected to be, assuming the parabolic trough technology reaches the projected levels of deployment. A comparison of key parameters used for the estimates is summarized on Table D-27.

Table D-27 - Key Parameters Comparison

\begin{tabular}{|l|c|c|c|c|c|c|c|c|c|c|}
\hline & \multicolumn{2}{|c|}{$\mathbf{2 0 0 4}$} & \multicolumn{2}{c|}{$\mathbf{2 0 0 7}$} & \multicolumn{2}{c|}{$\mathbf{2 0 1 0}$} & \multicolumn{2}{c|}{2015} & \multicolumn{2}{c|}{2020} \\
\cline { 2 - 12 } & SunLab & S\&L & SunLab & S\&L & SunLab & S\&L & SunLab & S\&L & SunLab & S\&L \\
\hline Deployment, MW & 300 & 300 & 600 & 300 & 1,200 & 750 & 2,400 & 1,000 & 400 & 400 \\
\hline $\begin{array}{l}\text { Cumulative } \\
\text { Deployment, MW }\end{array}$ & 650 & 300 & 1,250 & 600 & 2,450 & 1,350 & 4,850 & 2,350 & 5,250 & 2,750 \\
\hline
\end{tabular}




\begin{tabular}{|l|c|c|c|c|c|c|c|c|c|c|}
\hline & \multicolumn{2}{|c|}{2004} & \multicolumn{2}{c|}{2007} & \multicolumn{2}{c|}{2010} & \multicolumn{2}{c|}{2015} & \multicolumn{2}{c|}{2020} \\
\cline { 2 - 11 } & SunLab & S\&L & SunLab & S\&L & SunLab & S\&L & SunLab & S\&L & SunLab & S\&L \\
\hline $\begin{array}{l}\text { Net Annual Solar } \\
\text { Efficiency }\end{array}$ & $14.2 \%$ & $14.0 \%$ & $16.1 \%$ & $15.1 \%$ & $17.0 \%$ & $15.4 \%$ & $17.1 \%$ & $15.5 \%$ & $17.2 \%$ & $15.5 \%$ \\
\hline HCE Cost, \$/unit & 847 & 847 & 762 & 762 & 635 & 675 & 508 & 625 & 400 & 525 \\
\hline Mirror Cost, $\$ / \mathrm{m}^{2}$ & 40 & 40 & 36 & 36 & 28 & 32 & 20 & 29 & 16 & 26 \\
\hline
\end{tabular}

Table D-28 and Figure D-5 illustrates the SunLab projected total installed capital cost ( $\$ / \mathrm{kWe})$ compared to the more conservative S\&L values. Figure D-5 also shows the total installed capital cost based on achieving the annual net efficiencies projected by SunLab, but not the projected cost reductions. The curves highlight the impact of the annual net efficiencies on the capital cost. The curves also indicate that additional cost reductions above and beyond the more conservative S\&L values, due to technology improvements and increased deployment rates, will result in convergence of the capital costs toward the SunLab values.

Table D-28 - Comparison of Total Investment Cost Estimates (\$/kWe): SunLab vs. S\&L

\begin{tabular}{|l|r|r|r|r|r|}
\hline & $\mathbf{2 0 0 4}$ & $\mathbf{2 0 0 7}$ & $\mathbf{2 0 1 0}$ & $\mathbf{2 0 1 5}$ & $\mathbf{2 0 2 0}$ \\
\hline SunLab & $\$ 4,859$ & $\mathbf{\$ 3 , 4 0 8}$ & $\mathbf{\$ 2 , 8 7 6}$ & $\mathbf{\$ 2 , 5 4 6}$ & $\mathbf{\$ 2 , 2 2 1}$ \\
\hline S\&L - S\&L Efficiencies & 4,816 & 3,854 & 3,562 & 3,389 & 3,220 \\
\hline S\&L - SunLab Efficiencies & 4,791 & 3,687 & 3,331 & 3,165 & 2,725 \\
\hline S\&L - No Storage & 2,453 & 2,265 & 2,115 & 1,990 & 1,846 \\
\hline
\end{tabular}


Figure D-5 - Capital Cost Comparison

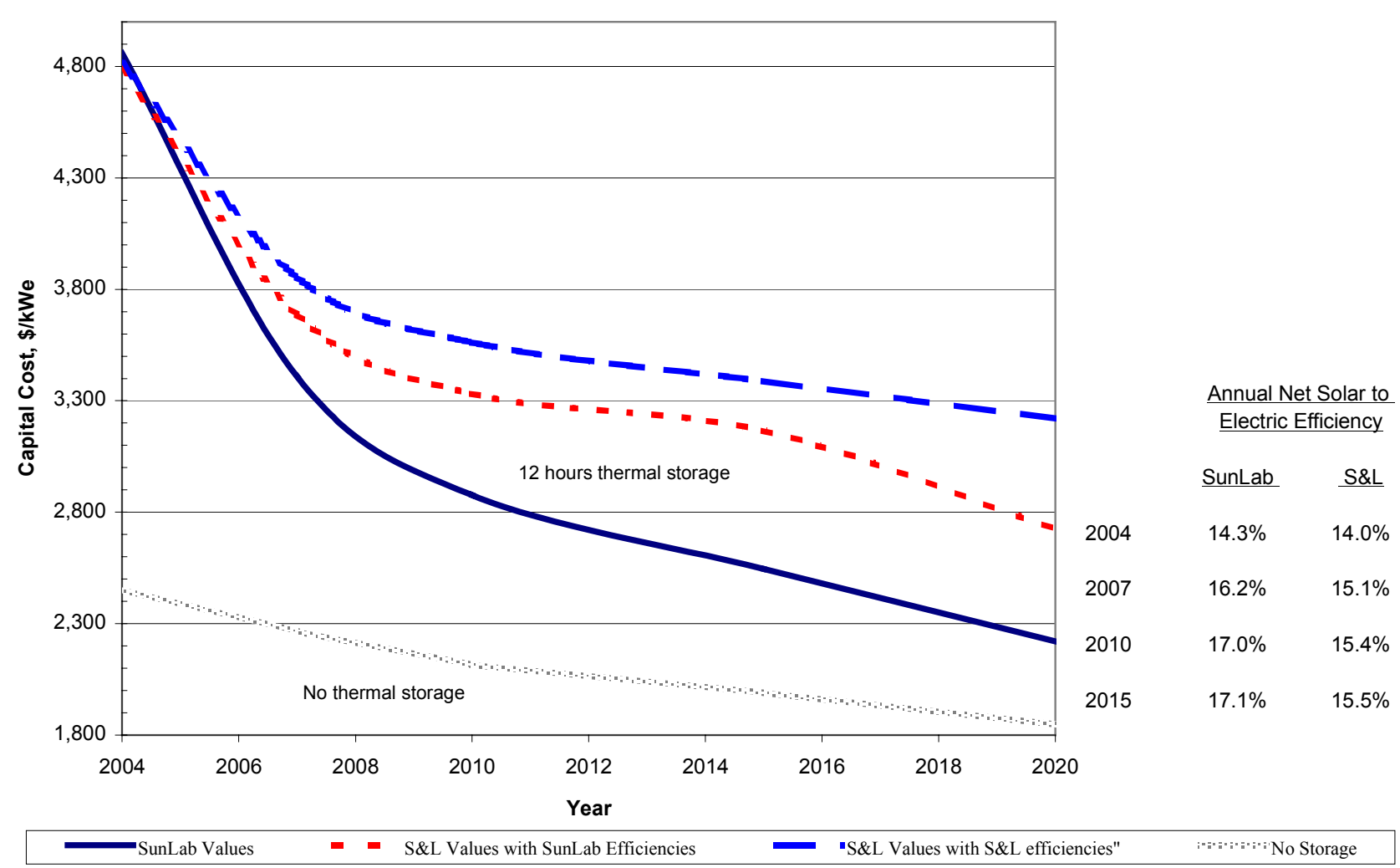

\section{D.10 OPERATIONS AND MAINTENANCE}

Sargent \& Lundy has reviewed the SunLab O\&M cost model based on our experience with fossil and other power plant technologies and in the course of a site visit to KJC Operating Company, the operator of the five 30-MWe trough projects located at Kramer Junction. KJC Operating Company provided proprietary information on the last five years of operation. The SunLab O\&M estimate is based largely on the experience at the KJC Operating Company SEGS plants. The model assumes a stand-alone trough power plant (as opposed to the five co-located plants at Kramer Junction) and adjusts cost depending on the size of the solar field and total electric generation per year. It breaks out the specific staffing requirements for operations and maintenance crews for both the conventional power plant and for the solar field. Administrative staffing is also included. In addition to labor breakdown, the model breaks out service contracts, water treatment costs, spares and equipment costs, miscellaneous costs, and periodic capital equipment requirements. S\&L conducted a detailed review of the SunLab model and compared it to general power industry experience. 
The S\&L O\&M costs for comparison to the SunLab projections are based on the following:

- $\quad$ Solar Field

- The initial unit costs are based on the SunLab values, and cost reductions for years beyond 2004 are based on a PR $=0.92$

- Replacement rate for the mirrors and HCE are based on the average actual replacement rates for SEGS III - VII for the period 1997-2001

- The replacement rates for the balance of the solar field are based on the SunLab values

- $\quad$ Power Block and Balance of Plant

- Costs are based on S\&L data for the respective MW size plant for the steam turbine systems and balance of plant

- Water and Process

- Costs are based on are based on the average actual costs for SEGS III - VII for the period 1997-2001

- $\quad$ Staffing, Services Contracts, Miscellaneous, and Capital Equipment

- The costs are based on the SunLab values since the SunLab values were determined to be reasonable

- Thermal Storage

— The costs are based on $0.4 \%$ of the capital cost per annum

Analyzing the two estimates revealed that the major component to account for the cost difference is the HCE replacement rate. Table D-29 shows a comparison of the SunLab and S\&L projected replacement rates.

Table D-29 — Projected Trough Receiver Replacement Rates

\begin{tabular}{|l|c|c|c|c|c|c|}
\hline $\begin{array}{c}\text { Annual Failures } \\
\text { (Percent of Field) }\end{array}$ & Current & $\mathbf{2 0 0 4}$ & $\mathbf{2 0 0 7}$ & $\mathbf{2 0 1 0}$ & $\mathbf{2 0 1 5}$ & $\mathbf{2 0 2 0}$ \\
\hline SunLab & $3.5 \%$ & $2.0 \%$ & $1 \%$ & $0.5 \%$ & $0.5 \%$ & $0.5 \%$ \\
\hline S\&L & $5.5 \%$ & $5.5 \%$ & $2.5 \%$ & $1.5 \%$ & $1.0 \%$ & $0.5 \%$ \\
\hline
\end{tabular}

The SunLab near-term values are not consistent with the average actual HCE replacement rate of 5.5\% reported for SEGS III - VII for the period 1997-2001.

Sargent \& Lundy reviewed the actual receiver (HCE) replacement rate reported by KJC Operating Company over the last five years. The S\&L evaluation is based on total HCE replacement reported for the SEGS III - VII 
for the period 1997-2001. S\&L's evaluation is based on the current replacement rate experienced at all the SEGS plants, with step reductions in the replacement rate based on the following considerations:

- The average actual HCE replacement rate of 5.5\% was reported for SEGS III - VII for the period 1997-2001. The total HCE replacement includes breakage and fluorescence. Fluorescence is due to cermet coating failures. This failure is due to the existence of molybdenum in the original Luz cermet coating. Solel no longer uses molybdenum in the UVAC cermet coating, so this type of failure will presumably no longer occur. Eliminating replacements due to these failures reduces the site failure/replacement rate.

- $\quad$ SunLab has used the SEGS VI plant as the baseline reference plant. The SEGS III - V plants had problems during initial startup and the early years of operation that caused bowing of the HCEs, which increased breakage at those plants. SEGS VII has had higher breakage on the LS3 half of the field, although the LS-2 failures are similar to SEGS VI. SEGS VI was the last full plant constructed with LS-2 collectors and represents the most mature version of this generation of collector technology. The HCE total replacement rate at SEGS VI during the 5 years is in the $5.5 \%$ range. Discounting the fluorescence failures, the replacement rate was $4.2 \%$ over the 5 -year period.

- The high HCE failure rate at the existing plants is in part due to issues that would not be found at a future plant. A significant portion of the failures has been due to the hydrogen remover (HR) device installed in the HCEs at SEGS VI - X, operational problems that caused bowing, and HCE installation procedures. The HR is no longer part of the HCEs provided by Solel.

Based on these factors, it is very possible that future plants will have substantially lower HCE failure rates than currently found at the SEGS plants. The SunLab assumption of a $2 \%$ failure rate assumes that current approaches for reducing failures are successful. S\&L believes this is an aggressive assumption that cannot be assured for future plants without the field data to verify the failure rate reduction. Using the current replacement rate at all the SEGS plants, with step reductions in the replacement rate, reflects the current conditions and allows for the aforementioned improvements to reduce the replacement rate.

Additional development of the HCE will likely be necessary to achieve the future receiver reliability goals. The current glass-to-metal seal is one of the more expensive elements and the key failure point of the current receiver design. The current design, known as a Housekeeper seal, relies on a sharp metal point being inserted into a glass bead. Failures occur when concentrated light focuses on the seal and the differential expansion between the glass and metal causes the failure of the seal. New designs are currently under investigation that attempt to improve the match between the coefficient of thermal expansion of the metal and glass. Kramer Junction is currently testing a new design UVAC2 with a revised internal shield. 
To achieve the SunLab projected replacement rates the reliability of the HCE will have to significantly improve. Figure D-6 compares the O\&M costs and illustrates the impact of the HCE replacement rate. The O\&M costs without thermal storage is included for informational purposes.

\section{Figure D-6 - Levelized O\&M Cost Comparison}

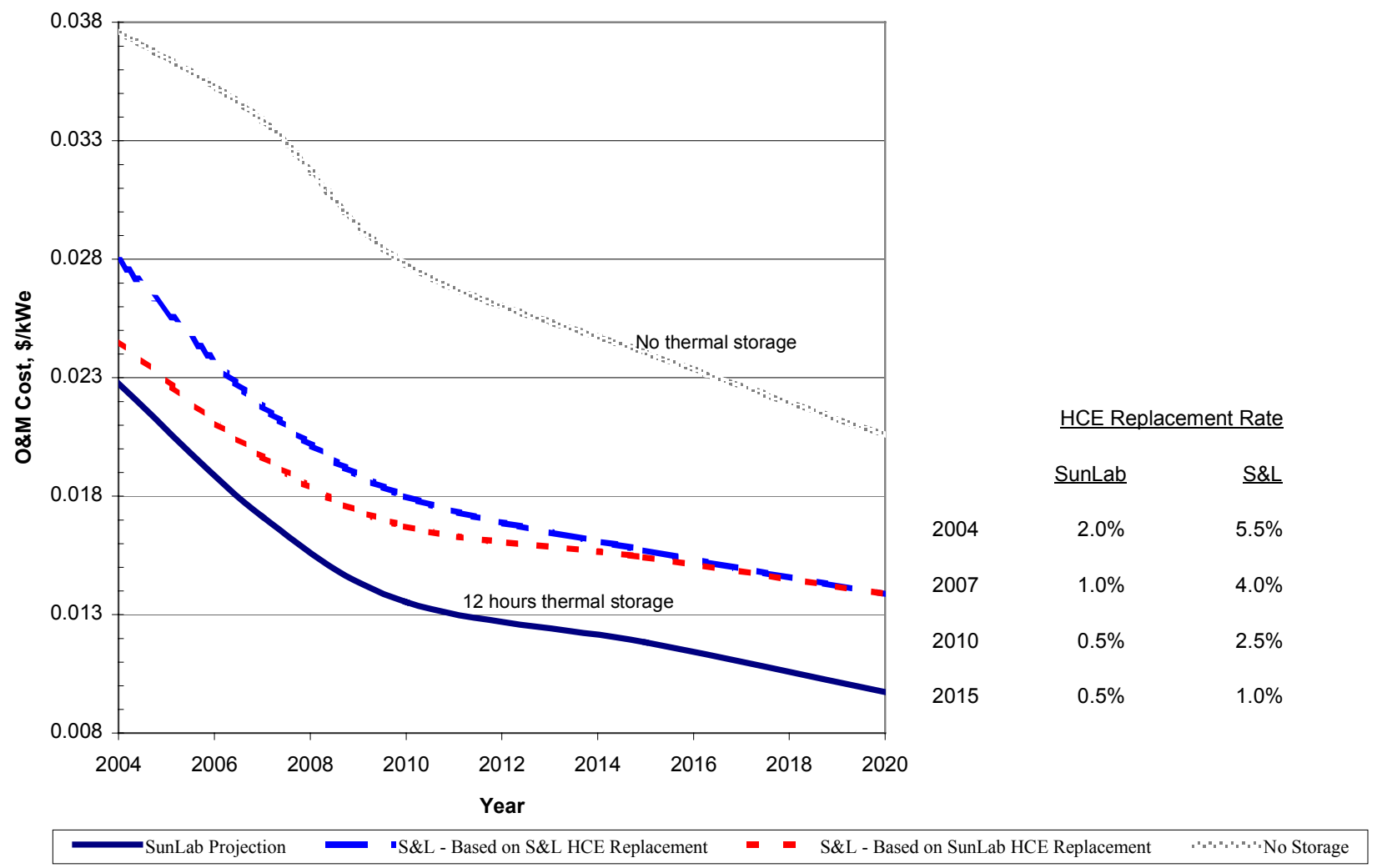

The reduction in O\&M cost is primarily a result of the increase in plant size and the increase in annual plant capacity factor. The plant capacity increases directly as a result of the increases in thermal storage. Increasing the size (MWe) and capacity factor of the power plant incurs minimal increase in the fixed O\&M expenses (\$/year).

\section{D.11 LEVELIZED ENERGY COSTS}

Figure D-7 illustrates the SunLab projected levelized energy cost ( $\$ / \mathrm{kWhe})$ compared to the S\&L values. The figure also shows the levelized energy cost based on achieving the annual net efficiencies projected by SunLab. 
For comparison, the estimated levelized energy cost for the trough plants without thermal storage is included to underscore the importance of thermal storage in the reduction of the levelized energy cost.

Figure D-7 — Levelized Energy Costs

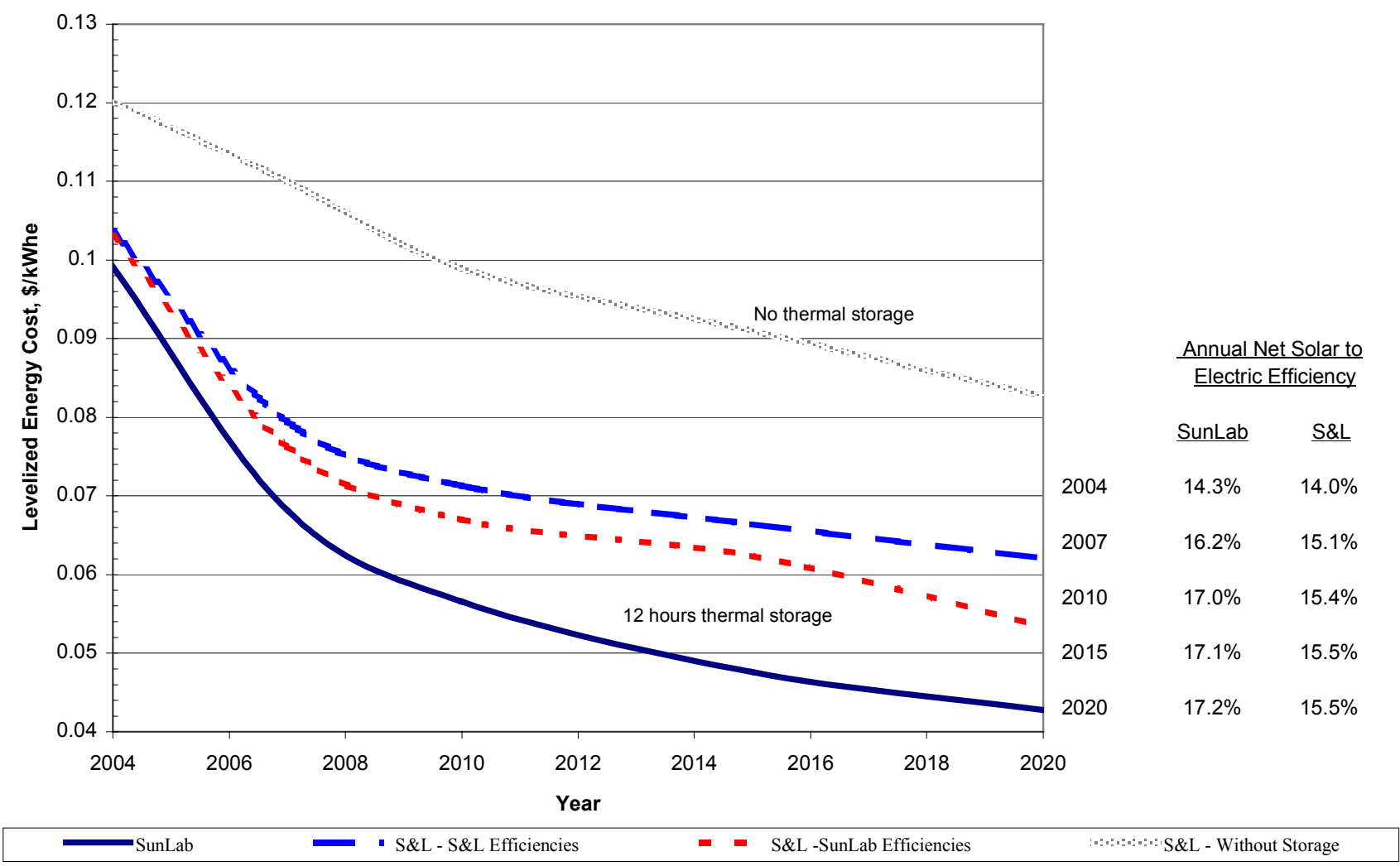

The curves highlight the impact of the annual net efficiencies on the levelized energy costs. The curves also indicate that additional cost reductions above and beyond the more conservative S\&L values, due to technology improvements, reduced HCE replacement rates, and increased deployment rates, will result in further convergence of the levelized energy costs toward the projected SunLab values.

Figure D-8 shows the levelized energy cost for the SunLab technology forecasts with a breakdown that shows the source of the cost reduction from plant scale-up, technology $R \& D$, and cost reduction through learning. Of the projected cost reduction in 2020, plant scale-up is projected to provide $20 \%$ of the total cost reduction, technology development will provide over half of the cost reduction at $54 \%$, and production volume and competition will provide approximately $26 \%$ of the cost reduction. 
Figure D-8 - Breakdown of LEC Cost Reduction (Scale-Up, R\&D, Volume Production)

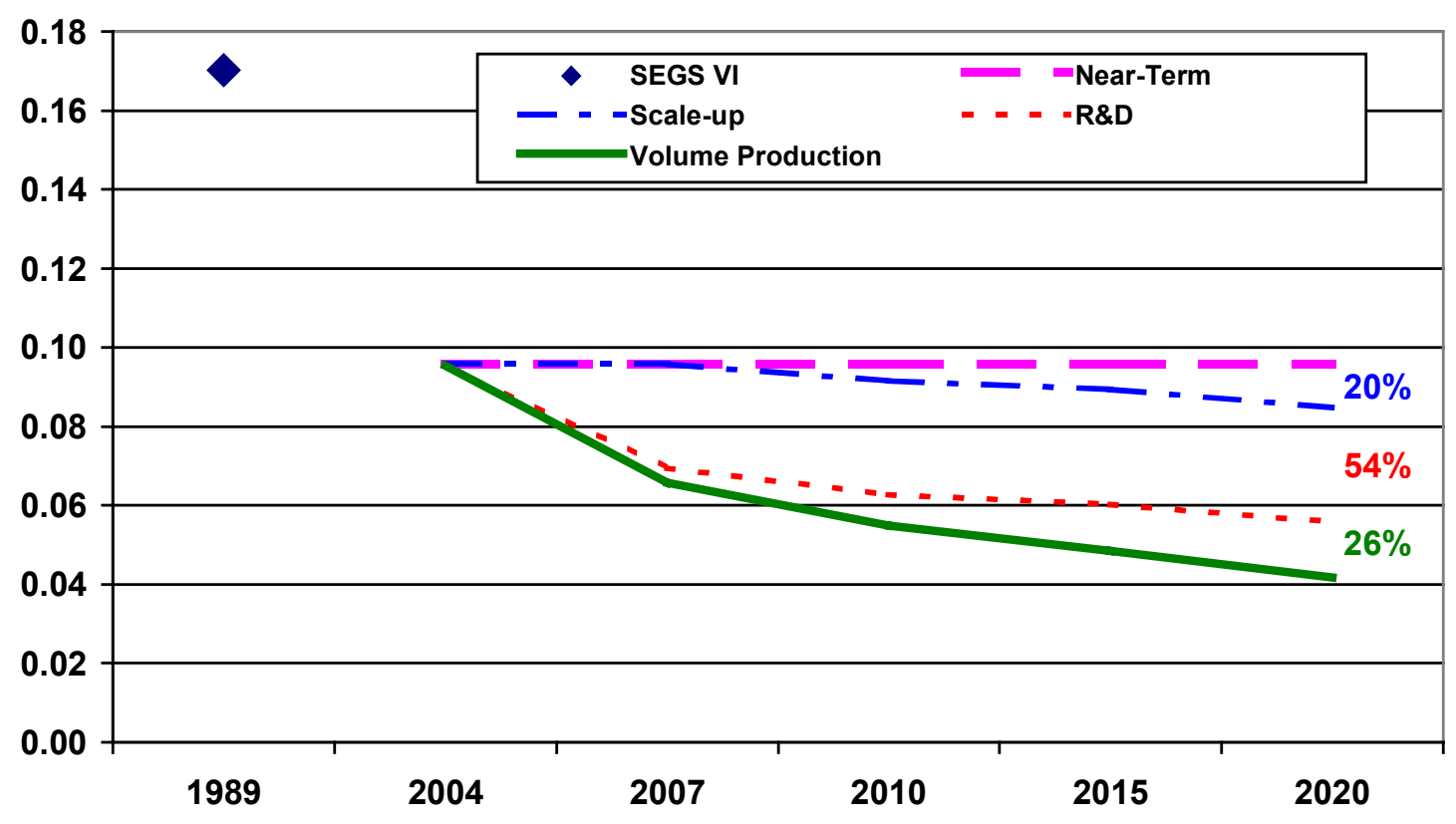

Figure D-9 below shows the importance of the five major cost components in reducing the LEC.

Figure D-9 - Breakdown of LEC Cost Reduction

(by Major Cost Component)

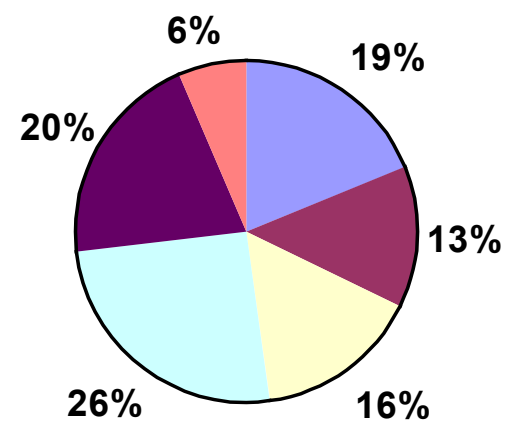

口Concentrator (19\%)

口Mirror (13\%)

口HCE (16\%)

$\square$ Storage (26\%)

DPower Block (20\%)

DOther $(6 \%)$ 


\section{Appendix E}

Evaluation of Technology Improvements and Capital Cost Projections - Tower 


\section{E. EVALUATION OF TECHNOLOGY IMPROVEMENTS AND CAPITAL COST PROJECTIONS - TOWER}

\section{CONTENTS}

$\underline{\text { Section }}$

$\underline{\text { Page }}$

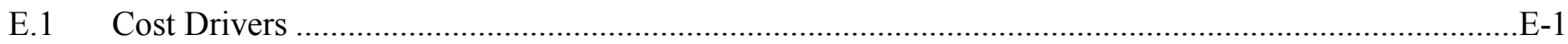

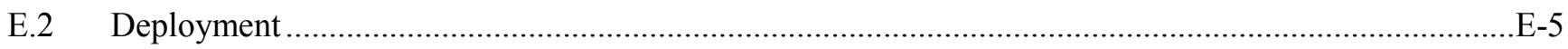

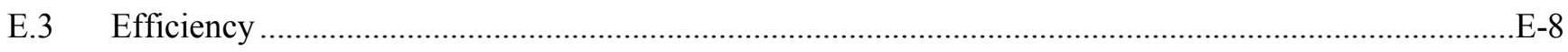

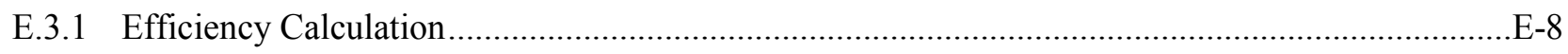

E.3.2 Net Annual Solar-to-Electric Efficiency Impact on Cost.............................................................

E.3.3 Steam Cycle (Electric Power Block) Efficiency ........................................................................ 12

E.3.4 Collector and Receiver Efficiency ……............................................................................... 12

E.3.5 Thermal to Power Plant Efficiency — Parasitics ............................................................................

E.3.6 Net Annual Solar-to-Electric Efficiency Impact on Cost (SunLab Model) ..................................E-13

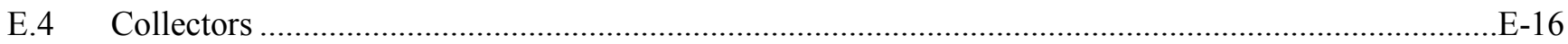

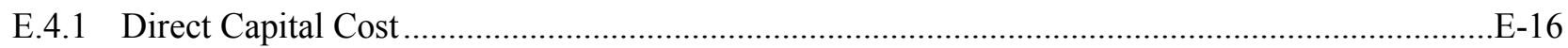

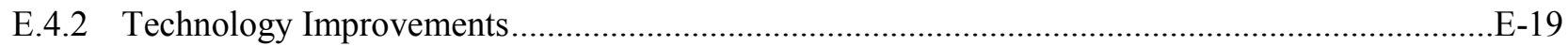

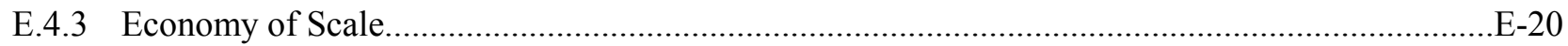

E.4.4 Estimate of Cost Reductions Due to Volume Production ...............................................................21

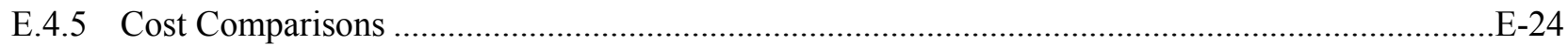

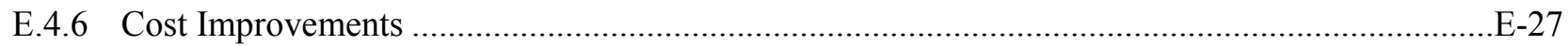

E.4.7 Heliostat Cost Improvement Breakout by Category ..................................................................28

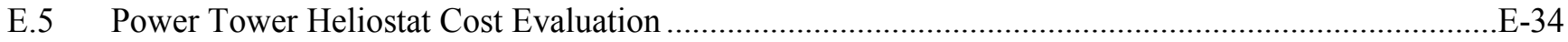

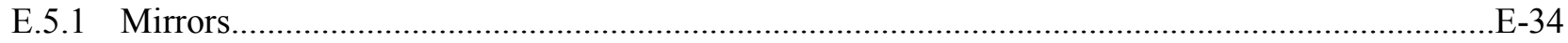

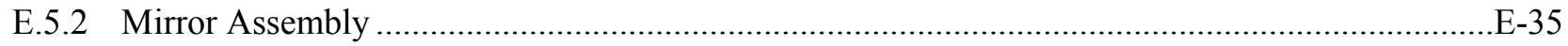

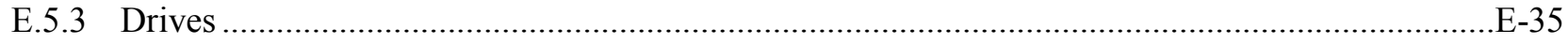

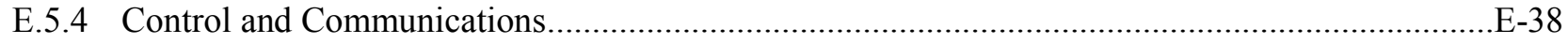

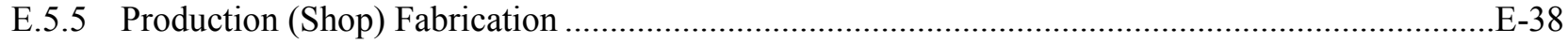

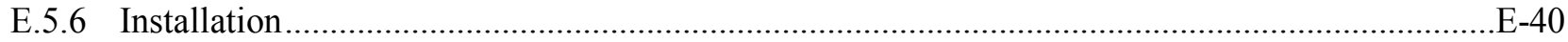




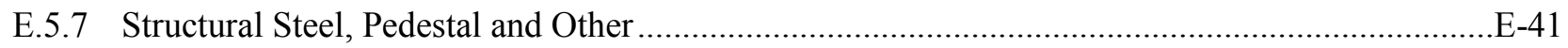

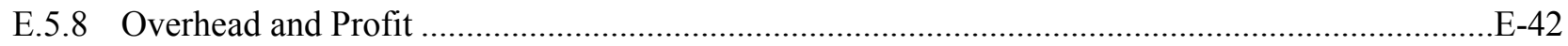

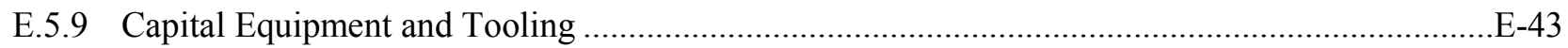

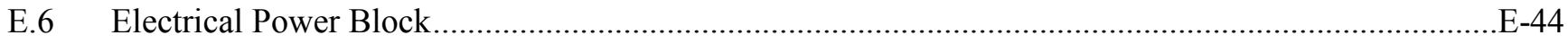

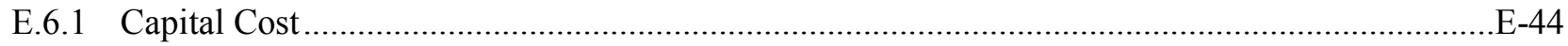

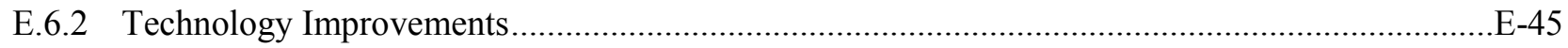

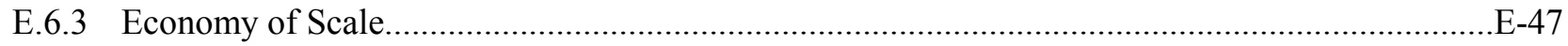

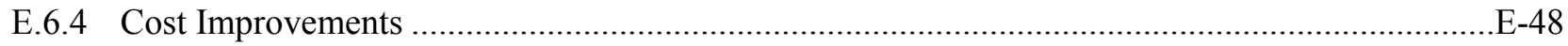

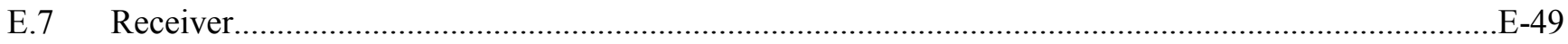

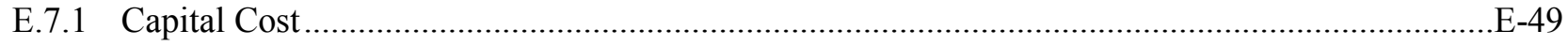

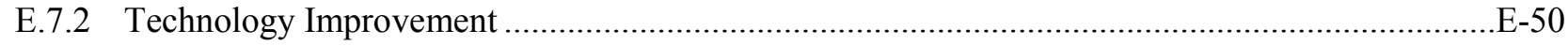

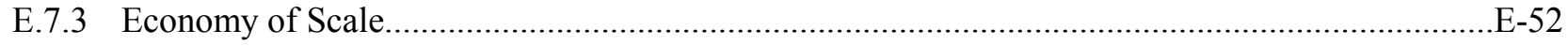

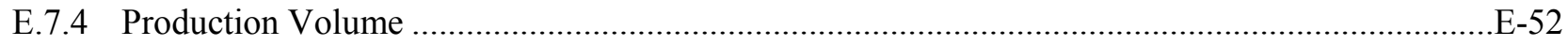

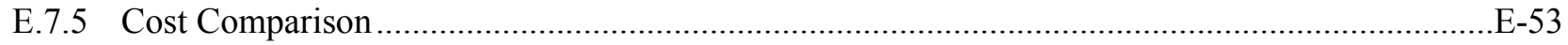

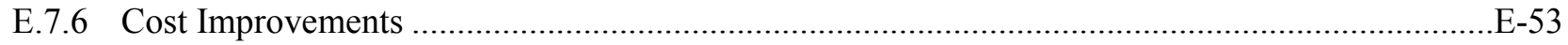

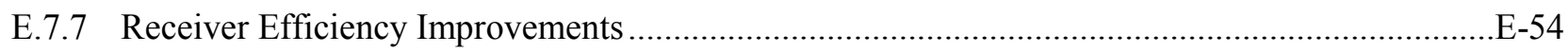

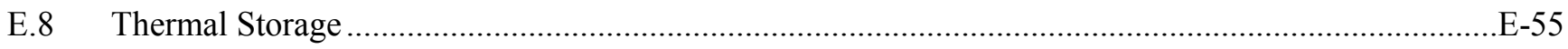

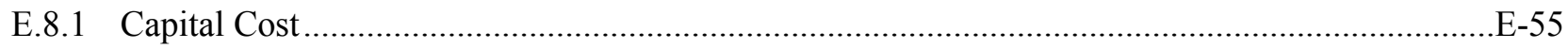

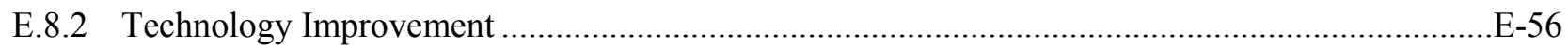

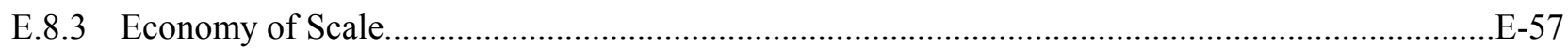

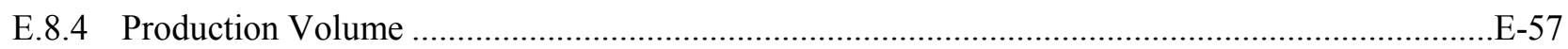

E.8.5 Cost Improvements - Thermal Storage and Parasitic .............................................................5

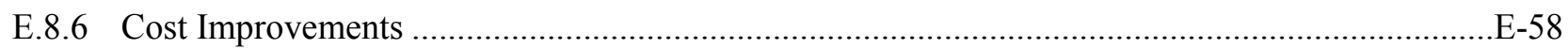

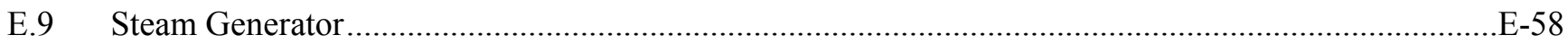

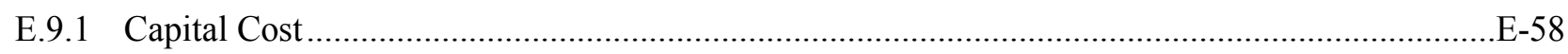

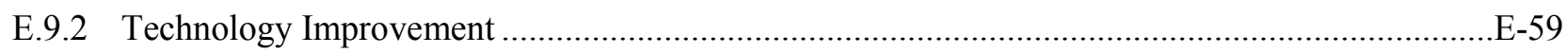

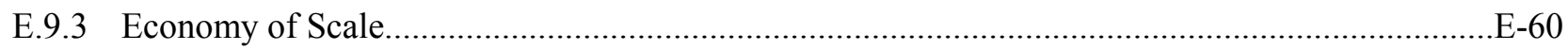

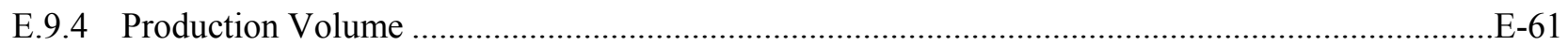

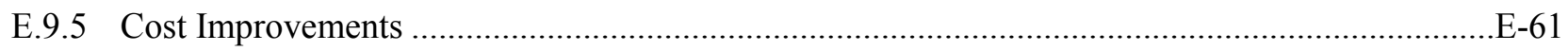

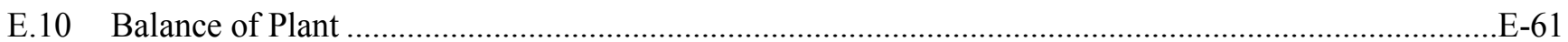

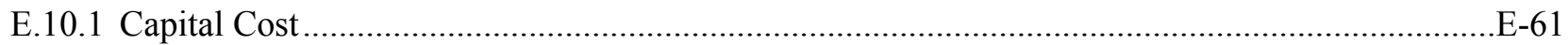




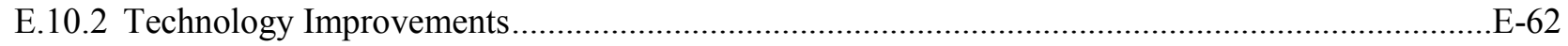

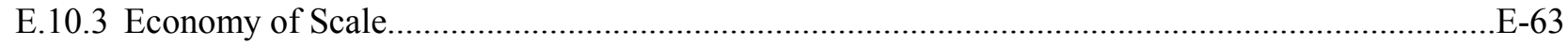

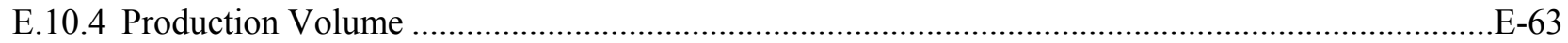

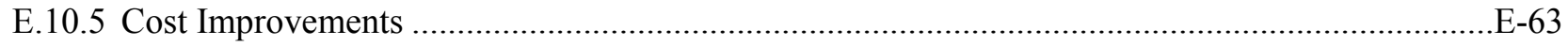

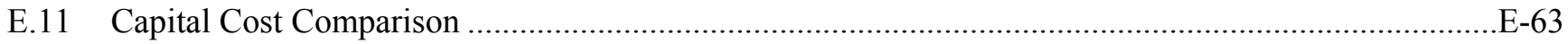

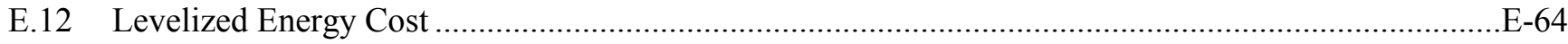




\section{E. EVALUATION OF TECHNOLOGY IMPROVEMENTS AND CAPITAL COST PROJECTIONS - TOWER}

\section{E.1 COST DRIVERS}

The direct cost of a solar power tower is divided into the following major categories:

- $\quad$ Structures and Improvements

- Heliostat Field

- Receiver System

- $\quad$ Tower + piping system

- $\quad$ Thermal Storage System

- $\quad$ Steam Generator System

- $\quad$ Electric Power Generation System

- $\quad$ Master Control System

- Balance-of-plant

The solar field, electric power block, receiver, and thermal storage encompass approximately $80 \%$ of the total direct costs as shown in Figures E-1 and E-2. The major cost component is the heliostat field, which encompasses $43 \%$ of total costs for Solar Tres and $47 \%$ of total cost for Solar 220 . The next two categories are electric power block (13\% for Solar Tres and $20 \%$ for Solar 220$)$ and receiver (18\% for Solar Tres and $8 \%$ for Solar 220). Our review is to determine if the capital cost estimates prepared by SunLab were within a reasonable range based on our review of available studies and reports, the SunLab cost estimate and our due diligence experience. The focus was primarily on the major cost categories: heliostats, electric power block, and receiver. The cost estimate reductions projected by SunLab from 2004 to 2020 are shown in Figure E-3. 
Figure E-1 - Capital Cost Categories for Solar Tres

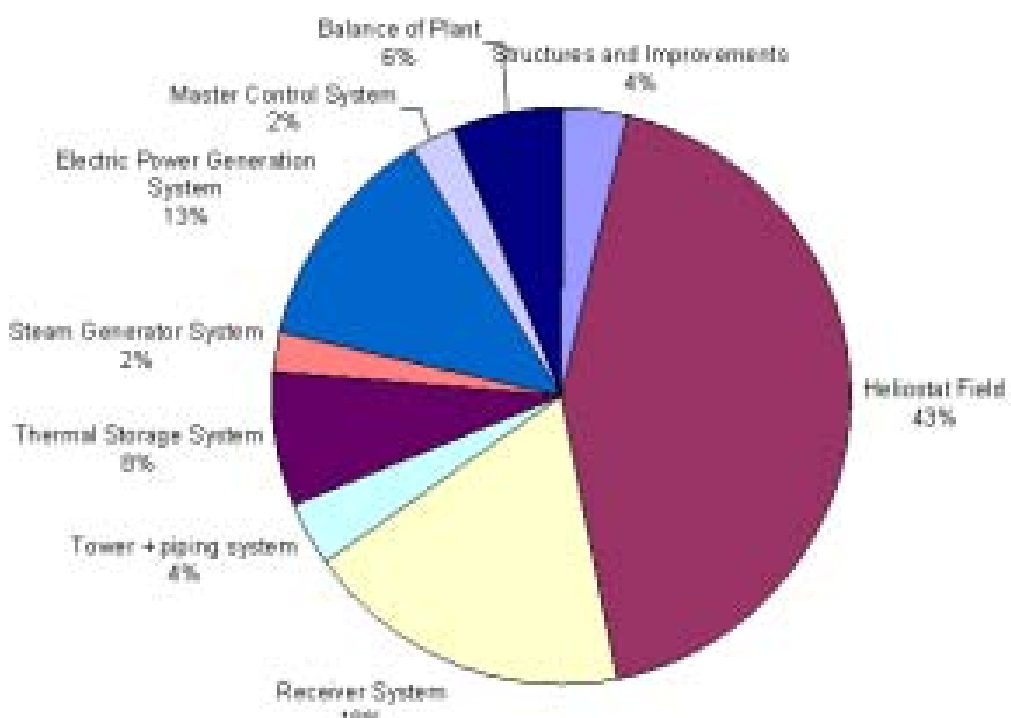

$10 \%$

Figure E-2 - Capital Cost Categories for Solar 220

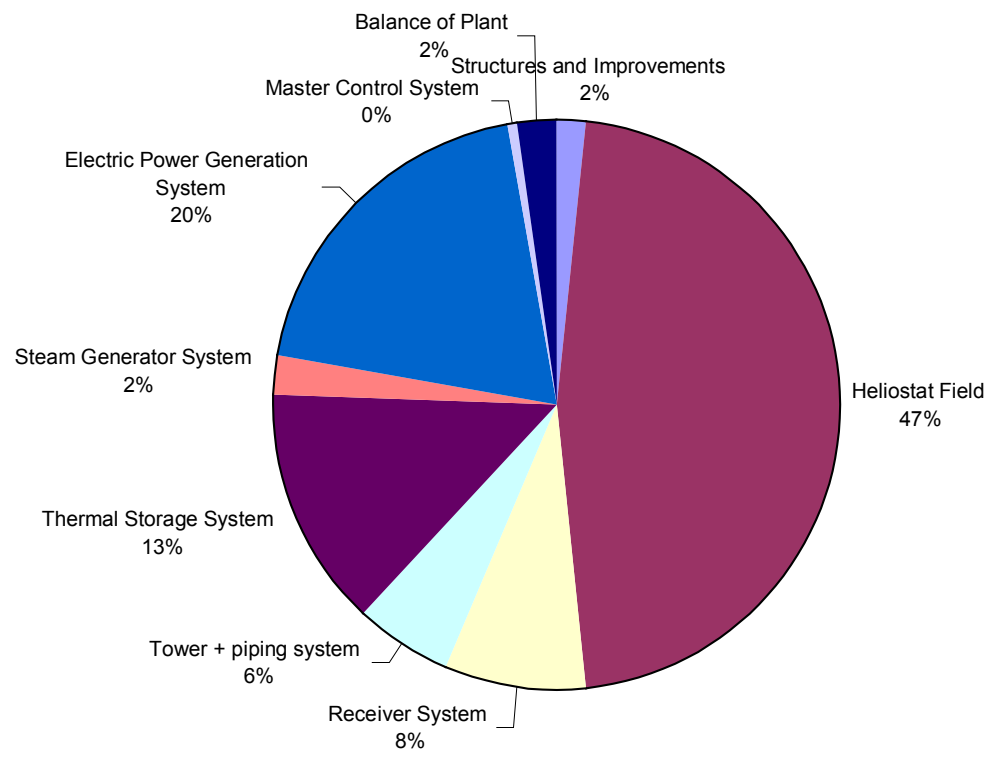




\section{Figure E-3 - Direct Capital Cost Power Tower Solar Plant (Projected Years 2004 and 2020)}

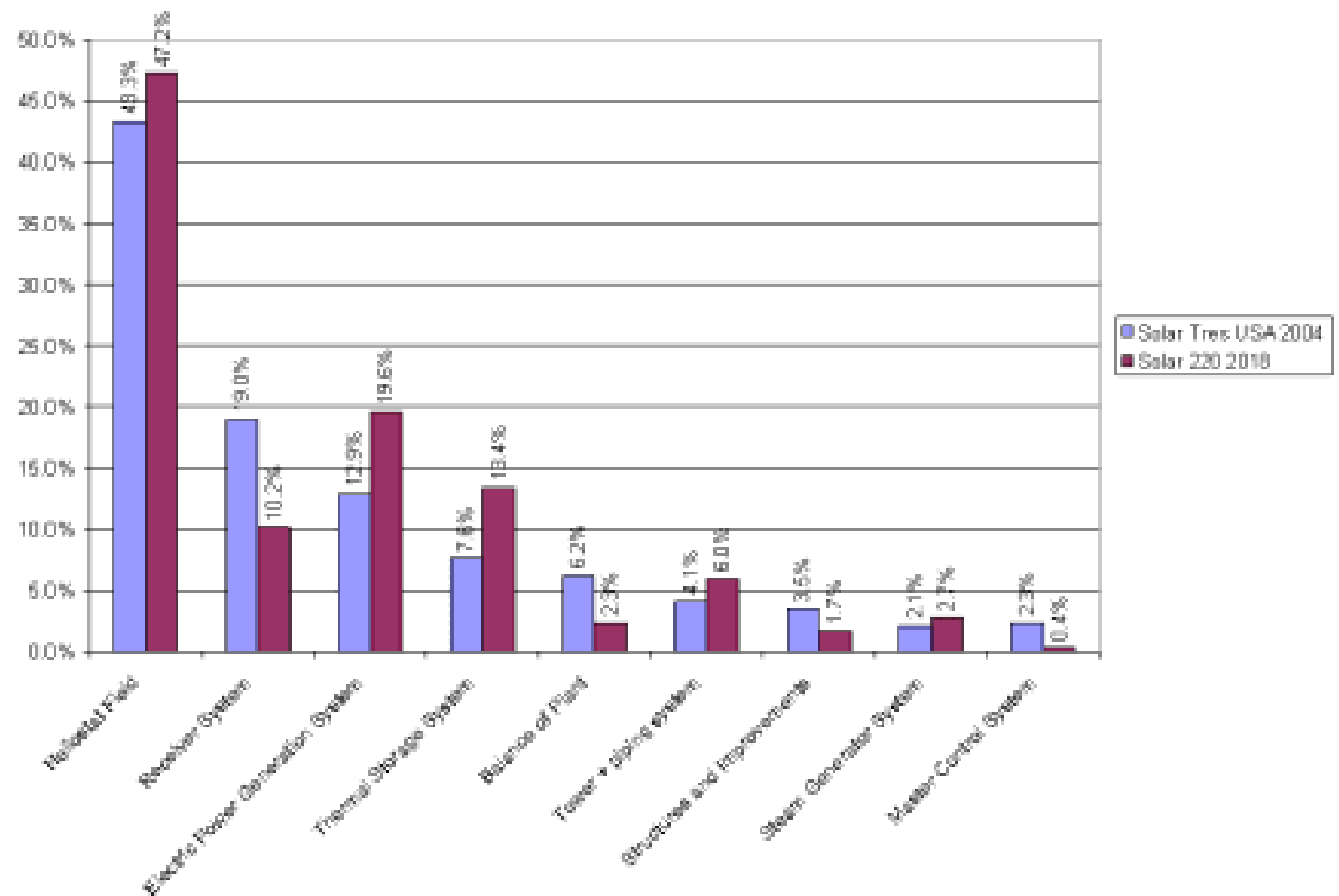

The total installed cost estimate by SunLab is shown in Table E-1. The values presented for Solar Tres throughout the report assume that the plant is located in the United States and not in Spain to provide more consistent comparison. The cost estimate by S\&L based on our review of the major cost drivers is shown in Table E-2. Shaded areas indicate differences between the S\&L and SunLab estimates.

Table E-1 — SunLab Capital Cost Estimate (Deployment of 8.7 GWe)

\begin{tabular}{|l|c|c|c|c|c|c|}
\hline & Case & $\begin{array}{c}\text { Solar } \\
\text { Tres USA }\end{array}$ & Solar 50 & Solar 100 & Solar 200 & Solar 220 \\
\hline & Year & $\mathbf{2 0 0 4}$ & $\mathbf{2 0 0 6}$ & $\mathbf{2 0 0 8}$ & $\mathbf{2 0 1 2}$ & $\mathbf{2 0 1 8}$ \\
\hline Description & Contingency & & & & & \\
\hline Land Area, km ${ }^{2}$ & & 1.1 & 3.4 & 6.6 & 13.7 & 13.9 \\
\hline Field Area, m ${ }^{2}$ & & 231,000 & 709,000 & $1,311,000$ & $2,600,000$ & $2,642,000$ \\
\hline Structures \& Improvements, \$M & $20 \%$ & $\$ 2.8$ & $\$ 4.1$ & $\$ 5.3$ & $\$ 7.2$ & $\$ 7.2$ \\
\hline Heliostat Field, \$M & $5 \%$ & $\$ 33.5$ & $\$ 89.8$ & $\$ 139.8$ & $\$ 249.6$ & $\$ 198.8$ \\
\hline
\end{tabular}




\begin{tabular}{|l|c|c|c|c|c|c|}
\hline & Case & $\begin{array}{c}\text { Solar } \\
\text { Tres USA }\end{array}$ & Solar 50 & Solar 100 & Solar 200 & Solar 220 \\
\hline & Year & $\mathbf{2 0 0 4}$ & $\mathbf{2 0 0 6}$ & $\mathbf{2 0 0 8}$ & $\mathbf{2 0 1 2}$ & $\mathbf{2 0 1 8}$ \\
\hline Description & Contingency & & & & & \\
\hline Receiver, \$M & $10 \%$ & $\$ 14.0$ & $\$ 19.8$ & $\$ 25.0$ & $\$ 36.9$ & $\$ 34.4$ \\
\hline Tower \& Piping, \$M & $10 \%$ & $\$ 2.8$ & $\$ 7.0$ & $\$ 11.9$ & $\$ 24.3$ & $\$ 24.3$ \\
\hline Thermal Storage, \$M & $10 \%$ & $\$ 5.9$ & $\$ 18.7$ & $\$ 28.9$ & $\$ 56.3$ & $\$ 57.2$ \\
\hline Steam Generator, \$M & $10 \%$ & $\$ 1.6$ & $\$ 3.7$ & $\$ 5.8$ & $\$ 9.4$ & $\$ 9.3$ \\
\hline Electric Power Block, \$M & $10 \%$ & $\$ 10.0$ & $\$ 24.5$ & $\$ 40.0$ & $\$ 64.0$ & $\$ 83.6$ \\
\hline Master Control System, \$M & $10 \%$ & $\$ 1.8$ & $\$ 1.8$ & $\$ 1.6$ & $\$ 1.6$ & $\$ 1.6$ \\
\hline Balance-of-plant, \$M & $10 \%$ & $\$ 4.8$ & $\$ 6.5$ & $\$ 7.8$ & $\$ 9.6$ & $\$ 9.9$ \\
\hline Direct Costs, \$M & & $\$ 77.3$ & $\$ 175.9$ & $\$ 266.1$ & $\$ 458.8$ & $\$ 426.3$ \\
\hline $\begin{array}{l}\text { Engineering, Management \& } \\
\text { Development (7.8\%), \$M }\end{array}$ & & $\$ 6.6$ & $\$ 13.7$ & $\$ 20.8$ & $\$ 35.8$ & $\$ 33.3$ \\
\hline $\begin{array}{l}\text { Land (no cost for Solar Tres and } \\
\text { Solar 50) (\$5,000 per hectare), \$M }\end{array}$ & & $\$ 0$ & $\$ 0$ & $\$ 3.3$ & $\$ 6.9$ & $\$ 7.0$ \\
\hline Contingency, \$M & $7.7 \%$ & $\$ 6.3$ & $\$ 13.5$ & $\$ 20.2$ & $\$ 34.1$ & $\$ 34.3$ \\
\hline $\begin{array}{l}\text { Risk Pool (Only for Solar Tres) - } \\
\text { (10\%), \$M }\end{array}$ & & $\$ 7.7$ & $\$ 0$ & $\$ 0$ & $\$ 0$ & $\$ 0$ \\
\hline & & $\$ 7,135$ & $\$ 4,063$ & $\$ 3,103$ & $\$ 2,678$ & $\$ 2,272$ \\
\hline Total Cost - SunLab, \$M & & & & & & \\
\hline Total Cost - SunLab, \$/kWe & & & & & & \\
\hline
\end{tabular}

Table E-2 - S\&L Capital Cost Estimate (Deployment of 2.6 GWe)

\begin{tabular}{|l|c|c|c|c|c|c|c|}
\hline & Case & $\begin{array}{c}\text { Solar } \\
\text { Tres USA }\end{array}$ & Solar 50 & Solar 100 & Solar 200 & Solar 200 & Solar 220 \\
\hline & Year & $\mathbf{2 0 0 4}$ & $\mathbf{2 0 0 7}$ & $\mathbf{2 0 1 0}$ & $\mathbf{2 0 1 5}$ & $\mathbf{2 0 2 0}$ & $\mathbf{2 0 2 0}$ \\
\hline Description & Contingency & & & & & & \\
\hline Land Area, km & & 1.1 & 3.4 & 6.6 & 13.7 & 13.7 & 13.9 \\
\hline Field Area, m & & 244,966 & 742,703 & $1,366,100$ & $2,667,099$ & $2,667,099$ & $2,789,322$ \\
\hline $\begin{array}{l}\text { Structures \& } \\
\text { Improvements, \$M }\end{array}$ & $20 \%$ & $\$ 2.8$ & $\$ 4.1$ & $\$ 5.3$ & $\$ 7.2$ & $\$ 7.2$ & $\$ 7.2$ \\
\hline Heliostat Field, \$M & $10 \%$ & $\$ 39.1$ & $\$ 111.7$ & $\$ 182.7$ & $\$ 330.0$ & $\$ 312.1$ & $\$ 263.0$ \\
\hline Receiver (Boeing), \$M & $10 \%$ & $\$ 16.0$ & $\$ 26.0$ & $\$ 34.0$ & $\$ 46.0$ & $\$ 46.0$ & $\$ 48.0$ \\
\hline
\end{tabular}




\begin{tabular}{|c|c|c|c|c|c|c|c|}
\hline & Case & $\begin{array}{c}\text { Solar } \\
\text { Tres USA }\end{array}$ & Solar 50 & Solar 100 & Solar 200 & Solar 200 & Solar 220 \\
\hline & Year & 2004 & 2007 & 2010 & 2015 & 2020 & 2020 \\
\hline Description & Contingency & & & & & & \\
\hline Tower \& Piping, \$M & $10 \%$ & $\$ 2.8$ & $\$ 7.0$ & $\$ 11.9$ & $\$ 24.3$ & $\$ 24.3$ & $\$ 24.3$ \\
\hline Thermal Storage, \$M & $10 \%$ & $\$ 5.9$ & $\$ 18.7$ & $\$ 28.9$ & $\$ 56.3$ & $\$ 56.3$ & $\$ 57.2$ \\
\hline Steam Generator, \$M & $10 \%$ & $\$ 1.6$ & $\$ 3.7$ & $\$ 5.8$ & $\$ 9.4$ & $\$ 9.4$ & $\$ 9.3$ \\
\hline Electric Power Block, \$M & $10 \%$ & $\$ 7.6$ & $\$ 18.6$ & $\$ 30.8$ & $\$ 46.2$ & $\$ 46.2$ & $\$ 61.8$ \\
\hline Master Control System, \$M & $10 \%$ & $\$ 1.8$ & $\$ 1.8$ & $\$ 1.6$ & $\$ 1.6$ & $\$ 1.6$ & $\$ 1.6$ \\
\hline Balance-of-plant, \$M & $10 \%$ & $\$ 10.0$ & $\$ 24.5$ & $\$ 36.7$ & $\$ 33.8$ & $\$ 33.8$ & $\$ 36.5$ \\
\hline Direct Cost, \$M & & $\$ 87.7$ & $\$ 216.1$ & $\$ 337.5$ & $\$ 554.7$ & $\$ 536.8$ & $\$ 508.9$ \\
\hline $\begin{array}{l}\text { Engineering, Management } \\
\text { \& Development - } \\
(15 \%), \$ M\end{array}$ & $20 \%$ & $\$ 15.5$ & $\$ 38.1$ & $\$ 59.6$ & $\$ 97.9$ & $\$ 97.9$ & $\$ 89.9$ \\
\hline $\begin{array}{l}\text { Land (no cost for Solar } \\
\text { Tres and Solar 50) (\$5,000 } \\
\text { per hectare), } \$ M\end{array}$ & & $\$ 0.0$ & $\$ 0.0$ & $\$ 3.3$ & $\$ 6.9$ & $\$ 6.9$ & $\$ 7.1$ \\
\hline Contingency, \$M & $10 \%$ & $\$ 12.1$ & $\$ 29.6$ & $\$ 46.2$ & $\$ 75.8$ & $\$ 74.0$ & $\$ 69.6$ \\
\hline $\begin{array}{l}\text { Cost Reduction } \\
\text { Contingency, \$M }\end{array}$ & $15 \%$ & & $\$ 15.6$ & $\$ 14.2$ & $\$ 18.1$ & $\$ 2.7$ & $\$ 15.2$ \\
\hline $\begin{array}{l}\text { Risk Pool - Upper ( } 10 \% \text { for } \\
\text { Solar Tres } / 5 \% \text { for Solar } \\
50 \text { ), \$M }\end{array}$ & & $\$ 8.8$ & $\$ 10.8$ & $\$ 0.0$ & $\$ 0.0$ & $\$ 0.0$ & $\$ 0.0$ \\
\hline Total Cost - S\&L, \$M & & $\$ 124.1$ & $\$ 310.3$ & $\$ 460.8$ & $\$ 753.3$ & $\$ 718.2$ & $\$ 690.5$ \\
\hline Total Cost - S\&L, \$kWe & & $\$ 9,090$ & $\$ 6,205$ & $\$ 4,608$ & $\$ 3,766$ & $\$ 3,591$ & $\$ 3,139$ \\
\hline
\end{tabular}

\section{E.2 DEPLOYMENT}

The deployment projections used by SunLab to develop their cost estimate is based on deployment (commercial operation) of Solar Tres in 2004 with successive initial deployments in 2006 for Solar 50, 2008 for Solar 100, 2012 for Solar 100 and 2018 for Solar 220 (see Table E-3). Deployment is dependent on Solar Tres being successful and on incorporating lessons learned into Solar 50 design. The duration between initial deployments from Solar Tres to Solar 50 and from Solar 50 to Solar 100 in the SunLab model allows only one year of operation. The duration between initial deployments should be at least two years to allow time to resolve operational issues, achieve dependable steady-state operation, and operate for a reasonable amount of time. The 
S\&L deployment projection taking these issues into consideration is shown in Table E-4. S\&L's projection is more conservative than the SunLab projection of $8.7 \mathrm{GWe}$. The S\&L projected range is from a maximum deployment of 4.7 GWe to a minimum deployment of $1.2 \mathrm{GWe}$. The S\&L base case is a deployment of 2.6 GWe.

Table E-3 - Power Tower Deployment Projection - SunLab

\begin{tabular}{|c|c|c|c|c|c|c|c|c|c|c|c|c|c|c|c|c|c|c|c|c|}
\hline & 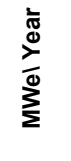 & ఫั & ֻั & : & ڤે̀ & ڤั & ठั & 울 & $\overline{\tilde{N}}$ & సั̀ & $\stackrel{m}{N}^{m}$ & $\stackrel{J}{\stackrel{J}{*}}$ & $\stackrel{10}{\stackrel{2}{N}}$ & $\stackrel{\circ}{\text { N้ }}$ & $\hat{\grave{N}}$ & $\stackrel{\infty}{N}^{\infty}$ & ํㅗㅇ & స్ํ & 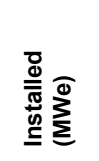 & 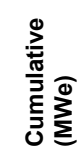 \\
\hline Solar Tres & 13.5 & 1 & & & & & & & & & & & & & & & & & 13.5 & 14 \\
\hline Solar 50 & 50 & & & 1 & 2 & 3 & & & & & & & & & & & & & 300 & 314 \\
\hline Solar 100 & 100 & & & & & 1 & 2 & 3 & 4 & 4 & 4 & 4 & 2 & 2 & 1 & & & & 2,700 & 3,014 \\
\hline Solar 200 & 200 & & & & & & & & & 1 & 1 & 1 & 3 & 3 & 4 & 4 & 5 & & 4,400 & 7,414 \\
\hline Solar 220 & 220 & & & & & & & & & & & & & & & 1 & & 5 & 1,320 & 8,734 \\
\hline Total & & 13.5 & 0 & 50 & 100 & 250 & 200 & 300 & 400 & 600 & 600 & 600 & 800 & 800 & 900 & 1,020 & 1,000 & 1,100 & 8,734 & \\
\hline
\end{tabular}


Table E-4 - Power Tower Deployment Projection -S\&L

\begin{tabular}{|c|c|c|c|c|c|c|c|c|c|c|c|c|c|c|c|c|c|c|c|c|}
\hline & 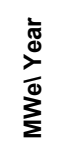 & ষ্ণ & 옹 & ஜ̊ํํ & 옹 & 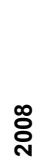 & 옹 & 웅 & Б্ & $\stackrel{\text { N }}{\text { ํ. }}$ & $\stackrel{m}{\grave{N}}$ & $\frac{⿱}{\text { ঠ }}$ & 옹 & $\stackrel{\bullet}{\grave{D}}$ & 동 & $\underset{\text { ㅇ }}{\infty}$ & $\stackrel{\circ}{\grave{\delta}}$ & ণ્ণ & 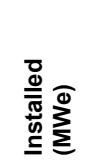 & 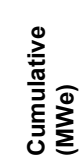 \\
\hline \multicolumn{21}{|l|}{$4.7 \mathrm{GWe}$} \\
\hline Solar Tres & 13.5 & 1 & & & & & & & & & & & & & & & & & 13.5 & 14 \\
\hline Solar 50 & 50 & & & & 1 & & 1 & 2 & 2 & & & & & & & & & & 300 & 314 \\
\hline Solar 100 & 100 & & & & & & & 1 & & 1 & 2 & 2 & 3 & 4 & & & & & 1,300 & 1,614 \\
\hline Solar 200 & 200 & & & & & & & & & & & 1 & & 1 & 2 & 3 & 3 & 3 & 2,600 & 4,214 \\
\hline Solar 220 & 220 & & & & & & & & & & & & & & & 1 & & 1 & $\underline{440}$ & 4,654 \\
\hline Total & & 13.5 & 0 & 0 & 50 & 0 & 50 & 200 & 100 & 100 & 200 & 400 & 300 & 600 & 400 & 820 & 600 & 820 & 4,654 & \\
\hline \multicolumn{21}{|l|}{$2.6 \mathrm{GWe}$} \\
\hline Solar Tres & 13.5 & 1 & & & & & & & & & & & & & & & & & 13.5 & 14 \\
\hline Solar 50 & 50 & & & & 1 & & 1 & 1 & 1 & 2 & 2 & & & & & & & & 400 & 414 \\
\hline Solar 100 & 100 & & & & & & & 1 & & 1 & 1 & 1 & 2 & 2 & 2 & & & & 1,000 & 1,414 \\
\hline Solar 200 & 200 & & & & & & & & & & & & 1 & & 1 & 1 & 1 & 2 & $\underline{1,200}$ & 2,614 \\
\hline Solar 220 & 220 & & & & & & & & & & & & & & & & & & & \\
\hline Total & & 13.5 & 0 & 0 & 50 & 0 & 50 & 150 & 50 & 200 & 200 & 100 & 300 & 200 & 300 & 200 & 200 & 400 & 2,614 & \\
\hline \multicolumn{21}{|l|}{$1.2 \mathrm{GW}$} \\
\hline Solar Tres & 13.5 & & & 1 & & & & & & & & & & & & & & & 13.5 & 14 \\
\hline Solar 50 & 50 & & & & & & 1 & & 1 & 1 & 1 & & & & & & & & 200 & 214 \\
\hline Solar 100 & 100 & & & & & & & & & & 1 & & 1 & 1 & 1 & & & & 400 & 614 \\
\hline Solar 200 & 200 & & & & & & & & & & & & & & 1 & & 1 & 1 & 600 & 1,214 \\
\hline Solar 220 & 220 & & & & & & & & & & & & & & & & & & 0 & 0 \\
\hline Total & & 0 & 0 & 13.5 & 0 & 0 & 50 & 0 & 50 & 50 & 150 & 0 & 100 & 100 & 300 & 0 & 200 & 200 & 1,214 & \\
\hline
\end{tabular}




\section{E.3 EFFICIENCY}

\section{E.3.1 Efficiency Calculation}

The Solar Field is defined by the collector area in square meters $\left(\mathrm{m}^{2}\right)$, which can be estimated by the simplified equation:

$$
\mathrm{C}=\underline{(\mathrm{kW}} \underline{\mathrm{d}} \frac{\mathrm{XF} \times \mathrm{h})}{\text { eff } \times \mathrm{I}}
$$

Where:

$\mathrm{C}=$ Collector area square meters $\left(\mathrm{m}^{2}\right)$

$\mathrm{kW}_{\mathrm{d}}=$ electric generation design capacity, kilowatts

$\mathrm{CF}=$ Capacity Factor $=\mathrm{kW}_{\mathrm{e}} \mathrm{h}$ actual $/\left(\mathrm{kW}_{\mathrm{d}} \times 8,760\right)$

$\mathrm{h}=$ hours per year $(8,760)$

eff $=$ net annual efficiency, Solar to Electric

$\mathrm{I}=$ annual insolation $\left(\mathrm{kWh}_{\mathrm{t}} / \mathrm{m}^{2}\right)$

$\mathrm{kW}_{\mathrm{e}}=$ kilowatts electric

$\mathrm{kWh}_{\mathrm{t}}=$ kilowatts thermal

For a given plant size and capacity factor, the net annual efficiency is the determining factor in the collector area; as the efficiency increases, the collector area decreases on the same percentage basis.

The annual net solar-to-electric efficiency determination and the efficiency of Solar Tres are shown in Table E-5.

Table E-5 - Annual Solar-to-Electric Efficiency

\begin{tabular}{|l|l|}
\hline Solar Field & \\
\hline Mirror Reflectivity & $93.5 \%$ \\
\hline Field Optical Efficiency & $64.6 \%$ \\
\hline Field Availability & $98.5 \%$ \\
\hline Mirror Corrosion Avoidance & $100 \%$ \\
\hline Mirror Cleanliness & $95 \%$ \\
\hline Field High Wind Outage & $99 \%$ \\
\hline Annual Heliostat Field Efficiency (HFE) & \\
\hline
\end{tabular}




\begin{tabular}{|l|l|}
\hline Annual Receiver Efficiency (RE) & $78.3 \%$ \\
\hline Annual Piping Efficiency (PE) & $99.5 \%$ \\
\hline Annual Thermal Storage Efficiency (TSE) & $98.3 \%$ \\
\hline Annual Electrical Steam Turbine Efficiency (ST) & $40.3 \%$ \\
\hline Startup Efficiency (SE) & $99.5 \%$ \\
\hline Parasitics (P) (1 - \% auxiliary power consumed by plant) & $86.4 \%$ \\
\hline Plant-wide Availability ( A ) & $92.0 \%$ \\
\hline $\left.\begin{array}{l}\text { Annual solar-to-electric efficiency ( E } \\
\left(E_{\text {net }}\right)=(\text { HFE ) }\end{array}\right)$ & $13.7 \%$ \\
\hline
\end{tabular}

The collector area is directly proportional to the plant megawatt size and the capacity factor, as evident in the preceding equation. There are economies of scale associated with increasing the plant megawatt size. To provide generation during non-solar periods and thereby increase the plant capacity factor, thermal storage is required. Thermal storage can reduce plant thermal losses by reducing the number of steam turbine start-stop cycles and decreasing the use of electrical heat tracing during no-load periods.

\section{E.3.2 Net Annual Solar-to-Electric Efficiency Impact on Cost}

The net annual solar-to-electric efficiency has a significant impact on the size of the collector field and hence the cost. The largest increase in efficiency is the step change from Solar Two to Solar Tres as shown in Figure E-4 (7.9\% to $13.1 \%)$. The comparison of the SunLab and S\&L projections for efficiency improvements is shown in Tables E-6 and E-7. In addition, S\&L considered a worst case with limited improvements in efficiencies, which are given in Table E-8. The cost reduction based on S\&L's evaluation of the SunLab reference case is shown in Section E.3.6. The net annual solar-to-electric efficiency impact on collector field cost for each change in size plant is shown in Section E.3.6.

Table E-6 - SunLab Net Solar-to-Electric Efficiency

\begin{tabular}{|c|c|c|c|c|c|c|}
\hline & Solar Two & Solar Tres & Solar 50 & Solar $\mathbf{1 0 0}$ & Solar $\mathbf{2 0 0}$ & Solar 220 \\
\hline Heliostat Field Efficiency & $50.3 \%$ & $56.0 \%$ & $56.5 \%$ & $56.3 \%$ & $56.1 \%$ & $57 \%$ \\
\hline Mirror Reflectivity & $90.7 \%$ & $93.5 \%$ & $94.0 \%$ & $94.0 \%$ & $95.0 \%$ & $95.0 \%$ \\
\hline Field Efficiency & $62.0 \%$ & $64.6 \%$ & $64.6 \%$ & $63.7 \%$ & $62.8 \%$ & $62.8 \%$ \\
\hline Field Availability & $98.0 \%$ & $99.5 \%$ & $99.0 \%$ & $99.5 \%$ & $99.5 \%$ & $99.5 \%$ \\
\hline
\end{tabular}




\begin{tabular}{|c|c|c|c|c|c|c|}
\hline & Solar Two & Solar Tres & Solar 50 & Solar 100 & Solar 200 & Solar 220 \\
\hline Mirror Corrosion & $97.0 \%$ & $100 \%$ & $100 \%$ & $100 \%$ & $100 \%$ & $100 \%$ \\
\hline Mirror Cleanliness & $95.0 \%$ & $95.0 \%$ & $95.0 \%$ & $96.0 \%$ & $96.0 \%$ & $97.0 \%$ \\
\hline Field High Wind Outage & $99.0 \%$ & $99.0 \%$ & $99.0 \%$ & $99.0 \%$ & $99.0 \%$ & $99.0 \%$ \\
\hline Receiver Efficiency & $76 \%$ & $78.3 \%$ & $80.9 \%$ & $83.1 \%$ & $83.5 \%$ & $82.0 \%$ \\
\hline Piping Efficiency & $99.0 \%$ & $99.5 \%$ & $99.5 \%$ & $99.9 \%$ & $99.9 \%$ & $99.9 \%$ \\
\hline Thermal Storage Efficiency & $97.0 \%$ & $98.3 \%$ & $99.5 \%$ & $99.5 \%$ & $99.5 \%$ & $99.5 \%$ \\
\hline EPGS Efficiency & $32.6 \%$ & $40.3 \%$ & $41.8 \%$ & $42.3 \%$ & $42.8 \%$ & $46.1 \%$ \\
\hline Parasitic (Auxiliary Power) Efficiency & $73.0 \%$ & $86.4 \%$ & $90.0 \%$ & $90.0 \%$ & $90.0 \%$ & $90.0 \%$ \\
\hline Plant Wide Availability & $90.0 \%$ & $92.0 \%$ & $94.0 \%$ & $94.0 \%$ & $94.0 \%$ & $94.0 \%$ \\
\hline Net Annual Solar-to-Electric Efficiency & $7.9 \%$ & $13.7 \%$ & $16.1 \%$ & $16.6 \%$ & $16.9 \%$ & $18.1 \%$ \\
\hline
\end{tabular}

Table E-7 — Sargent \& Lundy Net Solar-to-Electric Efficiency with Anticipated Improvements

\begin{tabular}{|c|c|c|c|c|c|c|}
\hline & Solar Two & Solar Tres & Solar 50 & Solar 100 & Solar 200 & Solar 220 \\
\hline Heliostat Field Efficiency & $50.3 \%$ & $56.0 \%$ & $56.5 \%$ & $56.0 \%$ & $55.2 \%$ & $55.2 \%$ \\
\hline Mirror Reflectivity & $90.7 \%$ & $93.5 \%$ & $94.0 \%$ & $94.0 \%$ & $94.0 \%$ & $94.0 \%$ \\
\hline Field Efficiency & $62.0 \%$ & $64.6 \%$ & $64.6 \%$ & $63.7 \%$ & $62.8 \%$ & $62.8 \%$ \\
\hline Field Availability & $98.0 \%$ & $99.5 \%$ & $99.0 \%$ & $99.5 \%$ & $99.5 \%$ & $99.5 \%$ \\
\hline Mirror Corrosion & $97.0 \%$ & $100 \%$ & $100 \%$ & $100 \%$ & $100 \%$ & $100 \%$ \\
\hline Mirror Cleanliness & $95.0 \%$ & $95.0 \%$ & $95.0 \%$ & $95.0 \%$ & $95.0 \%$ & $95.0 \%$ \\
\hline Field High Wind Outage & $99.0 \%$ & $99.0 \%$ & $99.0 \%$ & $99.0 \%$ & $99.0 \%$ & $99.0 \%$ \\
\hline Receiver Efficiency & $76.0 \%$ & $78.3 \%$ & $80.9 \%$ & $83.1 \%$ & $83.5 \%$ & $82.0 \%$ \\
\hline Piping Efficiency & $99.0 \%$ & $99.5 \%$ & $99.5 \%$ & $99.9 \%$ & $99.9 \%$ & $99.9 \%$ \\
\hline Thermal Storage Efficiency & $97.0 \%$ & $98.3 \%$ & $99.5 \%$ & $99.5 \%$ & $99.5 \%$ & $99.5 \%$ \\
\hline EPGS Efficiency & $32.6 \%$ & $38.0 \%$ & $40.4 \%$ & $41.2 \%$ & $42.6 \%$ & $45.4 \%$ \\
\hline Parasitic (Auxiliary Power) Efficiency & $73.0 \%$ & $86.4 \%$ & $90.0 \%$ & $90.0 \%$ & $90.0 \%$ & $90.0 \%$ \\
\hline Plant Wide Availability & $90.0 \%$ & $92.0 \%$ & $94.0 \%$ & $94.0 \%$ & $94.0 \%$ & $94.0 \%$ \\
\hline Net Annual Solar-to-Electric Efficiency & $7.9 \%$ & $13.0 \%$ & $15.5 \%$ & $16.1 \%$ & $16.5 \%$ & $17.3 \%$ \\
\hline
\end{tabular}


Table E-8 - Sargent \& Lundy Net Solar-to-Electric Efficiency with Limited Improvements

\begin{tabular}{|c|c|c|c|c|c|c|}
\hline & Solar Two & Solar Tres & Solar 50 & Solar 100 & Solar 200 & Solar 220 \\
\hline Heliostat Field Efficiency & $50.3 \%$ & $54.3 \%$ & $54.6 \%$ & $54.1 \%$ & $53.3 \%$ & $53.3 \%$ \\
\hline Mirror Reflectivity & $90.7 \%$ & $90.7 \%$ & $90.7 \%$ & $90.7 \%$ & $90.7 \%$ & $90.7 \%$ \\
\hline Field Efficiency & $62.0 \%$ & $64.6 \%$ & $64.6 \%$ & $63.7 \%$ & $62.8 \%$ & $62.8 \%$ \\
\hline Field Availability & $98.0 \%$ & $98.5 \%$ & $99.0 \%$ & $99.5 \%$ & $99.5 \%$ & $99.5 \%$ \\
\hline Mirror Corrosion & $97.0 \%$ & $100 \%$ & $100 \%$ & $100 \%$ & $100 \%$ & $100 \%$ \\
\hline Mirror Cleanliness & $95.0 \%$ & $95.0 \%$ & $95.0 \%$ & $95.0 \%$ & $95.0 \%$ & $95.0 \%$ \\
\hline Field High Wind Outage & $99.0 \%$ & $99.0 \%$ & $99.0 \%$ & $99.0 \%$ & $99.0 \%$ & $99.0 \%$ \\
\hline Receiver Efficiency & $76.0 \%$ & $78.3 \%$ & $78.3 \%$ & $78.3 \%$ & $78.3 \%$ & $78.3 \%$ \\
\hline Piping Efficiency & $99.0 \%$ & $99.5 \%$ & $99.5 \%$ & $99.9 \%$ & $99.9 \%$ & $99.9 \%$ \\
\hline Thermal Storage Efficiency & $97.0 \%$ & $98.3 \%$ & $98.3 \%$ & $99.5 \%$ & $99.5 \%$ & $99.5 \%$ \\
\hline EPGS Efficiency & $32.6 \%$ & $38.0 \%$ & $40.4 \%$ & $41.2 \%$ & $42.6 \%$ & $42.6 \%$ \\
\hline Parasitic (Auxiliary Power) Efficiency & $73.0 \%$ & $86.4 \%$ & $90.0 \%$ & $90.0 \%$ & $90.0 \%$ & $90.0 \%$ \\
\hline Plant Wide Availability & $90.0 \%$ & $92.0 \%$ & $92.0 \%$ & $92.0 \%$ & $92.0 \%$ & $92.0 \%$ \\
\hline Net Annual Solar-to-Electric Efficiency & $7.9 \%$ & $12.6 \%$ & $14.0 \%$ & $14.4 \%$ & $14.6 \%$ & $14.6 \%$ \\
\hline
\end{tabular}


Figure E-4 - Comparison of Annual Solar-to-Electrical Efficiency Technology Step Changes: SunLab vs. S\&L

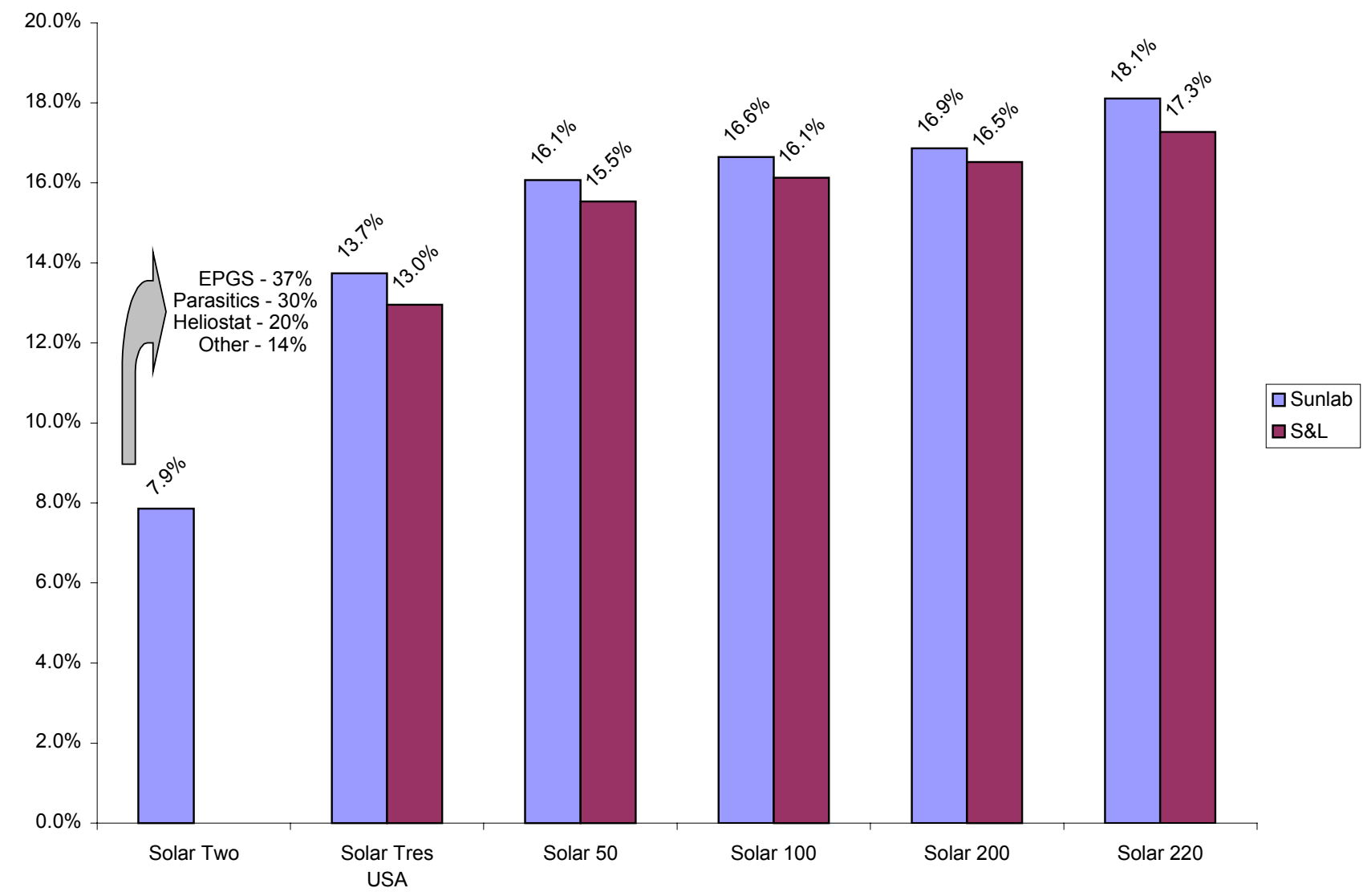

\section{E.3.3 Steam Cycle (Electric Power Block) Efficiency}

Increases in the steam cycle efficiency provide the largest cost reduction to the collector field cost. Discussion of the efficiency improvements is provided in Section E.6.2.

\section{E.3.4 Collector and Receiver Efficiency}

Increases in collector and receiver efficiency provide the next largest cost reduction to the collector field cost. Discussion of the efficiency improvements for the collector system is provided in Section E.4.2 and for the receiver system in Section E.7.2. 


\section{E.3.5 Thermal to Power Plant Efficiency — Parasitics}

The efficiency improvements are based on 16 hours of thermal storage for Solar Tres and Solar 50 and 13 hours for Solar 100 and Solar 200. The storage allows the plant to operate during non-insolation periods, thereby reducing thermal losses by minimizing the energy loss during plant start/stop cycles (thermal to plant power efficiency) and HTF heating (parasitics) during off-line periods. Even though efficiency improvements can be gained by thermal storage, additional direct costs will be incurred. First, the cost of the storage system is estimated by SunLab to be $\$ 4,940 / \mathrm{kWe}$ for Solar Tres, and second, the collector area required will be more than doubled for 16 hours storage capability. The 16 hours of thermal storage is reasonable since Solar Two successfully demonstrated operation with 3 hours of thermal storage. Thermal storage is discussed in greater detail later in this report.

\section{E.3.6 Net Annual Solar-to-Electric Efficiency Impact on Cost (SunLab Model) \\ Table E-9 - Solar Two to Solar Tres: Net Annual Solar-to-Electric Efficiency Impact on Cost (SunLab)}

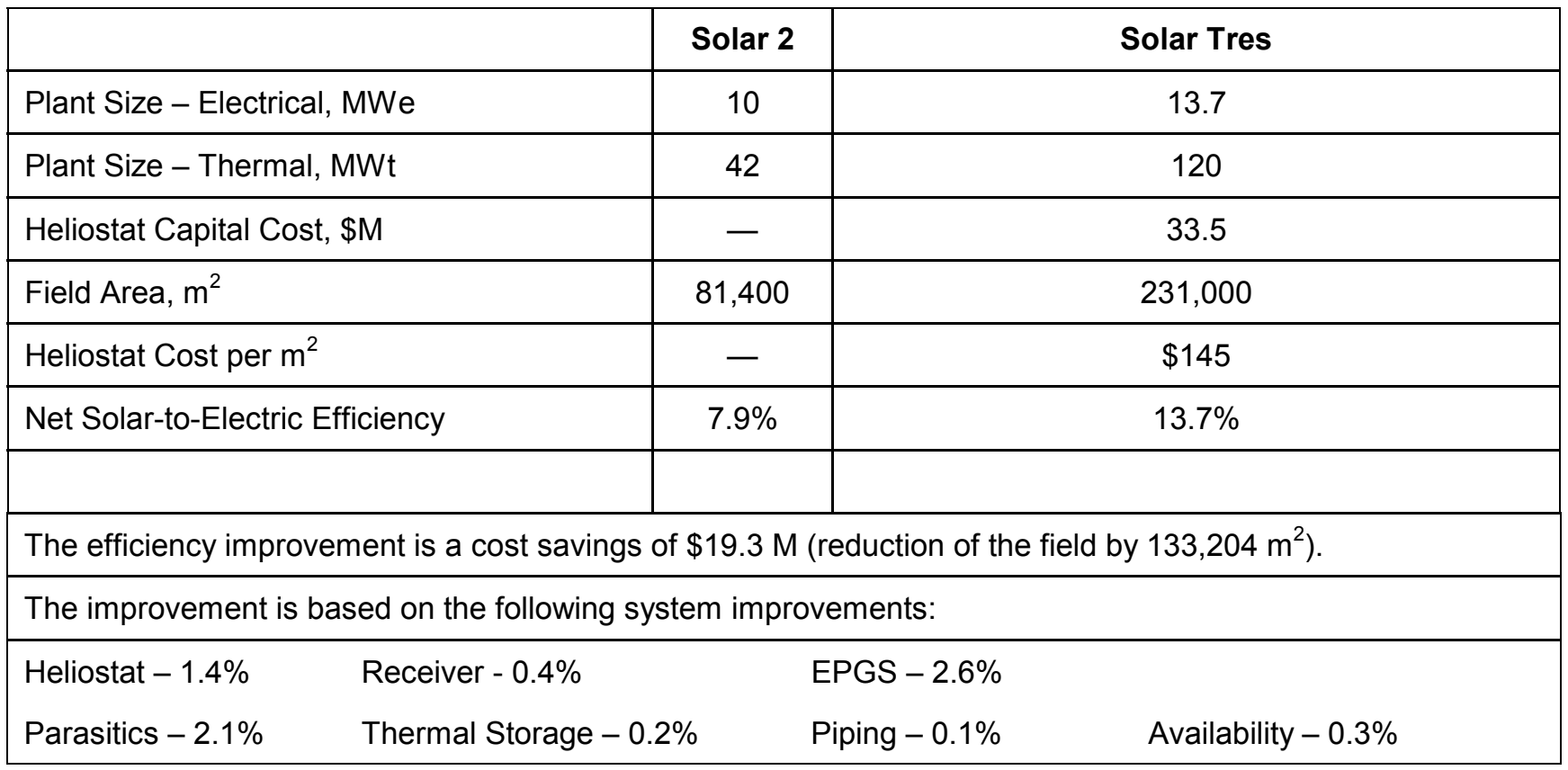


Table E-10 - Solar Tres to Solar 50:

Net Annual Solar-to-Electric Efficiency Impact on Cost (SunLab)

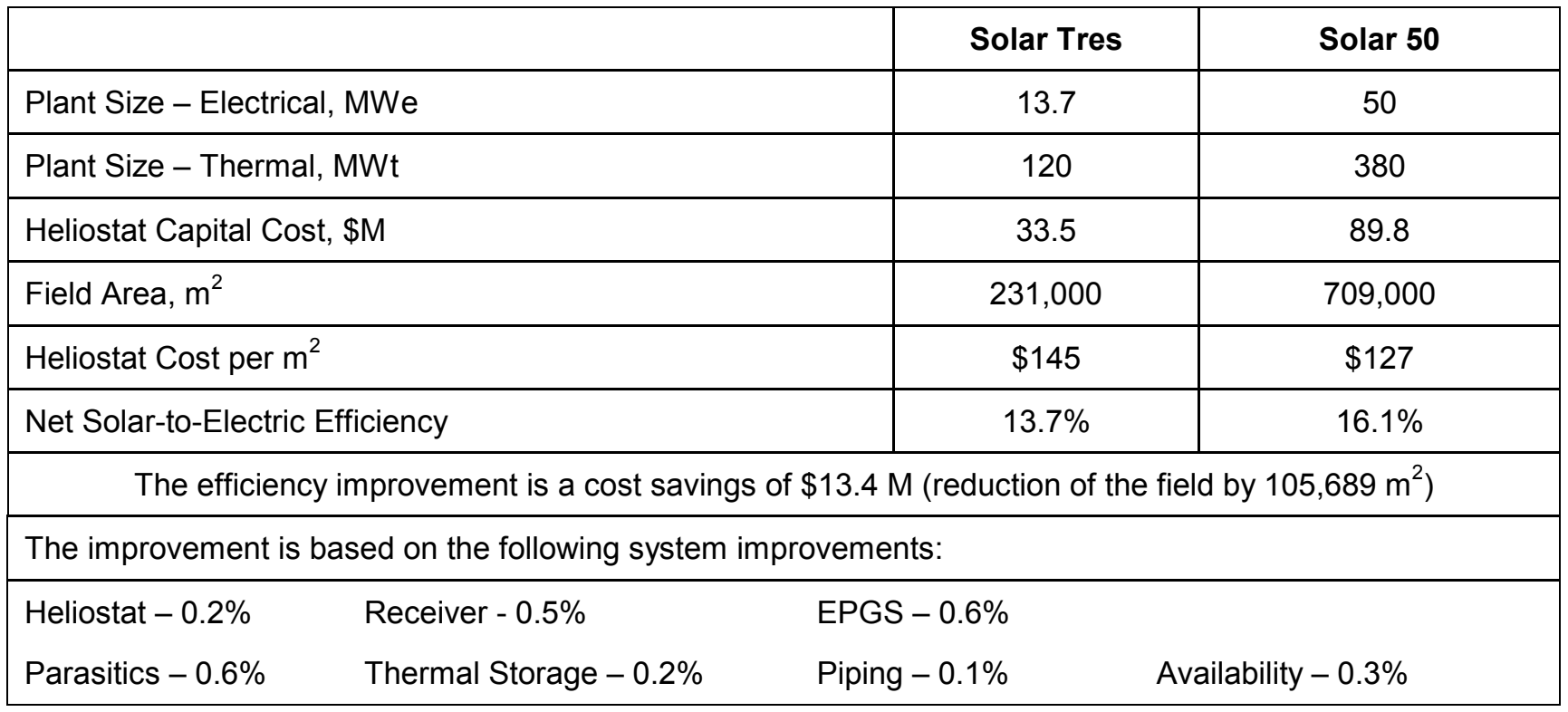

Table E-11 - Solar 50 to Solar 100:

Net Annual Solar-to-Electric Efficiency Impact on Cost (SunLab)

\begin{tabular}{|c|c|c|c|}
\hline & & Solar 50 & Solar 100 \\
\hline Plant Size - Electrical, MWe & & 50 & 100 \\
\hline Plant Size - Thermal, MWt & & 380 & 700 \\
\hline Heliostat Capital Cost, $\$ M$ & & 89.8 & 139.8 \\
\hline Field Area, $\mathrm{m}^{2}$ & & 709,000 & $1,311,000$ \\
\hline Heliostat Cost per $\mathrm{m}^{2}$ & & $\$ 127$ & $\$ 107$ \\
\hline Net Solar-to-Electric Efficiency & & $16.1 \%$ & $16.6 \%$ \\
\hline \multicolumn{4}{|c|}{ The efficiency improvement is a cost savings of $\$ 4.2 \mathrm{M}$ (reduction of the field by $39,488 \mathrm{~m}^{2}$ ) } \\
\hline \multicolumn{4}{|c|}{ The improvement is based on the following system improvements: } \\
\hline Heliostat - minus $0.1 \%$ (decrease in performance) & \multicolumn{2}{|l|}{ Receiver $-0.6 \%$} & EPGS $-0.2 \%$ \\
\hline Thermal Storage $-0 \%$ & \multicolumn{2}{|l|}{ Piping $-0 \%$} & Availability $-0 \%$ \\
\hline
\end{tabular}


Table E-12 - Solar 100 to Solar 200:

Net Annual Solar-to-Electric Efficiency Impact on Cost (SunLab)

\begin{tabular}{|c|c|c|}
\hline & Solar 100 & Solar 200 \\
\hline Plant Size - Electrical, MWe & 100 & 200 \\
\hline Plant Size - Thermal, MWt & 700 & 1,400 \\
\hline Heliostat Capital Cost, $\$ M$ & 139.8 & 249.6 \\
\hline Field Area, $\mathrm{m}^{2}$ & $1,311,000$ & $2,606,000$ \\
\hline Heliostat Cost per $\mathrm{m}^{2}$ & $\$ 107$ & $\$ 96$ \\
\hline Net Solar-to-Electric Efficiency & $16.6 \%$ & $16.9 \%$ \\
\hline \multicolumn{3}{|c|}{ The efficiency improvement is a cost savings of $\$ 4.4 \mathrm{M}$ (reduction of the field by $46,260 \mathrm{~m}^{2}$ ) } \\
\hline \multicolumn{3}{|c|}{ The improvement is based on the following system improvements: } \\
\hline Heliostat - minus $0.1 \%$ (decrease in performance) & Receiver $-0.1 \%$ & EPGS $-0.2 \%$ \\
\hline Thermal Storage $-0 \%$ & Piping $-0 \%$ & Availability - 0\% \\
\hline
\end{tabular}

Table E-13 - Solar 200 to Solar 220:

Net Annual Solar-to-Electric Efficiency Impact on Cost (SunLab)

\begin{tabular}{|c|c|c|c|c|}
\hline & & & Solar 200 & Solar 220 \\
\hline Plant Size - Elec & MWe & & 200 & 220 \\
\hline Plant Size - The & $1 \mathrm{Wt}$ & & 1,400 & 1,400 \\
\hline Heliostat Capital & & & 249.6 & 198.8 \\
\hline Field Area, $\mathrm{m}^{2}$ & & & $2,606,000$ & $2,642,000$ \\
\hline Heliostat Cost pe & & & $\$ 96$ & $\$ 75$ \\
\hline Net Solar-to-Elec & iciency & & $16.9 \%$ & $18.1 \%$ \\
\hline The efficiency im & ent is a cost savings of & (reduction of $\mathrm{tr}$ & eld by 175 & \\
\hline The improvemen & sed on the following syste & ovements: & & \\
\hline Heliostat $-0.3 \%$ & Receiver - minus $0.4 \%$ & EPGS - $1.3 \%$ & & \\
\hline Parasitics - 0\% & Thermal Storage $-0 \%$ & Piping $-0 \%$ & Availa & $0 \%$ \\
\hline
\end{tabular}




\section{E.4 COLLECTORS}

The first plants (Solar Tres and Solar 50) will use the $95-\mathrm{m}^{2}$ heliostats. The heliostat size will be increased to $148 \mathrm{~m}^{2}$ for Solar 100. S\&L's evaluation focused on the capital costs and cost improvement for the $148-\mathrm{m}^{2}$ heliostat. The S\&L review is primarily based on the SunLab model, the detailed cost models developed by AD Little (Arthur D. Little, 2001), Advanced Thermal Systems (1996), Solar Kinetics (1996), and the Peerless-

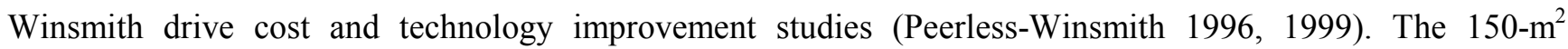
heliostat was then compared against the $95-\mathrm{m}^{2}$ heliostat. We reviewed the major cost components and provided a discussion of the assumptions and reasonableness of the cost estimate in Section E.5.

AD Little (ADL) was contracted by the DOE to prepare a detailed cost estimate for the current $150-\mathrm{m}^{2}$ heliostat design from Advanced Thermal Systems (ATS). The study was based on detailed design drawings, material takeoff, and proven assembly techniques (Advanced Thermal Systems 1996). Manufacturers and vendors were contacted to develop and validate material costs. ADL used the detailed design information from ATS ${ }^{*}(1996)$ to estimate the costs. This bottoms-up cost estimate is fairly rigorous and provides a fairly accurate cost estimate. S\&L compared and evaluated the detailed cost models and developed a cost estimate.

\section{E.4.1 Direct Capital Cost}

The cost summary of material, labor, overhead, and profit for the SunLab cost estimate is compared to the ADL cost estimate in the Table E-14. A composite cost estimate was developed by S\&L based on evaluation of the differences between the cost estimates.

\footnotetext{
* The heliostat was developed by ATS under contract with the DOE. DOE funded the development of the 'secondgeneration' $53-\mathrm{m}^{2}$ heliostat. ARCO funded the design, development, and first prototype $95-$ and $148-\mathrm{m}^{2}$ trackers for use as heliostats or PV trackers. Advanced Thermal Systems is a small company formed in 1985 by former ARCO engineers with licensing rights for the tracker technology. The early design was optimized to use the maximum number of commodity parts and provide the lowest possible cost for near-term deployment. Approximately 1000 solar trackers of this basic design have been built. Most were the $95-\mathrm{m}^{2}$ units. One hundred eight of the heliostats used at Solar Two were second-hand ATSbuilt trackers.
} 
Figure E-5 - Heliostat Cost Drivers

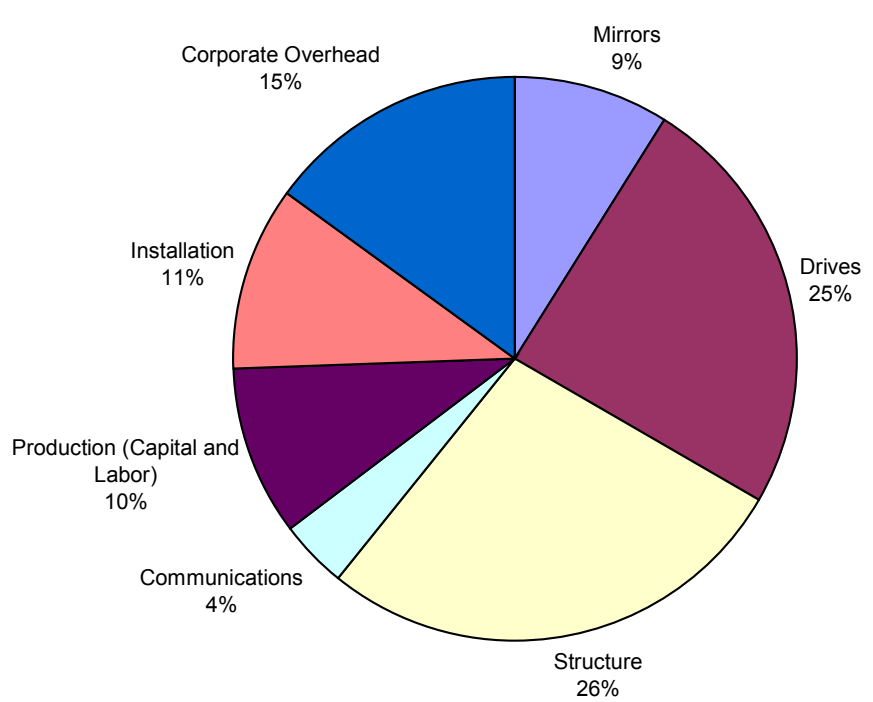

Table E-14 - $148 \mathrm{~m}^{2}$ Heliostat Direct Capital Cost: Comparison of SunLab and ADL

\begin{tabular}{|c|c|c|c|c|}
\hline $\begin{array}{l}\text { Summary of Cost } \\
\text { Comparison }\end{array}$ & SunLab & ADL & S\&L & Discussion \\
\hline Collector Area $\left(\mathrm{m}^{2}\right)$ & 227,000 & 444,000 & 444,000 & \\
\hline Quantity (units) & 1,534 & 3,000 & 3,000 & \\
\hline Mirrors & $\$ 1,924$ & $\$ 1,976$ & $\$ 1,976$ & $\begin{array}{l}\text { Mirror costs are based on vendor quotes and are the } \\
\text { same as ADL }\end{array}$ \\
\hline Drive (azimuth) & $\$ 4,035$ & $\$ 4,000$ & $\$ 4,035$ & Drive costs are based on vendor quotes. \\
\hline Drive (elevation) & $\$ 1,250$ & & $\$ 1,250$ & $\begin{array}{l}\text { ADL cost estimate included a dual drive (azimuth } \\
\text { and elevation). }\end{array}$ \\
\hline $\begin{array}{l}\text { Structural Steel, } \\
\text { Pedestal, \& Other }\end{array}$ & $\$ 5,887$ & $\$ 5,598$ & $\$ 5,887$ & $\begin{array}{l}\text { The composite of structural steel, pedestal and other } \\
\text { costs are about the same }\end{array}$ \\
\hline Communications & $\$ 875$ & & $\$ 875$ & The ADL estimate did not include communications. \\
\hline Labor & $\$ 800$ & $\$ 1,552$ & $\$ 800$ & $\begin{array}{l}\text { ADL included indirect costs whereas SunLab only } \\
\text { includes direct costs. We used SunLab direct costs } \\
\text { and increased Overhead \& Profit to } 20 \% \text { to cover } \\
\text { indirect costs. }\end{array}$ \\
\hline
\end{tabular}




\begin{tabular}{|c|c|c|c|c|}
\hline $\begin{array}{l}\text { Summary of Cost } \\
\text { Comparison }\end{array}$ & SunLab & ADL & S\&L & Discussion \\
\hline $\begin{array}{l}\text { Capital Equipment } \\
\text { and Tooling }\end{array}$ & $\$ 863$ & $\$ 301$ & $\$ 912$ & $\begin{array}{l}\text { The difference is attributed to ADL basing their cost } \\
\text { on a supplier setting up a manufacturing facility } \\
\text { whereas SunLab's estimate is based on a local } \\
\text { assembly shop associated with the construction } \\
\text { project. (See Appendix E.5.9) }\end{array}$ \\
\hline $\begin{array}{l}\text { Other Production } \\
\text { Costs }\end{array}$ & $\$ 419$ & $\$ 172$ & $\$ 419$ & $\begin{array}{l}\text { SunLab other includes } 3 \% \text { for shipping, whereas } \\
\text { ADL did not define other. }\end{array}$ \\
\hline $\begin{array}{l}\text { Total Fabrication } \\
\text { Costs }\end{array}$ & $\$ 16,053$ & $\$ 13,599$ & $\$ 16,102$ & \\
\hline $\begin{array}{l}\text { Corporate } \\
\text { Overhead }\end{array}$ & $\$ 2,408$ & $\$ 3,334$ & 3,211 & $\begin{array}{l}\text { SunLab is based on } 15 \% \text {, whereas ADL uses } 25 \% \text {. } \\
\text { The S\&L estimate is based on } 20 \% \text { since a local } \\
\text { production shop will be set up as part of construction } \\
\text { until the market for heliostats opens up. This will } \\
\text { reduce corporate overhead costs. }\end{array}$ \\
\hline System Cost & $\$ 18,461$ & $\$ 16,933$ & $\$ 19,322$ & \\
\hline Installation & $\$ 950$ & $\$ 2,036$ & $\$ 1,426$ & $\begin{array}{l}\text { ADL estimate is more reasonable and higher than } \\
\text { the SunLab estimate. }\end{array}$ \\
\hline Field Wiring & $\$ 877$ & & $\$ 877$ & $\begin{array}{l}\text { The ADL estimate did not include field wiring; } \\
\text { therefore, the SunLab cost estimate for field wiring } \\
\text { was added for comparison }\end{array}$ \\
\hline Total Installed Cost & $\$ 20,288$ & $\$ 18,969$ & $\$ 21,688$ & \\
\hline $\begin{array}{l}\text { Total Installed Cost } \\
\text { per } \mathrm{m}^{2} \text { for } 148-\mathrm{m}^{2} \\
\text { heliostat }\end{array}$ & $\$ 137$ & $\$ 128$ & $\$ 146$ & $\begin{array}{l}\text { The estimated cost range is between } \$ 137 \text { (SunLab } \\
\text { estimate) and } \$ 146 \text { ( } S \& L \text { estimate) for initial } \\
\text { deployment of } 148-\mathrm{m}^{2} \text { heliostats. The difference } \\
\text { between } S \& L \text { and } A D L \text { is } 7 \% \text {. }\end{array}$ \\
\hline
\end{tabular}

The cost estimates for both SunLab and ADL are based on the ATS detailed design drawings and material quantities. The material costs are essentially the same. The differences are labor, overhead, and capital for equipment and tooling. The S\&L estimate is based on a local production facility being developed at or near the construction site. This assumption is reasonable for the first several deployments since it will be difficult to entice a reputable manufacturer to establish a production facility without firm commitments and significant quantities. SunLab used a contingency of $+5 \%$. S\&L used a contingency of $+10 \%$ based on the uncertainties associated with estimating costs.

Therefore, S\&L estimates that the direct cost estimate for initial deployment of a $148-\mathrm{m}^{2}$ heliostat is $\$ 146$ per $\mathrm{m}^{2}$, plus a contingency of $10 \%\left(\$ 161\right.$ per $\left.\mathrm{m}^{2}\right)$. 
The main difference between the $95-\mathrm{m}^{2}$ and $148-\mathrm{m}^{2}$ heliostat is size, therefore it is reasonable to estimate the $95 \mathrm{~m}^{2}$ cost by extrapolating the $148 \mathrm{~m}^{2}$ cost using a scaling factor. SunLab used a scaling factor of 0.8 as shown in Table E-9. As a component, structure, or plant increases in size the increase in cost is not linear. Typical scaling factors, based on industry experience, are about 0.7 (S\&L uses 0.67 to 0.72 based on our experience with scaling of power generating plants, Boeing uses 0.7 to 0.8 based on their industrial experience).

The direct cost estimate for initial deployment of a $95-\mathrm{m}^{2}$ heliostat is $\$ 160$ per $\mathrm{m}^{2}$, plus a $10 \%$ contingency $\left(\$ 176\right.$ per $\left.\mathrm{m}^{2}\right)$.

Table E-15 - Heliostat Cost Estimate Comparison: Direct Capital Cost - Initial Deployment Scale from 148 to $95 \mathrm{~m}^{2}$

\begin{tabular}{|l|c|c|c|c|}
\hline & \multicolumn{2}{|c|}{ SunLab } & \multicolumn{2}{c|}{ Sargent \& Lundy } \\
\hline Heliostat Size & $\begin{array}{c}\text { Heliostat } \\
\text { Cost }\end{array}$ & $\$ / \mathrm{m}^{2}$ & $\begin{array}{c}\text { Heliostat } \\
\text { Cost }\end{array}$ & $\$ / \mathrm{m}^{2}$ \\
\hline $\begin{array}{l}95 \mathrm{~m}^{2} \text { (scaled from } 148 \mathrm{~m}^{2} \text { at } \\
\text { a scaling factor of 0.8 }\end{array}$ & $\$ 14,214$ & $\$ 150$ & $\$ 15,168$ & $\$ 160$ \\
\hline $148 \mathrm{~m}^{2}$ (from Table E-14) & $\$ 20,288$ & $\$ 137$ & $\$ 21,688$ & $\$ 146$ \\
\hline
\end{tabular}

The major cost categories of the SunLab cost estimate for heliostats as compared to ADL are evaluated and discussed in Section E.5.

\section{E.4.2 Technology Improvements}

The annual heliostat field efficiency projections based on the SunLab model for each new deployment is shown in Table E-16. The annual heliostat field efficiency is the product of all the factors beneath it.

Table E-16 - Annual Heliostat Efficiency (SunLab vs. S\&L)

\begin{tabular}{|r|c|c|c|c|c|c|c|}
\hline & $\begin{array}{c}\text { Solar } \\
\text { One }\end{array}$ & $\begin{array}{c}\text { Solar } \\
\text { Two }\end{array}$ & $\begin{array}{c}\text { Solar } \\
\text { Tres USA }\end{array}$ & $\begin{array}{c}\text { Solar } \\
\mathbf{5 0}\end{array}$ & $\begin{array}{c}\text { Solar } \\
\mathbf{1 0 0}\end{array}$ & $\begin{array}{c}\text { Solar } \\
\mathbf{2 0 0}\end{array}$ & $\begin{array}{c}\text { Solar } \\
\mathbf{2 2 0}\end{array}$ \\
\cline { 2 - 9 } & $\mathbf{1 9 8 8}$ & $\mathbf{1 9 9 9}$ & $\mathbf{2 0 0 4}$ & $\mathbf{2 0 0 6}$ & $\mathbf{2 0 0 8}$ & $\mathbf{2 0 1 2}$ & $\mathbf{2 0 1 8}$ \\
\hline $\begin{array}{r}\text { Annual Heliostat Field } \\
\text { Efficiency SunLab }\end{array}$ & $58.1 \%$ & $50.3 \%$ & $56.0 \%$ & $56.5 \%$ & $56.3 \%$ & $56.1 \%$ & $57.0 \%$ \\
S\&L & - & - & $56.0 \%$ & $56.5 \%$ & $56.0 \%$ & $55.2 \%$ & $55.2 \%$ \\
\hline
\end{tabular}




\begin{tabular}{|c|c|c|c|c|c|c|c|}
\hline & $\begin{array}{l}\text { Solar } \\
\text { One }\end{array}$ & $\begin{array}{l}\text { Solar } \\
\text { Two }\end{array}$ & $\begin{array}{l}\text { Solar } \\
\text { Tres USA }\end{array}$ & $\begin{array}{c}\text { Solar } \\
50\end{array}$ & $\begin{array}{c}\text { Solar } \\
100\end{array}$ & $\begin{array}{c}\text { Solar } \\
200\end{array}$ & $\begin{array}{l}\text { Solar } \\
220\end{array}$ \\
\hline & 1988 & 1999 & 2004 & 2006 & 2008 & 2012 & 2018 \\
\hline Mirror Reflectivity & $90.5 \%$ & $90.7 \%$ & $93.5 \%$ & $94.0 \%$ & $94.0 \%$ & $94.5 \%$ & $95.0 \%$ \\
\hline S\&L & - & - & $93.5 \%$ & $94.0 \%$ & $94.0 \%$ & $94.0 \%$ & $94.0 \%$ \\
\hline $\begin{array}{l}\text { Field Optical Efficiency } \\
\qquad \text { SunLab }\end{array}$ & $69.0 \%$ & $62.0 \%$ & $64.6 \%$ & $64.6 \%$ & $63.7 \%$ & $62.8 \%$ & $62.8 \%$ \\
\hline S\&L & - & - & $64.6 \%$ & $64.6 \%$ & $63.7 \%$ & $62.8 \%$ & $62.8 \%$ \\
\hline Field Availability & $99.0 \%$ & $98.0 \%$ & $98.5 \%$ & $99.0 \%$ & $99.5 \%$ & $99.5 \%$ & $99.5 \%$ \\
\hline S\&L & - & - & $98.5 \%$ & $99.0 \%$ & $99.5 \%$ & $99.5 \%$ & $99.5 \%$ \\
\hline $\begin{array}{r}\text { Mirror Corrosion Avoidance } \\
\text { SunLab }\end{array}$ & $100.0 \%$ & $97.0 \%$ & $100.0 \%$ & $100.0 \%$ & $100.0 \%$ & $100.0 \%$ & $100.0 \%$ \\
\hline S\&L & - & - & $100.0 \%$ & $100.0 \%$ & $100.0 \%$ & $100.0 \%$ & $100.0 \%$ \\
\hline $\begin{array}{l}\text { Mirror Cleanliness } \\
\text { SunLab }\end{array}$ & $95.0 \%$ & $95.0 \%$ & $95.0 \%$ & $95.0 \%$ & $95.5 \%$ & $96.0 \%$ & $97.0 \%$ \\
\hline S\&L & - & - & $95.0 \%$ & $95.0 \%$ & 95.0 & $95.0 \%$ & $95.0 \%$ \\
\hline $\begin{array}{l}\text { Field High Wind Outage } \\
\text { SunLab }\end{array}$ & $99.0 \%$ & $99.0 \%$ & $99.0 \%$ & $99.0 \%$ & $99.0 \%$ & $99.0 \%$ & $99.0 \%$ \\
\hline S\&L & - & - & $99.0 \%$ & $99.0 \%$ & $99.0 \%$ & $99.0 \%$ & $99.0 \%$ \\
\hline
\end{tabular}

The increase in heliostat field efficiency is primarily based on increases in mirror reflectivity, field availability, and mirror cleanliness. The heliostat field efficiency at Solar Two was lower than at Solar One due to the re-use of equipment that had been abandoned for approximately 7 years, the use of second-hand PV trackers and uncurved mirrors, and a general lack of emphasis on the field because it had already been proven at Solar One (Reilly and Kolb 2001; Pacheco et al. 2002). The S\&L evaluation of the efficiency for each deployment is shown in Section 5.6.

\section{E.4.3 Economy of Scale}

Cost improvements due to increasing the heliostat size goes from $95 \mathrm{~m}^{2}$ to $148 \mathrm{~m}^{2}$ (Solar 50 to Solar 100) are classed as scale improvements even though research, design, testing and manufacturing issues are associated with this change. The methodology to analyze this change is based on proven component scale-up techniques. 
The scaling factor for going from the $95-\mathrm{m}^{2}$ heliostat to the $148-\mathrm{m}^{2}$ heliostat is shown in Table E-17. The cost projection for cost reduction due to scaling factor is reasonable since the scaling factor of 0.8 is more conservative than the industry standard of 0.7

Table E-17 - Heliostat Scaling Factors - Direct Capital Cost Economy of Scale Change from 95 to $148 \mathrm{~m}^{2}$ (Solar 100)

\begin{tabular}{|l|l|c|c|c|c|c|}
\hline & \multicolumn{3}{|c|}{ SunLab } & \multicolumn{3}{c|}{ Sargent \& Lundy } \\
\hline Heliostat Size & Heliostat Cost & $\$ / \mathrm{m}^{2}$ & Size & Heliostat Cost & $\$ \mathrm{~m}^{2}$ & Size \\
\hline $95 \mathrm{~m}^{2}$ & $\$ 11,070$ & $\$ 117$ & 95 & $\$ 13,654$ & $\$ 144^{* *}$ & 95 \\
\hline $148 \mathrm{~m}^{2}$ & $\$ 15,783$ & $\$ 107^{*}$ & 148 & $\$ 19,466$ & $\$ 132 * * *$ & 148 \\
\hline Scaling Factor & \multicolumn{3}{|c|}{0.80} & \multicolumn{3}{c|}{0.80} \\
\hline
\end{tabular}

* From Table E-11; SunLab cost estimate for Solar 100, 148- $\mathrm{m}^{2}$ heliostat

** Estimated cost of $95-\mathrm{m}^{2}$ heliostat based on progress ratio of 0.971 (see Table E-19) with deployment of $4.7 \mathrm{GWe}$

*** Calculated based on scale-up from $95 \mathrm{~m}^{2}$ at $\$ 144$ per $\mathrm{m}^{2}$ to $\$ 132$ per $\mathrm{m}^{2}$

\section{E.4.4 Estimate of Cost Reductions Due to Volume Production}

This section explores cost reduction for heliostats, which is based on the number of heliostats being manufactured. As the number of heliostats increases, the cost will be reduced. The quantity of heliostats being manufactured is dependent on the deployment of plants. Deployment projections are discussed in Section 3. Heliostat production $\left(\mathrm{m}^{2}\right)$ based on a range of deployments $(2.2 \mathrm{GW}$ to $7.1 \mathrm{GW})$ is shown in Figure E-6. 
Figure E-6 - Cumulative Heliostat Production $\left(\mathrm{m}^{2}\right)$ vs. Deployment Projections (installed GWe)

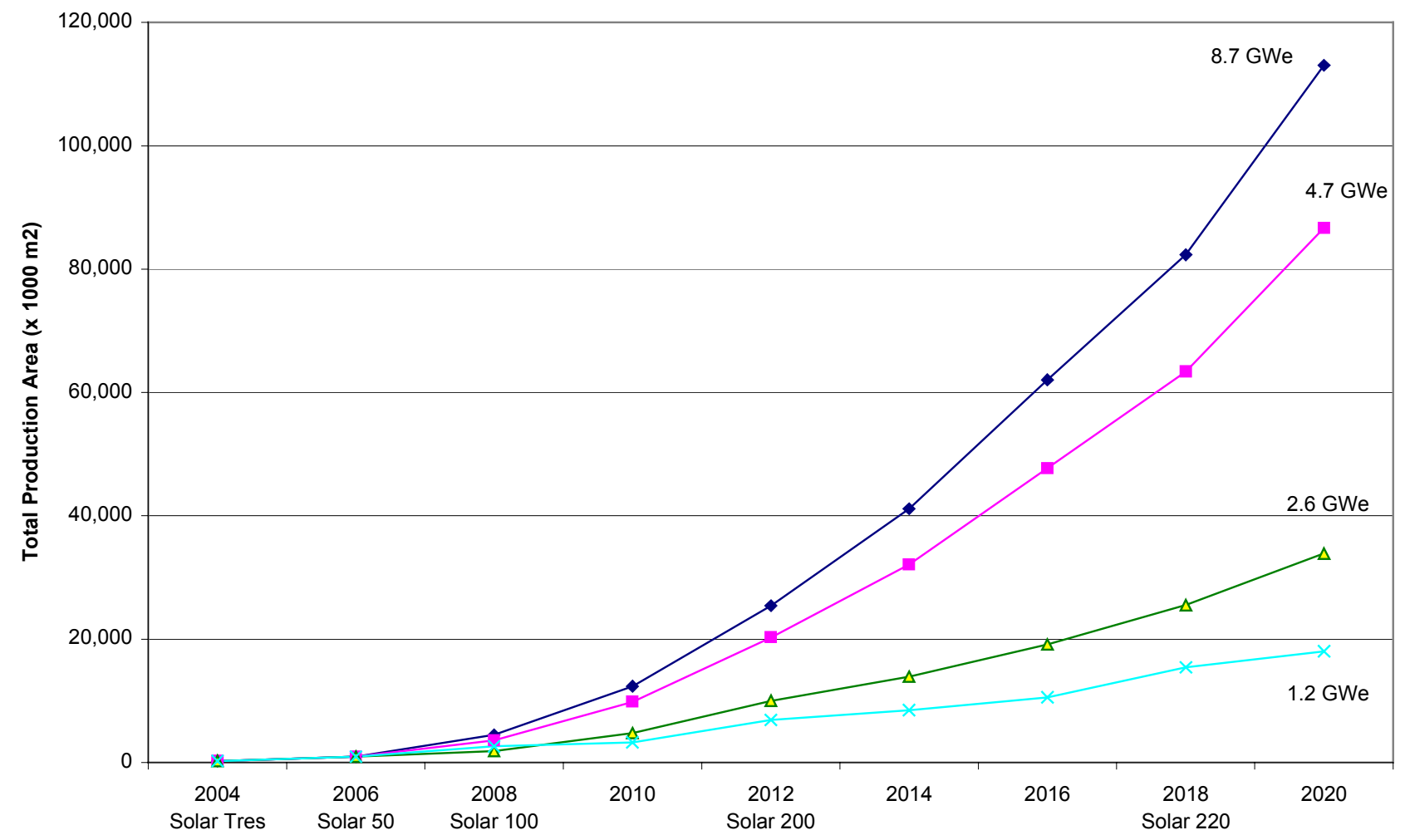

\section{E.4.4.1 Progress Ratio and Determination of Heliostat Costs}

Sargent \& Lundy calculated the progress ratio for heliostats. Each cost component was evaluated and based on our detailed review of the SunLab and ADL detailed cost estimates (see Appendix E.5). The progress ratio ratios changes from the SunLab model are highlighted in Table E-18. For example, we did not concur with SunLab's cost improvement for installation costs as discussed in Section E.5; therefore, we adjusted the progress ratio to 1.0. The differences identified by S\&L are as follows:

- $\quad$ Drives (azimuth) - Adjusted based on Section E.5.3.

- Structural Steel \& Pedestal - SunLab projected a 5\% weight improvement. There was no objective evidence; therefore, we projected a slight improvement for material quantity discounts (see Section E.5.7).

- Insulation and Field Wiring - SunLab projects a cost reduction for installation. Based on our experience, cost reductions are not as easily achieved for construction activities as manufacturing process. 
The progress ratio for each heliostat cost activity was calculated based on the SunLab cost estimate. S\&L estimated the final cost based on our evaluation and industry experience. The progress ratio was then calculated.

Table E-18 - Cost Improvements Due to Volume Production $\left(148 \mathrm{~m}^{2}\right)$

\begin{tabular}{|l|c|c|}
\hline & $\begin{array}{c}\text { Initial } \\
\text { Production } \\
\text { Volume }\end{array}$ & $\begin{array}{c}\text { Final } \\
\text { Production } \\
\text { Volume }\end{array}$ \\
\hline Annual Production, $\mathrm{m}^{2}$ & 227,000 & $100,000,000$ \\
\hline Doubling Factor & - & 8.78 \\
\hline
\end{tabular}

\begin{tabular}{|l|c|c|c|c|c|}
\hline \multirow{2}{*}{} & \multicolumn{3}{|c|}{ SunLab Model } & \multicolumn{2}{c|}{ S\&L Evaluation } \\
\cline { 2 - 6 } & Initial Cost & Final Cost & PR $^{*}$ & PR $^{*}$ & Cost \\
\hline Mirrors & $\$ 1,924$ & $\$ 1,470$ & 0.97 & 0.97 & $\$ 1,472$ \\
\hline Drive (azimuth) & $\$ 4,035$ & $\$ 1,670$ & 0.90 & 0.94 & $\$ 2,343$ \\
\hline Drive (elevation) & $\$ 1,250$ & $\$ 990$ & 0.97 & 0.97 & $\$ 990$ \\
\hline Structural Steel & $\$ 3,412$ & $\$ 2,930$ & 0.98 & 0.99 & $\$ 3,124$ \\
\hline Pedestal & $\$ 1,705$ & $\$ 1,530$ & 0.99 & 0.99 & $\$ 1,561$ \\
\hline Other & $\$ 770$ & $\$ 700$ & 0.99 & 0.99 & $\$ 700$ \\
\hline Communications & $\$ 875$ & $\$ 630$ & 0.96 & 0.96 & $\$ 630$ \\
\hline Labor & $\$ 800$ & $\$ 660$ & 0.98 & 0.98 & $\$ 660$ \\
\hline Capital Equipment \& Tooling & $\$ 863$ & $\$ 237$ & 0.86 & 0.86 & $\$ 237$ \\
\hline Other Production Costs & $\$ 419$ & $\$ 298$ & 0.96 & 0.96 & $\$ 298$ \\
\hline Total Fabrication Costs & $\$ 16,053$ & $\$ 11,114$ & 0.96 & - & $\$ 12,015$ \\
\hline Corporate Overhead & $\$ 2,408$ & $\$ 1,667$ & 0.96 & - & $\$ 1,802$ \\
\hline System Cost & $\$ 18,461$ & $\$ 12,782$ & 0.96 & 0.96 & $\$ 13,817$ \\
\hline Installation & $\$ 950$ & $\$ 836$ & 0.99 & 1.0 & $\$ 950$ \\
\hline Field Wiring & $\$ 877$ & $\$ 671$ & 0.97 & 1.0 & $\$ 877$ \\
\hline Total Installed Cost & $\$ 20,288$ & $\$ 14,288$ & 0.961 & 0.971 & $\$ 16,739 * *$ \\
\hline
\end{tabular}




\begin{tabular}{|l|c|c|c|c|c|}
\hline \multirow{2}{*}{} & \multicolumn{3}{|c|}{ SunLab Model } & \multicolumn{2}{c|}{ S\&L Evaluation } \\
\cline { 2 - 6 } & Initial Cost & Final Cost & PR $^{*}$ & PR $^{*}$ & Cost \\
\hline Total Installed Cost per $\mathrm{m}^{2}$ & $\$ 137$ & $\$ 97$ & - & - & $\$ 113$ \\
\hline
\end{tabular}

* Calculated based on the initial and final cost estimate

** Includes adjustment is the difference between SunLab cost estimate and S\&L: $7 \%$ as shown in Table E-14

The SunLab cost estimate of cost improvement was based on a final production of $100,000,000 \mathrm{~m}^{2}$. The first deployment with $148-\mathrm{m}^{2}$ heliostats is Solar 100, which requires a collector field of 5,239,500 $\mathrm{m}^{2}$ for each plant. The cost projection for going from $227,000 \mathrm{~m}^{2}$ to $5,239,000 \mathrm{~m}^{2}$ is shown in Table E-19.

Table E-19 - Final Cost for First Deployment of 148-m² Heliostats

\begin{tabular}{|c|c|c|c|c|}
\hline $\mathbf{1 4 8} \mathbf{~}^{\mathbf{2}} \mathbf{- S \& L}$ & Initial & Final & $\begin{array}{c}\text { Doubling } \\
\text { Factor }\end{array}$ & PR \\
\hline Volume, $\mathrm{m}^{2}$ & 227,000 & $100,000,000$ & 8.78 & 0.971 \\
\hline Total Cost, $\$ / \mathrm{m}^{2}$ & $\$ 146^{*}$ & $\$ 113$ & - & - \\
\hline Volume, $\mathrm{m}^{2}$ & 227,000 & $5,239,500$ & 4.53 & 0.971 \\
\hline Total Cost, $\$ / \mathrm{m}^{2}$ & $\$ 146^{*}$ & $\$ 128$ & - & - \\
\hline
\end{tabular}

* From Table E-18 calculated based on progress ratio of 0.971 for volume of $5,239,500 \mathrm{~m}^{2}$

\section{E.4.5 Cost Comparisons}

The comparison of heliostat cost improvements from 2004 to 2020 for a cumulative deployment of $8.7 \mathrm{GWe}$ is shown in Figure E-7. The range of progress ratios used for the comparison by S\&L is between 0.85 and 0.96. Various studies on learning curves from actual data suggest that a progress ratio of 0.82 has been observed for photovoltaics (PV) and 0.82 for development of wind energy during early deployment (1980 to 1995). The higher end of the range is from the Enermodal study for the World Bank, which identified a PV of 0.96 and the Wind Learning Rates compiled by Kobos for development of wind plants. (See Section B.6 for additional discussion.)

The progress ratio calculated for the S\&L base case is 0.97 and 0.96 for $95-\mathrm{m}^{2}$ heliostats and 0.93 for $148-\mathrm{m}^{2}$ heliostats. The average progress ratio calculated for SunLab is 0.93 . These values fall within the range of 0.85 to 0.96, as shown in Figure E-7. 
Figure E-7 — Heliostat Cost Improvements (8.7 GWe)

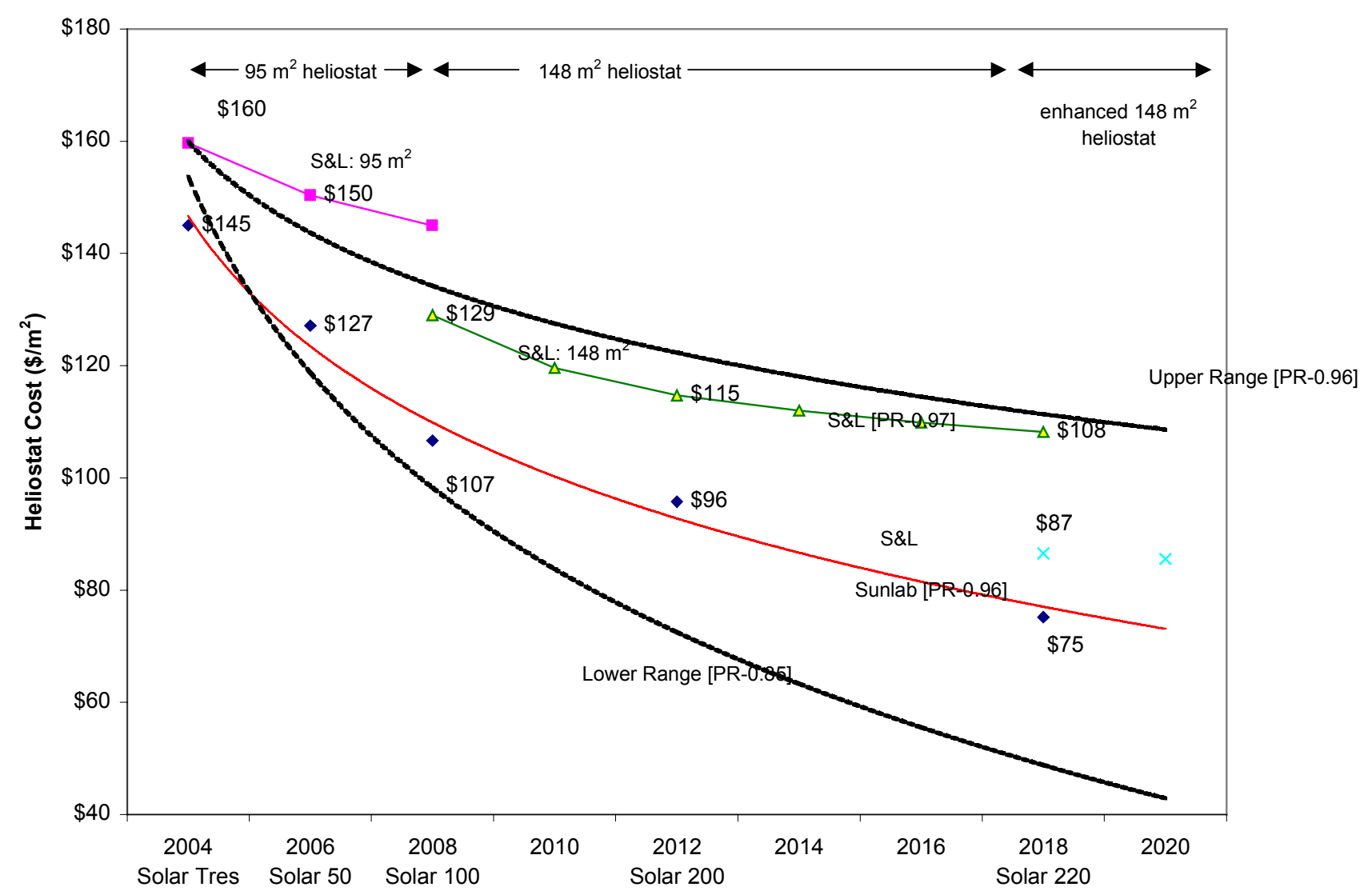

Sargent \& Lundy estimated heliostat costs based on a detailed review of the SunLab and ADL cost estimates. Cost reductions were then calculated as shown in Figure E-8. 
Figure E-8 — S\&L Cost Estimate of Heliostats (Solar Tres to Solar 200)

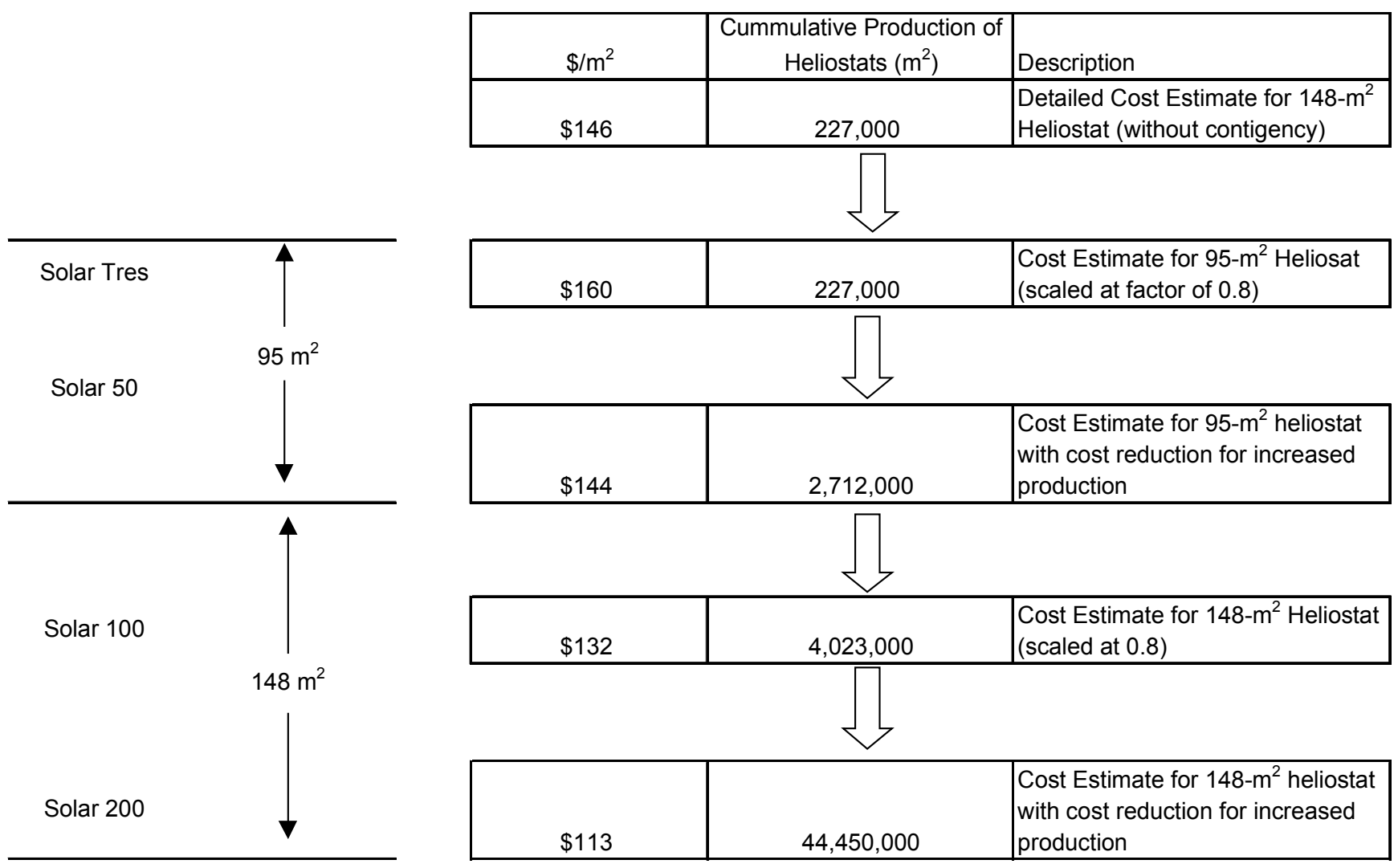

The comparison between S\&L and SunLab collector field costs is based on a maximum deployment: SunLab at 8.7 GWe and S\&L at 2.6 GWe. Heliostat costs for a range of deployment were calculated by S\&L as shown in Figure E-9. The impact on the heliostat cost between $1.4 \mathrm{GWe}$ and $4.7 \mathrm{GWe}$ is about 6\% for Solar 100 (2008), and $8.5 \%$ for Solar 220 (2018). 
Figure E-9 - Heliostat Cost per $\mathbf{m}^{2}$ versus Deployment

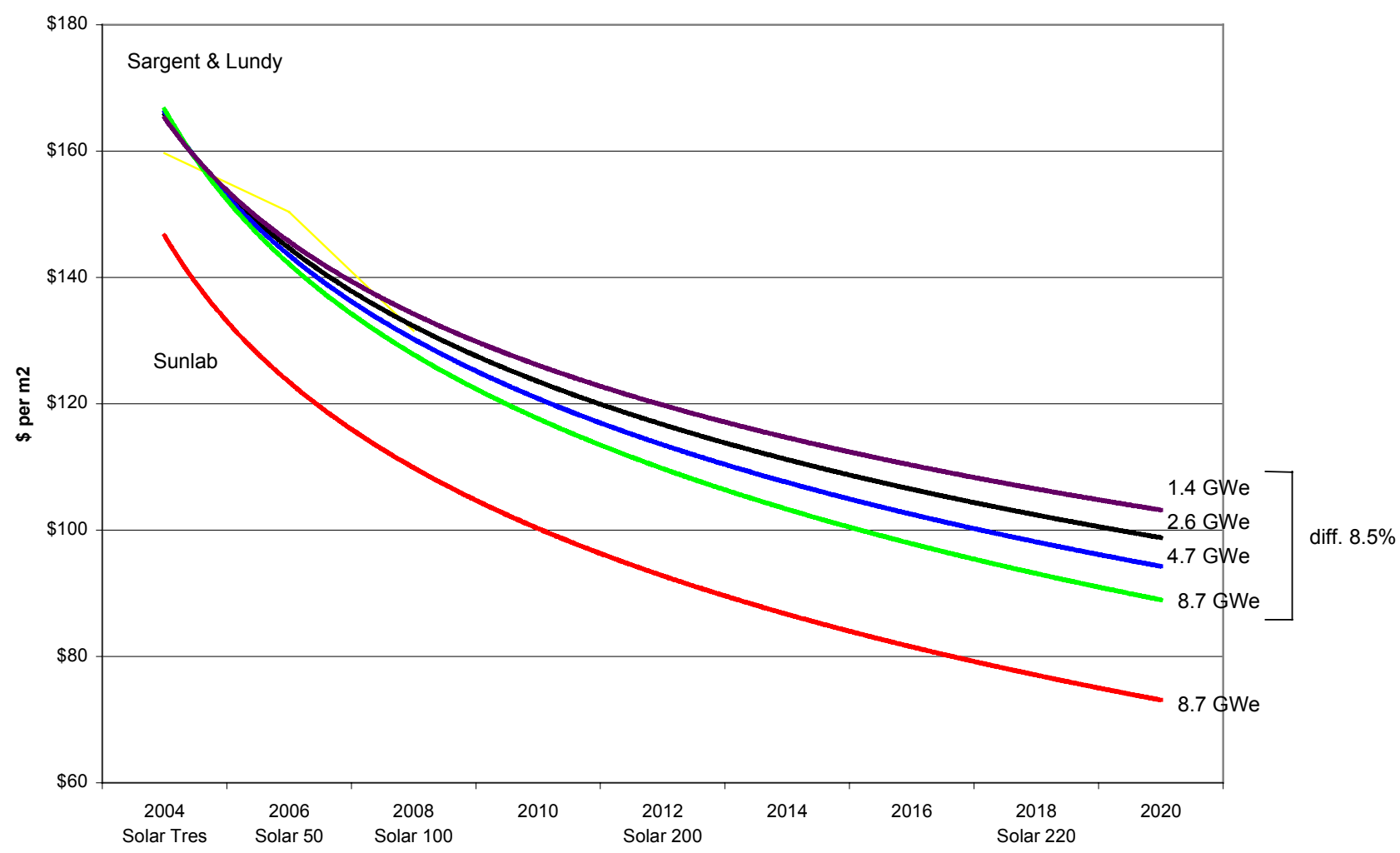

\section{E.4.6 Cost Improvements}

Cost improvements for heliostats are evaluated against three categories: technical (efficiency and design optimization), economy of scale and volume production. The cost reductions determined by S\&L for the heliostat are an average of $30 \%$ due to technical improvements, $19 \%$ for scale-up, and $51 \%$ for volume production. The cost improvements for heliostats based on each change in plant size are shown in Section E.4.7.

The methodology of determining the cost breakout for heliostats is shown in Section E.4.7. The three categories were reviewed, and $\mathrm{S} \& \mathrm{~L}$ assigned a percentage for each cost component. The total cost breakdown for the heliostat was then calculated based on the weighted average of the cost contribution of each component to the total cost. 


\section{E.4.7 Heliostat Cost Improvement Breakout by Category}

The heliostat cost improvement is summarized in the following table.

\section{Cost Improvement Summary}

\begin{tabular}{|l|c|c|c|c|c|c|}
\hline & $\begin{array}{c}\text { Solar Two to } \\
\text { Solar Tres }\end{array}$ & $\begin{array}{c}\text { Solar Tres to } \\
\text { Solar 50 }\end{array}$ & $\begin{array}{c}\text { Solar } \mathbf{5 0} \text { to } \\
\text { Solar } \mathbf{1 0 0}\end{array}$ & $\begin{array}{c}\text { Solar } \mathbf{1 0 0} \text { to } \\
\text { Solar 200 }\end{array}$ & $\begin{array}{c}\text { Solar 200 to } \\
\text { Solar 220 }\end{array}$ & Average \\
\hline Technical & $26 \%$ & $11 \%$ & $35 \%$ & $5 \%$ & $72 \%$ & $29.8 \%$ \\
\hline Scaling & $37 \%$ & $0 \%$ & $57 \%$ & $0 \%$ & $0 \%$ & $18.6 \%$ \\
\hline Volume & $37 \%$ & $89 \%$ & $8 \%$ & $95 \%$ & $28 \%$ & $51.4 \%$ \\
\hline
\end{tabular}

Table E-20 - Solar Two to Solar Tres: Heliostat Cost Improvement Breakout by Category

\begin{tabular}{|l|c|c|c|c|l|}
\hline Component & $\begin{array}{c}\text { Percent of } \\
\text { Total Cost }\end{array}$ & Technical & Scaling & $\begin{array}{c}\text { Volume } \\
\text { Production }\end{array}$ & Basis \\
\hline Mirrors & $8.6 \%$ & & & $100 \%$ & $\begin{array}{l}\text { The cost improvements are due to volume } \\
\text { productions }\end{array}$ \\
\hline Drive (azimuth) & $45.0 \%$ & $50 \%$ & $50 \%$ & $0 \%$ & $\begin{array}{l}\text { The design is based on enhancement of a } \\
\text { proven design. There will be technical } \\
\text { improvements. The scaling factor is based } \\
\text { on increasing the drive }\left(48 \mathrm{~m}^{2} \text { to } 95 \mathrm{~m}^{2}\right)\end{array}$ \\
\hline Drive (elevation) & $4.9 \%$ & $50 \%$ & $50 \%$ & $0 \%$ & $\begin{array}{l}\text { The design is based on enhancement of a } \\
\text { proven design. There will be technical } \\
\text { improvements. The scaling factor is based } \\
\text { on increasing the drive }\left(48 \mathrm{~m}^{2} \text { to } 95 \mathrm{~m}^{2}\right)\end{array}$ \\
\hline Structural Steel & $9.2 \%$ & $0 \%$ & $50 \%$ & $50 \%$ & $\begin{array}{l}\text { Cost improvement is based on purchasing } \\
\text { large quantities of commercially available } \\
\text { steel shapes and the scaling factor for a } \\
\text { larger structure }\left(48 \mathrm{~m}^{2} \text { to } 95 \mathrm{~m}^{2}\right)\end{array}$ \\
\hline Pedestal & $3.3 \%$ & $0 \%$ & $50 \%$ & $50 \%$ & $\begin{array}{l}\text { Cost improvement is based on purchasing } \\
\text { large quantities of commercially available } \\
\text { steel shapes and the scaling factor for a } \\
\text { larger structure }\left(48 \mathrm{~m}^{2} \text { to } 95 \mathrm{~m}^{2}\right)\end{array}$ \\
\hline Other & $1.3 \%$ & $0 \%$ & $50 \%$ & $50 \%$ & $\begin{array}{l}\text { Cost improvement based on scaling factor } \\
\text { (48 } \mathrm{m}^{2} \text { to 95 } \mathrm{m}^{2} \text { ) and volume production. }\end{array}$ \\
\hline Communications & $4.7 \%$ & $20 \%$ & $0 \%$ & $80 \%$ & $\begin{array}{l}\text { There will be technical improvements from } \\
\text { operating experience and better } \\
\text { production based on learning curve but } \\
\text { the majority of the cost improvement will } \\
\text { come from volume production. }\end{array}$ \\
\hline
\end{tabular}




\begin{tabular}{|l|c|c|c|c|l|}
\hline Component & $\begin{array}{c}\text { Percent of } \\
\text { Total Cost }\end{array}$ & Technical & Scaling & $\begin{array}{c}\text { Volume } \\
\text { Production }\end{array}$ & Basis \\
\hline Labor & $2.7 \%$ & $0 \%$ & $50 \%$ & $50 \%$ & $\begin{array}{l}\text { Cost improvement is based on scaling } \\
\text { factor }\left(48 \mathrm{~m}^{2} \text { to } 95 \mathrm{~m}^{2}\right) \text { and volume } \\
\text { production. }\end{array}$ \\
\hline $\begin{array}{l}\text { Capital Equipment } \\
\text { \& Tooling }\end{array}$ & $11.9 \%$ & $0 \%$ & $0 \%$ & $100 \%$ & $\begin{array}{l}\text { Cost improvement is based on better } \\
\text { production techniques and the majority on } \\
\text { volume production }\end{array}$ \\
\hline $\begin{array}{l}\text { Other Production } \\
\text { Costs }\end{array}$ & $2.3 \%$ & $0 \%$ & $0 \%$ & $100 \%$ & $\begin{array}{l}\text { Cost improvement is based on better } \\
\text { production techniques and the majority on } \\
\text { volume production }\end{array}$ \\
\hline $\begin{array}{l}\text { Installation } \\
\text { Pold Wiring }\end{array}$ & $3.9 \%$ & $0 \%$ & $50 \%$ & $50 \%$ & $\begin{array}{l}\text { Cost improvement is based on scaling } \\
\text { factor }\left(48 \mathrm{~m}^{2} \text { to } 95 \mathrm{~m}^{2}\right) \text { and volume } \\
\text { production. }\end{array}$ \\
\hline $\begin{array}{l}\text { Fotal (Weighted } \\
\text { Average) }\end{array}$ & - & $26 \%$ & $37 \%$ & $37 \%$ & $\begin{array}{l}\text { Cost improvement is based on scaling } \\
\text { factor }\left(48 \mathrm{~m}^{2} \text { to } 95 \mathrm{~m}^{2}\right) \text { and volume } \\
\text { production. }\end{array}$ \\
\hline
\end{tabular}


Table E-21 - Solar Tres to Solar 50:

Heliostat Cost Improvement Breakout by Category

\begin{tabular}{|c|c|c|c|c|c|}
\hline Component & $\begin{array}{l}\text { Percent of } \\
\text { Total Cost }\end{array}$ & Technical & Scaling & $\begin{array}{l}\text { Volume } \\
\text { Production }\end{array}$ & Basis \\
\hline Mirrors & $8.6 \%$ & $0 \%$ & $0 \%$ & $100 \%$ & $\begin{array}{l}\text { The cost improvements are due to volume } \\
\text { productions }\end{array}$ \\
\hline Drive (azimuth) & $45.0 \%$ & $20 \%$ & $0 \%$ & $80 \%$ & $\begin{array}{l}\text { The design is based on enhancement of a } \\
\text { proven design. There will be technical } \\
\text { improvements but the majority of } \\
\text { improvements will come from volume } \\
\text { production. }\end{array}$ \\
\hline Drive (elevation) & $4.9 \%$ & $20 \%$ & $0 \%$ & $80 \%$ & $\begin{array}{l}\text { The design is based on enhancement of a } \\
\text { proven design. There will be technical } \\
\text { improvements but the majority of the cost } \\
\text { improvements will come from volume } \\
\text { production. }\end{array}$ \\
\hline Structural Steel & $9.2 \%$ & $0 \%$ & $0 \%$ & $100 \%$ & $\begin{array}{l}\text { Cost improvement is based on purchasing } \\
\text { large quantities of commercially available } \\
\text { steel shapes. }\end{array}$ \\
\hline Pedestal & $3.3 \%$ & $0 \%$ & $0 \%$ & $100 \%$ & $\begin{array}{l}\text { Cost improvement is based on purchasing } \\
\text { large quantities of commercially available } \\
\text { steel shapes }\end{array}$ \\
\hline Other & $1.3 \%$ & $0 \%$ & $0 \%$ & $100 \%$ & $\begin{array}{l}\text { Cost improvement based on volume } \\
\text { production. }\end{array}$ \\
\hline Communications & $4.7 \%$ & $20 \%$ & $0 \%$ & $80 \%$ & $\begin{array}{l}\text { There will be technical improvements from } \\
\text { operating experience and better } \\
\text { production based on learning curve but } \\
\text { the majority of the cost improvement will } \\
\text { come from volume production. }\end{array}$ \\
\hline Labor & $2.7 \%$ & $0 \%$ & $0 \%$ & $100 \%$ & $\begin{array}{l}\text { All cost improvement is based on volume } \\
\text { production. }\end{array}$ \\
\hline $\begin{array}{l}\text { Capital Equipment } \\
\text { \& Tooling }\end{array}$ & $11.9 \%$ & $0 \%$ & $0 \%$ & $100 \%$ & $\begin{array}{l}\text { Cost improvement is based on better } \\
\text { production techniques and the majority on } \\
\text { volume production }\end{array}$ \\
\hline $\begin{array}{l}\text { Other Production } \\
\text { Costs }\end{array}$ & $2.3 \%$ & $0 \%$ & $0 \%$ & $100 \%$ & $\begin{array}{l}\text { Cost improvement is based on better } \\
\text { production techniques and the majority on } \\
\text { volume production }\end{array}$ \\
\hline Installation & $2.2 \%$ & $0 \%$ & $0 \%$ & $100 \%$ & $\begin{array}{l}\text { All cost improvement is based on volume } \\
\text { production }\end{array}$ \\
\hline Field Wiring & $3.9 \%$ & $0 \%$ & $0 \%$ & $100 \%$ & $\begin{array}{l}\text { All cost improvement is based on volume } \\
\text { production }\end{array}$ \\
\hline $\begin{array}{l}\text { Total (Weighted } \\
\text { Average) }\end{array}$ & - & $11 \%$ & $0 \%$ & $89 \%$ & \\
\hline
\end{tabular}


Table E-22 - Solar 50 to Solar 100:

Heliostat Cost Improvement Breakout by Category

\begin{tabular}{|c|c|c|c|c|c|}
\hline Component & $\begin{array}{l}\text { Percent of } \\
\text { Total Cost }\end{array}$ & Technical & Scaling & $\begin{array}{l}\text { Volume } \\
\text { Production }\end{array}$ & Basis \\
\hline Mirrors & $8.6 \%$ & $100 \%$ & $0 \%$ & $0 \%$ & $\begin{array}{l}\text { The cost improvements are due to } \\
\text { installation of thin mirrors to increase } \\
\text { reflectivity }\end{array}$ \\
\hline Drive (azimuth) & $45.0 \%$ & $50 \%$ & $50 \%$ & $0 \%$ & $\begin{array}{l}\text { The design is based on enhancement of a } \\
\text { proven design. There will be technical } \\
\text { improvements. The scaling factor is based } \\
\text { on increasing the drive }\left(95 \mathrm{~m}^{2} \text { to } 148 \mathrm{~m}^{2}\right)\end{array}$ \\
\hline Drive (elevation) & $4.9 \%$ & $50 \%$ & $50 \%$ & $0 \%$ & $\begin{array}{l}\text { The design is based on enhancement of a } \\
\text { proven design. There will be technical } \\
\text { improvements. The scaling factor is based } \\
\text { on increasing the drive }\left(95 \mathrm{~m}^{2} \text { to } 148 \mathrm{~m}^{2}\right)\end{array}$ \\
\hline Structural Steel & $9.2 \%$ & $20 \%$ & $80 \%$ & $0 \%$ & $\begin{array}{l}\text { Cost improvement is based on design } \\
\text { changes to accommodate the thin mirrors } \\
\text { and the scaling factor for a larger structure } \\
\left(95 \mathrm{~m}^{2} \text { to } 148 \mathrm{~m}^{2}\right)\end{array}$ \\
\hline Pedestal & $3.3 \%$ & $20 \%$ & $80 \%$ & $0 \%$ & $\begin{array}{l}\text { Cost improvement is based on design } \\
\text { changes to accommodate the thin mirrors } \\
\text { and the scaling factor for a larger structure } \\
\left(95 \mathrm{~m}^{2} \text { to } 148 \mathrm{~m}^{2}\right)\end{array}$ \\
\hline Other & $1.3 \%$ & $0 \%$ & $100 \%$ & $0 \%$ & $\begin{array}{l}\text { Cost improvement based on scaling factor } \\
\left(95 \mathrm{~m}^{2} \text { to } 148 \mathrm{~m}^{2}\right) \text { and volume production. }\end{array}$ \\
\hline Communications & $4.7 \%$ & $20 \%$ & $0 \%$ & $80 \%$ & $\begin{array}{l}\text { There will be technical improvements from } \\
\text { operating experience and better } \\
\text { production based on learning curve but } \\
\text { the majority of the cost improvement will } \\
\text { come from volume production. }\end{array}$ \\
\hline Labor & $2.7 \%$ & $0 \%$ & $100 \%$ & $0 \%$ & $\begin{array}{l}\text { Cost improvement is based on scaling } \\
\text { factor }\left(95 \mathrm{~m}^{2} \text { to } 148 \mathrm{~m}^{2}\right)\end{array}$ \\
\hline $\begin{array}{l}\text { Capital Equipment } \\
\& \text { Tooling }\end{array}$ & $11.9 \%$ & $0 \%$ & $0 \%$ & $100 \%$ & $\begin{array}{l}\text { Cost improvement is based on better } \\
\text { production techniques and the majority on } \\
\text { volume production }\end{array}$ \\
\hline $\begin{array}{l}\text { Other Production } \\
\text { Costs }\end{array}$ & $2.3 \%$ & $0 \%$ & $0 \%$ & $100 \%$ & $\begin{array}{l}\text { Cost improvement is based on better } \\
\text { production techniques and the majority on } \\
\text { volume production }\end{array}$ \\
\hline Installation & $2.2 \%$ & $0 \%$ & $100 \%$ & $0 \%$ & $\begin{array}{l}\text { Cost improvement is based on scaling } \\
\text { factor }\left(95 \mathrm{~m}^{2} \text { to } 148 \mathrm{~m}^{2}\right)\end{array}$ \\
\hline Field Wiring & $3.9 \%$ & $0 \%$ & $100 \%$ & $0 \%$ & $\begin{array}{l}\text { Cost improvement is based on scaling } \\
\text { factor }\left(95 \mathrm{~m}^{2} \text { to } 148 \mathrm{~m}^{2}\right)\end{array}$ \\
\hline $\begin{array}{l}\text { Total (Weighted } \\
\text { Average) }\end{array}$ & - & $35 \%$ & $57 \%$ & $8 \%$ & \\
\hline
\end{tabular}


Table E-23 - Solar 100 to Solar 200: Heliostat Cost Improvement Breakout by Category

\begin{tabular}{|c|c|c|c|c|c|}
\hline Component & $\begin{array}{l}\text { Percent of } \\
\text { Total Cost }\end{array}$ & Technical & Scaling & $\begin{array}{l}\text { Volume } \\
\text { Production }\end{array}$ & Basis \\
\hline Mirrors & $8.6 \%$ & $0 \%$ & $0 \%$ & $100 \%$ & $\begin{array}{l}\text { The cost improvements are due to volume } \\
\text { productions }\end{array}$ \\
\hline Drive (azimuth) & $45.0 \%$ & $10 \%$ & $0 \%$ & $90 \%$ & $\begin{array}{l}\text { The design is based on enhancement of a } \\
\text { proven design. There will be technical } \\
\text { improvements but the majority of } \\
\text { improvements will come from volume } \\
\text { production. }\end{array}$ \\
\hline Drive (elevation) & $4.9 \%$ & $10 \%$ & $0 \%$ & $90 \%$ & $\begin{array}{l}\text { The design is based on enhancement of a } \\
\text { proven design. There will be technical } \\
\text { improvements but the majority of the cost } \\
\text { improvements will come from volume } \\
\text { production. }\end{array}$ \\
\hline Structural Steel & $9.2 \%$ & $0 \%$ & $0 \%$ & $100 \%$ & $\begin{array}{l}\text { Cost improvement is based on purchasing } \\
\text { large quantities of commercially available } \\
\text { steel shapes. }\end{array}$ \\
\hline Pedestal & $3.3 \%$ & $0 \%$ & $0 \%$ & $100 \%$ & $\begin{array}{l}\text { Cost improvement is based on purchasing } \\
\text { large quantities of commercially available } \\
\text { steel shapes }\end{array}$ \\
\hline Other & $1.3 \%$ & $0 \%$ & $0 \%$ & $100 \%$ & $\begin{array}{l}\text { Cost improvement based on volume } \\
\text { production. }\end{array}$ \\
\hline Communications & $4.7 \%$ & $10 \%$ & $0 \%$ & $90 \%$ & $\begin{array}{l}\text { There will be technical improvements from } \\
\text { operating experience and better } \\
\text { production based on learning curve but } \\
\text { the majority of the cost improvement will } \\
\text { come from volume production. }\end{array}$ \\
\hline Labor & $2.7 \%$ & $0 \%$ & $0 \%$ & $100 \%$ & $\begin{array}{l}\text { All cost improvement is based on volume } \\
\text { production. }\end{array}$ \\
\hline $\begin{array}{l}\text { Capital Equipment } \\
\text { \& Tooling }\end{array}$ & $11.9 \%$ & $0 \%$ & $0 \%$ & $100 \%$ & $\begin{array}{l}\text { Cost improvement is based on better } \\
\text { production techniques and the majority on } \\
\text { volume production }\end{array}$ \\
\hline $\begin{array}{l}\text { Other Production } \\
\text { Costs }\end{array}$ & $2.3 \%$ & $0 \%$ & $0 \%$ & $100 \%$ & $\begin{array}{l}\text { Cost improvement is based on better } \\
\text { production techniques and the majority on } \\
\text { volume production }\end{array}$ \\
\hline Installation & $2.2 \%$ & $0 \%$ & $0 \%$ & $100 \%$ & $\begin{array}{l}\text { All cost improvement is based on volume } \\
\text { production }\end{array}$ \\
\hline Field Wiring & $3.9 \%$ & $0 \%$ & $0 \%$ & $100 \%$ & $\begin{array}{l}\text { All cost improvement is based on volume } \\
\text { production }\end{array}$ \\
\hline $\begin{array}{l}\text { Total (Weighted } \\
\text { Average) }\end{array}$ & - & $5 \%$ & $0 \%$ & $95 \%$ & \\
\hline
\end{tabular}


Table E-24 - Solar 200 to Solar 220:

Heliostat Cost Improvement Breakout by Category

\begin{tabular}{|c|c|c|c|c|c|}
\hline Component & $\begin{array}{l}\text { Percent of } \\
\text { Total Cost }\end{array}$ & Technical & Scaling & $\begin{array}{l}\text { Volume } \\
\text { Production }\end{array}$ & Basis \\
\hline Mirrors & $8.6 \%$ & $100 \%$ & $0 \%$ & $0 \%$ & $\begin{array}{l}\text { The cost improvements are technical } \\
\text { advances in developing an enhanced } \\
\text { heliostat }\end{array}$ \\
\hline Drive (azimuth) & $45.0 \%$ & $100 \%$ & $0 \%$ & $0 \%$ & $\begin{array}{l}\text { The cost improvements are technical } \\
\text { advances in developing an enhanced } \\
\text { heliostat }\end{array}$ \\
\hline Drive (elevation) & $4.9 \%$ & $100 \%$ & $0 \%$ & $0 \%$ & $\begin{array}{l}\text { The cost improvements are technical } \\
\text { advances in developing an enhanced } \\
\text { heliostat }\end{array}$ \\
\hline Structural Steel & $9.2 \%$ & $100 \%$ & $0 \%$ & $0 \%$ & $\begin{array}{l}\text { The cost improvements are technical } \\
\text { advances in developing an enhanced } \\
\text { heliostat }\end{array}$ \\
\hline Pedestal & $3.3 \%$ & $100 \%$ & $0 \%$ & $0 \%$ & $\begin{array}{l}\text { The cost improvements are technical } \\
\text { advances in developing an enhanced } \\
\text { heliostat }\end{array}$ \\
\hline Other & $1.3 \%$ & $0 \%$ & $0 \%$ & $100 \%$ & $\begin{array}{l}\text { Cost improvement based on volume } \\
\text { production. }\end{array}$ \\
\hline Communications & $4.7 \%$ & $10 \%$ & $0 \%$ & $90 \%$ & $\begin{array}{l}\text { There will be technical improvements from } \\
\text { operating experience and better } \\
\text { production based on learning curve but } \\
\text { the majority of the cost improvement will } \\
\text { come from volume production. }\end{array}$ \\
\hline Labor & $2.7 \%$ & $0 \%$ & $0 \%$ & $100 \%$ & $\begin{array}{l}\text { All cost improvement is based on volume } \\
\text { production. }\end{array}$ \\
\hline $\begin{array}{l}\text { Capital Equipment } \\
\text { \& Tooling }\end{array}$ & $11.9 \%$ & $0 \%$ & $0 \%$ & $100 \%$ & $\begin{array}{l}\text { Cost improvement is based on better } \\
\text { production techniques and the majority on } \\
\text { volume production }\end{array}$ \\
\hline $\begin{array}{l}\text { Other Production } \\
\text { Costs }\end{array}$ & $2.3 \%$ & $0 \%$ & $0 \%$ & $100 \%$ & $\begin{array}{l}\text { Cost improvement is based on better } \\
\text { production techniques and the majority on } \\
\text { volume production }\end{array}$ \\
\hline Installation & $2.2 \%$ & $0 \%$ & $0 \%$ & $100 \%$ & $\begin{array}{l}\text { All cost improvement is based on volume } \\
\text { production }\end{array}$ \\
\hline Field Wiring & $3.9 \%$ & $0 \%$ & $0 \%$ & $100 \%$ & $\begin{array}{l}\text { All cost improvement is based on volume } \\
\text { production }\end{array}$ \\
\hline $\begin{array}{l}\text { Total (Weighted } \\
\text { Average) }\end{array}$ & 一 & $72 \%$ & $0 \%$ & $28 \%$ & \\
\hline
\end{tabular}




\section{E.5 POWER TOWER HELIOSTAT COST EVALUATION}

\section{E.5.1 Mirrors}

Mirror costs in the SunLab model are essentially the same as ADL for one plant deployment as shown in Table E-25. The mirror cost estimate has a medium to high degree of accuracy based on vendor supplied pricing quotes. The mid point of the range of quotes $\$ 1.00$ to $\$ 1.50$ per $\mathrm{ft}^{2}$ was used by ADL. The cost improvement estimate based on quantity purchasing is a reasonable. The key difference between normal glass and that used for heliostats is that normal glass has iron whereas solar glass uses low iron. The manufacturers have the capability to manufacturer the glass, but the higher cost is due to a premium for shutting down production of normal glass and resetting for a production run of solar glass. Higher quantity of demand will increase the production run time for solar applications and reduce the premium cost. The SunLab estimate for cost improvement is $\$ 0.95$ per $\mathrm{ft}^{2}$ which is conservative since it is about twice the cost of normal glass of $\$ 0.47$ per $\mathrm{ft}^{2}$ estimated by Head West Inc. (Arthur D. Little 2001), which still allows for $\$ 0.48$ per $\mathrm{ft}^{2}$ premium for manufacturing production runs (see Table E-25).

Glass mirrors are expensive and heavy. Research in alternate mirrors is required to reduce costs. The new mirrors must have the same or better optical quality and have the same durability as glass mirrors. Glass mirrors have proven at SEGS and the Solar demonstration plants have shown that with proper design there has been no long-term degradation of the reflective quality. The alternate glass must be able to withstand continuous washing without damaging the reflective surface. The SunLab model does not assume a technology change to lighter glass until Solar 200.

Table E-25 - Mirrors: Cost Comparison between SunLab and ADL

\begin{tabular}{|c|c|c|c|c|}
\hline \multirow[b]{2}{*}{ Mirrors } & \multicolumn{2}{|c|}{ SunLab } & \multicolumn{2}{|c|}{ AD Little } \\
\hline & Cost & $\begin{array}{l}\text { Production } \\
\text { Volume } \\
\text { (cumulative) }\end{array}$ & Cost & $\begin{array}{l}\text { Production } \\
\text { Volume } \\
\text { (annual) }\end{array}$ \\
\hline Base Plant & $\begin{array}{c}\$ 1.21{\text { per } \mathrm{ft}^{2}}^{2} \\
\left(\$ 13.02{\left.\text { per } \mathrm{m}^{2}\right)}^{2}\right.\end{array}$ & $\begin{array}{l}227,000 \mathrm{~m}^{2} \\
(1,534 \text { units })\end{array}$ & $\begin{array}{c}\$ 1.24{\text { per } \mathrm{ft}^{2}}^{2} \\
\left(\$ 13.35 \text { per } \mathrm{m}^{2}\right)\end{array}$ & $\begin{array}{l}440,000 \mathrm{~m}^{2} \\
(3,000 \text { units })\end{array}$ \\
\hline $\begin{array}{l}\text { Production Cost } \\
\text { Improvement }\end{array}$ & $\begin{array}{c}\$ 0.95{\text { per } \mathrm{ft}^{2}}^{2} \\
\left(\$ 10.20{\left.\text { per } \mathrm{m}^{2}\right)}^{2}\right.\end{array}$ & $\begin{array}{l}100,000,000 \mathrm{~m}^{2} \\
(675,676 \text { units })\end{array}$ & Not Studied & $\begin{array}{l}4,440,000 \mathrm{~m}^{2} \\
(30,000 \text { units })\end{array}$ \\
\hline Description & \multicolumn{4}{|c|}{$\begin{array}{l}\text { Single sheet mirror construction. There are four mirror assemblies with } 25 \\
4^{\prime} \times 4^{\prime}\left(1.49 \mathrm{~m}^{2}\right) \text { mirrors for a total of } 100 \text { mirrors. }\end{array}$} \\
\hline
\end{tabular}




\section{E.5.2 Mirror Assembly}

The mirror assembly is not a complex structure. The cross members and hat sections are commercially available and are assembled by welding. There are four mirror assemblies with $254^{\prime} \mathrm{x} 4^{\prime}\left(1.49 \mathrm{~m}^{2}\right)$ mirrors for a total of 100 mirrors. The mirrors, which are commercially available low lead reflective glass, are attached with RTV. The only risk is the integrity of the bond between the mirrors and metal. This risk is low; these are the same mirrors as SEGS and the RTV is upgraded based on improvements developed to solve wind damage.

The carousel assembly system for mirrors has been used in the construction of about 13,000 mirror modules for $95 \mathrm{~m}^{2}$ trackers. The assembly of mirror will take place in a $10,000-\mathrm{ft}^{2}$ building at or near the plant site. The details of the facility, equipment, process sequence, man-loading and time sequence is provided the SolMaT study done by Solar Kinetics, Inc. (1996) for $148 \mathrm{~m}^{2}$. Solar Kinetics has independently documented their approach in the "Mirror Module Assembly Plan." The results of the study are summarized below:

- A list of major equipment required to build mirror modules is provided but there is no cost estimate. ATS stated that the \$1 million estimate used by SunLab was reasonable.

- Mirror module assembly estimate is 17 man-hours, which includes $10 \%$ fringe time and $20 \%$ down time. The estimate is based on 1,000 heliostats per year with two 6-day shifts working for 32 weeks (5.5 per shift: 3.5 workers, 1 supervisor, and 1 QA inspector. The SunLab estimate is 24 man-hours.

- The rack assemble consists of the pedestal, torque tube assembly and rack. The 'rack' is everything above the pedestal. The materials are commercially available and assembled by welding.

\section{E.5.3 Drives}

The estimated cost of the drive and cost improvement from production volume are essentially the same as the ADL study as shown in Table E-26. ADL's conclusion is based on discussions with vendors, specifically Peerless Winsmith and Hub City. ADL identified in their report that improvement in drive costs "are possible at higher volumes because this amount of business can justify a dedicated production facility." ADL assumptions were $\$ 6,000$ per unit for 1,000 annual production $\$ 4,000$ per unit for 3,000 annual production, and $\$ 3,000$ per unit for 30,000 annual production. The difference between the costs is that the SunLab cost estimate included a rotary azimuth drive and elevation drive whereas the ADL cost estimate included a dual axis drive. 
Table E-26 - Drives: Cost Comparison between SunLab and ADL

\begin{tabular}{|l|c|c|c|c|}
\hline \multirow{2}{*}{ Drives } & \multicolumn{2}{|c|}{ SunLab } & \multicolumn{2}{c|}{ AD Little } \\
\cline { 2 - 5 } & Cost & $\begin{array}{c}\text { Production } \\
\text { Volume } \\
\text { (cumulative) }\end{array}$ & Cost & $\begin{array}{c}\text { Production } \\
\text { Volume } \\
\text { (annual) }\end{array}$ \\
\hline Base Plant & $\$ 5,885$ & $\begin{array}{c}227,000 \mathrm{~m}^{2} \\
(1,534 \text { units) }\end{array}$ & $\$ 4,000$ & $\begin{array}{c}440,000 \mathrm{~m}^{2} \\
\left(3,000 \text { units }^{2}\right.\end{array}$ \\
\hline $\begin{array}{l}\text { Production Cost } \\
\text { Improvement }\end{array}$ & $\$ 3,030$ & $\begin{array}{c}100,000,000 \mathrm{~m}^{2} \\
(675,676 \text { units })\end{array}$ & $\$ 3,000$ & $\begin{array}{c}4,440,000 \mathrm{~m}^{2} \\
(30,000 \text { units })\end{array}$ \\
\hline Description & \multicolumn{3}{|l}{$\begin{array}{l}\text { The current technology solution of ball screw, worm gear, or hydraulic } \\
\text { drives for the azimuth and elevation drives. SunLab drive consists of a } \\
\text { lower cost azimuth drive developed by Peerless Winsmith and a separate } \\
\text { elevation drive. The ADL cost study included a single axis drive. }\end{array}$} \\
\hline
\end{tabular}

The next generation drive (Solar Tres) design is a planocentric azimuth drive coupled with a scissor joint and ball screw actuator. NREL contracted with Peerless-Winsmith in 1996 to define and develop the manufacturing procedures and costs for a dual axis drive system with focus on more accurate cost information (DFMA Workshop, contract ACG-5-15209-01). Peerless-Winsmith has designed this lower cost drive for Sandia, and therefore, DOE owns the rights to the drive. The drives are still in the development stage; about ten drives have been built. Peerless-Winsmith has a contract presently to provide detailed price projections for 1,500 units. Winsmith developed new cost data for the low cost azimuth solar drive in October 1999 "Enhanced Azimuth Solar Drive Project for Sandia National Laboratories," Contract Number BF-0031. The azimuth solar drive reflects the latest changes and improvements of the azimuth drive design, including o-ring seals and replacing the power transfer chain with eccentric drive shafts. The cost data were based on a detailed material list of parts, labor, and cost for pattern \& tooling and cost improvements up to 500 units (see Table E-27). These costs are provided by the manufacturer based on detailed design and therefore have a fairly high accuracy. Winsmith stated, "The project team feels that given even higher quantities, further cost improvements can be obtained with higher tooling and equipment outlays." 
Table E-27 - Peerless Cost Estimates for Drives

\begin{tabular}{|l|c|c|c|c|c|c|}
\hline & \multicolumn{3}{|c|}{ Cost for Ten Units } & \multicolumn{3}{c|}{ Cost for 500 Units } \\
\cline { 2 - 7 } & Unit Cost & $\begin{array}{c}\text { Pattern \& } \\
\text { Tooling }\end{array}$ & Total Cost & Unit Cost & $\begin{array}{c}\text { Pattern \& } \\
\text { Tooling }\end{array}$ & Total Cost \\
\hline $\begin{array}{l}\text { Worm \& } \\
\text { planocentric }\end{array}$ & $\$ 5,331$ & $\begin{array}{c}\$ 14,595 / 10= \\
\$ 1,460\end{array}$ & $\$ 6,791$ & $\$ 4,064$ & $\begin{array}{c}\$ 44,385 / 500 \\
=\$ 89\end{array}$ & $\$ 4,153$ \\
\hline $\begin{array}{l}\text { Planetary \& } \\
\text { planocentric }\end{array}$ & $\$ 5,377$ & $\begin{array}{c}\$ 14,595 / 10= \\
\$ 1,460\end{array}$ & $\$ 6,797$ & $\$ 4,035$ & $\begin{array}{c}\$ 44,385 / 500 \\
=\$ 89\end{array}$ & $\$ 4,124$ \\
\hline
\end{tabular}

Peerless-Winsmith designed, developed, and tested an azimuth drive in 1987 to handle loads for the $148-\mathrm{m}^{2}$ heliostat. The drive has been used for various applications, including a few prototype trackers, a prototype ATS heliostat located at Sandia, and a few units for testing. The estimated cost (see Table E-28) for the next generation heliostat drive (Solar Tres) is reasonable based on the following:

- Peerless cost estimate for the $148-\mathrm{m}^{2}$ azimuth drive (500 units) is $\$ 4,150$ per unit. This is for a two-stage azimuth drive only, not for elevation drive.

- SunLab cost estimate for the $148-\mathrm{m}^{2}$ azimuth drive (1,534 units) is $\$ 4,035$ per unit.

- Comparison of the SunLab cost estimate for $95 \mathrm{~m}^{2}$ and $148 \mathrm{~m}^{2}$ indicates a scaling factor of 0.62 based on weight (see Table E-28). This is within the range of an acceptable assumption.

- Nook industries quoted a cost of $\$ 805$ for 500 ball screws (elevation drives) for the $95-\mathrm{m}^{2}$ heliostats.

Table E-28 - Economy of Scale between the $95-\mathrm{m}^{2}$ and $148-\mathrm{m}^{2}$ Heliostat Drives

\begin{tabular}{|l|c|c|}
\hline Heliostat Size $\left(\mathrm{m}^{2}\right)$ & $\mathbf{9 5}$ & $\mathbf{1 4 8}$ \\
\hline Heliostat Weight & 10,890 & 16,490 \\
\hline Rotary azimuth drive & $\$ 3,400$ & $\$ 4,035$ \\
\hline Elevation drive pivot structure & $\$ 400$ & $\$ 600$ \\
\hline Elevation drive actuator & $\$ 750$ & $\$ 1,250$ \\
\hline Total Drive Cost & $\$ 4,550$ & $\$ 5,885$ \\
\hline Scaling factor based on weight & - & 0.62 \\
\hline
\end{tabular}




\section{E.5.4 Control and Communications}

The SunLab cost estimate for control and communications is shown in Table E-29. ADL did not include the cost of control \& communication in their estimate.

Table E-29 - Control \& Communications Cost

\begin{tabular}{|c|c|c|c|c|}
\hline \multirow{2}{*}{$\begin{array}{l}\text { Control \& } \\
\text { Communication }\end{array}$} & SunLab & & AD Little & \\
\hline & Cost & $\begin{array}{l}\text { Production } \\
\text { Volume }\end{array}$ & Cost & $\begin{array}{l}\text { Production } \\
\text { Volume }\end{array}$ \\
\hline Base Plant & $\$ 875$ & $\begin{array}{l}227,000 \mathrm{~m}^{2} \\
(1,534 \text { units })\end{array}$ & $\begin{array}{c}\text { Not } \\
\text { included }\end{array}$ & - \\
\hline $\begin{array}{l}\text { Production Cost } \\
\text { Improvement }\end{array}$ & $\$ 640$ & $\begin{array}{l}100,000,000 \mathrm{~m}^{2} \\
(675,676 \text { units })\end{array}$ & - & - \\
\hline
\end{tabular}

The SunLab estimate is based on the following:

- $\quad$ Logic Board \& Controller: base is $\$ 300 /$ production improvement is $\$ 130$.

- $\quad$ Encoders, wiring \& enclosure - base is $\$ 305$ / production is $\$ 260$.

- $\quad$ Two DC motors - base is $\$ 270$ / production is $\$ 250$.

The cost improvements projected by SunLab are reasonable. The largest contributor to the cost improvement is the logic board \& controller. The electronics business has shown significant cost improvements with increases in production (computer technology is an excellent example). The cost improvement has a progress ratio of 0.88 , which is a conservative assumption. Average module technologies based on electronics are 0.80 (Neij 1997). The other cost improvements are within the range of expected cost improvements: encoders, wiring \& enclosure - progress ratio of 0.98 and DC motors - progress ratio of 0.99 .

\section{E.5.5 Production (Shop) Fabrication}

The cost comparison for production fabrication costs is shown in Table E-30. 
Table E-30 - Production Fabrication Cost Comparison between SunLab and ADL

\begin{tabular}{|l|c|c|c|c|}
\hline \multirow{2}{*}{ Shop Fabrication } & \multicolumn{2}{|c|}{ SunLab } & \multicolumn{2}{c|}{ AD Little } \\
\cline { 2 - 5 } & Cost & $\begin{array}{c}\text { Production } \\
\text { Volume }\end{array}$ & Cost & $\begin{array}{c}\text { Production } \\
\text { Volume }\end{array}$ \\
\hline Base Plant & $\$ 800$ & $\begin{array}{c}227,000 \mathrm{~m}^{2} \\
(1,534 \text { units })\end{array}$ & $\$ 1,552$ & - \\
\hline $\begin{array}{l}\text { Production Cost } \\
\text { Improvement }\end{array}$ & $\$ 345$ & $\begin{array}{c}100,000,000 \mathrm{~m}^{2} \\
(675,676 \text { units })\end{array}$ & - & - \\
\hline
\end{tabular}

The SunLab cost estimate is based on the following assumptions shown in Table E-31:

Table E-31 - SunLab Assumptions

\begin{tabular}{|l|c|c|}
\hline Activity & Base Case & Production Volume \\
\hline Mirror Support & $8 \mathrm{mhrs}$ & $4.9 \mathrm{mhrs}$ \\
\hline Mirror Modules & $24 \mathrm{mhrs}$ & $8.9 \mathrm{mhrs}$ \\
\hline Total Manufacturing & $32 \mathrm{mhrs}$ & $14 \mathrm{mhrs}$ \\
\hline Labor Rate (including benefits) & $\$ 25$ & $\$ 25$ \\
\hline
\end{tabular}

The ADL cost estimate is based on the following assumptions:

- $\quad$ Labor cost (direct and indirect): $\$ 1,552$

- Labor Rate (including benefits): Assembly - \$12 per hour; Skilled Labor - \$18 per hour; Average $\$ 15$ per hour.

- Total manufacturing (direct and indirect): $103 \mathrm{mhrs}(\$ 1,552 / \$ 15)$

The Solar Kinetics, Inc. cost estimate is based on the following assumptions:

- A list of major equipment required to build mirror modules is provided but there is no cost estimate.

- Heliostat assembly estimate is 18 man-hours (not including painting, final assembly and checkout, which SKI estimates at $1+3.3+1=5.3$ hours or 23 hours total), which includes $10 \%$ fringe time and $20 \%$ down time. The estimate is based on 1,000 heliostats per year with two 6day shifts working for 32 weeks ( 6 per shift: 5 workers and 1 supervisor). 
SunLab projection for the base case is reasonable based on the following observations:

- The estimate for assembly hours (18 hrs) studied by Solar Kinetics is less than SunLab.

- The ADL study can not be used as a comparison since it includes direct and indirect costs.

- SunLab model is based on setting up the production facility at the site. ADL study is based on setting up an independent production facility.

SunLab projection for volume production cost improvements is optimistic based on the following observations:

- The Solar Kinetic estimate of $18 \mathrm{mnhrs}$ is based on 1,000 heliostats per year. It is not likely that there will be a significant improvement in manhours as a result of increasing production by a factor of 6 .

\section{E.5.6 Installation}

The installation cost estimate and comparison between SunLab and ADL is shown in Table E-32.

Table E-32 - Installation Costs Comparison between SunLab and ADL

\begin{tabular}{|l|c|c|c|c|}
\hline \multirow{2}{*}{$\begin{array}{l}\text { Installation \& } \\
\text { Checkout }\end{array}$} & \multicolumn{2}{|c|}{ SunLab } & \multicolumn{2}{c|}{ AD Little } \\
\cline { 2 - 5 } & Cost & $\begin{array}{c}\text { Production } \\
\text { Volume } \\
\text { (cumulative) }\end{array}$ & Cost & $\begin{array}{c}\text { Production } \\
\text { Volume }\end{array}$ \\
\hline Base Plant & $\$ 1,827$ & $\begin{array}{c}227,000 \mathrm{~m}^{2} \\
(1,534 \text { units) }\end{array}$ & $\$ 1,427$ & - \\
\hline $\begin{array}{l}\text { Production Cost } \\
\text { Improvement }\end{array}$ & $\$ 1,167$ & $\begin{array}{c}100,000,000 \mathrm{~m}^{2} \\
(675,676 \text { units) }\end{array}$ & - & - \\
\hline
\end{tabular}

The SunLab cost estimate is based on the following assumptions shown in Table E-33:

Table E-33 - SunLab Cost Assumptions

\begin{tabular}{|l|c|c|}
\hline Activity & Base Case & Production Volume \\
\hline Foundation & $\$ 200$ & $\$ 153$ \\
\hline Installation & & \\
\hline Pedestal & $3 \mathrm{mhrs}$ & $2.3 \mathrm{mhrs}$ \\
\hline Paint & $2 \mathrm{mhrs}$ & $1.5 \mathrm{mhrs}$ \\
\hline Final Assembly & $24 \mathrm{mhrs}$ & $8.9 \mathrm{mhrs}$ \\
\hline
\end{tabular}




\begin{tabular}{|l|c|c|}
\hline Activity & Base Case & Production Volume \\
\hline Checkout/Startup & $1 \mathrm{mhr}$ & $1 \mathrm{mhr}$ \\
\hline Total Installation & $30 \mathrm{mhrs}$ & $15 \mathrm{mhrs}$ \\
\hline Labor Rate (including benefits) & $\$ 25$ & $\$ 25$ \\
\hline Field Wiring & $\$ 877$ & $\$ 671$ \\
\hline
\end{tabular}

The ADL study was based on discussions with construction companies and their 2001 CostWorks analysis. The assumptions are as follows:

- Installation: 4 hours with 3 workers $=12$ man-hours

- $\quad$ Labor Rate (including benefits): $\$ 15$

- Vendor quote to drill hole, place pedestal and concrete: $\$ 800$

- Cost of aerial lift: $\$ 447$ (based on about 4 lifts a day at 5 ton crane rental of $\$ 1,738$ per day)

Note that the ADL study for installation cost does not add up correctly: $(12 \mathrm{mhrs} \times \$ 15=\$ 180)$ plus $(\$ 800)$ plus (\$447) equals $\$ 1,427$ not $\$ 2,072$

The SunLab cost projection for the base case is lower than expected based on the following observations:

- Comparison of the ADL and the SunLab cost estimates corrected for labor rate and field wiring indicate that ADL is higher (ADL is $\$ 1,622$ and SunLab is $\$ 950$ )

- The ADL cost estimate is based on vendor quotes

The SunLab cost projection for volume is optimistic based on the following observations. S\&L adjusted their cost estimate to compensate for these.

- The main cost improvement is the final assembly from 24 man-hours to 8.9 man-hours, which is not realistic. Cost improvements would only be expected with improvement in assembly techniques, equipment, and tools and there is really not much to improve for the installation process.

- Man-hour improvements are not as easily achieved for a construction activity as for a manufacturing process.

\section{E.5.7 Structural Steel, Pedestal and Other}

The SunLab cost projection for the base case (see Table E-34) is reasonable based on the following observations: 
- $\quad$ There is a difference of $\$ 289$ per unit for material costs of the structural steel, pedestal and other (see Table E-34). The difference is a result of two different cost estimating methods and is not significant ( $1.8 \%$ of total fabrication cost).

- The estimate is based on actual design drawings and material costs

\section{Table E-34 — Structural Steel and Pedestal Cost Comparison}

\begin{tabular}{|l|c|c|}
\hline $\begin{array}{l}\text { Structural Steel, } \\
\text { Pedestal, \& Other }\end{array}$ & $\begin{array}{c}\text { SunLab } \\
\text { Base Plant }\end{array}$ & $\begin{array}{c}\text { AD Little } \\
\text { Base Plant }\end{array}$ \\
\hline Structural Steel & $\$ 3,412$ & $\$ 2,122$ \\
\hline Pedestal & $\$ 1,705$ & $\$ 1,330$ \\
\hline Other & $\$ 770$ & $\$ 2,146$ \\
\hline \multicolumn{1}{|c|}{ Total } & $\$ 5,887$ & $\$ 5,598$ \\
\hline
\end{tabular}

The SunLab cost projection for volume is optimistic based on the following observations. S\&L adjusted their cost estimate to compensate for this.

- SunLab projects a 5\% weight improvement in the structural steel and pedestal based on a more rigorous design and analysis. The cost improvement is from $\$ 138$ per $\mathrm{m}^{2}$ to $\$ 127 \mathrm{per}^{2}$. There was no objective information to evaluate this cost improvement.

\section{E.5.8 Overhead and Profit}

Table E-35 - Overhead and Profit

\begin{tabular}{|l|c|c|c|c|}
\hline \multirow{2}{*}{} & \multicolumn{2}{|c|}{ SunLab } & \multicolumn{2}{c|}{ AD Little } \\
\cline { 2 - 5 } & Base Plant & $\begin{array}{c}\text { Production Cost } \\
\text { Improvement }\end{array}$ & Base Plant & $\begin{array}{c}\text { Production Cost } \\
\text { Improvement }\end{array}$ \\
\hline Overhead and Profit & $15 \%$ & $15 \%$ & $25 \%$ & N/A \\
\hline Fixed Costs & $\$ 5.83$ per unit & $\$ 1.60$ per unit & $\begin{array}{c}\text { Included in } \\
\text { Overhead and } \\
\text { Profit }\end{array}$ & - \\
\hline
\end{tabular}

The financial assumptions for ADL are shown below: 
Table E-36 - Financial Assumptions for ADL

\begin{tabular}{|l|l|}
\hline Equipment Depreciation & 7 years \\
\hline Cost of Capital & $15 \%$ \\
\hline Sales \& Distribution & $4 \%$ of sales \\
\hline General \& Administrative & $8 \%$ of sales \\
\hline R\&D & $0 \%$ of sales \\
\hline Insurance & $1 \%$ of sales \\
\hline Federal Taxes & $3 \%$ of sales \\
\hline State Taxes & $1 \%$ of sales \\
\hline Net Profit & $8 \%$ of sales \\
\hline Corporate Overhead & $25 \%$ of sales \\
\hline
\end{tabular}

The SunLab cost estimate is low based on the ADL cost estimate. S\&L adjusted their estimate to compensate for this.

\section{E.5.9 Capital Equipment and Tooling}

Table E-37 - Capital Equipment and Tooling

\begin{tabular}{|l|c|c|}
\hline $\begin{array}{l}\text { Capital Equipment and } \\
\text { Tooling }\end{array}$ & $\begin{array}{c}\text { SunLab Base } \\
\text { Plant }\end{array}$ & $\begin{array}{c}\text { AD Little } \\
\text { Base Plant }\end{array}$ \\
\hline Production & 1,534 & 3,000 \\
\hline Engineering Design & $\$ 259,000$ & - \\
\hline $\begin{array}{l}\text { Manufacturing Facilities and } \\
\text { Tooling }\end{array}$ & $\$ 800,000$ & - \\
\hline Equipment Lease & $\$ 200,000$ & - \\
\hline $\begin{array}{l}\text { Field Computer and BCS } \\
\text { System }\end{array}$ & $\$ 150,000$ & - \\
\hline Total & $\$ 1,400,000$ & $\$ 903,000$ \\
\hline Cost per Heliostat & $\$ 912.65$ & $\$ 301$ \\
\hline
\end{tabular}

The SunLab cost estimate is slightly less than the value shown in Table E-37. S\&L adjusted their cost estimate to compensate for this. 
The difference is attributed to ADL basing their cost on a supplier setting up a manufacturing facility whereas SunLab's estimate is based on a local assembly shop associated with the construction project.

Cost improvements based on volume production are shown in Figure E-10.

Figure E-10 - Heliostat Capital Cost and Equipment Cost Reductions

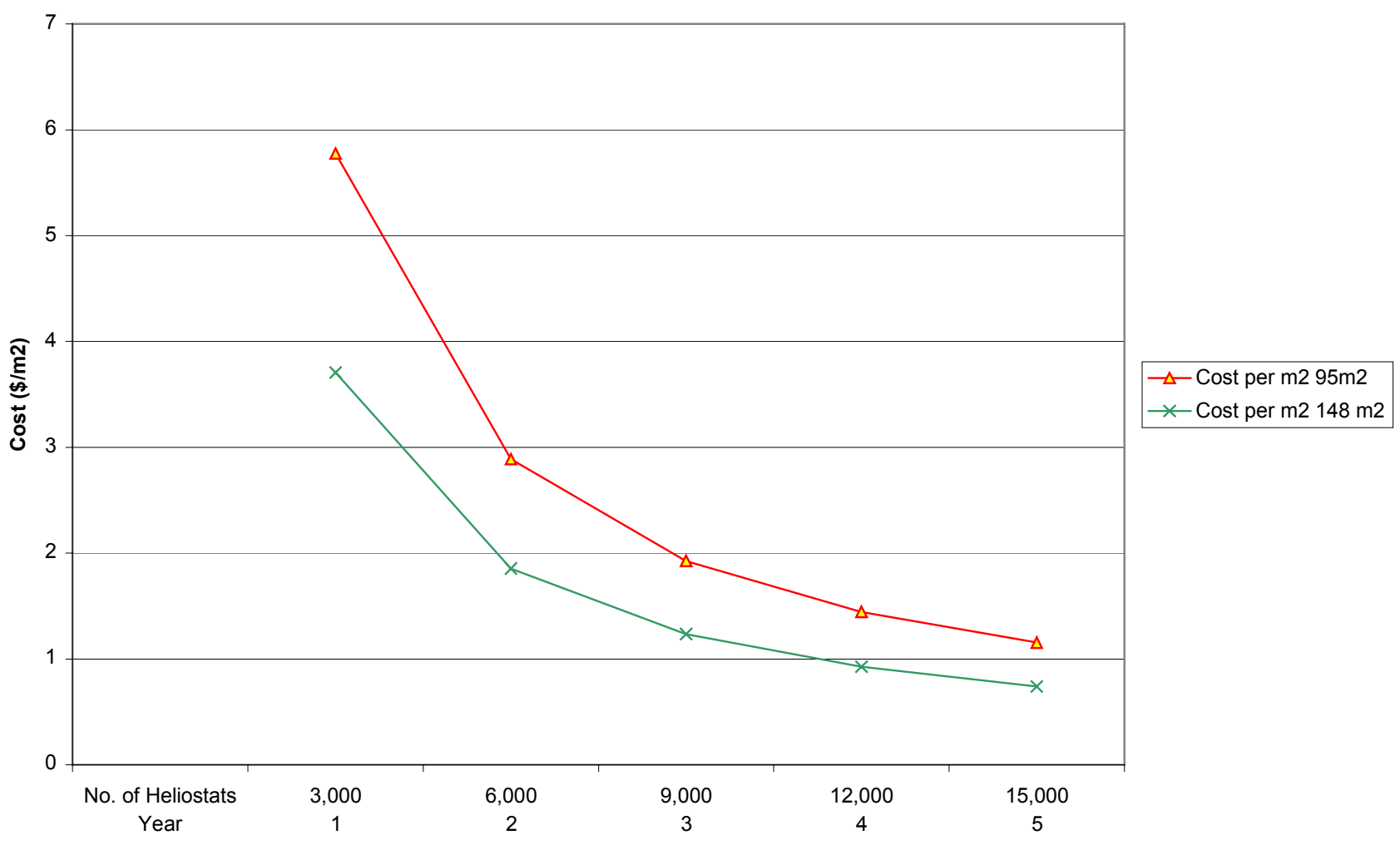

\section{E.6 ELECTRICAL POWER BLOCK}

\section{E.6.1 Capital Cost}

Sargent \& Lundy estimated the cost for the power block based on the SOAPP model, ${ }^{*}$ compared it to our internal database, and then adjusted the output for labor and productivity rates in the Southwest. The results of

\footnotetext{
* EPRI SOAPP is a fully integrated program for technology evaluation, conceptual design, costing, and financial analysis of combustion-turbine-based power plants for project and proposal development. SOAPP-CT integrates process design, costing, and financial analysis of combustion turbine simple- and combined-cycle power plants, including cogeneration. Sargent \& Lundy developed SOAPP under contract to EPRI.
} 
our review are shown in Table E-38 and Figure E-11. The power block costs include the steam turbine and generator, steam turbine and generator auxiliaries, feedwater, and condensate systems.

Table E-38 - Capital Cost of Electrical Power Block

\begin{tabular}{|c|c|c|c|c|c|c|c|}
\hline & & Solar Two & Solar Tres & Solar 50 & Solar 100 & Solar 200 & Solar 220 \\
\hline Power Block & MWe & - & 13.5 & 50 & 100 & 200 & 220 \\
\hline \multirow[t]{2}{*}{ SunLab } & $\$ M$ & - & $\$ 10.0$ & $\$ 24.5$ & $\$ 40.0$ & $\$ 64.0$ & $\$ 83.6$ \\
\hline & $\$ / \mathrm{kWe}$ & - & $\$ 730$ & $\$ 490$ & $\$ 400$ & $\$ 320$ & $\$ 380$ \\
\hline \multirow[t]{2}{*}{ S\&L } & $\$ M$ & - & $\$ 7.6$ & $\$ 18.6$ & $\$ 30.6$ & $\$ 46.2$ & $\$ 61.8$ \\
\hline & $\$ / \mathrm{kWe}$ & - & $\$ 563$ & $\$ 373$ & $\$ 306$ & $\$ 231$ & $\$ 281$ \\
\hline
\end{tabular}

\section{E.6.2 Technology Improvements}

\section{E.6.2.1 Efficiencies}

The power block is a conventional Rankine-cycle steam turbine. The Rankine-cycle steam turbine is an established technology with future major improvements focusing on increased inlet steam pressure and temperature conditions to increase the cycle efficiency.

The steam cycle foundation is the Rankine cycle. As the inlet steam conditions (pressure and temperature) increase, the Rankine cycle efficiency increases. The near-term steam cycle efficiency from $34 \%$ to $40.3 \%$ is predicated on increasing the inlet steam temperature from $510^{\circ} \mathrm{C}$ to without reheat $540^{\circ} \mathrm{C}$ with reheat. The longterm increase to $42.8 \%$ for Solar 200 is based on $540^{\circ} \mathrm{C}$ steam inlet temperature. The net steam turbine efficiency. The increase from Solar $200(42.8 \%)$ to Solar $220(46.1 \%)$ is based on $640^{\circ} \mathrm{C}$ steam inlet temperature with an advanced double reheat turbine. The summary of steam turbine efficiency projections is shown in Table E-39. 
Table E-39 - Turbine Projected Efficiencies

\begin{tabular}{|c|c|c|c|c|c|c|c|}
\hline \multirow{2}{*}{ Design Details } & $\begin{array}{c}\text { Solar } \\
\text { One }\end{array}$ & $\begin{array}{c}\text { Solar } \\
\text { Two }\end{array}$ & $\begin{array}{c}\text { Solar } \\
\text { Tres } \\
\text { USA }\end{array}$ & Solar 50 & $\begin{array}{c}\text { Solar } \\
\mathbf{1 0 0}\end{array}$ & $\begin{array}{c}\text { Solar } \\
\mathbf{2 0 0}\end{array}$ & $\begin{array}{c}\text { Solar } \\
\mathbf{2 2 0}\end{array}$ \\
\cline { 2 - 8 } & $\mathbf{1 9 8 8}$ & $\mathbf{1 9 9 9}$ & $\mathbf{2 0 0 4}$ & $\mathbf{2 0 0 6}$ & $\mathbf{2 0 0 8}$ & $\mathbf{2 0 1 2}$ & $\mathbf{2 0 1 8}$ \\
\hline Plant output, net, MWe & 10 & 10 & 13.7 & 50 & 100 & 200 & 220 \\
\hline Rankine Cycle & & & & & & & \\
\hline Pressure, Bar & 125 & 125 & 125 & 125 & 125 & 180 & 300 \\
\hline Live steam Temp, ${ }^{\circ} \mathrm{C}$ & 510 & 510 & 540 & 540 & 540 & 540 & 640 \\
\hline Reheat \#1 Temp, ${ }^{\circ} \mathrm{C}$ & - & - & 540 & 540 & 540 & 540 & 640 \\
\hline Reheat \#2 Temp, ${ }^{\circ} \mathrm{C}$ & - & - & - & - & - & 540 & 640 \\
\hline $\begin{array}{l}\text { Rankine Cycle Design } \\
\text { Point Efficiency }\end{array}$ & & & & & & & \\
\hline SunLab, \% & $32.0 \%$ & $34.0 \%$ & $40.3 \%$ & $41.8 \%$ & $42.3 \%$ & $42.8 \%$ & $46.1 \%$ \\
\hline S\&L, \% & - & - & $38.0 \%$ & $40.6 \%$ & $41.4 \%$ & $42.8 \%$ & $45.6 \%$ \\
\hline
\end{tabular}

The net steam turbine efficiency (gross efficiency minus the percentage of parasitic power consumption required for plant operation) is accounted for by calculation of the parasitic consumption separately. The near-term turbine efficiency was verified by S\&L based on the ABB-Brown Boveri heat balances (HTGD 582395, Sheets 1-7) for SEGS IX, which show an efficiency of 37.7\% (in LUZ International Limited 1990). The Rankine cycle efficiency gains for increasing the inlet steam temperature from $540^{\circ} \mathrm{C}$ to $640^{\circ} \mathrm{C}$ were verified by S\&L by using General Electric STGPER software program (Version 4.08.00, January 2002). The results from the STGPER software for Solar 200 and Solar 220 were extrapolated to account for dual reheat turbines. The turbine efficiencies are summarized in Table E-39.

The type of heat transfer fluid (HTF) determines the operational temperature and thus the maximum power cycle efficiency that can be obtained. The HTF molten nitrate salt (60 wt $\% \mathrm{NaNO}_{3}$ and $40 \mathrm{wt} \% \mathrm{KNO}_{3}$ ) nitrate salt used in Solar Two demonstrated that steam temperatures of $540^{\circ} \mathrm{C}$ were achieved (Pacheco et al. 2002); for example, test no. 5 at full flow conditions measured actual $\mathrm{HTF}$ at $557^{\circ} \mathrm{C}$ and steam temperature at $542^{\circ} \mathrm{C}$. 


\section{E.6.2.2 Discussion}

There are no steam turbine technological risks in achieving the SunLab projected efficiencies. There are currently numerous steam turbines operating with steam inlet conditions over 250 bar pressure and $590^{\circ} \mathrm{C}$ temperature, with gross efficiencies over 44\%. The advance from Solar 200 to Solar 220 is based on current research on increasing the inlet steam pressure and temperature conditions. This increase in efficiency for steam turbines is technically feasible and should be available by 2018. The major issue will be the higher temperatures and impact on materials.

\section{E.6.3 Economy of Scale}

There are recognized scale-up cost reductions for the power block. Using the SOAPP software program and S\&L's internal database, the scale-up factor was estimated for the increasing the power block from 13.5 MW to $200 \mathrm{MW}$, as depicted on Figure E-11. The S\&L trend curve is expressed as:

$$
\begin{aligned}
& \mathrm{Y}=(1,275.8) \mathrm{x}^{-0.3145} \\
& \text { Where: } \\
& \mathrm{Y}=\$ / \mathrm{kW} \\
& \mathrm{x}=\mathrm{MWe}
\end{aligned}
$$

\footnotetext{
* Plant (commercial operation date): Nanaoota 1 (1995), Noshiro 2 (1995), Haramachi 1 (1997), Haramachi 2 (1998), Millmerran (2002), Matauura 2 (1997), Misumi 1 (1998), Tachibana Bay (2000), Bexback (2002), Lubeck (1995), Aledore 1 (2000), Nordjylland (1998). From Power (Swanekamp 2002).
} 
Figure E-11 - Capital Cost of Electrical Power Block

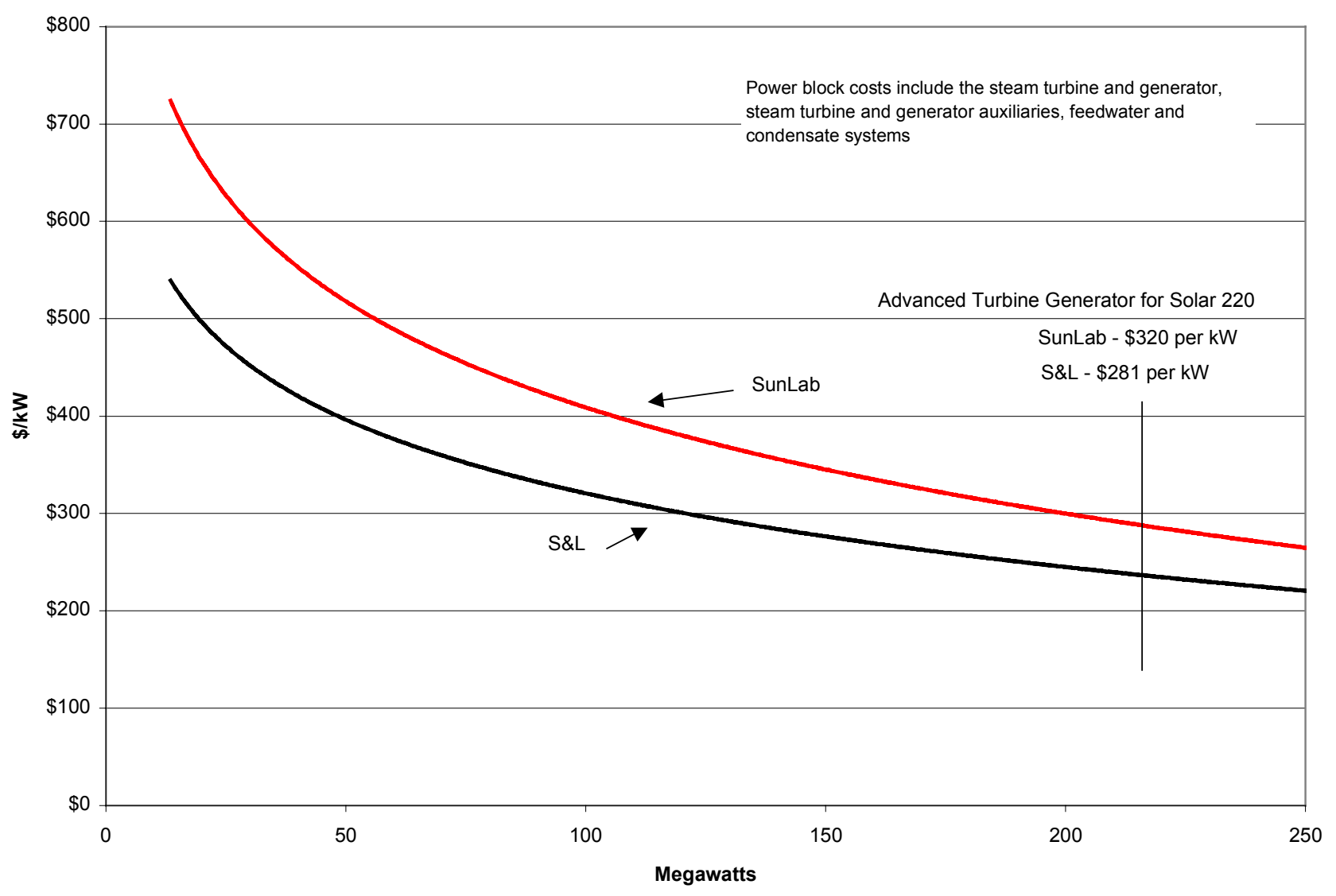

However, since a single steam turbine is supplied with each tower plant, production volume is not a consideration for cost reduction.

\section{E.6.4 Cost Improvements}

Cost improvements were evaluated by S\&L against three categories: technical (efficiency and design optimization), economy of scale, and volume production. The cost reductions determined by S\&L for the electric power block is an average of $18 \%$ due to technical improvements, $82 \%$ for scale-up, and $0 \%$ for volume production. The cost improvements for the electric power block based on step changes in plant size and breakdown comparison is shown in Section 5.7. 


\section{E.7 RECEIVER}

\section{E.7.1 Capital Cost}

Table E-40 - Capital Cost of Receiver

\begin{tabular}{|l|c|c|c|c|c|c|c|}
\hline & $\begin{array}{c}\text { Solar } \\
\text { One }\end{array}$ & $\begin{array}{c}\text { Solar } \\
\text { Two }\end{array}$ & $\begin{array}{c}\text { Solar } \\
\text { Tres }\end{array}$ & $\begin{array}{c}\text { Solar } \\
\mathbf{5 0}\end{array}$ & $\begin{array}{c}\text { Solar } \\
\mathbf{1 0 0}\end{array}$ & $\begin{array}{c}\text { Solar } \\
\mathbf{2 0 0}\end{array}$ & $\begin{array}{c}\text { Solar } \\
\mathbf{2 2 0}\end{array}$ \\
\cline { 2 - 8 } & $\mathbf{1 9 8 8}$ & $\mathbf{1 9 9 9}$ & $\mathbf{2 0 0 4}$ & $\mathbf{2 0 0 6}$ & $\mathbf{2 0 0 8}$ & $\mathbf{2 0 1 2}$ & $\mathbf{2 0 1 8}$ \\
\hline Net Plant Size - Thermal, MWt & 46 & 42 & 120 & 380 & 700 & 1,400 & 1,400 \\
\hline Receiver System Capital Cost -SunLab, \$M & $\$ 39.2$ & $\$ 9.1$ & $\$ 14.7$ & $\$ 23$ & $\$ 29.1$ & $\$ 39.4$ & $\$ 43.3$ \\
\hline $\begin{array}{l}\text { Receiver System Capital Cost -S\&L (based } \\
\text { on Boeing), \$M }\end{array}$ & - & - & $\$ 16$ & $\$ 26$ & $\$ 34$ & $\$ 46$ & - \\
\hline Receiver System Capital Cost, \$/kWt & - & - & $\$ 133$ & $\$ 68$ & $\$ 49$ & $\$ 33$ & - \\
\hline
\end{tabular}

The SunLab cost estimate for the capital cost for receiver is lower than the latest Boeing cost estimate. The SunLab cost estimate should be adjusted to be in accordance with the latest detailed Boeing cost estimate. S\&L determined that the Boeing cost estimate is reasonable based on the following:

- The cost estimate is based on actual costs from Solar Two, which adjustments to compensate for design improvements, manufacturing improvements, construction labor rates and escalation.

- The cost estimate is based on detailed design drawings and material take-offs (bottoms up cost estimate), which provides a higher degree of accuracy.

- Estimates for Solar 50, 100, and 200 receivers were developed from Solar Two and Solar Tres with appropriate scale up and available industry data.

- Boeing is a key player in developing tower technology with present focus on Solar Tres

- The business group that addresses CSP technology has the resources of one of the largest, reputable companies in the United States.

- Boeing is presently spending significant money (not disclosed due to confidentiality) on industry research and development. They spent $\$ 2$ million of funds for research on Solar Two. 


\section{E.7.2 Technology Improvement}

\section{E.7.2.1 Efficiency}

Table E-41 — Receiver Efficiency

\begin{tabular}{|c|c|c|c|c|c|c|}
\hline & $\begin{array}{c}\text { Solar } \\
\text { Two }\end{array}$ & $\begin{array}{c}\text { Solar } \\
\text { Tres }\end{array}$ & Solar $\mathbf{5 0}$ & $\begin{array}{c}\text { Solar } \\
\mathbf{1 0 0}\end{array}$ & $\begin{array}{c}\text { Solar } \\
\mathbf{2 0 0}\end{array}$ & $\begin{array}{c}\text { Solar } \\
\mathbf{2 2 0}\end{array}$ \\
\cline { 2 - 6 } & - & $\mathbf{2 0 0 4}$ & $\mathbf{2 0 0 6}$ & $\mathbf{2 0 0 8}$ & $\mathbf{2 0 1 2}$ & $\mathbf{2 0 1 8}$ \\
\hline Receiver Efficiency & $76.0 \%$ & $78.3 \%$ & $80.9 \%$ & $83.1 \%$ & $83.5 \%$ & $82.0 \%$ \\
\hline Defocus, Dump, Startup, Clouds & $90.0 \%$ & $92.7 \%$ & $93.4 \%$ & $93.4 \%$ & $93.4 \%$ & $93.4 \%$ \\
\hline Absorbance & $93.0 \%$ & $93.0 \%$ & $93.0 \%$ & $94.0 \%$ & $94.5 \%$ & $94.5 \%$ \\
\hline Receiver Thermal Losses & $90.7 \%$ & $90.9 \%$ & $93.1 \%$ & $94.7 \%$ & $94.7 \%$ & $92.9 \%$ \\
\hline Change in Receiver Efficiency & - & $2.39 \%$ & $2.53 \%$ & $2.23 \%$ & $0.44 \%$ & $-1.59 \%$ \\
\hline Percent Change in Field Area & - & $0.4 \%$ & $0.51 \%$ & $0.96 \%$ & $1.06 \%$ & $0.81 \%$ \\
\hline
\end{tabular}

The increased efficiency is from the following:

- Reduction in heat loss, which is approximately proportional to reduction in receiver surface area per incident power

- Increase of receiver absorbtivity through Industry Research \& Development (IR\&D)

- Decrease of receiver emissivity from selected coatings achieved through IR\&D

- High nickel tubes allow higher solar flux and smaller tube surface for Solar 200.

- Improved heliostat aiming allows higher average flux on receiver

- Gradual increase in solar flux as operating experience is gained from the preceding plant

- Improved insulation and receiver header oven covers further reduces heat loss.

The efficiency changes and basis for each change in plant size is shown in Section E.3.6.

\section{E.7.2.2 Other}

Solar Two demonstrated manufacturing, construction and operation of the molten salt tower receiver. The receiver system efficiency and thermal storage efficiency exceeded or met expectations. The feasibility of dispatchable solar power was proven. There were several problems encountered that have been evaluated and have been resolved for Solar Tres and future plants. 
- Downcomer piping failed near a horizontal pipe section below the receiver. Both the receiver and the down-comer piping grow considerably as they heat up to the $1,050^{\circ} \mathrm{F}\left(565^{\circ} \mathrm{C}\right)$ operating temperature. The piping design did not adequately cover the downcomers thermal growth during heat-up and cool down cycles. Larger expansion loops and a material change eliminated this concern.

- Receiver fill operation was changed from a flood fill to a more rapid serpentine fill technique.

- A number of receiver tubes developed slow leaks due to intergranular corrosion (IGC). The new tube material eliminated this problem.

- However, this change did not solve all receiver startup problems. As reported in "An Evaluation of Molten-Salt Power Towers Including Results of the Solar Two Project":

An inability to heat receiver header ovens to $450^{\circ} \mathrm{F}\left(232^{\circ} \mathrm{C}\right)$ often delayed introduction of salt into the receiver. In addition, frozen tubes (as revealed by the infrared camera) often delayed the transition from receiver fill to normal operation. During the downcomer outage, project personnel implemented a number of modifications, including changing the oven-to-tube seal, adding heat trace behind the tubes at the oven-to-tube interface, and adding baffles between oven covers. Since these modifications were only implemented on several of the west (windward) lower oven covers, they did not eliminate all receiver startup delays. The modifications did, however, indicate that receiver startup delays could be minimized or eliminated with some simple design changes. One simple change would be to locate the tube clips away from the oven-to-tube interface area, since the tube clips represent a heat sink, which is hard to heat when located at this interface. Another modification would be to change the oven-to-tube sealing technique.

Design improvements for Solar Tres include the following:

- Change from 316SS to high nickel alloy tubes, which allows higher peak solar flux and is "essentially immune" to chloride stress corrosion cracking (Boeing undated). The new material was tested at Sandia and in Solar Two in a full size panel.

- $\quad$ Redesign with inexpensive receiver cover ovens

- Improved inlet vessel operational design (Boeing patent pending)

- $\quad$ Simpler header design with fewer subcomponent parts (Boeing patent pending)

- Reduction of piping and valves. 


\section{E.7.3 Economy of Scale}

Table E-42 - Economies of Scale (Boeing)

\begin{tabular}{|c|c|c|c|c|c|c|c|}
\hline & $\begin{array}{l}\text { Solar } \\
\text { One }\end{array}$ & $\begin{array}{l}\text { Solar } \\
\text { Two }\end{array}$ & $\begin{array}{l}\text { Solar } \\
\text { Tres }\end{array}$ & $\begin{array}{c}\text { Solar } \\
50\end{array}$ & $\begin{array}{c}\text { Solar } \\
100\end{array}$ & $\begin{array}{c}\text { Solar } \\
200\end{array}$ & $\begin{array}{c}\text { Solar } \\
220\end{array}$ \\
\hline & 1988 & 1999 & 2004 & 2006 & 2008 & 2012 & 2018 \\
\hline Net Plant Size - Thermal, MWt & 46 & 42 & 120 & 380 & 700 & 1,400 & 1,400 \\
\hline Receiver Surface Area, $\mathrm{m}^{2}$ & - & 100 & 269 & 710 & 1,120 & 1,960 & 1,960 \\
\hline Receiver System Capital Cost, $\$ 1,000 / \mathrm{m}^{2}$ & - & $\$ 91$ & $\$ 59$ & $\$ 37$ & $\$ 30$ & $\$ 23$ & $\$ 24$ \\
\hline Receiver System Capital Cost-Boeing, \$M & - & $\$ 9.1$ & $\$ 16.0$ & $\$ 26.0$ & $\$ 34.0$ & $\$ 46.0$ & $\$ 48.3$ \\
\hline $\begin{array}{l}\text { Receiver System Capital Cost with a Scaling } \\
\text { Factor of } 0.7 \text { (calculated from Solar Two } \\
\text { based on increase in surface area) }\end{array}$ & - & - & $\$ 18.2$ & $\$ 31.6$ & $\$ 35.8$ & $\$ 50.3$ & $\$ 50.8$ \\
\hline
\end{tabular}

Boeing, based on their experience in manufacturing receivers and similar components, used a scaling factor of 0.7. The estimated capital cost for receivers was calculated based on a scaling factor of 0.7 , as shown in Table E-42. The difference between the capital cost calculated with a scale-up of 0.7 and the projected capital cost is a cost reduction, which is attributed to technical and volume production; for example, the receiver cost for Solar 50 is estimated to be $\$ 26$ million. The cost projection based on a scaling factor of 0.7 would be $\$ 31.6$ million [Receiver Cost for Solar $100=\$ 16 \times(710 / 269){ }^{0.7}=\$ 31.6$ million]. The difference is $\$ 5.6$, which is attributed to technical improvements and production volume, as discussed in Section E.7.4.

\section{E.7.4 Production Volume}

Since only one receiver is manufactured for each plant, production volume is not a consideration for cost improvement when evaluating a single plant. However, fabrication learning curve from previous projects will provide cost improvements due to the repetitive assembly related with manufacturing receiver panels and their subcomponent parts. For example, in Solar Tres, 6,000 clips are welded onto 850 individual tubes that are then welded to 34 headers, which are part of 17 identical receiver panels. Boeing is expecting $85 \%$ to $90 \%$ learning curve based on previous experience. Boeing has also identified cost improvements due to improved manufacturing tooling and automation and quantity discount of material, which are reasonable assumptions. Material and components are about $35 \%$ of receiver costs. 
Table E-43 - Effect of Production Volume (Percent of Total Savings)

\begin{tabular}{|l|c|c|c|c|c|c|c|}
\hline & $\begin{array}{c}\text { Solar } \\
\text { One }\end{array}$ & $\begin{array}{c}\text { Solar } \\
\text { Two }\end{array}$ & $\begin{array}{c}\text { Solar } \\
\text { Tres }\end{array}$ & $\begin{array}{c}\text { Solar } \\
\mathbf{5 0}\end{array}$ & $\begin{array}{c}\text { Solar } \\
\mathbf{1 0 0}\end{array}$ & $\begin{array}{c}\text { Solar } \\
\mathbf{2 0 0}\end{array}$ & $\begin{array}{c}\text { Solar } \\
\mathbf{2 2 0}\end{array}$ \\
\cline { 2 - 8 } & $\mathbf{1 9 8 8}$ & $\mathbf{1 9 9 9}$ & $\mathbf{2 0 0 4}$ & $\mathbf{2 0 0 6}$ & $\mathbf{2 0 0 8}$ & $\mathbf{2 0 1 2}$ & $\mathbf{2 0 1 8}$ \\
\hline Net Plant Size - Thermal, MWt & 46 & 42 & 120 & 380 & 700 & 1,400 & 1,400 \\
\hline Fabrication Learning Curve, \% & - & - & $5 \%$ & $9 \%$ & $7 \%$ & $3 \%$ & - \\
\hline $\begin{array}{l}\text { Improved Manufacturing Tools and } \\
\text { Automation, \% }\end{array}$ & - & - & $2 \%$ & $3 \%$ & $3 \%$ & $1 \%$ & - \\
\hline Quantity discount of material, \% & - & - & $0 \%$ & $2 \%$ & $2 \%$ & $1 \%$ & - \\
\hline \multicolumn{1}{|c|}{ Total, \% } & - & - & $7 \%$ & $14 \%$ & $12 \%$ & $5 \%$ & - \\
\hline
\end{tabular}

\section{E.7.5 Cost Comparison}

Table E-44 — Total Installed Cost

\begin{tabular}{|r|c|c|c|c|c|}
\hline Case & $\begin{array}{c}\text { Solar } \\
\text { Tres USA }\end{array}$ & Solar 50 & Solar 100 & Solar 200 & Solar 220 \\
\hline Year & $\mathbf{2 0 0 4}$ & $\mathbf{2 0 0 6}$ & $\mathbf{2 0 0 8}$ & $\mathbf{2 0 1 2}$ & $\mathbf{2 0 1 8}$ \\
\hline Receiver - Boeing, \$M & $\$ 16.0$ & $\$ 26.0$ & $\$ 34.0$ & $\$ 46.0$ & $\$ 48.3$ \\
\hline Receiver - SunLab, \$M & $\$ 14.0$ & $\$ 19.8$ & $\$ 25.0$ & $\$ 36.9$ & $\$ 34.4$ \\
\hline
\end{tabular}

\section{E.7.6 Cost Improvements}

Cost Improvements are evaluated against three categories: technical (efficiency and design optimization), economy of scale and volume production. The cost reduction determined by S\&L for the receiver is an average of $46 \%$ due to technical, $40 \%$ due to scale-up and $14 \%$ due to volume production. The method used by S\&L is shown below, and the detailed calculation is shown in Section E.7.7.

Cost Savings $=$ Cost Savings from Technical + Cost Savings from Scale-up + Cost savings from Volume Production

Where:

Cost savings from Technical $=$ Cost savings due to receiver flux increase + Cost savings due to receiver improved efficiency + Cost savings in heliostat field size due to improvements in receiver efficiency.

Cost savings from Scale-up $=$ Capital cost based on 0.7 scaling factor minus Capital cost based on 1.0 scaling factor 
Cost savings from Volume Production $=$ Cost savings from manufacturing receiver panels and subcomponent parts.

The cost improvements and basis for the improvements for each change in plant size are shown in Section 5.6.

\section{E.7.7 Receiver Efficiency Improvements}

Table E-45 - Sargent \& Lundy Determination of Receiver Cost Reduction Breakout

\begin{tabular}{|c|c|c|c|c|c|c|c|c|}
\hline & & $\begin{array}{l}\text { Solar } \\
\text { One }\end{array}$ & $\begin{array}{l}\text { Solar } \\
\text { Two }\end{array}$ & $\begin{array}{l}\text { Solar } \\
\text { Tres }\end{array}$ & $\begin{array}{c}\text { Solar } \\
50\end{array}$ & $\begin{array}{c}\text { Solar } \\
100\end{array}$ & $\begin{array}{l}\text { Solar } \\
200\end{array}$ & $\begin{array}{c}\text { Solar } \\
220\end{array}$ \\
\hline & Abbr. & 1988 & 1999 & 2004 & 2006 & 2008 & 2012 & 2018 \\
\hline Net Plant Size - Thermal, MWt & & 46 & 42 & 120 & 380 & 700 & 1,400 & 1,400 \\
\hline Receiver Surface Area, $\mathrm{m}^{2}$ & & - & 100 & 269 & 710 & 1,120 & 1,960 & 34.4 \\
\hline Receiver Peak Incident Flux, MW/m² & & 0.45 & 0.8 & 0.95 & 1.2 & 1.4 & 1.6 & 1.6 \\
\hline Ratio Average/Peak Incident Flux & & $43 \%$ & $60 \%$ & $51 \%$ & $50 \%$ & $50 \%$ & $50 \%$ & $50 \%$ \\
\hline Receiver Average Incident Flux, MW/m² & & 0.20 & 0.48 & 0.49 & 0.6 & 0.7 & 0.8 & 0.8 \\
\hline Receiver Efficiency (annual) & & $64.8 \%$ & $76 \%$ & $78.2 \%$ & $79.9 \%$ & $82.3 \%$ & $83.2 \%$ & $81.3 \%$ \\
\hline $\begin{array}{l}\text { Receiver System Capital Cost -Boeing, } \\
\text { \$M }\end{array}$ & $\mathrm{TC}$ & - & $\$ 9.1$ & $\$ 16.0$ & $\$ 26.0$ & $\$ 34.0$ & $\$ 46.0$ & $\$ 48.3$ \\
\hline $\begin{array}{l}\text { Receiver Capital Cost with a Scaling } \\
\text { Factor of } 0.7 \text { (calculated from Solar Two } \\
\text { based on increase in surface area), \$M }\end{array}$ & $\mathrm{TC}_{\mathrm{S}}$ & - & - & $\$ 18.2$ & $\$ 31.6$ & $\$ 35.8$ & $\$ 50.3$ & $\$ 50.8$ \\
\hline $\begin{array}{l}\text { Receiver Capital Cost without a scaling } \\
\text { factor (e.g., scaling factor = 1), } \$ M\end{array}$ & $\mathrm{TC}_{\mathrm{NS}}$ & - & - & $\$ 24.5$ & $\$ 42.3$ & $\$ 41.0$ & $\$ 59.5$ & $\$ 60.4$ \\
\hline $\begin{array}{l}\text { Cost Savings from scaling factor } \\
{\left[\mathrm{CS}_{\mathrm{s}}=\mathrm{TC}_{\mathrm{s}}-\mathrm{TC}_{\mathrm{NS}}\right]}\end{array}$ & $\mathrm{CS}_{\mathrm{S}}$ & - & - & $\$ 6.3$ & $\$ 10.7$ & $\$ 5.2$ & $\$ 9.2$ & $\$ 9.6$ \\
\hline $\begin{array}{l}\text { Receiver Cost Savings from Smaller } \\
\text { Receivers due to higher flux levels }\end{array}$ & & & & & & & & \\
\hline Area with Solar Two avg. flux, $\mathrm{m}^{2}$ & & - & - & 274 & 893 & 1,643 & 3,285 & 3,336 \\
\hline $\begin{array}{l}\text { Cost with Solar Two avg. flux and } \\
\text { scaling factor, } \$ M\end{array}$ & $\mathrm{TC}_{\mathrm{S}+\mathrm{F}}$ & - & - & $\$ 18.5$ & $\$ 37.0$ & $\$ 46.8$ & $\$ 72.2$ & $\$ 73.0$ \\
\hline $\begin{array}{l}\text { Cost savings from flux increase } \\
{\left[C S_{F}=T C_{S}-T C_{S+F}\right], \$ M}\end{array}$ & $\mathrm{CS}_{\mathrm{F}}$ & - & - & 0.26 & 5.48 & 11.00 & 21.91 & 22.15 \\
\hline & & & & & & & & \\
\hline
\end{tabular}




\begin{tabular}{|c|c|c|c|c|c|c|c|c|}
\hline & & $\begin{array}{l}\text { Solar } \\
\text { One }\end{array}$ & $\begin{array}{l}\text { Solar } \\
\text { Two }\end{array}$ & $\begin{array}{l}\text { Solar } \\
\text { Tres }\end{array}$ & $\begin{array}{c}\text { Solar } \\
50\end{array}$ & $\begin{array}{c}\text { Solar } \\
100\end{array}$ & $\begin{array}{l}\text { Solar } \\
200\end{array}$ & $\begin{array}{l}\text { Solar } \\
220\end{array}$ \\
\hline & Abbr. & 1988 & 1999 & 2004 & 2006 & 2008 & 2012 & 2018 \\
\hline \multicolumn{9}{|l|}{$\begin{array}{l}\text { Receiver cost savings from increased } \\
\text { efficiency due to higher flux levels }\end{array}$} \\
\hline Area with Solar Two avg. flux, $\mathrm{m}^{2}$ & & - & - & 277 & 747 & 1,213 & 2,148 & 2,129 \\
\hline $\begin{array}{l}\text { Cost with Solar Two avg. flux and } \\
\text { scaling factor, } \$ M\end{array}$ & $\mathrm{TC}_{\mathrm{S}+\mathrm{RE}}$ & - & - & 18.6 & 32.7 & 37.8 & 53.6 & 48.7 \\
\hline $\begin{array}{l}\text { Cost savings from flux increase } \\
{\left[C S_{R E}=T C_{S}-T C_{S+R E}\right], \$ M}\end{array}$ & $\mathrm{CS}_{\mathrm{RE}}$ & - & - & 0.38 & 1.14 & 2.06 & 3.33 & -2.10 \\
\hline $\begin{array}{l}\text { Heliostat cost savings (collector area) } \\
\text { from increased receiver efficiency - from } \\
\text { Table E-8), \$M }\end{array}$ & $\mathrm{CS}_{\mathrm{HE}}$ & - & - & $\$ 3.31$ & $\$ 2.21$ & $\$ 0.7$ & $\$ 0.042$ & $\$-0.958$ \\
\hline $\begin{array}{l}\text { Total Cost Savings from technology } \\
{\left[C S_{R E}=C S_{F}+C S_{R E}+C S_{H E}\right]}\end{array}$ & $\mathrm{CS}_{\mathrm{T}}$ & - & - & 3.95 & 8.83 & 13.76 & 25.29 & 19.09 \\
\hline $\begin{array}{l}\text { Cost Savings from Volume Production } \\
\left.\text { [CSV }=\mathrm{TCs}-\mathrm{TC}-\mathrm{CS}_{\mathrm{F}}-\mathrm{CS}_{\mathrm{RE}}\right]\end{array}$ & $\mathrm{CS}_{\mathrm{V}}$ & - & - & 1.56 & 5.56 & 1.77 & 4.30 & 2.54 \\
\hline Cost Reduction from Scaling, $\$ M$ & $\mathrm{CS}_{\mathrm{s}}$ & - & - & 6.3 & 10.7 & 5.2 & 9.2 & 9.6 \\
\hline Cost Reduction from Technical, \$M & $\mathrm{CS}_{\mathrm{t}}$ & - & - & 3.9 & 8.8 & 13.8 & 25.3 & 19.1 \\
\hline Cost Reduction from Production Vol., \$M & $\mathrm{CS}_{\mathrm{V}}$ & - & - & 2.2 & 5.6 & 1.8 & 4.3 & 2.5 \\
\hline $\begin{array}{l}\text { Total Cost Reduction, including receiver } \\
\text { and heliostat field, \$M }\end{array}$ & $\mathrm{CS}_{\mathrm{T}}$ & - & - & 12.4 & 25.1 & 20.8 & 38.8 & 31.2 \\
\hline Cost Reduction from Technical, \% & $\mathrm{CS}_{\mathrm{t}}$ & - & - & $32 \%$ & $35 \%$ & $66 \%$ & $65 \%$ & $31 \%$ \\
\hline Cost Reduction from Scaling, \% & $\mathrm{CS}_{\mathrm{s}}$ & - & - & $50 \%$ & $43 \%$ & $25 \%$ & $24 \%$ & $61 \%$ \\
\hline Cost Reduction from Production Vol., \% & $\mathrm{CS}_{\mathrm{v}}$ & - & - & $18 \%$ & $22 \%$ & $9 \%$ & $11 \%$ & $8 \%$ \\
\hline
\end{tabular}

\section{E.8 THERMAL STORAGE}

\section{E.8.1 Capital Cost}

The capital cost estimate for the thermal storage system is shown in Table E-46. 
Table E-46 - Capital Cost for Thermal Storage - SunLab Reference Case

\begin{tabular}{|l|c|c|c|c|c|c|c|}
\hline & $\begin{array}{c}\text { Solar } \\
\text { One }\end{array}$ & $\begin{array}{c}\text { Solar } \\
\text { Two }\end{array}$ & $\begin{array}{c}\text { Solar } \\
\text { Tres }\end{array}$ & $\begin{array}{c}\text { Solar } \\
\mathbf{5 0}\end{array}$ & $\begin{array}{c}\text { Solar } \\
\mathbf{1 0 0}\end{array}$ & $\begin{array}{c}\text { Solar } \\
\mathbf{2 0 0}\end{array}$ & $\begin{array}{c}\text { Solar } \\
\mathbf{2 2 0}\end{array}$ \\
\cline { 2 - 8 } & $\mathbf{1 9 8 8}$ & $\mathbf{1 9 9 9}$ & $\mathbf{2 0 0 4}$ & $\mathbf{2 0 0 6}$ & $\mathbf{2 0 0 8}$ & $\mathbf{2 0 1 2}$ & $\mathbf{2 0 1 8}$ \\
\hline $\begin{array}{l}\text { Thermal Storage - Duration at } \\
\text { peak output, hr }\end{array}$ & N/A & 3 & 16 & 16 & 13 & 13 & 12.7 \\
\hline Net Plant Size - Thermal, MWt & 46 & 42 & 120 & 380 & 700 & 1,400 & 1,400 \\
\hline $\begin{array}{l}\text { Thermal Storage System Direct } \\
\text { Cost, \$M }\end{array}$ & $\$ 20.1$ & $\$ 3.7$ & $\$ 5.9$ & $\$ 18.7$ & $\$ 28.9$ & $\$ 56.3$ & $\$ 57.2$ \\
\hline $\begin{array}{l}\text { Thermal Storage System Direct } \\
\text { Cost, \$/kWe }\end{array}$ & - & - & $\$ 431$ & $\$ 374$ & $\$ 289$ & $\$ 281$ & $\$ 261$ \\
\hline
\end{tabular}

The SunLab cost estimate for the capital cost for thermal storage is reasonable based on the following:

- The cost estimate is a definitive cost estimate based on detailed design drawings and material takeoff.

- The unit cost parameters are within typical industry values.

- The contingency is $10 \%$.

- The binary nitrate salt cost is based on vendor quotes, which includes shipping.

\section{E.8.2 Technology Improvement}

\section{E.8.2.1 Efficiency}

The storage design point efficiency is projected at $99.9 \%$ for all cases. The efficiency of Solar Two was demonstrated at $99.9 \%$, and since there is no significant technology changes, it can be expected to remain constant. With larger plants, tank volume-to-surface-area ratio increases further, which increases storage efficiencies.

\section{E.8.2.2 Discussion}

Solar Two demonstrated molten salt as a viable, large-scale thermal energy storage medium. Energy storage efficiencies of $99 \%$ were achieved. The design, construction, and performance of large, field-erected, externally insulated tanks for storing molten salt were demonstrated. 
There are several ongoing studies for improvement of the design and construction including the following:

- $\quad$ Alternative valve designs for hot salt service.

- Alternative salt downcomer designs.

- Materials testing on stainless steels 347 and 321 are planned to demonstrate their resistance to IGC in salt service.

\section{E.8.3 Economy of Scale}

Table E-47- Economy of Scale for Thermal Storage

\begin{tabular}{|l|c|c|c|c|c|c|}
\hline Steam Generator & $\begin{array}{c}\text { Solar } \\
\text { Two }\end{array}$ & $\begin{array}{c}\text { Solar } \\
\text { Tres }\end{array}$ & Solar 50 & $\begin{array}{c}\text { Solar } \\
\mathbf{1 0 0}\end{array}$ & $\begin{array}{c}\text { Solar } \\
\mathbf{2 0 0}\end{array}$ & $\begin{array}{c}\text { Solar } \\
\mathbf{2 2 0}\end{array}$ \\
\hline Direct Cost (SunLab) & $\$ 3.70$ & $\$ 5.90$ & $\$ 18.70$ & $\$ 29.30$ & $\$ 56.30$ & $\$ 57.30$ \\
\hline $\begin{array}{l}\text { Cost Reduction Due to Scaling based } \\
\text { on Scaling Factor of 0.78 }\end{array}$ & - & - & $\$ 3.75$ & $\$ 5.81$ & $\$ 9.69$ & $\$ 9.40$ \\
\hline Cost Reduction Due to Scaling, \$M & - & - & $\$ 14.50$ & $\$ 30.12$ & $\$ 50.31$ & $\$ 56.30$ \\
\hline $\begin{array}{l}\text { Cost Due to Technology } \\
\text { Improvements, \$M }\end{array}$ & - & - & $\$ 4.20$ & $(\$ 0.82)$ & $\$ 5.99$ & $\$ 1.00$ \\
\hline $\begin{array}{l}\text { Cost Due to Technology } \\
\text { Improvement, \% }\end{array}$ & - & - & $22.5 \%$ & $-2.8 \%$ & $10.6 \%$ & $1.7 \%$ \\
\hline
\end{tabular}

The scale-up from Solar Two to Solar 220 thermal storage for the SunLab cost estimate is 0.78. This is reasonable based on the following:

- The main components are the hot storage tank, cold storage tank and piping.

- $\quad$ The scale-up was calculated based on the difference between the actual cost for Solar Two and vendor quotes for Solar100 (Central Receiver Utility Studies 1989)

- The SunLab estimate is within the range of expected scale-up factors based on S\&L's experience with similar equipment in electric power plants.

\section{E.8.4 Production Volume}

Since the thermal storage system is comprised of single components, production volume is not a consideration for cost improvement. 


\section{E.8.5 Cost Improvements-Thermal Storage and Parasitic}

Cost improvements for thermal storage and parasitic were evaluated against technical efficiency improvements. Parasitic was included since thermal storage is the key contributor to minimizing parasitic losses. The cost improvements are shown in Table E-48.

Table E-48 - Thermal Storage and Parasitic Cost Improvements Due to Technology (Efficiency) Improvements (Effect on Collector Field)

\begin{tabular}{|c|c|c|c|c|c|}
\hline & $\begin{array}{c}\text { Solar Two to } \\
\text { Solar Tres }\end{array}$ & $\begin{array}{c}\text { Solar Tres to } \\
\text { Solar } \mathbf{5 0}\end{array}$ & $\begin{array}{c}\text { Solar } \mathbf{5 0} \text { to } \\
\text { Solar } \mathbf{1 0 0}\end{array}$ & $\begin{array}{c}\text { Solar } \mathbf{1 0 0} \text { to } \\
\text { Solar } \mathbf{2 0 0}\end{array}$ & $\begin{array}{c}\text { Solar 200 to } \\
\text { Solar 220 }\end{array}$ \\
\hline Thermal Storage & & & & & \\
\hline $\begin{array}{c}\text { Percent Effect on Cost } \\
\text { Reduction, \% }\end{array}$ & $-0.4 \%$ & $-0.1 \%$ & $-0.0 \%$ & $-0.0 \%$ & $-0.0 \%$ \\
\hline $\begin{array}{c}\text { Cost Reduction, \$M } \\
\text { Parasitic }\end{array}$ & $-\$ 0.41$ & $-\$ 0.17$ & $-\$ 0.02$ & $-\$ 0.01$ & $-\$ 0.05$ \\
\hline $\begin{array}{c}\text { Percent Effect on Cost } \\
\text { Reduction, \% }\end{array}$ & $-3.6 \%$ & $-0.7 \%$ & $-0.1 \%$ & $-0.1 \%$ & $-0.2 \%$ \\
\hline \begin{tabular}{c} 
Cost Reduction, \$M \\
\hline
\end{tabular} & $-\$ 3.72$ & $-\$ 1.39$ & $-\$ 0.36$ & $-\$ 0.25$ & $-\$ 1.08$ \\
\hline
\end{tabular}

\section{E.8.6 Cost Improvements}

Cost Improvements were evaluated by S\&L against three categories: technical (efficiency and design optimization), economy of scale, and volume production. The cost reductions determined by S\&L for the thermal storage system is an average of $7 \%$ due to technical improvements, $93 \%$ for scale-up, and $0 \%$ for volume production.

\section{E.9 STEAM GENERATOR}

\section{E.9.1 Capital Cost}

The capital cost estimated by SunLab for the steam generator system is shown in Table E- 49 .

Table E-49 - Steam Generator Capital Cost

\begin{tabular}{|l|c|c|c|c|c|c|}
\hline & Solar Two & Solar Tres & Solar 50 & Solar $\mathbf{1 0 0}$ & Solar 200 & Solar 220 \\
\hline Direct Cost & - & $\$ 1.6$ & $\$ 3.7$ & $\$ 5.8$ & $\$ 9.4$ & $\$ 9.3$ \\
\hline
\end{tabular}


The SunLab cost estimate for the steam generator (superheater, evaporator, preheater, and reheater) is based on actual costs for Solar Two and vendor quotes for a 100-MWe plant (ref: ASND93-7084).

\section{E.9.2 Technology Improvement}

The Solar Two design of the steam generator consisted of a straight-shell, $U$-tube preheater (salt on the shell side); a kettle-boiler evaporator (salt in the $\mathrm{U}$-tubes); and a straight-shell, $\mathrm{U}$-tube superheater (salt on the shell side). Intergranular corrosion (IGC) was a problem in some areas where high- carbon stainless steel piping and fittings were used for containment of molten salt. Future molten-salt power tower designs will use the following:

- $\quad$ Piping materials that are not susceptible to IGC.

- Four tube-in-shell vessels (preheater, evaporator, superheater, reheater) with salt on the shell side.

- Evaporator will be of a forced circulation design with separate steam drum.

- Vessels stacked to provide simplified drain and maintenance procedures.

The Solar Two demonstration project identified the following problems with the steam generator system:

- A number of receiver tubes developed slow leaks due to intergranular corrosion (IGC). The new tube material eliminated this problem.

- Poor water mixing in the evaporator shell which lead to salt freeze thaw cycles on the tubes resulting in a tube rupture and strained tubes.

- The recirculation pump's seals added considerable amount of cold water, which decreased the temperature of the recirculation flow.

- The preheater was bypassed during startup to prevent salt from freezing, but it resulted in feedwater entering the evaporator below minimum design temperature.

All problems were solved by the following means:

- Repairing the evaporator tubes and modifications of evaporator spargers,

- Adding a startup feedwater heater, adding a higher capacity canned-rotor recirculation pump,

- Eliminating the preheater bypass line,

- $\quad$ Adding a feedwater valve to the evaporator inlet piping, and

- Modifying the startup procedure to reflect the new configuration and incorporate lessons learned from the tube rupture. 
The modifications solved the problems as mentioned in the report: "No further tube ruptures occurred; temperature stratification in the evaporator was essentially eliminated; and the system performed more reliably for the remainder of the project. Operating experience also revealed that varying pump speed could reliably control salt flow to the SGS. This experience eliminated the need for flow control valves on the SGS salt supply piping."

The technology and lessons learned have been applied to the next generation design of Solar Tres. The successful operation of the system after repairs and modifications indicate that there is a low risk of significant problems occurring with the scale-up of the system.

\section{E.9.3 Economy of Scale}

Table E-50 - Economy of Scale for Steam Generator

\begin{tabular}{|l|l|l|l|l|l|l|}
\hline Steam Generator & $\begin{array}{l}\text { Solar } \\
\text { Two }\end{array}$ & $\begin{array}{l}\text { Solar } \\
\text { Tres }\end{array}$ & Solar $\mathbf{5 0}$ & $\begin{array}{l}\text { Solar } \\
\mathbf{1 0 0}\end{array}$ & $\begin{array}{l}\text { Solar } \\
\mathbf{2 0 0}\end{array}$ & $\begin{array}{l}\text { Solar } \\
\mathbf{2 2 0}\end{array}$ \\
\hline Direct Cost & - & $\$ 1.6$ & $\$ 3.7$ & $\$ 5.8$ & $\$ 9.4$ & $\$ 9.3$ \\
\hline $\begin{array}{l}\text { Cost Reduction Attributed to Scaling } \\
\text { based on Scaling Factor of 0.74 }\end{array}$ & - & - & $\$ 3.75$ & $\$ 5.81$ & $\$ 9.69$ & $\$ 9.69$ \\
\hline
\end{tabular}

Note: The difference between cost reduction due to scaling and direct cost is attributed to technology improvements and calculates to an average of $3.7 \%$.

The cost estimates for the other size plants were calculated based on a scaling factor of 0.7 , which was calculated from the steam generator size and cost of Solar Two to the quotes for Solar 100. The cost estimate is reasonable based on the following:

- The cost for Solar Two is an actual cost.

- The cost estimate for Solar 100 is based on vendor's designs and quotes.

- The SunLab estimate is within the range of expected scale-up factors based on S\&L's experience with similar equipment in electric power plants.

- A comparison of Solar Two of the preheater, evaporator, and superheater area to Solar 100 preheater, evaporator, and superheater results in a scaling factor of 0.69. Solar 100 has a reheater and the SunLab calculation included the reheater.

- The steam generator design is based on known and proven heat exchanger technology.

- A contingency of $10 \%$ is included in the cost estimate, which is reasonable. 
The SunLab cost estimate for the pumps is based on Solar Two actual costs and Solar Tres detailed budgetary quotes from vendors. Motor costs are based on standard industry motor costs. The cost estimate is reasonable based on the following:

- The cost for Solar Two is an actual cost

- The cost estimate for Solar Tres in based on actual budgetary quotes

- $\quad$ Motors are not a unique design but standard industry available models

- The cost scaling factors calculated between Solar Two and Solar Tres are lower than industry standard based on MWt: 0.65 for cold pumps and 0.55 for hot pumps. The reason is based on material changes for hot components, which are more costly.

\section{E.9.4 Production Volume}

Since the steam generator system is comprised of single components, production volume is not a consideration for cost improvement.

\section{E.9.5 Cost Improvements}

Cost Improvements were evaluated by S\&L against three categories: technical (efficiency and design optimization), economy of scale, and volume production. The cost reductions determined by S\&L for the steam generator system is an average of $4 \%$ due to technical improvements, $96 \%$ for scale-up, and $0 \%$ for volume production.

\section{E.10 BALANCE OF PLANT}

\section{E.10.1 Capital Cost}

Sargent \& Lundy estimated the cost for the balance of plant based on the SOAPP model, compared it to our internal database, and then adjusted the output for labor and productivity rates in the Southwest. The results of our review are shown in Table E-51 and Figure E-12. The balance-of-plant costs include general balance-ofplant equipment, condenser and cooling tower system, water treatment system, fire protection, piping, compressed air systems, closed cooling water system, instrumentation, electrical equipment, and cranes and hoists. 
Table E-51 - Capital Cost of Balance of Plant

\begin{tabular}{|c|c|c|c|c|c|c|c|}
\hline & & Solar Two & Solar Tres & Solar 50 & Solar 100 & Solar 200 & Solar 220 \\
\hline Power Block & MWe & - & 13.5 & 50 & 100 & 200 & 220 \\
\hline \multirow[t]{2}{*}{ SunLab } & $\$ M$ & - & $\$ 4.8$ & $\$ 6.5$ & $\$ 7.8$ & $\$ 9.6$ & $\$ 9.9$ \\
\hline & $\$ / k W e$ & - & $\$ 356$ & $\$ 130$ & $\$ 78$ & $\$ 48$ & $\$ 45$ \\
\hline \multirow[t]{2}{*}{ S\&L } & $\$ M$ & - & $\$ 10$ & $\$ 24.5$ & $\$ 36.7$ & $\$ 33.8$ & $\$ 35.5$ \\
\hline & $\$ / \mathrm{kWe}$ & - & $\$ 741$ & $\$ 490$ & $\$ 367$ & $\$ 169$ & $\$ 148$ \\
\hline
\end{tabular}

Figure E-12 - Balance of Plant

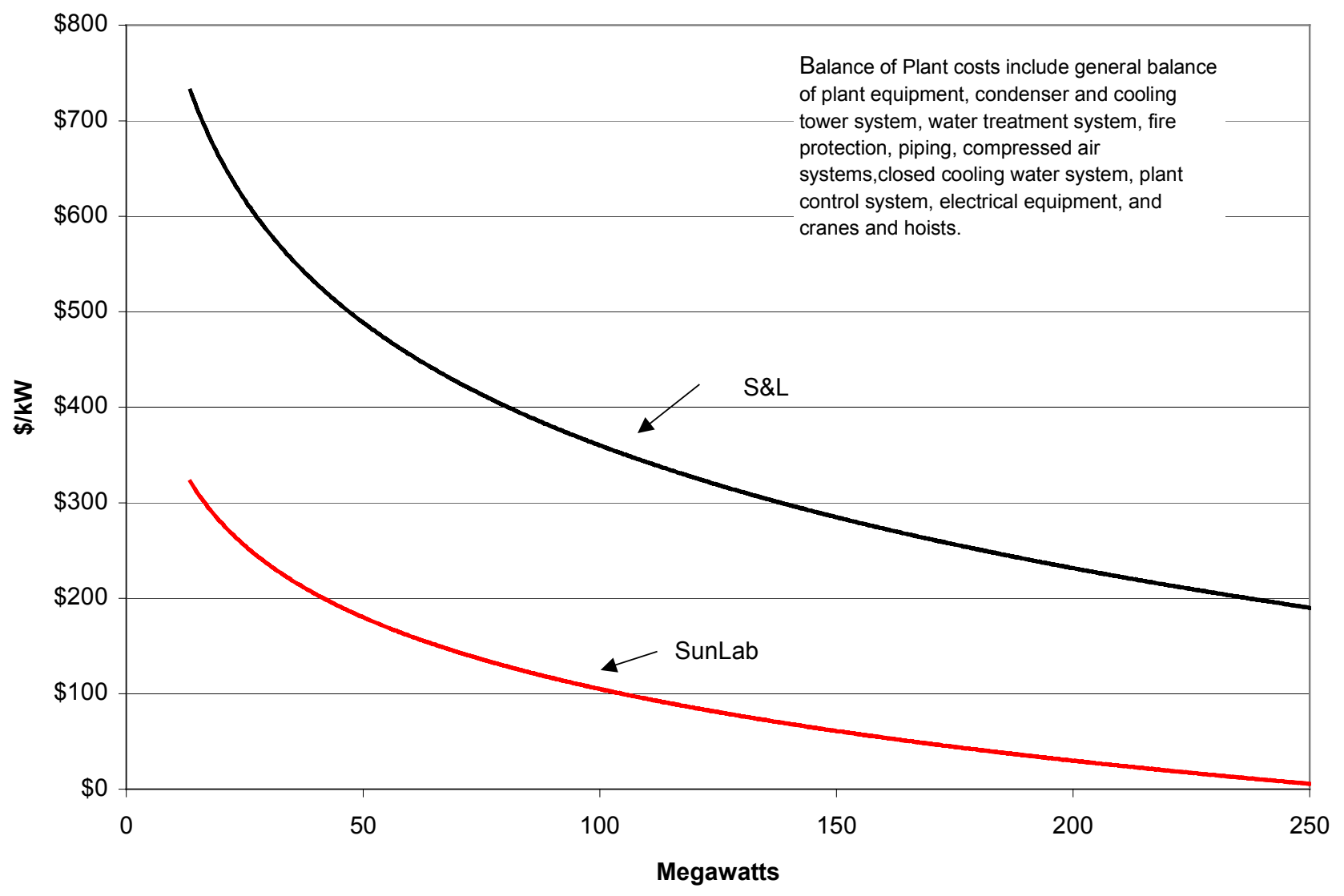

\section{E.10.2 Technology Improvements}

There are no efficiency improvements projected for balance of plant. 


\section{E.10.3 Economy of Scale}

There are recognized scale-up cost reductions for the balance of plant. Using the SOAPP software program (SOAPP undated) and S\&L's internal database, the scale-up factor was estimated for the increasing the balance of plant from 13.5 MW to $200 \mathrm{MW}$, as depicted on Figure E-12. The S\&L trend curve is expressed as follows:

$$
\begin{aligned}
& \mathrm{Y}=(461.3) \mathrm{x}^{-0.1896} \\
& \text { Where: } \\
& \mathrm{Y}=\$ / \mathrm{kW} \\
& \mathrm{x}=\mathrm{MWe}
\end{aligned}
$$

\section{E.10.4 Production Volume}

Production volume is not a consideration for cost reduction.

\section{E.10.5 Cost Improvements}

Cost Improvements were evaluated by S\&L against three categories: technical (efficiency and design optimization), economy of scale, and volume production. The cost reductions determined by S\&L for the balance of plant is an average of $0 \%$ due to technical improvements, $100 \%$ for scale-up, and $0 \%$ for volume production.

\section{E.11 CAPITAL COST COMPARISON}

The SunLab model projects tower plant capital and O\&M costs based on various technology advances and commercial deployment predictions. The SunLab projections are considered the best-case analysis where the technology is optimized and a high deployment rate is achieved. S\&L developed capital and O\&M costs based on a more conservative approach whereby the technology improvements are limited to current demonstrated or tested improvements and with a lower rate of deployment than used in the SunLab model. The two sets of estimates, SunLab's and S\&L's, provides a band in which the costs can be expected to be, assuming the parabolic trough technology reaches the projected levels of deployment. A comparison of key parameters used for the estimates is summarized on Table E-52. 
Table E-52 - Key Parameters Comparison

\begin{tabular}{|l|c|c|c|c|c|c|c|c|c|c|}
\hline & \multicolumn{2}{|c|}{2004} & \multicolumn{2}{c|}{2007} & \multicolumn{2}{c|}{2010} & \multicolumn{2}{c|}{2015} & \multicolumn{2}{c|}{2020} \\
\cline { 2 - 11 } & SunLab & S\&L & SunLab & S\&L & SunLab & S\&L & SunLab & S\&L & SunLab & S\&L \\
\hline Deployment, MW & 13.5 & 13.5 & 50 & 50 & 100 & 100 & 200 & 200 & 220 & 200 \\
\hline $\begin{array}{l}\text { Cumulative } \\
\text { Deployment, MW }\end{array}$ & 13.5 & 13.5 & 164 & 64 & 914 & 264 & 3,914 & 814 & 8,734 & 2,614 \\
\hline $\begin{array}{l}\text { Net Annual Solar } \\
\text { Efficiency }\end{array}$ & $13.7 \%$ & $13.0 \%$ & $16.1 \%$ & $15.5 \%$ & $16.6 \%$ & $16.1 \%$ & $16.9 \%$ & $16.5 \%$ & $18.1 \%$ & $16.5 \%$ \\
\hline Heliostat, $\$ / \mathrm{m}^{2}$ & $\$ 145$ & $\$ 160$ & $\$ 127$ & $\$ 150$ & $\$ 107$ & $\$ 134$ & $\$ 96$ & $\$ 124$ & $\$ 75$ & $\$ 117$ \\
\hline
\end{tabular}

The significant differences between the SunLab Reference Case and the S\&L estimate are the following:

- Deployment. SunLab projected 8.7 GWe whereas S\&L projected 2.6 GWe.

- Net Annual Solar Efficiencies. S\&L projected the net annual solar efficiency to be lower based on proven results and conservative design enhancements. S\&L did not include the advanced eliostat design and advance higher temperature steam turbine in their base case estimate.

- Heliostat Cost. S\&L cost estimate is based on a detailed evaluation of existing cost estimates and independent projection.

- Electric Power. S\&L cost estimate is based on the latest industry information and is lower than the SunLab estimate.

- Balance of Plant. S\&L cost estimate is based on the latest industry information and is higher than the SunLab estimate.

- O\&M Costs. S\&L estimate is based evaluation of the SunLab projection, visit to the SEGS site, and our review of conventional power plants. The main difference is scaled-up costs due to the increase in field size for grounds and vehicle maintenance, average burden rate and raw water cost.

- Engineering, Management and Development. SunLab projected that the Engineering, Management and Development at $7.8 \%$ of cost. S\&L projected the cost to be $15 \%$, based on recent industry experience in developing independent power plants.

- Contingency. SunLab projected the contingency at 7.7\%. S\&L projected the contingency to be $11.8 \%$ for the cost estimate and $15 \%$ for cost reductions.

\section{E.12 LEVELIZED ENERGY COST}

The projections by SunLab and S\&L for capital cost and operations \& maintenance were used to estimate levelized energy costs (LEC). After completing the report, SunLab revised its reference case (from August 2002 to October 2002) as shown below. The Sunlab LEC projections are based on the October 2002 reference case. 
Revised SunLab Reference Case

\begin{tabular}{|l|c|c|c|c|c|c|}
\hline & $\begin{array}{c}\text { Solar Two } \\
\mathbf{1 9 9 9}\end{array}$ & $\begin{array}{c}\text { Solar 15 } \\
\mathbf{2 0 0 4}\end{array}$ & $\begin{array}{c}\text { Solar 50 } \\
\mathbf{2 0 0 6}\end{array}$ & $\begin{array}{c}\text { Solar 100 } \\
\mathbf{2 0 0 8}\end{array}$ & $\begin{array}{c}\text { Solar 200 } \\
\mathbf{2 0 1 4}\end{array}$ & $\mathbf{2 0 1 8}$ \\
\hline Net Electrical (MWe) & 10 & 13.7 & 50 & 100 & 200 & 220 \\
\hline Plant Size Solar (MWt) & 42 & 120 & 380 & 700 & 1400 & 1400 \\
\hline Heliostat Size $\left(\mathrm{m}^{2}\right)$ & $39 / 95$ & 95 & 95 & 148 & 148 & 148 \\
\hline Heliostat Field $\left(\mathrm{m}^{2}\right)$ & 81,400 & 231,000 & 715,000 & $1,317,000$ & $2,614,000$ & $2,651,000$ \\
\hline $\begin{array}{l}\text { Annual Solar-to- } \\
\text { Electicity Efficiency }\end{array}$ & $7.6 \%$ & $13.7 \%$ & $15.7 \%$ & $16.5 \%$ & $16.8 \%$ & $17.8 \%$ \\
\hline Capital Cost (\$/kWe) & - & 7,180 & 4,160 & 3,160 & 2,700 & 2,340 \\
\hline O\&M Annual Cost (\$k) & - & 2,489 & 3,166 & 4,005 & 5,893 & 6,006 \\
\hline LEC (\$/kWh) & - & $\$ 114.8$ & $\$ 61.5$ & $\$ 47.6$ & $\$ 39.6$ & $\$ 35.0$ \\
\hline
\end{tabular}

The cost estimates were inputted to the financial model developed by S\&L (see Appendix B for a description of the financial model). The results are shown in Table E-53.

\section{Table E-53 - Capital Cost, O\&M Costs and Levelized Energy Cost Summary: SunLab and S\&L}

\begin{tabular}{|l|r|r|r|r|c|c|}
\hline \multirow{4}{*}{} & \multicolumn{2}{|c|}{ Near Term } & \multicolumn{2}{c|}{ Mid Term } & \multicolumn{2}{c|}{ Long Term } \\
\cline { 2 - 7 } & SunLab & S\&L & SunLab & S\&L & SunLab & S\&L \\
\cline { 2 - 7 } & \multicolumn{2}{|c|}{ Solar Tres USA } & \multicolumn{2}{c|}{ Solar 100 } & Solar 220 & Solar 200 \\
\cline { 2 - 7 } & $\mathbf{2 0 0 4}$ & $\mathbf{2 0 0 4}$ & $\mathbf{2 0 0 8}$ & $\mathbf{2 0 1 0}$ & $\mathbf{2 0 1 8}$ & $\mathbf{2 0 2 0}$ \\
\hline Capital Cost, \$/MWh & $\$ 77.4$ & $\$ 97.1$ & $\$ 36.3$ & $\$ 52.9$ & $\$ 27.0$ & $\$ 41.8$ \\
\hline Fixed O\&M Costs, \$/MWh & $\$ 37.4$ & $\$ 46.1$ & $\$ 11.3$ & $\$ 15.3$ & $\$ 8.0$ & $\$ 12.9$ \\
\hline Variable O\&M Costs, \$/MWh & $\$ 0.0$ & $\$ 0.0$ & $\$ 0.0$ & $\$ 0.0$ & $\$ 0.0$ & $\$ 0.0$ \\
\hline LEC, \$/MWh & $\$ 114.8$ & $\$ 143.1$ & $\$ 47.6$ & $\$ 68.2$ & $\$ 35.0$ & $\$ 54.7$ \\
\hline
\end{tabular}

SunLab - Deployment of 8.7 GWe / S\&L - Deployment of 2.6 GWe

Sargent \& Lundy's estimate of the direct capital cost and operation \& maintenance costs for the near-term deployment includes a contingency of about 10\%. Based on our review of the SunLab cost estimate, which we determined was based on industry cost data and engineering judgment, the cost estimate for the near-term deployment (Solar Tres) is reasonable. The projection from near-term deployment (2003) to long-term 
deployment (2020) includes cost reduction due to technology improvements, scaling, and volume production. S\&L included a composite contingency of $15 \%$ for cost reductions ( $15 \%$ for technology, $10 \%$ for scaling, and $20 \%$ for volume production). For comparison, the effect of deployment and annual net efficiencies are shown in Table E-54.

Table E-54 — Impact of Deployment and Net Solar-to-Electric Efficiency on LEC

\begin{tabular}{|c|c|c|c|c|}
\hline \multirow[b]{2}{*}{ Year 2020} & \multirow{2}{*}{$\begin{array}{l}\text { Total } \\
\text { Deployment } \\
(G W e)\end{array}$} & \multirow{2}{*}{$\begin{array}{l}\text { Net Solar-to- } \\
\text { Electric Efficiency } \\
(\%)\end{array}$} & \multicolumn{2}{|r|}{ LEC } \\
\hline & & & (\$/kWh) & $\begin{array}{l}\text { Percent change from } \\
\text { S\&L Base Case }\end{array}$ \\
\hline SunLab & 8.7 & 18.1 & 0.0350 & SunLab Base \\
\hline S\&L & 8.7 & $16.5^{*}$ & 0.0524 & $-4.2 \%$ \\
\hline S\&L & 4.7 & $16.5^{*}$ & 0.0538 & $-1.6 \%$ \\
\hline S\&L & 2.6 & $16.5^{*}$ & 0.0547 & S\&L Base \\
\hline S\&L & 1.2 & $16.5^{*}$ & 0.0559 & $2.2 \%$ \\
\hline S\&L & $2.6^{* *}$ & 17.3 & 0.0476 & $-13.0 \%$ \\
\hline S\&L & $2.6^{* *}$ & 16.5 & 0.0547 & S\&L Base \\
\hline S\&L & $2.6^{\star *}$ & 14.6 & 0.0590 & $7.9 \%$ \\
\hline
\end{tabular}

* Fixed net solar-to-electric efficiency

${ }^{* *}$ Fixed total deployment.

The range of LEC between the SunLab cost estimate and S\&L's estimate is about 56\% as shown in Figure E-13. 
Figure E-13 - Levelized Energy Cost Comparison: SunLab and S\&L

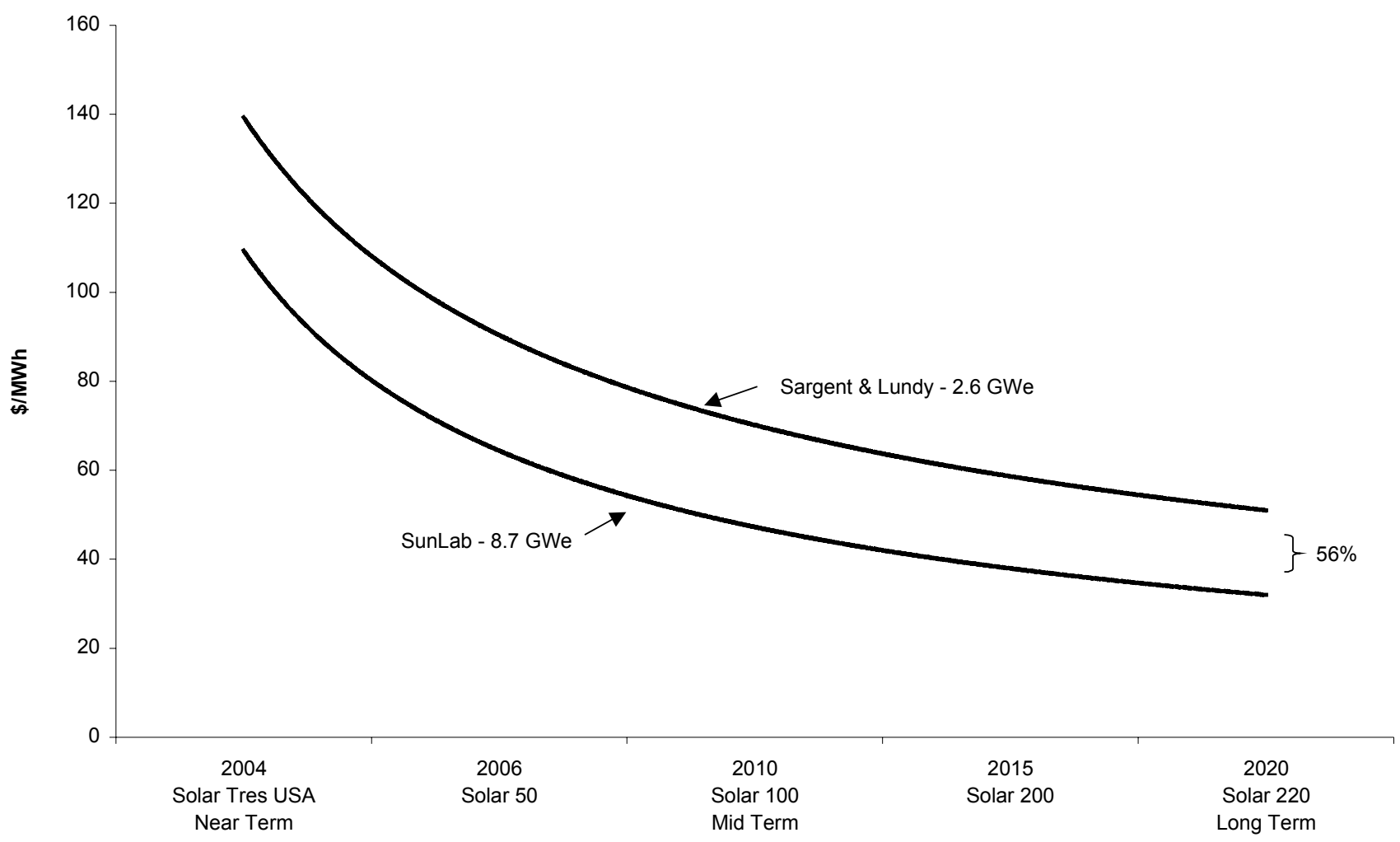

Cost improvements were evaluated by S\&L against three categories: technical improvements, scale-up, and production volume. The contribution of these three categories against the S\&L LEC projection is shown in Figure E-14. 
Figure E-14 - Sargent \& Lundy LEC Projection Breakout by Category

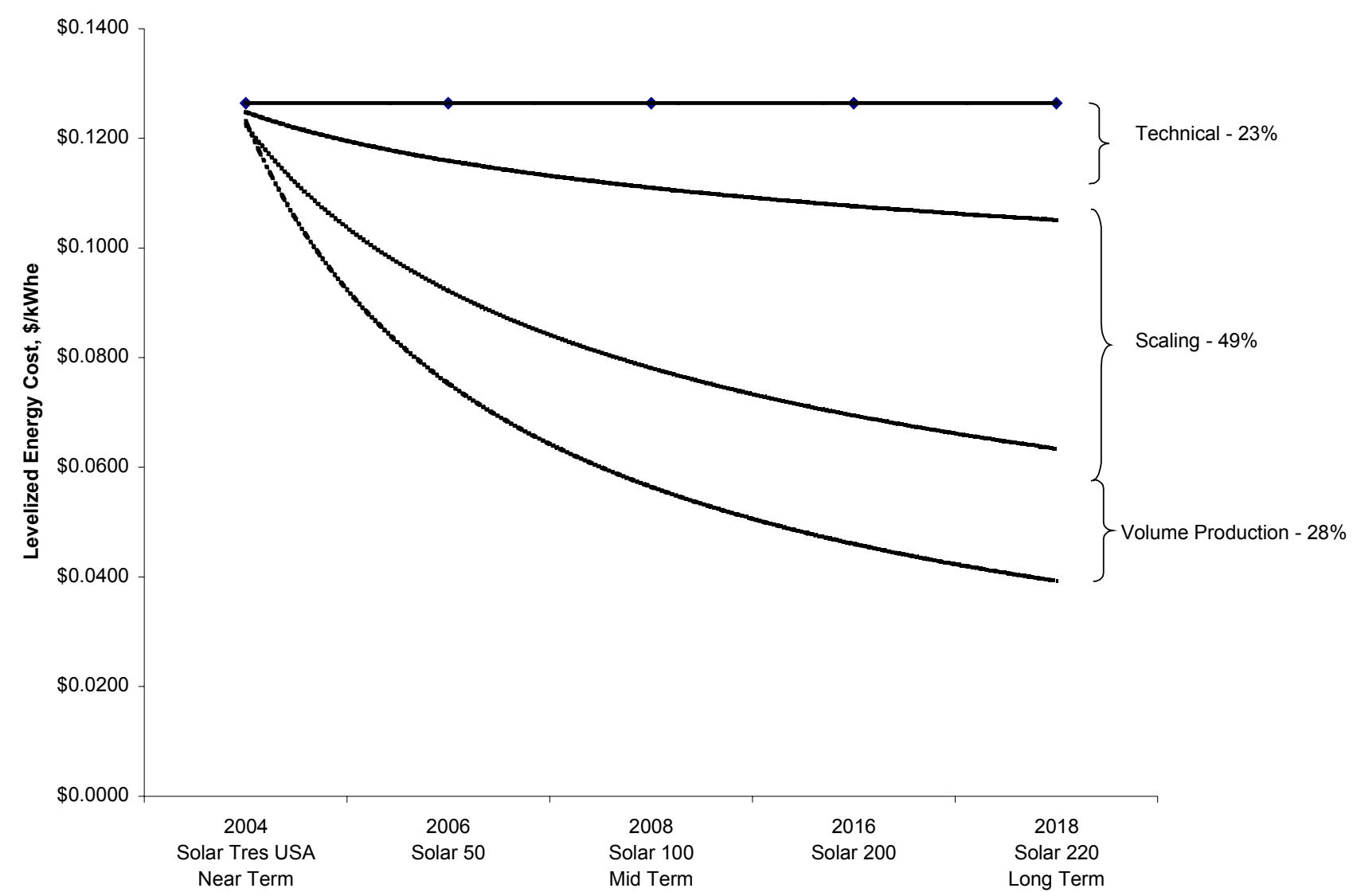

The major contributor to cost reduction from Solar Tres to Solar 50 is due to the increase in electrical generation (13.5 MWe to $50 \mathrm{MWe}$ ) as shown in Figure E-15. The annual net energy production increased from 93.2 GWh/yr to $331 \mathrm{GWh} / \mathrm{yr}$. 
Figure E-15 - Comparison of SunLab and S\&L LEC Estimates: 2004 to 2020

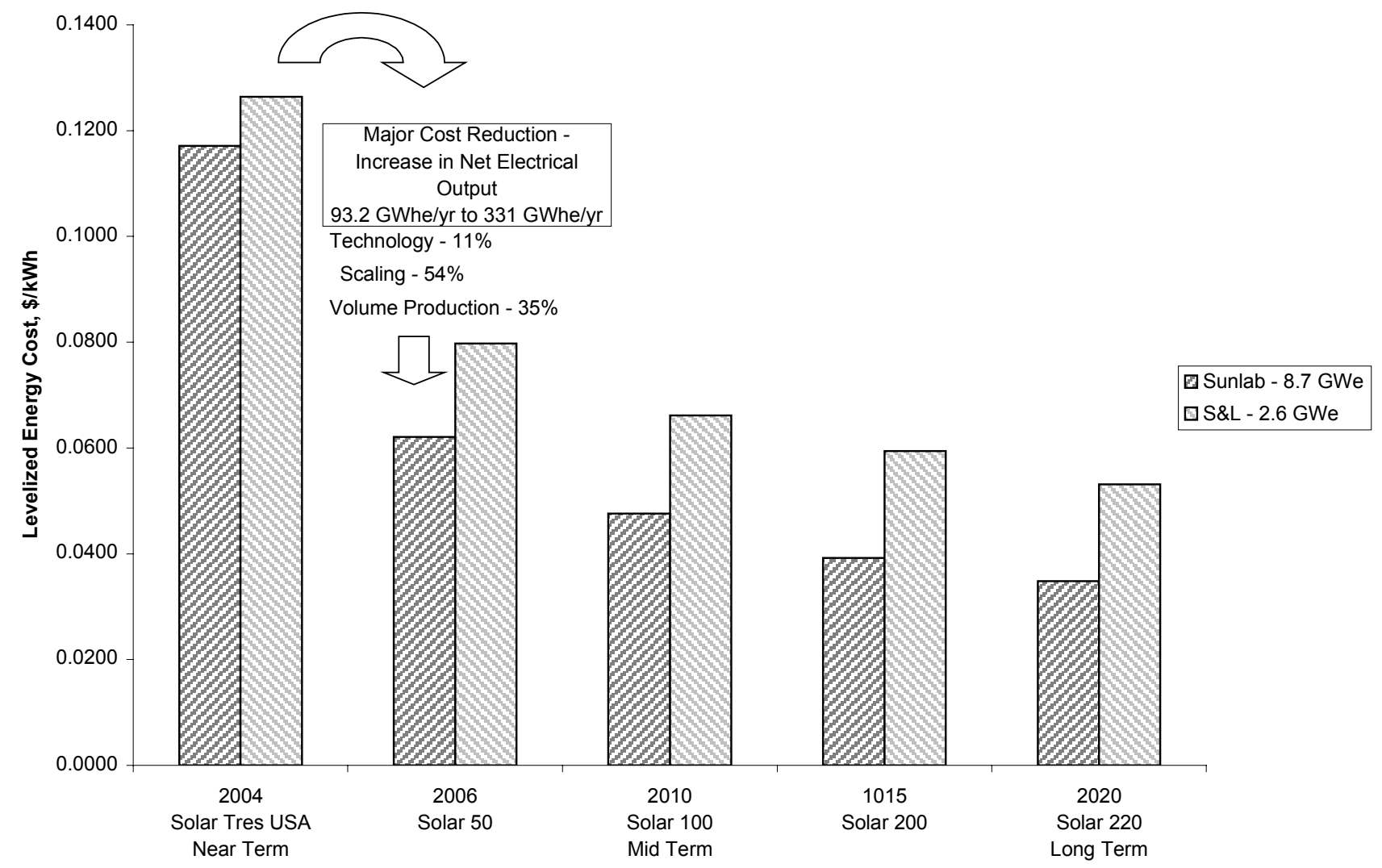


Appendix F

Evaluation of O\&M Costs - Trough 


\section{F. EVALUATION OF O\&M COSTS - TROUGH}

\section{F.1 SUMMARY}

Table F-1 shows the SunLab projected O\&M costs.

\section{Table F-1 - CSP Trough Technology O\&M Costs - SunLab Projections}

\begin{tabular}{|l|c|c|c|c|c|}
\hline & $\begin{array}{c}\text { Trough } \\
\mathbf{2 0 0 4}\end{array}$ & $\begin{array}{c}\text { Trough } \\
\mathbf{2 0 0 7}\end{array}$ & $\begin{array}{c}\text { Trough } \\
\mathbf{2 0 1 0}\end{array}$ & $\begin{array}{c}\text { Trough } \\
\mathbf{2 0 1 5}\end{array}$ & $\begin{array}{c}\text { Trough } \\
\mathbf{2 0 2 0}\end{array}$ \\
\hline Annual Net Generation, MWhe & 468,617 & 492,175 & 738,922 & 984,831 & $1,981,490$ \\
\hline Field Aperture Area, ${ }^{2}$ & $1,120,480$ & $1,037,760$ & $1,477,680$ & $1,955,200$ & $3,910,400$ \\
\hline Staff & 45 & 44 & 51 & 58 & 90 \\
\hline Average Annual Cost (with burden), \$1,000 & 58.8 & 62.0 & 60.8 & 59.9 & 57.7 \\
\hline Staff Cost, \$1,000 & 2,643 & 2,705 & 3,081 & 3,490 & 5,164 \\
\hline Annual Material \& Services Cost, \$1,000 & 3,054 & 2,243 & 2,507 & 2,952 & 5,029 \\
\hline Total O\&M Cost, \$1,000 & 5,697 & 4,948 & 5,588 & 6,442 & 10,193 \\
\hline Total O\&M Cost, \$/kWhe & 0.012 & 0.010 & 0.008 & 0.007 & 0.005 \\
\hline
\end{tabular}

\section{F.2 O\&M STAFF}

The staffing in the SunLab model was reviewed and is a reasonable estimate. The staffing compares with SEGS, power-generating facilities and the recent O\&M Cost Reduction Study performed at Kramer Junction (KJCOC 1999). The staffing for trough technology is shown in Table F-2.

\section{Table F-2 - Staffing for Trough Technology - SunLab Projections}

\begin{tabular}{|l|c|c|c|c|c|}
\hline & $\mathbf{2 0 0 4}$ & $\mathbf{2 0 0 7}$ & $\mathbf{2 0 1 0}$ & $\mathbf{2 0 1 5}$ & $\mathbf{2 0 2 0}$ \\
\hline Administrative & 7 & 7 & 7 & 7 & 7 \\
\hline Plant Operations & 15.5 & 15.2 & 16.9 & 18.8 & 26.6 \\
\hline Power Plant Maintenance & 8 & 8 & 8 & 8 & 8 \\
\hline Solar Field Maintenance & 14.4 & 13.5 & 18.7 & 24.5 & 47.9 \\
\hline \multicolumn{1}{|c|}{ Total } & 44.9 & 43.6 & 50.6 & 58.3 & 89.6 \\
\hline
\end{tabular}


The power plant staffing, exclusive of solar field maintenance, is comparable to the industry average for a 120-MWe combined-cycle power plant.

The estimated staff increases were determined to be reasonable based on the following evaluation.

The SunLab model estimated a staff of approximately 45 for trough 2004 and 2007 (100-MW plant each).

- $\quad$ The administrative staff would be the same for the increased plant sizes through 2020.

- The increase in plant size from $100 \mathrm{MWe}$ to $400 \mathrm{MWe}$ will not require additional maintenance staff for maintenance of the power plant. The difference between 100 and $400 \mathrm{MWe}$ does not increase the quantity or complexity of the equipment.

- $\quad$ Each additional 50-MW plant size will require two additional mirror wash technicians in the operations staff to account for the increased field aperture area.

- The increase in the solar field maintenance staff is required to support the increase in the solar field. For Kramer Junction, approximately 0.03 maintenance staff is required per $1,000 \mathrm{~m}^{2}$ of solar field aperture area. The larger solar plant is estimated to be approximately directly proportional to increase of the solar field. For example, the solar field maintenance staff for 2020 is estimated to be $\left(3,910,400 \mathrm{~m}^{2} / 1,120,480 \mathrm{~m}^{2}\right)=3.49 \times 14$ maintenance staff $($ in 2004$)=$ 49 maintenance staff (in 2020).

\section{F.3 O\&M MATERIAL AND SERVICE COSTS}

\section{F.3.1 Service Contract}

The service contracts include typical contracts and costs expected for this type of facility (control computers, office equipment, waste disposal, road maintenance, vehicle maintenance, etc.).

\section{F.3.2 Raw Water and Chemicals}

The SunLab estimate is based on water usage and chemical costs from SEGS VI/VII as shown below. The costs and estimated usage values are consistent with industry averages.

\section{Table F-3 - Water Usage and Chemical Costs - SunLab Projections}

\begin{tabular}{|l|l|}
\hline Raw Water Costs & $\$ 0.32$ per $^{3}$ \\
\hline Cooling Water Chemical Cost & $\$ 0.043$ per $\mathrm{m}^{3}$ cooling tower make-up \\
\hline Demineralizer Chemical Cost & $\$ 0.540$ per $\mathrm{m}^{3}$ condensate make-up \\
\hline Cooling Tower Make-up & $2.90 \mathrm{~m}^{3} / \mathrm{MWhe}$ \\
\hline
\end{tabular}




\begin{tabular}{|l|l|}
\hline Power Cycle Condensate Make-up & $0.17 \mathrm{~m}^{3} / \mathrm{MWhe}$ \\
\hline Demineralizer Blowdown & $10 \%$ \\
\hline Mirror Wash Water Consumption & $0.022 \mathrm{~m}^{3}$ (water) $/ \mathrm{m}^{2}$ (of collector) /year \\
\hline
\end{tabular}

\begin{tabular}{|l|c|c|}
\hline & Raw Water $\left(\mathbf{m}^{3}\right)$ & Percentage \\
\hline Cooling Tower Make-up & $1,031,547$ & $93.5 \%$ \\
\hline Power Cycle Demin. Make-up & 67,189 & $6.1 \%$ \\
\hline Mirror Wash Demin Make-up & 4,596 & $0.4 \%$ \\
\hline Total & $1,103,332$ & \\
\hline
\end{tabular}

\section{F.3.3 Parts and Material}

The SunLab projections are based on the following unit costs and annual replacement rates.

Table F-4 - Parts and Materials Cost Basis -
SunLab Projections

\begin{tabular}{|l|c|c|}
\hline & $\begin{array}{c}\text { Unit Cost } \\
\text { (\$) }\end{array}$ & $\begin{array}{c}\text { Replacement } \\
\text { Rate }\end{array}$ \\
\hline Mirrors & 80 & 0.005 \\
\hline HCEs & 847 & 0.02 \\
\hline Sun Sensors & 150 & 0.005 \\
\hline LOCs & 200 & 0.005 \\
\hline Ball Joints & 2,100 & 0.005 \\
\hline Hdr. Drive & 3,000 & 0.005 \\
\hline Miscellaneous & $5 \%$ of total equipment costs \\
\hline HTF Pump Seals & 1,200 & 2 \\
\hline HTF Makeup & 9 & 0.01 \\
\hline
\end{tabular}

\section{F.3.4 Miscellaneous}

Miscellaneous costs include administration costs (safety, training, travel, supplies, telephones, etc) and vehicle fuel and repair. The cost of $\$ 253,000$ per year is reasonable for this size of power plant. 


\section{F.3.5 Capital Equipment}

Capital equipment covers the equipment required to operate and maintain the facility (dump truck, operator vehicles, mirror-washing equipment, mirror container carrier, lube trailer and tractor). The cost of the equipment is based on the recent O\&M Cost Reduction Study performed at Kramer Junction (KJCOC 1999) and Kramer Junction's latest information. The quantity of equipment is increased proportionally to the size of the solar field, which is a reasonable assumption.

\section{F.4 ESTIMATED O\&M COSTS BASIS}

The O\&M costs for comparison to the SunLab projections are based on the following:

- Solar Field

- The initial unit costs are based on the SunLab values

- Replacement rate for the mirrors and HCE are based on the average actual replacement rates for SEGS III - VII for the period 1997-2001

- The replacement rates for the balance of the solar field are based on the SunLab values

- $\quad$ Power Block and Balance of Plant

- Costs are based on S\&L data for the respective MW size plant for the steam turbine systems and balance of plant

- Water and Process

- Costs are based on are based on the average actual costs for SEGS III - VII for the period 1997-2001

- $\quad$ Staffing, Services Contracts, Miscellaneous, and Capital Equipment

- The costs are based on the SunLab values since the SunLab values were determined to be reasonable

- Thermal Storage

- The costs are based on $0.4 \%$ of the capital cost per annum

\section{F.5 O\&M COST COMPARISON}

The SunLab and S\&L estimated O\&M costs are compared in Table F-5. 
Table F-5 - O\&M Cost Comparison

\begin{tabular}{|cl|c|c|c|c|c|}
\hline & & $\mathbf{2 0 0 4}$ & $\mathbf{2 0 0 7}$ & $\mathbf{2 0 1 0}$ & $\mathbf{2 0 1 5}$ & $\mathbf{2 0 2 0}$ \\
\hline SunLab & $\$(2002)$ & $5,697,000$ & $4,948,000$ & $5,588,000$ & $6,442,000$ & $10,193,000$ \\
Levelized & $\$ / k W h e$ & 0.012 & 0.010 & 0.008 & 0.007 & 0.005 \\
\hline S\&L & $\$(2002)$ & $\$ 8,114,516$ & $\$ 6,611,838$ & $\$ 7,553,692$ & $\$ 8,286,682$ & $\$ 13,731,497$ \\
Levelized & $\$ / k W h e$ & $\$ 0.0173$ & $\$ 0.0134$ & $\$ 0.0102$ & $\$ 0.0084$ & $\$ 0.0069$ \\
\hline
\end{tabular}

Analyzing the two estimates revealed the major component to account for the cost difference is the HCE replacement rate. The SunLab projections indicate the following replacement rates:

- $2004-2 \%$

- $2007-1 \%$

- 2010 through $2020-0.5 \%$

compared to the following S\&L values:

- $2004-5.5 \%$

- $2007-4.0 \%$

- $2010-2.5 \%$

- $2015-1.0 \%$

- $2020-0.5 \%$

The SunLab near-term values are not consistent with the average actual HCE replacement rate of 5.5\% reported for SEGS III - VII for the period 1997-2001.

Sargent \& Lundy reviewed the actual receiver (HCE) replacement rate reported by KJC Operating Company over the last five years. The S\&L evaluation is based on total HCE replacement reported for the SEGS III - VII for the period 1997-2001. S\&L's evaluation is based on the current replacement rate at all the SEGS plants, with step reductions in the replacement rate based on the following:

- The average actual HCE replacement rate of 5.5\% was reported for SEGS III - VII for the period 1997-2001. The total HCE replacement includes breakage and fluorescence. Fluorescence is due to cermet coating failures. This failure is due to the existence of molybdenum in the original Luz cermet coating. Solel no longer uses molybdenum in the UVAC cermet coating, so this type of failure will presumably no longer occur. Eliminating replacements due to these failures reduces the site failure/replacement rate. 
- $\quad$ SunLab has used the SEGS VI plant as the baseline reference plant. The SEGS III - V plants had problems during initial startup and the early years of operation that caused bowing of the HCEs, which increased breakage at those plants. SEGS VII has had higher breakage on the LS3 half of the field, although the LS-2 failures are similar to SEGS VI. SEGS VI was the last full plant constructed with LS-2 collectors and represents the most mature version of this generation of collector technology. The HCE total replacement rate at SEGS VI during the 5 years is in the $5.5 \%$ range. Discounting the fluorescence failures, the replacement rate was $4.2 \%$ over the 5 -year period.

- The high HCE failure rate at the existing plants is in part due to issues that would not be found at a future plant. A significant portion of the failures has been due to the hydrogen remover (HR) device installed in the HCEs at SEGS VI - X, operational problems that caused bowing, and HCE installation procedures. The HR is no longer part of the HCEs provided by Solel.

Based on these factors, it is possible that future plants will have substantially lower HCE failure rates than currently occur at the SEGS plants; however, the SunLab assumption of a $2 \%$ failure rate assumes that current approaches for reducing failures are successful. S\&L believes this is an aggressive assumption that cannot be assured for future plants without the field data to verify the failure rate reduction. Using the current replacement rate at all the SEGS plants, with step reductions in the replacement rate, reflects the current conditions and allows for the aforementioned improvements to reduce the replacement rate.

Additional development of the HCE will likely be necessary to achieve the future receiver reliability goals. The current glass-to-metal seal is one of the more expensive elements and the key failure point of the current receiver design. The current design, known as a Housekeeper seal, relies on a sharp metal point being inserted into a glass bead. Failures occur when concentrated light focus on seal and the differential expansion between the glass and metal causes the failure of the seal. New designs are currently under investigation that attempt to improve the match between the coefficient of thermal expansion of the metal and glass. Kramer Junction is currently testing a new design UVAC2 with a revised internal shield.

Another factor that contributes to the higher S\&L-estimated O\&M costs is the higher component costs, as detailed in Appendix D.

If the HCE reliability can be improved to reduce the replacement rate to that projected by SunLab, the O\&M costs converge on the values projected by SunLab. 
Appendix G

Evaluation of O\&M Costs - Tower 


\section{G. EVALUATION OF O\&M COSTS - TOWER}

\section{G.1 OPERATION AND MAINTENANCE COSTS}

The SunLab O\&M estimate is based on the actual costs from SEGS and adjusted accordingly for tower solar field and technology. The reduction in O\&M cost is primarily a result of the increase in annual plant capacity factor, as shown in Table G-1. The plant capacity increases directly as a result of the increases in thermal storage. Increasing the size (MWe) and utilization (capacity factor) of the power plant incurs very little increase in O\&M expenses (\$/year). This is because the quantity and complexity of the equipment remain constant and staffing remains fairly constant. Our review of conventional fossil power plants show this "economy of scale" in staffing for increases in plant size.

Solar O\&M expenses and staff increase with the field size. There are significant cost improvements from increases in solar system efficiency, which reduce the solar field size (see Section E.4.2).

Table G-1 - SunLab CSP Tower Technology O\&M Cost Estimate

\begin{tabular}{|l|c|c|c|c|c|c|c|}
\hline & Solar One & Solar Two & Solar Tres & Solar 50 & Solar 100 & Solar 200 & Solar 220 \\
\hline Net Power, MWe & 10 & 10 & 15 & 50 & 100 & 200 & 220 \\
\hline Plant Capacity Factor, \% & N/A & $19 \%$ & $78 \%$ & $76 \%$ & $73 \%$ & $74 \%$ & $73 \%$ \\
\hline $\begin{array}{l}\text { Annual Net Generation, } \\
\text { GWh/yr }\end{array}$ & N/A & 16.6 & 93.3 & 335 & 642 & 1,292 & 1,406 \\
\hline Thermal Storage, hrs & 0 & 3 & 16 & 16 & 13 & 13 & 12.7 \\
\hline Solar Field, m & 71,100 & 81,400 & 231,000 & 709,000 & $1,311,000$ & $2,606,000$ & $2,642,000$ \\
\hline Number of Heliostats & 1,818 & 1,912 & 2,432 & 7,463 & 8,858 & 17,608 & 17,851 \\
\hline Staff & 32 & 33 & 31 & 38 & 47 & 67 & 67 \\
\hline $\begin{array}{l}\text { Average Annual Cost (with } \\
\text { burden) }\end{array}$ & $\$ 71$ & $\$ 71$ & $\$ 62$ & $\$ 56$ & $\$ 50$ & $\$ 42$ & 42 \\
\hline Staff Cost & $\$ 2,272$ & $\$ 2,343$ & $\$ 1,922$ & $\$ 2,128$ & $\$ 2,350$ & $\$ 2,814$ & $\$ 2,814$ \\
\hline $\begin{array}{l}\text { Annual Material \& } \\
\text { Services Cost }\end{array}$ & $\$ 1,000$ & $\$ 400$ & $\$ 600$ & $\$ 900$ & $\$ 1,200$ & $\$ 1,900$ & $\$ 1,900$ \\
\hline Total O\&M Cost, \$k & $\$ 3,272$ & $\$ 2,743$ & $\$ 2,522$ & $\$ 3,028$ & $\$ 3,550$ & $\$ 4,714$ & $\$ 4,714$ \\
\hline Total O\&M Cost, \$/kWhe & N/A & $\$ 0.165$ & $\$ 0.027$ & $\$ 0.010$ & $\$ 0.006$ & $\$ 0.004$ & $\$ 0.003$ \\
\hline
\end{tabular}




\section{G.2 O\&M STAFF}

The staffing in the SunLab model was reviewed, and it is a reasonable estimate. The staffing compares with SEGS power-generating facilities and the recent O\&M Cost Reduction Study performed at Kramer Junction (KJCOC 1999). The staffing for tower technology is shown in Table G-2.

Table G-2 - Staffing for Tower Technology

\begin{tabular}{|l|c|c|c|c|c|c|}
\hline & \multicolumn{3}{|c|}{ SunLab } & \multicolumn{3}{c|}{ Sargent \& Lundy } \\
\cline { 2 - 7 } & $\begin{array}{c}\text { Solar } \\
\text { Tres USA }\end{array}$ & Solar 100 & Solar 200 & $\begin{array}{c}\text { Solar } \\
\text { Tres USA }\end{array}$ & Solar 100 & Solar 200 \\
\hline Administrative & - & - & - & 7 & 7 & 7 \\
\hline Plant Operations & - & - & - & 11 & 11 & 11 \\
\hline Power Plant Maintenance & - & - & - & 7 & 7 & 7 \\
\hline $\begin{array}{l}\text { Solar Field Maintenance \& } \\
\text { Wash Crew }\end{array}$ & - & - & - & 8 & 21 & 42 \\
\hline \multicolumn{1}{|c|}{ Total } & 31 & 47 & 67 & 33 & 46 & 67 \\
\hline
\end{tabular}

The power block staffing (33 minus 8 for solar field equals 25) is comparable to the industry average for a 120 -MWe combined-cycle power plant. The total staffing for a 120 -MWe combined-cycle power plant is 25 based on the SOAPP model.

The staffing was determined to be reasonable based on the following evaluation:

- The administrative staff would be the same for the increased plant size.

- $\quad$ The increase in plant size from 50 MWe to 220 MWe will not require additional operations or maintenance staff for operations and maintenance of the power plant. The difference between 50 and $220 \mathrm{MWe}$ does not increase the quantity or complexity of the equipment.

- The increase in the solar field maintenance staff, including mirror wash crew, is required to support the increase in the solar field. For Kramer Junction, approximately 0.03 maintenance staff is required per $1,000 \mathrm{~m}^{2}$ of solar field aperture area. 


\section{G.3 O\&M MATERIAL AND SERVICE COST}

\section{G.3.1 Service Contract}

The service contracts include typical contracts and costs expected for this type of facility, including control computers, office equipment, waste disposal, road maintenance, and vehicle maintenance, and are shown in Table G-3. The contract for weed control, road maintenance, and vehicle maintenance was scaled up to account for the larger field area.

Table G-3 - Service Contracts

\begin{tabular}{|l|r|r|r|r|r|}
\hline & Solar Tres & Solar 50 & Solar 100 & Solar 200 & Solar 220 \\
\hline Control System Computers & $\$ 24,000$ & $\$ 24,000$ & $\$ 24,000$ & $\$ 24,000$ & $\$ 24,000$ \\
\hline Personal Computer/Office Equip. & $\$ 5,000$ & $\$ 5,000$ & $\$ 5,000$ & $\$ 5,000$ & $\$ 5,000$ \\
\hline Nitrogen Supply & $\$ 27,000$ & $\$ 27,000$ & $\$ 27,000$ & $\$ 27,000$ & $\$ 27,000$ \\
\hline Sanitary Service & $\$ 6,000$ & $\$ 6,000$ & $\$ 6,000$ & $\$ 6,000$ & $\$ 6,000$ \\
\hline Waste Disposal & $\$ 34,000$ & $\$ 34,000$ & $\$ 34,000$ & $\$ 34,000$ & $\$ 34,000$ \\
\hline Weed Control & $\$ 55,000$ & $\$ 70,232$ & $\$ 107,995$ & $\$ 174,689$ & $\$ 176,375$ \\
\hline Road maintenance & $\$ 27,000$ & $\$ 34,478$ & $\$ 53,016$ & $\$ 85,756$ & $\$ 86,584$ \\
\hline Vehicle Maintenance & $\$ 2,000$ & $\$ 2,554$ & $\$ 3,927$ & $\$ 6,352$ & $\$ 6,414$ \\
\hline \multicolumn{1}{|c|}{ Total } & $\$ 180,000$ & $\$ 203,264$ & $\$ 260,939$ & $\$ 362,798$ & $\$ 365,372$ \\
\hline
\end{tabular}

\section{G.3.2 Raw Water and Chemicals}

The estimate is based on water usage and chemical costs from SEGS VI/VII as shown below in Table G-4. Water and chemical usage for the power plant thermal is consistent with industry averages for power plants. The additional usage for solar (e.g. mirror wash) is based on the O\&M Cost Reduction Study (KJCOC 1999). Raw water cost is based on actual costs reports at SEGS of $\$ 0.00122$ per gallon $\left(\$ 0.32 \mathrm{per}^{3}\right)$. The main difference between the SunLab reference case and S\&L's case is the cost of raw water. SunLab estimated the cost to be $\$ 0.021$ per $\mathrm{m}^{3}$ ), which is about 15 times less than the $\mathrm{S} \& \mathrm{~L}$ estimate.

Table G-4 - Water Usage and Chemical Costs

\begin{tabular}{|c|c|}
\hline Raw Water Cost & $\$ 0.32$ per $\mathrm{m}^{3}$ \\
\hline Cooling Water Chemical Cost & $\$ 0.043$ per $\mathrm{m}^{3}$ cooling tower make-up \\
\hline
\end{tabular}




\begin{tabular}{|l|l|}
\hline Demineralizer Chemical Cost & $\$ 0.540 \mathrm{per} \mathrm{m}^{3}$ Condensate make-up \\
\hline Cooling Tower Make-up & $2.90 \mathrm{~m}^{3} / \mathrm{MWhe}$ \\
\hline Power Cycle Condensate Make-up & $0.17 \mathrm{~m}^{3} / \mathrm{MWhe}$ \\
\hline Demineralizer Blowdown & $10 \%$ \\
\hline Mirror Wash Water Consumption & $0.022 \mathrm{~m}^{3}$ (water) $/ \mathrm{m}^{2}$ (of collector) /year \\
\hline
\end{tabular}

\section{G.3.3 Parts and Material}

Parts and material for the conventional power plant range between $0.3 \%$ and $0.4 \%$, depending on the age and type of facility. S\&L used $0.35 \%$ of the capital cost for parts and materials related to the power block and balance of plant.

Parts and material for the solar field are based on the O\&M study (KJCOC 1999) for 500,000 $\mathrm{m}^{2}$ and adjusted for the increase in solar size. The estimate is reasonable since it is based on the recent O\&M Cost Reduction Study performed at Kramer Junction, incorporates the latest cost information from Kramer Junction, and was adjusted to account for tower technology. Parts and material costs for a solar field are shown in Table G-5.

Table G-5 - Parts and Material Costs for a Solar Field

\begin{tabular}{|l|c|c|c|}
\hline & Unit Cost (\$) & Replace (\%) & $\$ / \mathbf{m}^{2}$-yr \\
\hline Mirrors & 26 & $0.5 \%$ & $\$ 0.130$ \\
\hline LOCs & 200 & $0.5 \%$ & $\$ 0.010$ \\
\hline Hdr. Drives & 4,500 & $0.5 \%$ & $\$ 0.093$ \\
\hline Miscellaneous & $5 \%$ of total equipment costs & $\$ 0.01$ \\
\hline HTF Pump Seals & 1,200 & 2 & $\$ 0.05$ \\
\hline \multicolumn{1}{|c|}{ Total } & - & - & $\$ 0.25$ \\
\hline
\end{tabular}

\section{G.3.4 Miscellaneous}

Miscellaneous costs include administration costs (such as safety, training, travel, supplies, and telephones) and vehicle fuel and repair (see Table G-6). The cost of $\$ 253,000$ per year is reasonable for this size of power plant. S\&L projected increases for vehicle and fuel to account for the larger number of vehicles needed to support maintenance of the larger collector fields. 
Table G-6 - Miscellaneous Costs

\begin{tabular}{|l|r|r|r|r|r|}
\hline & Solar Tres & Solar 50 & Solar 100 & Solar 2002 & Solar 220 \\
\hline Vehicle Fuel & $\$ 17,000$ & $\$ 21,708$ & $\$ 33,380$ & $\$ 53,995$ & $\$ 54,516$ \\
\hline Vehicle Parts and Supplies & $\$ 28,000$ & $\$ 35,755$ & $\$ 54,980$ & $\$ 88,933$ & $\$ 89,791$ \\
\hline Site Improvements & $\$ 2,000$ & $\$ 2,000$ & $\$ 2,000$ & $\$ 2,000$ & $\$ 2,000$ \\
\hline Safety \& Training School & $\$ 10,000$ & $\$ 10,000$ & $\$ 10,000$ & $\$ 10,000$ & $\$ 10,000$ \\
\hline Travel & $\$ 5,000$ & $\$ 5,000$ & $\$ 5,000$ & $\$ 5,000$ & $\$ 5,000$ \\
\hline Office Supplies & $\$ 28,000$ & $\$ 28,000$ & $\$ 28,000$ & $\$ 28,000$ & $\$ 28,000$ \\
\hline Telephones & $\$ 67,000$ & $\$ 67,000$ & $\$ 67,000$ & $\$ 67,000$ & $\$ 67,000$ \\
\hline Rental Equipment & $\$ 34,000$ & $\$ 34,000$ & $\$ 34,000$ & $\$ 34,000$ & $\$ 34,000$ \\
\hline First Aid Equipment & $\$ 6,000$ & $\$ 6,000$ & $\$ 6,000$ & $\$ 6,000$ & $\$ 6,000$ \\
\hline Other Miscellaneous & $\$ 56,000$ & $\$ 56,000$ & $\$ 56,000$ & $\$ 56,000$ & $\$ 56,000$ \\
\hline \multicolumn{1}{|c|}{ Total } & $\$ 253,000$ & $\$ 265,463$ & $\$ 296,360$ & $\$ 350,927$ & $\$ 352,307$ \\
\hline
\end{tabular}

\section{G.3.5 Capital Equipment}

Capital equipment (see Table G-7) covers the equipment required to operate and maintain the facility (including dump truck, operator vehicles, mirror washing equipment, and tractor). The cost of the equipment is based on the recent O\&M Cost Reduction Study performed at Kramer Junction (KJCOC 1999) and on Kramer Junction's latest information. The quantity of equipment is scaled-up to account for the increase in the size of the field.

Table G-7 - Capital Equipment

\begin{tabular}{|l|c|c|c|c|c|c|c|}
\hline & Cost $^{*}$ & Number & Solar Tres & Solar 50 & Solar 100 & Solar 2002 & Solar 220 \\
\hline & & & $\$ / \mathrm{m}^{2}$ & $\$ / \mathrm{m}^{2}$ & $\$ / \mathrm{m}^{2}$ & $\$ / \mathrm{m}^{2}$ & $\$ / \mathrm{m}^{2}$ \\
\hline Dump Truck & $\$ 30,000$ & 1 & $\$ 0.01$ & $\$ 0.02$ & $\$ 0.02$ & $\$ 0.04$ & $\$ 0.04$ \\
\hline SF Operator Vehicle & $\$ 20,000$ & 3 & $\$ 0.02$ & $\$ 0.03$ & $\$ 0.05$ & $\$ 0.08$ & $\$ 0.08$ \\
\hline Mirror Wash Rig - Twister & $\$ 100,000$ & 2 & $\$ 0.04$ & $\$ 0.05$ & $\$ 0.08$ & $\$ 0.13$ & $\$ 0.13$ \\
\hline Mirror Wash Rig - Deluge & $\$ 30,000$ & 1 & $\$ 0.02$ & $\$ 0.03$ & $\$ 0.05$ & $\$ 0.08$ & $\$ 0.08$ \\
\hline Mirror Container Carrier & $\$ 17,000$ & 1 & $\$ 0.01$ & $\$ 0.01$ & $\$ 0.01$ & $\$ 0.02$ & $\$ 0.02$ \\
\hline Tractor & $\$ 20,000$ & 1 & $\$ 0.01$ & $\$ 0.01$ & $\$ 0.02$ & $\$ 0.03$ & $\$ 0.03$ \\
\hline \multicolumn{1}{|c|}{ Total } & & & $\$ 0.12$ & $\$ 0.15$ & $\$ 0.23$ & $\$ 0.37$ & $\$ 0.38$ \\
\hline
\end{tabular}

* Capital equipment cost was calculated based on a 5-year equipment life. 


\section{G.3.6 O\&M Cost Comparison}

The comparison between the SunLab cost estimate and S\&L's estimate is shown in Table G-8. The major differences are the following:

- Sargent \& Lundy scaled-up the cost of contracts associated with increase in field size (e.g., weed control).

- Sargent \& Lundy scaled-up the cost of fuel and maintenance of vehicles to account for the increase in field size.

- Sargent \& Lundy assumed that the average burdened rate would not decrease between Solar 100 and Solar 220.

- Raw water cost used by S\&L is based on actual costs reports at SEGS of $\$ 0.00122$ per gallon $\left(\$ 0.32\right.$ per $\left.\mathrm{m}^{3}\right)$. SunLab estimated the cost to be $\left.\$ 0.021 \mathrm{per}^{3}\right)$, which is about 15 times less than the S\&L estimate.

- $\quad$ Sargent \& Lundy included a contingency of $10 \%$.

Table G-8 - Comparison of O\&M Cost Estimates: SunLab vs. S\&L

\begin{tabular}{|c|c|c|c|c|c|c|c|}
\hline & \multirow{2}{*}{$\begin{array}{c}\text { Current } \\
1987 / 1999\end{array}$} & \multicolumn{3}{|c|}{ SunLab Estimates } & \multicolumn{3}{|c|}{ S\&L Estimates } \\
\hline & & 2004 & 2008 & 2020 & 2004 & 2008 & 2020 \\
\hline Plant Characteristics & $\begin{array}{c}\text { Solar } \\
\text { One/Two }\end{array}$ & $\begin{array}{l}\text { Solar } \\
\text { Tres }\end{array}$ & Solar 100 & Solar 220 & $\begin{array}{l}\text { Solar } \\
\text { Tres }\end{array}$ & Solar 100 & Solar 220 \\
\hline Net Power, MWe & 10 & 15 & 100 & 220 & 15 & 100 & 220 \\
\hline Plant Capacity Factor, \% & $19.0 \%$ & $78.0 \%$ & $73.2 \%$ & $72.9 \%$ & $78.0 \%$ & $73.2 \%$ & $72.9 \%$ \\
\hline Annual Solar-Electric Efficiency & $7.6 \%$ & $13.7 \%$ & $16.6 \%$ & $18.1 \%$ & $13.0 \%$ & $16.5 \%$ & $17.3 \%$ \\
\hline Thermal Storage, hrs & 3 & 16 & 13 & 13.1 & 16 & 13 & 13.1 \\
\hline Solar Field, $\mathrm{m}^{2}$ & 81,400 & 231,000 & $1,311,000$ & $2,642,000$ & 233,772 & $1,354,452$ & $2,771,730$ \\
\hline \multicolumn{8}{|l|}{ O\&M Characteristics } \\
\hline Number of Staff (FTE) & 35 & 31 & 47 & 67 & 33 & 46 & 67 \\
\hline Avg. Burdened Labor Rate, \$k/yr & $\$ 71$ & $\$ 62$ & $\$ 50$ & 42 & $\$ 62$ & $\$ 50$ & $\$ 50$ \\
\hline Staff Cost, \$k/yr & $\$ 2,485$ & $\$ 1,922$ & $\$ 2,350$ & $\$ 2,814$ & $\$ 2,046$ & $\$ 2,299$ & $\$ 3,364$ \\
\hline $\begin{array}{l}\text { Ann. Material \& Services Cost, } \\
\$ \mathrm{k} / \mathrm{yr}\end{array}$ & $\$ 750$ & $\$ 600$ & $\$ 1,200$ & $\$ 1,900$ & $\$ 686$ & $\$ 2,065$ & $\$ 4,277$ \\
\hline Total O\&M Cost, \$k/yr & $\$ 3,235$ & $\$ 2,522$ & $\$ 3,550$ & $\$ 4,714$ & $\$ 3,041$ & $\$ 5,127$ & $\$ 9,132$ \\
\hline Total O\&M Cost, \$/kWhe & $\$ 0.194$ & $\$ 0.027$ & $\$ 0.006$ & $\$ 0.003$ & $\$ 0.033$ & $\$ 0.008$ & $\$ 0.006$ \\
\hline
\end{tabular}

Note: the Solar One/Two values are a blend from both plants to provide a "best available" estimate for a typical salt plant of this size with utility operations. 
Appendix $\mathbf{H}$

Mirror Reflectivity (SunLab Input) 


\section{H. MIRROR REFLECTIVITY (SUNLAB INPUT)}

The terms "mirror reflectivity" and "reflectivity" are used throughout this report, unless specified otherwise, to refer to the solar-weighted specular reflectivity - the fraction of the incident solar energy reflected in a specular (rather than diffuse) fashion. The solar-weighting of reflectivity is achieved by measuring the spectral reflectivity across a wide range of solar-thermal wavelengths (typically $0.3 \mu$ to $2.5 \mu$ ), then weighting by the ASTM-accepted wavelength-dependant energy content of sunlight after it passes through the earth's atmosphere (ASTM G159-98 air mass 1.5 solar spectral irradiance is the standard). The specular nature of a mirror's reflectivity is quantified by measuring the intensity of reflected light only in a limited collection region along the ideal angle of reflection. Both laboratory and field portable instruments have been developed that measure the specular reflectivity at adjustable acceptance apertures ranging from 1 to 100 milli-stearadian ( $2 \pi$ stearadian equals the complete hemisphere of possible reflection). A tower receiver subtends about 5 milli-stearadian from the furthest heliostat at a very large plant. The accuracy of both the spectral reflectivity and specular reflectivity are assured when the measurements are referenced to directly traceable NIST standard reference materials, the fundamental geometric optics of the instrumentation is determined, and the mirror scattering characteristics are known. The Optical Materials Branch at the National Renewable Energy Laboratory and the Primary Standards Laboratory at Sandia National Laboratories provide support in characterizing the reflectivity of mirror materials.

Microscopic surface irregularities, called specularity errors, in a mirror's substrate or superstrate material slightly reduce a mirror's measured specular reflectivity because they cause non-specular (scattered) reflections that fall outside the acceptance aperture of the measurement instrument. Specularity errors can be measured on small mirror samples and generally have a much smaller impact on plant performance than "slope" and "curvature" errors, which are errors in the shape of the mirror surface over larger (macroscopic) areas of the surface that must be measured on full-size samples. Slope and curvature errors are included and reported in the optical performance (efficiency) metric of CSP plants, not in the mirror reflectivity.

The reflectivity of an ideal (front-surface) silvered mirror is approximately $97 \%$. Since silver degrades quickly in the outdoor environment, more durable back-surface glass mirrors have typically been used at CSP plants. Glass superstrates result in transmission losses (increased absorption) through the glass medium, with losses increasing as a function of both iron content in the glass and thickness. The reflectivity of typical, 4-mm thick, low-iron, float glass mirrors, such as the SEGS trough plants in California, is approximately 94\%. The manufacturing technology for mass-produced commercial glass, which employs formulations with higher iron 
content, is extensive and mature. Mirrors constructed from this type of glass exhibit lower reflectivity, $\leq 90 \%$, due to increased absorption and thickness. Large amounts of low-iron glass are manufactured for use in flatplate collectors used for water heating, but the manufacturing volume is much less than conventional glass. Because of the current, low-volume manufacturing capability for low-iron glass products, small order quantities of low-iron glass mirrors are expensive. As larger or more numerous CSP plants are built, the cost of low-iron mirrors should approach the price-point of the mass-produced conventional glass.

An approach to increasing reflectivity using conventional glass formulations is to use thin glass mirrors, produced in large quantities for commercial applications such as compact cosmetic mirrors, to reduce the transmission losses. Thin glass mirrors are typically no less expensive per square meter of reflector than thick glass mirrors because the raw material cost savings are offset by increased handling costs and breakage. The baseline trough and tower designs use thicker glass as a structural element. The conversion to thin glass in these designs would require additional structural support. Additional mirror module support elements could be justified in stable markets where high volume, low-cost production approaches would become practical, e.g., metal forming of automotive body panels.

Flexible ultra-thin mirror constructions consisting of silvered micro-thin glass superstrates, all-dielectric (nonmetallic) multilayer constructions, and silvered polymer or sheet metal substrates are being investigated and could enable innovative concentrator designs that offer the possibility of lower costs than current designs. Reflectivity values $>94 \%$ have been demonstrated, but a cost-effective mirror product durable enough for use in a CSP plant, which requires both long-term outdoor exposure and frequent cleaning, must still be developed and proven. 
Appendix I

Sargent \& Lundy Response to the NRC Issues and Observations 


\section{SARGENT \& LUNDY RESPONSE TO THE NRC ISSUES AND OBSERVATIONS}

Sargent \& Lundy reviewed the National Research Council (NRC) Committee's "Critique of the Sargent \& Lundy Assessment of Cost and Performance Forecasts for Concentrating Solar Power, October 12, 2002." The NRC review was performed on Draft 3 of the Sargent \& Lundy Report, SL-5641, dated October 2002. S\&L was authorized by NREL to update the report to expand the executive summary to provide more information as suggested by the NRC and perform additional sensitivity analysis. This included the following:

- $\quad$ Executive Summary

- Section 4.6, "Risk Assessment for Trough Technology"

- Section 4.7, “Cost Sensitivities” (Trough)

- Section 5.8, "Risk Assessment for Tower Technology"

- Section 5.9, “Cost Sensitivities" (Tower)

- Appendix I, "Sargent \& Lundy Response to the NRC Issues and Observations"

S\&L's general comments to the NRC critique and response to specific comments are as follows:

\section{$\underline{\text { General Comments }}$}

A. The NRC review found that "Since 1999, significant progress has been made in understanding the potential impacts of thermal storage technologies, thin film glass mirrors, improved heat collection units, improved trough support structures, and other technical opportunities to improve CSP technology" (NRC, page 4). The NRC review of S\&L's analysis of trough technology found that "Based on the level of uncertainty that is inherently present in projecting these deployment rates and technology advances, a more plausible estimate would lie somewhere between the two projections (S\&L's and SunLab's) in 2020. However, if deployment does not proceed at the assumed rate, the projected LEC could be much higher than either of these estimates" (NRC page 6). S\&L welcomes the NRC endorsement of our analysis, finding that projected costs are likely to lie somewhere between our high-cost and SunLab's low-cost estimates for the assumed deployment rates.

B. The NRC Committee also noted “...that S\&L took any potential conflict of interest very seriously and made a concerted effort to address and avoid it. No obvious example of bias was apparent in S\&L's interpretation 
of the available data nor was there any deliberate omission of pertinent facts. If anything, the S\&L analysis was more conservative than SunLab's estimates in assessing areas like time to develop new materials or power conversion technologies" (NRC, page 18); and: “...that S\&L attempted to maintain a credible process by filling in the gaps in its knowledge base with the advice of world-recognized experts" (NRC page 18).

C. On page 20, the NRC Committee noted: “...that within the time and resources available for this study, S\&L did a reasonable job in digesting the information provided to it by DOE, S\&L expert consultants, and members of the CSP industry. For example, S\&L's selection of component costs and economic parameters and assumptions regarding performance is well documented."

D. Much of the NRC critique of the S\&L analysis centered around assumed rates of deployment and incentive issues. Deployment and incentive issues were outside the scope of work for S\&L. As noted by the NRC: "The committee notes that CSP technology is not unique in the requirement for incentivizing the early market phases of emerging energy technologies [8]. The committee notes the extensive reports and study literature on these issues cited by S\&L, including DOE/EERE's own August 2002 Report to Congress on the Feasibility of 1,000 Megawatts of Solar Power in the Southwest by 2006..." DOE noted in their presentations to the NRC and S\&L that because such studies were available, DOE's primary concern, and the reason for this study, was to determine the potential technical feasibility of CSP. Nevertheless, there are several deployment issues worth considering. First, the chicken-and-egg problem of driving down costs by deploying technologies, but facing high initial costs that impede deployment, is true of all energy technologies, not just CSP. Second, as noted by the NRC and S\&L, incentives are a key determinant of the rate at which CSP, or any new energy technology, penetrates the market. Evaluating this lies well outside the technical analysis requested of S\&L. Third, the level of deployment identified by S\&L is modest, at 1.5 to $2.8 \mathrm{GW}$ by 2020 for towers and troughs respectively. The NRC also noted this: "The SunLab deployment scenarios evaluated by S\&L represent a range from a modest rate of adding one $100 \mathrm{MWe}$ plant per year (the first becoming operational in 2004) to an aggressive approach that would result in almost 5,000 MWe of new capacity by 2020" (NRC page 5). To place this level of deployment in context, the wind industry added 1,700 MW of new capacity in the U.S. in 2001 alone. 


\section{Sargent \& Lundy Comments to Specific Observations Made by the NRC}

\section{Observation 1: 'S\&L's modeling approach parallels SunLab's in almost all aspects.' [NRC page 4]}

Comment: S\&L's scope of work was to perform a review of the SunLab model (ref: Section 1.3.2) and to comment on the accuracy of the inputs and the results, not to develop an independent bottoms-up cost estimate, which would involve a much more detailed engineering cost analysis. In addition to its own experience, S\&L drew heavily from industry experience, vendor quotes, and other independent sources to evaluate cost and performance projections. Separately, S\&L developed a financial model of the type used in competitive industry to support power project planning and financing (ref: Section 1.3.7).

\section{Observation 2: '...its review did not sufficiently examine the effect of uncertainties on these parameters.' [NRC page 5]}

Comment: S\&L conducted a limited number of sensitivity studies as pointed out by the NRC (page 5), but due to the work scope changes requested by the NRC and DOE and compressed schedule, S\&L did not have time to develop a full range of sensitivity studies. S\&L performed additional cost sensitivities and risk assessments per the NRC's suggestion (see Section 4.6, 4.7, 5.8, and 5.9) for the final report.

\section{Observation 3: 'The discussion of risks and uncertainty is extremely shallow' [NRC page 8]}

Comment: S\&L conducted a limited number of sensitivity studies as pointed out by the NRC (page 5), but due to the work scope changes requested by the NRC and DOE and compressed schedule, S\&L did not have time to develop a full range of sensitivity studies. S\&L performed additional cost sensitivities and risk assessments per the NRC's suggestion (see Section 4.6, 4.7, 5.8, and 5.9) for the final report.

\section{Observation 4: Heliostats 'S\&L appears to have accepted ADL's (Arthur D. Little) analysis without much question and has not commented on the viability of ADL's vendor estimates' [NRC page 8]}

Comment: S\&L reviewed available information on heliostat costs and found that the ADL analysis was the most thorough available and therefore used it as a basis for comparison. The viability of the ADL estimate was reviewed in detail. The comparison of S\&L, SunLab, and ADL cost estimates is shown in Table E-14. Where we accepted the ADL cost estimate, a discussion of the reasoning is provided in Appendix E.5. The discussion documenting our review for each cost category for manufacturing and installation of heliostats is also provided in Appendix E.5. Several examples are provided below: 
- The cost of mirrors referenced in the ADL report was based on actual cost estimates from mirror manufacturers (ref: Appendix E.5.1). The SunLab estimate is about twice the cost of normal glass, which allows for a premium for manufacturing production runs. The opportunities this suggests for further cost reductions were not considered in the analysis.

- Evaluation of mirror assembly costs was based on ADL and the SolMaT study done by Solar Kinetics, Inc. (ref: Appendix E.5.2)

- Drive costs are based on detailed studies and cost estimates by Peerless-Winsmith, a manufacturer of commercial drive mechanisms. The cost data were based on a detailed material list of parts, labor, and cost for pattern \& tooling. (Ref: Appendix E.5.3)

- Evaluation of Production (Shop) Fabrication was based on studies done by ADL and Solar Kinetics. Both studies were reviewed, and the Solar Kinetics estimate was used for comparison instead of the ADL study. (ref: Appendix E.5.5)

\section{Observation 5: ..scale-up of heliostats from $95 \mathrm{~m}^{2}$ to $148 \mathrm{~m}^{2}$. S\&L has not commented on the viability of this scale-up.' [NRC page 8]}

Comment: The reasoning behind not including additional discussion is that $148-\mathrm{m}^{2}$ heliostats have been manufactured and prototypes are in service (ref: Section 5.8.2.2). We concur that additional discussion of the viability of the scale-up could be provided, but since operational units of that size are available, it is not truly a scale-up concern.

Observation 6: Thinner glass, improved aiming, etc. '....assumptions without much to back up how such improvements will be accomplished' [NRC page 8]

Comment: The current development of thinner glass is identified in Section 4.3.3 for troughs and has been referenced in the tower section (Section 5.3.1.1) for the final report.

\section{Observation 7: It is unlikely that it (steam inlet) will go to $640^{\circ} \mathrm{C}$ in the next 18 years. [NRC page 8]}

Comment: There is ongoing research to increase steam turbine efficiency by increasing the steam inlet temperature. There are units currently operating at $1,100^{\circ} \mathrm{F}\left(593^{\circ} \mathrm{C}\right)$. The question of likely or unlikely is dependent on what the demand for solar units is over the next 16 years. Sixteen years ago no one projected today's current market for combustion turbine combined-cycle power plants. For the final report, S\&L adjusted the base case for tower technology in 2020 not to include the higher temperature turbine or advanced heliostat design. We then performed a sensitivity analysis to calculate the change in LEC for the higher temperature turbine and advanced heliostat design. 
Observation 8: Furthermore, it is not clear that $S \& L$ really determined efficiency levels from GE data systems for small-plants.... [NRC page 8]

Comment: The near-term turbine efficiency was verified based on the ABB-Brown Boveri heat balance diagrams for SEGS IX 89-MW unit (ref: Appendix E.6.2.1). S\&L used the GE program STGPERF to estimate efficiencies, which is typically used for steam turbines in combined-cycle power plant (e.g., 'small plants') (ref: Section 5.3.2).

Observation 9: Receivers. 'S\&L makes no comment about the severe technical risk in developing hightemperature and high-heat flux systems for the future.' [NRC page 9]

Comment: The overall technical feasibility of high temperature, high heat-flux systems was demonstrated by Solar Two in the late 1990s. There remain challenges in scaling up these systems while meeting performance and lifetime requirements, but there do not appear to be any fundamental technical limits or "severe" risks. S\&L did not go into considerable detail, but did indicate that the advance from Solar 200 to Solar 220 (turbine inlet steam temperature increase from $540^{\circ} \mathrm{C}$ to $640^{\circ} \mathrm{C}$ ) would result in several areas of concern. Relative to this scale-up, our report states that "The major issue will be the higher temperatures and impact on materials" (ref: Appendix E.6.2.2). For the final report, S\&L adjusted the base case for tower technology in 2020 not to include the higher temperature turbine or advanced heliostat design. We then performed a sensitivity analysis to calculate the change in LEC for the higher temperature turbine and advanced heliostat design.

Observation 10: Thermal Storage. '...that advantages were assumed without significant consideration of all the side issues that might result with molten salts, e.g. pumps, seals, and pipes at temperature levels of $>500^{\circ} \mathrm{C}$. [NRC page 9]

Comment: The overall technical feasibility of high-temperature molten salt storage was demonstrated by Solar Two in the late 1990s. There remain substantial challenges in scaling up these systems while meeting performance and lifetime requirements, but there do not appear to be any fundamental technical limits. S\&L did not go into considerable detail, but did indicate that the advance from Solar 200 to Solar 220 (turbine inlet steam temperature increase from $540^{\circ} \mathrm{C}$ to $640^{\circ} \mathrm{C}$ ) would result in scale up concerns as documented in the statement that "The major issue will be the higher temperatures and impact on materials" (ref: Appendix E.6.2.2). For the final report, S\&L adjusted the base case for tower technology in 2020 not to include the higher temperature turbine or advanced heliostat design. We then performed a sensitivity analysis to calculate the change in LEC for the higher temperature turbine and advanced heliostat design. 


\section{Observation 11: O\&M. 'However, there should be more comment about O\&M practices and the differences between tower and trough technology.' [NRC page 11]}

Comment: The differences between towers and troughs are provided in Appendix G. For example:

- The solar field maintenance staff, including mirror wash crew, is adjusted based on the difference in the collector fields.

- Parts and material, which are similar to both types of plants, are based on actual costs from SEGS.

- Parts and material, which are unique to towers, are estimated based on experience from the demonstration projects.

\section{Observation 12: ‘...is clear that $S \& L$ did not do a “due-diligence-like” analysis.' [NRC page 11]}

Comment: S\&L agrees that the review is not a due-diligence review for the deployment of the units. In particular, "due-diligence" reviews are of commercially available technologies under consideration for investment. In contrast, this review was "due-diligence-like" as the technologies are not commercially available, but the intent was to have a similarly rigorous review of the projected technologies' cost and performance using independent reviewers. A due-diligence review would also require estimating the incentive support levels necessary for technology deployment, which was not part of the Scope of Work for this study. It is clear that without incentives the capital cost cannot be supported by the market and capital cost will not be reduced without deployment of significant units to obtain manufacturing efficiencies. Therefore, unless support incentives are contemplated, deployment will not occur in any case.

Observation 13: 'The committee believes that the S\&L projection of a 100-MW plant being operational in calendar year 2004 is not credible....'. S\&L's report and projection are deficient in this regard. '...the committee believes that $S \& L$ 's projections is still unrealistically optimistic.' [NRC page 12]

Comment: S\&L's scope of work did not include an assessment of market conditions and deployment projections. The report clearly identifies that deployment is assumed to occur based on the dates provided by the DOE based on earlier, now outmoded, scenarios and projections developed by SunLab. Since this was outside of our work scope, we take exception that the 'report is deficient in this regard.' As noted previously, DOE has separately provided Congress with an analysis of deployment issues. We do, however, agree that no one is developing the 100-MW unit, and therefore, it will not occur in the 2004 time frame, although a 50-MW unit is now under development in Nevada. 
Observation 14: These time delays (2-year minimum construction delay between new generation plants) were not factored into the deployment rate assumed in the S\&L study. [NRC page 12]

Comment: These delays were factored into the deployment rate assumed by S\&L. Ref: Appendix E.2 and Table E-3. The final report includes a sensitivity analysis for increases in construction duration in Section 4.7 and 5.9.

Observation 15: It would have helped if S\&L had commented on what would have to be done to reduce the risk so that investors would be willing to invest this level of capital....' [NRC page 13]

Comment: This was not included in our original scope of work. The final report includes sections on risk assessment (Section 4.6 and 5.8).

Observation 16: However, the set of assumptions used in the LEC calculation forced the debt/equity ratio from 59.9 percent to 66.5 percent debt, and it did not make much sense to the committee to allow the inference that removing one tax incentive would induce a commercial lender to accept more, higher-risk debt without raising the interest rate. [NRC page 13]

Comment: Removing the tax credit has two effects: (1) The project company loses a big offset against other income tax during Year 1 because it cannot take the investment tax credit deduction against other income tax. (2) The project company has higher depreciation charges without the ITC, because when the ITC is present, the depreciable base for the project must be reduced to exclude the ITC.

Consider Case 5 (Towers, 2020 Startup, SunLab Data). If one simply removes the ITC without increasing revenue requirement, the combination of the two impacts mentioned above is to reduce the after-tax return on equity (ROE) to $9.4 \% / y r$, which is considerably lower than our study assumption of $14 \% / \mathrm{yr}$. (These all are nominal dollar values being citing here for illustration, not constant-dollar.) Since we should recognize the ROE as a project cost that has to be covered, it is logical to adjust revenues upward until we have restored the $14 \%$ after-tax return.

If the leverage is not changed and ROE is restored to $14 \%$ by increasing the capacity revenue requirement (is an increase of around 20\%), then the minimum debt service coverage ratio (DSCR) becomes 1.60 instead of the 1.35 study assumption, indicating a larger margin of safety for lenders for uncertainties in costs than in the base case at 1.35 DSCR. Since interest is covered at a higher multiple, it is reasonable to think the credit spread component of the debt interest rate for the 1.60 case would be lower, and the debt interest rates thus would be 
lower than the $7.00 \%$ value in the reference 1.35 DSCR case because DSCR is an indicator that is commonly used by lenders to assess the level of risk in a deal. Basically, the lenders would be more comfortable with the project because the capacity component of the revenue stream would be $20 \%$ higher, giving greater margin before some adverse event (e.g., unexpectedly higher cost) might prevent debt from being serviced.

Because we would like to evaluate the various alternatives using the same costs of inputs (which include costs of equity capital, the ROE, and debt capital, the rate of interest), it is reasonable to adjust the leverage and capacity payment until the DSCR for the no-ITC case is the same as in the base case, and the ROE also is at $14 \%$. If this is done, both cases will roughly correspond to a similar level of perceived risk from the lenders' standpoints, and thus the costs of debt capital (and equity capital) for each alternative are the same. This is why the leverage was increased from $59.9 \%$ debt to $66.5 \%$ : to equate the costs of debt in the two cases.

The NRC has a point in that larger loans and greater leverage generally causes lenders to want a higher interest rate, but our assumption here is that DSCR is a reasonable proxy for how the lenders would perceive risk--which is true to a first order of approximation (actual underwriting takes into account many factors), so we have adjusted leverage to get the same degree of perceived risk, from the lenders' point of view, in both the base case and the sensitivity case.

\section{Observation 17: To a large degree, the S\&L team relied on information provided by DOE, NREL, SNL.... [NRC page 14]}

Comment: The work scope was for S\&L to perform a 'due-diligence-like' review on information provided by the client, with additional information provided during the first NRC meeting. The work scope did not include independent research for information or developing independent cost estimates. The S\&L work did include review and assessment of available reports and information, including information from industry and vendors. In addition, it should be noted that in the time period that we had to complete the work, we did contact vendors and visit the Kramer Junction power station. The limited information we were able to obtain from these sources was used to adjust the DOE, NREL, and SunLab data as appropriate. Developing completely independent information for the reviews would have increase the cost considerably, increased the schedule significantly, and probably not have identified a significant amount of truly new information. 


\section{Observation 18: '...S\&L claimed that its cost and performance projections came from "industrial projections", a large part of the cost information was generated using the SunLab cost model with a few changes to reflect the view of S\&L' [NRC page 14]}

Comment: This is in conflict with the NRC committee's statement 'The SunLab cost model has been developed with substantial industry input over the years and is backed by industry experience and engineering studies, often developed under contract to SunLab of in collaborations among SunLab, industry, and consultants.'(NRC page 14) For example, the cost estimate for tower receivers was provided by Boeing, who manufactured the receivers for Solar Two and will be the manufacturer for Solar Tres.

Sargent \& Lundy made numerous changes as identified below:

1. Annual Solar-to-Electric Efficiency (Section 4.2 and 5.2)

- Trough: S\&L estimated $15.5 \%$ in comparison to SunLab projection of $17.2 \%$

- Tower: S\&L estimated $17.7 \%$ in comparison to SunLab projection of $18.1 \%$

2. Capital Cost (Section 4.3 and Appendix E.1)

- Trough: S\&L estimated the total plant cost of $\$ 3,220$ per $\mathrm{kWe}$ in comparison to SunLab projection of $\$ 2,225 \mathrm{kWe}$. Each cost category was reviewed, and S\&L made our estimate based on the best available information.

- Trough: S\&L estimated the total plant cost of \$590.7 M in comparison to SunLab projection of $\$ 506.1 \mathrm{M}$. Each cost category was reviewed, and S\&L made our estimate based on the best available information.

3. The net annual solar-to-electric efficiency has a significant impact on the size of the collector field and hence the cost. S\&L evaluated the efficiencies and made projections based on our review of the available information. (Ref: Appendixes D.3.5 and E.3.2)

- Trough: The three major differences for tower technology were the following:

- S\&L assumed that efficiency for reflectivity would only reach $94 \%$ in 2018 as compared to the SunLab estimate of $95 \%$.

- S\&L assumed that efficiency for mirror cleanliness would only reach $95 \%$ in 2018 as compared to the SunLab estimate of $97 \%$.

- S\&L assumed that efficiency for EPGS would only reach $45.4 \%$ in 2018 as compared to the SunLab estimate of $46.1 \%$. 
- Tower: The major differences for trough technology were the following:

- S\&L assumed that efficiency for reflectivity would only reach $9.5 \%$ in 2020 as compared to the SunLab estimate of $95 \%$.

- S\&L assumed that efficiency for mirror cleanliness would only reach $95 \%$ in 2018 as compared to the SunLab estimate of $96 \%$.

- S\&L assumed that efficiency for receiver would only reach $81 \%$ in 2020 as compared to the SunLab estimate of $85.3 \%$.

As can be seen, S\&L did not just accept the assumptions for the SunLab model, but performed an independent evaluation. In cases where we used the SunLab number, the numbers were reviewed and found to be reasonable for the purpose of the study.

\section{Observation 19: '...the S\&L report did not present sufficient evidence of the likelihood of success for each projected advance in technology. [NRC page 16]}

Comment: Appendix D and E discuss the details of our evaluation. For example, Appendix E.9.2 discusses the technology improvement for the tower steam generator. The discussion includes the problems encountered during the Solar Two demonstration project and what was or is being done to solve the problems.

\section{Observation 20: '...there is no discussion in the $\mathrm{S} \& \mathrm{~L}$ report as how these incentives will come about in the} United States or if they will be sufficient to induce the assumed deployment rates. [NRC page 17]

Comment: This issue was not included in S\&L's scope of work as discussed above, nor is this issue within the NRC's domain; it properly lies with the President and the Congress.

\section{Observation 21: 'All required capital expenditure should include investment in manufacturing capacity required, cost for project formation, and so on. [NRC page 17]}

Comment: This was not included in S\&L's scope of work. The pricing of the equipment from the vendors will reflect this investment and their projections on the number of units, which will be manufactured allowing them to recover their investment costs. Therefore, this issue is really irrelevant for the current discussion. It is relevant only to the extent that the manufacturers of the equipment may never develop if the capital costs are too high. 
Observation 22: 'S\&L should have attempted to identify a basis for comparing these two systems (towers and troughs) even though both are at a different stage of technical development.' [NRC page 17]

Comment: This comparison was not included in S\&L's scope of work, but one indicator can be observed in the cost projections for the various systems.

Observation 23: '...mention should have been made of potential siting issues in achieving the level of deployment that has been assumed.' [NRC page 17]

Comment: The S\&L draft report issued September 2002 included a discussion of power generation markets, which included siting issues. Subsequently, due to a tight schedule and because deployment issues were addressed separately, the DOE directed that the scope of work not include an evaluation of deployment and associated issues.

Observation 24: 'S\&L did not consider the probability that the efficiencies resulting from these technical developments might not occur' [NRC page 18]

Comment: Additional sensitivity analysis and risk assessment were performed in the final report (Sections 4.6, 4.7, 5.8, and 5.9).

Observation 25: 'S\&L did not consider possible accidents that might happen in handling very large quantities of potentially hazardous materials for more than 30 years.' [NRC page 18]

Comment: The scope of work did not include an environmental impact study. As mentioned in the report, SEGS has been operating since 1984 with no significant accidents from the heat transfer fluid. The financial impact of significant accidents is no different than for any other industry handling potentially hazardous materials. The risk is minimized with (1) proper engineering, design, manufacturing, and construction; (2) proper operating and maintenance procedures and methods; and (3) insurance.

Observation 26: 'Other sources of uncertainty that were not discussed in the S\&L report...' [NRC page 18]

Comment: S\&L's estimate of LEC of tower technology included a 10\% contingency for deployment and an uncertainty factor for technology (15\%), scaling (10\%), and volume production (20\%). (ref: Appendix E.12) 
Additional sensitivity analysis and risk assessment were performed in the final report (Sections 4.6, 4.7, 5.8, and 5.9).

Observation 27: The S\&L report has little of no discussion of the risks of not achieving these R\&D goals nor of the magnitude of the $R \& D$ program necessary to accomplish these advances. [NRC page 19]

Comment: S\&L identified the R\&D required to achieve cost reductions (for example: Section 4.2.1 discussed the R\&D required for solar field optical efficiency.) S\&L solicited information on the magnitude of the R\&D program, but a significant portion of the developmental work is being performed by the manufacturers and is confidential. Additional sensitivity analysis and risk assessment were performed in the final report (Sections 4.6, 4.7, 5.8, and 5.9).

Observation 28: 'Regrettably, the rational behind S\&L's selections (LEC) is incompletely described in its report.' [NRC page 21]

Comment: Section 4 (trough technology) and Section 5 (tower technology) discusses our review of major cost components. The rational of our evaluation is presented in more detail in Appendix D (trough) and Appendix E (tower). The S\&L financial model was used to calculate LEC based on our estimated capital cost and annual O\&M for trough and tower technologies. The rational for the financial model is presented in Appendix B.8, "Financial Modeling," and Appendix C, "Levelized Cost for Ranking Alternatives and Example Calculations."

Observation 29: 'In none of these areas (compound risks associated with the advanced technical development and current level of deployment) does S\&L clearly articulate the rational and methodology used to arrive at component costs and system performance. In light of these deficiencies, the committee is unable to ascertain whether S\&L's projected capital costs and LECs are more accurate than those of SunLab and others.' [NRC page 22]

Comment: Again, the work scope did not include an assessment of deployment and incentives. The rational to arrive at component costs and system performance is discussed in the report, in particular Appendixes D, E, F, and G.

Observation 30: '...the committee finds that insufficient attention is given to the sensitivity of the projected LEC's to the financial parameters used in the modeling.' The committee finds that the above 
omission calls into question the reliability, accuracy, credibility, and utility of the S\&L analysis. However, the committee also finds that these omissions are a correctable defect in the report. [NRC page 22]

Comment: S\&L disagrees with the statement "above omission calls into question the reliability, accuracy, credibility, and utility of the S\&L analysis." A more detailed sensitivity analysis was not performed in the draft report due to schedule and budget constraints. Additional sensitivity analysis and risk assessment were performed in the final report (Sections 4.6, 4.7, 5.8, and 5.9) as a "correctable defect in the report."

Observation 31: 'the committee urges DOE to request a revised executive summary that clarifies and points out the important limitations of the analysis methods, assumptions, and parameters in this study. [NRC page 22]

Comment: The executive summary has been revised to include the limitations that we feel are important, but we do not agree with all the 'limitations' pointed out by the NRC committee are valid.

Observation 32: '...the S\&L team did not do a bottoms-up cost analysis of the possibilities (or probabilities) of reducing the cost of CSP plants. Rather it relied on a SunLab model and put in some of its own judgement. [NRC page 22]

Comment: Again, our scope of work did not include a bottoms-up cost estimate. Our scope was to review and provide an opinion on the cost estimates prepared by SunLab, which was prepared with input from industry and vendors. 


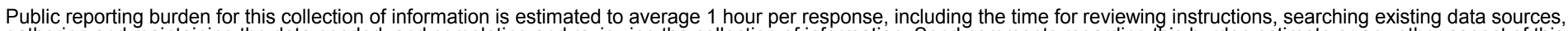

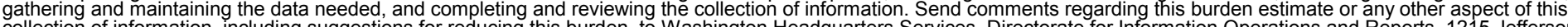

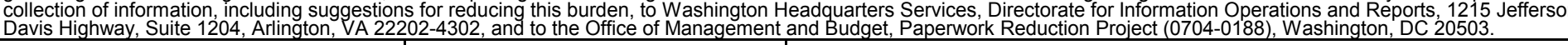

\begin{tabular}{|l|l|l|}
\hline 1. AGENCY USE ONLY (Leave blank) & $\begin{array}{l}\text { 2. REPORT DATE } \\
\text { October } 2003\end{array}$ & $\begin{array}{l}\text { 3. REPORT TYPE AND DATES COVERED } \\
\text { Subcontract Report }\end{array}$ \\
\hline
\end{tabular}

4. TITLE AND SUBTITLE
Assessment of Parabolic Trough and Power Tower Solar Technology Cost and
Performance Forecasts

5. FUNDING NUMBERS

CP032000

6. AUTHOR(S)

Sargent \& Lundy LLC Consulting Group

7. PERFORMING ORGANIZATION NAME(S) AND ADDRESS(ES)

Sargent \& Lundy Consulting Group

8. PERFORMING ORGANIZATION

55 East Monroe Street

Chicago, IL 60603-5780

REPORT NUMBER

9. SPONSORING/MONITORING AGENCY NAME(S) AND ADDRESS(ES)

National Renewable Energy Laboratory

1617 Cole Blvd.

Golden, CO 80401-3393

11. SUPPLEMENTARY NOTES

NREL Technical Monitor: H. Price

12a. DISTRIBUTION/AVAILABILITY STATEMENT

National Technical Information Service

U.S. Department of Commerce

5285 Port Royal Road

Springfield, VA 22161

13. ABSTRACT (Maximum 200 words)

Sargent \& Lundy LLC conducted an independent analysis of parabolic trough and power tower solar technology cost and performance.

14. SUBJECT TERMS

15. NUMBER OF PAGES

parabolic trough, power tower, solar, solar technology, concentrating solar power,

CSP, power generation

16. PRICE CODE

17. SECURITY CLASSIFICATION OF REPORT

Unclassified
18. SECURITY CLASSIFICATION OF THIS PAGE Unclassified
19. SECURITY CLASSIFICATION OF ABSTRACT

Unclassified
10. SPONSORING/MONITORING O REPORT NUMBER NREL/SR-550-34440

NSN 7540-01-280-5500

Standard Form 298 (Rev. 2-89) Prescribed by ANSI Std. Z39-18 